\title{
Preliminary Total-System Analysis of a Potential High-Level Nuclear Waste Repository at Yucca Mountain
}
P. W. Eslinger
W. E. Nichols
L. A. Doremus
M. D. White
D. W. Engel
T. B. Miley
D. W. Langford(a)
M. T. Murphy
S. J. Ouderkirk(a)

January 1993

Prepared for

U.S. Department of Energy

under Contract DE-AC06-76RLO 1830

Pacific Northwest Laboratory

Richland, Washington 99352

(a) Westinghouse Hanford Company Richland, Washington 99352

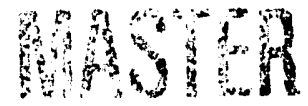




\section{Summary}

The placement of high-level radioactive wastes in mined repositories deep underground is considered a disposal method that would effectively isolate these wastes from the environment for long periods of time. In the United States, the U.S. Department of Energy (DOE) is responsible, and, within certain limitations, has the authority to implement the provisions of the Nuclear Waste Policy Act of 1982, as amended in 1987, that provides the regulatory framework for development of a mined geologic repository. However, before a repository can be used for the disposal of nuclear waste it must meet standards established by the U.S. Nuclear Regulatory Commission (NRC 1985), the Environmental Protection Agency (EPA 1985), and must be licensed by the NRC. The Performance Assessment Scientific Support (PASS) program at Pacific Northwest Laboratory (PNL) provides modeling capabilities to the DOE to assist in assessing the performance of any potential repositories.

This report describes modeling performed at PNL between May and November 1991 addressing the performance of the entire repository system related to regulatory criteria established by the EPA in 40 CFR Part 191. The geologic stratigraphy and material properties used in this study were chosen in cooperation with performance assessment modelers at Sandia National Laboratories (SNL). Sandia modeled a similar problem using different computer codes and a different modeling philosophy. Pacific Northwest Laboratory performed a few model runs with very complex models, and SNL performed many runs with much simpler (abstracted) models.

The modeling presented here is substantially different from previous modeling attempts. Models have been added for gas-phase movement of ${ }^{14} \mathrm{C}$, human intrusion, volcanic intrusion, glass waste forms, and tectonic induced variations. When compared to earlier calculations, a much broader set of conditions has been addressed. The new models consider thermally driven gasphase movement of radionuclides, and movement of radionuclides in the saturated zone. In addition to model development, new information on radionuclide sorption has been obtained, and new geochemical calculations have been performed to estimate the waste form solubility.

The modeling approach described in this report incorporated the latest known data and conceptual model assumptions. However, definitive data from the site are not yet available for many parameters. Consequently, many values were chosen for this exercise based on expert judgment or modeling convenience. Unfortunately, this work did not receive the widespread review within DOE required to ensure that the latest available data were used. For these reasons, the results presented here are not sufficiently advanced to be useful in formulating prudent judgments about site suitability or the expected risk of the potential repository. As a result, the work reported here does not provide a sufficient basis to establish a "baseline" performance assessment.

In addition to the cumulative release modeling, doses were estimated for several of the release scenarios. Working Draft 4 of 40 CFR Part 191 (February 3, 1992) includes the possibility that both individual and population dose limits may be established as repository performance criteria. The dose results presented here indicate that the potential repository may be able to meet both individual and population dose criteria. Substantial work is still required to define the exposure scenarios and environmental radionuclide concentrations needed to complete a definitive analysis of the doses that will be caused by postclosure repository operation. 
The scenarios modeled are not exhaustive of all possible scenarios that will have to be considered for licensing. However, they were selected because they are believed to contribute the largest releases of any scenarios to be considered. In summary, the analyses accomplished for this report support the continued site characterization of Yucca Mountain as a potential site for a highlevel nuclear waste repository and indicate that the limits established by the EPA relative to cumulative release of radionuclides are not exceeded. 


\section{Contents}

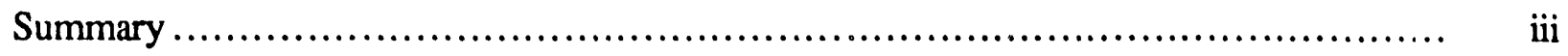

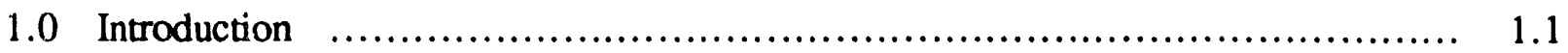

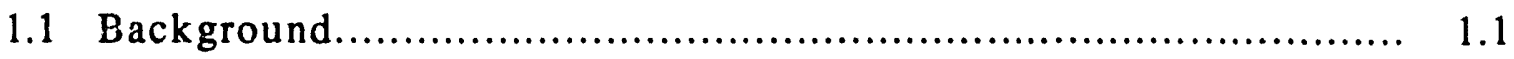

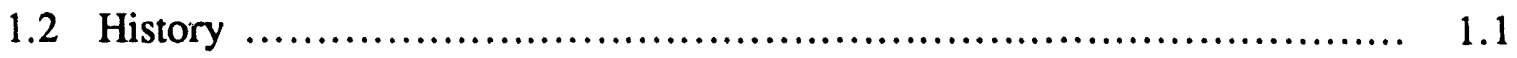

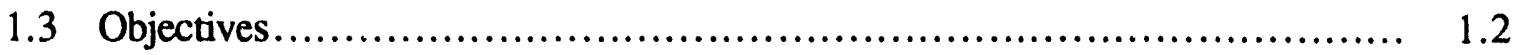

1.4 Link with Other OCRWM Tasks............................................. 1.3

1.5 Differences from Previous Calculations........................................ 1.3

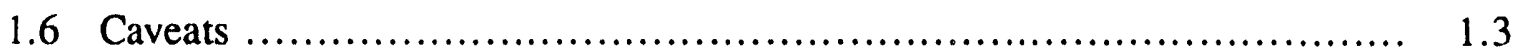

2.0 Overview of Modeling Approach......................................... 2.1

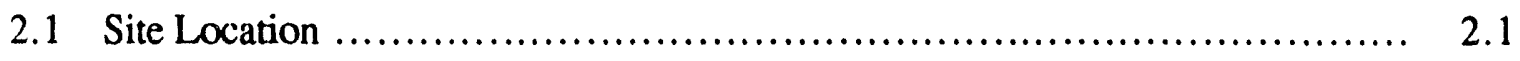

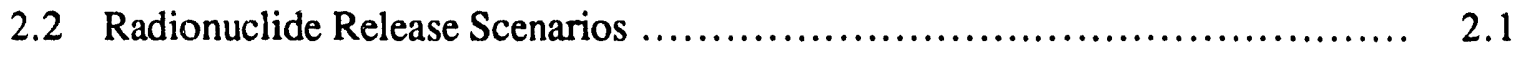

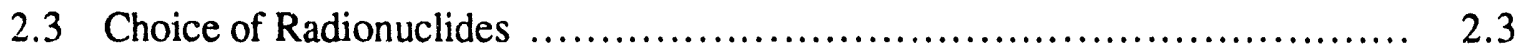

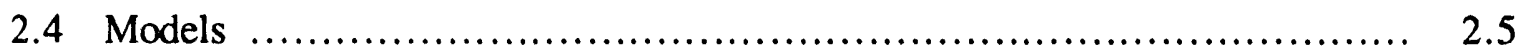

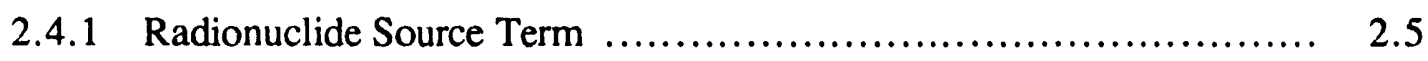

2.4.2 Unsaturated Zone Hydrology and Specie Mass Transport ........... 2.5

2.4.3 Saturated Zone Hydrology and Specie Mass Transport .............. 2.6

2.4.4 Human Intrusion ............................................ 2.6

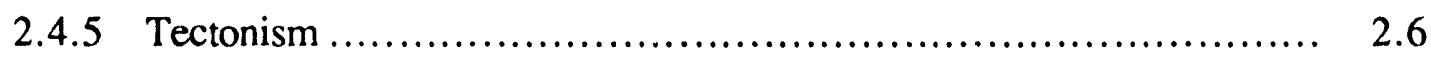

2.4.6 Basaltic Volcanism ............................................ 2.6

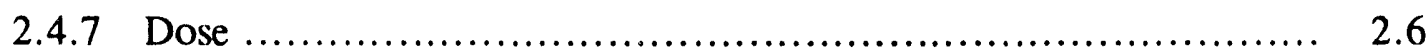

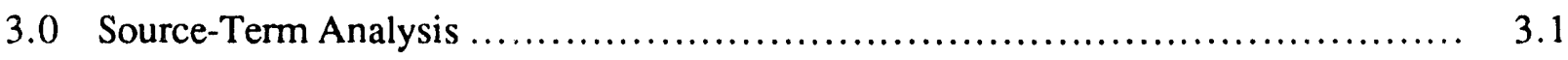

3.1 Description of Release Models ....................................... 3.1

3.1.1 Unsaturated Zone................................................ 3.1

3.1.2 Saturated Zone ............................................... 3.2 


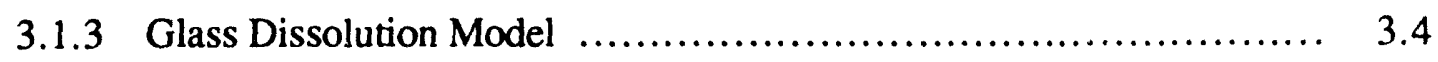

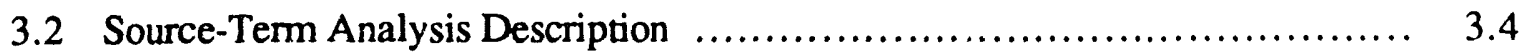

3.3 Source-Term Data Description ........................................ 3.6

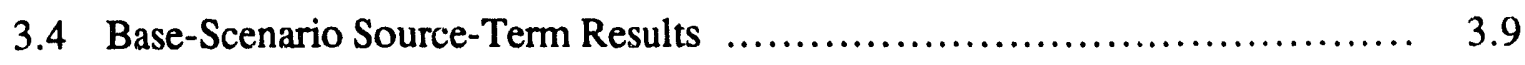

3.5 Human-Intri@ion Scenario Source-Term Results ........................ 3.15

4.0 Unsaturated Zone Hydrology and Transport ................................. 4.1

4.1 Unsaturated Zone Description .......................................... 4.1

4.1.1 Hydrologic and Transport Properties ............................. 4.1

4.1.2 Fracture/Matrix Equivalent-Continuum Model ...................... 4.3

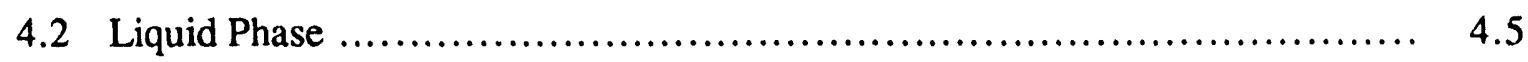

4.2.1 Method and Assumptions ........................................ 4.9

4.2.2 Conceptual and Numerical Models............................... 4.9

4.2 .3 Simulation Results ............................................. 4.12

4.2 .4 Analysis ..................................................... 4.15

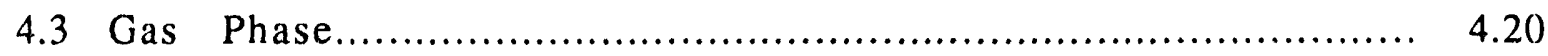

4.3.1 Conceptual and Numerical Models............................... 4.21

4.3.2 Simulation Results ........................................... 4.30

4.3 .3 Assumptions ............................................... 4.50

5.0 Saturated Zone Hydrology and Transport ..................................... 5.1

5.1 Base Scenario ........................................................ 5.1

5.1 .1 Regional Hydrogeology ........................................ 5.1

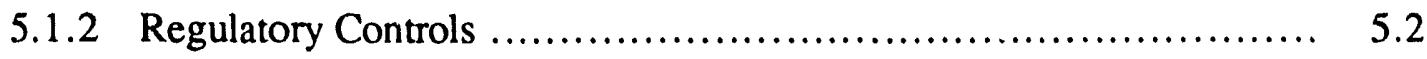

5.1.3 Conceptual and Numerical Models.............................. 5.2

5.1.4 Hydrogeologic Data ................................................ 5.5

5.1.5 Simulation Case Descriptions........................................ 5.5 


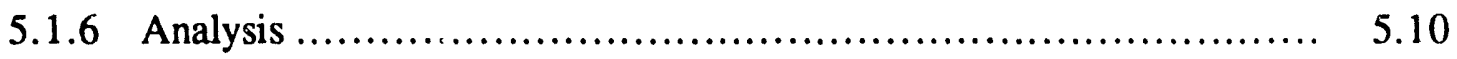

5.2 Human-Intrusion Scenario .......................................... 5.12

5.2.1 Method and Assumptions ...................................... 5.12

$5.2 .2 \quad$ Simulation Descriptions ....................................... 5.12

$5.2 .3 \quad$ Analysis .................................................. 5.21

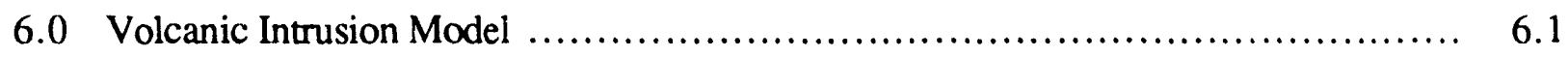

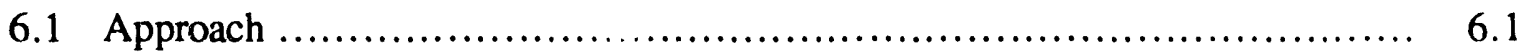

6.2 Basaltic Volcanism-Consequence Model Selection ....................... 6.2

6.3 Input Parameters ...................................................... 6.6

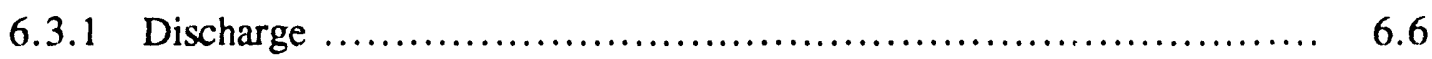

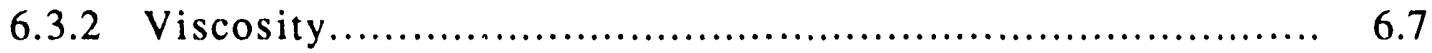

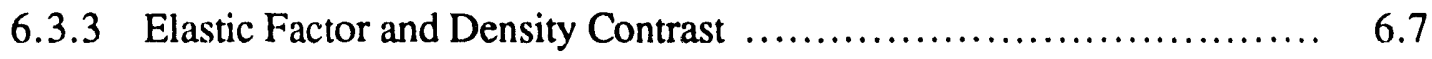

6.3 .4 Source Depth ............................................... 6.8

6.3.5 Entrainment Factor ........................................... 6.8

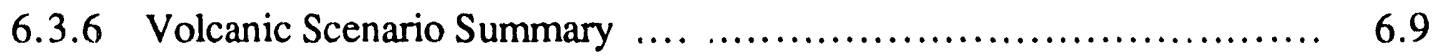

6.4 Results of Basaltic Volcanism-Consequence Model.......................... 6.10

6.5 Basaltic Volcanism-Occurrence Model ..................................... 6.10

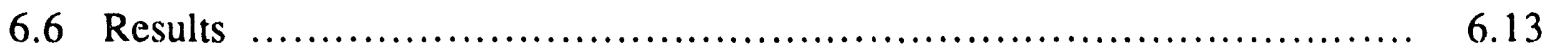

6.6.1 Modeling Link for Volcanic Extrusions ........................... 6.14

6.6.2 Complementary Cumulative Distribution Function for the Volcanic Scenario .............................................................. 6.14

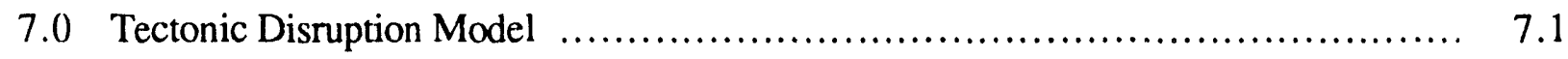

7.1 Identification of Several Initiating Events............................... 7.1

7.2 Choice of Representative Initiating Events ............................. 7.2

7.3 Coupling of Tectonic and Transport Models ............................... 7.3 


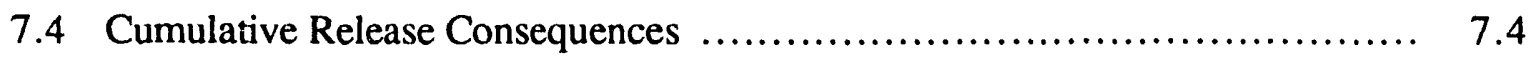

8.0 Human-Intrusion Model ..................................................... 8.1

8.1 Assumptions ..................................................... 8.1

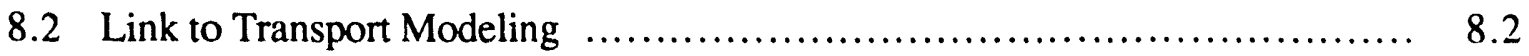

8.2.1 Modeling Link for Exhumed Drill Cuttings ....................... 8.2

8.2.2 Modeling Link for Drilling Event Intercepting a Waste Container ...... 8.2

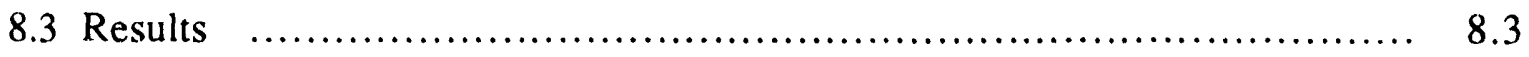

9.0 Cumulative Releases for the Total System........................................ 9.1

9.1 Definition of Accessible Environment................................ 9.1

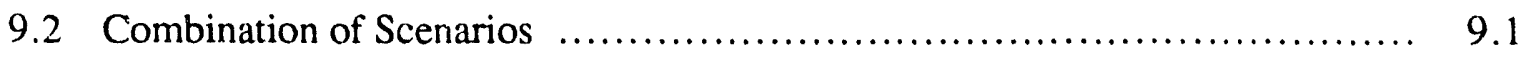

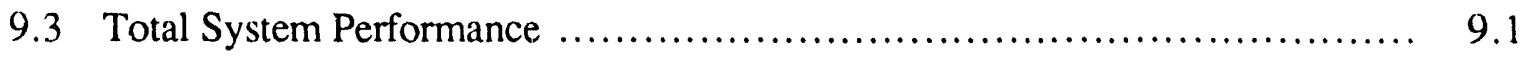

10.0 Dose Modeling Description and Results ................................. 10.1

10.1 Regulatory Requirements for Dose Modeling ........................ 10.1

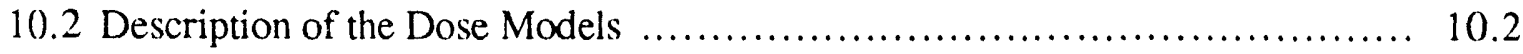

10.3 Scenario Description............................................... 10.3

10.3.1 Waterborne Exposure Scenarios ............................. 10.3

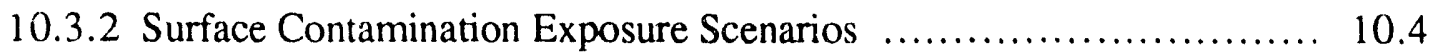

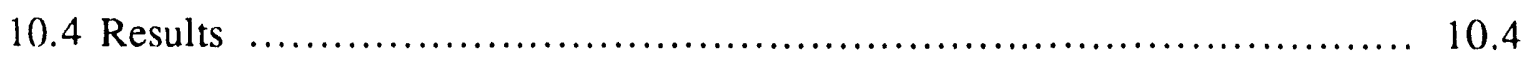

10.4.1 Waterborne Scenarios ...................................... 10.5

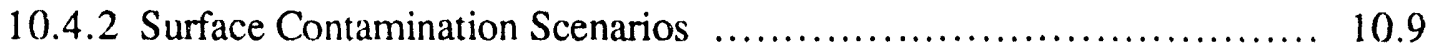

10.5 Comparison with the Waste Isolation Systems Panel Report.................... 10.12

10.6 Discussion and Conclusions ....................................... 10.13

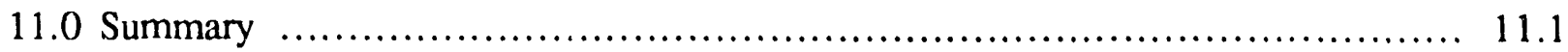

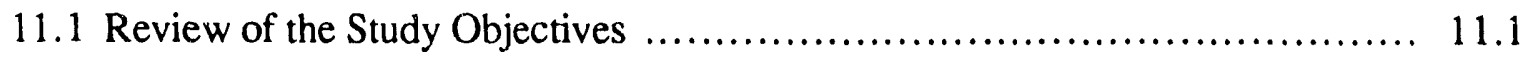

11.2 Recommendations for Future Work ................................. 11.1 
11.2.1 Recommendations for the Choice of Scenarios

11.2.2 Recommendations for Modeling the Engineered Barriers

11.2.3 Recommendations for Modeling Gas-Phase Transport

11.3

11.2.4 Recommendations for Modeling Liquid-Phase Transport.

11.2.5 Recommendations for Modeling Tectonism

11.4

11.2.6 Recommendations for Modeling Volcanism

11.4

11.2.7 Recommendations for Combining Consequences into a Complementary Cumulative Distribution Function

11.2.8 Recommendations for Dose Modeling. 


\section{Figures}

2.1 Location of Yucca Mountain Site in Southern Nevada ........................... 2.2

2.2 Total-System Performance Assessment Scenarios for Radionuclide Release to the Accessible Environment and Relationship to Performance Measures ............... 2.4

3.1 Source-Term Gas-Phase Plus Liquid-Phase Release of ${ }^{14} \mathrm{C}$ : Base Scenario for Spent Fuel Using "Flow-Through" Model at $0.01 \mathrm{~mm} / \mathrm{yr}$ Infiltration Rate

3.2 Source-Term Gas-Phase Plus Liquid-Phase Release of ${ }^{14} \mathrm{C}$ : Base Scenario for Spent Fuel Using "Flow-Througin" Model at $0.05 \mathrm{~mm} / \mathrm{yr}$ Infiltration Rate

3.3 Source-Term Liquid-Phase Release: Base Scenario for Spent Fuel Using "FlowThrough" Model at $0.01 \mathrm{~mm} / \mathrm{yr}$ Infiltration Rate

3.4 Source-Term Liquid-Phase Release: Base Scenario for Spent Fuel Using "FlowThrough" Model at $0.05 \mathrm{~mm} / \mathrm{yr}$ Infiltration Rate

3.5 Source-Term Liquid-Phase Release: Base Scenario for Spent Fuel Using "Flow-

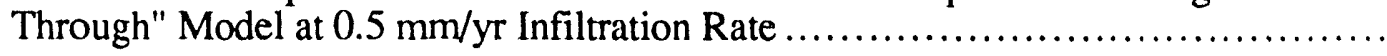

3.6 Source-Term Liquid-Phase Release: Base Scenario for Spent Fuel Using "WetContinuous" Model at $3.0 \mathrm{~mm} / \mathrm{yr}$ Infiltration Rate

3.7 Source-Term Liquid-Phase Release: Base Scenario for Glass Waste Using "Flow-

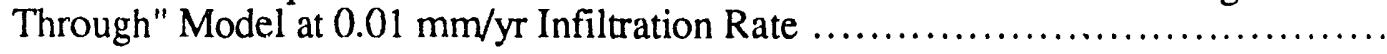

3.8 Source-Term Liquid-Phase Release: Base Scenario for Glass Waste Using "FlowThrough" Model at $0.05 \mathrm{~mm} / \mathrm{yr}$ Infiltration Rate

3.9 Source-Term Liquid-Phase Release: Base Scenario for Glass Waste Using "FlowThrough" Model at $0.5 \mathrm{~mm} / \mathrm{yr}$ Infiltration Rate

3.10 Source-Term Liquid-Phase Release: Base Scenario for Glass Waste Using "WetContinuous" Model at $3.0 \mathrm{~mm} / \mathrm{yr}$ Infiltration Rate

3.11 Source-Term Release Rate: Human-Intrusion Tuff Simulation $1 \ldots \ldots \ldots \ldots \ldots \ldots \ldots . \ldots \ldots$

3.12 Source-Term Release Rate: Human-Intrusion Tuff Simulation 11 ............... 3.16

3.13 Source-Term Release Rate: Human-Intrusion Tuff Simulation 12 ............. 3.17

3.14 Source-Term Release Rate: Human-Intrusion Carbonate Simulation $1 \quad \ldots \ldots \ldots \ldots \ldots$

3.15 Source-Term Release Rate: Human-Intrusion Carbonate Simulation 12 .......... 3.18

3.16 Source-Term Release Rate: Human-Intrusion Carbonate Simulation 12 .......... 3.18 
4.1 West-East Cross-Section: Physical and Hydrogeologic System .................. 4.2

4.2 Water-Retention and Hydraulic-Conductivity Curves for Layer 1, Welded ......... 4.6

4.3 Water-Retention and Hydraulic-Conductivity Curves for Layer 2, Vitrophyre ...... 4.7

4.4 Water-Retention and Hydraulic-Conductivity Curves for Layer 3, Vitric .......... 4.7

4.5 Water-Retention and Hydraulic-Conductivity Curves for Layer 4, Zeolitic ......... 4.8

4.6 Water-Retention and Hydraulic-Conductivity Curves for Layer 5, Partially Welded. 4.8

4.7 One-Dimension Multiphase Subsurface Transport Simulator Solutions for Liquid

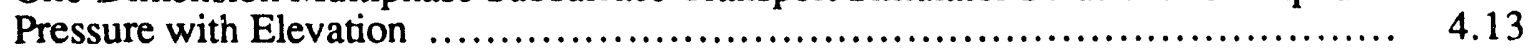

4.8 One-Dimension Multiphase Subsurface Transport Simulator Solutions for Liquid Saturation with Elevation

4.9 Hydraulic-Head Contours for SUMO Steady-State Solution at $0.01 \mathrm{~mm} / \mathrm{yr}$ Recharge

4.10 Liquid-Saturation Contours for SUMO Steady-State Solution at $0.01 \mathrm{~mm} / \mathrm{yr}$ Recharge...

4.11 Darcian Velocity Vectors for SUMO Steady-State Solution at $0.01 \mathrm{~mm} / \mathrm{yr}$ Recharge

4.12 Hydraulic Head Contours for SUMO Approximate-Steady-State Solution at 0.05 $\mathrm{mm} / \mathrm{yr}$ Recharge.

4.13 Hydraulic Head Contours for SUMO Approximate-Steady-State Solution at 0.1 $\mathrm{mm} / \mathrm{yr}$ Recharge.

4.14 Hydraulic Head Contours for SUMO Steady-State Solution at $0.01 \mathrm{~mm} / \mathrm{yr}$ Recharge and Tectonic Disruption

4.15 Liquid-Saturation Contours for SUMO Steady-State Solution at $0.01 \mathrm{~mm} / \mathrm{yr}$ Recharge and Tectonic Disruption

4.16 Darcian Velocity Vectors for SUMO Steady-State Solution at $0.01 \mathrm{~mm} / \mathrm{yr}$ Recharge and Tectonic Disruption

4.17 Travel Particle Pathlines from Repository to Saturated Zone for $0.01 \mathrm{~mm} / \mathrm{yr}$ Base Scenario

4.18 Travel Time as a Function of Path Distance for $0.01 \mathrm{~mm} / \mathrm{yr}$ Base Scenario.

4.19 Travel Particle Pathlines from Repository to Saturated Zone for $0.01 \mathrm{~mm} / \mathrm{yr}$ Tectonic Scenario

4.20 Travel Time as a Function of Path Distance for $0.01 \mathrm{~mm} / \mathrm{yr}$ Tectonic Scenario....... 


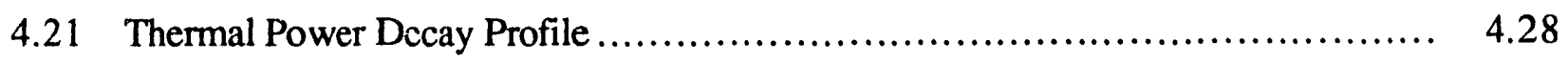

4.22 Potential Repository ${ }^{14} \mathrm{C}$ Release Rates and Total Activity Outside the Repository . 4.28

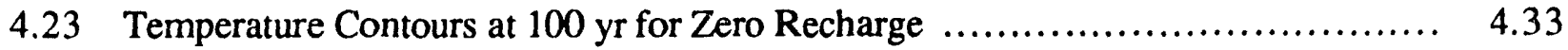

4.24 Liquid-Saturation Contours at $100 \mathrm{yr}$ for Zero Recharge ...................... 4.33

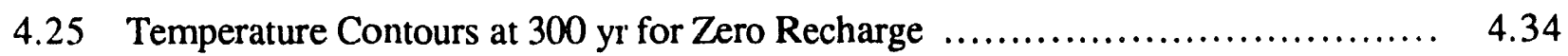

4.26 Liquid-Saturation Contours at $300 \mathrm{yr}$ for Zero Recharge ........................ 4.34

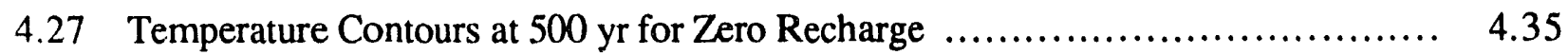

4.28 Liquid-Saturation Contours at $500 \mathrm{yr}$ for Zero Recharge ....................... 4.35

$4.29{ }^{14} \mathrm{C}$-Concentration Contours at $500 \mathrm{yr}$ for Zero Recirarge Using the Millington and Quirk Tortuosity Model

4.30 14C-Concentration Contours at $500 \mathrm{yr}$ for Zero Recharge Using the Penman

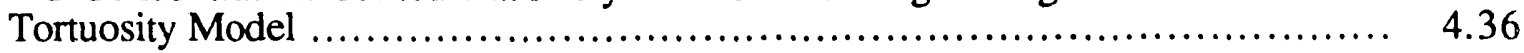

4.31 Temperature Contours at $1000 \mathrm{yr}$ for Zero Recharge.................................... 4.38

4.32 Liquid-Saturation Contours at $1000 \mathrm{yr}$ for Zero Recharge.............................. 4.38

4.33 14C-Concentration Contours at $1000 \mathrm{yr}$ for Zero Recharge Using the Millington and Quirk Tortuosity Model

4.34 $14 \mathrm{C}$-Concentration Contours at 1000 yr for Zero Recharge Using the Penman

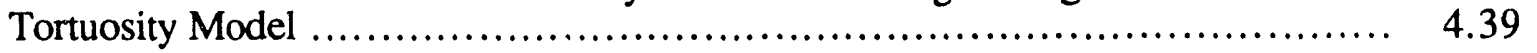

4.35 Temperature Contours at $2000 \mathrm{yr}$ for Zero Recharge..................................... 4.40

4.36 Liquid-Saturation Contours at $2000 \mathrm{yr}$ for Zero Recharge............................... 4.40

4.37 $14 \mathrm{C}$-Concentration Contours at $2000 \mathrm{yr}$ for Zero Recharge Using the Millington and Quirk Tortuosity Model

4.38 ${ }^{14} \mathrm{C}$-Concentration Contours at $2000 \mathrm{yr}$ for Zero Recharge Using the Penman

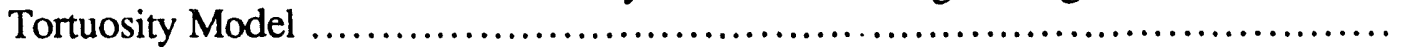

4.39 Temperature Contours at $4000 \mathrm{yr}$ for Zero Recharge.................................... 4.42

4.40 Liquid-Saturation Contours at $4000 \mathrm{yr}$ for Zero Recharge.............................. 4.42

4.41 ${ }^{14} \mathrm{C}$-Concentration Contours at $4000 \mathrm{yr}$ for Zero Recharge Using the Millington and Quirk Tortuosity Modd 
$4.42{ }^{14} \mathrm{C}$-Concentration Contours at 4000 yr for Zero Recharge Using the Penman Tortuosity Model

4.43 Temperature Contours at $6000 \mathrm{yr}$ for Zero Recharge............................... 4.44

4.44 Liquid-Saturation Contours at $6000 \mathrm{yr}$ for Zero Recharge............................ 4.44

4.45 14C-Concentration Contours at $6000 \mathrm{yr}$ for Zero Recharge Using the Millington and Quirk Tortuosity Model

4.46 14C-Concentration Contours at 6000 yr for Zero Recharge Using the Penman Tortuosity Model

4.47 Temperature Contours at 8000 yr for Zero Recharge.

4.48 Liquid-Saturation Contours at 8000 yr for Zero Recharge.

$4.49{ }^{14} \mathrm{C}$-Concentration Contours at $8000 \mathrm{yr}$ for Zero Recharge Using the Millington and Quirk Tortuosity Model

4.50 14C-Concentration Contours at 8000 yr for Zero Recharge Using the Penman Tortuosity Model

4.51 Temperature Contours at $10,000 \mathrm{yr}$ for Zero Recharge

4.52 Liquid-Saturation Contours at $10,000 \mathrm{yr}$ for Zro Recharge

$4.53{ }^{14} \mathrm{C}$-Concentration Contours at $10,000 \mathrm{yr}$ fo: $<1$. Recharge Using the Millington and Quirk Tortuosity Model

$4.54{ }^{14} \mathrm{C}$-Concentration Contours at $10,000 \mathrm{yr}$ for Zero Recharge Using the Penman Tortuosity Model

4.55 ${ }^{14} \mathrm{C}$ Ground-Surface Releases Using the Penman Tortuosity Model.

5.1 Configuration of Hydrologic Domain for the Modeled Tuff Aquifer and the Carbonate Aquifer

5.2 RFIELD-Generated Logarithmic Saturated Hydraulic Conductivity Field for Carbonate Simulation 1

5.3 RFIELD-Genurated Logarithmic Saturated Hydraulic Conductivity Field for Tuff Simulation 3

5.4 Hydraulic Head Distribution for Carbonate Simulation 1

5.5 Travel Particle Pathlines Carbonate Simulation 1 .................................

5.6 Travel Time as a Function of Path Distance for Carbonate Simulation 1 
5.7 Hydraulic Head Distribution for Tuff Simulation 3.................................. 5.9

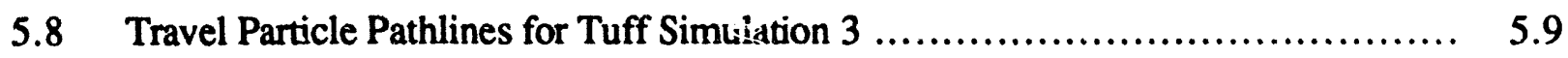

5.9 Travel Time as a Function of Path Distanu for Tuff Simulation 3 ............... 5.10

5.10 Grid Node Configuration for Simulated Carbonate Hydrologic Domain ........... 5.11

5.11 Radionuclide Flux at 5-km Boundary for Carbonate Simulation 1 ............... 5.14

5.12 Radionuclide Flux at 5-km Boundary for Carbonate Simulation 2 ............... 5.14

5.13 Radionuclide Flux at 5-km Boundary for Carbonate Simulation 3 …........... 5.15

5.14 Radionuclide Flux at 5-km Boundary for Carbonate Simulation 4 ............... 5.15

5.15 Radionuclide Flux at 5-km Boundary for Carbonate Simulation 5 .............. 5.16

5.16 Radionuclide Flux at 5-km Boundary for Carbonate Simulation $6 \ldots \ldots \ldots \ldots \ldots \ldots . \quad 5.16$

5.17 Radionuclide Flux at 5-km Boundary for Carbonate Simulation $7 \ldots \ldots \ldots \ldots \ldots \ldots . \quad 5.17$

5.18 Radionuclide Flux at 5-km Boundary for Carbonate Simulation $8 \ldots \ldots \ldots \ldots \ldots \ldots . \quad 5.17$

5.19 Radionuclide Flux at 5-km Boundary for Carbonate Simulation $9 \ldots \ldots \ldots \ldots \ldots \ldots . \ldots .18$

5.20 Radionuclide Flux at 5-km Boundary for Carbonate Simulation $10 \ldots \ldots \ldots \ldots \ldots \ldots . .18$

5.21 Radionuclide Flux at 5-km Boundary f Carbonate Simulation 11 .............. 5.19

5.22 Radionuclide Flux at 5-km Boundary for Carbonate Simulation $12 \ldots \ldots \ldots \ldots \ldots . . \ldots .19$

5.23 Radionuclide Flux at 5-km Boundary for Tuff Simulation 12........................ 5.23

$5.24{ }^{14} \mathrm{C}$ Flux Across the 5-km Boundary Using Maximum-Flow Field Parameters .... 5.23

6.1 Volcanic Centers Near Yucca Mountain ...................................... 6.3

6.2 Volcanic Dike Dimensions................................................... 6.11

6.3 Conditional Complementary Cumulative Distribution Function for Basaltic Dike

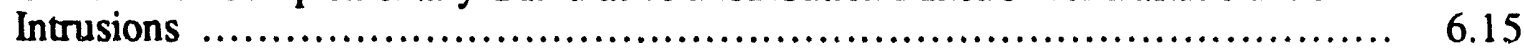

7.1. Probability of Coseismic Water Table Change ................................ 7.4

8.1 Conditional Complementary Cumulative Distribution Function for Rock Column Releases to the Surface ............................................................... 8.4

8.2 Conditional Complementary Cumulative Distribution Function for Surface Releases from Direct Container Hits. 


\subsection{Conditional Complementary Cumulative Distribution Function for Carbonate}

Aquifer Waste Injection .................................................... 9.5

9.1 Combination of Conditional Complementary Cumulative Distribution Functions ... 9.2

9.2 Complementary Cumulative Distribution Function for Total System Performance... 9.3 


\section{Tables}

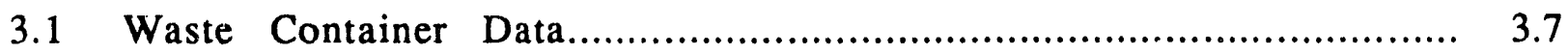

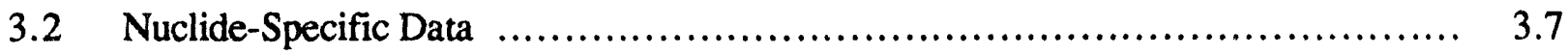

3.3 Base-Scenario Solubility Data ................................................ 3.7

3.4 Base-Scenario Repository Liquid Saturation for Various Recharge Rates........... 3.8

3.5 Human-Yntzision Scen ario Aquifer Data....................................... 3.8

3.6 Human-Intrusion Scenario Drilling Times and Flow Rates ...................... 3.8

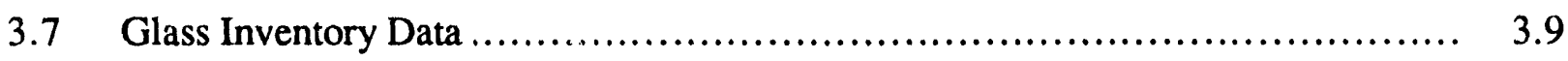

4.1 Mean Hydrologic Parameters .................................................. 4.2

4.2 Radionuclide Half-Lives and Sorption Coefficients .............................. 4.3

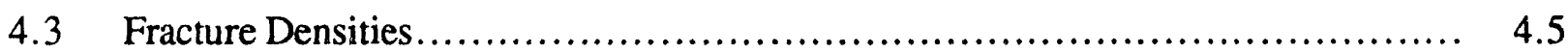

4.4 Computed Rock Parameter Values for Equivalent-Continuum Model ............... 4.6

4.5 Computed Fault Parameter Values for Equivalent-Continuum Model .............. 4.6

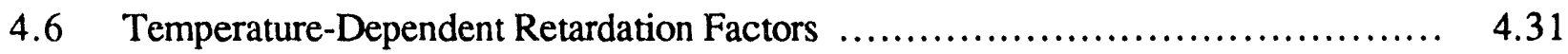

5.1 Aquifer Physical Properties for Saturated Zone Modeling......................... 5.3

5.2 Hydraulic Gradients, Hydraulic Conductivities and Time of Drilling Intrusion Under the Human-Intrusion Scenario for Each Simulation for the (a) Tuff Aquifer and (b) Carbonate Aquifer

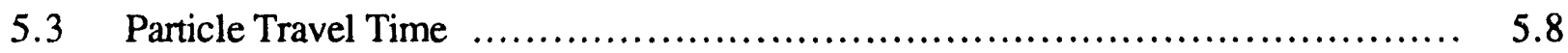

$5.4 \quad$ Deterministic and Stochastic Sorption Values............................... 5.13

5.5 Cumulative Radionuclide Releases at 10,000 Years Across the 5-km Boundary for Carbonate-Aquifer Simulations of Human-Intrusion Scenario Direct-Injection Case

5.6 Cumulative Release of Radionuclides to the Saturated Zone at 10,000 Years with

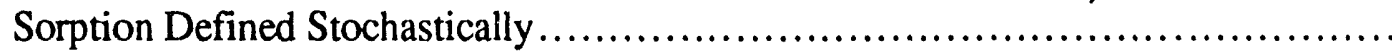

6.1 Parameters Used in Basaltic Dike Simulation ................................. 6.7

6.2 Dimensions of Various Basaltic Dikes ....................................... 6.11

8.1 Human-Intrusion Pathways .................................................. 8.1 
10.1 Whole Body Organ Weighing Factors ...................................... 10.3

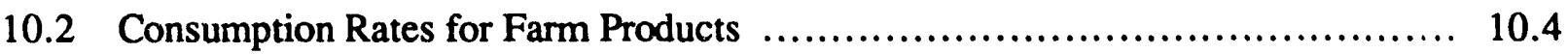

10.3 Radioactive Decay Chains and Half-Lives................................. 10.5

10.4 Summary of Simuiations for Which Doses Were Estimated............................... 10.5

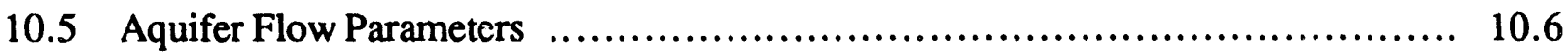

10.6 Dose Summary for Pacific Northwest Laboratory Waterborne Human-Intrusion

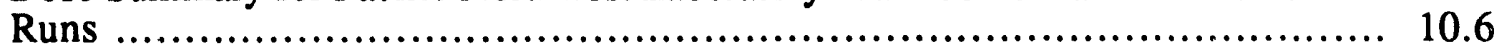

10.7 Dose by Organ for the Pacific Northwest Laboratory Maximum Flow-Rate

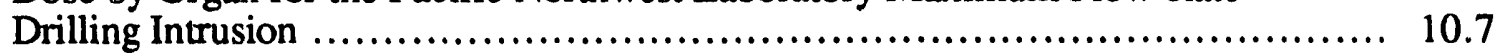

10.8 Dose by Pathway for the Pacific Northwest Laboratory Maximum Flow-Rate Drilling Intrusion ....................................................... 10.7

1C.9 Dose Summary for Sandia National Laboratories Waterborne Runs ............... 10.9

10.10 Dose by Organ (mrem/yr) for Sandia National Laboratories TOS Undisturbed Performance Run

10.11 Dose by Organ (mrem/yr) for Sandia National Laboratories WEE Undisturbed Performance Run

$10.12{ }^{237} \mathrm{~Np}$ Dose by Organ (mrem/yr) for Sandia National Laboratories Human-Intrusion Runs

10.13 Pacific Northwest Laboratory ${ }^{14} \mathrm{C}$ Gas-Phase Release Summary

10.14 Pacific Northwest Laboratory Direct-Hit Spent Fuel Drilling Intrusion Summary ...

10.15 Pacific Northwest Laboratory Direct-Hit Glass Fuel Drilling Intrusion Summary ...

10.16 Sandia National Laboratories ${ }^{14} \mathrm{C}$ Gas-Phase Release Summary .....

10.17 Sandia National Laboratories ${ }^{14} \mathrm{C}$ Gas-Phase Weeps Model Release Summary ..... 10.13

10.18 Comparison of SUMO and Waste Isolation Systems Panel Dose Results 10.13 


\subsection{Introduction}

Certain background information, a brief history of performance assessment efforts for the potential Yucca Mountain high-level nuclear waste repository, and the objectives of this totalsystem performance assessment and its linkages to other similar tasks are discussed in this section. Differences between this total-system performance assessment and previous calculations are also discussed, and several important caveats regarding this study are presented.

\subsection{Background}

Operation of commercial nuclear reactors to provide electric energy yields the byproduct of spent nuclear fuel. Additional high-level nuclear waste has also been produced by reprocessing spent fuel and through defense-related activities. The placement of radioactive wastes in mined repositories deep underground is considered a disposal method that would effectively isolate these wastes from the accessible environment for long periods of time.

The U.S. Department of Energy (DOE) is responsible, and, within certain limitations, has the authority to implement the provisions of the Nuclear Waste Policy Act (NWPA) of 1982, as amended in 1987, that provides the regulatory framework for development of a mined geologic repository. However, before a repository can be used for the disposal of nuclear waste it must meet standards established by the U.S. Nuclear Regulatory Commission (NRC 1985) and the U.S. Environmental Protection Agency (EPA 1985)(a), and must be licensed by the NRC.

The DOE, through the Office of Civilian Radioactive Waste Management (OCRWM), is responsible for implementing requirements of the NWPA. This inciudes DOE review, concurrence, and sign-off on activities identified as Secretaria'i actions (e.g., the Site Characterization Plan [SCP], Environmental Impact Statemen a S Safety Analysis Report). Because the NRC and EPA regulations base the final determinat in: i a site's suitability on a calculational projection of its performance well into the future, the DOE must ensure that recommendations and decisions are based on technically defensible, independently verified predictions of the performance of a potential repository. The Performance Assessment Scientific Support (PASS) program at Pacific Northwest Laboratory(b) (PNL) provides modeling capabilities to assist the DOE in assessing the performance of potential repositories.

\subsection{History}

This is not the first attempt to model the performance of a potential repository at Yucca Mountain, a volcanic-tuff site in Nye County of southern Nevada that is a potential host for a highlevel nuclear waste geologic repository. The earliest extensive modeling was reported in the Environmental Assessment (DOE 1986). The Office of Civilian Radioactive Waste Management also sponsored a study, performed by PNL and ending in 1987, to perform a preliminary

(a) Some sections of the EPA standard (40 CFR 191) were vacated by a Federal Appeals Court decision. A revised standard has not yet been formally implemented, although Working Draft 4 of 40 CFR 191, dated February 3 , 1992, has been issued for review and comment.

(b) Pacific Northwest Laboratory is operated by Battelle Memorial Institute for the U.S. Department of Energy. 
assessment of Yucca Mountain as a repository site (Doctor et al. 1992). The performance measure for that study was risk expressed as population dose. Subsequently, an SCP (DOE 1988) was written to guide data collection and modeling activities in determining the suitability of the geologic setting for siting a repository at Yucca Mountain.

In fiscal year (FY) 1990, DOE sponsored a total-system modeling effort, identified as PACE-90 and, in FY 1991, sponsored activities aimed at developing the models and knowledge required to establish a baseline performance-assessment estimate. To date, a baseline performance assessment has not been established because the DOE has just initiated site characterization activities that are scheduled to last several years. In addition to DOE-sponsored ruodeling, the Electric Power Research Institute (EPRI) has completed a total-system performance estimate (McGuire et al. 1990).

Models for evaluating the performance of Yucca Mountain are under development for the DOE at PNL and Sandia National Laboratories (SNL). In addition, the NRC has contracted Southwest Research Institute (San Antonio, Texas) to develop modeling capabilities that will allow them to evaluate the performance estimates developed by the DOE and its contractors.

Most of the total-system performance models for Yucca Mountain address the cumulative release of radionuclides to the "accessible environment." A limit on the cumulative release of radionuclides to the accessible environment for the first 10,000 years of repository performance is one of the quantitative requirements set by the EPA (EPA 1985). In addition, the EPA regulation addresses, for some sources of groundwater, the risk of a repository expressed as a maximum dose from drinking water. Only a limited amount of modeling for the purpose of estimating doses from the potential repository at Yucca Mountain has been sponsored by OCRWM.

On February 3, 1992, the EPA issued Working Draft 4 of the revisions to 40 CFR Part 191 (EPA, 1985). In this draft the EPA is considering a population dose criteria as an alternative to the cumulative release criteria. In addition, the individual protection criteria is extended to 10,000 years after repository closure. These criteria require dose modeling for both individuals and populations.

\subsection{Objectives}

This report describes modeling performed at PNL between May and November 1991 that addressed the performance of the entire potential repository system. Specific objectives of the modeling task were to:

- identify further conceptual and calculational model development needs

- refine and more fully prioritize identified data needs and help guide site characterization

- define relative sensitivities of total-system performance to the conceptual model, data assumptions, and computational methods

- make a preliminary evaluation of the potential repository total-system performance.

All of these general objectives were met in the course of the total-system performance assessment embodied in this report. 


\subsection{Link With Other OCRWM Tasks}

The geologic stratigraphy and material properties used in this study were chosen in cooperation with performance assessment modelers at SNL. They modeled a similar problem using different computer codes and a different modeling philosophy. The main difference between the modeling philosophies was that PNL performed a few model runs with very complex models, and SNL performed many runs with much simpler (abstracted) models. The PNL and SNL results were simultaneously presented to the DOE in November 1991, for a discussion of the results and comparison of the modeling techniques. SNL total-system performance assessment results are reported in Barnard et al. (1992).

\subsection{Differences From Previous Calculations}

The modeling presented here is substantially different from previous attempts. Models have been added for gas-phase movement of $14 \mathrm{C}$, human intrusion, volcanic intrusion, glass-waste forms, and tectonic-induced variations. When compared to the PACE-90 calculations, a much broader set of conditions has been addressed. The new models consider thermally driven, gasphase movement of radionuclides, and movement of radionuclides in the saturated zone. In addition to model development, new information on radionuclide sorption has been obtained, and new geochemical calculations have been performed to estimate the waste form solubility.

\subsection{Caveats}

Four objectives for this modeling task were given in Section 1.3. The first three objectives were accomplished. The final objective, to make a preliminary evaluation of the potential repository performance, was not fully achieved. The approach chosen, and described in this report, incorporated the most recent data and conceptual model assumptions available to the modelers. However, definitive data from the site are not yet available for many parameters, so many values were chosen for this exercise based on expert judgment or modeling convenience. In addition, this work did not receive the widespread review within DOE required to ensure that the latest available data and information were used.

To achieve a baseline performance assessment, several additional things must be done. First, a complete set of nuc lides of regulatory interest must be analyzed. This study analyzed 10 nuclides out of a set of severai jozen of interest. Second, additional site-specific data are needed to calibrate existing models and other data are required to check the validity of the modeling assumptions. Finally, the computer codes used must be subjected to formal Quality Assurance (QA) requirements. The current models were used while still in the development and documentation stages. Formal testing has not been completed.

For these reasons, the modeling results presented here are not sufficiently advanced to be useful in formulating prudent judgments about site suitability or the expected risk of the repository. Specifically, the work reported here does not provide a sufficient basis to establish a "baseline" performance assessment. 


\subsection{Overview of Modeling Approach}

The location of Yucca Mountain, the site of a potential high-level nuclear waste repository in southern Nevada, and the scenarios for radionuclide release modeled in this total-system performance assessment are discussed in this Section. The representative radionuclides chosen for modeling in this study are presented along with the rationale for examining each. Finally, the specific models used to predict each scenario : nnsidered in this study are presented.

\subsection{Site Location}

The Yucca Mountain site is located in southern Nevada about $160 \mathrm{~km}$ northwest of Las Vegas and is situated on land controlled by three federal agencies: the U.S. Air Force, the DOE, and the Bureau of Land Management (Figure 2.1).

\subsection{Radionuclide Release Scenarios}

Four primary scenarios for release of radionuclides from the potential repository to the accessible environment were modeled for this total-system performance assessment iteration: base (expected conditions), human intrusion, volcanic disruption, and tectonic disruption. The accessible environment for this assessment is taken to be the ground surface in the vertical direction and a distance of $5 \mathrm{~km}$ from the repository in the horizontal direction, as defined in 40 CFR Part 191.12. Because the ground-surface is a physical boundary while the $5-\mathrm{km}$ boundary is a regulatory concern, these boundaries do not necessarily coincide.

The base scenario addresses waste container degradation and failure under expected conditions in the potential repository, followed by waste migration through the unsaturated (vadose) zone in liquid phase to the regional ground-water table and in gas phase to the ground surface. Releases to the water table migrate to the 5-km accessible-environment boundary and are assumed to be extracted by a water well for human-population dose calculations, while releases to the ground surface contribute to dose calculations through atmospheric pathways.

The human-intrusion scenario is divided into four cases, all of which are based on assumptions regarding future exploratory drilling by persons unaware of the repository's existence. These cases are: 1) exhumed container waste, 2) an exhumed column of contaminated rock, 3) deep injection of waste into the tuff aquifer, and 4) deep injection of waste into the Paleozoic (carbonate) aquifer. The first two cases envision a driller intercepting rock with migrating radionuclides from failed containers, or contaminated rock and a waste container by means of a "direct hit," and exhuming these to the surface. The last two cases envision a driller intercepting a waste container such that the container integrity is compromised, drilling on into an aquifer below the potential repository, and ultimately causing the displacement of the container's waste to the aquifer.

The volcanic-disruption scenario addresses the consequences of a disruption of the potential repository and the uncontrolled release of radionuclides to the accessible environment because of the subsurface and surface activity of a basaltic magmatic center. The subsurface activity would comprise dikes, sills, and/or other intruded magma modes, and the surface activity is assumed to be a Strombolian eruption of alkalic basalt and the construction of one or more cinder cones. 


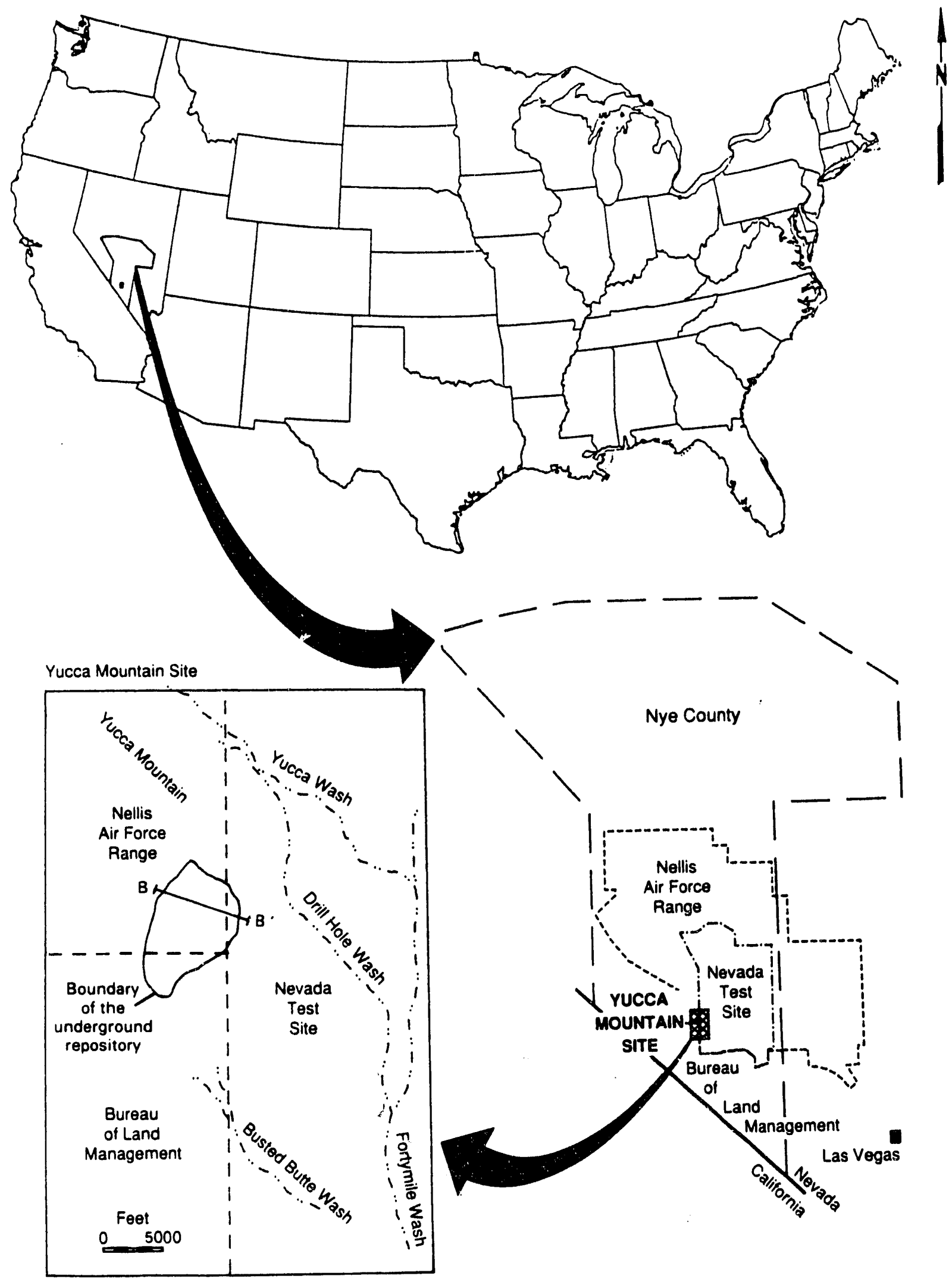

Figure 2.1. Location of Yucca Mountain Site in Southern Nevada (DOE, 1988) 
The tectonic-disruption scenario addresses the possibility of coseismic water table change because of a tectonic disruption. The chief impact of this disruption is assumed to be the permanent elevation of the regional water table and subsequent change in the hydrology and mass transport of radionuclides in the unsaturated zone in the vicinity of the potential repository.

Figure 2.2 depicts the interaction of the four scenarios addressed in this total system performance assessment iteration. All of the release paths by which radionuclides may be released to the accessible environment that are addressed by this total-system performance assessment are shown in Figure 2.2, beginning with inventory tracking of waste accounting for radioactive decay of the inventory and container degradation, failure, and release. Container inventory as well as release rates are necessary because four disruptive events accounted for in this assessment (three human-intrusion cases and the volcanic disruption) involve displacement of the contents of an entire container or containers. Ultimately, all processes modeled in this total-system performance assessment lead either to a surface release or the arrival of water-borne contaminants at the 5-km boundary. Hence, all processes contribute to the cumulative release calculation for radionuclides or the human-dose calculation under a number of dose scenarios.

\subsection{Choice of Radionuclides}

One of the objectives for this analysis was to demonstrate the capability to conduct a totalsystem performance assessment. It was felt that the analysis capability could be demonstrated without analyzing all radionuclides of regulatory concern. Additional chemical and physical data are needed to properly assess the impact of many of the nuclides excluded from this analysis. Ten

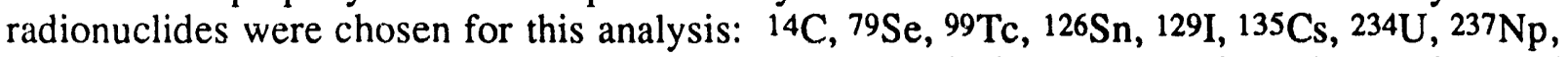
${ }^{239} \mathrm{Pu}$, and $243 \mathrm{Am}$. Because of retardation in transport, only four nuclides from the uranium and neptunium decay chains were chosen. The other nuclides chosen are expected to be transported faster. Specific reasons for selecting these radionuclides are as follows:

- ${ }^{14} \mathrm{C}$ - the only nuclide considered to have the potential for significant releases via gas-phase pathways

- ${ }^{79} \mathrm{Se}$ - moderate-inventory nuclide, moderately delayed in transport by sorption processes

- $\quad 99 \mathrm{Tc}$ - high-inventory nuclide, moderately delayed in transport by sorption processes

- $\quad 126 \mathrm{Sn}$ - moderate-inventory nuclide with a long half-life

- $129 \mathrm{I}$ - not delayed in transport by sorption processes, has a high concentration to doseconversion factor

- $135 \mathrm{Cs}$ - moderate-inventory nuclide, moderately delayed in transport by sorption processes

- $234 \mathrm{U}$ - uranium isotope with the highest 1000 -year inventory

- ${ }^{237} \mathrm{~Np}$ - high-inventory nuclide with very long half-life and a high concentration to doseconversion factor 


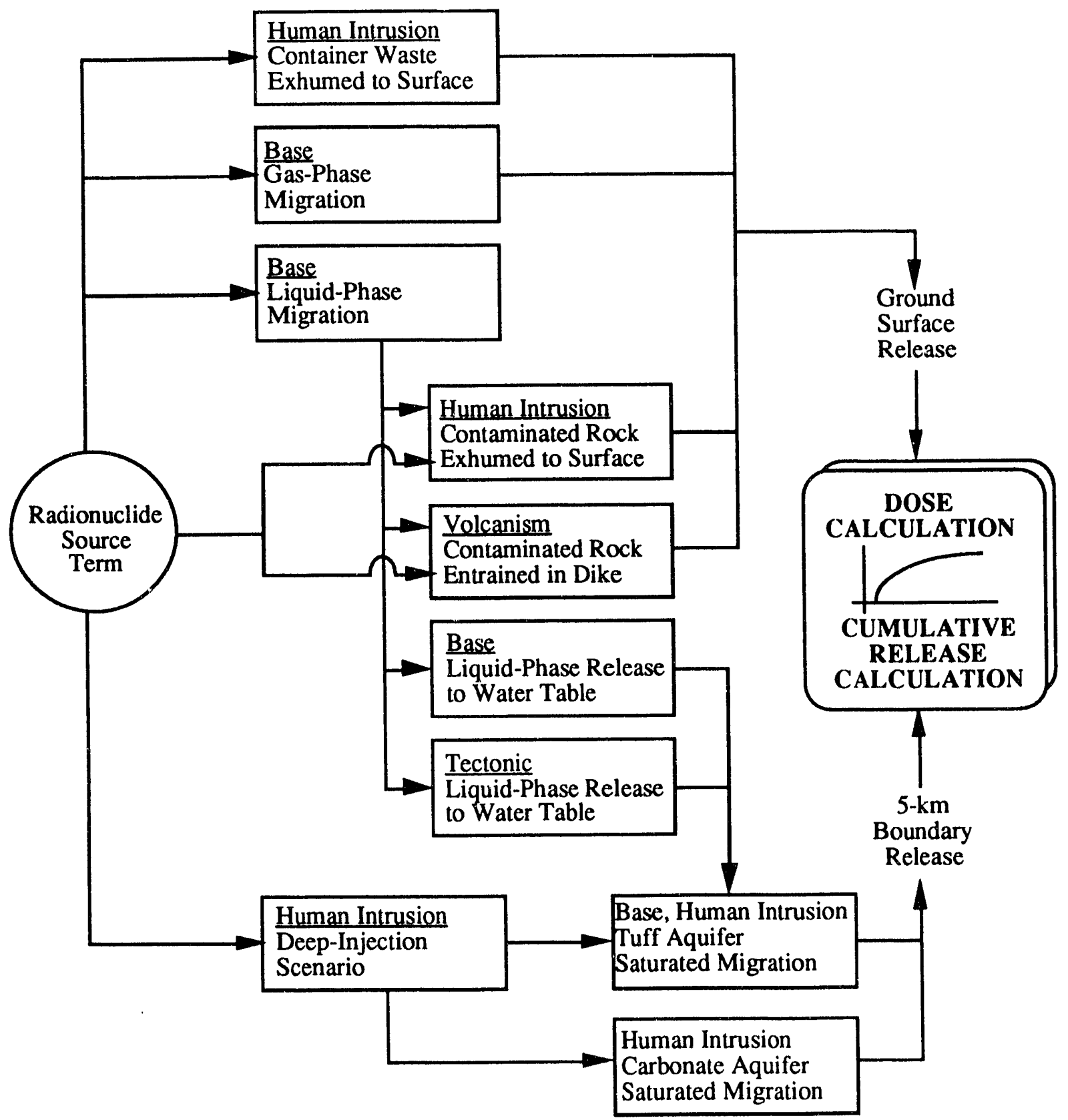

Figure 2.2. Total-System Performance Assessment Scenarios for Radionuclide Release to the Accessible Environment and Relationship to Performance Measures 
- $\quad 239 \mathrm{Pu}$ - high-inventory nuclide that has received significant press exposure, chosen over the higher inventory $240 \mathrm{Pu}$ because it is in the decay chain for ${ }^{243} \mathrm{Am}$

- $243 \mathrm{Am}$ - high-inventory nuclide that is also highly retarded, providing an example of radionuclide decay-chain modeling.

\subsection{Models}

The summary performance measure utilized in this study was the complementary cumulative distribution function (CCDF) for cumulative release of radionuclides to the accessible environment (Table 1 of 40 CFR Part 191; EPA 1985). The CCDF includes information from base-case results and disruptive scenarios. The CCDF is based on releases to the accessible environment. A number of parameters were varied stochastically to generate the required (example) distribution function.

In addition, doses were estimated for many radionuclide-release scenarios. The doses were estimated using models and scenarios that were designed to estimate cumulative release of radionuclides rather than dose. A careful study of the risk of the potential repository in terms of individual or population doses would probably use different release and transport scenarios. The major reason for this is that maximum dose results are determined by maximum radionuclide concentrations rather than cumulative flux over a 10,000-year time period.

\subsubsection{Radionuclide Source Term}

Engineered-barrier source term release rates were computed for a total of 10 nuclides. The nuclides were chosen to represent a cross section of physical properties and repository inventories that emphasized large impacts in the dose models. Source terms were computed for spent fuel and a representative glass-waste form. The spent-fuel inventories were taken from ORIGEN runs at SNL that incorporated recent fuel-burnup assumptions. Source terms were computed for basescenario analyses (incorporating a range of infiltration rates and rock saturation conditions) and human-intrusion scenario cases involving deep injection of waste into the saturated zone.

\subsubsection{Unsaturated Zone Hydrology and Specie Mass Transport}

Based on the problem consensus, the unsaturated zone model was modeled as a twodimensional (East-West) cross section of Yucca Mountain that included the Ghost Dance fault, a fault that transects the potential underground repository (DOE 1988). The vertical extent of this cross section was from the regional water table to just above the repository horizon, except for the multiphase model, for which the vertical extent was from the regional water table to the ground surface.

A liquid-phase analysis considered the combined effects of matrix and fracture flow in an equivalent-continuum model (i.e., fractures were not modeled explicitly). SUMO, a steady-state, isothermal, liquid-phase ground-water flow model (Eslinger et al. 1990) was used to predict basescenario flow and dilute-species mass transport of the 10-radionuclide inventory examined for this total-system performance assessment for a range of recharge rates.

The gas-phase (multiphase) analysis was performed using the Multiphase Subsurface Transport Simulator (MSTS) code to model dilute-specie mass transport of the single radionuclide 
${ }^{14} \mathrm{C}$ in both the gas and the liquid phases, including the effects of thermal loading of the repository. The air, water, and thermal-energy conservation equations for this model were solved in a fully coupled manner. Exchange of carbon between water vapor and liquid water was also addressed in the model.

\subsubsection{Saturated Zone Hydrology and Specie Mass Transport}

Saturated zone flow and transport was modeled for the human-intrusion scenario cases involving injection of waste, and those base-scenario analyses that predicted contaminant movement into the saturated zone. A two-dimensional domain and a steady-state hydrology solution were used. Simulations were performed for transport in both tuff and carbonate aquifers.

\subsubsection{Human Intrusion}

Human-intrusion analyses considered four release cases. These cases were: 1) exhumed container waste, 2) an exhumed column of contaminated rock, 3 ) injection of waste into the tuff aquifer, and 4) injection of waste into the Paleozoic (carbonate) aquifer. The range of outcomes depended on the time of occurrence and drill hole location.

\subsubsection{Tectonism}

The tectonism analysis consisted of a literature review of postulated tectonic activity at Yucca Mountain and identification of several initiating events that may influence transport of radionuclides. Transport models were evaluated for an event associated with water-table rise. This effort was not as extensive as other aspects of the modeling because of the late start for this sub-activity and budget constraints.

\subsubsection{Basaltic Volcanism}

The volcanic analysis modeled radionuclide releases due to mobilization of waste by a basaltic dike. The models for basaltic dike formation are based on simplified analytic models. Transient changes to the hydrological flow field were not modeled. The range of outcomes will depend on such factors as temperature of the magma, size of the dike, and fraction of waste mobilized.

\subsubsection{Dose}

Doses were computed for all PNL release scenarios except basaltic eruptions. The dose model is based on the International Commission on Radiological Protection's concept of committed effective dose equivalent (ICRP 1977; 1979; 1984; 1991). Doses were computed for a "reference" individual. In addition, PiNL computed doses for some scenarios using radionuclide release profiles provided by SNL. The dose calculations for SNL used the same exposure pathways as PNL's dose model. 


\subsection{Source-Term Analysis}

The source-term for this total-system performance assessment analysis was calculated using the Analytical Repository Source-Term (A.NEST) code (Liebetrau et al. 1987; Engel et al. 1989). The AREST code can be used for estimating release rates from the engineered barrier system. (EBS) of an underground geologic repository for either spent-fuel or glass-waste forms. The release rates from the EBS are then transferred to a hydrologic flow and transport model such as SUMO (Eslinger et al. 1990) or MSTS to predict ground-water mass transport (see Section 4), which is, in turn, used to calculate dose to humans (Section 10). The release rates were calculated for a set of 10 nuclides $\left({ }^{14} \mathrm{C},{ }^{79} \mathrm{Se},{ }^{99} \mathrm{Te},{ }^{126 \mathrm{Sn}}, 129 \mathrm{I},{ }^{135 \mathrm{Cs},}{ }^{234 \mathrm{U}},{ }^{237} \mathrm{~Np}, 239 \mathrm{Pu}\right.$, and $243 \mathrm{Am}$ ). The 10 nuclides were chosen to represent a range of physical and chemical properties, inventories, and dose-conversion factors as described in Section 2.3. This section briefly describes the AREST code and the analyses performed for this total-system performance assessment analysis.

\subsection{Description of Release Models}

At the potential repository site at Yucca Mountain, high-level nuclear waste is to be stored in a canister that would be overpacked with a container designed to assure compliance with regulatory containment requirements. The container will then be emplaced in an excavated opening, leaving a small air gap between the emplacement container and the host rock. After the containment barriers are breached (containment failure), there are three general modes of radionuclide release from the EBS: "dry," "wet-drip," and "wet/moist-continuous." The AREST code contains specific models for these three modes.

\subsubsection{Unsaturated Zone}

Under anticipated conditions, no liquid should contact the waste form even after container failure because of the air gap. These conditions are referred to as a "dry mode." Thus, gaseous transport is the only available pathway for release, assuming a "dry" mode. For this analysis, the AREST code models gaseous transport as a pulse release at the time of container failure.

As a result of local variations in rock permeability, water may drip onto the waste container after temperatures have dropped below a rewetting temperature. Such conditions are referred to as a "wet-drip" mode. After containment failure, it is assumed that there is a hole near the top of the waste container, allowing the interior of the container to become wet and the waste to dissolve. Release from the waste form can then be estimated based on assumptions about the remaining containment capability. Two assumptions can be made with the AREST code. The first assumption is that the container is still intact and that release from the waste container will not occur until the container is filled with water. This assumption is known as a "bathtub" type mode. The second mode, or assumption, is that the container no longer forms a barrier to transport and, thus, release can occur at the time of rewetting. This type of release mode is known as a "flowthrough" type. The AREST code incorporates existing models for both solubility-limited and reaction-rate limited release for the "wet-drip" modes (Sadeghi et al. 1990).

For the analysis in this report, the flow-through release models were used for the unsaturated conditions. These models were selected to obtain release-rate estimates beginning at the time of 
failure, instead of waiting for the container to be filled. The time-dependent, solubility-limited release rate due to convection in a wet-drip environment is calculated as follows:

$$
\dot{M}_{i}(t)=C_{i}^{s} \frac{N_{i}(t)}{N_{e}(t)} Q, \quad t \leq t_{3}
$$

where $C_{s}^{i}$ is the elemental solubility of nuclide $i, N_{i}$ and $N_{e}$ are the species and elemental concentrations in the undissolved solid, respectively, $Q$ is the volumetric flow rate of the water into and out of the container, and $t_{3}$ is the time when all the element has dissolved. The release rate after the element has all been dissolved is calculated using the following equation:

$$
\dot{M}_{i}(t)=C_{i}^{s} \frac{N_{i}\left(t_{3}\right)}{N_{e}\left(t_{3}\right)} Q \exp \left[\left(-\lambda-\frac{Q}{V\left(t_{2}\right)}\right)\left(t-t_{3}\right)\right], \quad t_{3} \leq t
$$

where $\lambda$ is the decay constant and $V\left(t_{2}\right)$ is the volume of water if the container were full.

The mass-transfer equations for calculating release rates under wet-drip, flow-through conditions using a reaction-rate, limited-boundary condition at the waste-form surface are as follows:

$$
\dot{M}\left(R_{1}, t\right)=f_{a} M_{i}^{0} \exp \left[-(\alpha+\lambda) t\left(e^{\alpha_{t}}-e^{\alpha_{t}}\right)\right], \quad t \leq \frac{1}{f_{a}}
$$

where $R_{1}$ is the radius to the waste container/host rock boundary, $f_{a}$ is the fractional alteration rate of the waste form, $M_{0}^{i}$ is the initial inventory of the specific nuclide $i, t_{1}$ is the time of first water contact after containment failure, and $\alpha$ is defined as:

$$
\alpha=\frac{Q}{V(h)}
$$

and

$$
\dot{M}\left(R_{1}, t\right)=f_{a} M_{i}^{0} \exp \left[-(\alpha+\lambda) t\left(\exp \left(\alpha\left(t_{1}+\frac{1}{f_{a}}\right)\right)-\exp \left(\alpha t_{1}\right)\right)\right], \quad t \geq \frac{1}{f_{a}}
$$

\subsubsection{Saturated Zone}

The last mode for radionuclide release is for the "wet-continuous" condition. This may occur when the waste container contacts the host rock either by physical displacement or by sedimentation of the air gap, allowing a diffusive pathway to exist. The AREST code contains models for the diffusive transpori of radionuclides and assumes either a solubility-limited or reaction-rate, limited-boundary condition at the waste-form surface. The models that have been incorporated into the AREST code were developed by T. H. Pigford, P. L. Chambré, and their colleagues at the University of California at Berkeley.

The diffusive mass transport release rates for either a spent-fuel or glass-waste form assuming a solubility-iimited boundary condition at the waste-form surface is (Chambré et al. 1985): 


$$
\dot{M}(r, t)=4 \pi \varepsilon_{1} \sigma_{1} D_{f} R_{0} r C_{i}^{s} \psi_{i}(r, t), \quad R_{0} \leq r \leq R_{1}, t \geq 0
$$

where $\varepsilon_{1}=$ backfill porosity

$$
\begin{aligned}
& \sigma_{1}=\text { backfill tortuosity factor } \\
& D_{\mathrm{f}}=\text { diffusion coefficient for nuclide } \mathrm{i} \text { in water } \\
& R_{0}=\text { waste-form radius } \\
& C_{s}^{\prime}=\text { surface concentration for nuclide } \mathrm{i} \\
& R_{1}=\text { radius to the waste container/host rock boundary }
\end{aligned}
$$

and $\psi_{i}(r, t)$ is a complicated function of previously defined parameters $\varepsilon_{1}, \sigma_{1}, D_{f}, R_{1}, C_{s}^{\prime}, R_{1}, \psi$, and the additional parameters

$$
\begin{aligned}
& \mathrm{b}=\text { the backfill thickness }\left(\mathrm{R}_{1}-\mathrm{R}_{2}\right) \\
& \mathrm{K}_{1}=\text { retardation coefficients for nuclide } \mathrm{i} \text { in the backfill } \\
& \mathrm{K}_{2}=\text { retardation coefficients for nuclide } \mathrm{i} \text { in the host rock }
\end{aligned}
$$

The mass-transfer rate for highly soluble nuclides may be limited by the rate of reaction of the waste form. For a planar geometry, the time-dependent, mass-transfer rate of nuclide i for a single time step $n$, is (Kang 1990) as follows:

$$
\dot{\mathrm{M}}_{\mathrm{i}, \mathrm{n}}\left(\mathrm{R}_{1}, \mathrm{t}\right)=2 \mathrm{~K}_{1} \sigma_{1} \varepsilon_{1} \frac{\mathrm{m}_{\mathrm{i}}}{\mathrm{V}_{\mathrm{v}}} \mathrm{S}_{\mathrm{v}} \omega_{\mathrm{i}}(\mathrm{t})
$$

where $m_{i}$ is the mass of nuclide $i t$ that is dissolved at the beginning of this time step $(n), V_{v}$ is the interior volume of the waste container, $S_{v}$ is the surface area of the cylindrical waste container, and $\omega_{\mathrm{i}}(\mathrm{t})$ is a complicated function of $\varepsilon_{1}, \varepsilon_{2}, \sigma_{1}, \sigma_{2}, K_{1}, K_{2}, \lambda, D_{f}, b, V_{v}$, and $S_{v}$.

The total release into the host rock for radionuclide i over time is derived by summing over $\mathrm{n}$ the series of terms for each series of $\dot{M}_{i, n}\left(R_{1}, t\right)$ successive time steps:

$$
\dot{\mathrm{M}}_{1}\left(\mathrm{R}_{1}, \mathrm{t}\right)=\sum \dot{\mathrm{M}}_{\mathrm{i}, \mathrm{n}}\left(\mathrm{R}_{1}, \mathrm{t}\right)
$$

This summation is continued until the waste form is completely dissolved, or the inventory of nuclide $i$ is exhausted in the waste form as a result of radioactive decay, whichever comes first. 


\subsubsection{Glass Dissolution Model}

The AREST code also contains a mechanistic model describing a dynamic mass balance between the production and consumption of silicic acid, coupled with a near-field mass transport model to predict the dissolution kinetics of a high-level waste glass in a deep geologic repository (McGrail et al. 1990). The kinetic model is used to transform radionuclide concentration-versusreaction-progress values, to concentration-versus-time values that are used to calculate the rate of radionuclide release by mass transfer to the surrounding rock. The reaction-progress values are predicted using a geochemical reaction-path computer code, such as EQ3/6 (Wolery 1983). The model provides for both solubility-limited and kinetically-limited release, with the rate-controlling mechanism being dependent on the predicted glass/ground-water chemistry.

The following equation describes the mass balance used for calculating the time-dependent reaction progress $(\xi)$ :

$$
\phi V \frac{d \xi}{d t}=A_{g}(t) \frac{d X}{d t}-\dot{M}\left(\xi, R_{0}, t\right)
$$

where $\phi$ is the volume fraction of the aqueous phase in the annular volume $(V), A_{g}(t)$ is the timedependent glass surface area, $M$ is the mass-transfer rate at the waste-glass surface, $\xi$ is the reaction progress, and $\mathrm{dX} / \mathrm{dt}$ is the rate at which the glass is dissolving, given by:

$$
\frac{\mathrm{dX}}{\mathrm{dt}}=\mathrm{K}+\left(1-\frac{\mathrm{Q}}{\mathrm{K}}\right)
$$

where $\mathrm{X}$ is the amount of dissolveci glass, $\mathrm{K}_{+}$is the forward rate of glass dissolution, $\mathrm{Q}$ is the activity of silicic acid, and $\mathrm{K}$ is the equilibrium constant corresponding to the reaction:

$$
\mathrm{SiO}_{2}(\mathrm{~s})+2 \mathrm{H}_{2} \mathrm{O} \Leftrightarrow \mathrm{H}_{4} \mathrm{SiO}_{4}(\mathrm{aq})
$$

and

$$
\frac{\mathrm{dX}}{\mathrm{dt}} \geq \mathrm{K}_{1}
$$

where $\mathrm{K}_{\mathrm{r}}$ is the residual rate of glass dissolution under near-saturation conditons.

\subsection{Source-Term Analysis Description}

Four different scenarios were analyzed for the total-system performance assessment analysis, as described in Section 2. These scenarios were: 1) base (undisturbed), 2) human-intrusion, 3) volcanic disruption, and 4) tectonic disruption. Source-term release rates were used for estimating transport to the accessible environment (Sections 4 and 5) and for human-dose calculations (Sections 5 and 10) for both the base scenario and the human-intrusion scenario. The inventories calculated for the base-scenario analysis were also used (indirectly) for the volcanicand tectonic-disruption analyses (Sections 6 and 7). 
The waste-container releases for the base scenario were estimated by simulating seveial waste containers located in an undisturbed, unsaturated media. Each simulation was based on time- and temperature-independent infiltration rates (five different infiltration rates were used in the analysis; refer to Section 4 for additional information). The containment failure time for each waste container was assumed to be a realization from a uniform distribution between 2000 and 5000 years. A temperature profile was also simulated for each waste container. In the base-scenario analysis, both spent-fuel and glass-waste forms were considered. The base-scenario source-term releases rates were used by unsaturated zone models (Section 4 ) for the base-scenario (nuclide migration in gas and liquid phases associated with ground-water movement in the unsaturated zone). This indirectly provided the source term for the volcanic- and tectonic-disruption scenarios also, which at random disruption times used the remaining inventory in waste containers for the base scenario, together with the unsaturated-zone model predictions of nuclide distribution at that time due to migration from failed containers.

The human-intrusion scenario included four cases that were defined in Section 2.2:

1. Exhumed container waste - a driller directly entrains a waste container in the drill rig and exhumes the total inventory of a single container

2. Exhumed column of contaminated rock - a driller misses the waste containers but exhumes rock that contains dilute waste that has migrated from failed waste containers

3. Direct waste injection inte tuff aquifer - a driller intercepts a waste container with the drill rig, compromising the container integrity without entraining the waste, which falls to the bottom of the drill hole into the tuff aquifer after rig extraction

4. Direct waste injection into Paleozoic (carbonate) aquifer - same case as (3) above, but waste falls into the carbonate aquifer rather than the tuff aquifer

The base-scenario source-term release rates were used for cases number 1 (exhumed container waste) and 2 (exhumed contaminated rock). The source-term calculations for cases numbers 3 and 4 (direct waste injection into an aquifer) are the same except that the flow and mass transport calculations (Section 5.0) vary following the differences in physical properties of the tuff and carbonate aquifers. Ten simulations of saturated ground-water flow and radionuclide transport were performed each for the tuff and carbonate aquifers to model the two direct-waste-injection human-intrusion-scenario cases (Section 5). These simulations are identified as tuff simulations 01 through 10 for the tuff aquifer and carbonate simulations 01 through 10 for the paleozoic (carbonate) aquifer. The drilling time for the 10 tuff and 10 carbonate simulations was selected from a loguniform distribution between 100 and 10,000 years. The hydraulic conductivity field for the 10 tuff and 10 carbonate simulations was a stochastically generated, spatially correlated field (Section 5). In addition to these stochastic simulations, two bounding simulations were performed for both the tuff and carbonate aquifers using minimum or maximum hydraulic gradients and a deterministic, constant-value conductivity of minimum or maximum value. The minimum flow simulations are tuff simulation 11 and carbonate simulation 11, and the maximum flow simulations are tuff simulation 12 and carbonate simulation 12. In all simulations, the container is assumed to fail because of vertical displacement to the aquifer. Spent fuel was the only type of waste form that was modeled for the direct-waste-injection cases of the human-intrusion analysis. 
In short, two basic types of source-term calculations are required to meet the needs of this total-system performance assessment: base and human-intrusion. The data required for both types of analyses are presented in Section 3.3. The base-scenario releases are used to meet the requirements of the base scenario, two of the four human-intrusion scenario cases, and the volcanic- and tectonic-disruption scenarios. The results of the base-scenario source-term analysis are discussed in Section 3.4. The human-intrusion release rates are used to meet the requirements of the two direct-injection cases of the human-intrusion scenario. Human-intrusion source-term analysis results are discussed in Section 3.5.

\subsection{Source-Term Data Description}

The data for this effort were compiled from several different sources and are shown in Tables 3.1 through 3.7. Table 3.1 gives the waste-container parameters. These values are from a preliminary site-suitability study performed at the University of California at Berkeley (Lee et al. 1991). The specific nuclide inventories, distribution in the spent fuel, and sorption are shown in Table 3.2. The inventories were calculated using ORIGEN (Croff 1983), with decay referenced to the year 2040, while the distributions in the spent fuel were taken from the Spent Fuel Report (Apted et al. 1989). Table 3.3 contains the temperature-dependent elemental solubilities used for the base-scenario analysis. The solubilities were estimated using the EQ3/6 geochemical code (Wolery 1983). Table 3.4 shows the infiltration rates and resulting saturation values predicted by unsaturated zone modeling (Section 4.0) for the base scenario.

The solubilities calculated from $\mathrm{EQ} 3 / 6$ tended to differ from values used in other analyses. For instance, the solubility of $237 \mathrm{~Np}$ (at $44^{\circ} \mathrm{C}$ ) used in this analysis is 3160 times greater than the solubility used for $237 \mathrm{~Np}$ in the preliminary site-suitability study mentioned earlier (Lee et al. 1991). On the other hand, the Pu solubilities were four orders of magnitude lower than those used by Wilson (1991). The difference in solubilities lead to similar differences in the calculated release rates. The calculated values were used instead of literature values in this analysis because the purpose of this total-system performance assessment is to demonstrate current capabilities.

Tables 3.5 and 3.6 provide data used for the human-intrusion scenario deep-aquifer-injection cases. A median darcy flow rate in the waste container was used for the 10 random drilling times (tuff simulations 1 through 10 and carbonate simulations 1 through 10). The median flow rate was estimated using Equation (3.13):

$$
\text { Velocity }=K_{\mathrm{S}} \frac{\Delta \mathrm{H}}{\Delta \mathrm{L}}
$$

where $\mathrm{K}_{\mathbf{S}}$ is a median conductivity of the stochastically-generated hydraulic conductivity field (Section 5.0) in $\mathrm{m} / \mathrm{yr}(0.4418 \mathrm{~m} / \mathrm{yr}$ for the tuff aquifer and $98.7 \mathrm{~m} / \mathrm{yr}$ for the carbonate aquifer), $\Delta \mathrm{H}$ is an average hydraulic head (78.75 $\mathrm{m}$ for tuff and $265.24 \mathrm{~m}$ for carbonate) minus the hydraulic head on the right end of the potential repository $(50 \mathrm{~m})$, and $\Delta \mathrm{L}$ is the length of the potential repository $(7000 \mathrm{~m})$.

Glass inventories were estimated from an SRL-202 glass (Table 3.7). These were used with the ground-water composition from well $\mathrm{J}-13$ for calculating reaction progress and concentrations used in the glass-dissolution model contained in the AREST code. 
Table 3.1. Waste Container Data

Waste Radius (cm)

Waste Length $(\mathrm{cm})$

Gap/Void Width (cm)

Container Thickness $(\mathrm{cm})$

Air Gap/Backfill Thickness (cm)

Diffusion Coefficient $\left(\mathrm{cm}^{2} / \mathrm{s}\right)$

Reaction Rate ( $\mathrm{g} / \mathrm{m}^{2} /$ day)

Alteration Period (yr)

Number of Waste Containers

Total Amount of Waste (MTU)

Waste-Container Loading (MTU/container)

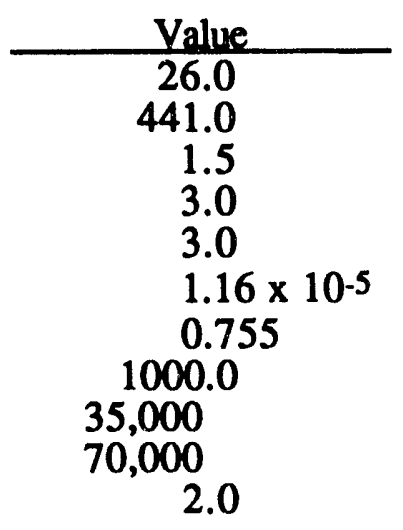

Table 3.2. Nuclide-Specific Data

\begin{tabular}{|c|c|c|c|c|c|c|}
\hline \multirow[b]{2}{*}{ Nuclide } & \multirow{2}{*}{$\begin{array}{c}\text { Half Life } \\
(\mathrm{yr})\end{array}$} & \multirow{2}{*}{$\begin{array}{l}\text { Inventory } \\
\text { (Ci/pack) }\end{array}$} & \multirow{2}{*}{$\begin{array}{l}\% \text { in } \\
\text { Matrix }\end{array}$} & \multirow{2}{*}{$\begin{array}{l}\% \text { in } \\
\text { Gap }\end{array}$} & \multicolumn{2}{|c|}{$\mathrm{K}_{\mathrm{d}}(\mathrm{mL} / \mathrm{g})$} \\
\hline & & & & & Tuff & Carbonate \\
\hline${ }^{14} \mathrm{C}$ & $5.73 \times 10^{3}$ & $3.29 \times 10^{0}$ & $98.0(a)$ & 1.0 & 0.0 & 0.0 \\
\hline${ }^{79 S e}$ & $6.50 \times 10^{4}$ & $9.52 \times 10^{-1}$ & 98.0 & 2.0 & 2.5 & 3.0 \\
\hline 99 Tc & $2.11 \times 10^{5}$ & $2.99 \times 10^{1}$ & 98.0 & 2.0 & 0.0 & 0.0 \\
\hline $126 \mathrm{~S} n$ & $1.00 \times 10^{5}$ & $1.77 \times 100$ & 98.0 & 2.0 & 100.0 & 110.0 \\
\hline $129 \mathrm{I}$ & $1.57 \times 10^{7}$ & $7.28 \times 10^{-2}$ & 98.0 & 2.0 & 0.0 & 0.0 \\
\hline${ }^{135} \mathrm{Cs}$ & $2.30 \times 10^{6}$ & $9.93 \times 10^{-1}$ & 98.0 & 2.0 & 50.0 & 10.0 \\
\hline $234 \mathrm{U}(\mathrm{b})$ & $2.45 \times 10^{5}$ & $4.97 \times 10^{0}$ & 100.0 & 0.0 & 2.5 & 3.0 \\
\hline $237 \mathrm{~Np}$ & $2.14 \times 10^{6}$ & $8.59 \times 10^{-1}$ & 100.0 & 0.0 & 2.0 & 0.5 \\
\hline${ }^{239} \mathrm{Pu}$ & $2.41 \times 10^{4}$ & $6.65 \times 10^{2}$ & 100.0 & 0.0 & 100.0 & 80.0 \\
\hline $243 \mathrm{Am}$ & $7.38 \times 10^{3}$ & $4.86 \times 10^{1}$ & 100.0 & 0.0 & 100.0 & 100.0 \\
\hline
\end{tabular}

(a) $1 \%$ of $14 \mathrm{C}$ in gas phase

(b) $234 U=234 U+238 \mathrm{Pu}$

Table 3.3. Base-Scenario Solubility Data

\begin{tabular}{lrc} 
Element & Temperature $\left({ }^{\circ} \mathrm{C}\right)$ & Solubility $\left(\mathrm{g} / \mathrm{m}^{3}\right)$ \\
\cline { 2 - 3 } $\mathrm{U}$ & 100.0 & $4.52 \times 10^{-3}$ \\
$\mathrm{U}$ & 44.0 & $8.57 \times 10^{1}$ \\
$\mathrm{~Np}$ & 100.0 & $7.58 \times 10^{-2}$ \\
$\mathrm{~Np}$ & 44.0 & $9.48 \times 10^{-1}$ \\
$\mathrm{Pu}$ & 100.0 & $1.00 \times 10^{-7}$ \\
$\mathrm{Pu}$ & 44.0 & $4.54 \times 10^{-6}$ \\
$\mathrm{Am}$ & 100.0 & $1.51 \times 10^{-3}$ \\
$\mathrm{Am}$ & 44.0 & $4.62 \times 10^{-3}$
\end{tabular}


Table 3.4. Base-Scenario Repository Liquid Saturation for Various Recharge Rates (refer to Section 4 for additional information on saturation predictions)

\begin{tabular}{cc} 
Infiltration (mm/yr) & Liquid Saturat \\
\hline 0.0 & 0.590 \\
0.01 & 0.730 \\
0.05 & 0.805 \\
0.5 & 0.945 \\
3.0 & 0.945 \\
20.0 & 0.945
\end{tabular}

Table 3.5. Human-Intrusion Scenario (Deep-Injection Cases) Aquifer Data

\begin{tabular}{lccc} 
Variable & Radionuclide & Tuff Aquifer & Carbonate Aquifer \\
\cline { 3 - 4 } Porosity & & 0.24 & 0.05 \\
Density $\left(\mathrm{g} / \mathrm{cm}^{3}\right)$ & & 2.23 & 2.76 \\
& & 0.0 & 0.0 \\
$\mathrm{~K}_{\mathrm{d}}(\mathrm{mL} / \mathrm{g})$ & $14 \mathrm{C}$ & 2.5 & 3.0 \\
& $79 \mathrm{Se}$ & 0.0 & 0.0 \\
& $99 \mathrm{Tc}$ & 100.0 & 110.0 \\
& $126 \mathrm{Sn}$ & 0.0 & 0.0 \\
& $129 \mathrm{I}$ & 50.0 & 10.0 \\
& $135 \mathrm{Cs}$ & 2.5 & 3.0 \\
& $234 \mathrm{U}$ & 2.0 & 0.5 \\
& $237 \mathrm{~Np}$ & 100.0 & 80.0 \\
& $239 \mathrm{Pu}$ & 100.0 & 110.0
\end{tabular}

Table 3.6. Human-Intrusion Scenario (Deep-Injection Cases) Drilling Times and Flow Rates

Simulation
Number

$\begin{array}{rrr}1 & 357.9 & 2465.6 \\ 2 & 2289.4 & 146.8 \\ 3 & 647.7 & 589.2 \\ 4 & 1108.9 & 259.1 \\ 5 & 3076.3 & 1190.8 \\ 6 & 2530.6 & 8336.1 \\ 7 & 9088.8 & 3811.8 \\ 8 & 443.0 & 128.5 \\ 9 & 159.6 & 2615.6 \\ 10 & 109.5 & 1308.0 \\ 11 & 300.0 & 300.0 \\ 12 & 300.0 & 300.0\end{array}$

Flow Rate $(\mathrm{m} / \mathrm{vr})$

\begin{tabular}{|c|c|}
\hline Tuff & Carbonate \\
\hline 0.00181 & 3.035 \\
\hline 0.00181 & 3.035 \\
\hline 0.00181 & 3.035 \\
\hline 0.00181 & 3.035 \\
\hline 0.00181 & 3.035 \\
\hline 0.00181 & 3.035 \\
\hline 0.00181 & 3.035 \\
\hline 0.00181 & 3.035 \\
\hline 0.00181 & 3.035 \\
\hline 0.00181 & 3.035 \\
\hline $\begin{array}{l}8.90 \times 10^{-6} \\
0.274\end{array}$ & $\begin{array}{l}5.17 \times 10^{-3} \\
69.7\end{array}$ \\
\hline
\end{tabular}


Table 3.7. Glass Inventory(a) Data

\begin{tabular}{|c|c|c|c|c|c|c|}
\hline Nuclide & Oxide & MW & $\underline{\mathrm{FI}^{(b)}}$ & Wt\% & $\underline{\mathbf{f}}(\mathbf{c})$ & $\begin{array}{l}\text { Inventory } \\
\text { (g/pack)(d) }\end{array}$ \\
\hline${ }^{4} \mathrm{C}$ & -.. & ..- & $\ldots$ & --- & -.- & -.. \\
\hline $79 \mathrm{Se}$ & $\mathrm{SeO}_{2}$ & 111.0 & 0.7118 & $1.00 \times 10^{-4}$ & $7.117 \times 10^{-5}$ & 119.78 \\
\hline Tc & $\mathrm{TcO}_{2}$ & 131.0 & 0.7557 & $4.10 \times 10^{-5}$ & $3.098 \times 10^{-5}$ & 52.15 \\
\hline $6 \mathrm{Sn}$ & --- & --- & -- & -- & -- & --- \\
\hline 129 I & -..- & ..- & -.. & -.- & -.- & --- \\
\hline${ }^{5} \mathrm{Cs}$ & $\mathrm{Cs}_{2} \mathrm{O}$ & 281.81 & 0.9581 & $1.23 \times 10^{-3}$ & $1.178 \times 10^{-3}$ & $1,983.0$ \\
\hline $4 \mathrm{U}$ & $\mathrm{UO}_{2}$ & 270.03 & 0.8666 & $1.96 \times 10^{-2}$ & $1.698 \times 10^{-2}$ & $28,585.0$ \\
\hline $237 \mathrm{~Np}$ & $\mathrm{NpO}_{2}$ & 269.0 & 0.8810 & $1.29 \times 10^{-4}$ & $1.137 \times 10^{-4}$ & 119.28 \\
\hline $9 \mathrm{Pu}$ & $\mathrm{PuO}_{2}$ & 271.0 & 0.8819 & $5.70 \times 10^{-5}$ & $5.027 \times 10^{-5}$ & 84.60 \\
\hline $43 \mathrm{Am}$ & $\mathrm{Am}_{2} \mathrm{O}_{3}$ & 530.0 & 0.9170 & $5.64 \times 10^{-6}$ & $5.172 \times 10^{-6}$ & 8.704 \\
\hline
\end{tabular}

(a) Glass Total Inventory $=1.683+06(\mathrm{~g} /$ container $)$

(b) $\mathrm{FI}=$ (Atomic Mass) $/ \mathrm{MW}$

(c) $\mathrm{fi}=\mathrm{Fl} \times \mathrm{Wt} \%$

(d) Inventory $=(\text { Glass Total Inventory })^{(d)} \times$ fi

\subsection{Base-Scenario Source-Term Results}

Results from the base-scenario source-term analysis are shown in Figures 3.1 through 3.10. Figures 3.1 and 3.2 show ${ }^{14} \mathrm{C}$ release rates for gas release plus waterborne release. Release rates where spent fuel was ùsed as the waste form are shown in Figures 3.3 through 3.6. Figures 3.7 through 3.10 show release from a glass-waste form for the base scenario. For all spent-fuel analyses, the nuclides were divided into two sets. The first set includes the nuclides that were modeled using a solubility-limited boundary condition at the waste-form surface $(234 \mathrm{U}, 237 \mathrm{~Np}$, ${ }^{239} \mathrm{Pu}$, and $\left.243 \mathrm{Am}\right)$. The second set includes the nuclides that are highly soluble and were modeled using a reaction-rate limited boundary condition $\left(14 \mathrm{C},{ }^{79} \mathrm{Se},{ }^{99} \mathrm{Tc}, 126 \mathrm{Sn}, 129 \mathrm{I}\right.$, and $\left.{ }^{135 \mathrm{Cs}}\right)$.

Gas release of ${ }^{14} \mathrm{C}$ was estimated using a pulse-release rate, with all of the gas inventory released in one year. The waterborne release of the $14 \mathrm{C}$ was estimated using a flow-through release rate based on the alteration rate of the fuel. Two infiltration rates were used for calculating release of ${ }^{14} \mathrm{C}$ using both gas and waterborne release, $0.01 \mathrm{~mm} / \mathrm{yr}$ and $0.05 \mathrm{~mm} / \mathrm{yr}$. Figure 3.1 shows the release of $14 \mathrm{C}$ using an infiltration rate of $0.01 \mathrm{~mm} / \mathrm{yr}$, while Figure 3.2 shows the release using a $0.05 \mathrm{~mm} / \mathrm{yr}$ infiltration rate. Failure times, for this analysis, were uniformly distributed between 300 and 2000 years. However, no waterborne release of $14 \mathrm{C}$ begins before 1300 years because the repository is hot and has not yet reached the time of "rewetting."

The remaining base scenario calculations, Figures 3.9 through 3.10 , were calculated using either the flow-through release models, with an infiltration rate less than $10.0 \mathrm{~mm} / \mathrm{yr}$ (Figure 3.9 through 3.11 and 3.13 through 3.15 ), or the "wet-continuous" release models, with an infiltration rate greater than $10.0 \mathrm{~mm} / \mathrm{yr}$ (Figures 3.12 and 3.16). The cutoff point of $10.0 \mathrm{~mm} / \mathrm{yr}$ for using a flow-through release model versus a "wet-continuous" diffusive model was arbitrary. 


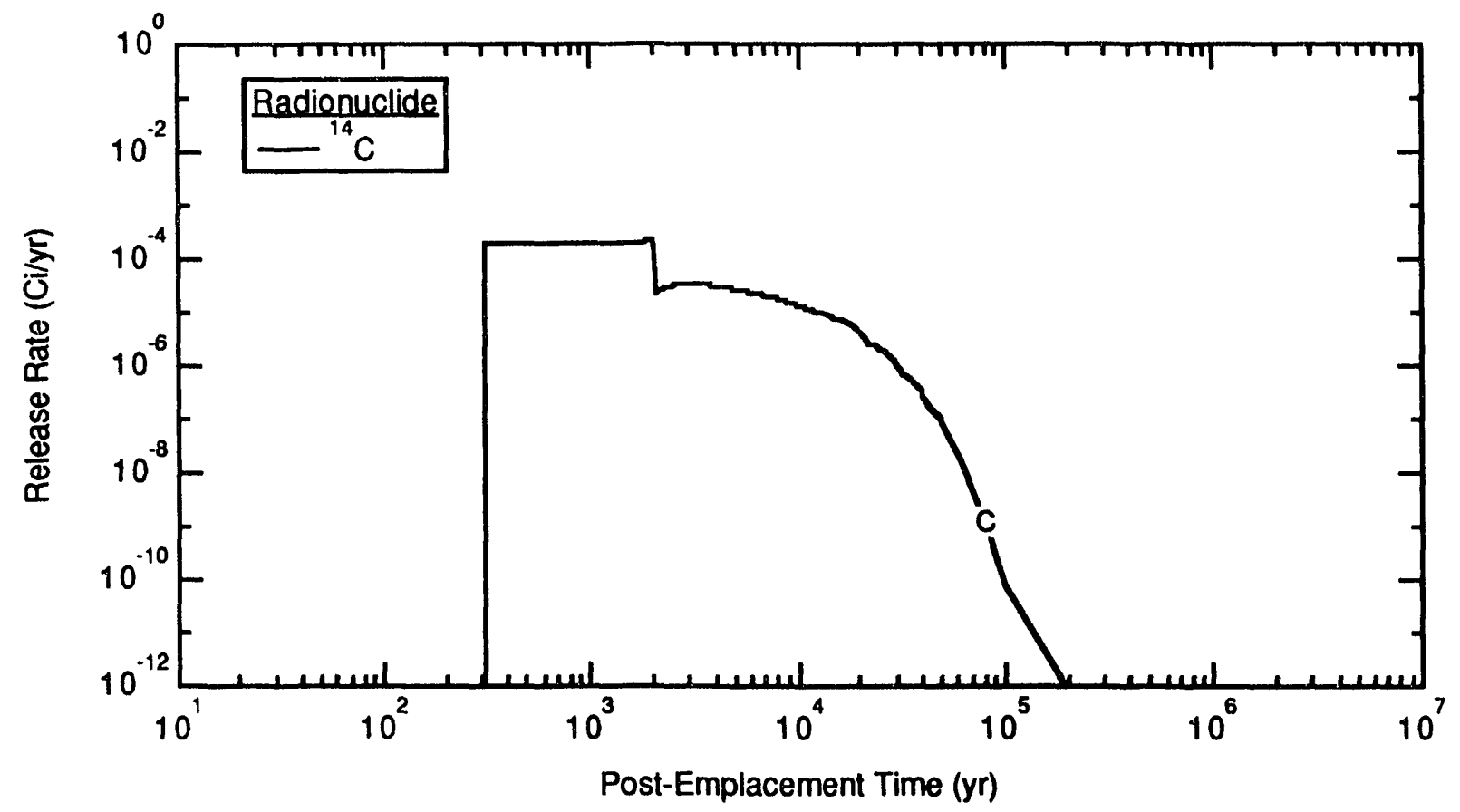

Figure 3.1. Source-Term Gas-Phase Plus Liquid-Phase Release of ${ }^{14} \mathrm{C}$ : Base Scenario for Spent Fuel Using "Flow-Through" Model at $0.01 \mathrm{~mm} / \mathrm{yr}$ Infiltration Rate

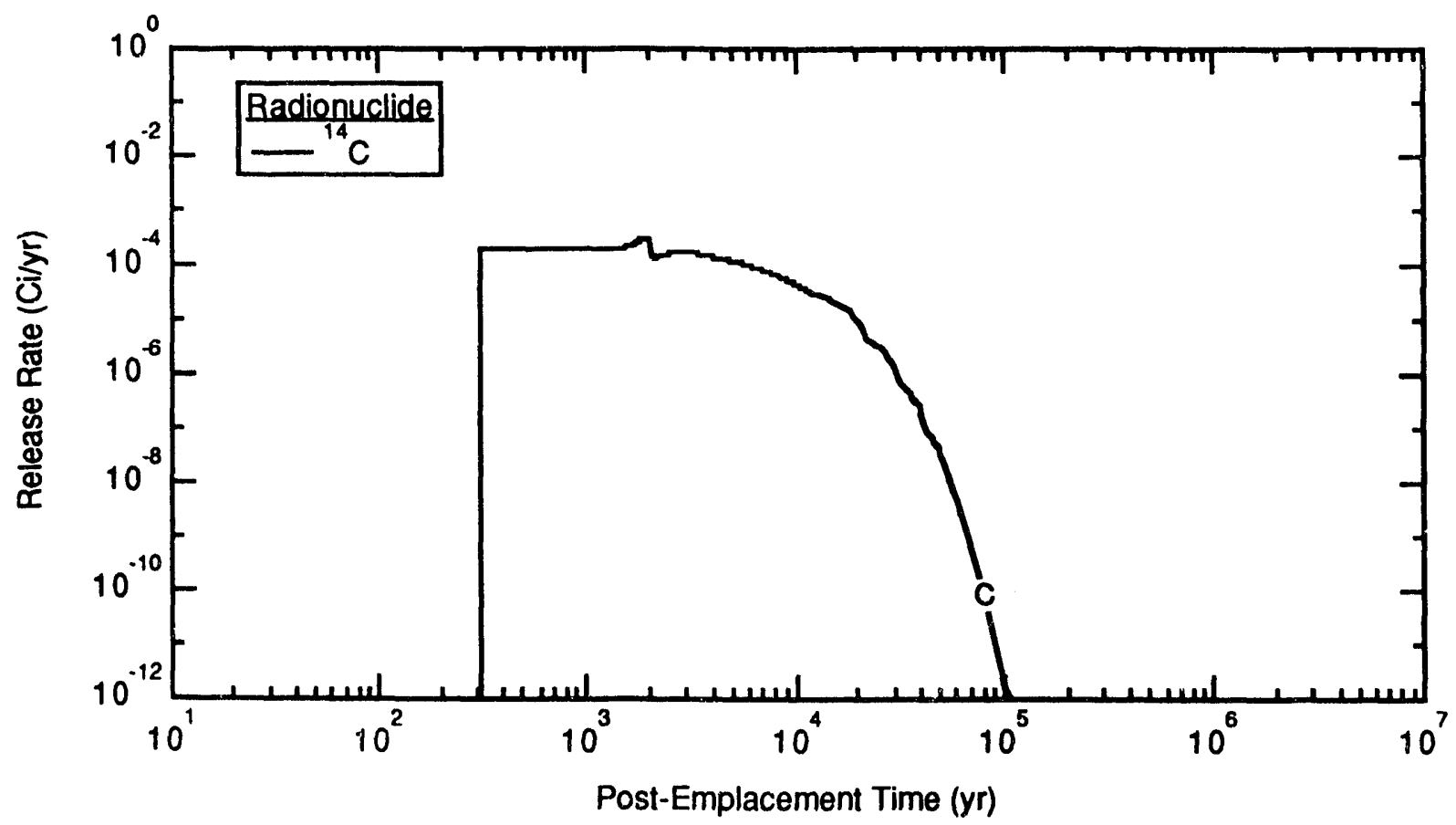

Figure 3.2. Source-Term Gas-Phase Plus Liquid-Phase Release of ${ }^{14} \mathrm{C}$ : Base Scenario for Spent Fuel Using "Flow-Through" Model at $0.05 \mathrm{~mm} / \mathrm{yr}$ Infiltration Rate 


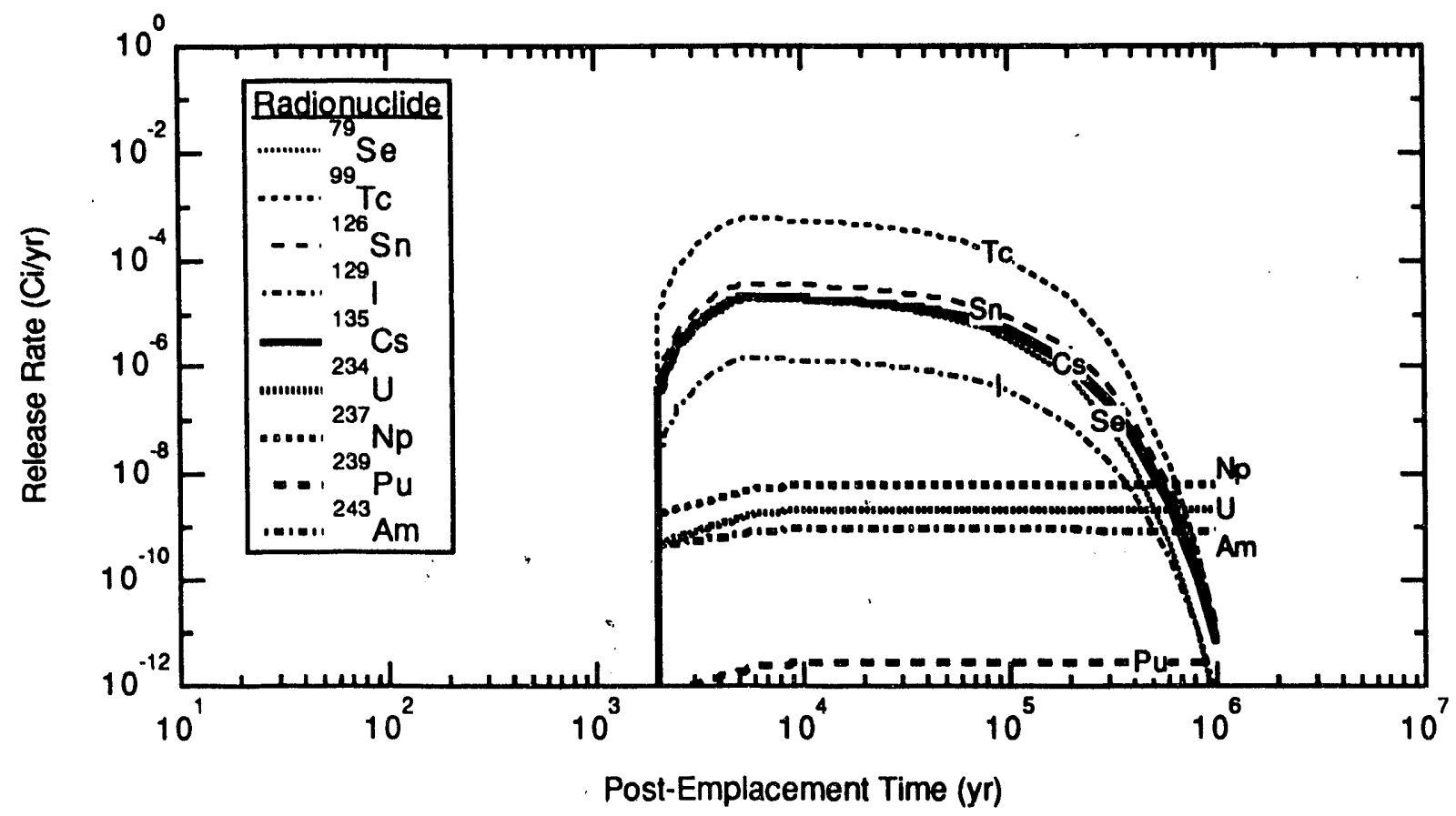

Figure 3.3. Source-Term Liquid-Phase Release: Base Scenario for Spent Fuel Using "FlowThrough" Model at $0.01 \mathrm{~mm} / \mathrm{yr}$ Infiltration Rate

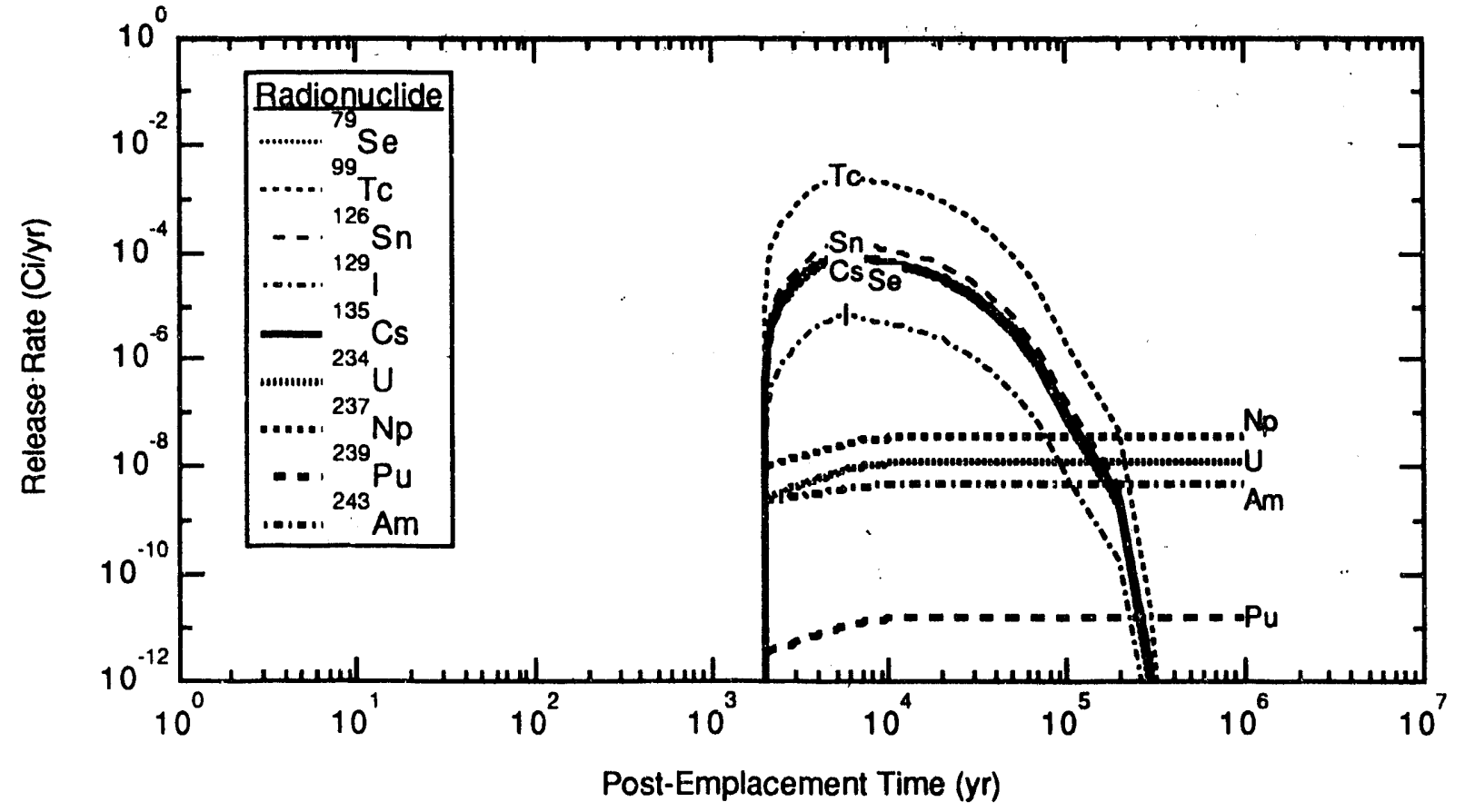

Figure 3.4. Source-Term Liquid-Phase Release: Base Scenario for Spent Fuel Using "FlowThrough" Model at $0.05 \mathrm{~mm} / \mathrm{yr}$ Infiltration Rate 


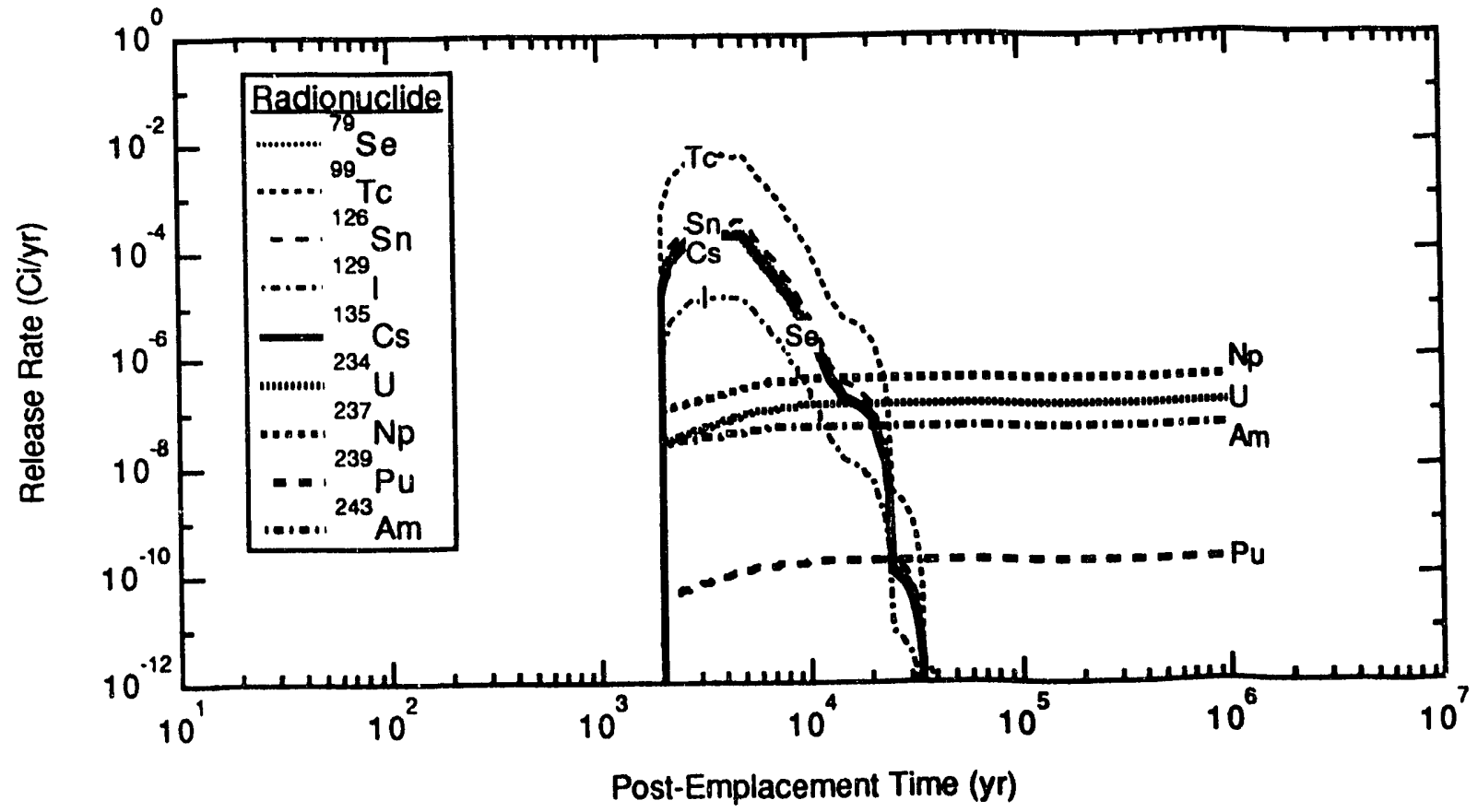

Figure 3.5. Source-Term Liquid-Phase Release: Base Scenario for Spent Fuel Using "FlowThrough" Model at $0.5 \mathrm{~mm} / \mathrm{yr}$ Infiltration Rate

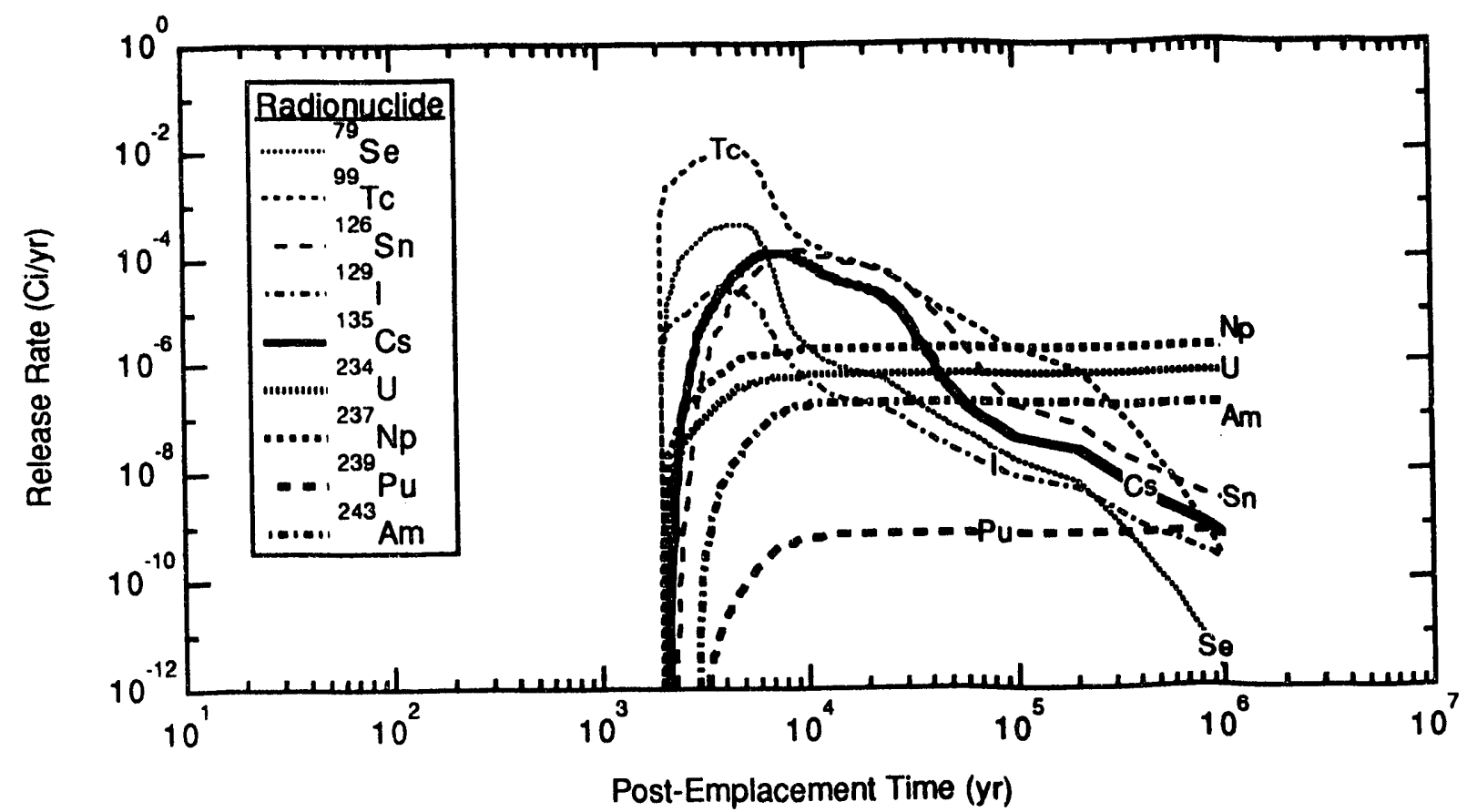

Figure 3.6. Source-Term Liquid-Phase Release: Base Scenario for Spent Fuel Using "WetContinuous" Model at $3.0 \mathrm{~mm} / \mathrm{yr}$ Infiltration Rate 


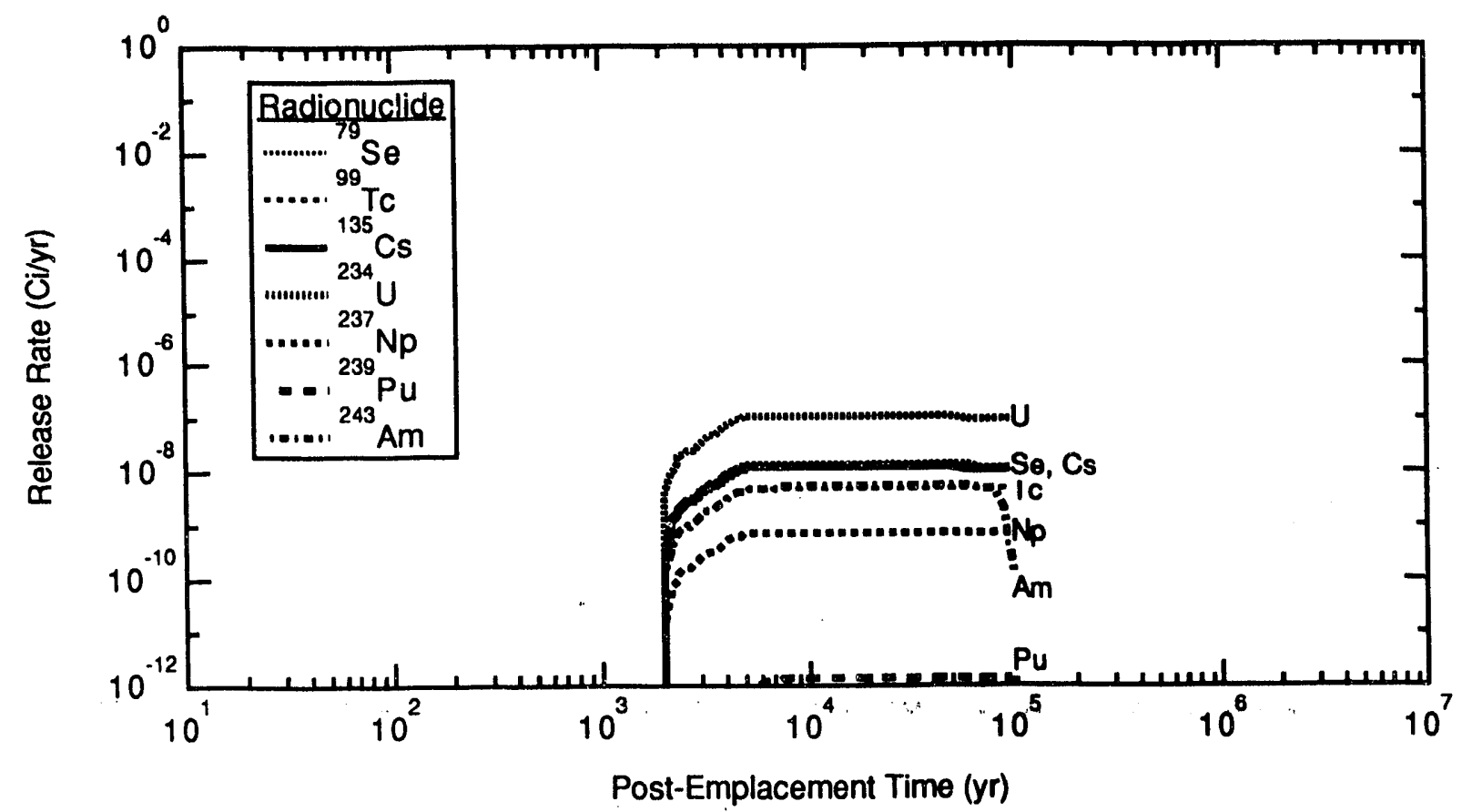

Figure 3.7. Source-Term Liquid-Phase Release: Base Scenario for Glass Waste Using "FlowThrough" Model at $0.01 \mathrm{~mm} / \mathrm{yr}$ Infiltration Rate

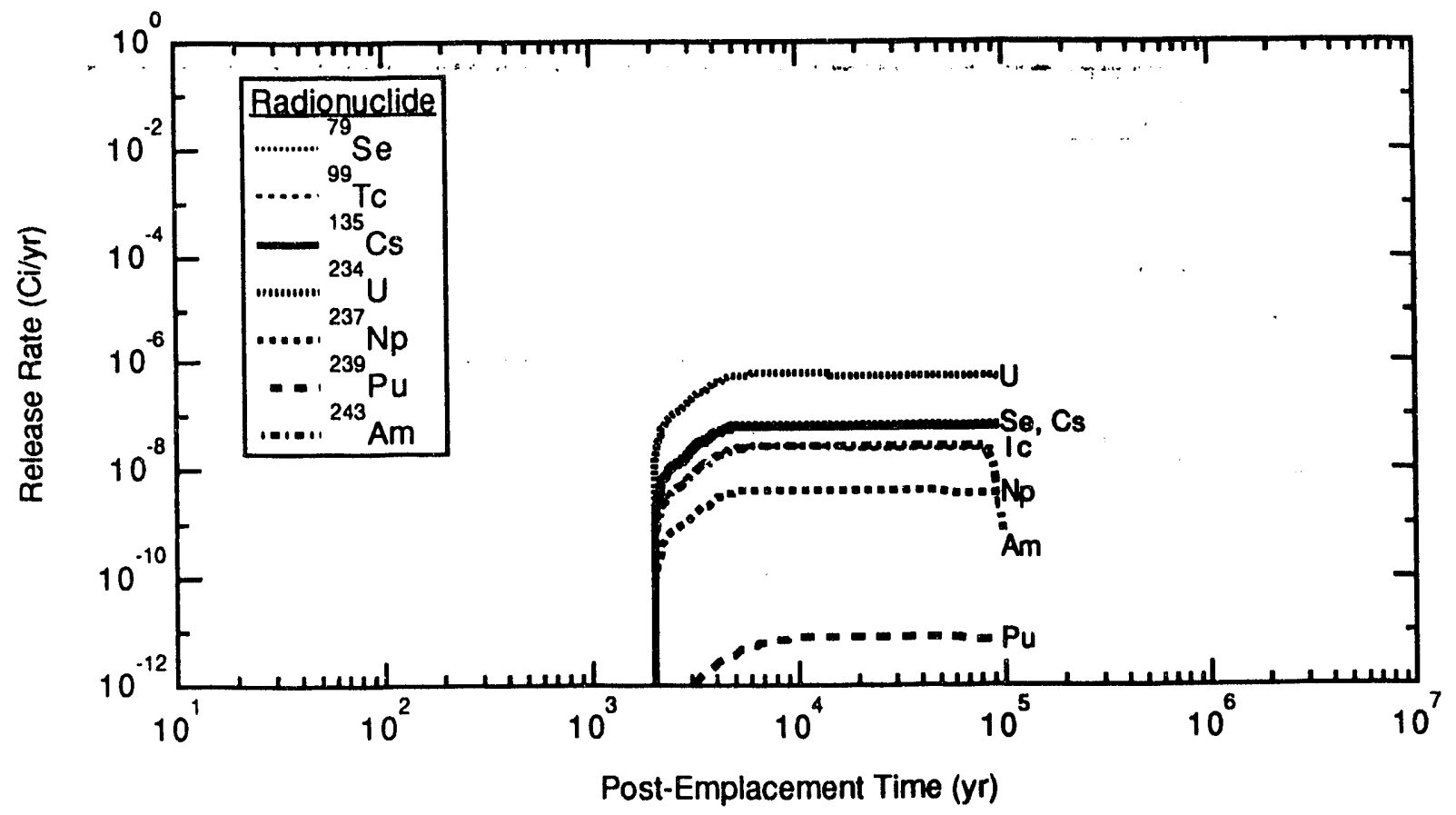

Figure 3.8. Source-Term Liquid-Phase Release: Base Scenario for Glass Waste Using "FlowThrough" Model at $0.05 \mathrm{~mm} / \mathrm{yr}$ Infiltration Rate 


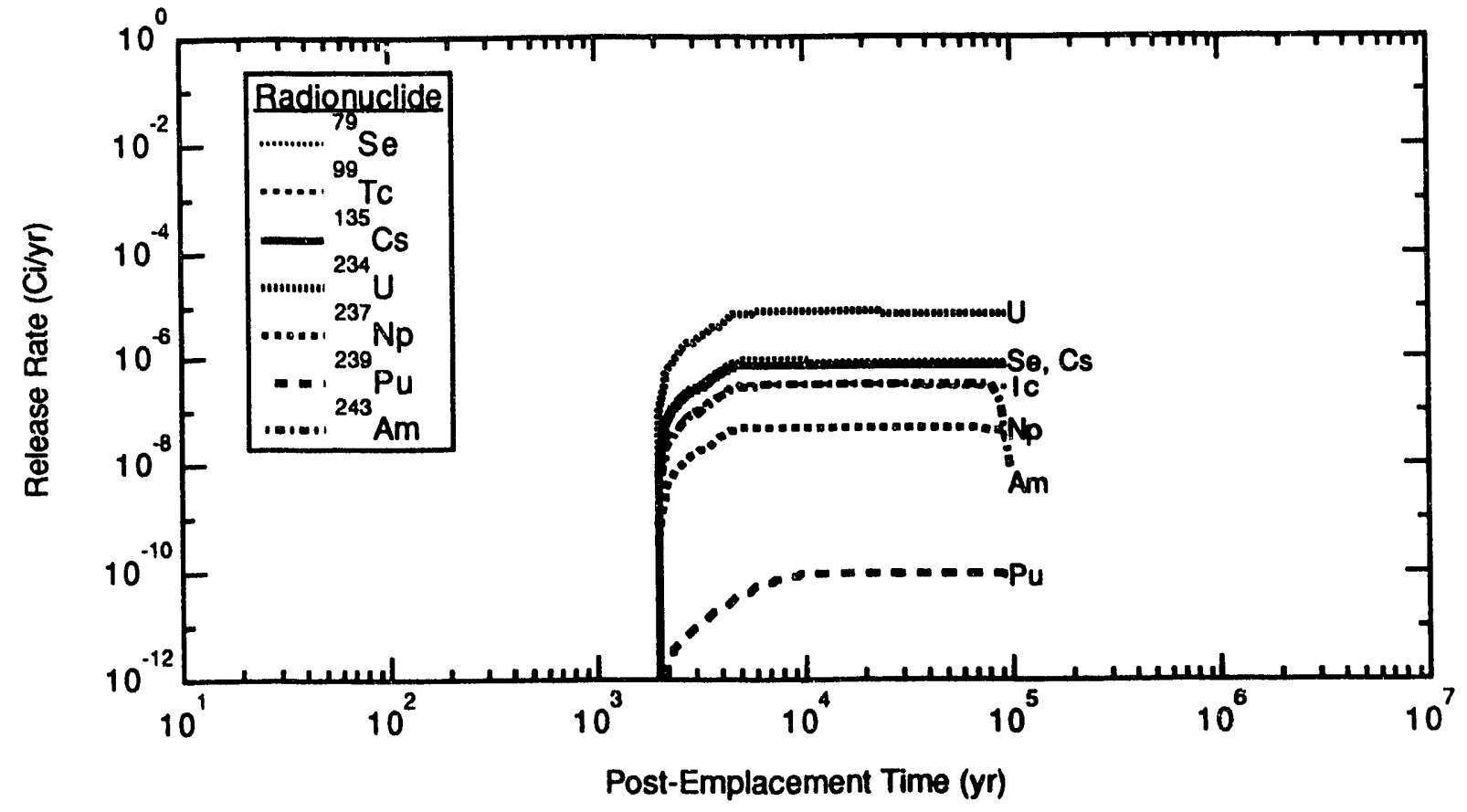

Figure 3.9. Source-Term Liquid-Phase Release: Base Scenario for Glass Waste Using "FlowThrough" Model at $0.5 \mathrm{~mm} / \mathrm{yr}$ Infiltration Rate

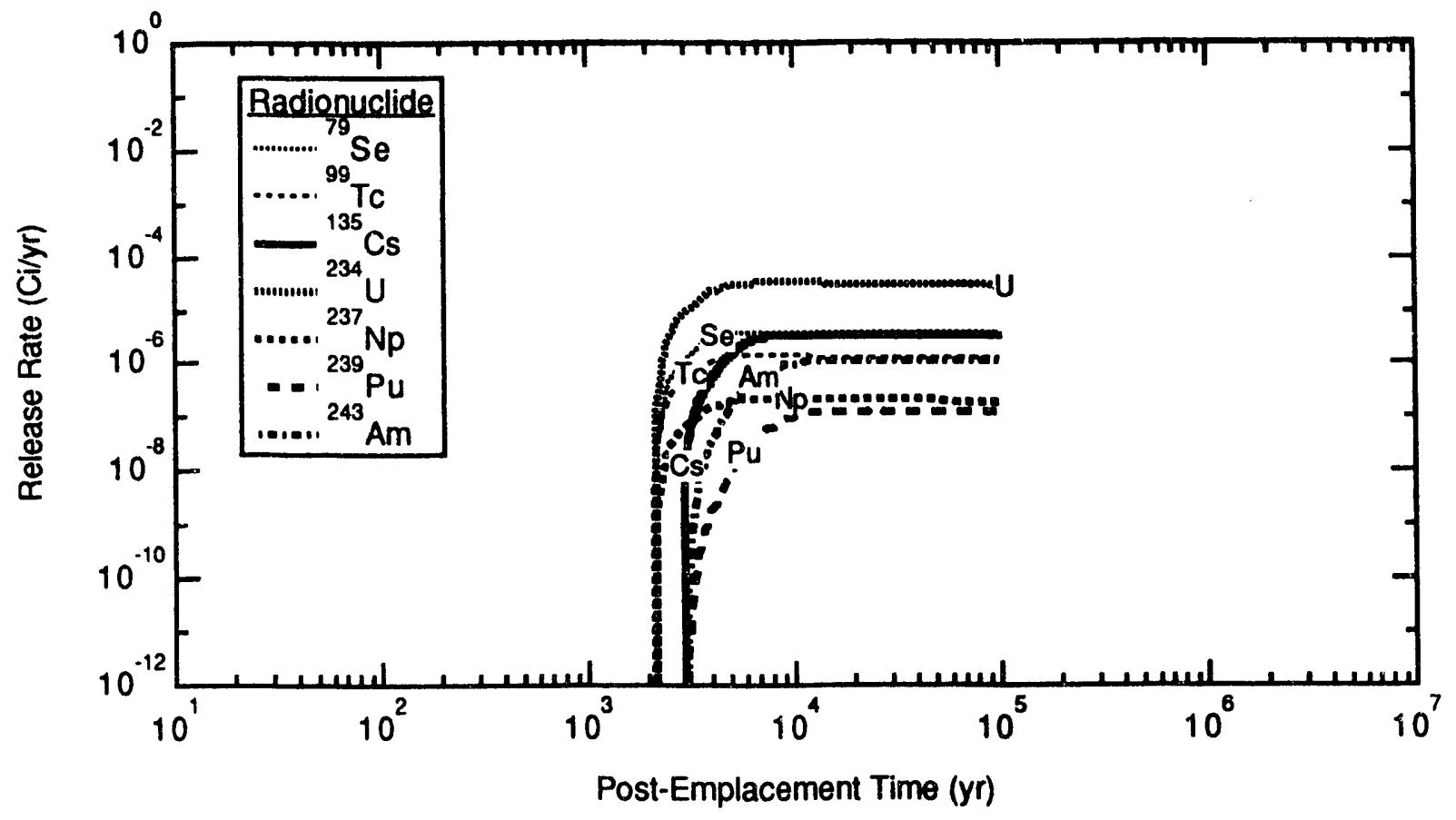

Figure 3.10. Source-Term Liquid-Phase Release: Base Scenario for Glass Waste Using "WetContinuous" Model at $3.0 \mathrm{~mm} / \mathrm{yr}$ Infiltration Rate 


\subsection{Human-Intrusion Scenario Source-Term Results}

The source-term estimates for the human-intrusion scenario deep-aquifer-injection cases are shown in Figures 3.11 through 3.16. For the reaction-rate limited nuclides $\left({ }^{14} \mathrm{C},{ }^{79} \mathrm{Se},{ }^{99} \mathrm{Tc}\right.$, $126 \mathrm{Sn}, 129 \mathrm{I}$, and $135 \mathrm{Cs}$ ), either the flow-through release model or the "wet-continuous" diffusive release model was used. Only the flow-through release model was used for the solubility-limited nuclides $\left(234 \mathrm{U},{ }^{237} \mathrm{~Np},{ }^{239} \mathrm{Pu}\right.$, and $\left.243 \mathrm{Am}\right)$. The flow-through model was used for the alterationlimited nuclides when flow velocities were less than or equal to $10 \mathrm{~mm} / \mathrm{yr}$ (Figures $3.11,3.12$, and 3.15), while the "wet-continuous" diffusive release models were used when flow velocities where greater than the arbitrarily-selected $10 \mathrm{~mm} / \mathrm{yr}$ cutoff (Figures 3.13, 3.14, and 3.16).

Figures 3.11 through 3.13 show the results for the tuff aquifer. Figure 3.11 shows the results for tuff simulation 1 . For the analysis of tuff simulations 1 through 10 , the flow-through release models were used with a median ground-water velocity for the tuff aquifer $(0.00181 \mathrm{~m} / \mathrm{yr}$; Table 3.6). Because the water velocities are the same for tuff simulations 1 through 10 , the release profiles will be similar for all 10 cases. Hence, only the results for tuff simulation 1 are shown (Figure 3.1). A minimum-flow velocity for the tuff aquifer was used to calculate the release rates shown in Figure 3.12 (tuff simulation 11), while a maximum-flow velocity was used for calculating the release shown in Figure 3.13 (tuff simulation 12).

The results for displacing a failed container into the carbonate (Paleozoic) aquifer are shown in Figures 3.14 through 3.16. Similar to the tuff results, only carbonate simulation 1 is shown for the representative release profile for the 10 simulations where a median flow velocity $(3.035 \mathrm{~m} / \mathrm{yr}$; Table 3.6) was used. This case is shown in Figure 3.14. The flow-through release models were used for the minimum-flow simulation (tuff simulation 11), and are shown in Figure 3.15. Figure 3.16 shows the results of using a maximum-flow velocity in the carbonate aquifer (tuff simulation 12). 


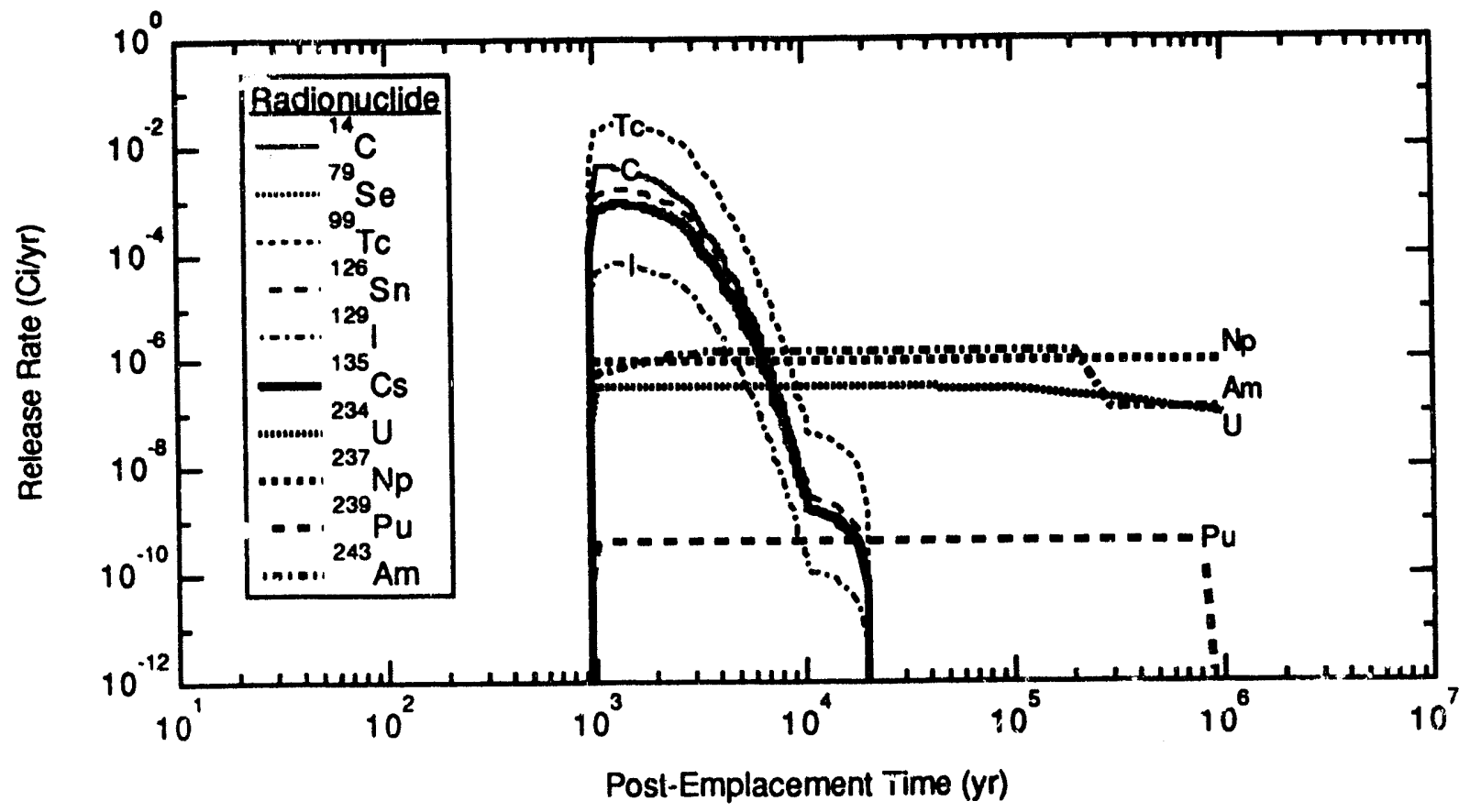

Figure 3.11. Source-Term Release Rate: Huma.7-Intrusion Tuff Simuiation 1

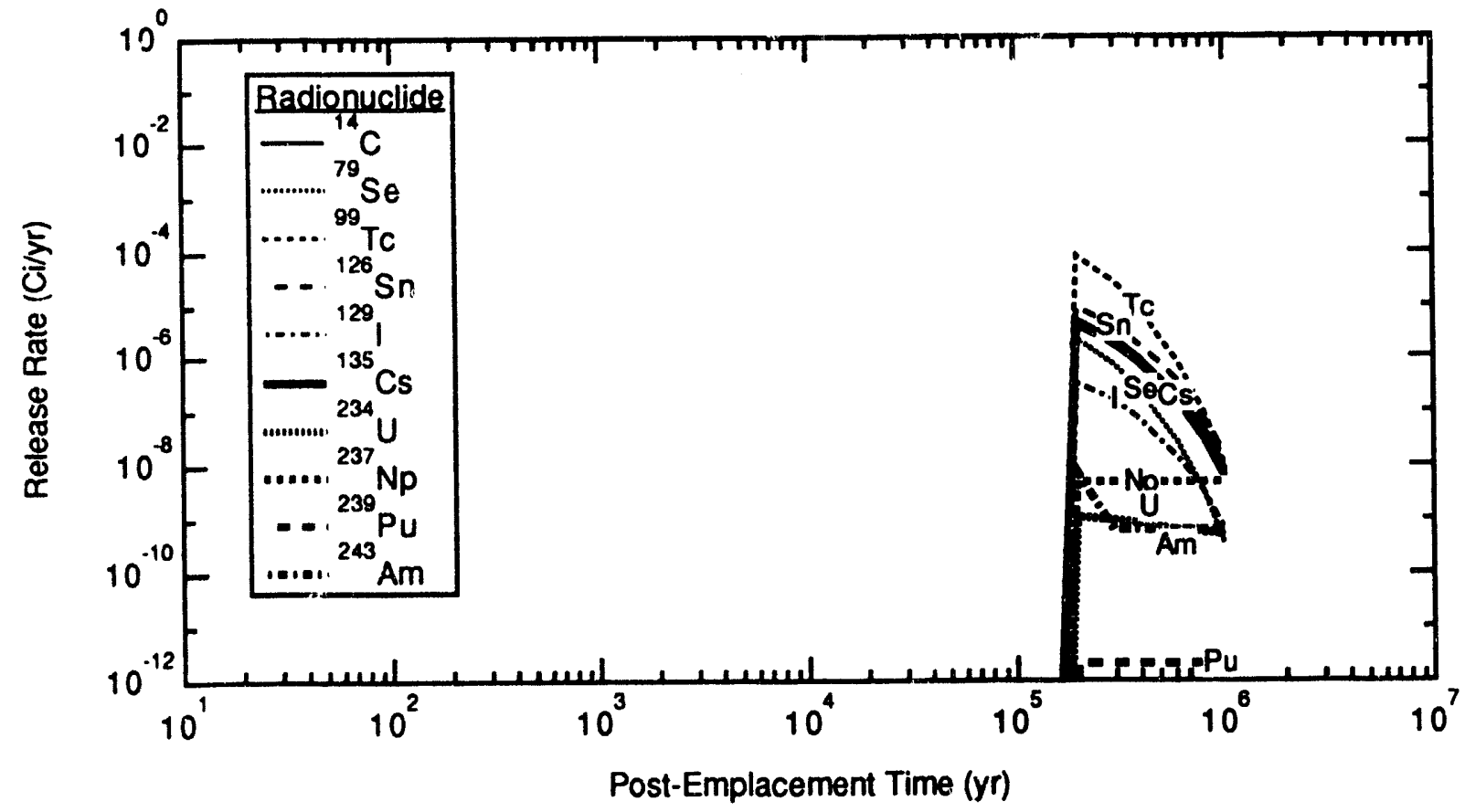

Figure 3.12. Source-Term Release Rate: Human-Intrusion Tuff Simulation 11 


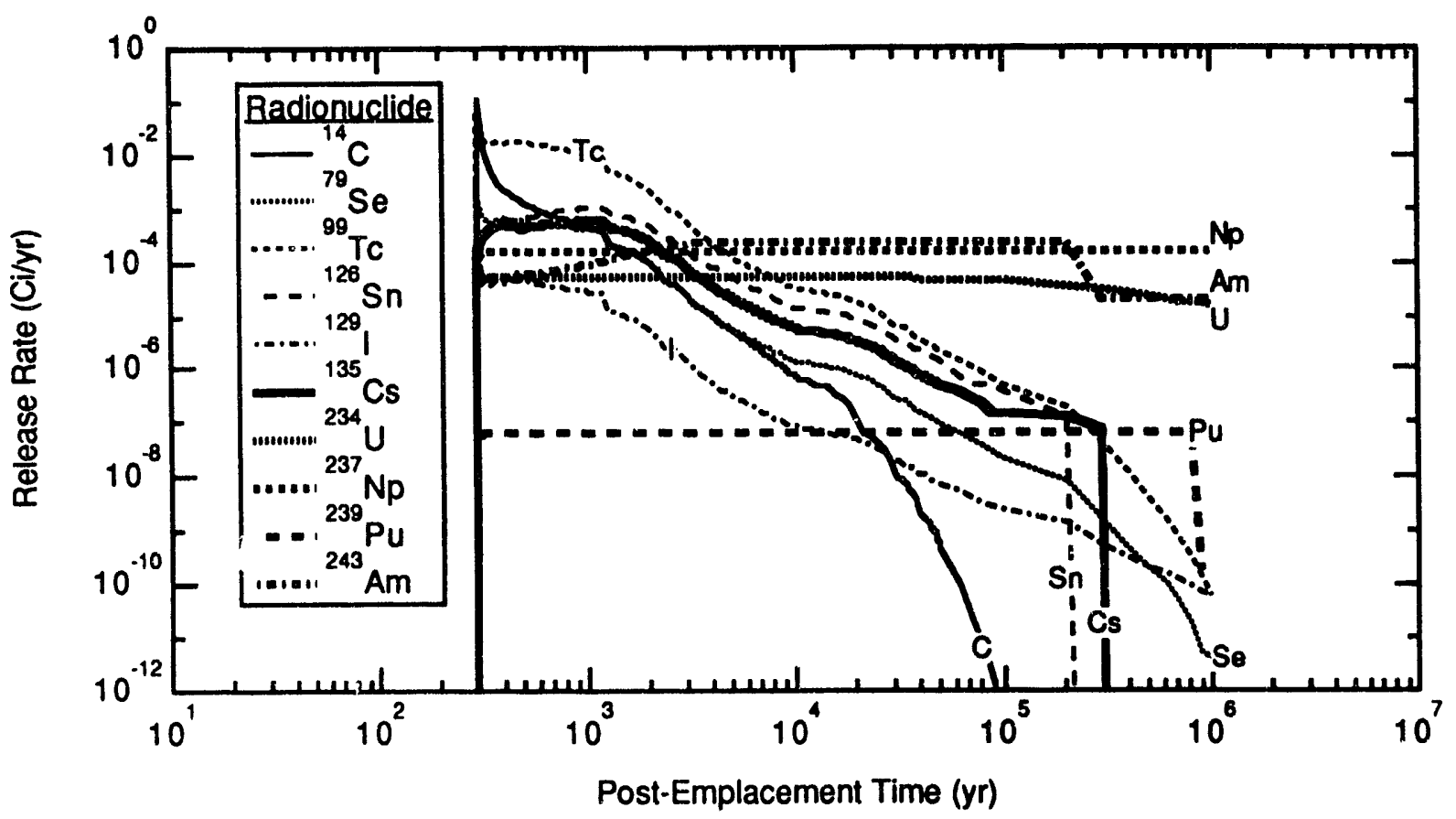

Figure 3.13. Source-Term Release Rate: Human-Intrusion Tuff Simulation 12

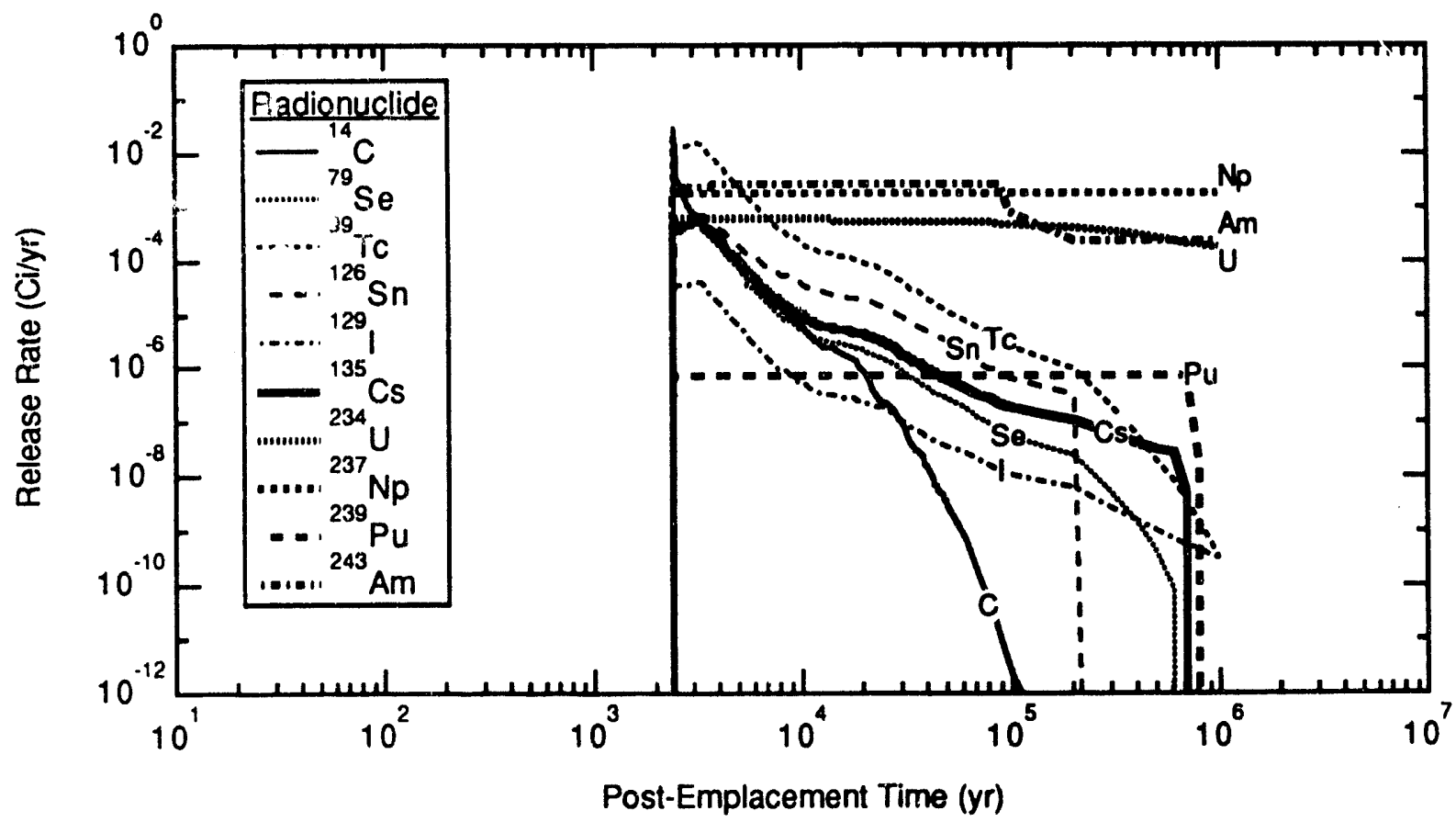

Figure 3.14. Source-Term Release Rate: Human-Intrusion Carbonate Simulation 1 


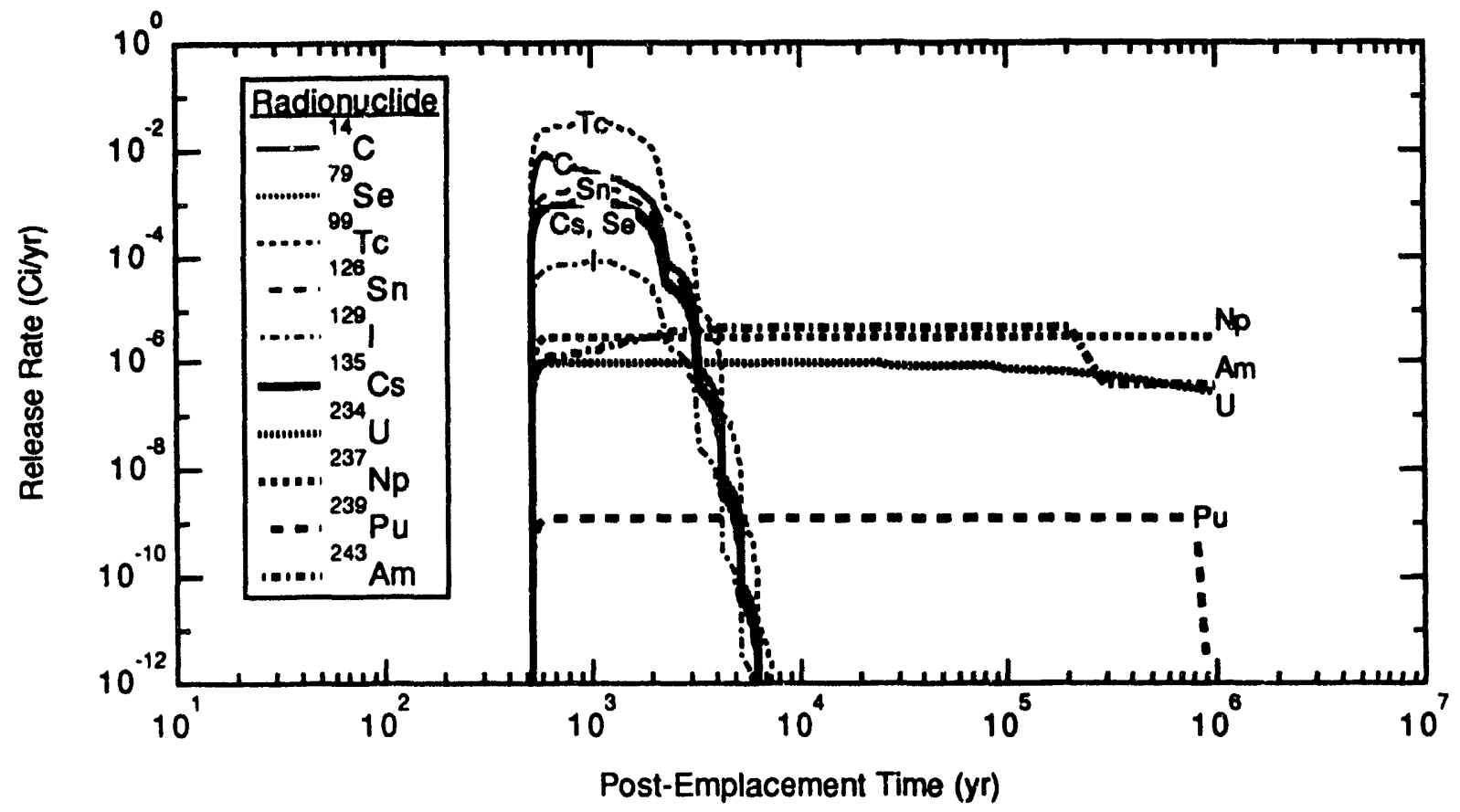

Figure 3.15. Source-Term Release Rate: Human-Intrusion Carbonate Simulation 11

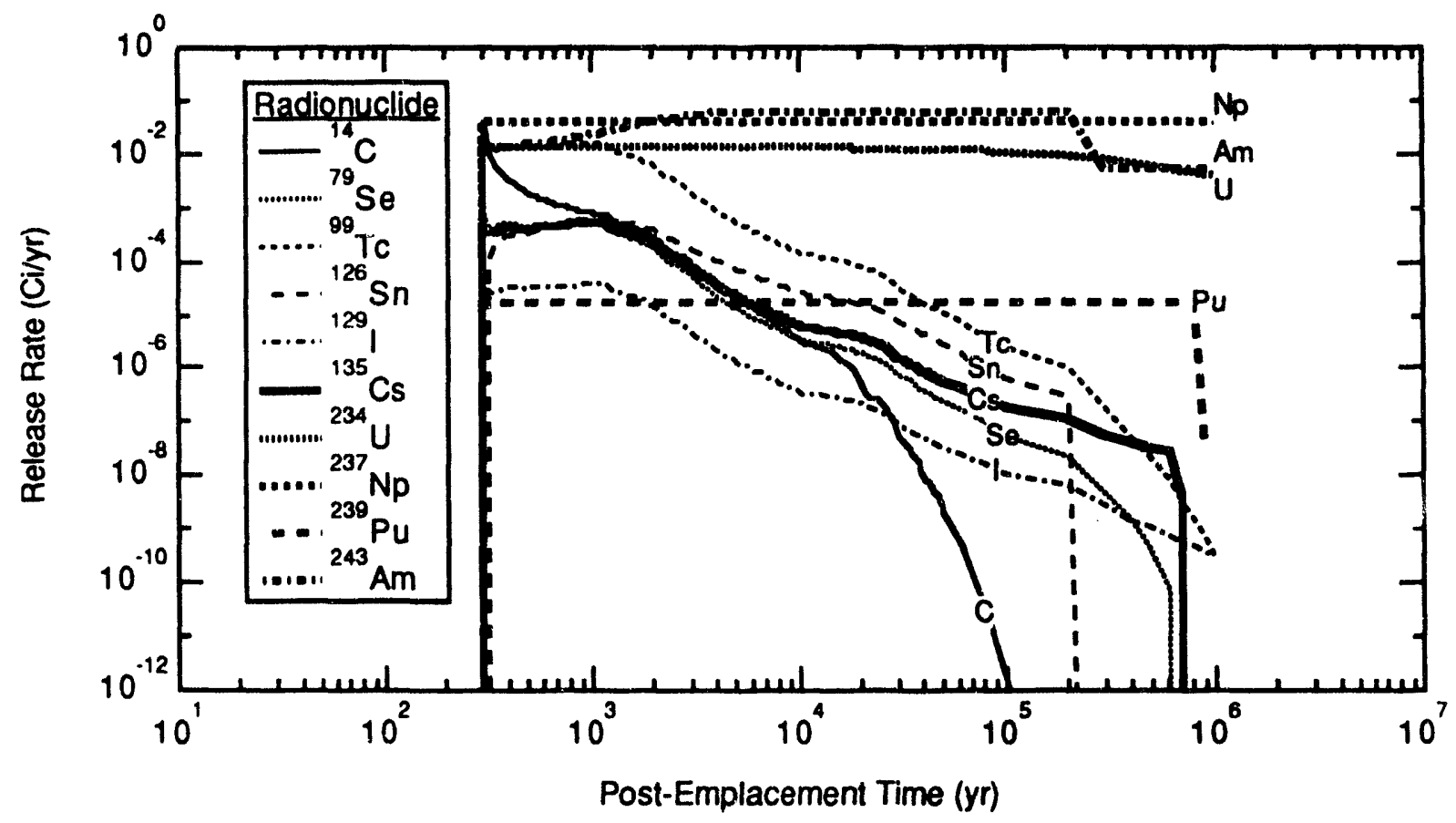

Figure 3.16. Source-Term Release Rate: Human-Intrusion Carbonate Simulation 12 


\subsection{Unsaturated Zone Hydrology and Transport}

Two approaches were used to model the unsaturated zone at Yucca Mountain for the totalsystem performance assessment exercise. For the liquid-phase approach, the unsaturated zone was modeled as an isothermal, liquid-phase hydrogeologic system for the purpose of simulating transport of 10 radionuclides from the potential repository to the regional water table. For the vapor-phase approach, the unsaturated zone was modeled as a nonisothermal, multiphase system while simulating transport of a single radionuclide $(14 \mathrm{C})$ from the potential repository to both the regional water table (liquid phase) and to the surface (vapor phase).

Although the modeling techniques and conceptual models differ for these methods, both approaches required the same hydrogeologic parameters. A general description of the unsaturated zone at Yucca Mountain and the hydrogeologic parameters used to describe its physical behavior are presented in Section 4.1. The liquid-phase modeling approach, results, and analysis are presented in Section 4.2, and the vapor-phase modeling approach, results, and analysis are presented in Section 4.3.

\subsection{Unsaturated Zone Description}

The current conceptual design for the potential repository at Yucca Mountain locates the potential repository horizon approximately $300 \mathrm{~m}$ above the regional water table and approximately $200 \mathrm{~m}$ below the land surface. Low recharge rates and low hydraulic conductivities in this deep unsaturated environment are expected to function as natural barriers to radionuclide transport from the engineered barriers of the potential repository to the accessible environment. Once in the unsaturated zone, radionuclides may be transported to the accessible environment by several paths, e.g., to the saturated zone through liquid-phase transport (Sections 4.2 and 4.3) and from there to the accessible environment (Section 5.0), or directly to the surface through vapor transport (Section 4.3). In addition, both unmobilized waste in the potential repository and waste transported into the unsaturated zone may be subject to disruptive scenarios such as volcanic activity or human intrusion events. Analysis of disruptive conditions is, therefore, dependent on unsaturated-zone model predictions of the spatial and temporal distribution of water and waste.

Figure 4.1 depicts the generalized conceptual model of the unsaturated zone at Yucca Mountain that was the basis for all unsaturated-zone modeling described in this report. This system consists of a two-dimensional domain comprised of five stratigraphic layers as shown. The potential repository location is represented in Figure 4.1 as a bold line that extends from borehole USW H-5 at an elevation of $1030 \mathrm{~m}$ above mean sea level east $1972 \mathrm{~m}$ to $895 \mathrm{~m}$ above sea level. The regional water table was assumed horizontal at an elevation of $730 \mathrm{~m}$, its present static position at boreholes USW G-4 and UE-25a\#1.

\subsubsection{Hydrologic and Transport Properties}

The five lithological units included in both conceptual models are listed in Table 4.1. Key hydrologic parameters are saturated hydraulic conductivity $\left(K_{S}\right)$, total porosity $\left(n_{T}\right)$, residual saturation $\left(S_{\mathrm{r}}\right)$, and the van Genuchten curve-fitting parameters, $\alpha$ and $\beta$ (van Genuchten, 1980). The mean values for these five parameters for each layer and for fractures are tabulated in Table 4.2. Matrix parameter values in Table 4.1 are derived from Peters et al. (1984), which was subsequently published in the PACE-90 report. Fracture parameter values in Table 4.1 are taken 


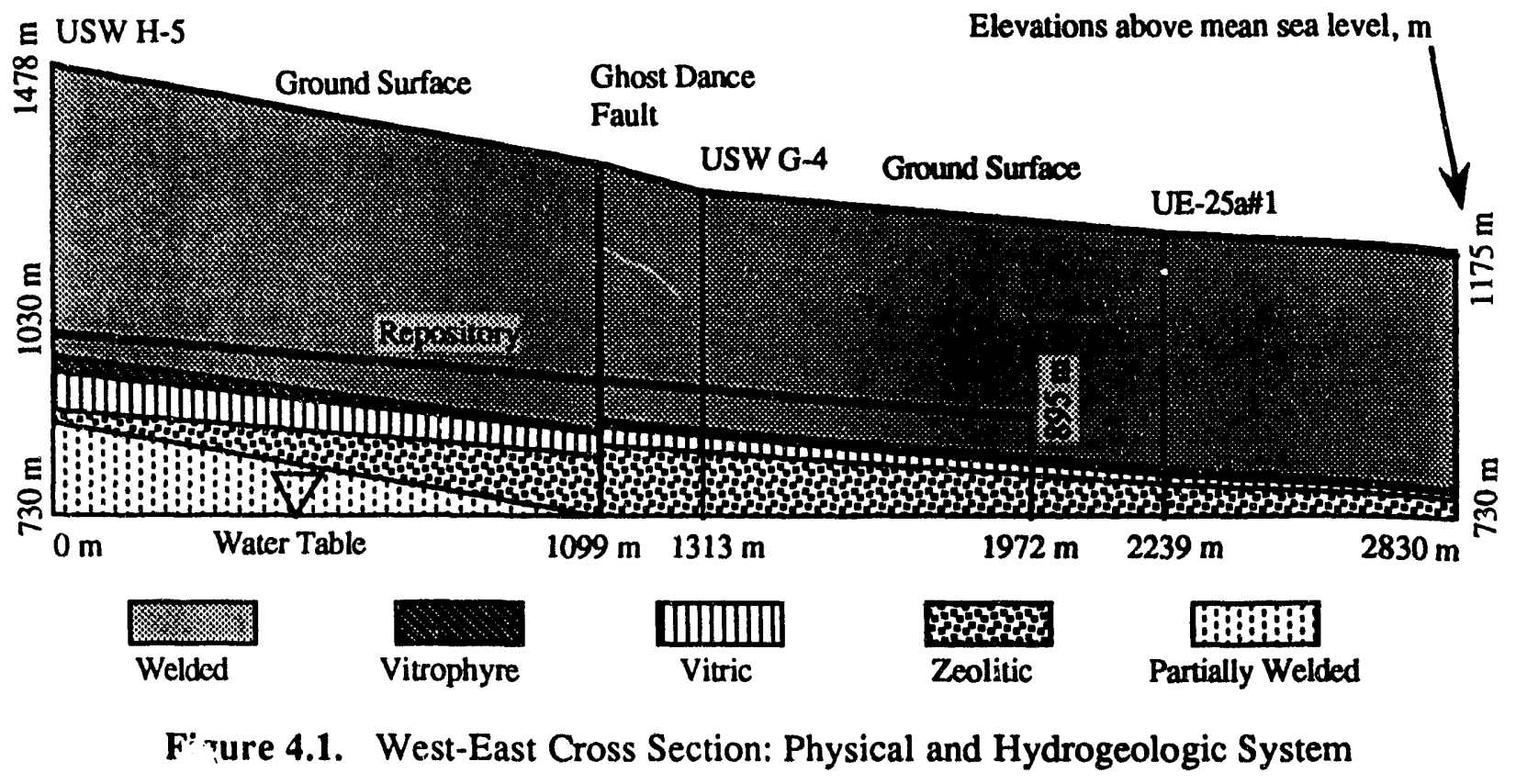

Table 4.1. Mean Hydrologic Parameters

\begin{tabular}{|c|c|c|c|c|c|}
\hline Layer & $\mathrm{K}_{S}(\mathrm{~m} / \mathrm{s})$ & $n_{T}$ & $S_{r}$ & $\alpha(1 / \mathrm{m})$ & $\beta$ \\
\hline $\begin{array}{l}\text { Welded } \\
\text { Vitrophyre } \\
\text { Nonwelded Vitric } \\
\text { Nonwelded Zeolitic } \\
\text { Partially Welded }\end{array}$ & $\begin{array}{l}2.00 \times 10^{-11} \\
3.01 \times 10^{-12} \\
7.99 \times 10^{-11} \\
3.01 \times 10^{-12} \\
1.40 \times 10^{-8}\end{array}$ & $\begin{array}{l}0.11 \\
0.09 \\
0.21 \\
0.41 \\
0.24\end{array}$ & $\begin{array}{l}0.080 \\
0.052 \\
0.164 \\
0.010 \\
0.066\end{array}$ & $\begin{array}{l}0.0057 \\
0.0033 \\
0.0265 \\
0.0220 \\
0.0140\end{array}$ & $\begin{array}{l}1.798 \\
1.798 \\
2.223 \\
1.236 \\
2.640\end{array}$ \\
\hline Fractures & $8.25 \times 10^{-5}$ & 0.43 & 0.045 & 14.5 & 2.680 \\
\hline
\end{tabular}

from Carsel and Parish (1988). All hydrogeologic parameter values for use in the total-system performance assessment exercise were set forth in Kaplan et al. (1991)(a).

Additional parameter values were required to model radionuclide transport in the unsaturated zone. These parameters were the sorption coefficients $\left(\mathrm{K}_{\mathbf{d}}\right)$ for each radionuclide with respect to stratigraphic layers and isotope half-lives $\left(t_{1 / 2}\right)$. The half-lives and the mean $K_{d}$ values are shown in Table 4.2. Transport of all ten radionuclides listed in Table 4.2 was simulated in liquid-phase modeling, including decay of $243 \mathrm{Am}$ into $239 \mathrm{Pu}$, while only $14 \mathrm{C}$ transport was simulated in the vapor-phase modeling. Dockery (1991)(b) reports that the $K_{d}$ values in Table 4.2 are derived from sorption data from the Culebra formation at the Waste Isolation Pilot Project

(a) Kaplan, P., G. Gainer, H. Dockery, and R. Barnard. 1991. Distributions of Hydrogeologic Parameters for the TSA Problem. This July 25, 1991 letter report is reproduced in Appendix A.

(b) Dockery, H. 1991. Additional $K_{d}$ information from A. Meijer (9/26/91). This October 2, 1991 memo is reproduced in Appendix B. 
Table 4.2. Radionuclide Half-Lives and Sorption Coefficients

Sorption Coefficient

\begin{tabular}{|c|c|c|c|c|c|c|}
\hline Nuclide & $t_{1 / 2}(y r)$ & Welded & Vitrophyre & Vitric & Zeolitic & P. Welded \\
\hline $234 \mathrm{U}$ & $2.45 \times 10^{5}$ & 2.5 & 2 & 2 & 10 & 2.5 \\
\hline 237Np & $2.14 \times 10^{6}$ & 2 & 0.5 & 0.5 & 4 & 2 \\
\hline $243 \mathrm{Am}$ & $7.38 \times 10^{3}$ & 100 & 100 & 100 & 100 & 100 \\
\hline $239 \mathrm{Pu}$ & $2.41 \times 10^{4}$ & 100 & 100 & 100 & 100 & 100 \\
\hline${ }^{14} \mathrm{C}$ & $5.73 \times 10^{3}$ & 0 & 0 & 0 & 0 & 0 \\
\hline${ }^{79} \mathrm{Se}$ & $6.50 \times 10^{4}$ & 2.5 & 2 & 2 & 10 & 2.5 \\
\hline $99 \mathrm{Tc}$ & $2.11 \times 10^{5}$ & 0 & 0 & 0 & 0 & 0 \\
\hline $126 \mathrm{~S} n$ & $1.00 \times 10^{5}$ & 100 & 100 & 100 & 100 & 100 \\
\hline $129 \mathrm{~J}$ & $1.57 \times 10^{7}$ & 0 & 0 & 0 & 0 & 0 \\
\hline $135 \mathrm{Cs}$ & $2.30 \times 10^{6}$ & 50 & 50 & 50 & 2000 & 50 \\
\hline
\end{tabular}

(WIPP) site. These values are for matrix rock only. Three radionuclides, ${ }^{14} \mathrm{C}$, $99 \mathrm{Tc}$, and $129 \mathrm{I}$, are assumed to have zero retardation. However, carbon will probably be exhanged with stable carbon or precipitated onto carbonate rocks. For additional geochemistry details concerning the selection of sorption values used in this exercise, the reader is encouraged to refer to Dockery (1991), which is reproduced as Appendix B.

\subsubsection{Fracture/Matrix Equivalent-Continuum Model}

Given the constraints of computer technology at present, it is impractical to explicitly address fractures with apertures on the order of $10^{-5} \mathrm{~m}$ while modeling a flow domain on the order of $10^{3} \mathrm{~m}$. Therefore, we must rely on an equivalent-continuum approach that incorporates aspects of both matrix and fracture flow into a single porous-media model. For both the liquid-phase and multiphase approaches, the equivalent-continuum model was based on the assumption that fracture and matrix pressures are in equilibrium at all points in the model's domain. Future work in this field will probably expand to include non-equilibrium fracture/matrix interactions, but the capability was not available for this exercise.

The pressure-equilibrium assumption allowed us to compute a bulk-equivalent saturation $\left(\mathrm{S}_{\mathrm{b}}\right)$ at a given tension head $(\psi)$ based on the matrix saturation $\left(\mathrm{S}_{\mathrm{m}}\right)$ and fracture saturation $\left(\mathrm{S}_{\mathrm{f}}\right)$ computed at that pressure:

$$
S_{b}=\frac{S_{f} n_{T I f}+S_{m}\left(1-n_{T I f}\right) n_{T l m}}{n_{T I f}+\left(1-n_{T I f}\right) n_{T / m}}
$$

where $n_{T I f}$ and $n_{T / m}$ are the total porosities in the fractures and matrix, respectively. Similarly, the bulk-equivalent saturated hydraulic conductivity $\left(\mathrm{K}_{\mathrm{Slb}}\right)$ at a given pressure head is computed using this general relationship for bulk-equivalent hydraulic conductivity $\left(\mathrm{K}_{\mathrm{b}}\right)$ :

$$
\mathrm{K}_{\mathrm{b}}=\mathrm{K}_{\mathrm{m}}\left(1-\mathrm{n}_{\mathrm{T} \mid \mathrm{f}}\right)+\mathrm{K}_{\mathrm{f}} \mathrm{n}_{\mathrm{TIf}} \mathrm{K}_{\mathrm{b}}=\mathrm{K}_{\mathrm{m}}\left(1-\mathrm{n}_{\mathrm{T} \mid \mathrm{f}}\right)+\mathrm{K}_{\mathrm{f}} \mathrm{n}_{\mathrm{TI}}
$$

where $K_{m}$ and $K_{f}$ are the hydraulic conductivities in the matrix and fractures, respectively. The equivalent-continuum conductivity curves can be generated for a range of pressure heads by 
computing the saturation and conductivity for both fractures and matrix regimes using their respective characteristic parameters and then substituting those values into Equations (4.1) and (4.2) to obtain the bulk-equivalent values. The resulting equivalent-continuum curve is then used to describe unsaturated hydraulic characteristics to the numerical model that solves the flow equation.

Kaplan et al. (1991) and Barnard and Dockery (1991)(a) specified that the Ghost Dance fault was to be modeled both as a 14-m offset and as a zone of increased permeability (based on fracture density and aperture differences). Fracture densities presented in Kaplan et al. (1991), based on Spengler et al. (1984), are shown in Table 4.3 for the rock and fault zones.

The following example calculation illustrates how the equivalent-continuum characteristic curves are generated and how fracture densities are used to differentiate between the properties of the Ghost Dance fault and the surrounding rock. Fracture total porosity $\left(\mathrm{n}_{\mathrm{TIf}}\right)$, the ratio of the total volume of fractures to the total volume of rock, is computed as the product of fracture density, mean fracture aperture, and within-fracture saturated moisture content $\left(\theta^{*} \mathrm{Str}_{\mathrm{r}}\right)$. Using values for the welded unit (layer 1) rock, and the $210 \mu \mathrm{m}$ aperture specified by Kaplan et al. (1991), we calculate

$$
\begin{aligned}
\mathrm{n}_{\mathrm{TIf}} & =(\text { fracture density })(\text { fracture aperture }) \theta_{\text {SIf }}^{*} \\
& =\left(28.3 \mathrm{~m}^{-1}\right)(210 \mu \mathrm{m})\left(\frac{1 \mathrm{~m}}{10^{6} \mu \mathrm{m}}\right)(0.43) \\
& =2.555 \times 10^{-3} .
\end{aligned}
$$

This value is used in Equation (4.4) to calculate the fracture residual moisture content $\left(\theta_{\mathrm{RIf}}\right)$, expressed as a fraction of the total rock volume. We assume that the fracture residual saturation $\left(\mathrm{S}_{\mathrm{R} \mid \mathrm{f}}\right)$, computed as the ratio of residual and saturated moisture contents reported in Carsel and Parish (1988), is constant.

$$
\begin{aligned}
\theta_{\mathrm{RIf}} & =\left(\mathrm{n}_{\mathrm{TIf}}\right)\left(\mathrm{S}_{\mathrm{RIf}}\right)=\left(\mathrm{n}_{\mathrm{T} \mid \mathrm{f}}\right)\left(\frac{\theta_{\mathrm{RIf}}^{*}}{\theta_{\mathrm{SIf}}^{*}}\right) \\
& =\left(2.555 \times 10^{-3}\right)\left(\frac{0.045}{0.43}\right) \\
& =2.674 \times 10^{-4} .
\end{aligned}
$$

Finally, substituiting values for the appropriate terms in Equation (4.2), we obtain

(a) Barnard, R., and H. Dockery. 1991. TSA Problem Outline Consensus. This July 26, 1991 letter report is reproduced in Appendix $C$. 
Table 4.3. Fracture Densities $(1 / \mathrm{m})$

\begin{tabular}{lrrrr}
\multicolumn{1}{c}{ Layer } & & Rock & & Fault \\
\cline { 1 - 1 } Welded & & & \\
Vitrophyre & & 35.3 & & 283 \\
Nonwelded Vitric & & & 356 \\
Nonwelded Zeolitic & & 1.6 & & 20 \\
Partially Welded & & 4.4 & & 44
\end{tabular}

$$
\begin{aligned}
\mathrm{K}_{\mathrm{SIb}} & =\mathrm{K}_{\mathrm{SIm}}\left(1-\mathrm{n}_{\mathrm{T} \mid \mathrm{f}}\right)+\mathrm{K}_{\mathrm{SIf}} \mathrm{n}_{\mathrm{TIf}} \\
& =\left(2.00 \times 10^{-11} \mathrm{~m} / \mathrm{s}\right)\left(1-2.555 \times 10^{-3}\right)+\left(8.25 \times 10^{-5} \mathrm{~m} / \mathrm{s}\right)\left(2.555 \times 10^{-3}\right) \\
& =2.11 \times 10^{-7} \mathrm{~m} / \mathrm{s}
\end{aligned}
$$

where $\mathrm{K}_{\mathrm{S} \mid \mathrm{b}}$ is the value of saturated hydraulic conductivity used to represent the Welded unit (layer 1 ) in solving the governing flow equation with a numerical model.

Equations (4.3) through (4.5) illustrate how we calculated equivalent-continuum model parameters using the rock properties of the Welded unit. The calculated rock parameter values for all five units are summarized in Table 4.4. The parameter values for the Ghost Dance fault zone are computed in the same manner using the higher fracture densities (Tabi: 4.3) in the calculation shown in Equation (4.3). The calculated fault parameter values are given in Table 4.5.

The values in Tables 4.1 through 4.5 are sufficient to permit the use of Equations (4.1) and (4.2) to generate equivalent-continuum composite unsaturated-characteristic curves. For a prescribed pressure head, which is the same for the matrix and fracture regimes under the pressureequilibrium assumption, saturation and hydraulic conductivity are computed separately for matrix and fracture regimes. The resulting values are then substituted into Equations (4.1) and (4.2) to obtain the composite values for these variables. Repeating this process over a range of pressure heads yields the unsaturated-characteristic curves. Figures 4.2 through 4.6 depict the water retention and hydraulic conductivity curves for both rock and fault zones for layers 1 through 5 , respectively. For liquid-phase modeling, tabulated values based on approximately 200 points per curve were used to represent the unsaturated curve to the numerical model. A better approach was used for vapor-phase modeling, wherein the MSTS code was enhanced to solve the equivalentcontinuum relations directly. This eliminated the need for a separate computer program to generate tabular values and greatly reduced preparation time, while offering a small increase in performance because linear interpolation between tabulated values was not required.

\subsection{Liquid Phase}

The approach, results, and analysis for liquid-phase modeling conducted for the totalsystem performance assessment exercise are presented in this section. The hydrogeologic and contaminant-transport parameters used for this exercise were presented in Section 4.1. 
Table 4.4. Computed Rock Parameter Values for Equivalent-Continuum Model

\begin{tabular}{|c|c|c|c|}
\hline Layer & $\mathrm{n}_{\mathrm{Tle}}$ & $\theta_{\text {RIf }}$ & $\mathrm{K}_{\mathrm{b}}(\mathrm{m} / \mathrm{s})$ \\
\hline Welded Nonlithophysal & $2.555 \times 10^{-3}$ & $2.674 \times 10^{-4}$ & $2.108 \times 10^{-7}$ \\
\hline Vitrophyre & $3.215 \times 10^{-3}$ & $3.364 \times 10^{-4}$ & $2.652 \times 10^{-7}$ \\
\hline Nonwelded Vitric & $1.806 \times 10^{-4}$ & $1.890 \times 10^{-5}$ & $1.498 \times 10^{-8}$ \\
\hline Nonwelded Zeolitic & $1.445 \times 10^{-4}$ & $1.512 \times 10^{-5}$ & $1.192 \times 10^{-8}$ \\
\hline Partially Welded & $3.973 \times 10^{-4}$ & $4.158 \times 10^{-5}$ & $4.677 \times 10^{-8}$ \\
\hline
\end{tabular}

Table 4.5. Computed Fault Parameter Values for Equivalent-Continuum Model

\begin{tabular}{|c|c|c|c|}
\hline Layer & $\mathrm{n}_{\text {Tle }}$ & $\theta_{\mathrm{RIf}}$ & $\mathrm{K}_{\mathrm{b}}(\mathrm{m} / \mathrm{s})$ \\
\hline Welded Nonlithophysal & $2.555 \times 10^{-2}$ & $2.674 \times 10^{-3}$ & $2.108 \times 10^{-6}$ \\
\hline Vitrophyre & $3.215 \times 10^{-2}$ & $3.364 \times 10^{-3}$ & $2.652 \times 10^{-6}$ \\
\hline Nonwelded Vitric & $1.806 \times 10^{-3}$ & $1.890 \times 10^{-4}$ & $1.491 \times 10^{-7}$ \\
\hline Nonwelded Zeolitic & $1.445 \times 10^{-3}$ & $1.512 \times 10^{-4}$ & $1.192 \times 10^{-7}$ \\
\hline Partially Welded & $3.973 \times 10^{-3}$ & $4.158 \times 10^{-4}$ & $3.417 \times 10^{-7}$ \\
\hline
\end{tabular}
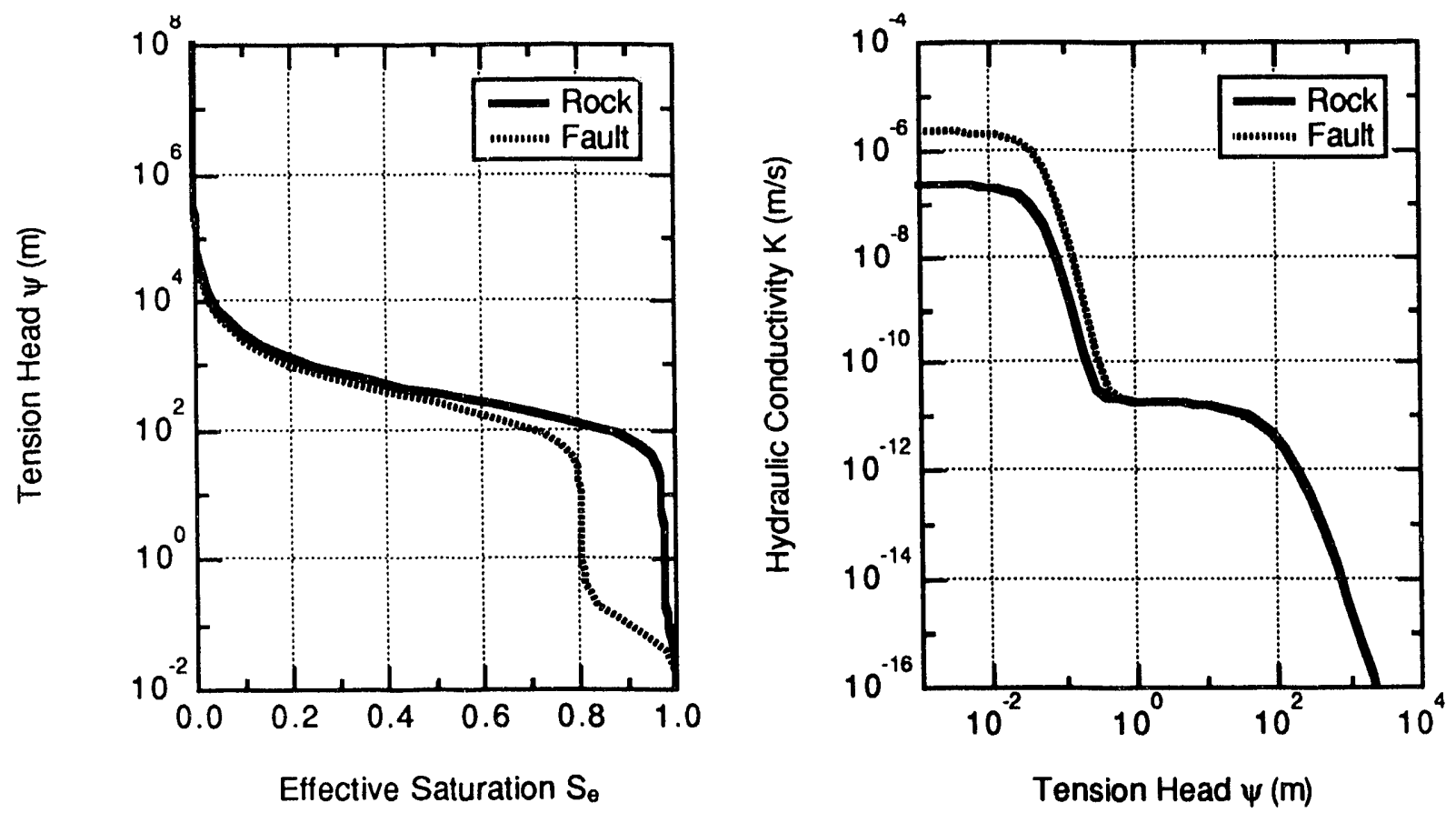

Figure 4.2. Water-Retention and Hydraulic-Conductivity Curves for Layer 1, Welded 


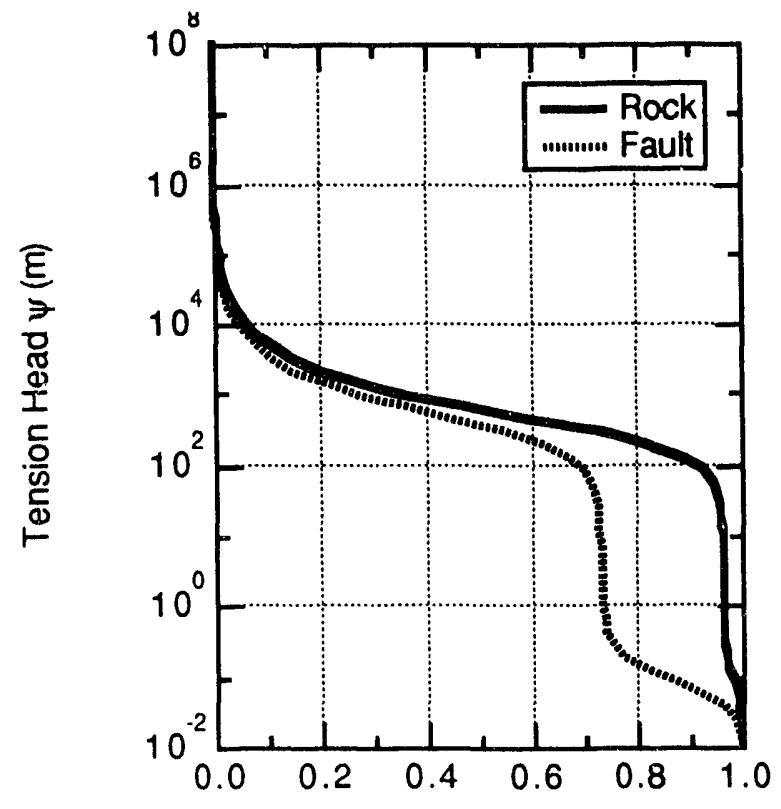

Effective Saturation $S_{e}$

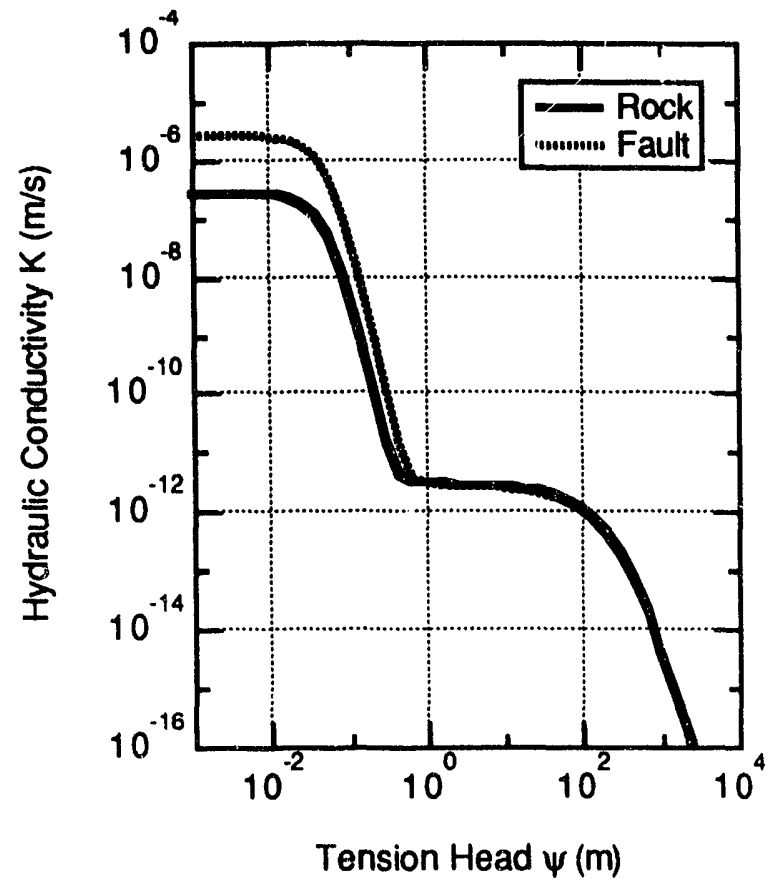

Figure 4.3. Water-Retention and Hydraulic-Conductivity Curves for Layer 2, Vitrophyre

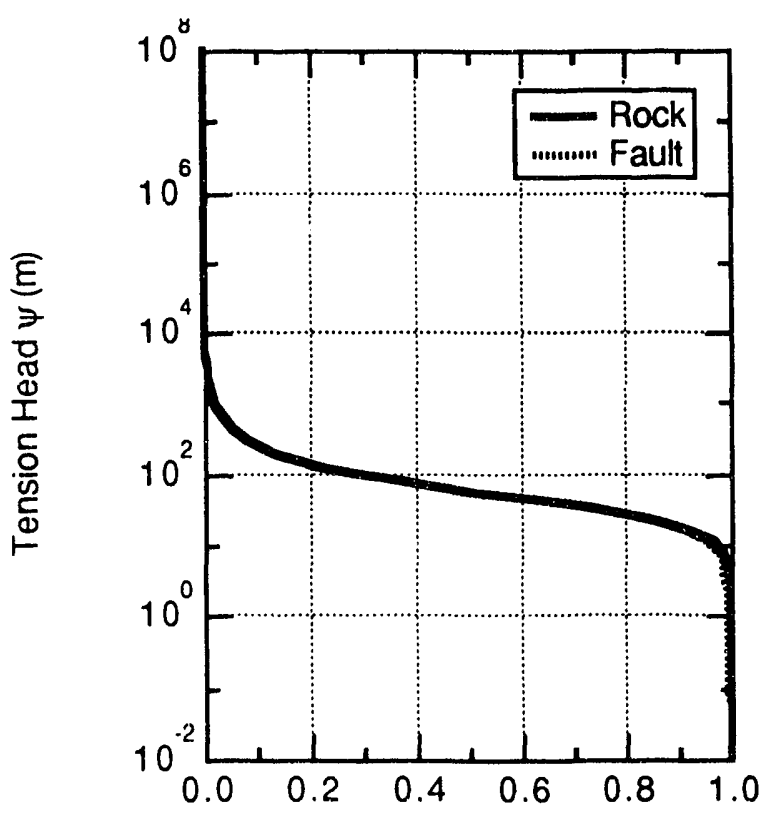

Effective Saturation $S_{e}$

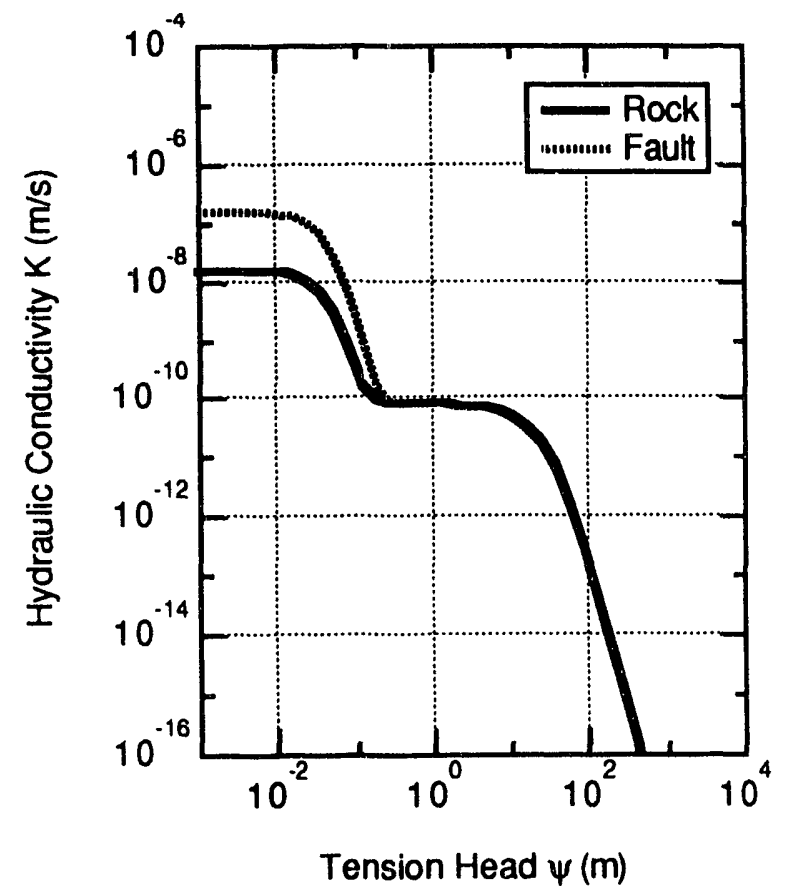

Tension Head $\Psi(m)$

Figure 4.4. Water-Retention and Hydraulic-Conductivity Curves for Layer 3, Vitric 

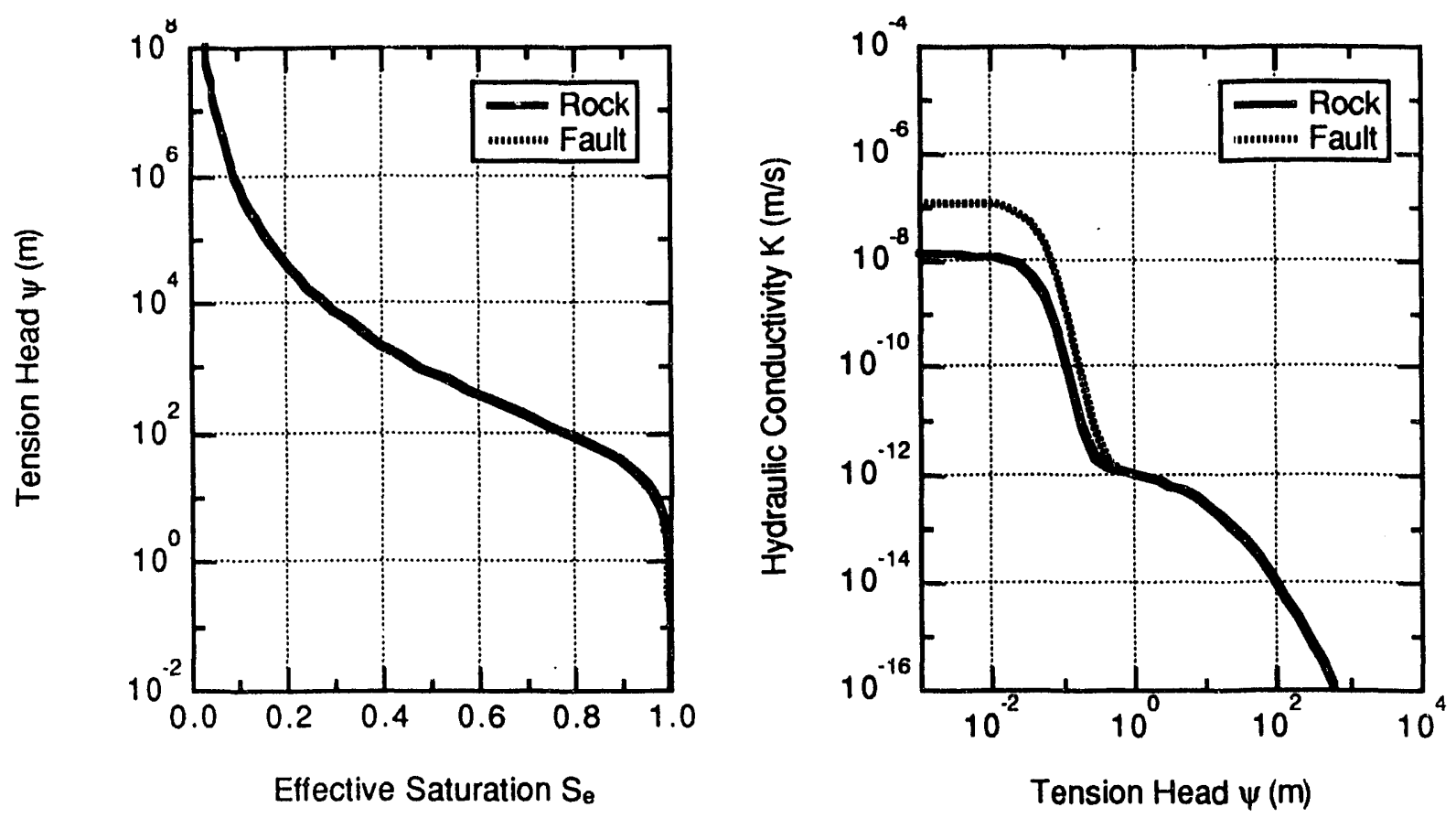

Figure 4.5. Water-Retention and Hydraulic-Conductivity for Layer 4, Zeolitic
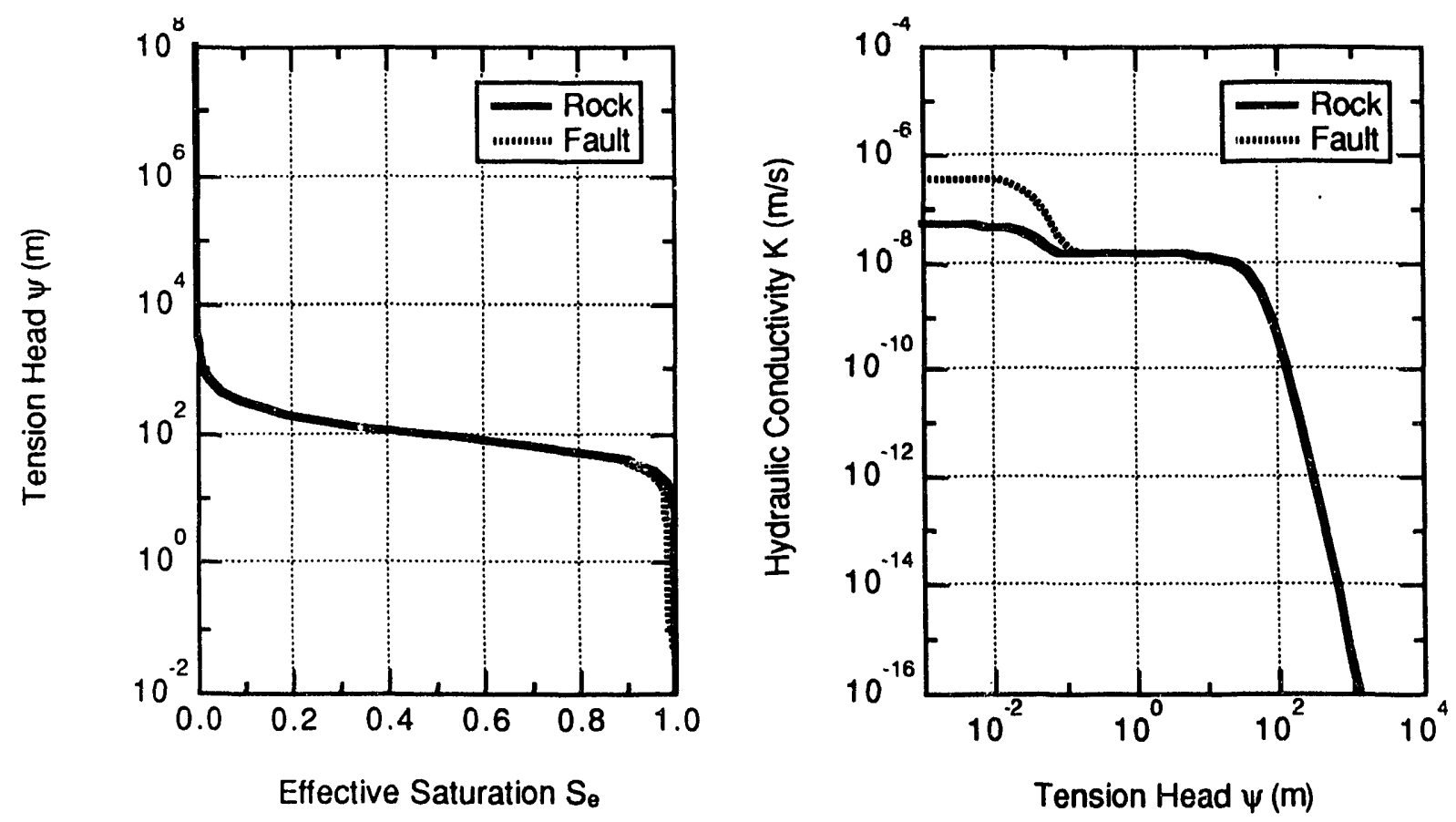

Figure 4.6. Water-Retention and Hydraulic-Conductivity Curves for Layer 5, Partially Welded 


\subsubsection{Method and Assumptions}

Several simplifying assumptions were made to constrain the liquid-phase problem for the total-system performance assessment exercise. The assumptions are stated here to reflect the level of detail of the analysis but do not comprise an exhaustive list of assumptions made. First, we assumed that flow in the unsaturated zone of Yucca Mountain is described by Darcy's Law. The hydrogeologic properties of the porous media that comprise Yucca Mountain are assumed to be homogeneous and isotropic within the stratigraphic layers identified in the conceptual model. Recharge is assumed to be time-invariant and spatially uniform at the depth of the potential repository. All flow was treated as isothermal, single phase (nonisothermal, multiphase flow is the topic of Section 4.3). Water pressure in the fractures and matrix was assumed to be in equilibrium, permitting use of equivalent-continuum ("dual-porosity") characteristic curves (discussed in Section 4.2.2). Treatment of the Ghost Dance fault relied on two principal assumptions: first, that the fault is a $1-\mathrm{m}$-wide feature representing a 14-m offset in adjoining stratigraphic units, and second, that the hydrologic properties of the fauli differ from the surrounding rock units only by an order-of-magnitude increase in fracture density in the fault zone.

\subsubsection{Conceptual and Numerical Models}

The generalized conceptual model was presented in Section 4.1. The significant change to that model for liquid-phase analysis was that the vertical extent of the liquid-phase model was reduced to extend from the water table at $730 \mathrm{~m}$ to an elevation of $1050 \mathrm{~m}$, which is just above the potential repository horizon. For liquid-phase modeling under the given assumptions it was unnecessary to model the strata above $1050 \mathrm{~m}$.

The governing flow equation solved by the SUMO computer code is based on the equation of continuity and Darcy's Law for flow dynamics. The equation for conservation of a slightly compressible fluid mass in nondeforming media is expressed as

$$
\partial_{\mathrm{l}}(\theta \rho)+\nabla \cdot(\rho \mathrm{V})-\mathrm{M}=0
$$

where $\partial_{t}=$ partial derivative with respect to time

$\theta=$ volumetric moisture content $\left(\mathrm{m}^{3} / \mathrm{m}^{3}\right)$

$\rho=$ fluid density $\left(\mathrm{kg} / \mathrm{m}^{3}\right)$

$\nabla=$ vector differential operator

$\mathbf{V}=$ Darcy velocity vector $(\mathrm{m} / \mathrm{s})$

$M=$ fluid source $/$ sink term $(\mathrm{kg} / \mathrm{s})$.

The Darcy equation for isothermal flow is

$$
\mathbf{V}=-\left(\frac{\mathbf{k}}{\mu}\right)(\nabla p+\rho g \nabla z)
$$

where $\mathbf{k}=$ intrinsic permeability tensor $\left(\mathrm{m}^{2}\right)$ 
$\mu=$ dynamic fluid viscosity $(1 / \mathrm{m} \mathrm{s})$

$\mathrm{p}=$ fluid pressure $\left(\mathrm{kg} / \mathrm{m} \mathrm{s}^{2}\right)$

$\mathrm{g}=$ acceleration due to gravity $\left(\mathrm{m} / \mathrm{s}^{2}\right)$

$\mathrm{z}=$ vertical direction in cartesian coordinate system, taken as positive upwards (m).

Equation (4.7) is substituted into Equation (4.6) to obtain the governing equation for single-phase fluid flow under isothermal conditions that is solved in the SUMO code, expressed for the two dimensions addressed in this exercise:

$$
S_{S} \partial_{t} H=\partial_{x}\left(R K_{x} \partial_{x} H\right)+\partial_{z}\left(R K_{z} \partial_{z} H\right)+M_{V}
$$

where $\quad S_{S}=$ fluid storage term $(1 / \mathrm{m})$

$\mathrm{t}=$ time $(\mathrm{s})$

$\mathrm{H}=$ hydraulic head with respect to reference fluid density (m)

$\mathrm{x}, \mathrm{y}, \mathrm{z}=$ directions in cartesian coordinate system (m)

$\mathrm{R}=$ ratio of fluid density

$\mathrm{K}=$ hydraulic conductivity in the direction denoted by $\mathrm{x}$ or $\mathrm{z}$ subscripts $(\mathrm{m} / \mathrm{s})$

$M_{V}=$ fluid source term $\left(\mathrm{m}^{3} / \mathrm{s}\right)$.

The fluid-storage term $\left(\mathrm{S}_{\mathrm{S}}\right)$ is defined by the following equations:

$$
S_{S}=\left(\alpha_{s}+n_{E} \alpha_{f}\right) \rho g
$$

if $\theta=n_{E}$. If $\theta<n_{E}$,

$$
S_{S}=\frac{\partial \theta}{\partial \psi}
$$

where $\alpha_{s}=$ compressibility of solid media $\left(\mathrm{m} \mathrm{s}^{2} / \mathrm{kg}\right)$

$n_{E}=$ effective or flow porosity $\left(\mathrm{m}^{3} / \mathrm{m}^{3}\right)$

$\alpha_{\mathrm{f}}=$ compressibility of fluid ( $\mathrm{m} \mathrm{s}^{2} / \mathrm{kg}$ )

$\psi=$ soil moisture potential or tension head, equal to $-\mathrm{P}$ when $\mathrm{P}<0(\mathrm{~m})$.

The hydraulic conductivity tensor $(\mathbf{K})$ is computed using 


$$
K=\frac{\rho g k}{\mu}
$$

where all terms are as previously defined.

The above equations were written under the assumption that the principal directions of the hydraulic-conductivity tensor coincide with the coordinate directions $(\mathbf{x}, \mathbf{y}, \mathbf{z})$ such that only the diagoral terms of the tensor are nonzero (Runchal and Sagar 1989; Sagar and Runchal 1990).

Hydraulic head $(\mathrm{H})$ and pressure head $(\mathrm{P})$ are related by

$$
\mathrm{H}=\mathrm{P}+\left(\mathrm{z}-\mathrm{z}^{*}\right)
$$

where $z^{*}$ is an arbitrary elevation datum, and the pressure head is defined by

$$
P=\frac{p}{\rho g}
$$

The pressure head $(\mathrm{P})$ is larger than the atmospheric pressure head (and hence positive) for saturated flow, and is less than atmospheric pressure (and hence negative) for unsaturated flow. The volumetric moisture content $(\theta)$ is equal to the effective porosity $\left(n_{E}\right)$ for saturated flow. The soil moisture potential $(\psi)$ and intrinsic permeability $(\mathbf{k})$ are functions of the volumetric moisture content $(\theta)$.

The governing equations are solved with an integrated finite-difference scheme by the SUMO code for a rectangular grid mesh. The solution of the general equation for fluid flow and the coupling equations leads to values of hydraulic head $(\mathrm{H})$, relative saturation $\left(\theta^{*}\right)$, and fluid velocity $(\mathrm{U}, \mathrm{V}$, and $\mathrm{W}$ in the $\mathrm{x}, \mathrm{y}$, and $\mathrm{z}$ directions, respectively). The resolution of the rectangular grid mesh was, in general, $5 \mathrm{~m}$ in the vertical dimension and $10 \mathrm{~m}$ in the horizontal. The only exception was near the Ghost Dance fault, where the mesh was refined to accommodate the $1-\mathrm{m}$-wide fault.

With respect to boundary conditions, we assigned no-flow (Neumann condition) constraints to the eastern and western boundaries of the two-dimensional geometry. The $500 \mathrm{~m}$ eastern extent of the model beyond borehole UE-25a\#1 was included to prevent the no-flow condition imposed on that boundary from introducing modeling artifacts into the flow domain near the repository or in the regions where radionuclide migration might occur. The lower boundary is the regional water table, a Dirichlet condition of zero pressure head. Finally, the upper boundary is a constant liquid flux equal to the recharge rate to be modeled. It was the intent of this exercise to simulate flow and transport for recharge rates of $0.01,0.05,0.1,3.0$, and $20.0 \mathrm{~mm} / \mathrm{yr}$, but for reasons discussed in the results and analysis sections (Section 4.2 .3 and 4.2 .4 ), only the $0.01 \mathrm{~mm} / \mathrm{yr}$ condition was successfully simulated, and the 0.05 and $0.1 \mathrm{~mm} / \mathrm{yr}$ conditions were only approximated.

Steady-state hydrology conditions were assumed as the initial conditions for contaminant transport simulations. For example, at a recharge rate of $0.01 \mathrm{~mm} / \mathrm{yr}$, a hydraulic head gradient of zero was assigned to the entire model domain, which was then solved for the no-flow east and west boundaries, for the water table lower boundary, and for $0.01 \mathrm{~mm} / \mathrm{yr}$ flux at the upper boundary until steady-state conditions were reached. The pressure field for steady-state conditions 
was then saved. The saturation in the repository horizon was noted for this recharge rate and provided to source-term release models (Section 3.0). Finally, transport for $0.01 \mathrm{~mm} / \mathrm{yr}$ recharge was modeled using the saved pressure field as a constant condition and the release rates for radionuclides generated by the source-term models (dependent on the saturation predicted from the flow modeling).

\subsubsection{Simulation Results}

Simulation of the model was exceptionally difficult numerically. SUMO was able to solve the governing flow equation for a recharge rate of $0.01 \mathrm{~mm} / \mathrm{yr}$ until steady state was reached, as measured by comparing total liquid flux across the upper and lower boundaries of the model. Higher recharge rates proved more and more difficult to solve because of the contrast in bulkequivalent hydraulic conductivities between the upper three layers and the lower two. The contrast was about one order of magnitude, as shown by the saturated bulk-equivalent hydraulic conductivity values in Table 4.4. For any simulation, started at time zero, the wetting front that began with the recharge flux applied at the upper boundary would be simulated with increasing time steps until it reached the fourth layer, and then the simulation would either fail after a maximum number of time-step divisions or it would proceed with very small, non-increasing time steps for as long as the modeler would care to run the simulation. (We allowed one simulation to run for 18 CPU hours on a Cray XMP.)

Because of the numerical difficulties experienced in solving the two-dimensional liquid-phase problem with SUMO at recharge rates greater than $0.01 \mathrm{~mm} / \mathrm{yr}$, a series of simplified, onedimensional simulations based the stratigraphy of borehole USW G-4 were run using both the SUMO and the MSTS codes (the MSTS code is discussed in detail in Section 4.3). The SUMO code was unable to solve the governing flow equation in the one-dimensional domain at any recharge rate using the direct steady-state solver or by transient simulation for a long time period. The MSTS code (discussed in more detail in Section 4.3) did simulate the whole set of simulations, however, and the results illustrate the nature of the flow regime defined by the conceptual model and hydrologic parameter values. The recharge rates simulated by MSTS for the one-dimensional model were $0.01,0.05,0.1,3.0$, and $20.0 \mathrm{~mm} / \mathrm{yr}$. The liquid-pressure profiles predicted by MSTS are shown in Figure 4.7, and the liquid-saturation profiles are shown in Figure 4.8. An important feature of these profiles is that the profiles coincide for all recharge rates greater than $1.0 \mathrm{~mm} / \mathrm{yr}$. Also notice in Figure 4.7 that for recharge rates higher than $0.01 \mathrm{~mm} / \mathrm{yr}$, the liquid pressure in the $730 \mathrm{~m}$ to $850 \mathrm{~m}$ elevation range also coincides with atmospheric pressure, i.e., the domain is saturated. This violates the presumption that this range is in the vadose zone and makes the problem exceptionally difficult to solve numerically because of the forced atmospheric pressure boundary at the lower end of the domain. The problem is even more difficult to solve for the two-dimensional domain that is both more complex geometrically and larger in terms of the number of equations to be solved.

The SUMO simulations for lower recharge rates were enlightening, though limited. Figure 4.9 shows hydraulic head contours predicted by SUMO for steady-state conditions in the twodimensional model. Important features of this result are the vertical contour lines in layer 3 (vitric) and the absence of contour lines in layer 5 (partially welded). Remember, in examining this and the following figures depicting the model domain, that the vertical exaggeration is large, approximately 10 to 1 . Figure 4.10 shows the liquid-saturation contours for this solution. Note that the repository horizon is approximately $80 \%$ saturated throughout its extent. Figure 4.11 shows the relative velocity vectors for the $0.01 \mathrm{~mm} / \mathrm{yr}$ solution. This plot indicates a largely onedimensional 


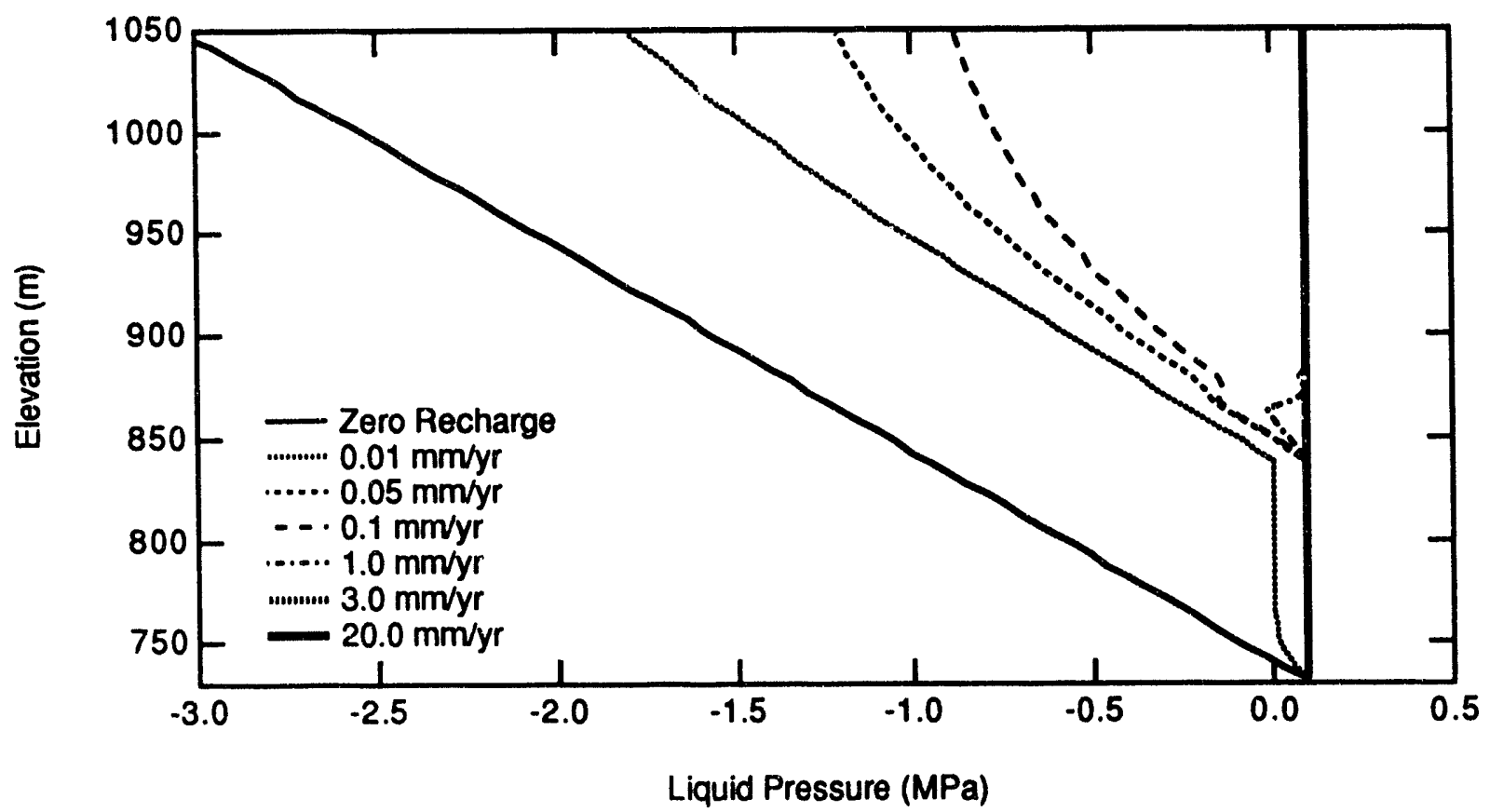

Figure 4.7. One-Dimension Multiphase Subsurface Transport Simulator Solutions for Liquid Pressure with Elevation

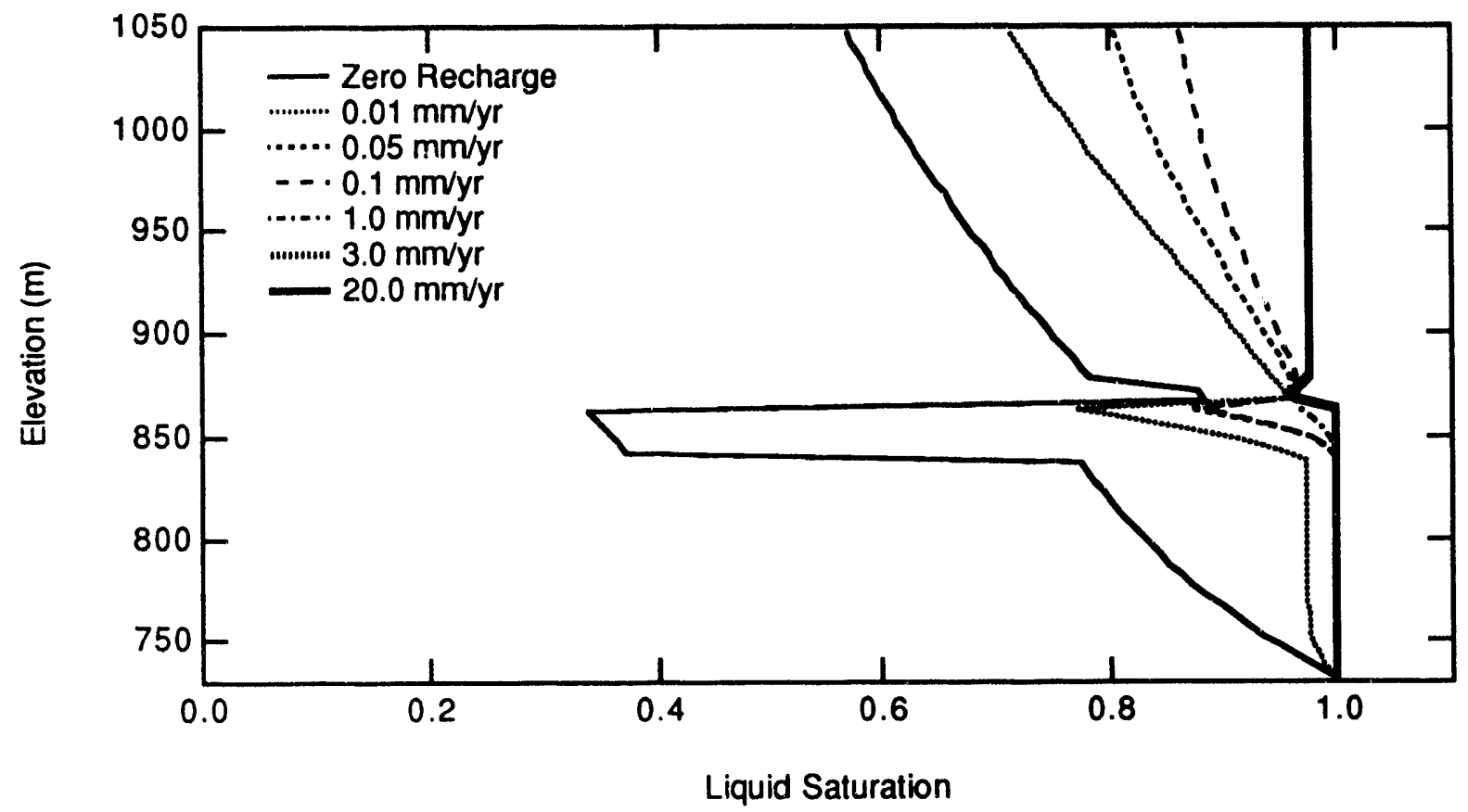

Figure 4.8. One-Dimension Multiphase Subsurface Transport Simulator Solutions for Liquid Saturation with Elevation 


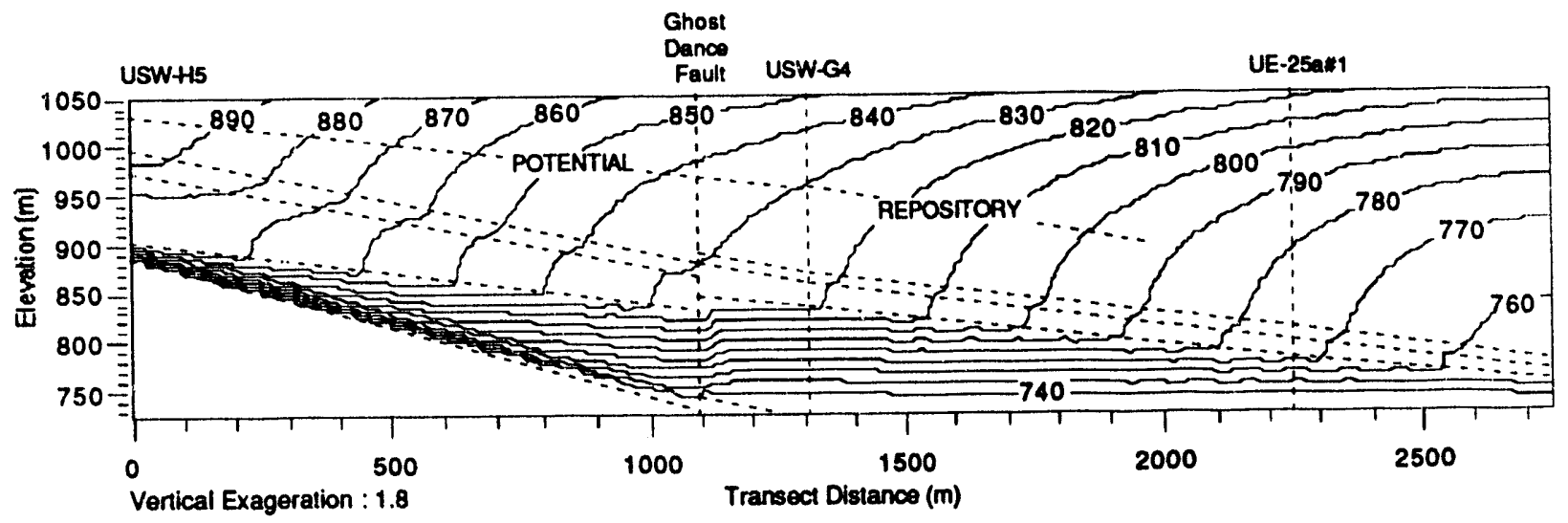

Figure 4.9. Hydraulic-Head Contours for SUMO Steady-State Solution at $0.01 \mathrm{~mm} / \mathrm{yr}$ Recharge

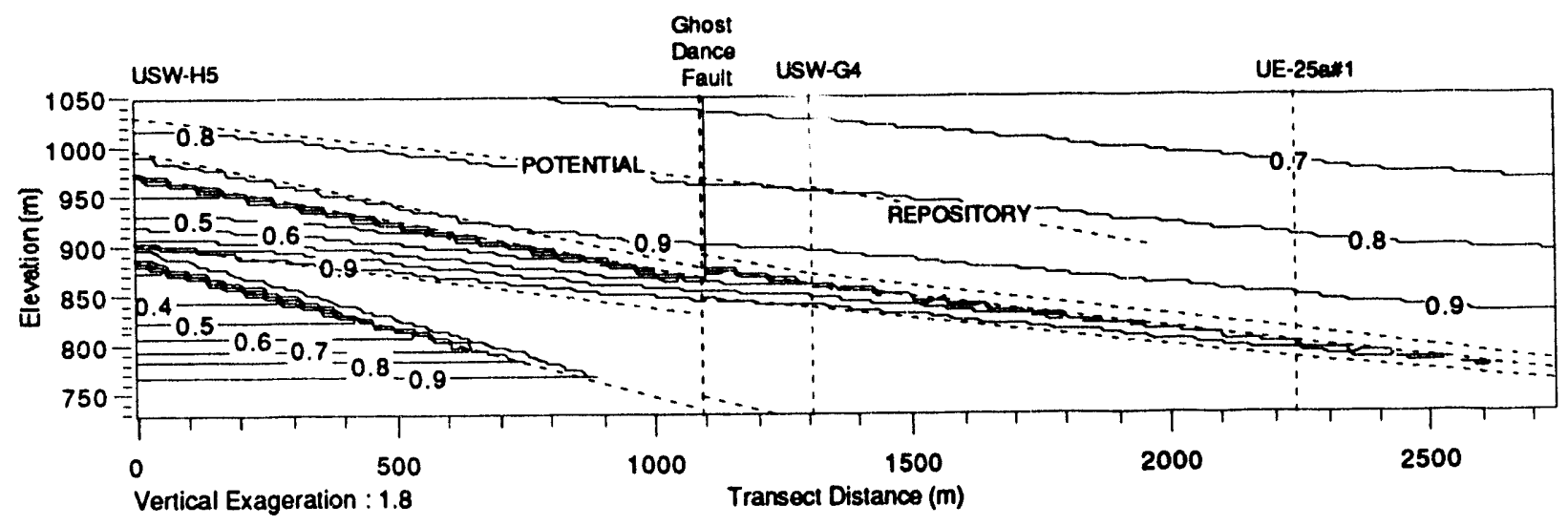

Figure 4.10. Liquid-Saturation Contours for SUMO Steady-State Solution at $0.01 \mathrm{~mm} / \mathrm{yr}$ Recharge

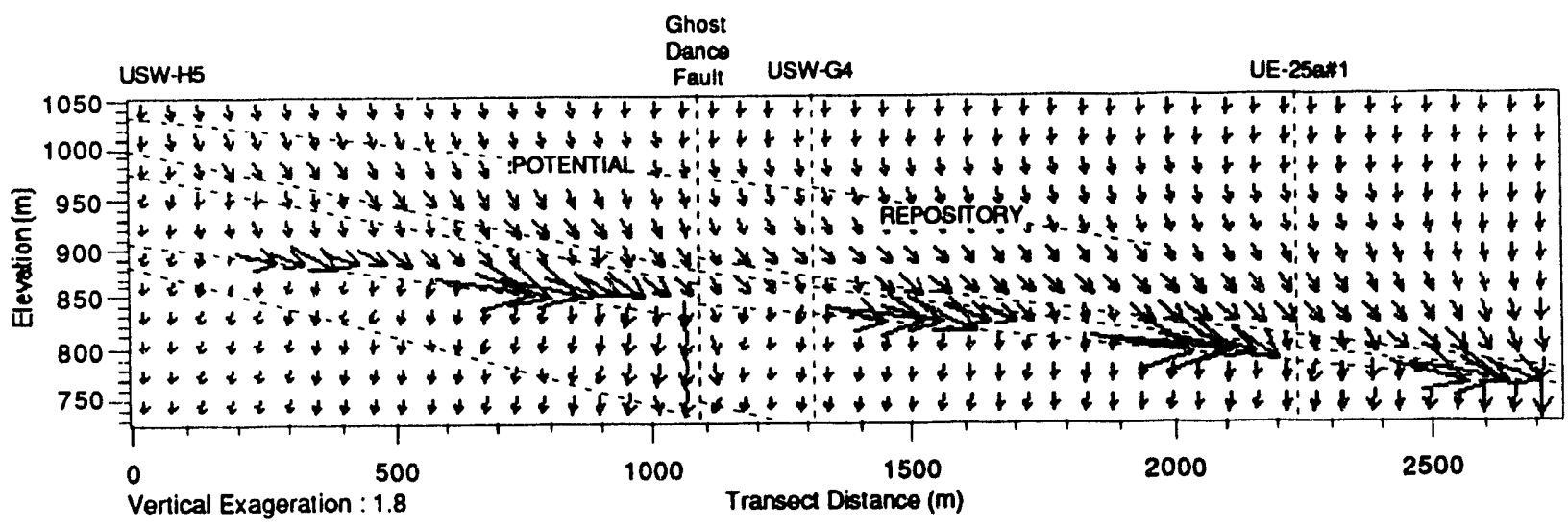

Figure 4.11. Darcian Velocity Vectors for SUMO Steady-State Solution at $0.01 \mathrm{~mm} / \mathrm{yr}$ Recharge 
flow regime, except for the interface between layers 3 and 4 (vitric and zeolitic) where the strong contrast in hydraulic conductivities occurs. This contrast leads to lateral flow above the interface, and hence some lateral diversion is expected. It is important to remember that this lateral-flow effect, though not pronounced for the $0.01 \mathrm{~mm} / \mathrm{yr}$ condition, is likely to become larger with higher recharge rates. Unfortunately, the numerical difficulties inentioned with regard to simulation rates higher than $0.01 \mathrm{~mm} / \mathrm{yr}$ prevented us from demonstrating this.

Approximate solutions were obtained for recharge rates $0.05 \mathrm{~mm} / \mathrm{yr}$ and $0.1 \mathrm{~mm} / \mathrm{yr}$. These were only approximations because the pressure field did not reach ultimate steady-state conditions as indicated by global liquid-mass balance comparisons. Figure 4.12 shows the hydraulic head contours for the $0.05 \mathrm{~mm} / \mathrm{yr}$ condition and Figure 4.13 shows the same for the $0.1 \mathrm{~mm} / \mathrm{yr}$ condition. These approximations are most in error in the lower two layers (zeolitis and partially welded) where conditions were most difficult to model because of the conductivity contrast. Observe as well that the fault zones representing the Ghost Dance fault begin to experience a higher liquid pressure than the surrounding rock at $0.05 \mathrm{~mm} / \mathrm{yr}$, an effect not seen in the $0.01 \mathrm{~mm} / \mathrm{yr}$ condition. This may have contributed to the numerical problems.

In conjunction with tectonic analysis, simulation of the model domain under a $100-\mathrm{m}$ water table rise caused by coseismic water table rise (Section 7.0) was also required. To perform this task, the liquid-phase simulations were repeated with the water table at $830 \mathrm{~m}, 100 \mathrm{~m}$ higher than in the base scenario. Figure 4.14 shows the hydraulic head contours for steady-state conditions and a recharge rate of $0.01 \mathrm{~mm} / \mathrm{yr}$. Figure 4.15 depicts liquid-saturation contours for these conditions, and Figure 4.16 shows the velocity vectors for the same. Hydrologically, the repository conditions do not change much as a result of the 100 -m water-table rise. It appeared that the most significant impact was simply the decrease in the travel path required for contaminants to reach the saturated zone, now $100 \mathrm{~m}$ closer than in the base scenario.

Transport modeling depended on successful completion of flow modeling, so the numerical difficulties encountered in the flow solution restricted our ability to model transport at higher recharge rates as well. Radionuclide movement was modeled with the steady-state flow field for the $0.01 \mathrm{~mm} / \mathrm{yr}$ recharge solution and with the approximate steady-state solutions for 0.05 and $0.1 \mathrm{~mm} / \mathrm{yr}$ recharge rates. Simulations of transport were performed for 10,000 years after emplacement of the waste. For the $0.01 \mathrm{~mm} / \mathrm{yr}$ solution and the approximate 0.05 and $0.1 \mathrm{~mm} / \mathrm{yr}$ recharge rates, no radionuclide mass reached the saturated zone within 10,000 years. We would expect, based on one-dimensional travel-time calculations and results for the lower recharge rates, that breakthrough would occur in simulations at higher recharge rates had we been successful with those simulations.

\subsubsection{Analysis}

Water travel time from the potential repository to the saturated zone is often taken as an indicator of the characteristic time for radionuclide travel over the same space. We tracked water particle mean travel time over nine paths beginning in the potential repository and terminating at the saturated zone. This was done only for the $0.01 \mathrm{~mm} / \mathrm{yr}$ recharge rate as it was the only condition for which completely steady-state conditions were predicted. For the higher recharge conditions, the velocity fields in the lowest two stratigraphic units (zeolitic and partially welded) were too low, and the computer CPU time required to achieve complete steady-state conditions for these recharge rates was prohibitive. As a consequence, travel time calculations based on the near-steady-state solutions for the 0.05 and $0.1 \mathrm{~mm} / \mathrm{yr}$ recharge rates will be artifically long due to the low velocities in the lower units. 


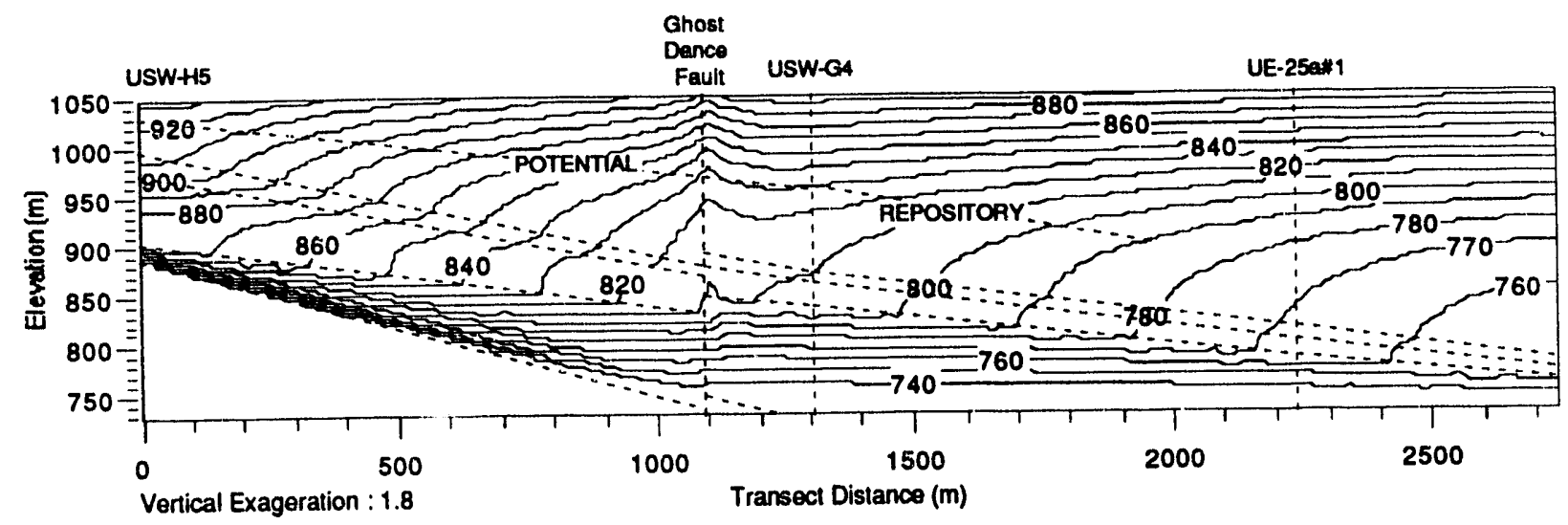

Figure 4.12. Hydraulic-Head Contours for SUMO Approximate-Steady-State Solution at 0.05 $\mathrm{mm} / \mathrm{yr}$ Recharge

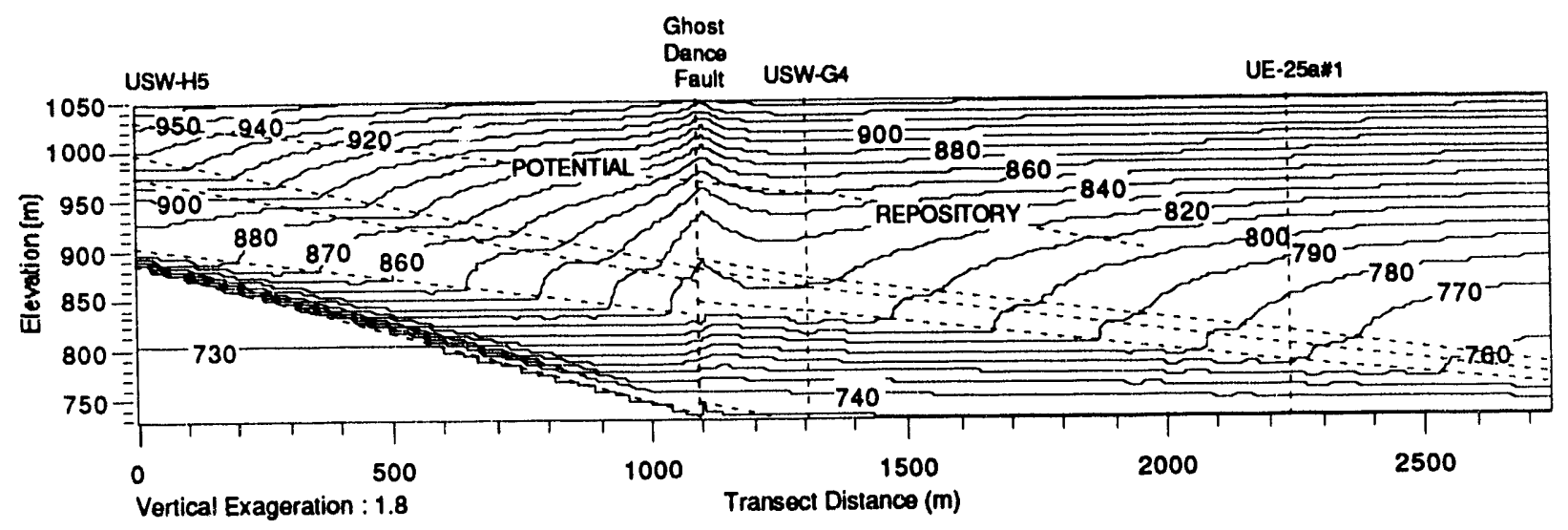

Figure 4.13. Hydraulic-Head Contours for SUMO Approximate-Steady-State Solution at 0.1 $\mathrm{mm} / \mathrm{yr}$ Recharge

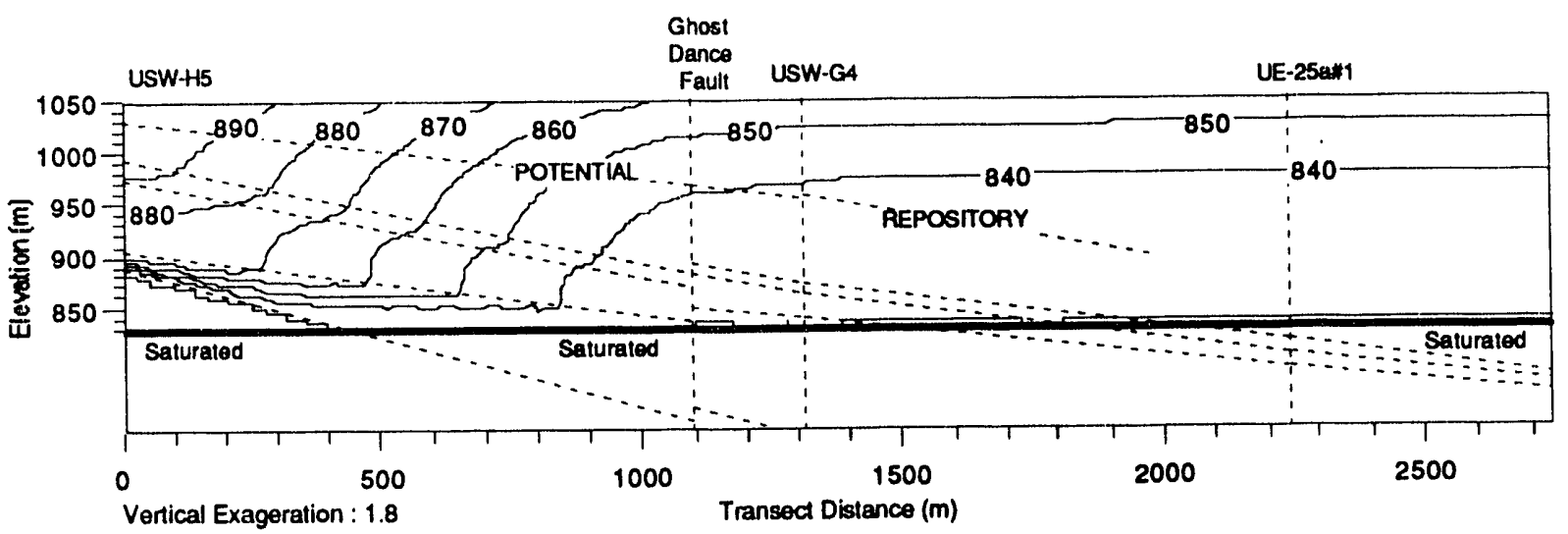

Figure 4.14. Hydraulic-Head Contours for SUMO Steady-State Solution at $0.01 \mathrm{~mm} / \mathrm{yr}$ Recharge and Tectonic Disruption (100-m Water-Table Rise) 


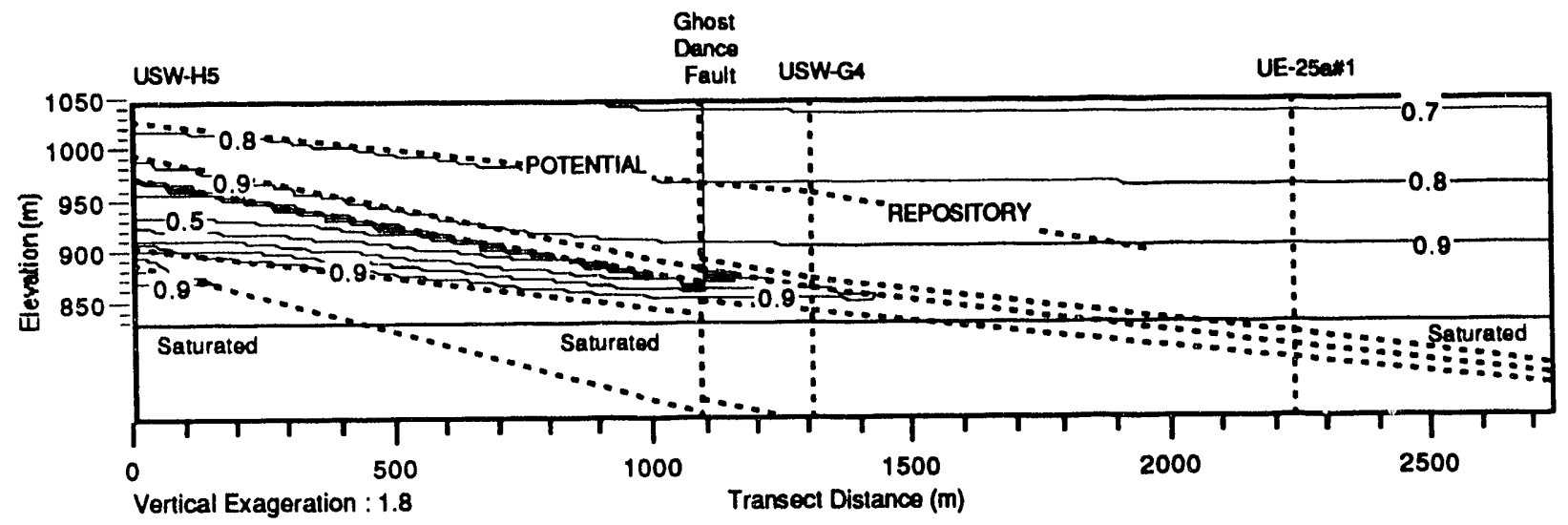

Figure 4.15. Liquid-Saturation Contours for SUMO Steady-State Solution at $0.01 \mathrm{~mm} / \mathrm{yr}$ Recharge and Tectonic Disruption (100-m Water-Table Rise)

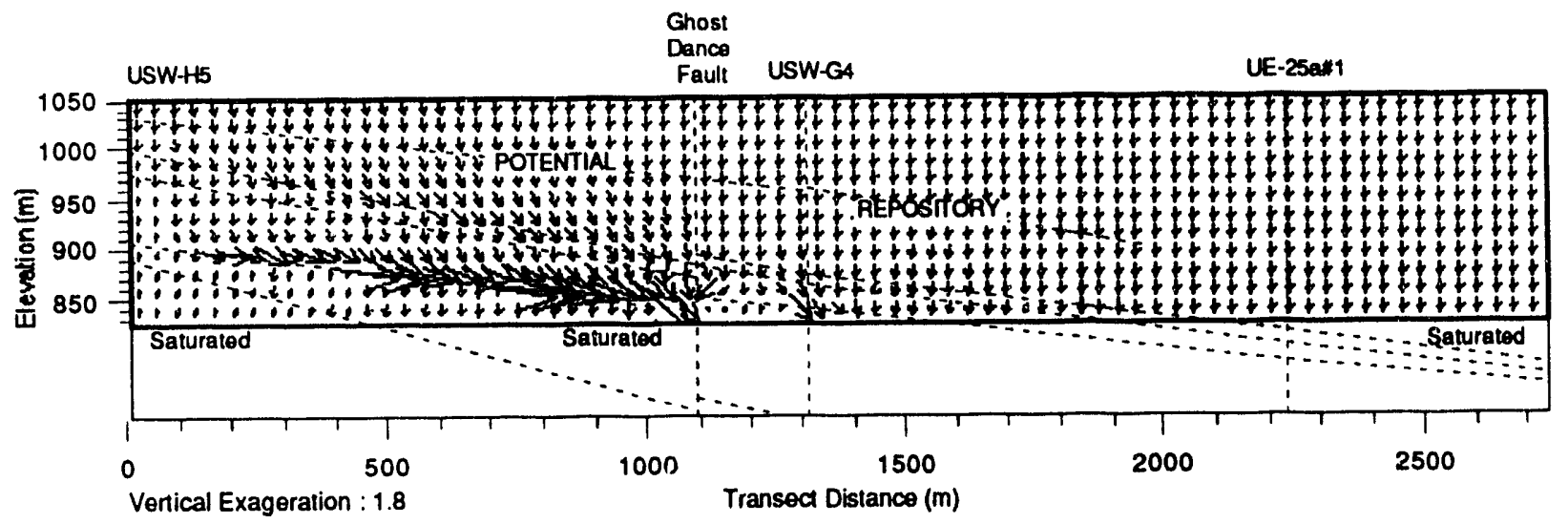

Figure 4.16. Darcian Velocity Vectors for SUMO Steady-State Solution at $0.01 \mathrm{~mm} / \mathrm{yr}$ Recharge and Tectonic Disruption (100-m Water-Table Rise)

For the $0.01 \mathrm{~mm} / \mathrm{yr}$ condition, the particle pathlines from the potential repository to the saturated zone for all nine paths examined are shown in Figure 4.17. This plot reveals the degree of lateral diversion present in the two-dimensional flow system at this recharge rate. The diversion is most significant in the vitric layer, and least important in the zeolitic and partially welded units where the paths are nearly vertical. Figure 4.18 shows the travel time for each particle as a function of its path distance, that is, distance along the path shown in Figure 4.17 rather than axial distance. The traces in Figure 4.18 typically have "elbows" where the particle crosses an interface between stratigraphic layers. Travel times for this recharge rate are on the order of $5.0 \times 10^{6} \mathrm{yr}$. As the recharge rate increases, which again we were unable to demonstrate because of numerical difficulties, the travel times would decrease.

The travel-time analysis applied to the base scenario $0.01 \mathrm{~mm} / \mathrm{yr}$ condition was repeated for the tectonic (water-table rise) scenario $0.01 \mathrm{~mm} / \mathrm{yr}$ condition. The particle paths are shown in Figure 4.19 and the travel times for each particle as a function of its path distance is shown in Figure 4.20 for the tectonic scenario. The hydrology is different for this scenario because of the 


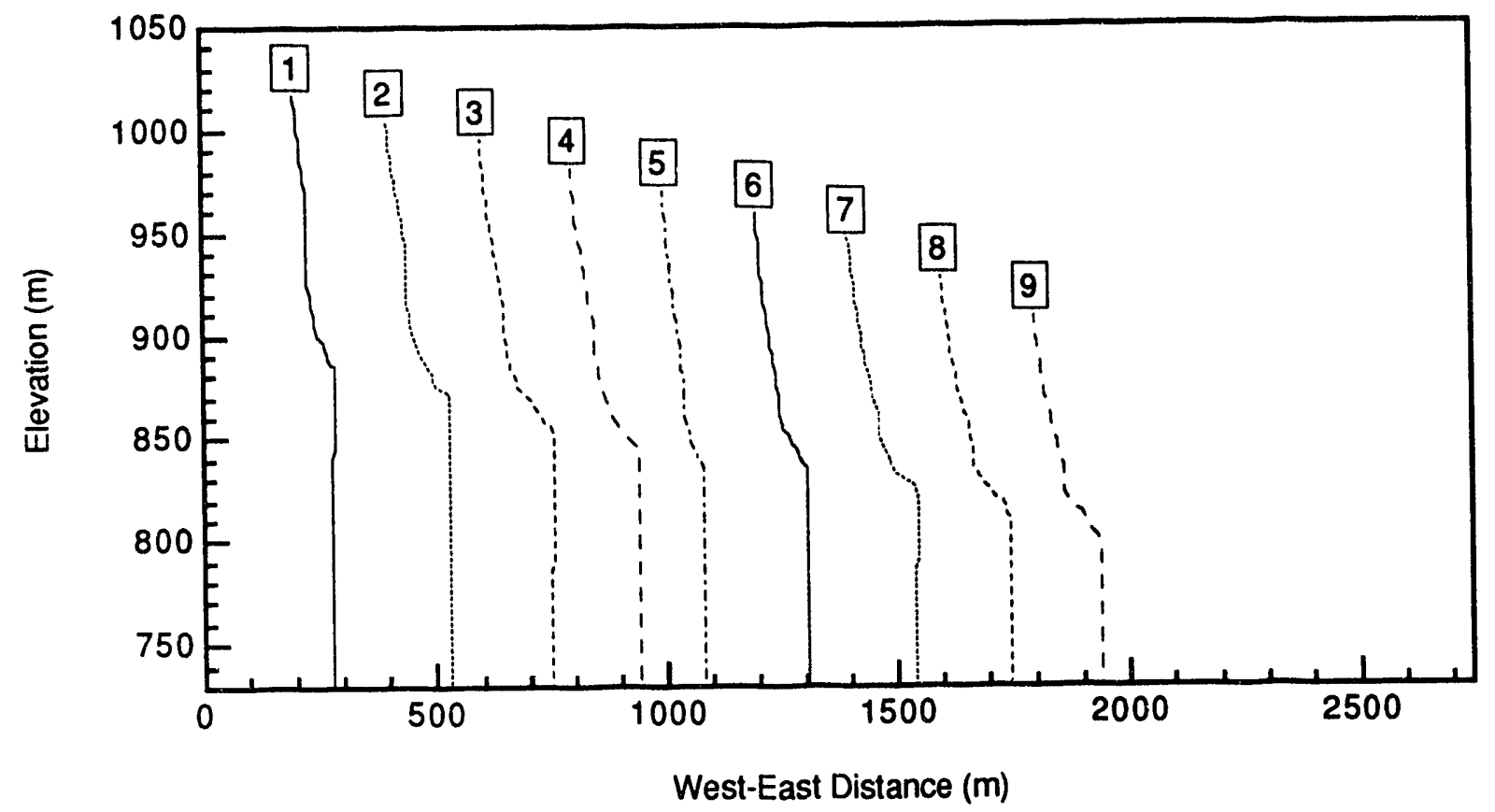

Figure 4.17. Travel Particle Pathlines from Repository to Saturated Zone for $0.01 \mathrm{~mm} / \mathrm{yr}$ Base Scenario

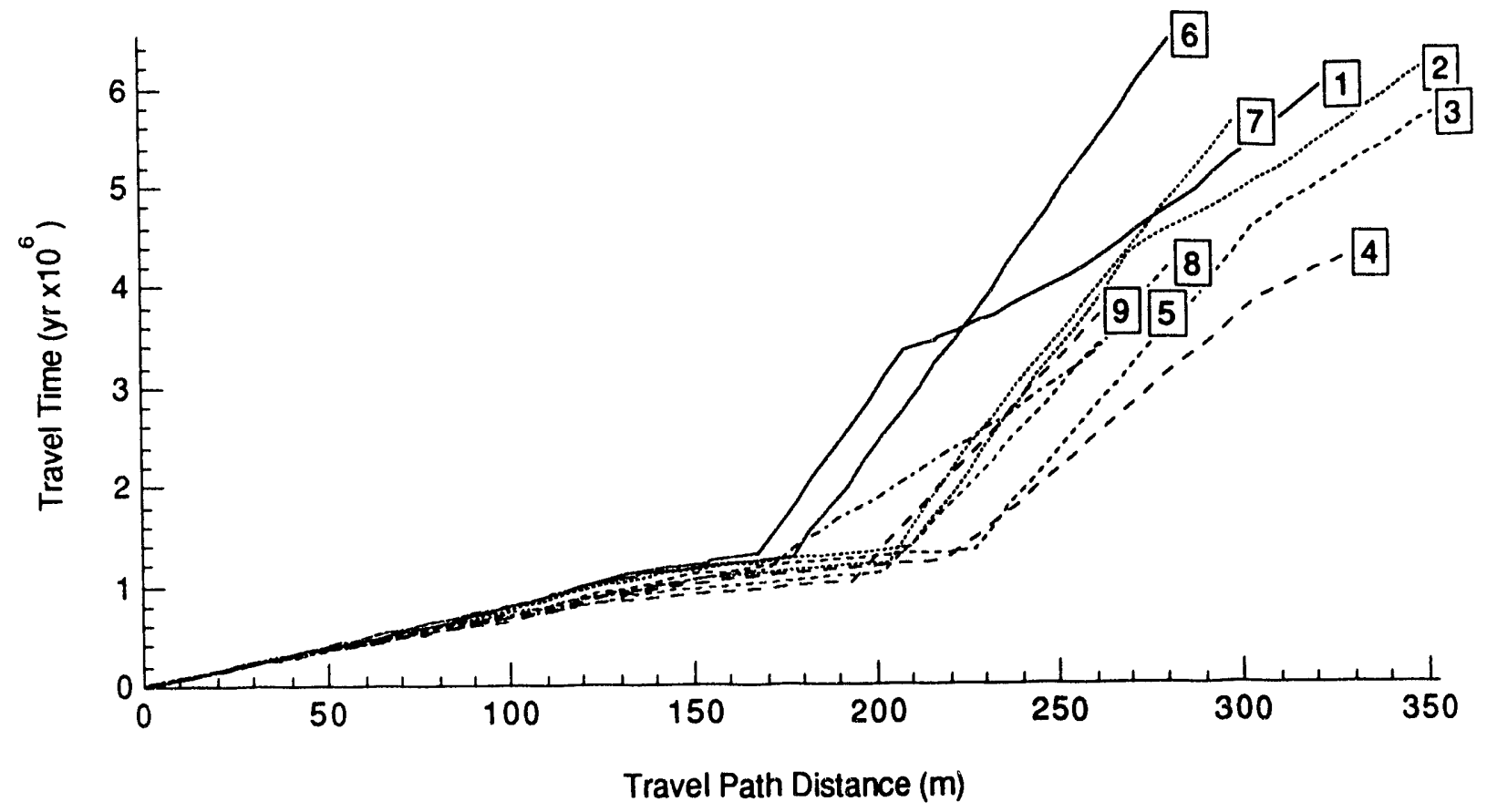

Figure 4.18. Travel Time as a Function of Path Distance for $0.01 \mathrm{~mm} / \mathrm{yr}$ Base Scenario 


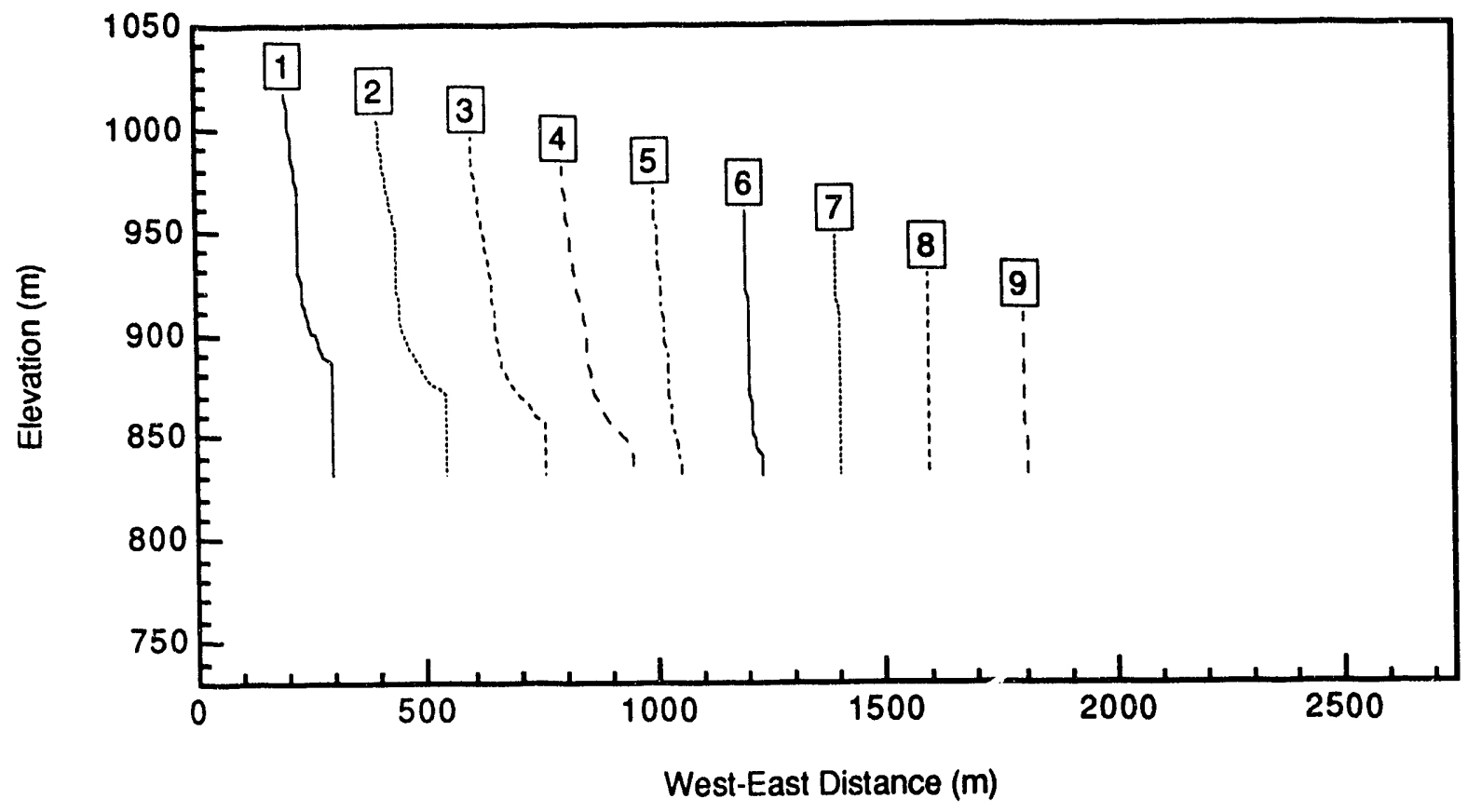

Figure 4.19. Travel Particle Pathlines from Repository to Saturated Zone for $0.01 \mathrm{~mm} / \mathrm{yr}$ Tectonic Scenario

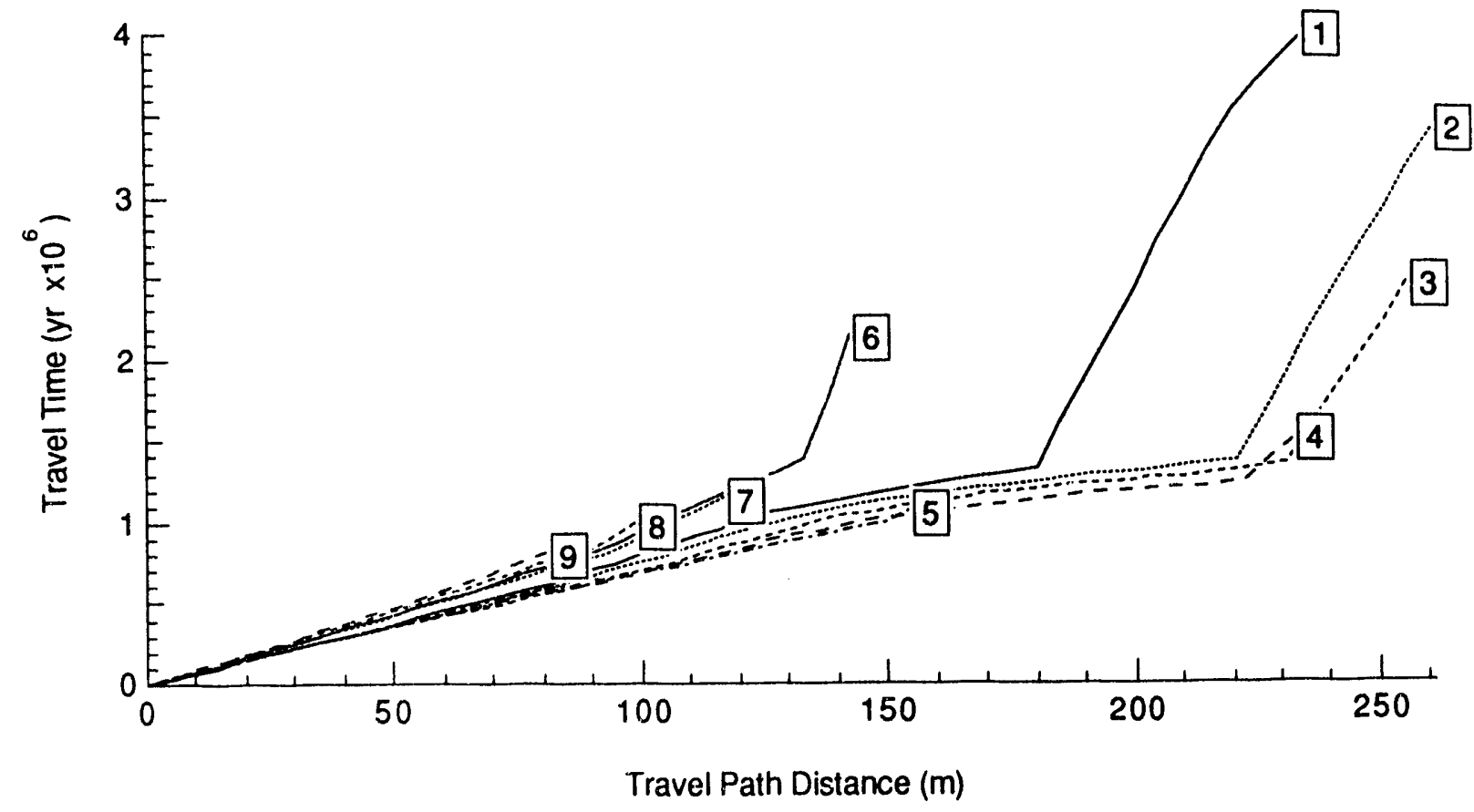

Figure 4.20. Travel Time as a Function of Path Distance for $0.01 \mathrm{~mm} / \mathrm{yr}$ Tectonic Scenario 
higher water table, and the travel paths are shorter as can be seen in Figure 4.19. The same starting coordinates were used for all nine particles as for the base scenario travel time particles. Notice that the same vertical scale was used as for Figure 4.17, but the particles now terminate at the elevation of $830 \mathrm{~m}$ (the elevated water table surface) instead of $730 \mathrm{~m}$. In contrast to the base scenario, particles 1 through 4 still experience lateral diversion in the vitric layer while particles 5 through 9 travel nearly vertical paths the entire distance.

\subsection{Gas Phase}

A principal concern of performance assessment involves the prediction of cumulative radionuclide releases to the accessible environment and radiation doses received by individuals within the accessible environment. Radioactive ${ }^{14} \mathrm{C}$ has been included among the radionuclides that will be considered for predicting cumulative radionuclide releases. Predictions of cumulative radionuclide releases require predictions of radionuclide transport from the waste container to the accessible environment. This section describes the simulations of $14 \mathrm{C}$ transport from the potential repository horizon to the ground surface and water table. Because ${ }^{14} \mathrm{C}$ exists in equilibrium as gaseous carbon-dioxide and dissolved carbonates in the aqueous phase, ${ }^{14} \mathrm{C}$ transport at Yucca Mountain was numerically modeled as a two-phase system.

A primary difficulty in predicting ${ }^{14} \mathrm{C}$ transport through the vadose zone at Yucca Mountain siems from the requirement for a numerical description of the phase equilibrium for ${ }^{14} \mathrm{C}$. Ross (1988) developed a conceptual model for ${ }^{14} \mathrm{C}$ phase partitioning at Yucca Mountain that was directily applied in the subject study. All assumptions taken in developing Ross' geochemical model apply to the subject study, including the assumption of zero partitioning of ${ }^{14} \mathrm{C}$ to the solid phase. Ross' geochemical model expresses chemical equilibrium of the carbon species between the liquid and gas phases through temperature-dependent retardation factors. These same factors have been corverted to a gas-phase-to-aqueous-phase partition coefficient for the present application.

Three principal differences exist between Ross' conceptual modeling approach and our approach. Ross' investigation restricted predictions of ${ }^{14} \mathrm{C}$ transport within the vadose zone at Yucca Mountain to steady-state conditions. Gas-phase velocity fields were computed for a series of constant temperature fields. Gas-phase physical properties and water concentrations were computed by assuming thermodynamic equilibrium and saturated moist-air conditions. Gas-phase flows were generated by gradients in gas pressure and gas density, which result from elevated repository temperatures. The investigations described in this section modeled ${ }^{14} \mathrm{C}$ transport within the vadose zone at Yucca Mountain as a transient process by addressing the transient thermal and hydrogeologic response of the unsaturated environment to repository heating. Moreover, this investigation considered the transient nature of $14 \mathrm{C}$ release from the containers. The second principal difference between the simulation approaches involves the number of phases. Ross' gasphase-only approach was founded on the assumption that the liquid-phase advection contributes negligibly to ${ }^{14} \mathrm{C}$ transport. This investigation addresses $14 \mathrm{C}$ transport by advection and diffusion through both the gas and aqueous phases. The third principal difference between the approaches pertains to the computational domain and tuff hydrogeologic properties. Ross' simulations encompassed the entire length of the repository, whereas this investigation considers only that portion east of Yucca Mountain's ridge. With respect to hydrogeologic properties, Ross used intrinsic permeabilities for the tuff layers that were several orders of magnitude higher than those used here. While the liquid relative permeabilities for this simulation were dependent on liquid saturation, both investigations used unity gas-phase permeabilities. 
The following subsections give a brief overview of the conceptual model of the unsaturated zone at Yucca Mountain, a review of Ross' geochemical conceptual model, and a synopsis of the MSTS numerical model. The conceptual and numerical model subsections are followed by a presentation of the simulation results, which include field values of temperature, liquid saturation, gas saturation, and specie concentration along with phenomenological descriptions of the thermal and hydrogeological response of the vadose zone to the repository thermal transient. These subsections conclude with preliminary predictions of $14 \mathrm{C}$ releases to the water table and ground surface. Section 4 concludes with a discussion of physical and numerical assumptions and a perspective on future prediction techniques.

\subsubsection{Conceptual and Numerical Models}

The transport of ${ }^{14} \mathrm{C}$ within the vadose zone at Yucca Mountain was computed with the nonisothermal, two-phase, transport MSTS morlel. The conceptual model of the vadose zone at Yucca Mountain was based on a two-dimensional, west-east transect from Yucca Ridge to $500 \mathrm{~m}$ east of borehole UE-25a\#1 through boreholes USW G-4 and USW H-5 (the transect depicted in Figure 4.1). The vertical domain of the conceptual model extended from the water table to the ground surface through the sloped repository horizon. Although the domain of the conceptual model included the Ghost Dance fault, the fault was essentially ignored (except for an offset in tuff layers). This section describes the complex numerical transport model, the conceptual model, and the geochemical model with respect to the computational domain.

Computer codes that simulate transport processes in geologic media are typically classified according to capabilities related to phases, components, saturations, transport, and dimensionality. Under this classification strategy, MSTS would be classified as a two-phase, two-component, three-dimensional numerical simulator, for variably saturated geologic media, with dilute species transport capabilities. This classification arises because MSTS models two phases (liquid and gas), two components (water and air), and solves equations for dilute species transport through variably saturated geologic media. MSTS uses a finite-difference-based numerical scheme to solve a nonlinear system of conservation and constitutive equations. The conservation equations in partial differential form for the conservation of water mass, air mass, thermal energy, and species concentration (Equations [4.14] through [4.17]) appear as follows:

Mass Conservation of Water:

$$
\begin{aligned}
& \frac{\partial}{\partial t}\left[n_{d} y_{w} \rho_{l} s_{l}+n_{d} x_{w} \rho_{g} s_{g}\right]=\nabla\left[\frac{y_{w} \tilde{k} k_{l l} \rho_{1}}{\mu_{1}}\left(\nabla P_{1}+\rho_{1} g \hat{z}\right)\right] \\
& +\nabla\left[\frac{y_{w} \tilde{k} k_{t g} \rho_{g}}{\mu_{g}}\left(\nabla P_{g}+\rho_{g} g \hat{z}\right)+\tau_{g} n_{d} \rho_{g} s_{g} D_{a w} \nabla x_{w}\right]+\dot{m}_{w}
\end{aligned}
$$


Mass Conservation of Air:

$$
\begin{aligned}
& \frac{\partial}{\partial t}\left[n_{d} y_{a} \rho_{1} s_{1}+n_{d} x_{a} \rho_{g} s_{g}\right]=\nabla\left[\frac{y_{a} \tilde{k}_{r l} \rho_{l}}{\mu_{1}}\left(\nabla P_{1}+\rho_{1} g \hat{z}\right)\right] \\
& +\nabla\left[\frac{y_{a} \tilde{k}_{r g} \rho_{g}}{\mu_{g}}\left(\nabla P_{g}+\rho_{g} g \hat{z}\right)-\tau_{g} n_{d} \rho_{g} s_{g} D_{a w} \nabla x_{w}\right]+\dot{m}_{a}
\end{aligned}
$$

Thermal Energy Conservation:

$$
\begin{aligned}
& \frac{\partial}{\partial t}\left[\frac{\left(1-n_{t}\right) \rho_{s} u_{s}+\eta_{d} \rho_{1} u_{1}+n_{d} s_{g} \rho_{g} u_{g}}{\partial t}\right]+\nabla\left[\rho_{1} h_{1} V_{1}+\rho_{g} h_{g} V_{g}\right]= \\
& \nabla\left[\left[\tilde{k}_{e}+n_{d} \rho_{1} c_{1} \tilde{D}_{1}\right] \nabla T\right]+\dot{q}+h_{w} \dot{m}_{w}+h_{a} \dot{m}_{a}
\end{aligned}
$$

Specie Concentration Conservation:

$$
\begin{gathered}
\frac{\partial \mathrm{C}}{\partial \mathrm{t}}+\nabla\left[\mathrm{C}_{\mathrm{l}} \mathrm{V}_{1}+\mathrm{C}_{\mathrm{g}} \mathrm{V}_{\mathrm{g}}\right]= \\
\nabla\left[\tau_{1} \mathrm{~s}_{1} \mathrm{n}_{\mathrm{d}} \dot{\mathrm{D}}_{\mathrm{cl}} \nabla \mathrm{C}_{1}+\tau_{\mathrm{g}} \mathrm{s}_{\mathrm{g}} \mathrm{n}_{\mathrm{d}} \dot{\mathrm{D}}_{\mathrm{cg}} \nabla \mathrm{C}_{\mathrm{g}}\right]+\dot{\mathrm{s}}_{\mathrm{c}}-\dot{\mathrm{R}}_{\mathrm{c}} \mathrm{C}
\end{gathered}
$$

where the following subscripts indicate the phase or constituent;

$$
\begin{aligned}
& \mathrm{l}=\text { liquid phase } \\
& \mathrm{g}=\text { gas phase } \\
& \mathrm{w}=\text { water phase } \\
& \mathrm{a}=\text { air } \\
& \mathrm{s}=\text { soil or rock }
\end{aligned}
$$

and variables are defined as

$$
\begin{aligned}
& \partial=\text { partial derivative } \\
& \mathrm{t}=\text { time, } \mathrm{s} \\
& \mathrm{n}_{\mathrm{d}}=\text { diffusive porosity } \\
& \mathrm{y}=\text { liquid phase mass fraction }
\end{aligned}
$$




$$
\begin{aligned}
& \rho=\text { density, } \mathrm{kg} / \mathrm{m}^{3} \\
& \mathbf{S}=\text { saturation } \\
& \mathrm{x}=\text { gas phase mass fraction } \\
& \nabla=\text { gradient operator } \\
& \tilde{\mathrm{k}}=\text { intrinsic permeability tensor, } \mathrm{m}^{2} \\
& \mathrm{k}_{1}=\text { relative permeability } \\
& \mu=\text { viscosity, } \mathrm{Pa} \mathrm{s} \\
& \mathrm{P}=\text { pressure, } \mathrm{Pa} \\
& \mathrm{g}=\text { acceleration due to gravity, } \mathrm{m} / \mathrm{s}^{2} \\
& \mathrm{z}=\text { elevation } \\
& \tau=\text { tortuosity } \\
& \mathrm{D}_{\mathrm{aw}}=\text { air-water binary diffusion coefficient, } \mathrm{m}^{2} / \mathrm{s} \\
& \dot{\mathrm{m}}=\text { mass source rate, } \mathrm{kg} / \mathrm{s} \\
& \mathrm{n}_{\mathrm{t}}=\text { total porosity } \\
& \mathrm{u}=\text { internal energy, } \mathrm{J} / \mathrm{kg} \\
& \eta=\text { total water content } \\
& \mathrm{h}=\text { enthalpy, } \mathrm{J} / \mathrm{kg} \\
& \mathrm{V}=\text { Darcy velocity vector, } \mathrm{m} / \mathrm{s} \\
& \tilde{D}_{1}=\text { mechanical dispersion coefficient tensor, } \mathrm{m}^{2} / \mathrm{s} \\
& \tilde{\mathrm{k}}_{\mathrm{e}}=\text { effective thermal conductivity tensor, } \mathrm{W} / \mathrm{m} \mathrm{K} \\
& c_{p}=\text { specific heat capacity, } J / \mathrm{kg} \mathrm{K} \\
& \mathrm{T}=\text { temperature, } \mathrm{K} \\
& \dot{q}=\text { thermal energy source, } \mathrm{W} \\
& \mathrm{C}=\text { specie concentration, } \mathrm{Ci} / \mathrm{m}^{3}
\end{aligned}
$$




$$
\begin{aligned}
& \dot{\mathrm{D}}_{\mathrm{c}}=\text { specie diffusion coefficient, } \mathrm{m}^{2} / \mathrm{s} \\
& \dot{\mathrm{s}}_{\mathrm{c}}=\text { specie source rate, } \mathrm{Ci} / \mathrm{m}^{3} \mathrm{~s} \\
& \dot{\mathrm{R}}_{\mathrm{c}}=\text { specie decay rate, } 1 / \mathrm{s}
\end{aligned}
$$

The mass conservation equations for water and air were written to include Darcy flow for both phases and binary diffusion of water vapor and gaseous air for the gas phase. Molecular diffusion of dissolved air in the liquid phase is ignored. The thermal energy conservation equation includes heat transfer through advection of fluids for both phases and heat transfer by conduction through the solid and liquid phases. A mechanical dispersion coefficient may be invoked to model the phenomenon of kinematic dispersion, which occurs because of the heterogeneity of the pre velocities within the porous medium. Heat transfer by conduction and heat transfer by binary diffusion within the gas phase have been ignored.

The species-concentration conservation equation includes species transport by advection and molecular diffusion for both phases. A primary assumption associated with the speciesconservation equation is that species-partitioning between the solid, aqueous, and gas phases always exists under chemical equilibrium conditions. As with the thermal-energy conservation equation, a mechanical dispersion coefficient may be specified to model kinematic dispersion in the aqueous phase. Radioactive decay of the species concentration is modeled, but no accounting of decay products is made.

The MSTS model allows for multiple porosities: total porosity, diffuse porosity, and effective porosity. The total porosity represents the entire fractional pore spaci within the geologic medium. The diffuse porosity accounts for the fractional pore space that is connected, and the effective porosity represents the diffusive porosity less the fractional pore space occupied by the residual moisture. Unconnected pore space is assumed to be filled with stationary water. The thermal capacitance and conductance of unconnected pore water is considered; however, species transport between connected and unconnected pores is ignored.

The primary dependent variables for the water-mass, air-mass, thermal energy, and speciesconcentration conservation equations are, respectively, liquid pressure, gas pressure, temperature, and species concentration. For desaturated conditions, the primary variable for the water-mass equation is switched from the liquid pressure to the mass fraction of vapor in the gas phase. The constitutive equations are complex expressions that relate the primary dependent variables to the secondary variables. Secondary variables and constants make up the coefficients in the governing conservation equations. In general, the relationships between the primary and secondary variables are complex and nonlinear. These nonlinear dependencies of the secondary variables on the primary dependent variables yield nonlinearities in the finite-difference-based algebraic expressions of the governing conservation equations.

The constitutive equations may be lumped into two categories: physical-property relationships and hydrogeologic relationships. The physical-property relationships provide dependencies for the primary dependent variables for physical properties such as density, viscosity, internal energy, enthalpy, saturation pressures, and component mass fractions for both phases. Water physical properties are computed from American Society of Mechanical Engineers 
steam table functions (ASME 1967) while air physical properties are computed from empirical functions and the ideal gas law. Gas-phase properties are computed by combining air and watervapor physical properties through either Dalton's partial pressure ideal gas laws or from the relationships from the kinetic theory of gas mixtures. The hydrogeologic constitutive equations relate the primary dependent variables to hydrogeologic characteristic and transport properties such as liquid and gas saturations, phase-relative permeabilities, and effective thermal conductivity. The hydrogeologic constitutive equations are generally based on empirical and semi-empirical relationships.

The governing conservation equations are solved by discretizing their partial differential forms with a finite-difference scheme. Spatial discretization is currently limited to multi-dimensional, regular and irregular, Cartesian or cylindrical grid systems, where the cylindrical grid systems are limited to cylinders aligned with the gravitational field. Temporal discretization uses the fully implicit method. Interface diffusion conductances, such as hydraulic and thermal conductivities, may be specified with arithmetic, geometric, or harmonic means-or an upwind weighting scheme. Phase densities for the water- and air-mass conservation equations are upwind weighted. Geometric mean interface diffusion conductances were used for the reported simulations. The advection terms of the thermal energy conservation equation are formulated with an upwind weighting scheme for the advected properties, while the species-conservation equation combines the advection and diffusion terms with a Peclet number-dependent power-law scheme (Patankar 1980) formulated for two-phase flow. The two-phase power-law scheme for combining the advection and diffusion components of the species-conservation equation is shown in Equations (4.18) through (4.20) for a single dimension, where $a_{e}$ represents the transport coefficient for the neighboring cell at the upper node index, $a_{w}$ represents the transport coefficient for the neighboring cell at the lower node index, and $a_{p}$ represents the transport coefficient for the local cell.

$$
\begin{gathered}
a_{e}=D_{l_{e}}\left[\left[0,\left(1-\frac{0.1\left|F_{l_{e}}\right|}{D_{l_{e}}}\right)\right]\right]+\left[\left[0,-F_{l_{e}}\right]\right]+ \\
D_{g_{e}}\left[\left[0,\left(1-\frac{0.1\left|F_{g_{e}}\right|}{D_{g_{e}}}\right)\right]\right]+\left[\left[0,-F_{g_{e}}\right]\right] \\
a_{w}=D_{I_{w}}\left[\left[0,\left(1-\frac{0.1\left|F_{I_{w}}\right|}{D_{I_{w}}}\right)\right]\right]+\left[\left[0, F_{I_{w}}\right]\right]+ \\
D_{g_{w}}\left[\left[0,\left(1-\frac{0.1\left|F_{g_{w}}\right|}{D_{g_{w}}}\right)\right]\right]+\left[\left[0, F_{g_{w}}\right]\right] \\
a_{p}=a_{e}+a_{w}+F_{l_{e}}+F_{g_{e}}-F_{l_{w}}-F_{g_{w}}
\end{gathered}
$$

where

$$
\begin{aligned}
& D_{1}=\text { liquid phase diffusion conductance, } \mathrm{Ci} / \mathrm{m}^{3} \mathrm{~s}, \\
& \mathrm{D}_{\mathrm{g}}=\text { gas phase diffusion conductance, } \mathrm{C} \mathrm{i} / \mathrm{m}^{3} \mathrm{~s},
\end{aligned}
$$




$$
\begin{aligned}
& F_{1}=\text { liquid phase advection conductance, } \mathrm{Ci} / \mathrm{m}^{3} \mathrm{~s}, \\
& \mathrm{~F}_{\mathrm{g}}=\text { gas phase advection conductance, } \mathrm{Ci} / \mathrm{H}^{3} \mathrm{~s}
\end{aligned}
$$

The dilute-concentration assumption associated with the species-conservation equation implies that the species respor:d as a passive scalar with respect to the other governing equations. That is, the physical and transport properties of the other governing equations are assur.led to be independent of species concentrations. This assumption allows the species-conservation equation to be decoupled and solved independently from the other governing equations. The finitedifference forms of the governing equations for water-mass, air-mass, and thermal energy are solved simultaneously in an iterative scheme. The nonlinear finite-difference equations are converted to a linear form and solved iteratively following the Newton-Raphson technique for multiple variables. The computed gas- and liquid-phase flow fields, from a converged solution for the coupled mass and heat transport equations, are then applied to the solution of the speciestransport equations. For single-phase, nonisothermal flow problems, only the water-mass and thermal-energy-transport equations are so'ved in a coupled manner. Likewise, for single-phase, isothermal flow problems only the warer-rnass transport equation is solved.

The physical and hydrogeological system relevant to the Yucca Mountain total-system performance assessment exercises consisted of a two-dimensional domain divided into five hydrogeologic strata, as shown in Figure 4.1. The physical domain extended vertically from the water table to the ground surface, and horizontally as an east-west transect that extended from borehole USW H-5 at the crest of Yucca Mountain to roughly 500 m east of borehole UE-25a\#1. The potential repository is illustrated by a downward-sloping line at elevations of $1030 \mathrm{~m}$ beneath the crest of Yucca Mountain and $895 \mathrm{~m}$ at the eastern facility boundary. This hydrogeological system differs significantly from previous gas-phase research (Ross 1988) because the different tuff layers above the repository horizon were lumped into a single welded unit. Ross has demonstrated, for steady-state flow fields, that gas-phase transport within the vadose at Yucca Mountain is strongly dependent on the permeability contrasts between the Paintbrush Nonwelded unit and the Tiva Canyon and Topopah Springs Welded units.

The computational model used to simulate the physical domain was structured on a uniform two-dimensional Cartesian grid with 50 rows and 94 columns. The vertical and horizontal grid dimensions were uniform over the computational domain, at 15 and $30 \mathrm{~m}$, respectively. Of the 4700 nodes within the computational domain, 776 nodes were treated as noncomputational nodes, which yields 3924 active computational nodes. The noncomputational nodes were used to generate the irregular boundary of the Yucca Mountain ground surface with a stair-stepped approach. The five lithological units were modeled on the computational domain as zones of differing hydrogeologic and thermal physical properties. The sloped characteristic of the tuff layers was modeled with "stair-stepped" nodes on the computational domain. The Ghost Dance fault was ignored on the computational domain except for the 14-m offset in tuff layers.

The water table was modeled as a saturated boundary for the liquid phase, a zero-flux boundary for the gas phase, a constant-temperature boundary $\left(30^{\circ} \mathrm{C}\right)$ for heat transport, and a zero- ${ }^{14} \mathrm{C}$ concentration boundary for species transport. The ground surface was modeled with "stair stepped" horizontal boundaries with specified uniform liquid recharge rates for the liquid phase, with standard atmospheric gas pressures for the gas phase, with $10 \%$ relative humidity for vapor-binary diffusion, with a constant temperature boundary $\left(20^{\circ} \mathrm{C}\right)$ for heat transport, and with a zero-14C concentration boundary for species transport. Vertical boundaries were modeled as zero- 
flux boundaries. Initial conditions were those computed for steady-state saturation conditions with the applied surface recharge and reported Yucca Mountain geothermal gradient (Schelling 1987).

The potential repository horizon was modeled using the thermal and hydrogeological transport properties of welded tuff with a decaying internal heat-generation source. Heat generation was computed assuming a design repository loading (Schelling 1987) of 49.9 MTHM/acre composed of 40\% 27,500 MWd/MTHM BWR fuel and 60\% 33,000 MWd/MTHM PWR fuel (5-year spent fuel), thus producing an initial heat source of roughly $76 \mathrm{~kW} /$ acre. Radioactive decay heat generation within the repository was modeled with a uniform source applied to the repository nodes. The power decay time profile from time zero at emplacement to 10,000 years is shown in Figure 4.21 in terms of areal power density.

Carbon-14 releases were also assumed to occur within the potential repository horizon. Although ${ }^{14} \mathrm{C}$ release rates were computed separately for gas and liquid phases, the chemical equilibrium assumption of the geochemical model partitioned the $14 \mathrm{C}$ species between the liquid and gas phase according to phase-equilibrium relations. Carbon-14 release rates and cumulative releases for the simulated recharge rates of $0.0 \mathrm{~mm} / \mathrm{yr}$ and $0.01 \mathrm{~mm} / \mathrm{yr}$ are shown in Figure 4.22. For the $0.0 \mathrm{~mm} / \mathrm{yr}$ recharge condition, $14 \mathrm{C}$ releases were assumed to occur solely through the gas phase. For the $0.01 \mathrm{~mm} / \mathrm{yr}$ recharge condition, ${ }^{14} \mathrm{C}$ releases occurred initially through the gas phase and subseq jently with a lower release rate through the liquid phase. Values shown in Figure 4.22 represent release rates and cumulative releases for the entire repository. The cumulative release values account for radioactive decay of the ${ }^{14} \mathrm{C}$ species.

The majority of the hydrogeologic and thermal transport properties for the subject simulations were specified by SNL staff, the other major participant in the Yucca Mountain total-system performance assessment exercise (Kaplan 1991). A description of the equivalent-continuum model for lumping matrix and fracture properties and hydrogeologic property data were reported in Section 4.1. Not included among the specified transport properties were the thermal physical properties, gas-phase relative permeabilities, carbon dioxide gas-phase diffusion coefficients, carbonate liquid-phase diffusion coefficients, and tortuosities. Because of the preliminary nature of the subject simulations, the thermal transport properties were assigned constant values across the five tuff layers. The solid-phase specific heat and density equaled $840 \mathrm{~J} / \mathrm{kg} \mathrm{K}$ and $2300 \mathrm{~kg} / \mathrm{m}^{3}$, respectively. The combined solid and aqueous-phase thermal conductivity was linearly dependent on liquid saturation and varied between the desaturated and saturated limits of $1.74 \mathrm{~W} / \mathrm{m} \mathrm{K}$ and $2.30 \mathrm{~W} / \mathrm{m} \mathrm{K}$. Although the liquid-phase relative permeability was specified as a complex function of both the fracture and matrix saturations, a constant gas-phase relative permeability of 1.0 was chosen. A constant gas-phase relative permeability of 1.0 represents a conservative choice with respect to predictions on $14 \mathrm{C}$ transport to the accessible environment. Diffusion coefficients for carbon dioxide through the gas phase and carbonate through the aqueous phase were set to constant values of $0.152 \mathrm{~cm}^{2} / \mathrm{s}$ and $1.77 \times 10-5 \mathrm{~cm}^{2} / \mathrm{s}$, respectively.

Liquid- and gas-phase tortuosities modify the diffusion-path lengths for binary diffusion of water vapor and air in the gas phase and ${ }^{14} \mathrm{C}$ diffusion in both phases. The liquid-phase tortuosity was computed based on a semi-empirical model proposed by Millington and Quirk (1959), as shown in Equation (4.21). Because precursory simulations to the subject simulations showed significant sensitivity of ${ }^{14} \mathrm{C}$ transport to the gas-phase tortuosity, two gas-phase tortuosity functional relationships were considered. The subject simulations were duplicated, with one simulation using a gas-phase version of the Millington and Quirk model, Equation (4.22), and the other simulation using a gas-phase tortuosity function proposed by Penman (1940a,b), 


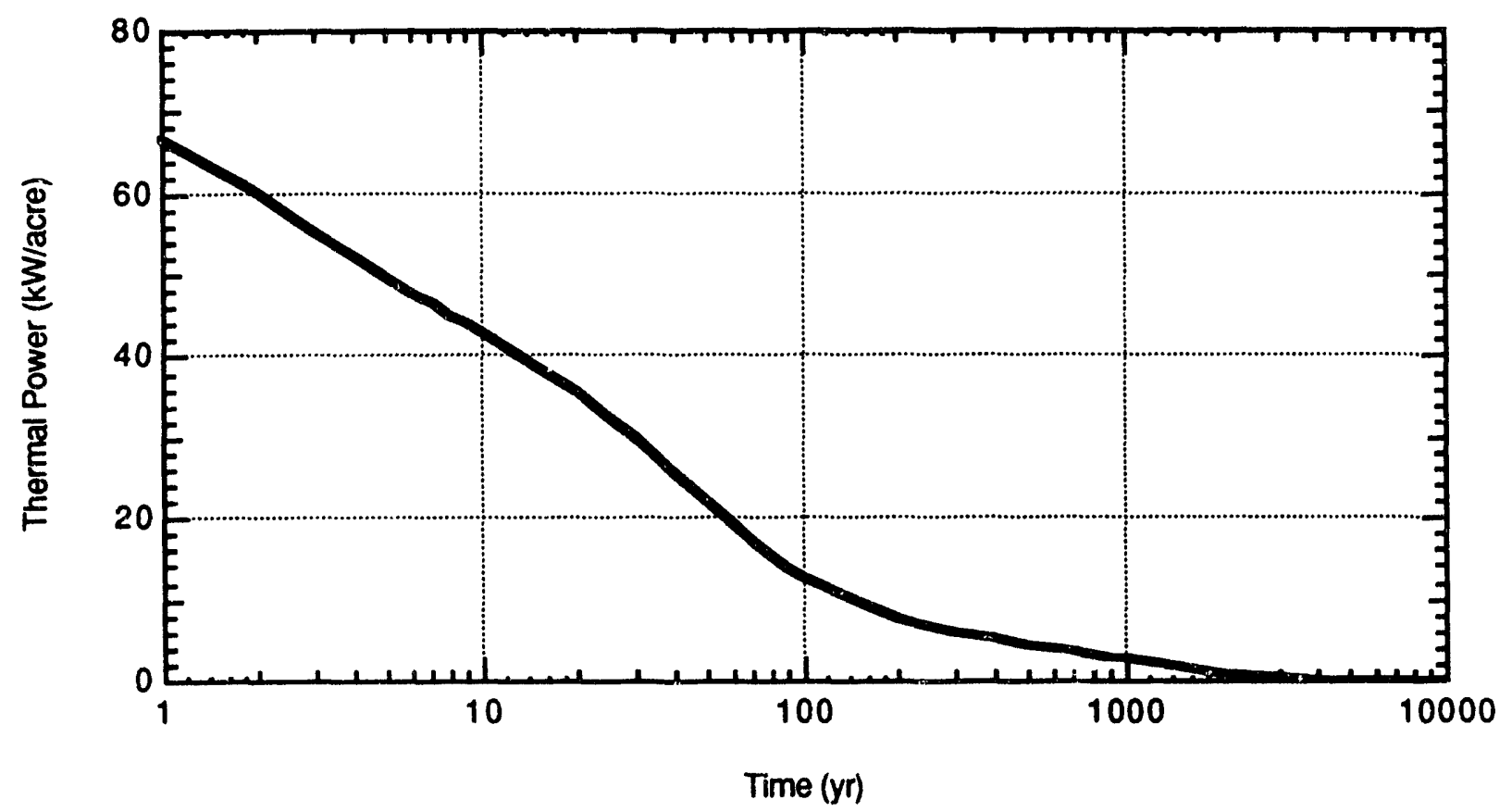

Figure 4.21. Thermal Power Decay Profile

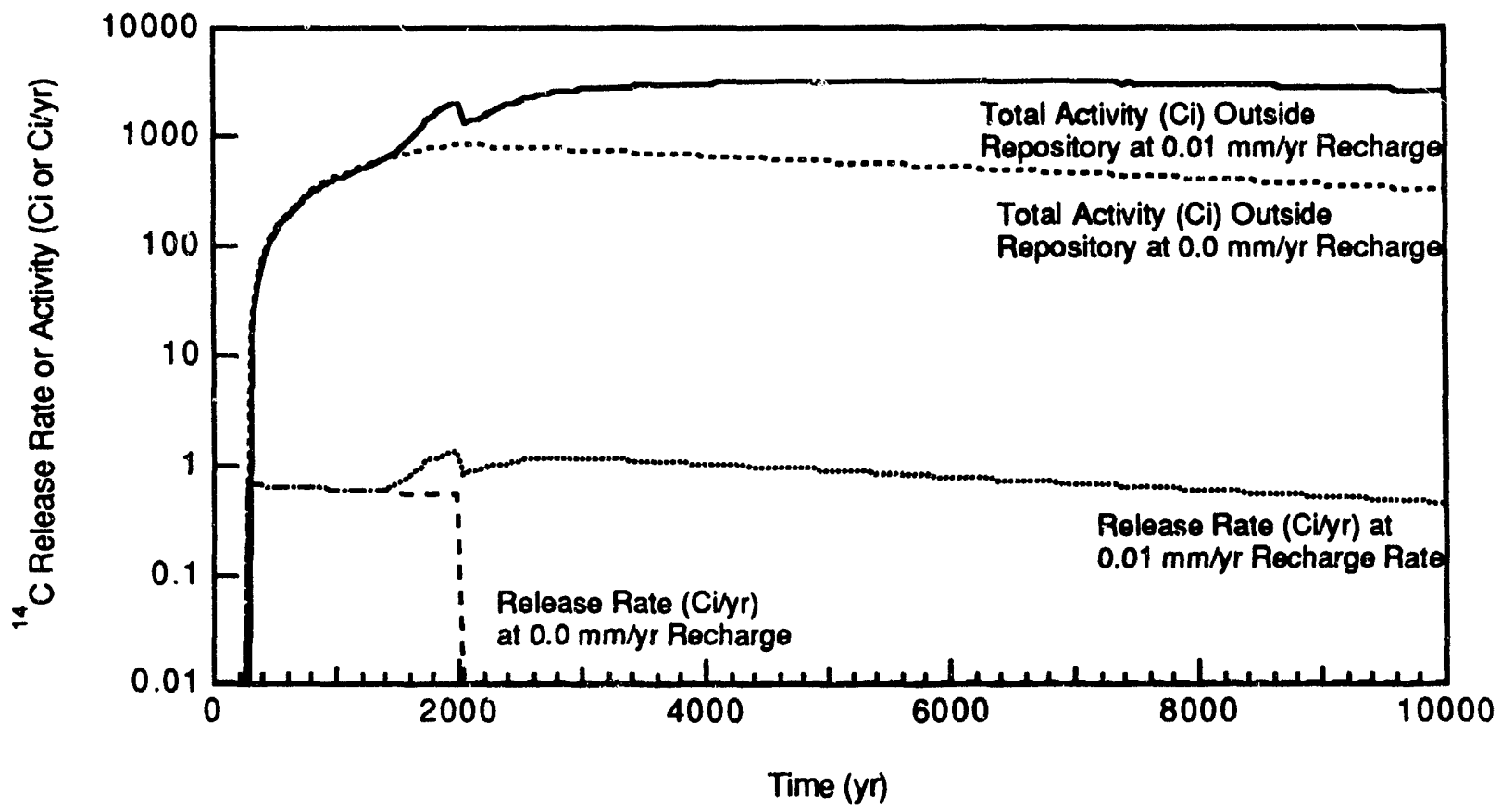

Figure 4.22. Potential Repository ${ }^{14} \mathrm{C}$ Release Rates and Total Activity Outside the Repository (total activity represents the cumulative source-term release less radioactive decay) 
Equation (4.23). Penman's model was based on experimental studies of carbon dioxide diffusion through packed soil cores of varying moisture content.

$$
\begin{aligned}
& \tau_{\mathrm{l}}=\mathrm{n}_{\mathrm{d}}{ }^{10 / 3} \mathrm{~s}_{\mathrm{l}}{ }^{4 / \mathrm{z}} \\
& \tau_{\mathrm{g}}=\mathrm{n}_{\mathrm{d}}{ }^{10 / 3} \mathrm{~s}_{\mathrm{g}}{ }^{4 / \mathrm{z}} \\
& \tau_{\mathrm{g}}=0.66\left(\mathrm{n}_{\mathrm{d}} \mathrm{s}\right)
\end{aligned}
$$

The Yucca Mountain tuff layers are characterized by small pore sizes and large matrix potentials under low liquid-saturation conditions. Because of the local drying which would occur around the repository after waste emplacement, the phenomenon of lowering vapor-pressure was included in the reported simulations. Vapor-pressure lowering, as shown in Equation (4.24) is an experimentally observed phenomenon (Nitao 1988) that effectively lowers the vapor pressure above the pore water, i.e., raises the pore-water boiling point.

$$
P_{v}=P_{\text {sat }} \exp \left(\frac{-P_{c}}{\rho_{1} R_{1} T}\right)
$$

where $P_{v}=$ vapor pressure $(\mathrm{Pa})$

$$
\begin{aligned}
\mathrm{P}_{\text {sat }} & =\text { saturation pressure }(\mathrm{Pa}) \\
\mathrm{P}_{\mathrm{c}} & =\text { capillary pressure }(\mathrm{Pa}) \\
\rho_{1} & =\text { liquid mass density }\left(\mathrm{kg} / \mathrm{m}^{3}\right) \\
\mathrm{R}_{1} & =\text { gas constant } \\
\mathrm{T} & =\text { temperature }(\mathrm{K})
\end{aligned}
$$

The geochemical conceptual model for ${ }^{14} \mathrm{C}$ within the vadose zone at Yucca Mountain was based on observed characteristics of the geology and aqueous chemistry as reported by Amter et al. (1988). For the purposes of modeling ${ }^{14} \mathrm{C}$ transport, the geochemical model describes the equilibrium state of the ${ }^{14} \mathrm{C}$ species; i.e., the partitioning of $14 \mathrm{C}$ between the solid, aqueous, and gas phases. According to Amter, the geochemical system within the vadose zone at Yucca Mountain is fundamentally dependent on the mineral phases that govern the aqueous-phase chemistry. Moreover, the aqueous-phase chemistry for Amter's conceptual model is based on four underlying assumptions:

- Calcium carbonate dominates the chemistry of the vadose zone.

- Calcium concentrations result from equilibrium with calcium carbonate.

- ${ }^{14} \mathrm{C}$ concentrations are proportional to $12 \mathrm{C}$ concentrations.

- No isotopic exchange of ${ }^{14} \mathrm{C}$ with the solid phase occurs. 
Amter's geochemical conceptual model describes isotopic equilibrium of ${ }^{14} \mathrm{C}$ between dissolved carbon and gaseous $\mathrm{CO}_{2}$. Equilibrium conditions are expressed with a retardation factor, which is proportional to the ratio of liquid to gas-phase concentrations (Equation [4.25]).

$$
B=1+\frac{\left(n_{t}-n_{d}\right)}{n_{d}}\left(\frac{C_{l}}{C_{g}}\right)
$$

Retardation factors as a function of temperature were computed for three tuff layers with a reactionpath model that used available chemical data concerning the reactions of carbonate species. The model yields expected mineral-phase equilibria and changes in speciation with temperature. The geochemical modeling was a two-step procedure. The initial step involved computing equilibrium concentrations for carbonate species in the liquid and gas phase from limited chemical data at ambient temperatures. The second step involved predicting speciation changes with temperature based on the chemical model generated from the first step for ambient temperatures. The retardation factor expressions reported by Amter et al. (1988) for three tuff layers are show in Table 4.6. Because the hydrogeologic stratigraphy for the total-system performance assessment exercises does not distinguish between layers within the Welded Unit, only the Topopah Springs Welded retardation factors were used in the reported results.

\subsubsection{Simulation Results}

Carbon-14 transport was predicted for a 10,000-year period following waste emplacement for two surface recharge rates. Waste-package failures and ${ }^{14} \mathrm{C}$ releases for both surface recharge rates were assumed to initiate 300 years after waste-package emplacement. During the initial 300 years of the simulation, only the coupled conservation equations for water mass, air mass, and thermal energy were solved. Because the initial 300 years after waste emplacement are predicted to be characterized with peak repository temperatures and heat flux rates, this period of the simulation requires a majority of the computational effort. Drying of the repository horizon and countercurrent heat-pipe-type flow structures limit the computational time steps during the initial 300 years of simulation time. Waste-package failures and $14 \mathrm{C}$ releases to the unsaturated zone environment are simulated as a species source uniformly spread along the repository horizon. During the 300 to 10,000 -year simulation period, both the coupled conservation equations and the species transport equations are solved. Because the thermal and liquid-saturation gradients at 300 years have decayed from their peak values, computational time steps during the 300 to 10,000-year simulation period were only restricted by the Courant limit. Because waste-package failure times were not coordinated with the thermal and hydrogeologic histories computed by these simulations, these ${ }^{14} \mathrm{C}$ transport calculations should be considered an example with respect to predicting total-system performance.

The geochemical equilibrium model for the carbon element within the vadose zone at Yucca Mountain predicts significantly higher ${ }^{14} \mathrm{C}$ mass fractions for the aqueous phase compared with the gas phase. Nevertheless, $14 \mathrm{C}$ transport through the unsaturated zone is strongly dependent on both advection and diffusion through the gas phase. Because $14 \mathrm{C}$ diffusion through the aqueous phase is drastically slower than through the gas phase, saturated or nearly saturated conditions within the vadose zone behave as ${ }^{14} \mathrm{C}$ transport inhibitors. Moreover, the strong dependence of gas-phase tortuosity, e.g., the Millington and Quirk model, on water content emphasizes the importance of liquid-saturation levels on ${ }^{14} \mathrm{C}$ transport. These characteristics of ${ }^{14} \mathrm{C}$ transport through the unsaturated zone within Yucca Mountain suggest that accurate predictions of ${ }^{14} \mathrm{C}$ 
Table 4.6. Temperature-Dependent Retardation Factors

\author{
Tuff Layer \\ Tiva Canyon Welded \\ Paintbrush Non-Welded \\ Topopah Springs Welded
}

\author{
Retardation Factor Equation \\ $\mathrm{B}(\mathrm{T})=92.7-(0.948) \mathrm{T}$ \\ $\mathrm{B}(\mathrm{T})=71.7-(0.731) \mathrm{T}$ \\ $\mathrm{B}(\mathrm{T})=84.9-(0.867) \mathrm{T}$
}

transport are partially dependent on accurate predictions of the liquid-saturation field with the vadose zone and particularly in the region surrounding the potential repository horizon. Accurate predictions of liquid saturations surrounding the potential repository after waste emplacement require the coupled solution of the thermal and hydrogeologic response of the unsaturated zone to the repository's release of decay heat.

The computational efforts required during the initial 300-year simulation period are justified by the need for an accurate prediction of the liquid-saturation field surrounding the repository. Simulation of ${ }^{14} \mathrm{C}$ transport, therefore, actually starts with the emplacement of waste containers and subsequent alteration of the ambient hydrogeologic conditions.

Initial conditions for the simulations were established for the liquid pressure, gas pressure, and temperature fields through three partially independent code executions. The liquid pressure initial conditions were determined from a steady-state solution of the single-phase hydrologic conditions with surface-flux boundary conditions imposed along the ground surface and saturatedboundary conditions imposed at the water table. Thermal initial conditions were established by the solution of a steady-state, heat-conduction model with constant temperature boundary conditions imposed along the ground surface and at the water table. The thermal conductivities were computed as a function of the liquid-saturation field established from the steady-state hydrologic simulation. The gas-pressure initial conditions were computed from a steady-state solution of the air-mass conservation equation with the gas density dependent on the temperature and water vapor mass fraction in the gas phase. Initial water vapor conditions were established from thermodynamic equilibrium states based on the initial thermal, hydrological, and gas-pressure conditions. Initial conditions were computed with this partially independent approach to conserve computer execution time over a fully coupled steady-state solution. Comparisons between initial conditions computed using the fully coupled and partially independent approaches for computational domains with fewer horizontal nodes demonstrated the accuracy of the partially independent approach. The only notable differences between the two approaches occurred in the liquid-saturation profiles-where the maximum difference was roughly $2 \%$.

Uniform repository heating occurs throughout the entire 10,000-year simulation period. This approach to modeling the repository heating ignores the disproportionate heating rates and heat losses through drift ventilation, which would occur during the repository-loading period. The approach also assumes that the emplacement boreholes and access drifts have been completely backfilled with native material. Because of the complex interaction between ${ }^{14} \mathrm{C}$ transport, container failure times, and the thermal and hydrogeologic response of the unsaturated zone, it remains inconclusive whether these assumptions concerning repository heating are conservative or unconservative with respect to ${ }^{14} \mathrm{C}$ releases to the accessible environment. For example, reduced heating rates result in lower gas-phase velocities, but could also yield earlier container failures because of earlier contact with liquid water and reduced alterations to the liquid-satiration fields. 
Simulation results for the $0.0 \mathrm{~mm} / \mathrm{yr}$ (zero recharge) condition will be described, followed by those for the $0.01 \mathrm{~mm} / \mathrm{yr}$ (low recharge) condition. Thermal and liquid-saturation contour plots within the unsaturated zone at Yucca Mountain at 100 years are show.l in Figures 4.23 and 4.24. Peak potential repository temperatures of $109^{\circ} \mathrm{C}$ for the zero-recharge simulation occurred at 77 years. The temperature contours show relatively steep thermal gradients surrounding the potential repository horizon with peak temperatures of $107.2^{\circ} \mathrm{C}$. The liquid-saturation contours surrounding the repository horizon illustrate the steep gradients in moisture content adjacent to the repository. Repository temperatures are sufficient to boil the ground water adjacent to the potential repository, thus producing desaturated conditions. Water vapor formed near the repository condenses in the lower temperature regions beyond the dried-out region adjacent to the repository, thus producing a region of saturation greater than ambient. This structure characterized by a zone of above-boiling temperatures and low saturations adjacent to a zone of condensing temperatures and high saturations is commonly referred to as heat-pipe type flow. These counter-current flow structures surrounding the repository differ from conventional heat pipes because the boundaries are dynamic. Under high heat-flux conditions the counter-current flow region migrates away from the heat source, i.e., the repository. Conversely, under low heat-flux conditions the counter-current flow region moves toward the repository and eventually collapses when the heat flux is insufficient to sustain the counter-current flow structure.

The thermal and liquid-saturation contour plots at 300 years are shown in Figures 4.25 and 4.26 , respectively. The peak temperature at 300 years equaled $99.7^{\circ} \mathrm{C}$, which remained above the boiling point under the local capillary pressure and gas-phase pressure conditions. The heat-pipe flow structure continues to surround the repository, thus producing an oblong ring of nearly saturated conditions slightly offset from the repository. Because of the repository's slope and the higher permeability of the fractures to saturated liquid flow, the saturated zones surrounding the repository drain along and off the lower end of the repository. The 300-year point in the simulation marks the onset of container failures and the release of $14 \mathrm{C}$ into the unsaturated environment.

The thermal, liquid-saturation, and $14 \mathrm{C}$-concentration contour plots at 500 years are shown in Figures 4.27 through 4.30 , respectively. Peak temperatures at 500 years equaled $96.6^{\circ} \mathrm{C}$, a value below the boiling point. The liquid-saturation contours show a reduction in gradients surrounding the repository horizon, which indicates the initial retreat and collapse of the heat-pipe flow structure. The lower peak temperatures and collapse of the heat-pipe flow structure are a direct result of the decay in internal heat generation produced by the repository through radioactive decay of the waste isotopes.

The 500-year point marks 200 years of $14 \mathrm{C}$ release from the waste containers. Two plots of ${ }^{14} \mathrm{C}$-concentration contours are shown for 500 years. Figure 4.29 shows $14 \mathrm{C}$-concentration contours using the Millington and Quirk model for gas-phase tortuosity and Figure 4.30 shows ${ }^{14} \mathrm{C}$-concentration contours using the Penman model for gas-phase tortuosity. Except for the heatpipe flow region immediately surrounding the repository, where gas-phase velocities are elevated, the $14 \mathrm{C}$ transport through the unsaturated zone is dominated by diffusion processes. Carbon-14 transport is diffusion-dominated primarily because of the relatively low gas-phase velocities, which result primarily from the low permeabilities computed for the unsaturated zone tuff layers from the dual-porosity conceptual model. Because the Millington and Quirk gas-phase tortuosity model has a stronger dependence on moisture content than the Penman model, $14 \mathrm{C}$ diffusion with the Millington and Quirk model is significantly retarded from that with the Penman model. Peak ${ }^{14} \mathrm{C}$ concentrations at 500 years for the Millington and Quirk model equal $1.17 \times 10^{-6} \mathrm{Ci} / \mathrm{m}^{3}$ and for the Penman model equal $9.82 \times 10^{-7} \mathrm{Ci} / \mathrm{m}^{3}$. 


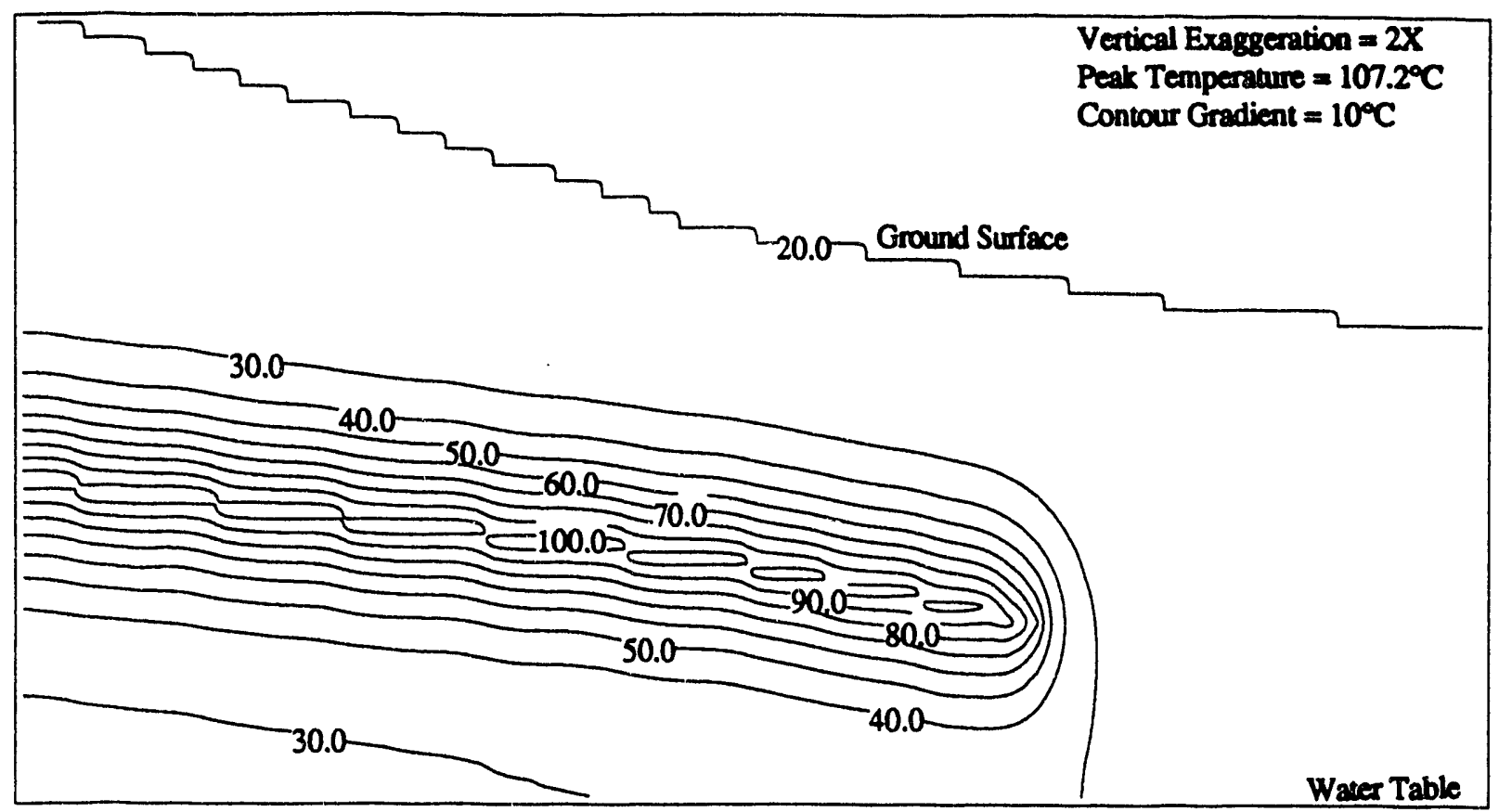

Figure 4.23. Temperature Contours $\left({ }^{\circ} \mathrm{C}\right)$ at $100 \mathrm{yr}$ for ${ }^{2}$ exo Recharge

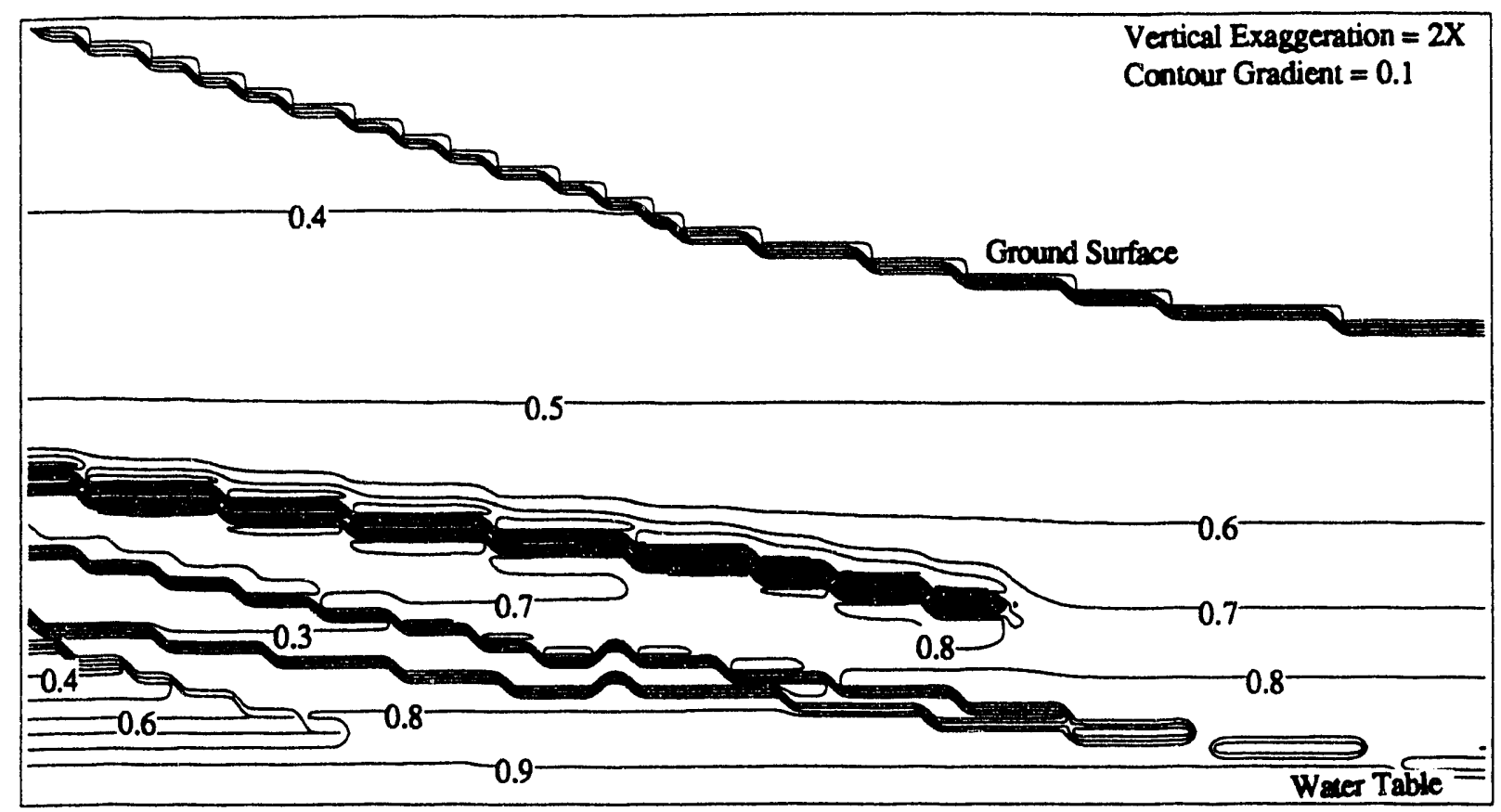

Figure 4.24. Liquid-Saturation Contours at $100 \mathrm{yr}$ for Zero Recharge 


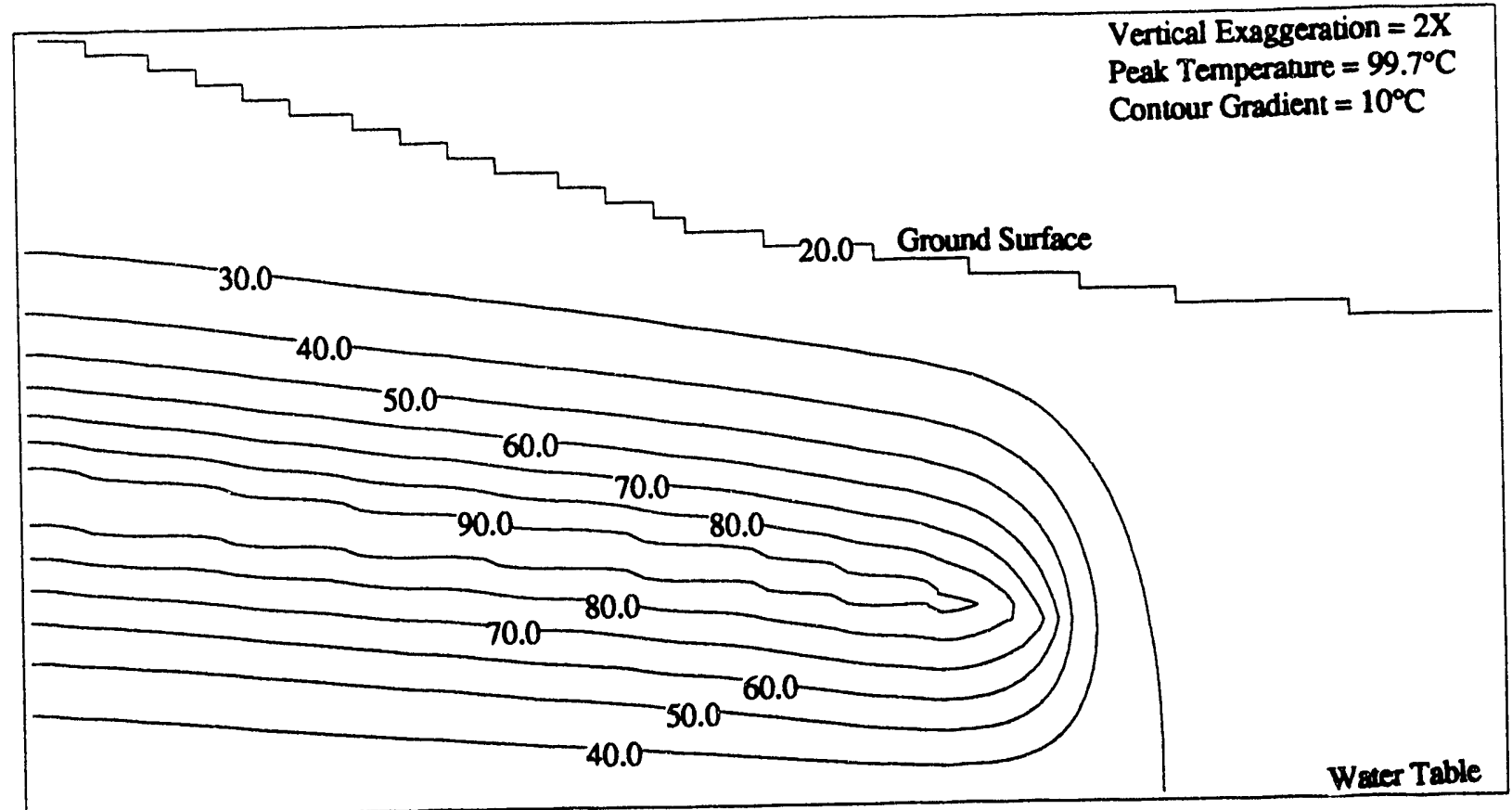

Figure 4.25. Temperature Contours $\left({ }^{\circ} \mathrm{C}\right)$ at $300 \mathrm{yr}$ for Zero Recharge

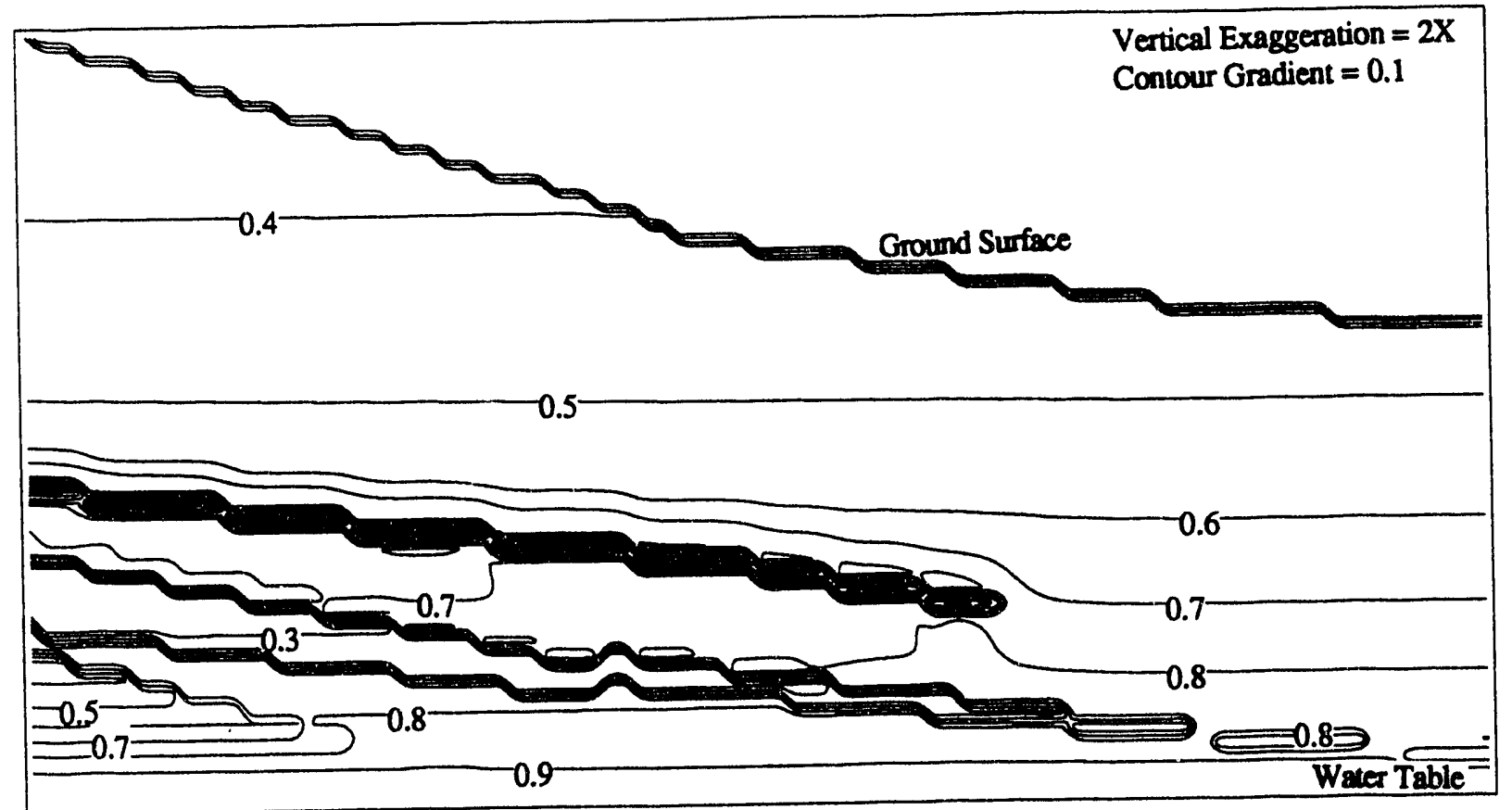

Figure 4.26. Liquid-Saturation Contours at $300 \mathrm{yr}$ for Zero Recharge 


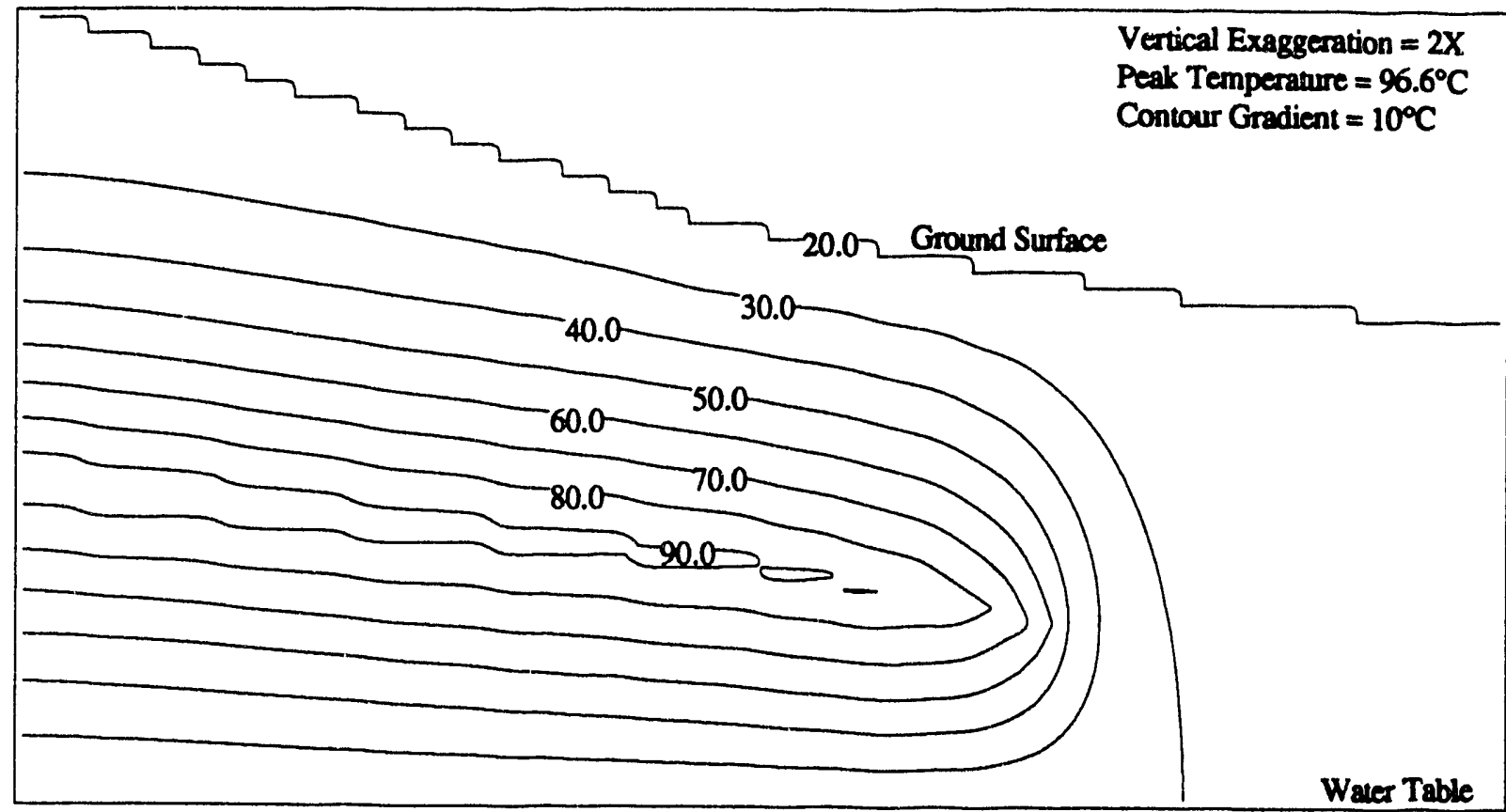

Figure 4.27. Temperature Contours $\left({ }^{\circ} \mathrm{C}\right)$ at $500 \mathrm{yr}$ for Zero Recharge

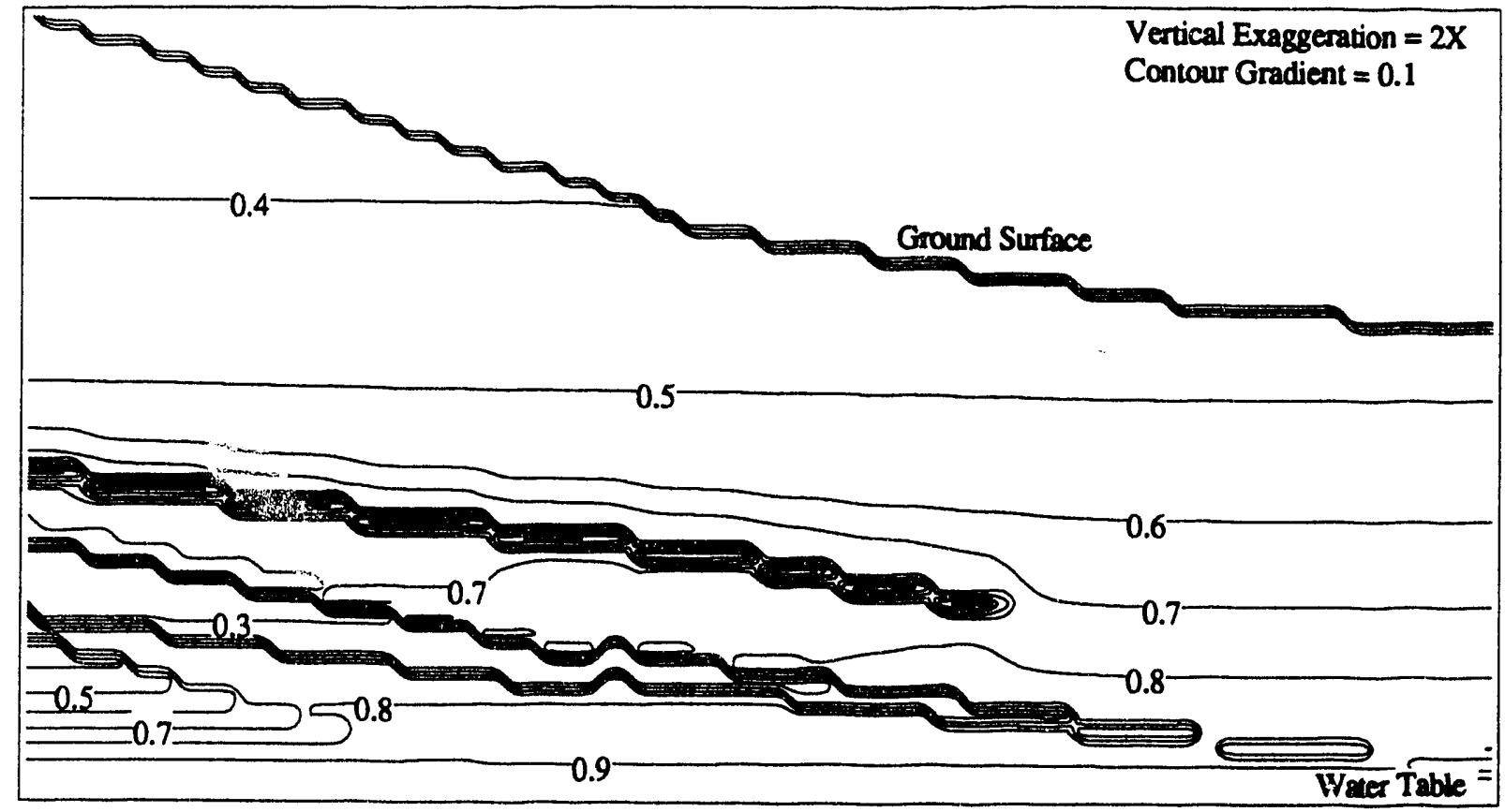

Figure 4.28. Liquid-Saturation Contours at $500 \mathrm{yr}$ for Zero Recharge 


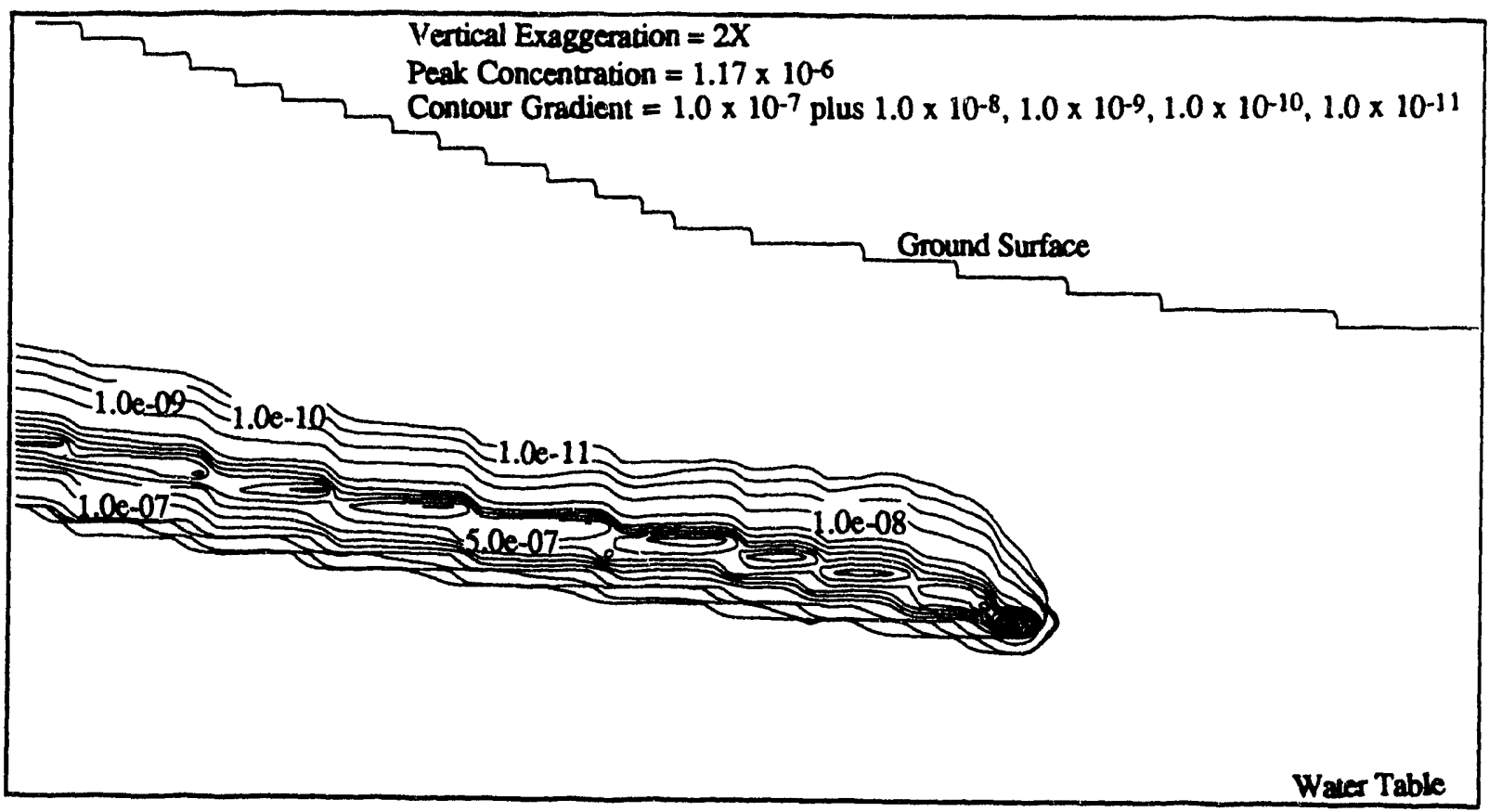

Figure 4.29. $14 \mathrm{C}$-Concentration Contours $\left(\mathrm{Ci} / \mathrm{m}^{3}\right)$ at $500 \mathrm{yr}$ for Zero Recharge Using the Millington and Quirk Tortuosity Model

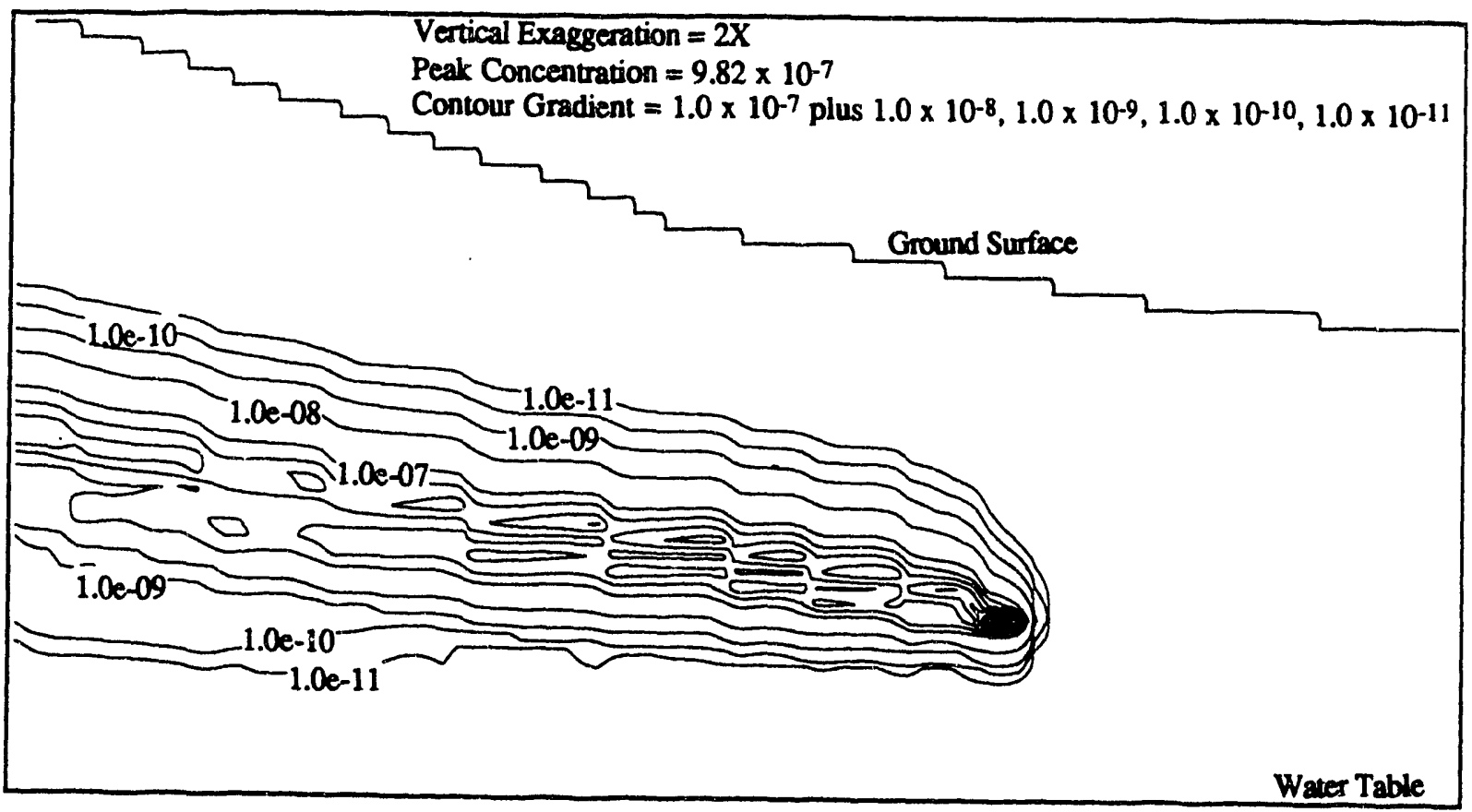

Figure 4.30. ${ }^{14} \mathrm{C}$-Concentration Contours $\left(\mathrm{Ci} / \mathrm{m}^{3}\right)$ at $500 \mathrm{yr}$ for Zero Recharge Using the Penman Tortuosity Model 
The thermal, liquid-saturation, and $14 \mathrm{C}$-concentration contours at the 1000- and 2000-year marks are shown in Figures 4.31 through 4.38. Peak repository temperatures have fallen to $88.7^{\circ} \mathrm{C}$ at 1000 years and to $65.6^{\circ} \mathrm{C}$ at 2000 years. The reflected thermal boundary condition imposed on the vertical surface below the Yucca Mountain ridge significantly affects temperature contour profiles. At 1000 years the heat-pipe structure that surrounded the repository at earlier periods practically disappeared, as shown in the liquid-saturation contours of Figure 4.32. The influence of repository heating on the liquid-saturation contours is nearly indiscernible at 2000 years, as shown in Figure 4.36. Peak $14 \mathrm{C}$ concentrations at 1000 years for the Millington and Quirk model equal $3.19 \times 10^{-6} \mathrm{Ci}^{3} \mathrm{~m}^{3}$ and for the Penman model equal $2.20 \times 10^{-6} \mathrm{Ci} / \mathrm{m}^{3}$. Peak ${ }^{14} \mathrm{C}$ concentrations at 2000 years for the Millington and Quirk model equal $7.30 \times 10^{-6} \mathrm{Ci} / \mathrm{m}^{3}$ and for the Penman model equal $3.96 \times 10^{-6} \mathrm{Ci} / \mathrm{m}^{3}$. For the zero-flux condition, ${ }^{14} \mathrm{C}$ releases from the containers were assumed to conclude at the 2000-year point; therefore, the 2000-year concentrations represent the peak ${ }^{14} \mathrm{C}$ concentrations during the 10,000 -year period. Although indiscernible in the ${ }^{14} \mathrm{C}$-concentration contour plots, $14 \mathrm{C}$ concentrations along the repository horizon are lower than those in the regions immediately adjacent to the repository. This result arises because of the non-linear aspects of combined advection and diffusion transport.

The thermal, liquid-saturation, and $14 \mathrm{C}$-concentration contours at the $4000-, 6000-, 8000$ - and 10,000-year marks are shown in Figures 4.39 through 4.54. The temperature and liquidsaturation profiles over the period from 4000 to 10,000 years, trend towards the ambient hydrologic and geothermal gradient conditions imposed by the boundary conditions. The contrast in ${ }^{14} \mathrm{C}$-concentration profiles between the Millington and Quirk and Penman gas-phase tortuosities dramatically increases during this simulation time period. For example at 4000 years, ${ }^{14} \mathrm{C}$ concentrations at the ground surface have become notable for the Penman model, Figure 4.42, but ground-surface concentrations of ${ }^{14} \mathrm{C}$ for the Millington and Quirk model remain below $1.0 \times 10^{-11} \mathrm{Ci} / \mathrm{m}^{3}$, Figure 4.41 . Because of radioactive decay of $14 \mathrm{C}$ and the low gas-phase tortuosities predicted by the Millington and Quirk model, ground-surface concentrations of $14 \mathrm{C}$ never reach the $1.0 \times 10^{-11} \mathrm{Ci} / \mathrm{m}^{3}$ level. The Penman gas-phase tortuosity model, however, results in significant fluxes of ${ }^{14} \mathrm{C}$ across the ground surface and water table. Cumulative releases to the ground surface for the Penman model are shown in Figure 4.55. The total released in 10,000 years is $2.41 \mathrm{Ci}$. The maximum flux rate is $0.01 \mathrm{Ci} / \mathrm{yr}$, and occurs at the end of the 10,000 -year period.

The simulation results for the $0.01-\mathrm{mm} / \mathrm{yr}$-recharge condition qualitatively resemble those for the zero-recharge condition. The primary difference between the two simulations results from the generally higher liquid saturations from surface recharge. Higher initial liquid saturations, computed from steady-state solutions, around the repository horizon resulted in lower peak temperatures and increased migration of liquid water down the slope of the repository horizon. Peak repository temperatures at 100 years were $100.3^{\circ} \mathrm{C}$ compared with temperatures of $107.2^{\circ} \mathrm{C}$ computed for the zero-recharge condition. Peak temperatures are lower because of increased sensible and latent thermal capacitance at higher liquid saturations and increased heat-tranisfer rates from the repository.

Because higher liquid saturations decrease the gas-phase tortuosity for both the Millington and Quirk, and Penman models, gas-phase transport of ${ }^{14} \mathrm{C}$ were diminished, therefore yielding higher concentrations and narrower ranges of ${ }^{14} \mathrm{C}$ along the repository. Transport of $14 \mathrm{C}$ from the repository to the ground surface and ground water were negligible for the $0.01 \mathrm{~mm} / \mathrm{yr}$ condition, because of the diffusion barriers produced by the saturated zones surrounding the repository and the generally higher liquid-saturation values. At $20^{\circ} \mathrm{C}$ carbon partitions between the aqueous and gas phase with a 32.3-to-1 ratio by phase volume. Higher recharge rates could invert the dominant 


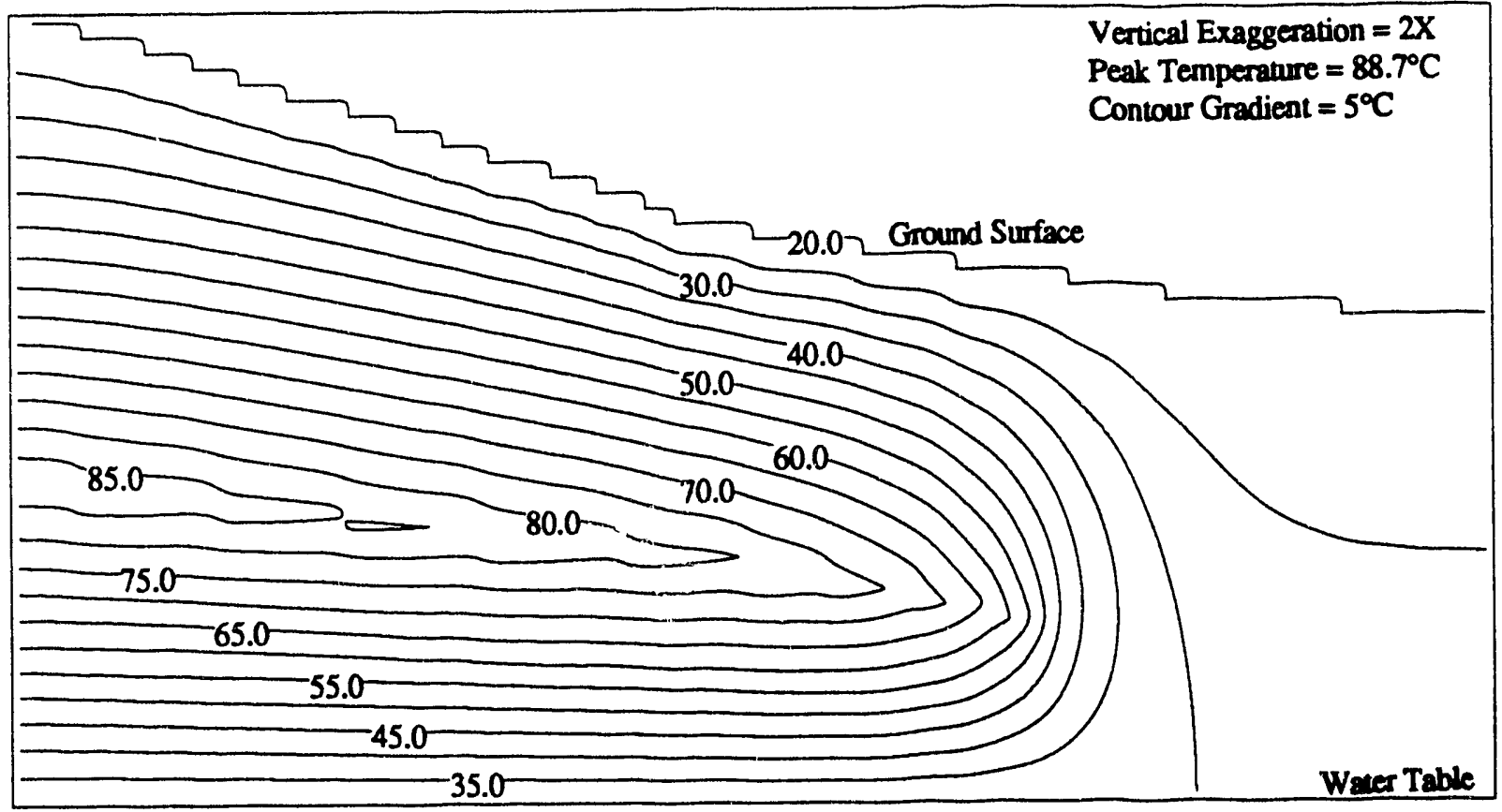

Figure 4.31. Temperature Contours $\left({ }^{\circ} \mathrm{C}\right)$ at 1000 yr for Zero Recharge

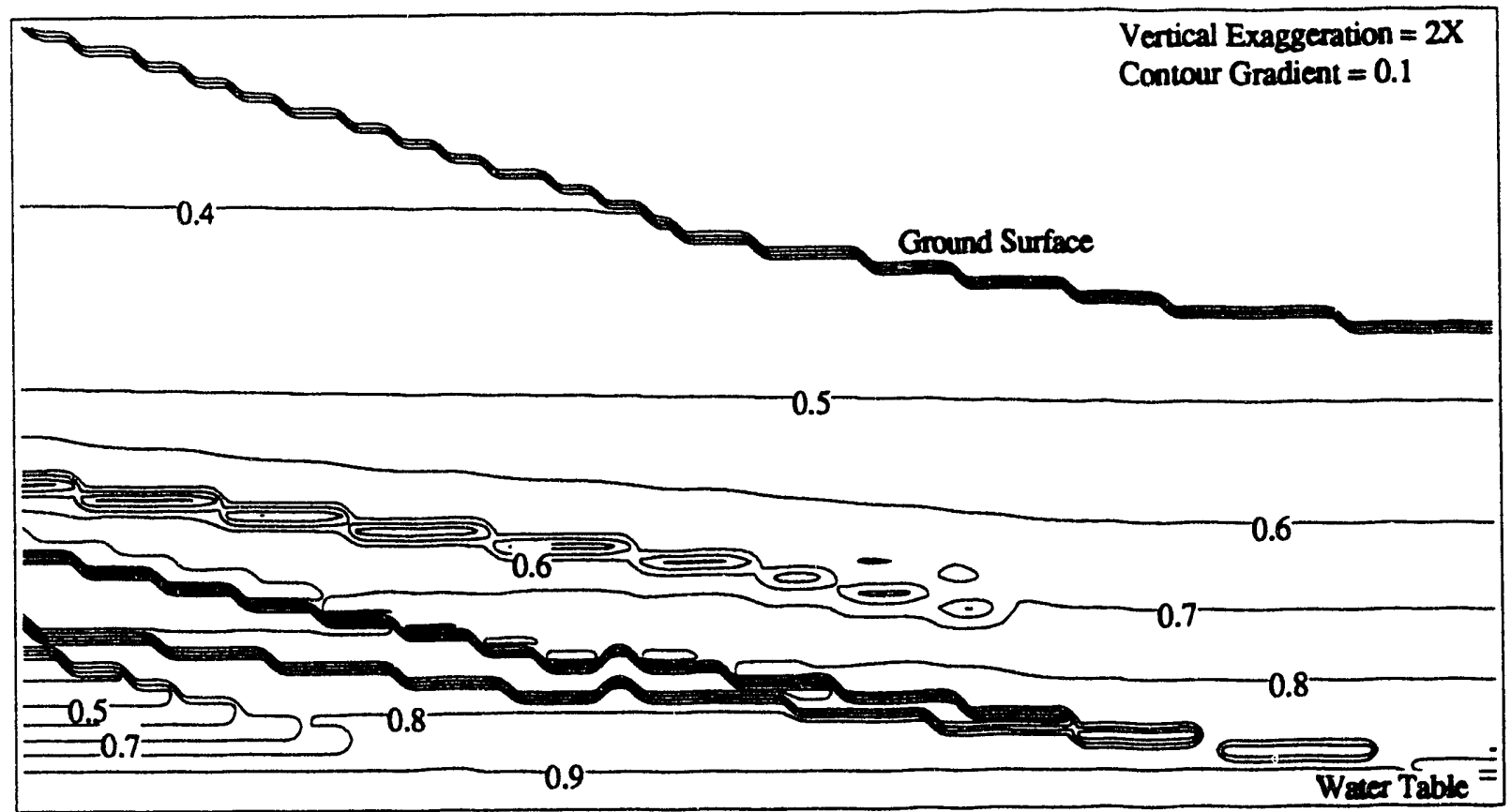

Figure 4.32. Liquid-Saturation Contours at $1000 \mathrm{yr}$ for Zero Recharge 


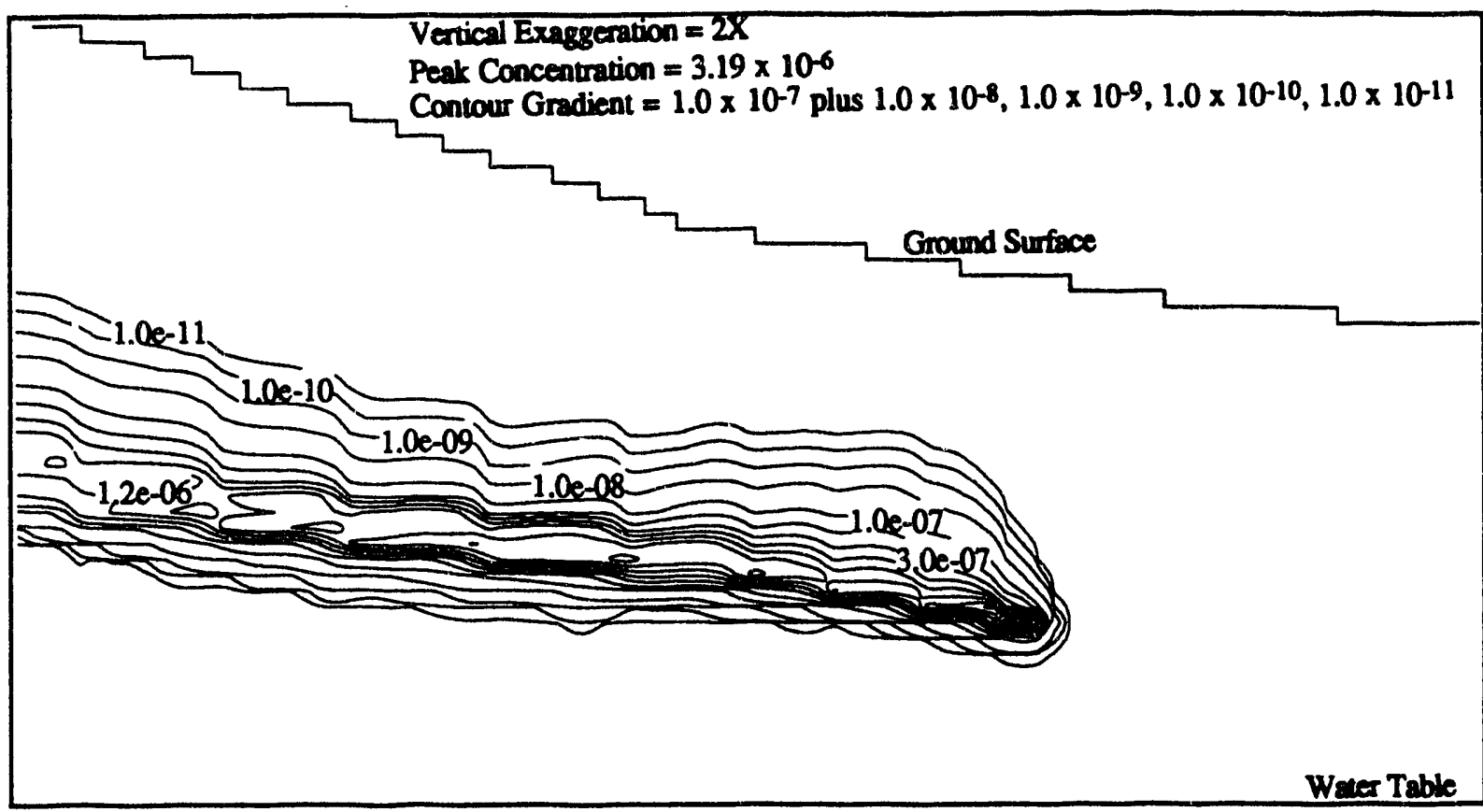

Figure 4.33. ${ }^{14} \mathrm{C}$-Concentration Contours $\left(\mathrm{Ci} / \mathrm{m}^{3}\right)$ at $1000 \mathrm{yr}$ for Zero Recharge Using the Millington and Quirk Tortuosity Model

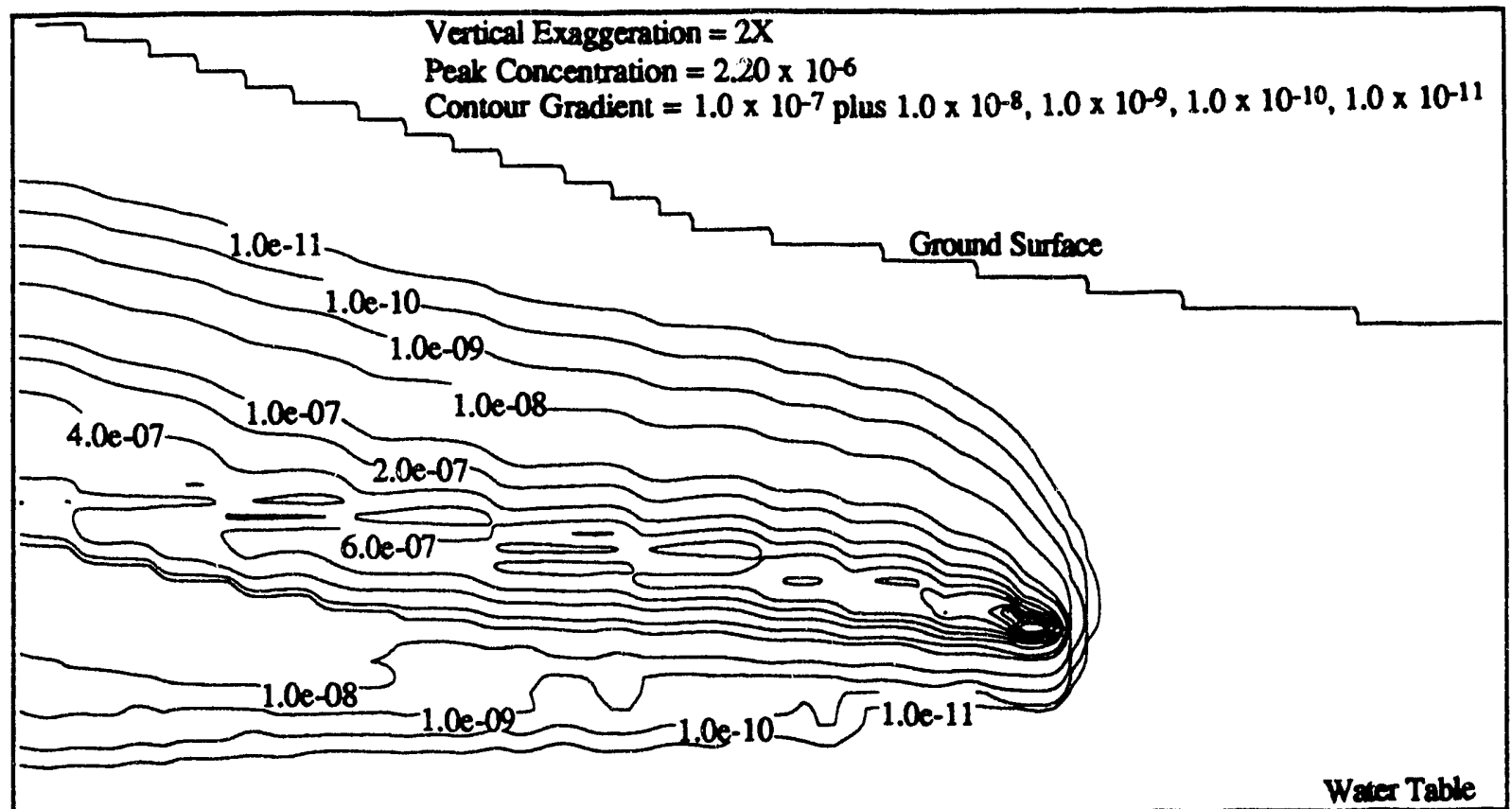

Figure 4.34. ${ }^{14} \mathrm{C}$-Concentration Contours $\left(\mathrm{Ci} / \mathrm{m}^{3}\right)$ at $1000 \mathrm{yr}$ for Zero Recharge Using the Penman Tortuosity Model 


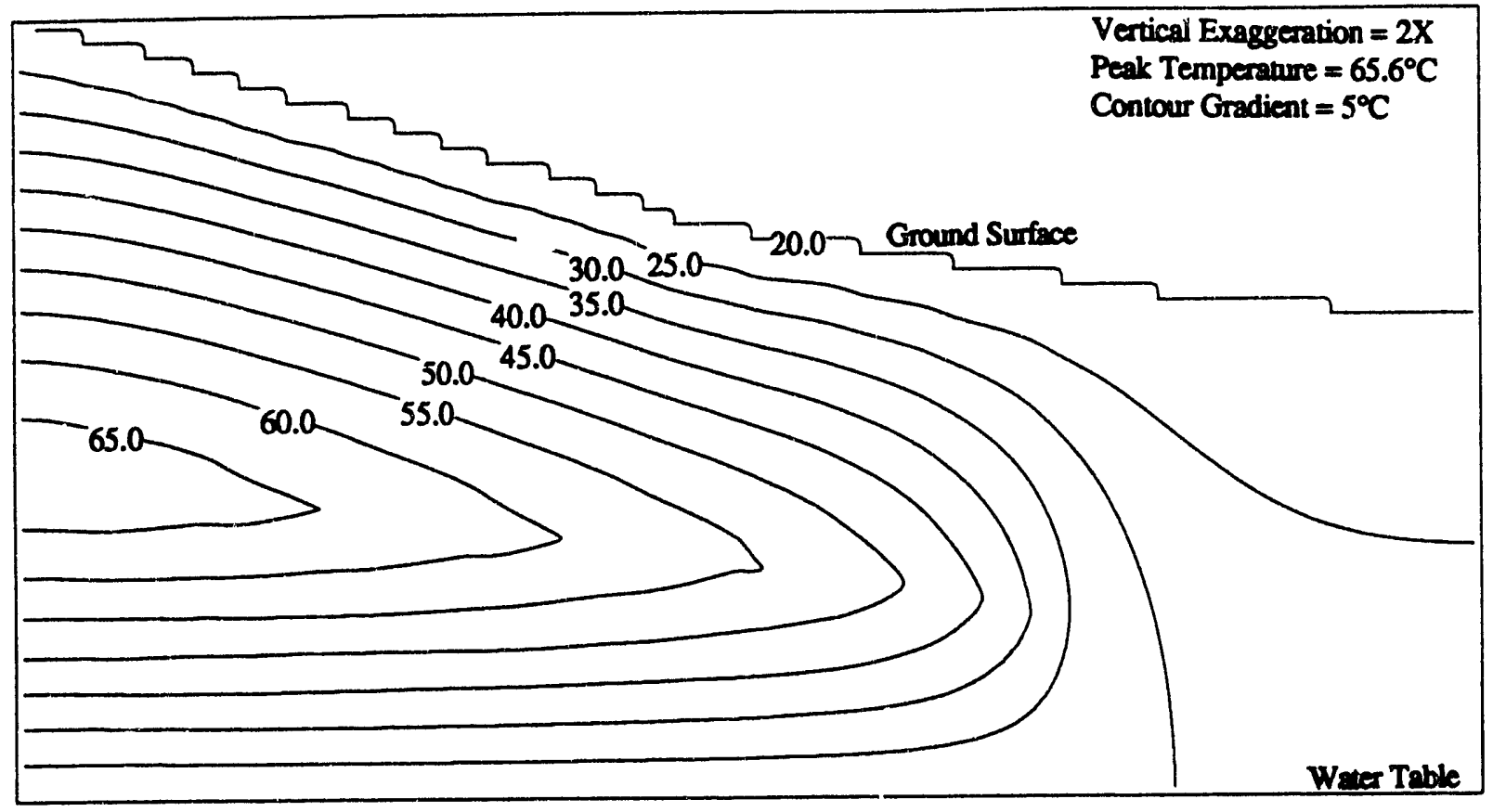

Figure 4.35. Temperature Contours $\left({ }^{\circ} \mathrm{C}\right)$ at $2000 \mathrm{yr}$ for Zero Recharge

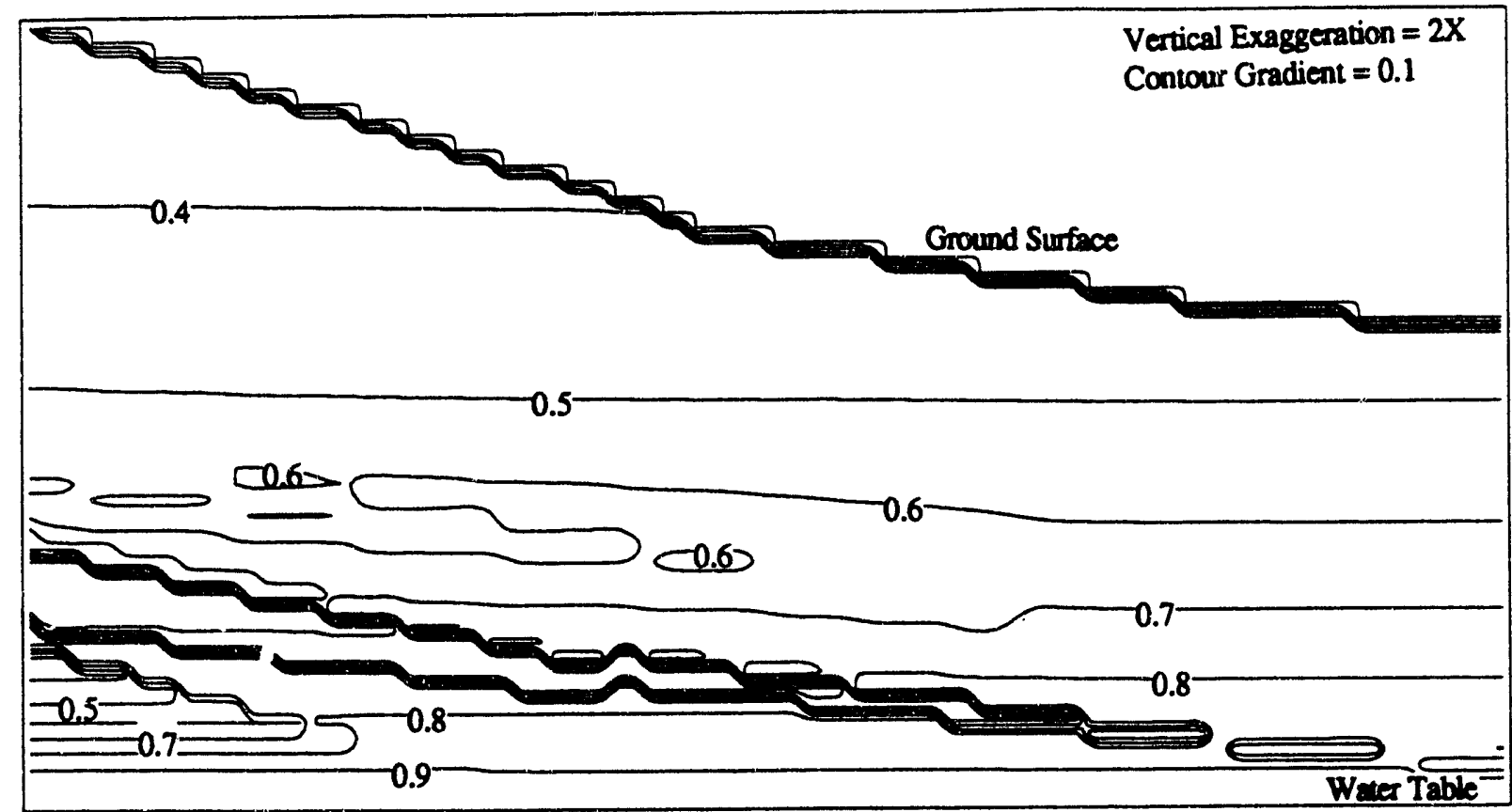

Figure 4.36. Liquid-Saturation Contours (at 2000 yr for Zero Recharge 


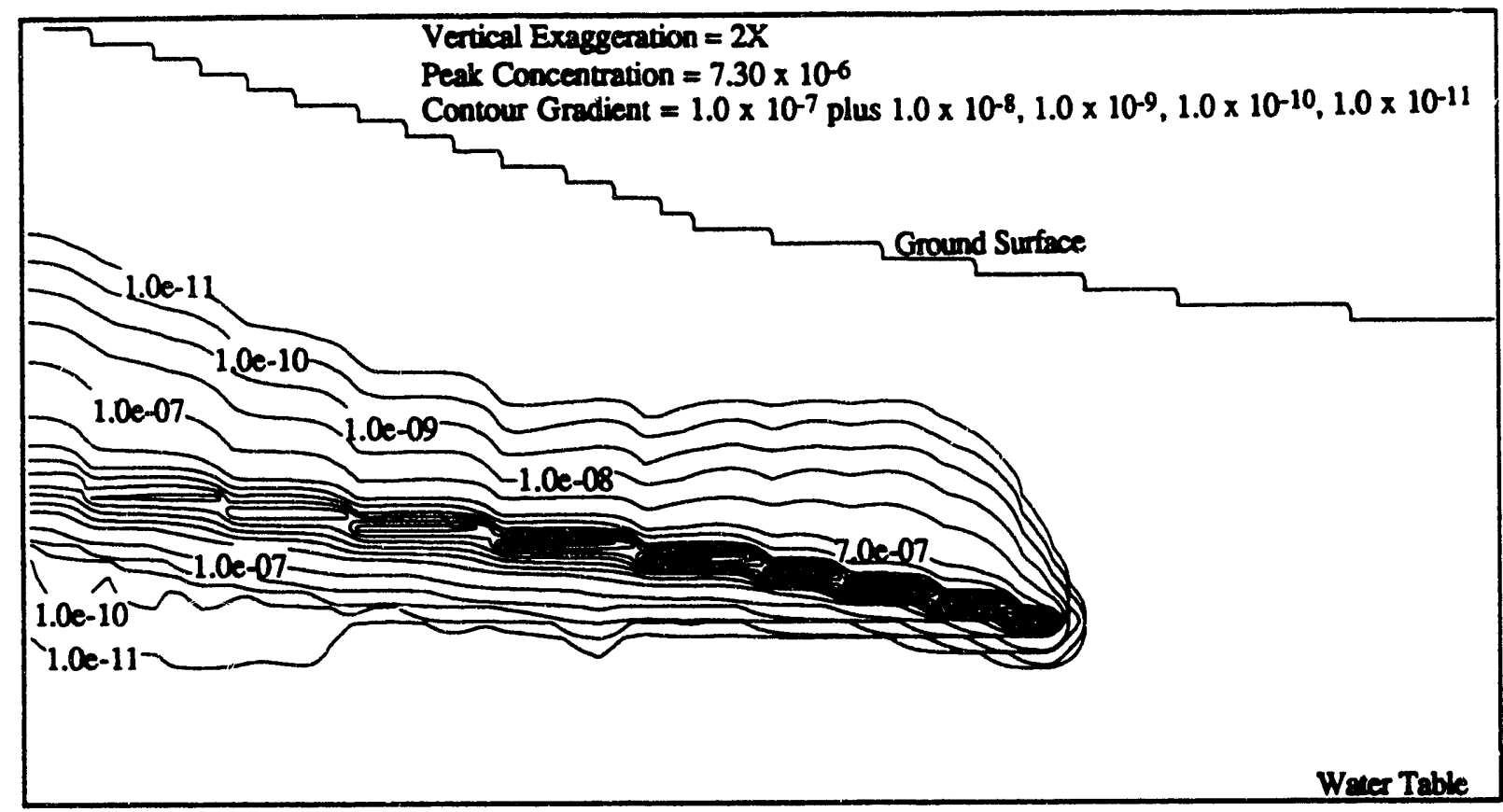

Figure 4.37. ${ }^{14} \mathrm{C}$-Concentration Contours $\left(\mathrm{Ci} / \mathrm{m}^{3}\right)$ at $2000 \mathrm{yr}$ for Zero Recharge Using the Millington and Quirk Tortuosity Model

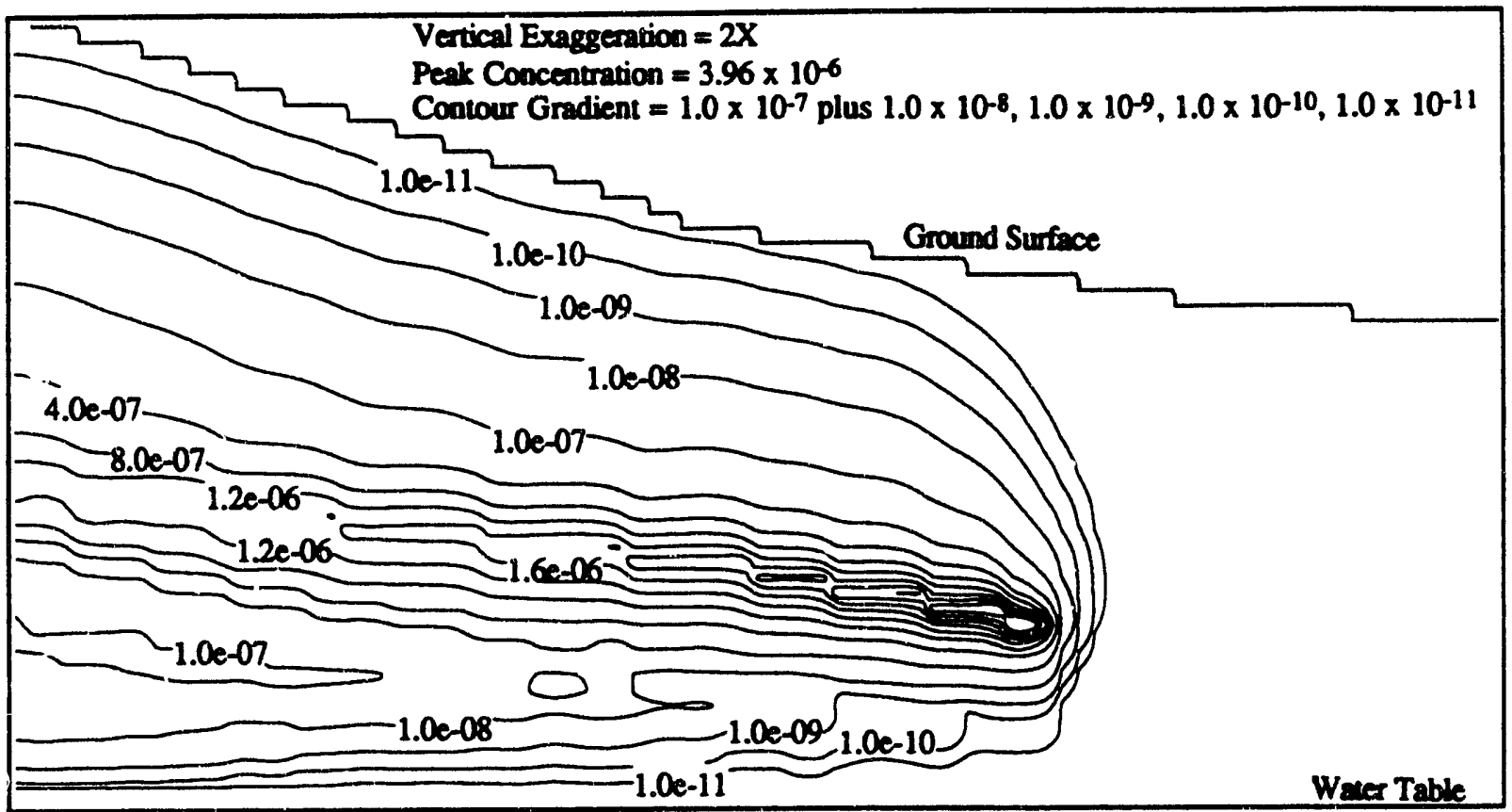

Figure 4.38. ${ }^{14} \mathrm{C}$-Concentration Contours $\left(\mathrm{Ci} / \mathrm{m}^{3}\right)$ at $2000 \mathrm{yr}$ for Zero Recharge Using the Penman Tortuosity Model 


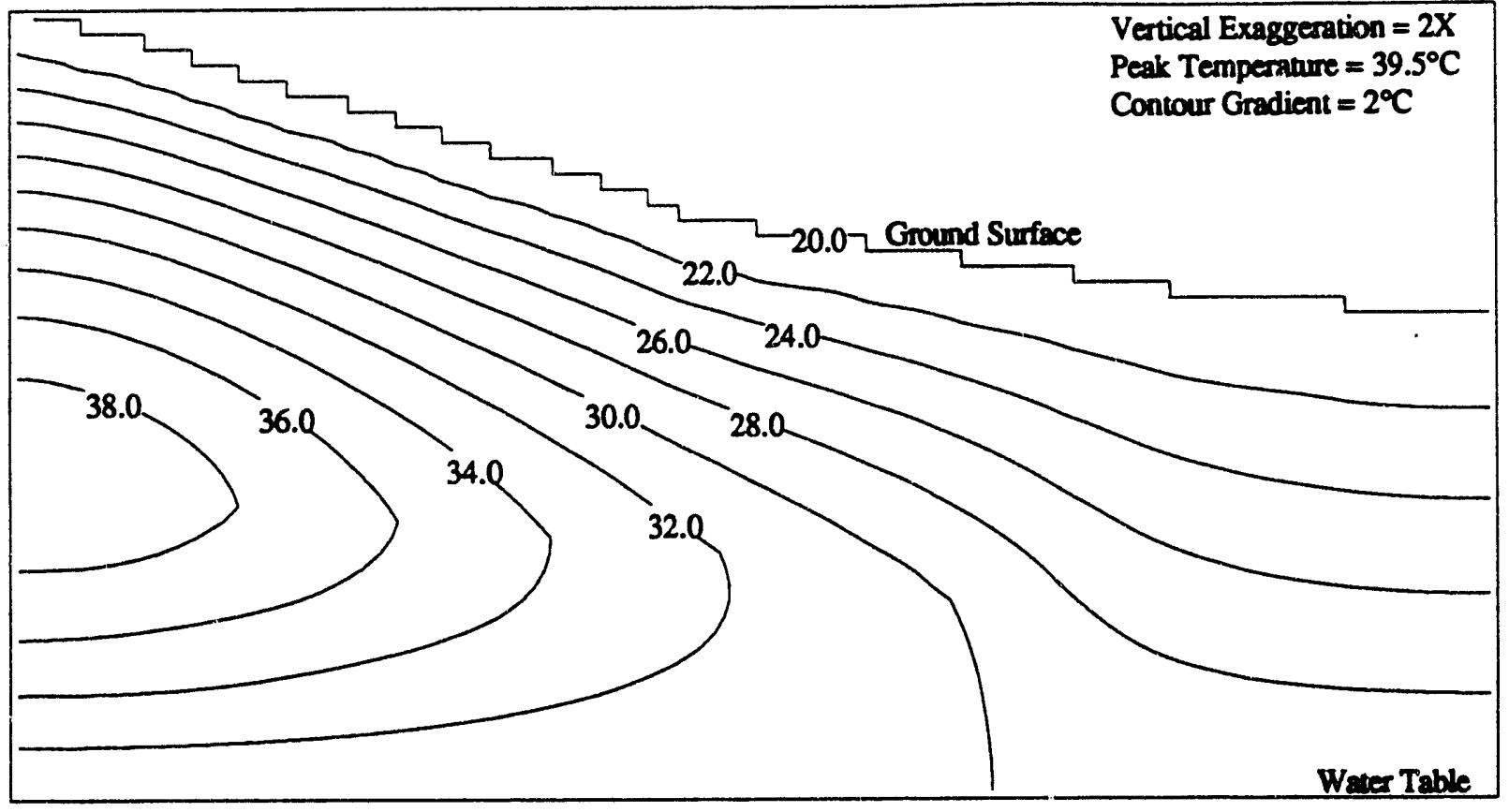

Figure 4.39. Temperature Contours $\left({ }^{\circ} \mathrm{C}\right)$ yr for Zero Recharge

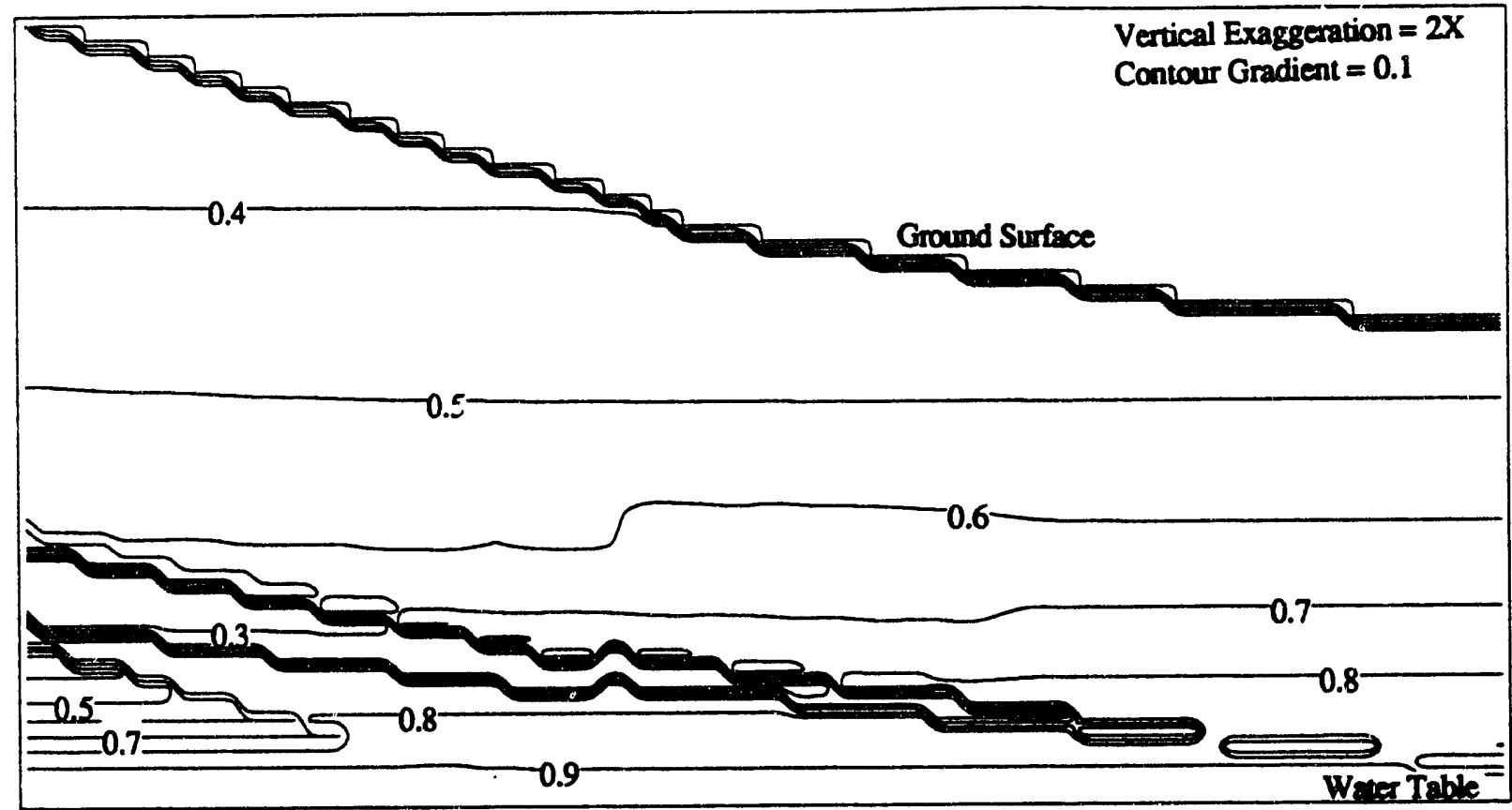

Figure 4.40. Liquid-Saturation Contours at 4000 yr for Zero Recharge 


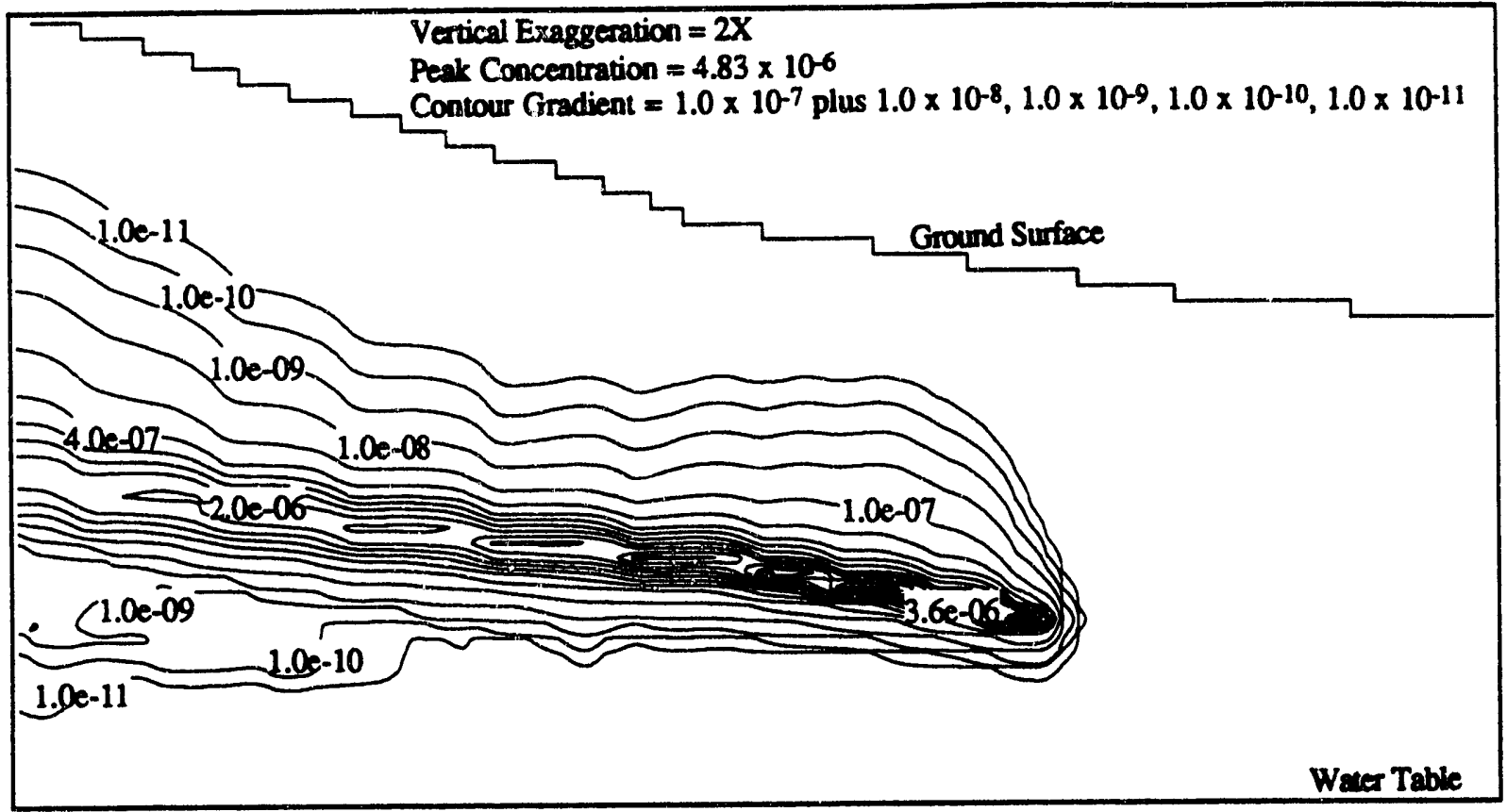

Figure 4.41. ${ }^{14} \mathrm{C}$-Concentration Contours $\left(\mathrm{Ci} / \mathrm{m}^{3}\right)$ at $4000 \mathrm{yr}$ for Zero Recharge Using the Millington and Quirk Tortuosity Model

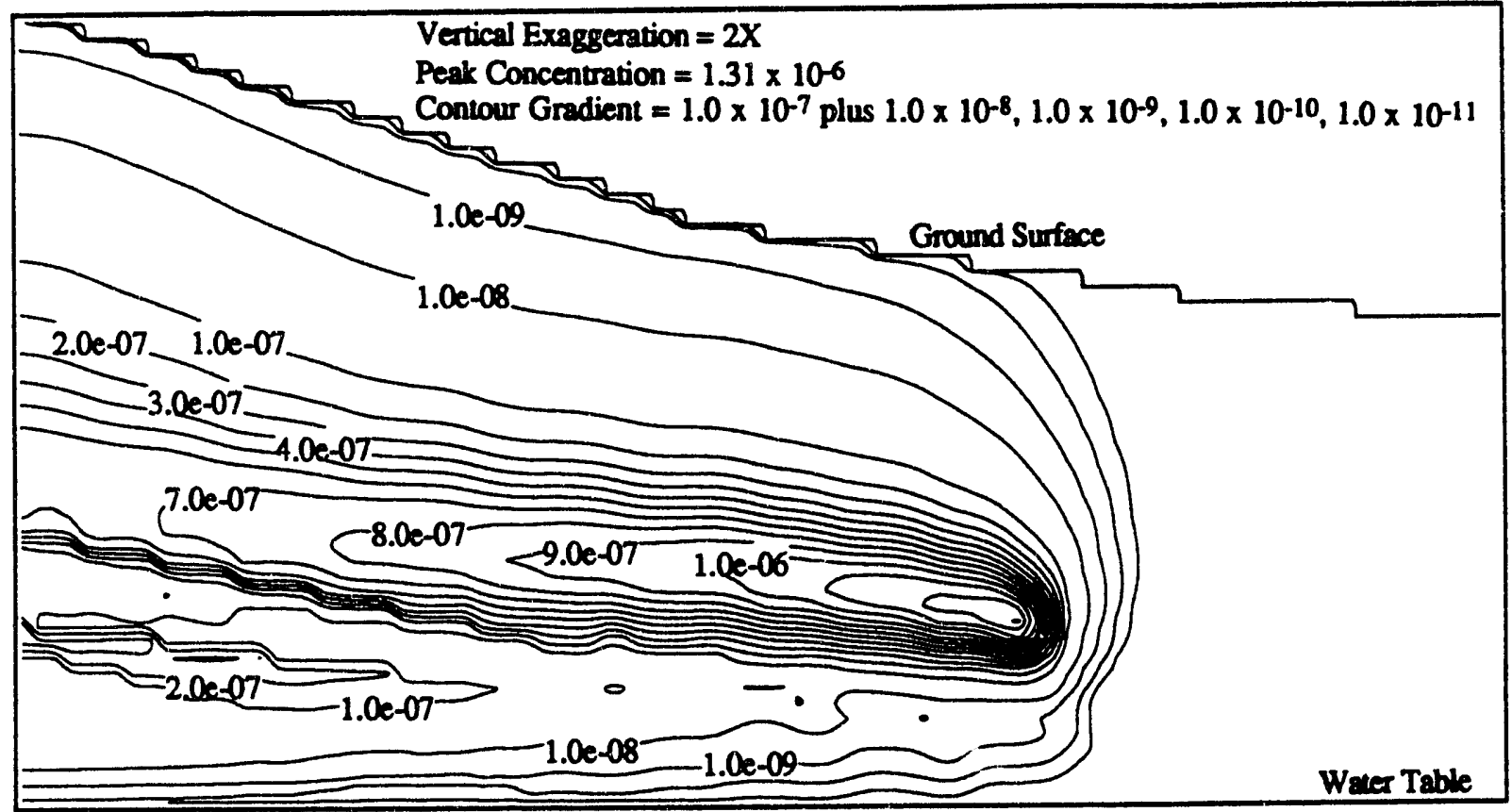

Figure 4.42. $14 \mathrm{C}$-Concentration Contours $\left(\mathrm{Ci} / \mathrm{m}^{3}\right)$ at $4000 \mathrm{yr}$ for Zero Recharge Using the Penman Tortuosity Model 


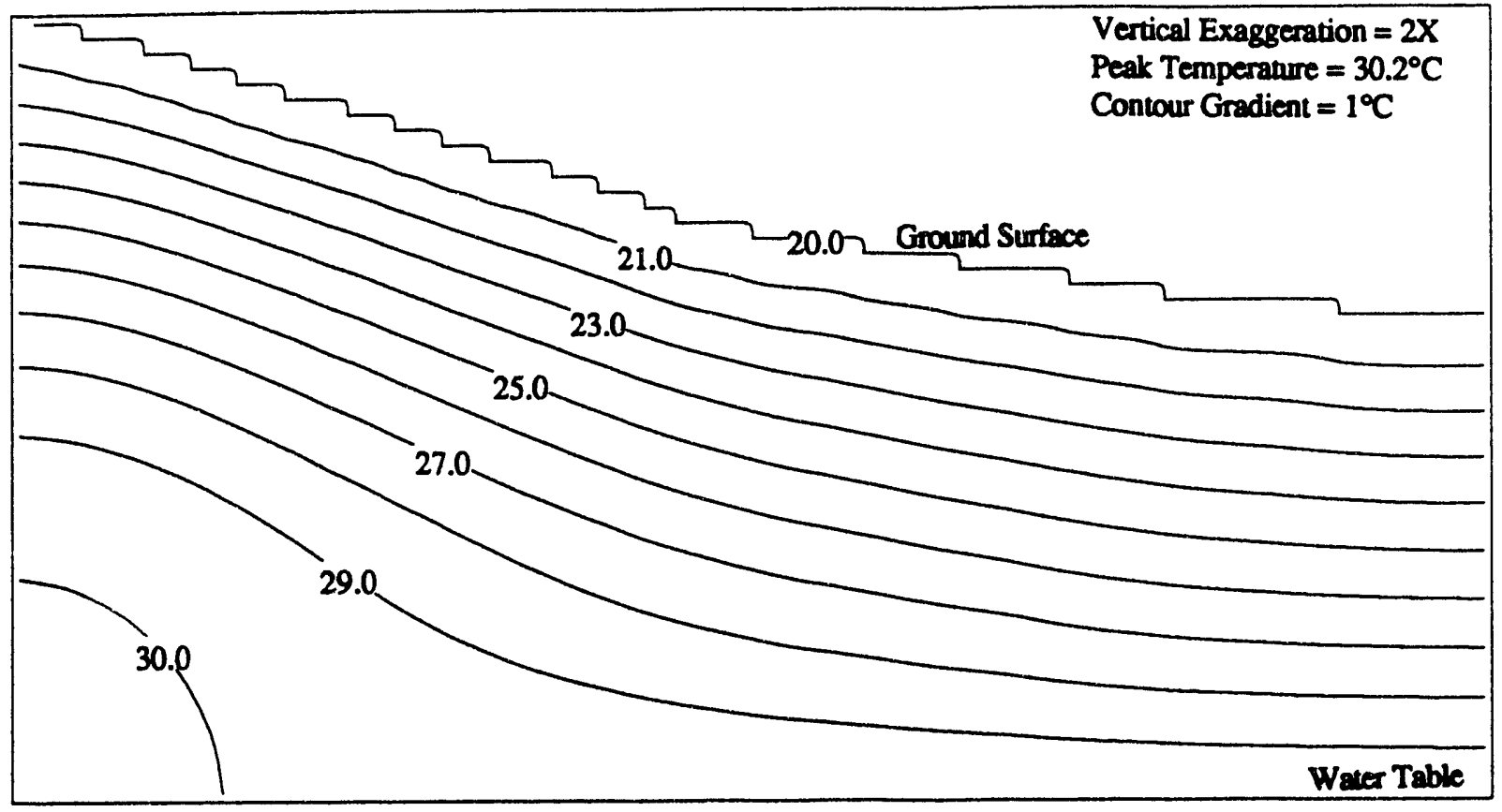

Figure 4.43. Temperature Contours $\left({ }^{\circ} \mathrm{C}\right)$ at 6000 yr for Zero Recharge

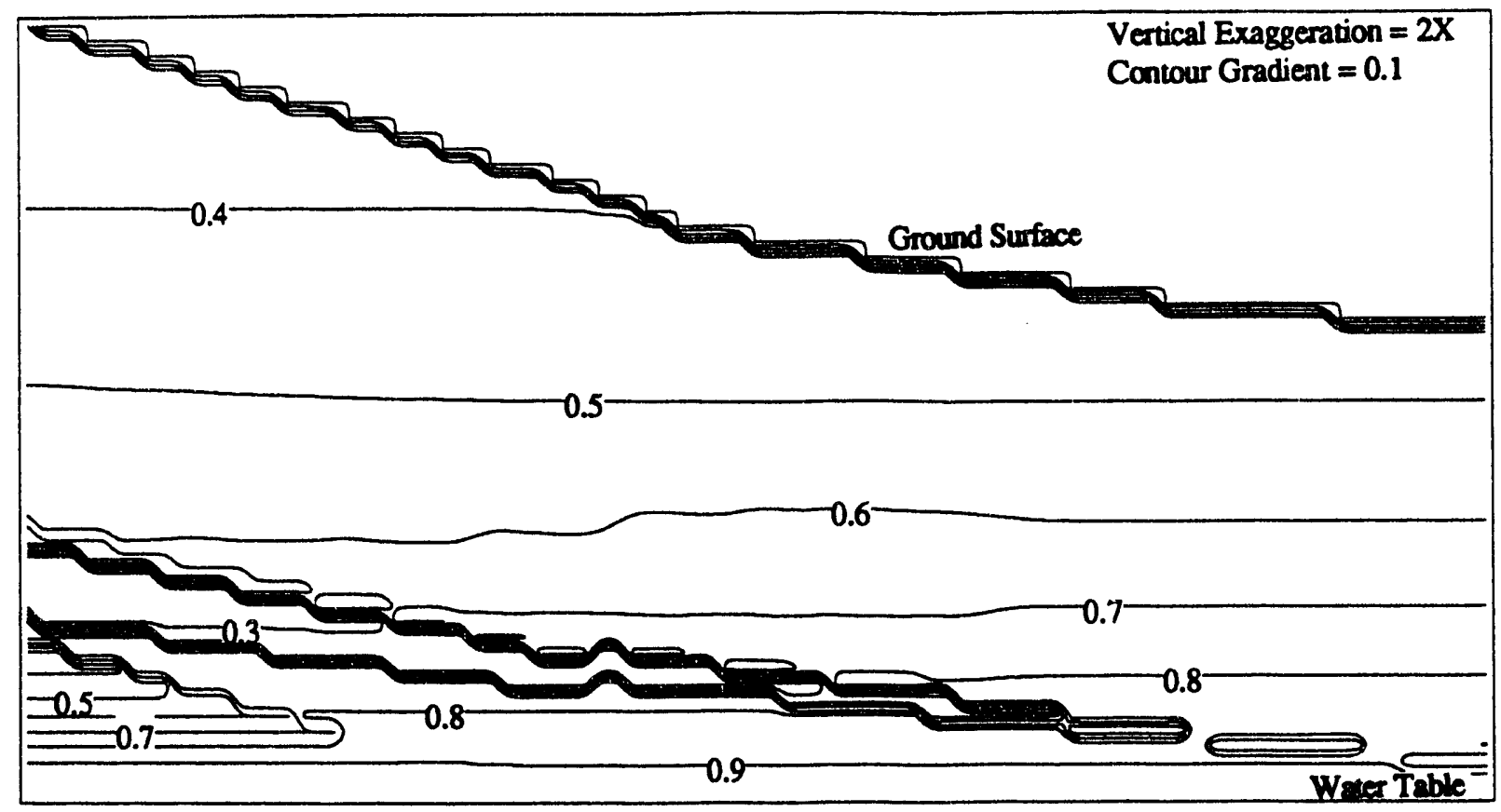

Figure 4.44. Liquid-Saturation Contours at $6000 \mathrm{yr}$ for Zero Recharge 


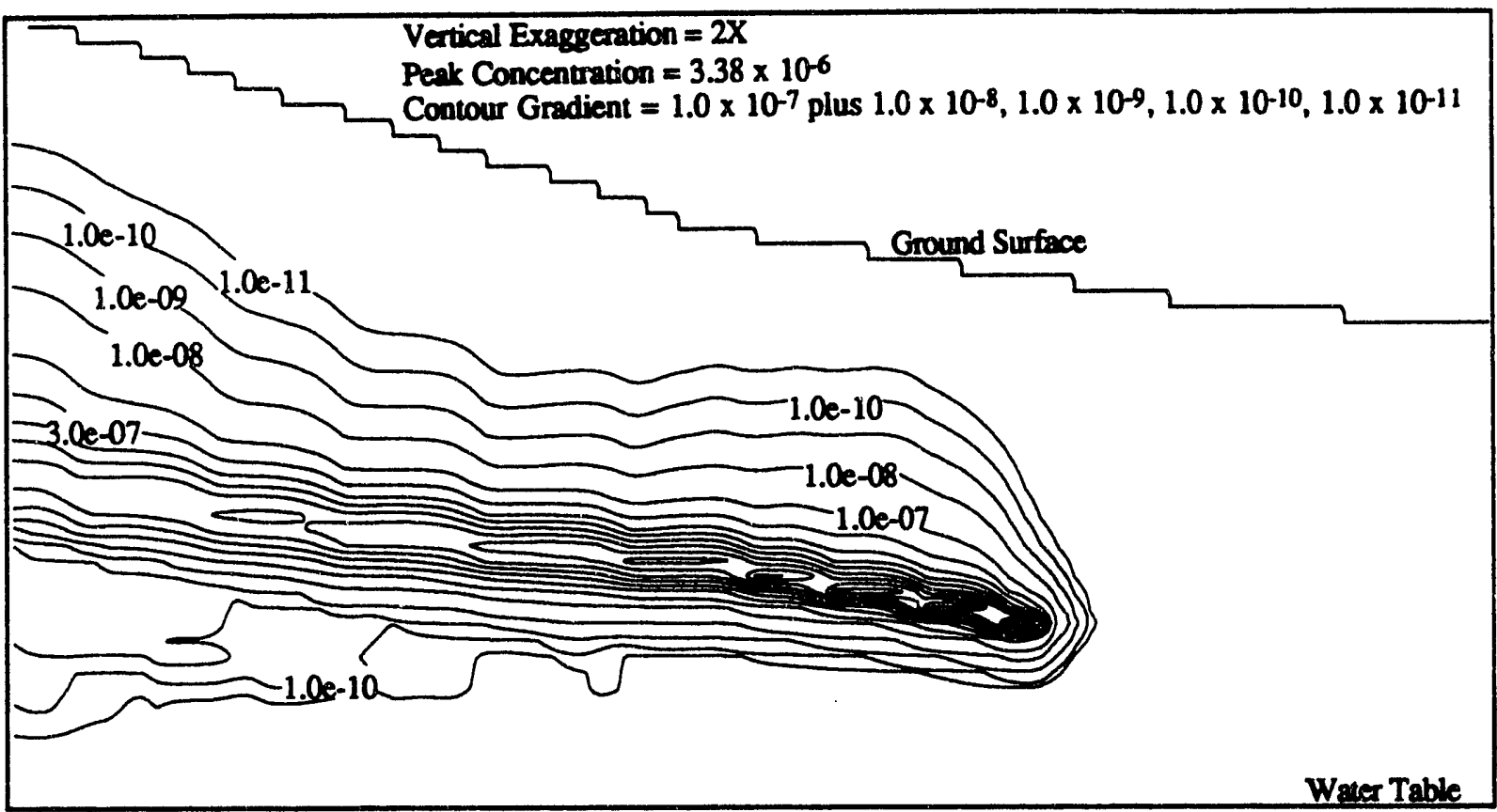

Figure 4.45. ${ }^{14} \mathrm{C}$-Concentration Contours $\left(\mathrm{Ci} / \mathrm{m}^{3}\right)$ at $6000 \mathrm{yr}$ for Zero Recharge Using the Millington and Quirk Tortuosity Model

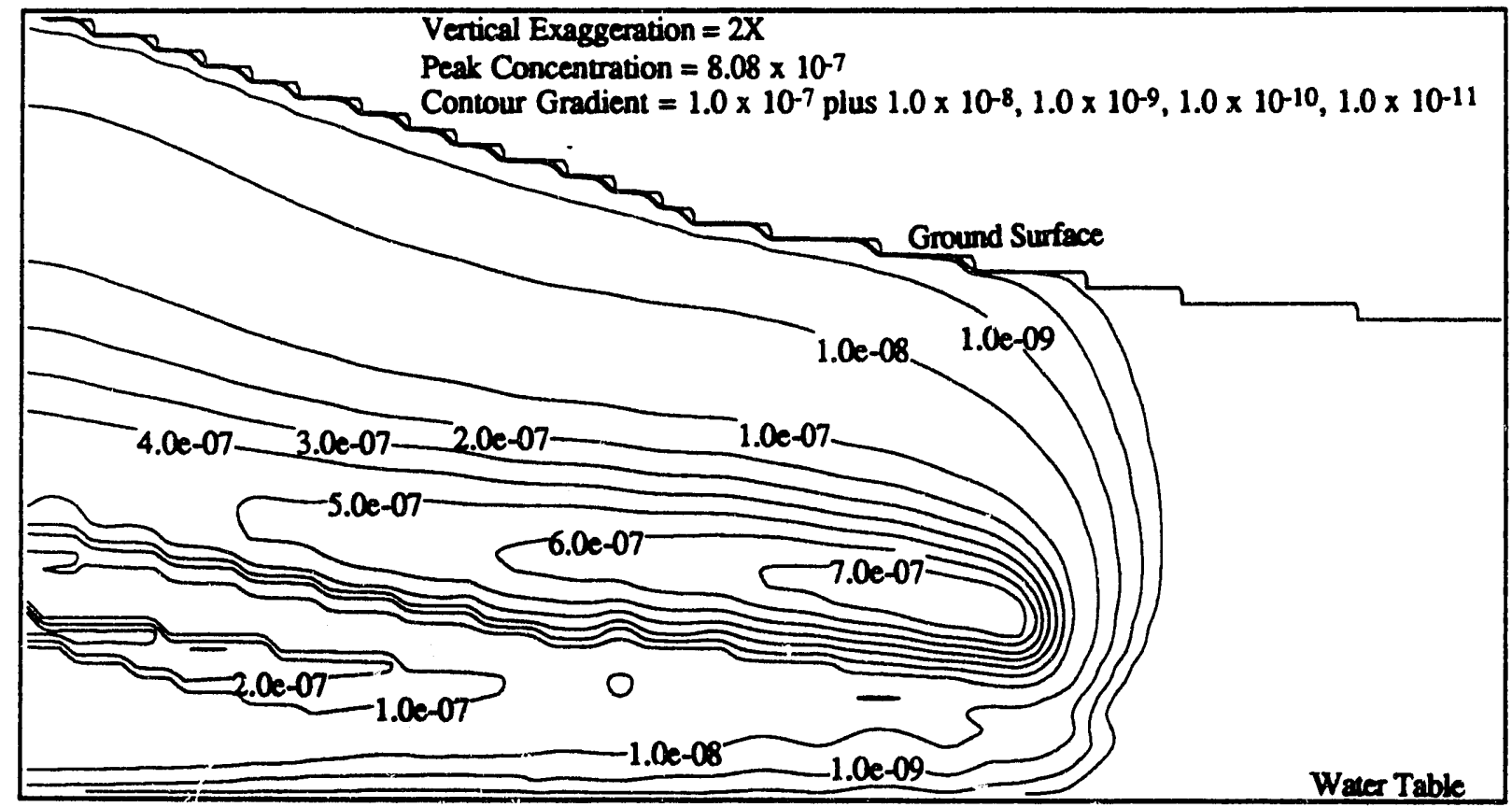

Figure 4.46. $14 \mathrm{C}$-Concentration Contours $\left(\mathrm{Ci} / \mathrm{m}^{3}\right)$ at $6000 \mathrm{yr}$ for Zero Recharge Using the Penman Tortuosity Model 


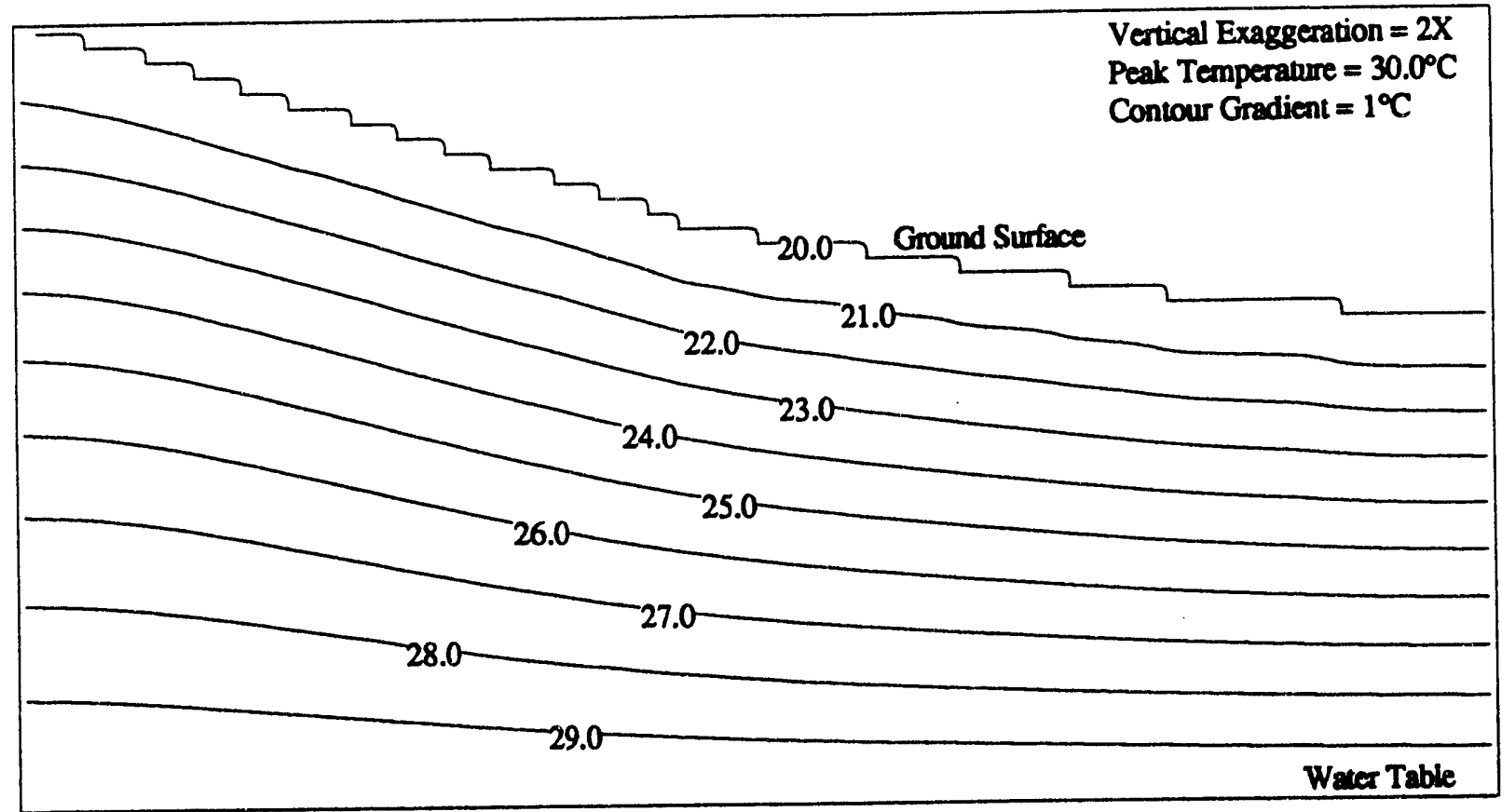

Figure 4.47. Temperature Contours $\left({ }^{\circ} \mathrm{C}\right)$ at $8000 \mathrm{yr}$ for Zero Recharge

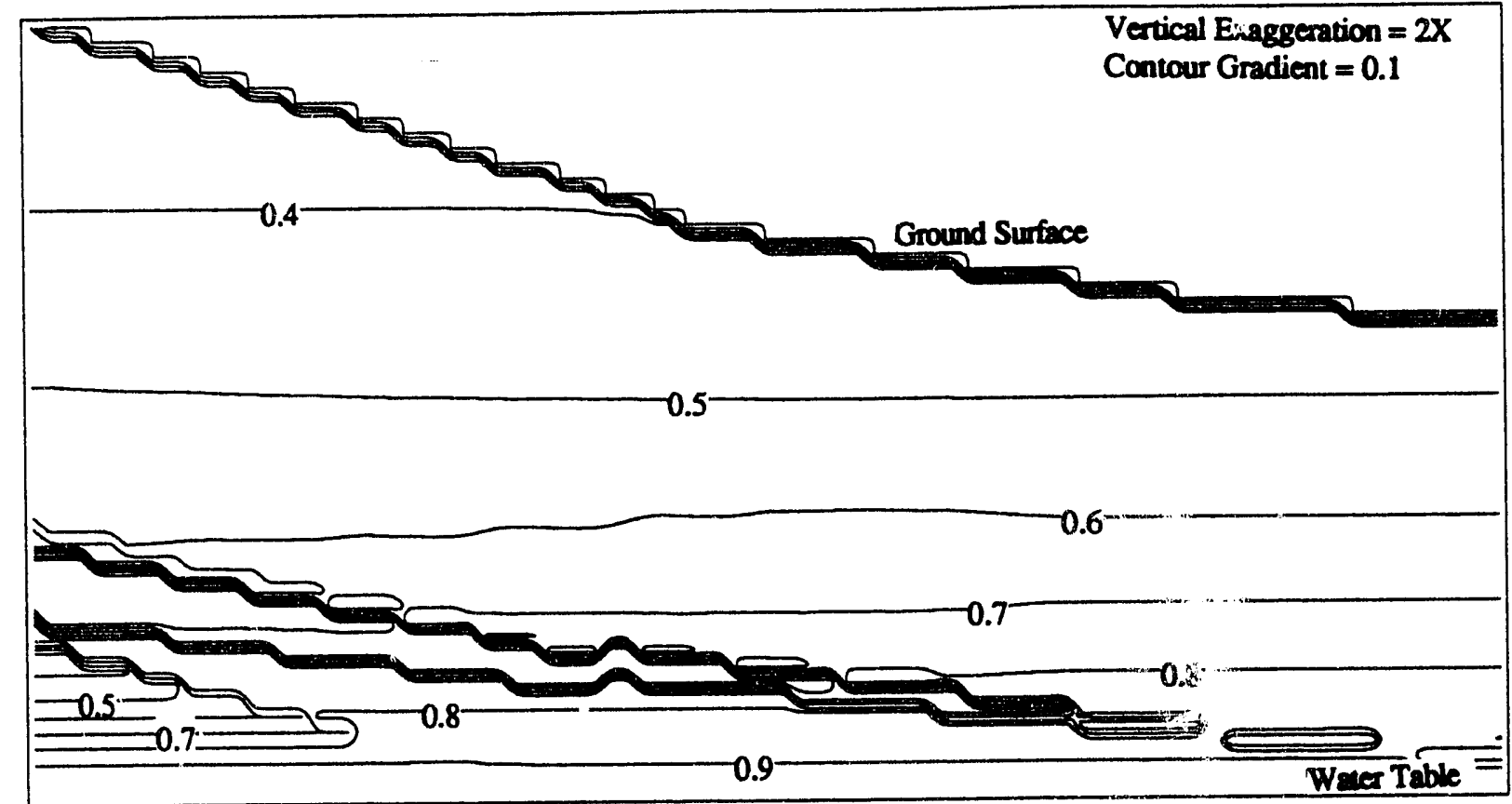

Figure 4.48. Liquid-Saturation Contours at 8700 ye fin Zero Recharge 


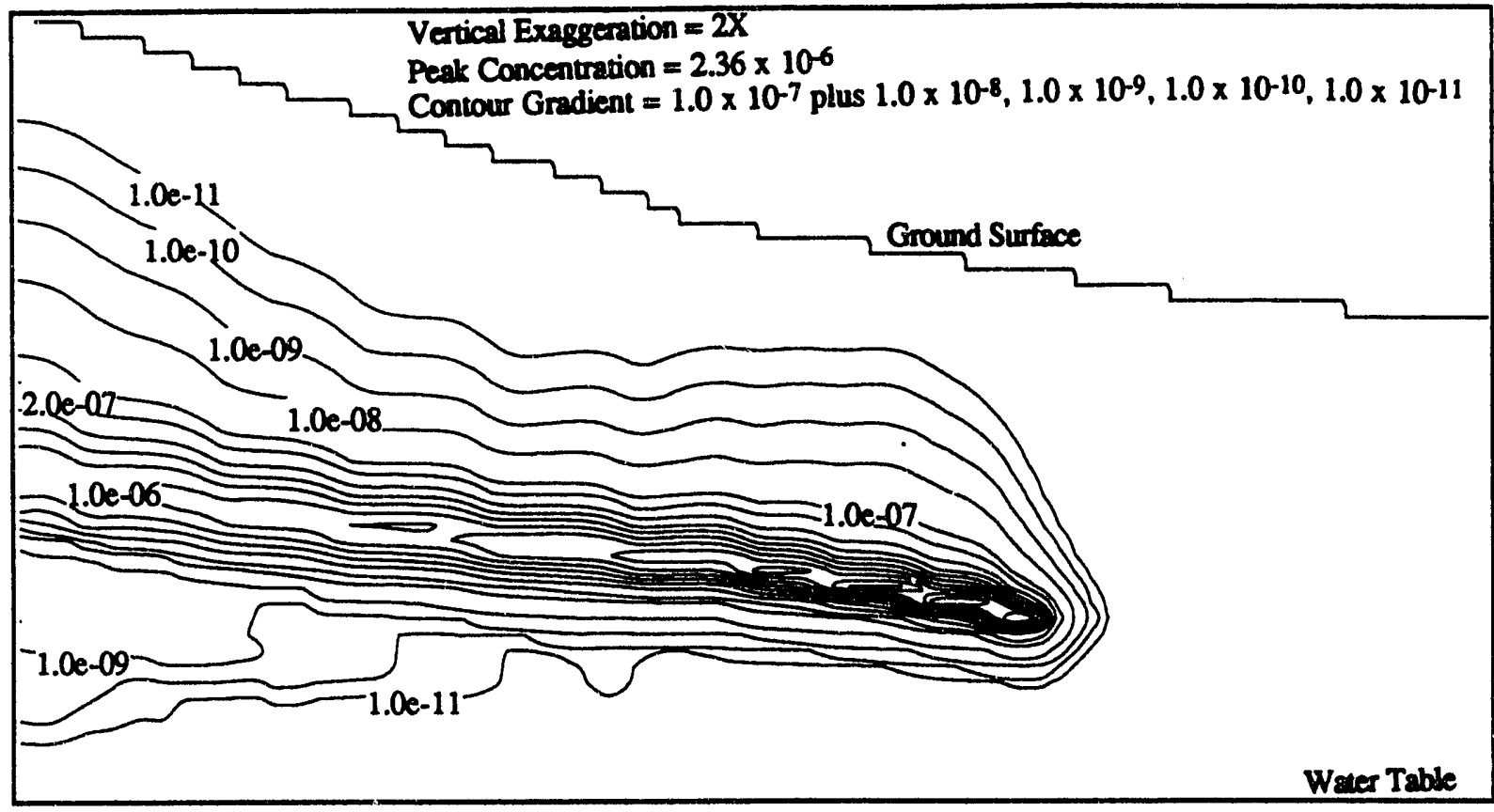

Figure 4.49. ${ }^{14} \mathrm{C}$-Concentration Contours $\left(\mathrm{Ci} / \mathrm{m}^{3}\right)$ at $8000 \mathrm{yr}$ for Zero Recharge Using the Millington and Quirk Tortuosity Model

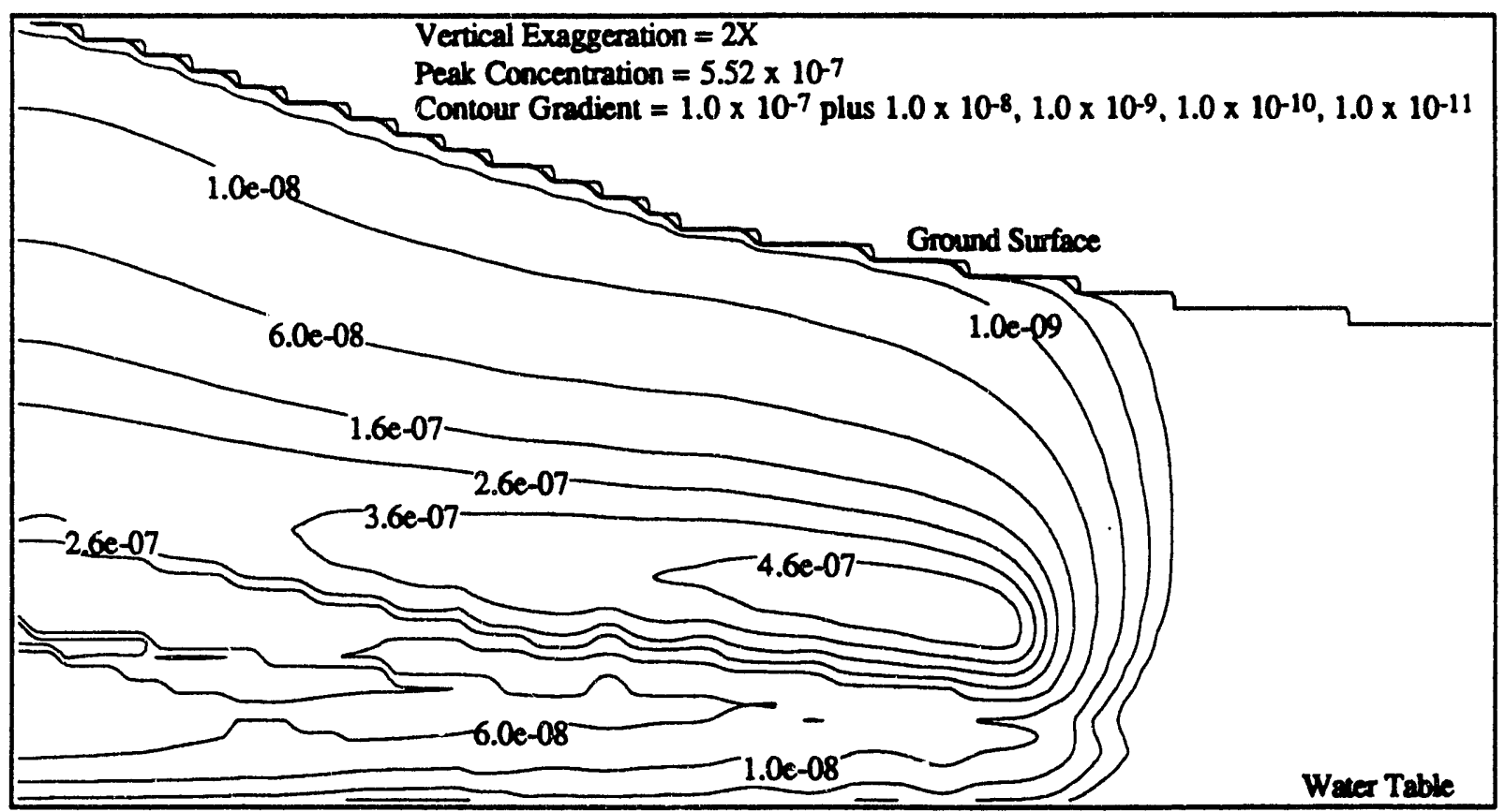

Figure 4.50. ${ }^{14} \mathrm{C}$-Concentration Contours $\left(\mathrm{Ci} / \mathrm{m}^{3}\right)$ at $8000 \mathrm{yr}$ for Zero Recharge Using the Penman Tortuosity Model 


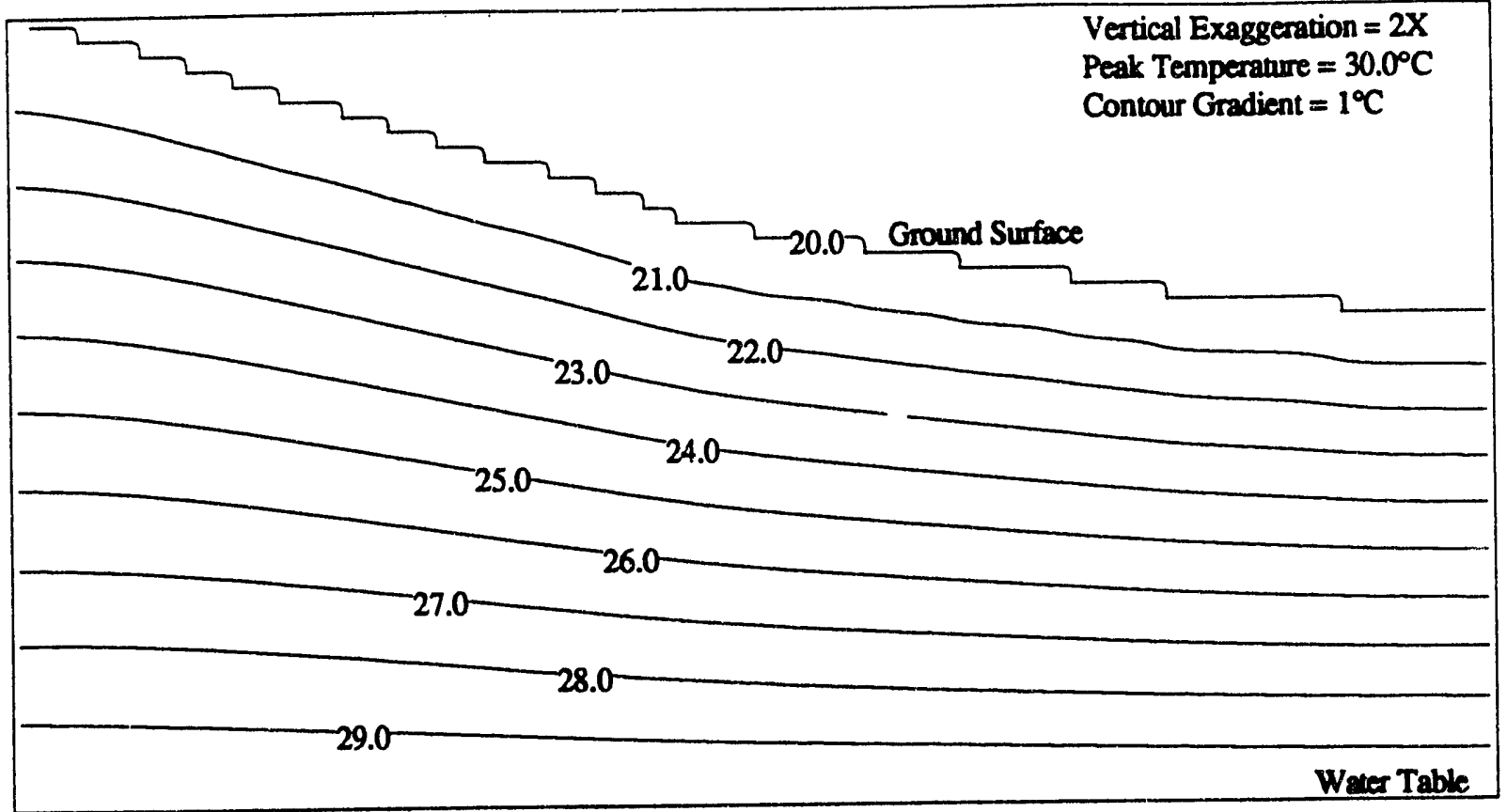

Figure 4.51. Temperature Contours $\left({ }^{\circ} \mathrm{C}\right)$ at $10,000 \mathrm{yr}$ for Zero Recharge

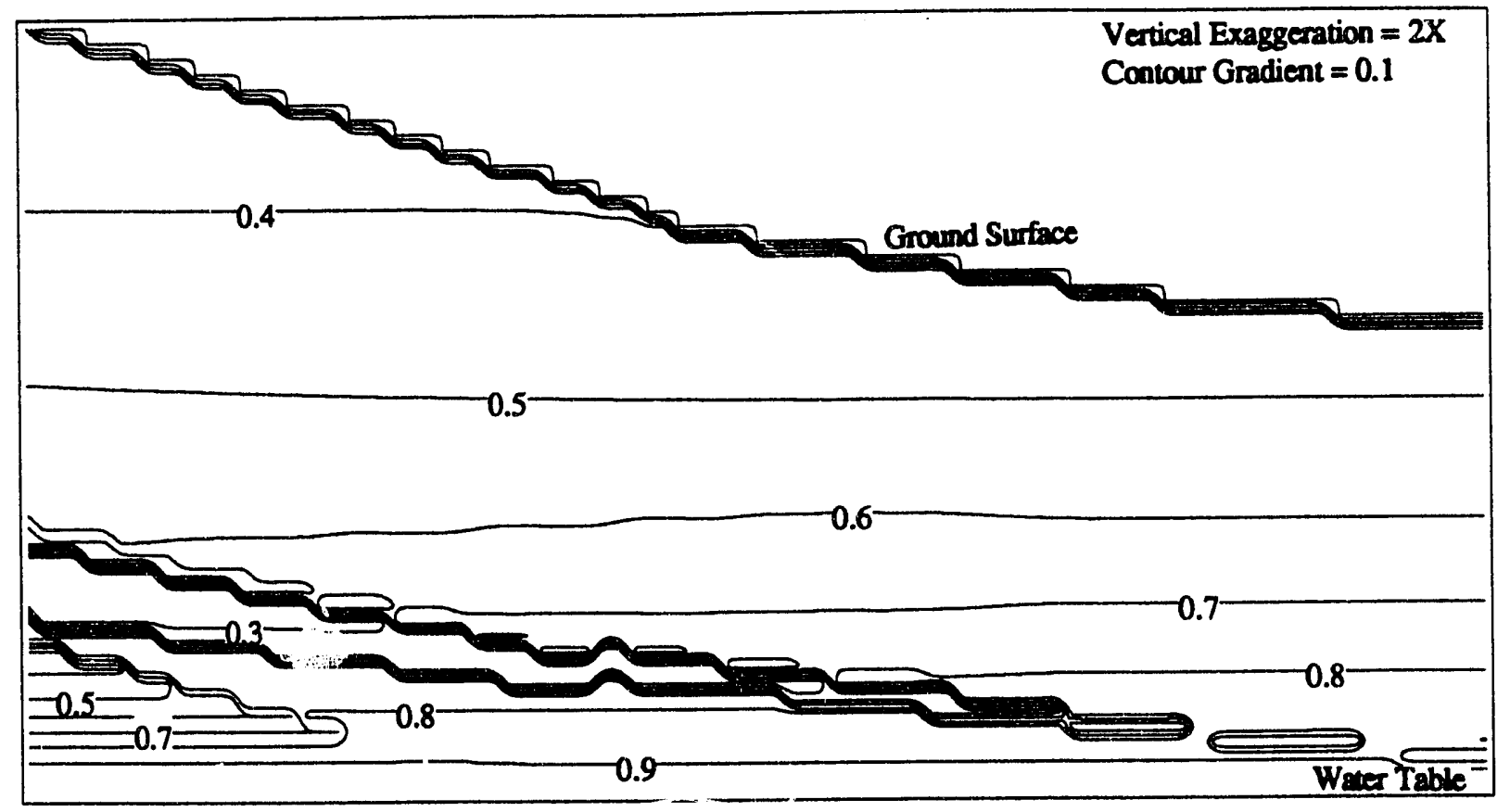

Figure 4.52. Liquid-Saturation Contours at $10,000 \mathrm{yr}$ for Zero Recharge 


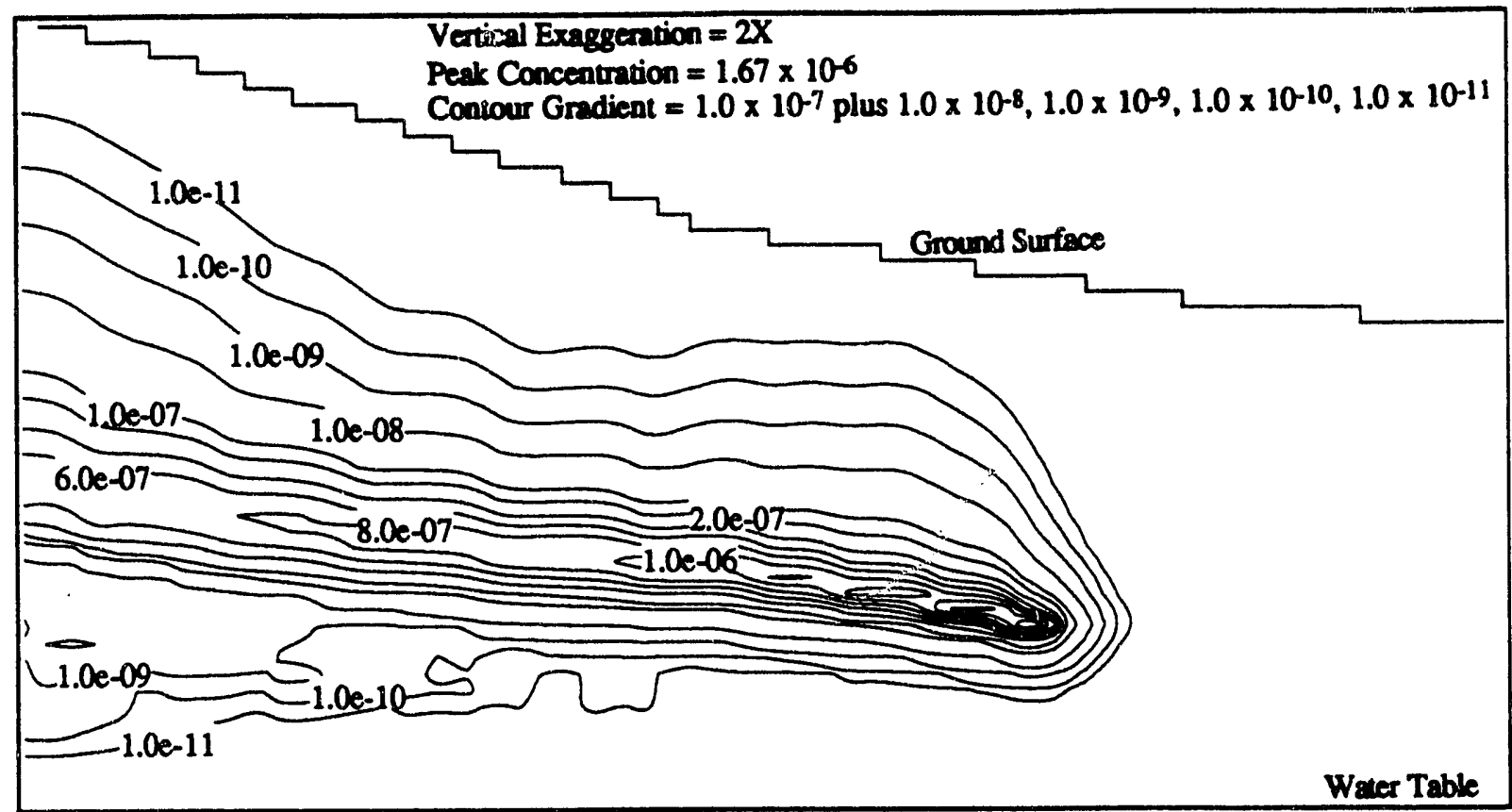

Figure 4.53. ${ }^{14} \mathrm{C}$-Concentration Contours $\left(\mathrm{Ci} / \mathrm{m}^{3}\right)$ at $10,000 \mathrm{yr}$ for Zero Recharge Using the Millington and Quirk Tortuosity Model

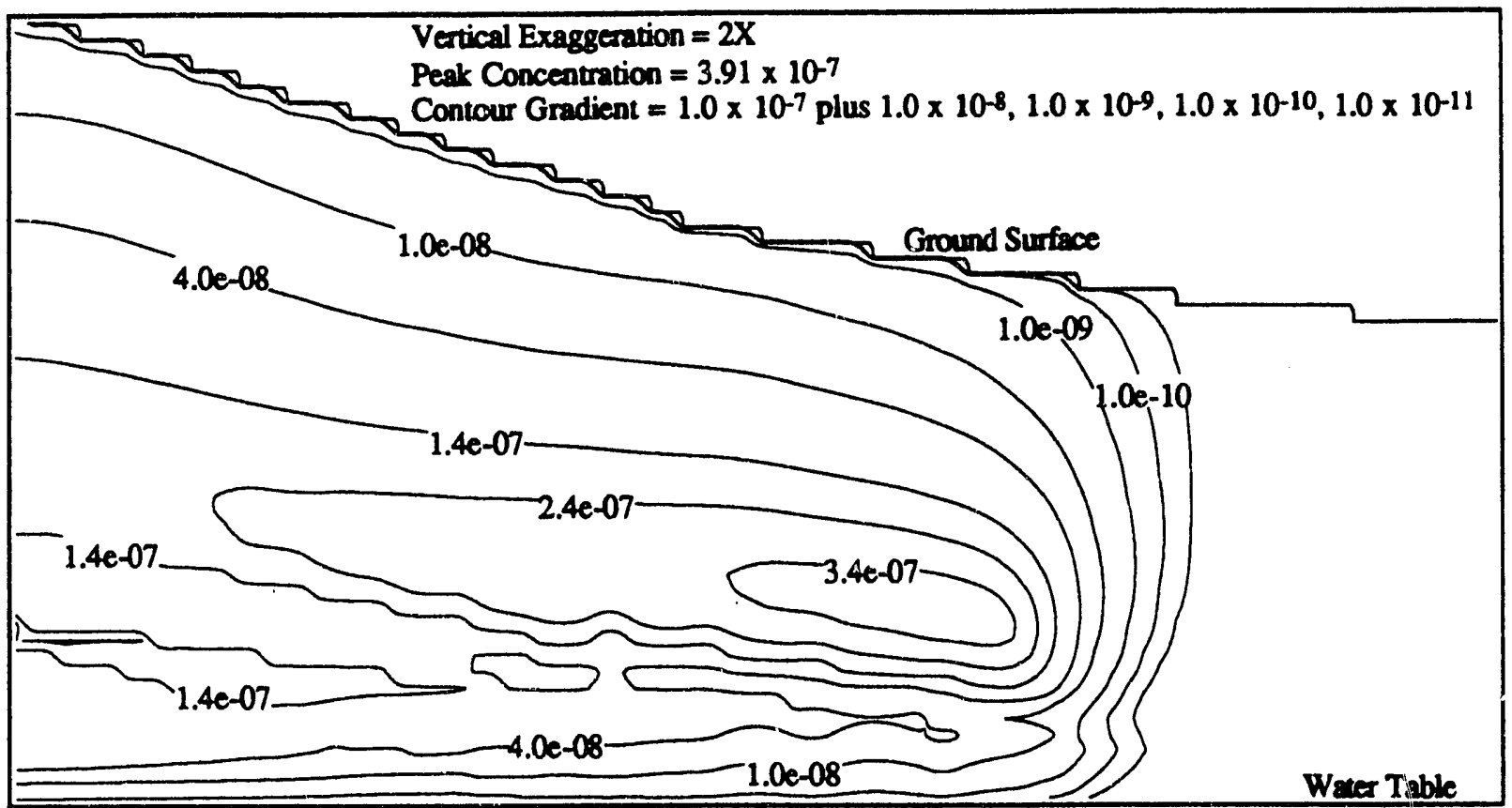

Figure 4.54. ${ }^{14} \mathrm{C}$-Concentration Contours $\left(\mathrm{Ci} / \mathrm{m}^{3}\right)$ at $10,000 \mathrm{yr}$ for Zero Recharge Using the Penman Tortuosity Model 


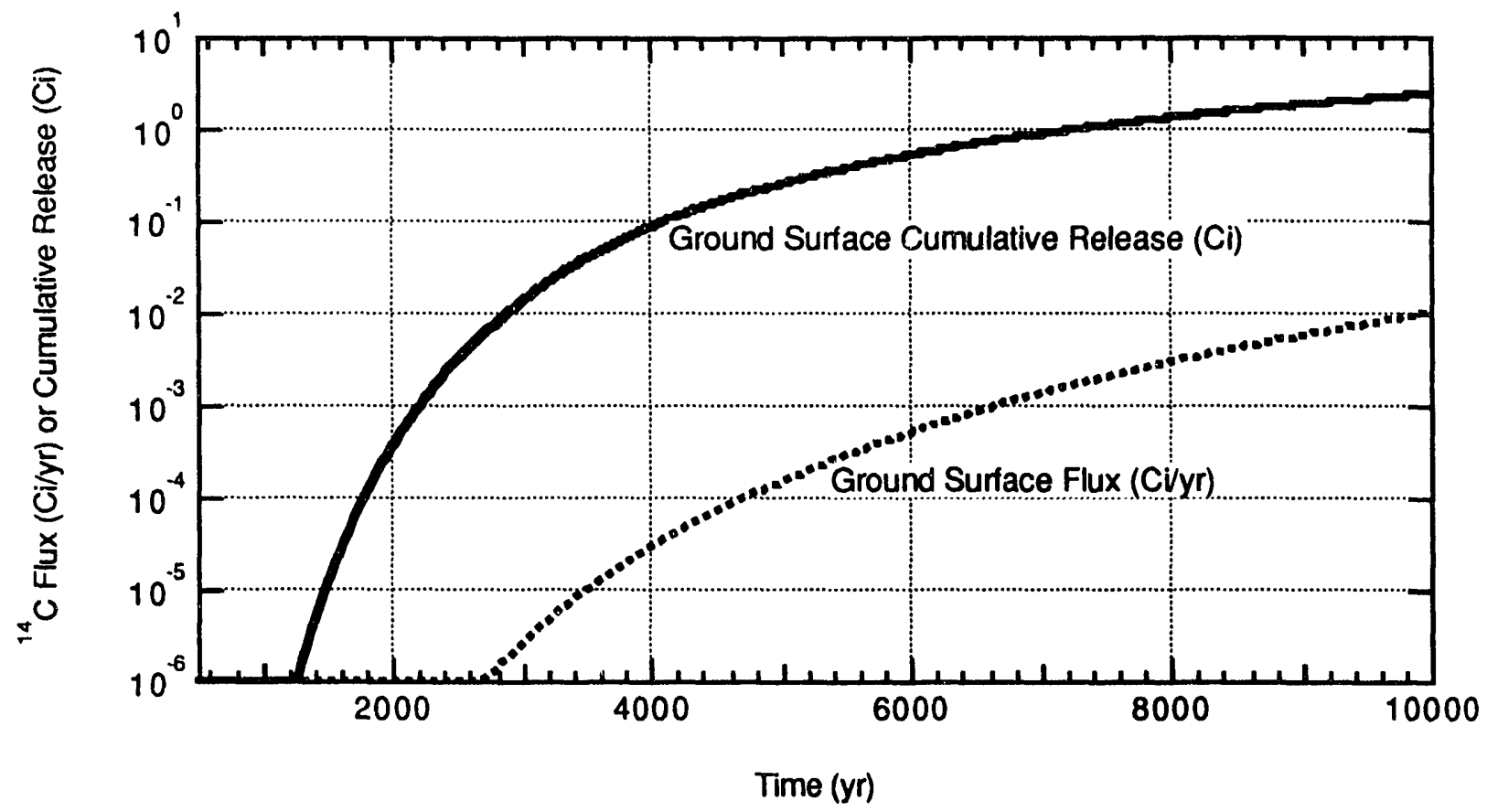

Figure 4.55. ${ }^{14} \mathrm{C}$ Ground-Surface Releases Using the Penman Tortuosity Model

transport mechanism for ${ }^{14} \mathrm{C}$ from gas diffusion to liquid advection, thus producing increased transport rates to the ground water and decreased transport rates to the ground surface. Releases to the ground water could become significant if fracture pathways contribute to the aqueous-phase migration.

\subsubsection{Assumptions}

Predictions made with numerical models about physical phenomena generally require assumptions concerning the physical processes being modeled. The complex numerical models used to predict the transport of ${ }^{14} \mathrm{C}$ within the vadose zone at Yucca Mountain require numerous assumptions to make the problem tractable. Three types of assumptions may be identified: those related to the physical data, those related to the conceptual models, and those related to tie numerical models. Physical-data assumptions are those assumptions associated with hydrogeologic, thermal, or other physical data that are supplied as inputs to the numerical model. Conceptual-model assumptions are assumptions that pertain to the application of the numerical model to a particular problem. Numerical-model assumptions deal specifically with numerical models, including the governing and constitutive equations, and numerical approaches. Because most of the required physical data were supplied with the total-system performance assessment exercise, orly the more important conceptual-model and numerical-model assumptions will be discussed in this section.

Yucca Mountain's topography, hydrogeologic stratigraphy, and proposed repository composes a complex three-dimensional system. The surface of Yucca Mountain has differing east and west slopes, with numerous washes. The mountain is composed of highly fractured tuff layers with contrasting and heterogeneous properties, which are transected with various faults that 
include local faults related to the formation of calderas and longer faults of the basin-and-range type. The repository conceptual design involves a network of ärifts, emplacement panels, and boreholes large enough to accommodate the equivalent of 70,000 MTHM. The two-dimensional system modeled here ignores all three-dimensional aspects of the physical system, and the coarse mesh, designed for investigating far-field transport, is incapable of capturing repository-scale phenomena. For example, reported peak repository temperatures of $108^{\circ} \mathrm{C}$ are considerably lower than those reported from container-scale thermal and hydrogeologic models. These lower temperatures are primarily due to the application of repository decay heat powers over larger volumes than those for individual waste containers. Another critical modeling assumption was to neglect the Ghost Dance fault.

The boundary conditions chosen actually represent a reflected mountain existing on both sides of the zero-flux vertical boundaries. Because of the asymmetries in the ridge shape, the tilt of the tuff layers, and the slope in the repository horizon, the vertical symmetry boundary condition at borehole USW H-5 is not completely appropriate. From the simulation results it appears that the eastern vertical boundary is enough removed from the domain of interest to be a satisfactory boundary condition. The effects of the vertical boundary at the mountain crest on ${ }^{14} \mathrm{C}$ transport have not been addressed. The boundary conditions on the horizontal surfaces represent constant ambient conditions over a 10,000-year period. It seems unlikely that the climatic and water-table conditions will remain constant over the next 10,000 years. Sensitivity studies on climatic parameters would be required to estimate their affects on ${ }^{14} \mathrm{C}$ transport.

The preliminary design for the potential repository involves nonuniform power distributions throughout the repository. Nonuniform power densities will produce irregular saturation fields and heat-pipe type flow fields during the thermal transient portion of the repository lifespan. For the reported simulations the repository was assumed to have uniform power densities, thus generating relatively smooth saturation fields during the periods of high thermal gradients. Whether ${ }^{14} \mathrm{C}$ transport would be retarded or accelerated by irregular saturation fields occurring during the thermal transient period is unknown.

The conceptual model used for the repository ignores any details with respect to the waste container design or emplacement. For example, the resistance for heat transfer between the waste container and the surrounding tuffaceous rock or backfill through air gaps or other mechanisms has been ignored. Applying the repository thermal loads to the relatively large node volumes effectively eliminates the thermal resistance between waste containers and the adjacent tuff. Zero thermal resistance between the waste containers reduces peak temperatures and increases heattransfer rates from the repository. The same resistance arguments may be applied to species transport. It is uncertain whether lower peak temperatures with higher species flux rates are more or less conservative with respect to predicting ${ }^{14} \mathrm{C}$ species transport within the vadose zone at Yucca Mountain.

The reported simulations of rock properties and gas-phase transport of ${ }^{14} \mathrm{C}$ are probably not conservative. The only transport pathways for the migration of $14 \mathrm{C}$ from the repository to the ground surface or water table were through tuff layers-where the properties of the matrix and fractures were lumped into equivalent-continuum bulk properties. Inhomogeneities, such as the Ghost Dance fault and highly rubblized shear zones found in G-tunnel complex at the Nevada Test Site, were not considered as transport pathways. Because of the relatively high gas permeabilities of faults and shear zones under unsaturated conditions, these pathways could significantly contribute to, or even dominate, ${ }^{14} \mathrm{C}$ release rates to both the surface and ground water. 
The primary assumption associated with the equivalent-continuum model for fracture and matrix flow through partially saturated porous media is that pressure equilibrium occurs between the fracture and matrix over times sufficiently shorter than the time constants for the flow phenomena of interest. Recent research by Nitao (1989) and Nitao and Buscheck (1989) have shown that this assumption may be inconsistent with the fracture-flow phenomena within Yucca Mountain. One other assumption associated with the equivalent-continuum model that may prove inconsistent with experimental data is that the fractures are sufficiently random in orientation to be considered isotropic.

Because of the saturation-dependent tortuosities used for the reported simulations, gas-phase diffusion of ${ }^{14} \mathrm{C}$ was strongly dependent on the saturation fields. Simulations of repository perform-ance at higher recharge rates predicted lower gas-phase transport of ${ }^{14} \mathrm{C}$, because of the inhibition of gas-phase advection and diffusion by the liquid-saturation barrier surrounding the repository. The accuracy of saturation-dependent tortuosities relative to gas-phase diffusion $0 .{ }^{4} \mathrm{C}$ in the vadose zone at Yucca Mountain is not completely known.

The spatial and temporal extent of the thermally driven liquid-saturation field surrounding the repository is critical to predicting container failures and radionuclide transport. Capillary hysteresis has been ignored, but may prove to be a critical phenomenon for predicting saturation fields immediate to the repository because of the drying and rewetting events produced by the thermal transient. Vapor pressure lowering, a model used for the reported results, effectively lowers peak temperatures and limits pore desaturation. Because the vapor pressure-lowering model was based on experiments conducted at room temperature, it may significantly overpredict the amount of absorbed water. To model this phenomenon accurately would require data about temperaturedependent water-retention characteristics. 


\subsection{Saturated Zone Hydrology and Transport}

To characterize the water movement in the saturated zone below the potential Yucca Mountain Repository, two sets of 12 simulations were done for each of two aquifer lithologies. The 12 simulations represent a statistical range that encompasses the conditions of the saturated zone as they are presently understood.

\subsection{Base Scenario}

The base scenario with regards to the saturated zone requires modeling flow in the saturated zone and the transport of radionuclides (if any) predicted by unsaturated flow models (Section 4.0) to reach the water table. This section reviews the regional hydrogeology with special attention to the aquifers that underlie the potential repository site, the regulations that govern flow modeling and, hence, this assessment, the numerical and conceptual models employed in this study to examine the saturated zone, and the data used with those models. With this background established, the simulations performed for this study are described and analyzed.

\subsubsection{Regional Hydrogeology}

Previous investigations have shown that the unconfined aquifer encompasses two basic lithologic units: Tertiary tuff and the underlying Paleozoic carbonate. The sequence of Paleozoic clastics and carbonates was deposited in a thick miogeosyncline that contains a thickness of up to 12,000 meters of Paleozoic and Precambrian sediments. Tertiary ash flow tuffs of rhyolitic and quartz-latitic composition were deposited unconformably on the Paleozoic carbonates. Approximately $1200 \mathrm{~m}$ of tuff unconformably overlies the Paleozoic Carbonates at the Yucca Mountain crest (Craig and Reed 1991). Miocene tuffs are exposed at the surface of Yucca Mountain. A thin layer of alluvium and colluvium exists on the tuffs in the drainages and this layer thickens in the valley floors. The tuff that was modeled for this problem was divided into two horizontal units: the overlying unit defined by properties of the zeolotized tuff (see Section 4.0), and the underlying unit by those of the partially welded tuff. Flow within these units was modeled as a two-dimensional flow regime to address the spatial variability of physical properties. The twodimensional cross section was aligned such that the $x$-direction was parallel to the hydraulic gradient.

The regional water table is from 500 to $750 \mathrm{~m}$ below the ground surface in the area of the potential repository. Water movement in the saturated zone is generally from north to south below Yucca Mountain. The desert climate of the Yucca Mountain area receives an average precipitation of 150 to $220 \mathrm{~mm}$ per year (Quiring 1965). Of this, between 2 and $11 \mathrm{~mm}$ are thought to infiltrate the unsaturated zone and recharge the aquifer (Montazer and Wilson 1984). The average gradient directly below the mountain is $10^{-4}$, from north to south, as calculated from water-level measurements reported by O'Brien (1991). However, the gradient increases sharply to the north and west (upgradient of the potential repository location). Water discharges from the unconfined aquifer to springs south of the Yucca Mountain area, in the Amargosa Desert and Oasis Valley, and by evapotranspiration from playas in Death Valley. Water stored in tuffs also moves downward to recharge the carbonate aquifer. In the simulations done for this analysis, water is assumed to move from north to south. Because the volume of recharge from the surface is so small, vertical recharge is not modeled for these simulations; vertical recharge is assumed to be small compared with the influence of the hydraulic gradient on fluid transport. 


\subsubsection{Regulatory Controls}

Simulations of saturated ground-water flow under the potential repository at Yucca Mountain are motivated by federal regulations which specify limits for high-level radioactive waste release to the "accessible environment," which is defined as a 5-km distance from the disturbed zone of the potential repository. The potential for radionuclide release to the accessible environment has been defined (40 CFR Part 191.13) as the statistical probability of transport of a specific radionuclide concentration (40 CFR Part 191.16) to a distance $5 \mathrm{~km}$ from the potential repository in particulia concentrations. To provide an adequate statistical description of the probability of radionuclide transport, twelve simulations were performed each for the tuff and carbonate aquifers. Each of the twelve simulations included two simulations that defined the limits of potential release: transport under minimum and maximum hydraulic gradients and conductivities.

\subsubsection{Conceptual and Numerical Models}

Saturated flow in both the carbonate and tuff aquifers was simulated in two dimensions $(x-y$, where $\mathrm{x}$ is west-east and $\mathrm{y}$ is south-north; vertical dimension $\mathrm{z}$ neglected) using the Darcy equation, which assumes pressure-driven fluid-flow through a continuous porous media. Preferential flow through fractures or faults in the porous media composing the carbonate and the tuff aquifers was not considered for these simulations. The equivalent-continuum mordel that was used represented fracture and porous-media hydraulic conductivities as a single weighted value in the minimum and maximum-flow field simulations, or a range of values for the stochastically derived flow fields. Hydraulic conductivity fields were generated using the RFIELD code.

The two-dimensional hydrologic regime this problem simulates was defined by the hydraulic properties of the fluid, the porous media, and the hydraulic gradient that drives fluid movement. The fluid modeled was subject to a variety of simplifying assumptions, so that the results of these simulations are a consequence of the properties attributable to the physical aquifer through which the fluid moves. The saturated-fluid movement modeled was limited to that of a single liquid phase; the fluid was assumed incompressible and isothermal. The porous media composing the modeled aquifers was assumed in both cases to be continuous and isotropic; and the porosity and density of the porous media were assumed constant. Porous media properties are listed in Table 5.1. The hydraulic gradients imposed were unique for each of the twelve simulations and for each aquifer. Gradients for the tuff aquifer were defined statistically using a uniform distribution of hydraulic head values taken from Doctor et al. (1992), with limits of $2.018 \times 10^{-3}$ and $6.196 \times 10^{-3}$. Carbonate hydraulic gradients were derived from a uniform distribution of values with limits of $6.089 \times 10^{-2}$ and $6.089 \times 10^{-4}$. Gradients and the deterministic hydraulic conductivity values used for the tuff and the carbonate simulations are listed in Tables 5.2a and $5.2 \mathrm{~b}$, respectively.

The problem defined here was modeled with the integrated finite-difference SUMO code, which calculated a numerical solution. SUMO generated a steady-state flow-field and calculated particle travel times for a hydrologic domain defined by a constant hydraulic gradient and unique hydraulic conductivity. The ten radionuclides considered for transport in the Human-Intrusivin Scenario were introduced by direct injection with a drilling rig at a point in the simulated domain shown in Figure 5.1. The AREST code generated a source term for radionuclide release into the domain over time. Simulated radionuclide fluxes and concentrations within the aquifer were calculated for the steady-state flow system simulated for each case. Fluxes at a plane $5 \mathrm{~km}$ downgradient from the point source (from which dose calculations were made) are presented in the following section. 
Table 5.1. Aquifer Physical Properties for Saturated Zone Modeling

\begin{tabular}{|c|c|c|c|}
\hline \multirow[b]{2}{*}{ Aquifer Property } & \multirow[b]{2}{*}{ Carbonate } & \multicolumn{2}{|c|}{ Tuff } \\
\hline & & Zeolitic & Partially Welded \\
\hline $\begin{array}{l}\text { Porosity } \\
\text { Density } \\
\text { Longitudinal Dispersivity }\end{array}$ & $\begin{array}{l}0.05 \\
2.76\end{array}$ & $\begin{array}{l}0.41 \\
2.35\end{array}$ & $\begin{array}{l}0.24 \\
2.23\end{array}$ \\
\hline $\begin{array}{l}\text { (deterministic runs) } \\
\text { (stochastic runs) } \\
\text { Transverse Dispersivity }\end{array}$ & $\begin{array}{r}1 \\
500\end{array}$ & $\begin{array}{r}1 \\
500\end{array}$ & $\begin{array}{r}1 \\
500\end{array}$ \\
\hline $\begin{array}{l}\text { (deterministic runs) } \\
\text { (stochastic runs) }\end{array}$ & 200 & $\begin{array}{r}1 \\
200\end{array}$ & $\begin{array}{r}1 \\
200\end{array}$ \\
\hline $\begin{array}{l}\text { Diffusivity } \\
\text { Storativity }\end{array}$ & $\begin{array}{l}0.0365 \\
0.0\end{array}$ & $\begin{array}{l}0.0365 \\
0.0\end{array}$ & $\begin{array}{l}0.0365 \\
0.0\end{array}$ \\
\hline
\end{tabular}

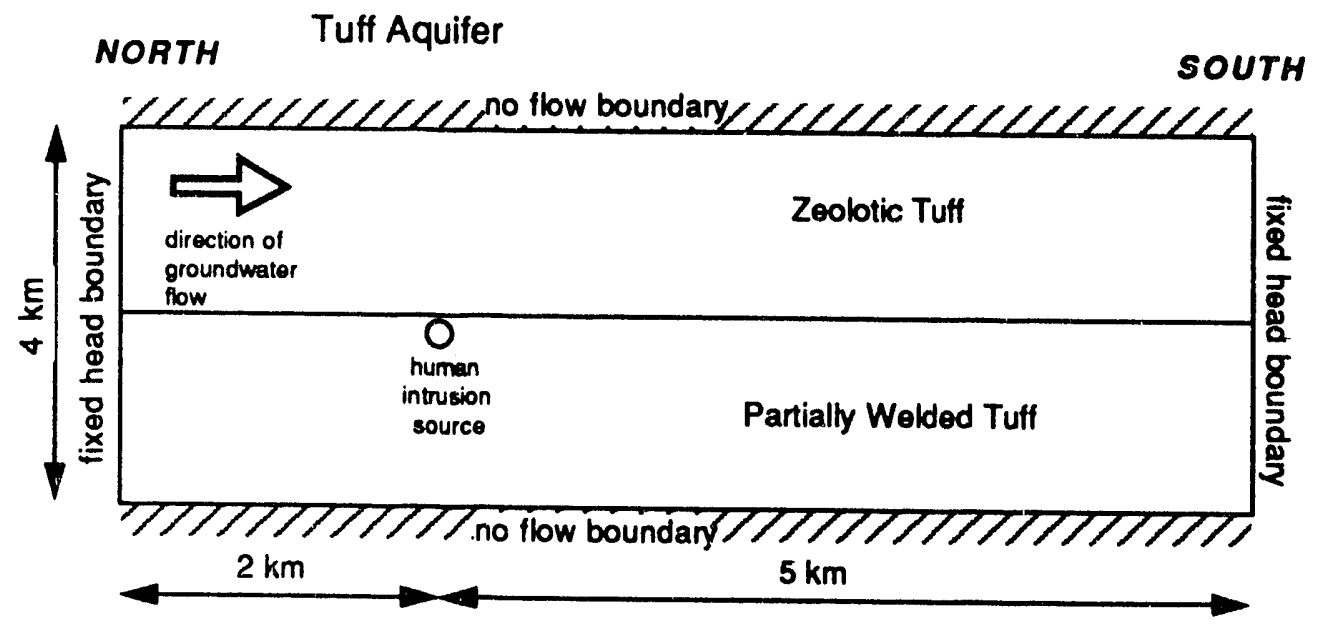

Carbonate Aquifer

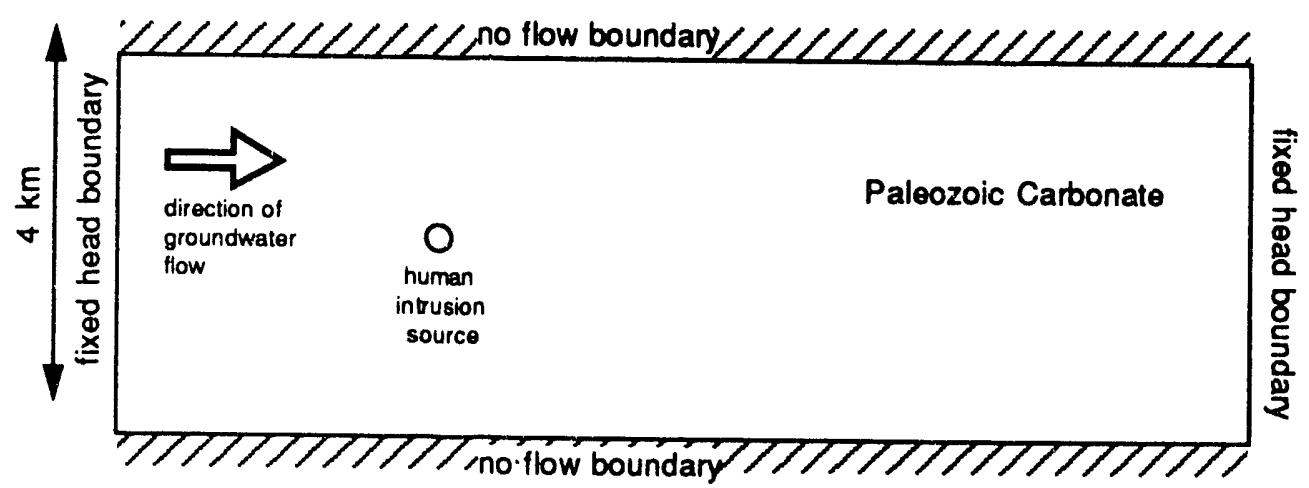

Figure 5.1. Configuration of Hydrologic Domain for the Modeled Tuff Aquifer and the Carbonate Aquifer (both dimensions are in the horizontal plane) 
Table 5.2. Hydraulic Gradients, Hydraulic Conductivities, and Time of Drilling Intrusion Under the Human-Intrusion Scenario for Each Simulation for the (a) Tuff Aquifer and (b) Carbonate Aquifer (simulation numbers correspond to Table 3.4b)

\section{A. Tuff Aquifer}

\begin{tabular}{c} 
Simulation Numbe \\
\hline 1 \\
2 \\
3 \\
4 \\
5 \\
6 \\
7 \\
8 \\
9 \\
10 \\
11 \\
12
\end{tabular}

\begin{tabular}{l} 
Gradient $(\mathrm{m} / \mathrm{m})$ \\
\hline $5.200 \times 10^{-3}$ \\
$4.710 \times 10^{-3}$ \\
$3.143 \times 10^{-3}$ \\
$5.174 \times 10^{-3}$ \\
$2.400 \times 10^{-3}$ \\
$4.871 \times 10^{-3}$ \\
$6.157 \times 10^{-3}$ \\
$3.014 \times 10^{-3}$ \\
$3.029 \times 10^{-3}$ \\
$6.086 \times 10^{-3}$ \\
$2.017 \times 10^{-3}$ \\
$6.190 \times 10^{-3}$
\end{tabular}

Hydraulic Conductivity (m/yr)

\begin{tabular}{cc}
\hline Partially Welded & Zeolitic \\
\cline { 2 - 2 }$*$ & $*$ \\
$*$ & $*$ \\
$*$ & $*$ \\
$*$ & $*$ \\
$*$ & $*$ \\
$*$ & $*$ \\
$*$ & $*$ \\
$*$ & $*$ \\
$4.418 \times 10^{-3}$ & $*$ \\
$4.418 \times 10^{1}$ & $9.499 \times 10^{-7}$ \\
& $9.499 \times 10^{-3}$
\end{tabular}

\section{B. Carbonate Aquifer}

Simulation Number Gradient $(\mathrm{m} / \mathrm{m})$

1
2
3
4
5
6
7
8
9
10
11
12

$$
\begin{aligned}
& 4.216 \times 10^{-2} \\
& 3.974 \times 10^{-2} \\
& 5.077 \times 10^{-2} \\
& 1.790 \times 10^{-2} \\
& 1.443 \times 10^{-2} \\
& 3.451 \times 10^{-2} \\
& 3.329 \times 10^{-3} \\
& 1.456 \times 10^{-2} \\
& 2.657 \times 10^{-2} \\
& 2.028 \times 10^{-2} \\
& 6.089 \times 10^{-4} \\
& 1.630 \times 10^{-1}
\end{aligned}
$$$$
\text { Hydraulic Conductivity (m/yr) }
$$

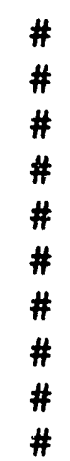

$8.500 \times 100$

$1.148 \times 10^{2}$

\footnotetext{
* Stochastic; refer to Section 5.1.4 for a the statistical parameters used to describe the hydraulic conductivity of the Partially Welded unit and the Zeolitic unit. Also refer to Figure 5.3 for an illustration of an example stochastic hydraulic conductivity field.

\# Stochastic; refer to Section 5.1.4 for the statistical parameters used to define the hydraulic conductivity of Carbonate aquifer. Also refer to Figure 5.4 for an illustration of an example stochastic field hydraulic conductivity field.
} 


\subsubsection{Hydrogeologic Data}

The twelve simulations each of ground-water flow in the two aquifers were divided into stochastic and deterministic flow representations. Ten simulations for each aquifer used a statistically derived description of hydraulic gradient, aquifer intrusion time, and radionuclide sorption coefficients in the specific aquifer. The stochastic representations of the hydraulic condictivity fields were generated using spatially correlated values derived from samples taken at the Yucca Mountain Site. The hydraulic conductivity values for the tuff aquifer simulations are from Kaplan et al. (1991), which is reproduced in Appendix A. The hydraulic conductivities for the carbonate aquifer simulations are from McGraw et al. (1991). A lognormal distribution of the reported values was used for both aquifers. Hydraulic conductivity values are reproduced in Tables 5.2a and 5.2b. Examples of the hydraulic conductivity fields that were generated for a carbonate aquifer and for a tuff aquifer for the stochastic simulations are shown in Figures 5.2 and 5.3 , respectively.

The two remaining deterministic simulations represented the minimum and maximum-flow fields for each aquifer, using the largest and smallest hydraulic gradient (values provided in Table 5.2). A constant value was used to describe the whole hydraulic-conductivity field from the hydraulic conductivity values derived from a lognormal distribution of the values reported in Kaplan et al. (1991) and McGraw et al. (1991).

\subsubsection{Simulation Descriptions}

For each of the carbonate aquifer simulations, a unique steady-state pressure field was generated from the hydraulic gradients and hydraulic conductivity values shown in Table 5.2a. An example of the pressure field generated for carbonate simulation 1 is shown in Figure 5.4. The pressure field displays essentially one-dimensional flow because a hydraulic gradient was defined only in the horizontal direction; no vertical recharge from the overlying tuff aquifer to the carbonate aquifer was simulated. The variations in the pressure contours are a result of the variability in the hydraulic conductivity field.

The paths of the seven particles tracked through the simulated carbonate aquifer are shown in Figure 5.5 for carbonate simulation 1, depicting an essentially one-dimensional flow field. An inverse relationship between travel time and the hydraulic gradient can be observed if the gradients shown in Tables 5.2 are compared with the particle travel times shown in Table 5.3. Relative particle travel times can be interpreted from Figure 5.6 for carbonate simulation 1 , where the distance of particle transport is plotted as a function of the time of transport.

Data for the twelve tuff-aquifer simulations were generated in a similar manner to those of the carbonate aquifer; a unique steady-state pressure field was generated for each simulation from data shown in Table 5.2b. One-dimensional flow is indicated by the pressure field simulated for tuff simulation 03, illustrated in Figure 5.7.

Seven particle paths were tracked for each of the twelve tuff pressure fields simulated. The minimum and maximum travel times for each simulation are shown in Table 5.3. Paths for the particles tracked in tuff simulation 3 are shown in Figure 5.8. The plot of time versus distance for the particle travel paths for tuff simulation 3 (Figure 5.9) shows a distinct bimodal distribution to the travel times, a result of the hydraulic conductivity values of the two different lithologic units that constitute the aquifer and the grid spacing of the simulated domain. 


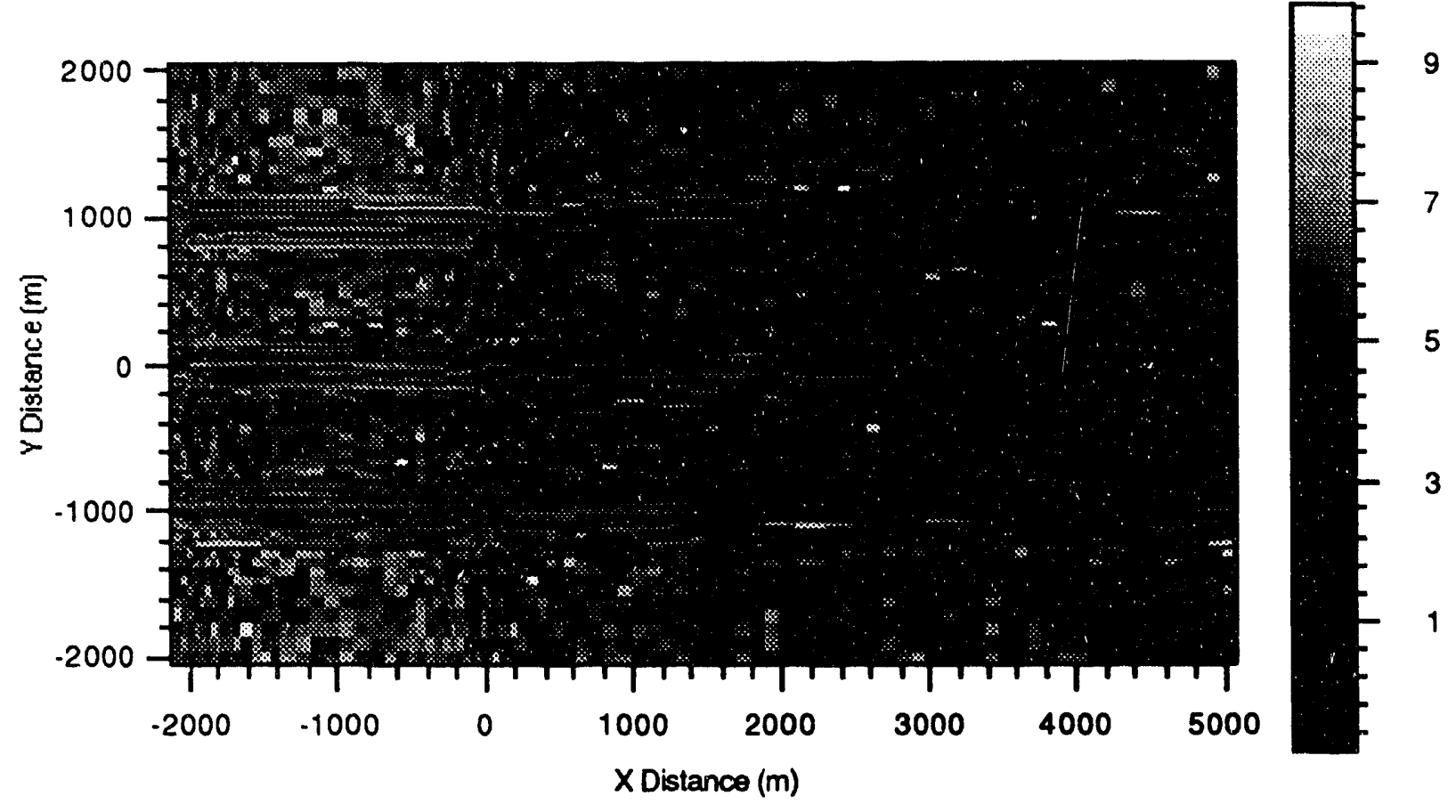

Figure 5.2. RFIELD-Generated Logarthmic Saturated Hydraulic Conductivity Field for Carbonate Simulation 1

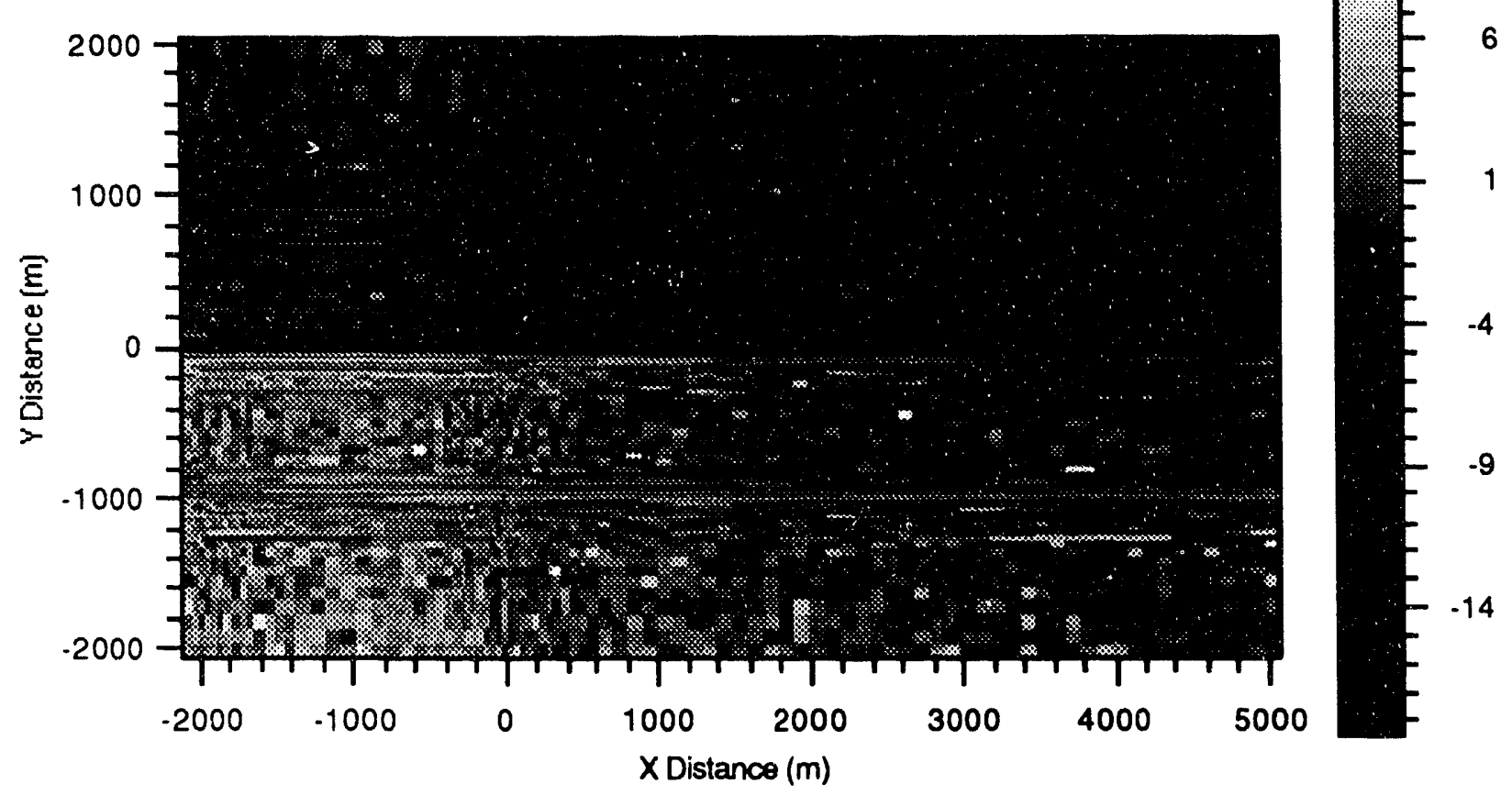

Figure 5.3. RFIELD-Generated Logarhmic Saturated Hydraulic Conductivity Field for Tuff Simulation 3 


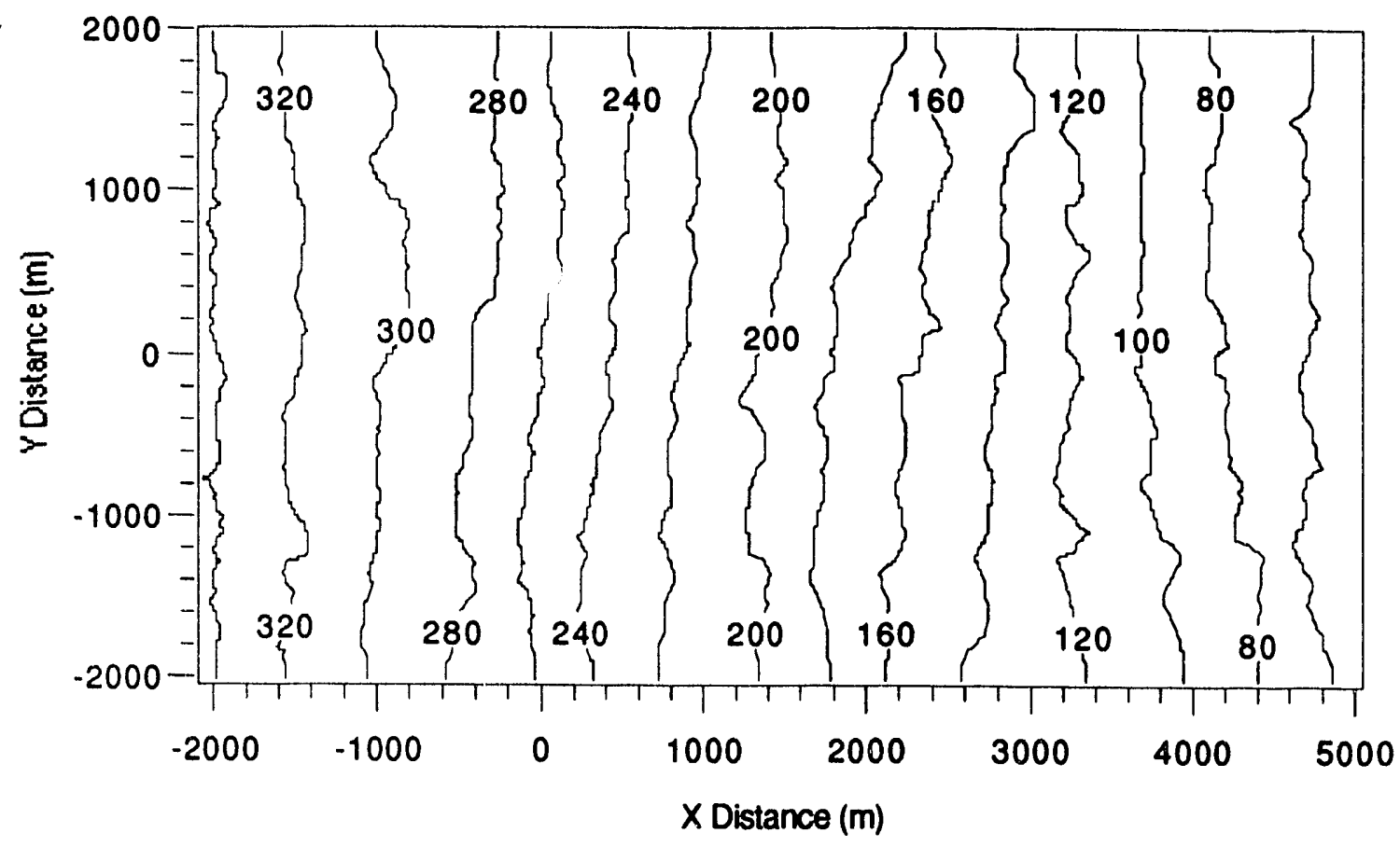

Figure 5.4. Hydraulic Head (m) Distribution for Carbonate Simulation 1

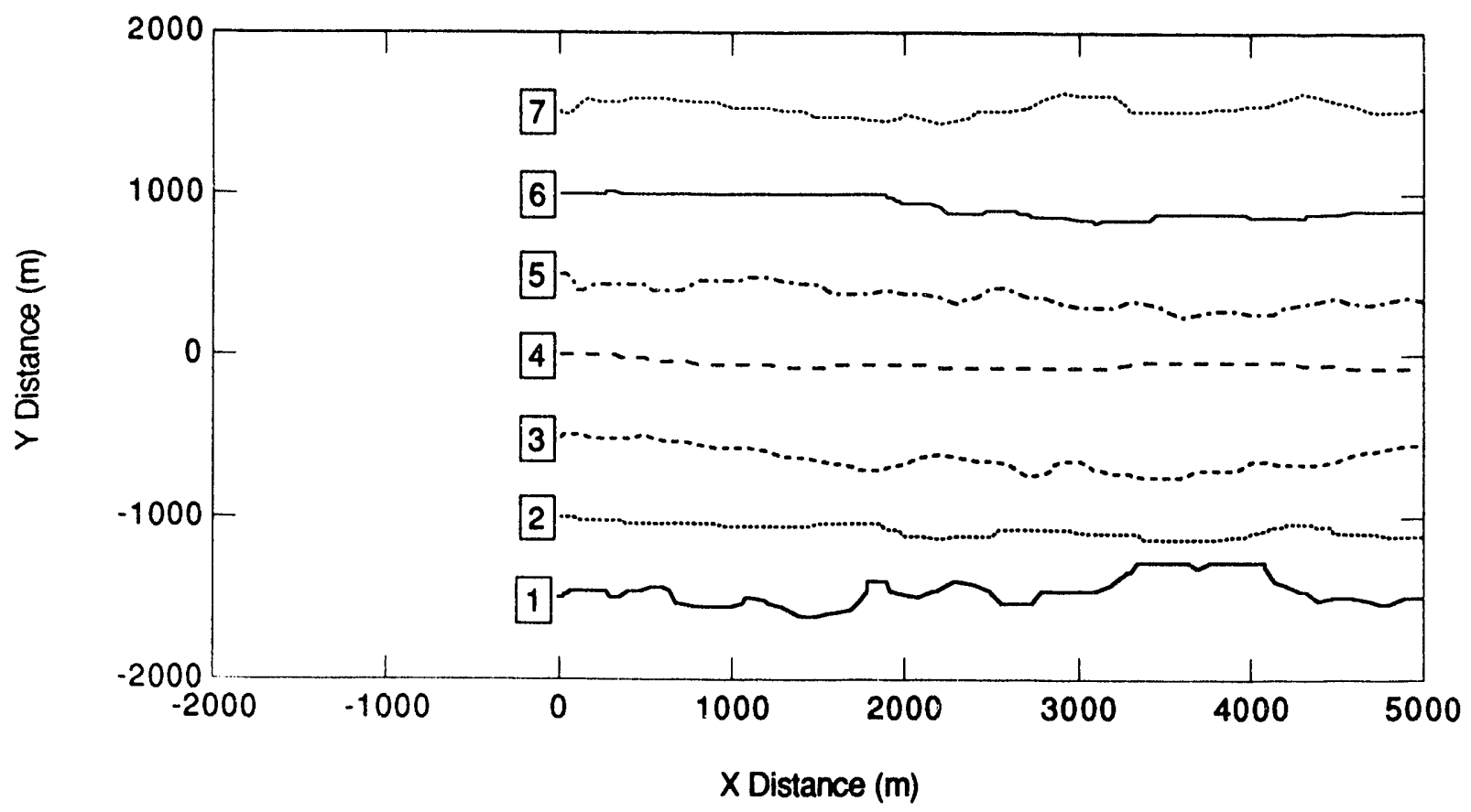

Figure 5.5. Travel Particle Pathlines for Carbonate Simulation 1 
Table 5.3. Particle Travel Time (yr)

Simulation

No. Carbonate

$\begin{array}{lcc}1 & 34 & 65 \\ 2 & 15 & 82 \\ 3 & 18 & 55 \\ 4 & 62 & 200 \\ 5 & 791 & 3020 \\ 6 & 14 & 162 \\ 7 & * & * \\ 8 & 72 & 281 \\ 9 & 15 & 145 \\ 10 & 41 & 122 \\ 11 & 9790 & 9790 \\ 12 & 3.6 & 3.6\end{array}$

Tuff Partially Welded Minimum Maximum

$6.21 \times 10^{4}$

$2.57 \times 10^{4}$

$5.34 \times 10^{4}$

$2.10 \times 104$

$5.47 \times 10^{4}$

$5.11 \times 10^{4}$

$1.49 \times 10^{4}$

$6.37 \times 10^{4}$

$2.34 \times 10^{5}$

$5.20 \times 10^{3}$

$4.45 \times 10^{3}$
$4.46 \times 10^{5}$

$1.18 \times 106$

$1.11 \times 106$

$3.55 \times 10^{5}$

$1.87 \times 106$

$8.67 \times 10^{5}$

$6.73 \times 10^{5}$

$1.52 \times 10^{6}$

$2.86 \times 106$

$1.27 \times 106$

$4.45 \times 10^{3}$
Tuff Zeolitic Unit Minimum Maximum

$5.13 \times 10^{8}$

$8.84 \times 10^{9}$

$6.60 \times 108$

$3.16 \times 10^{9}$

$2.97 \times 10^{7}$

$3.41 \times 10^{9}$

$3.11 \times 108$

$2.71 \times 10^{9}$

$6.73 \times 10^{7}$

$1.25 \times 10^{10}$

$1.08 \times 10^{8}$

$8.11 \times 10^{7}$

$4.83 \times 10^{9}$

$4.51 \times 10^{7}$

$1.59 \times 109$

$5.05 \times 10^{9}$

$4.16 \times 10^{9}$

$1.40 \times 10^{7}$

$4.56 \times 10^{10}$

$2.85 \times 10^{9}$

$3.53 \times 10^{7} \quad 3.53 \times 10^{7}$

results not available

\# travel time exceeds 10,000 -year simulation period

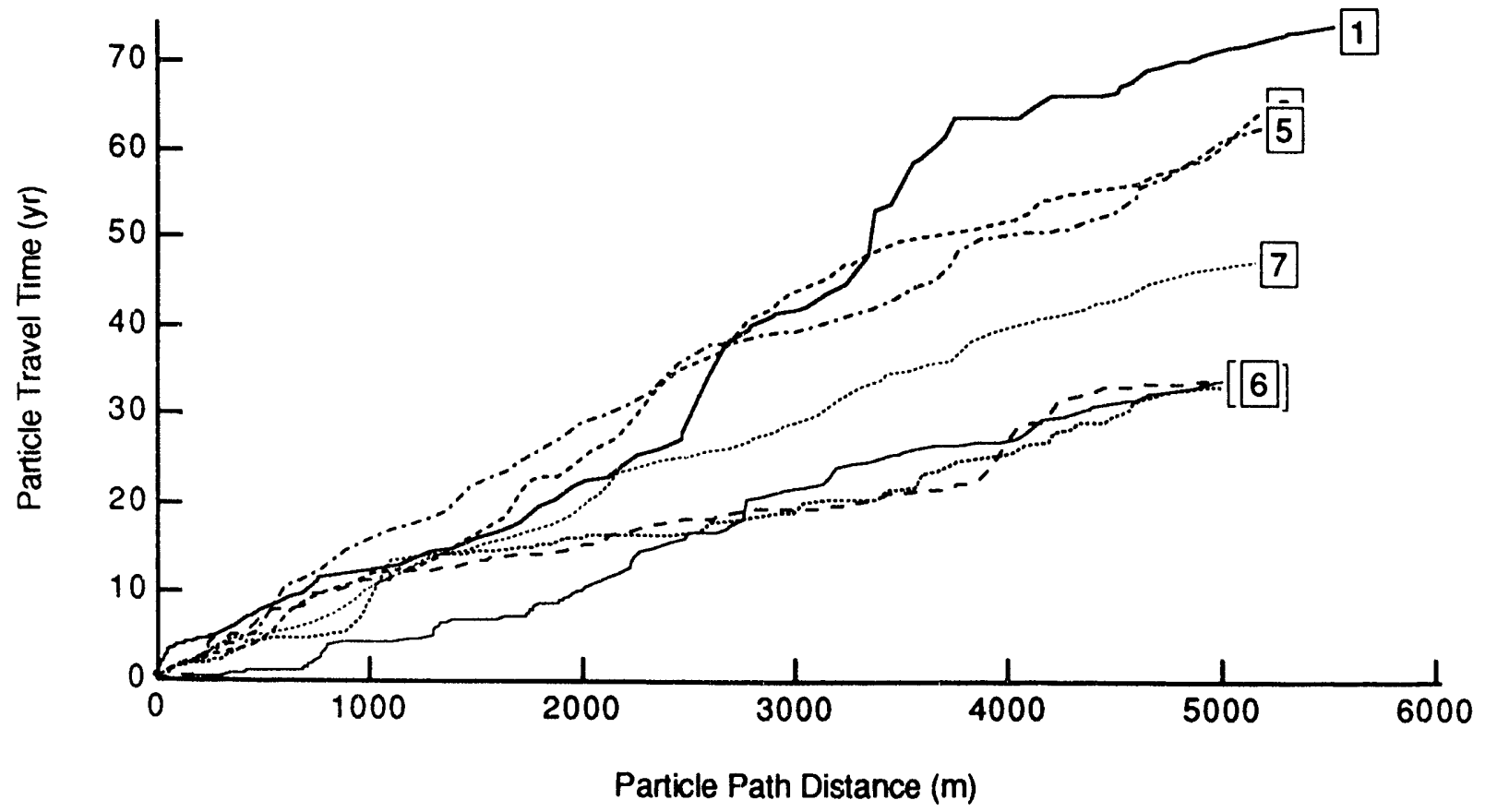

Figure 5.6. Travel Time as a Function of Path Distance for Carbonate Simulation 1 


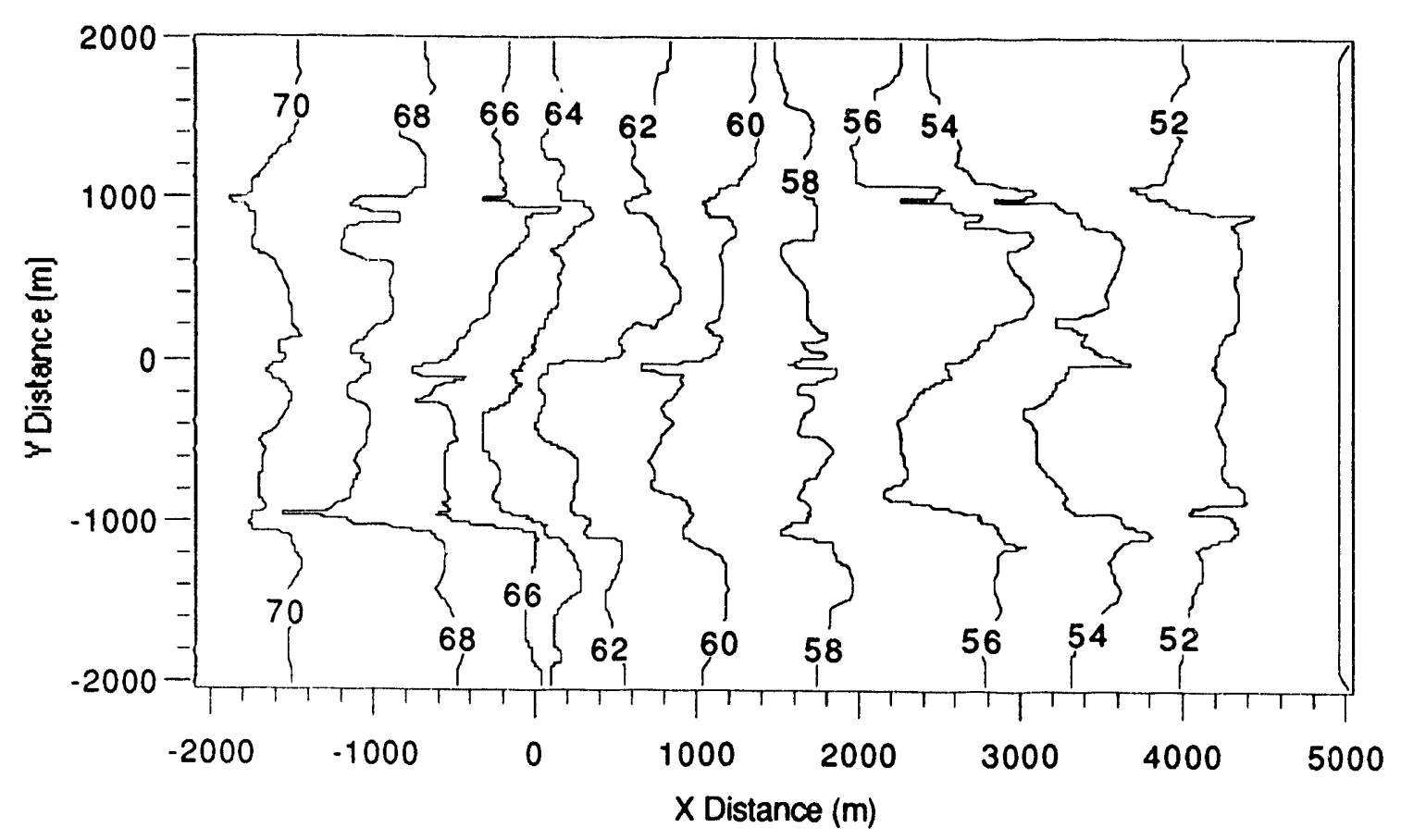

Figure 5.7. Hydraulic Head (m) Distribution for Tuff Simulation 3

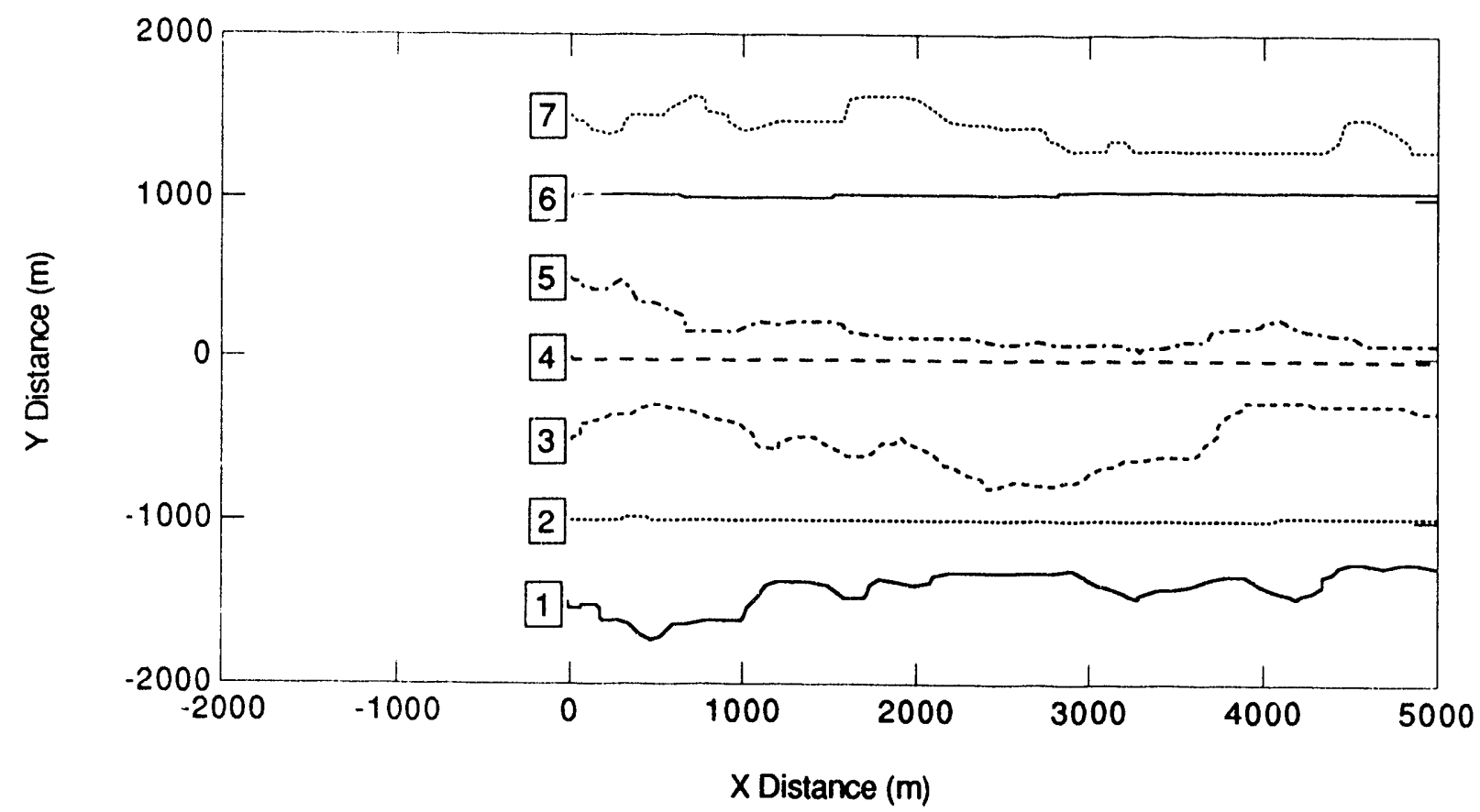

Figure 5.8. Travel Particle Pathlines for Tuff Simulation 3 


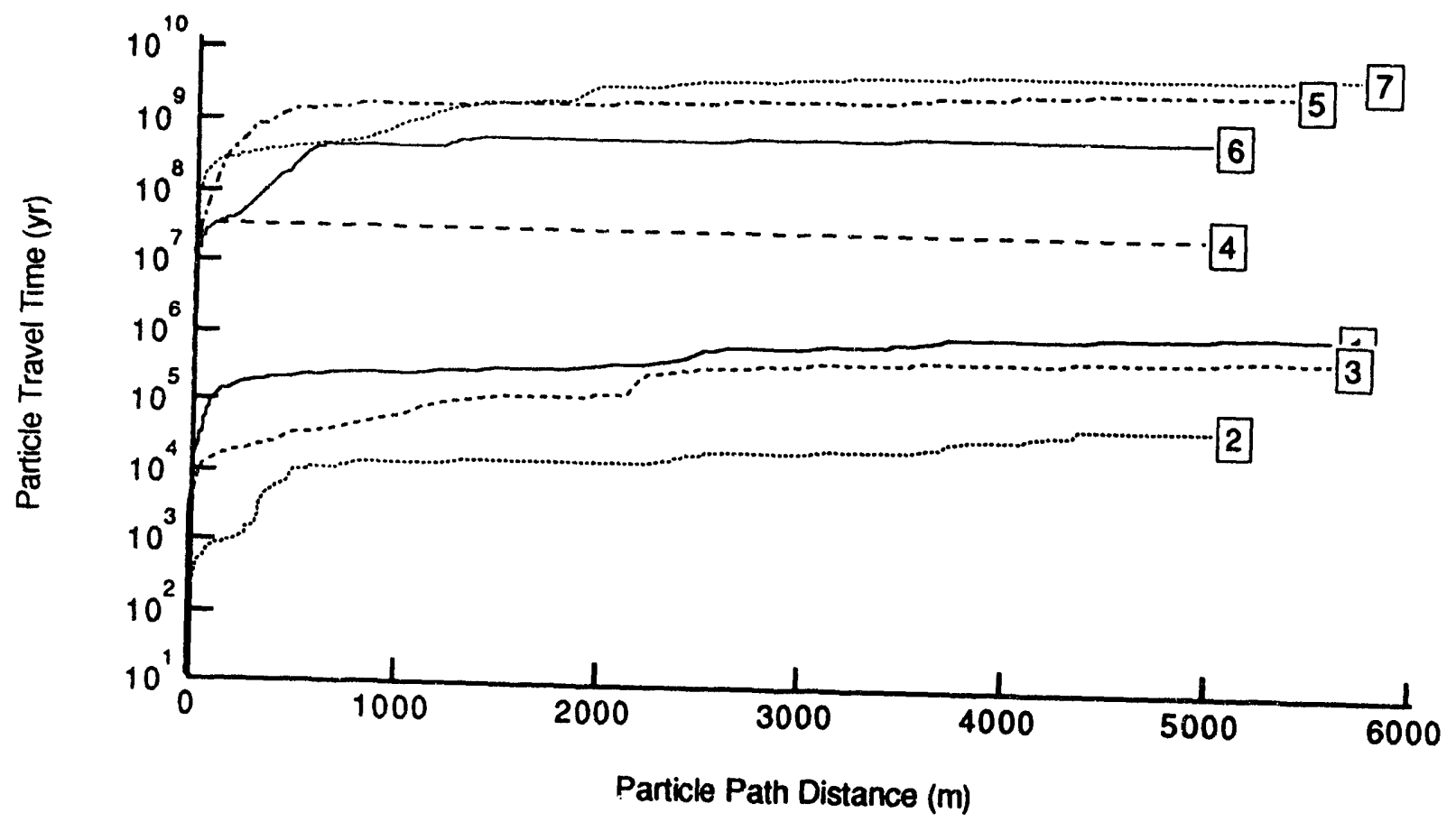

Figure 5.9. Travel Time as a Function of Path Distance for Tuff Simulation 3

\subsubsection{Analysis}

The pressure fields simulating steady-state conditions in both the carbonate and tuff aquifers are strongly dependent on the hydraulic gradient imposed and on the simulated hydraulic conductivity field for the aquifer. The larger hydraulic gradient results in a greater hydraulic potential driving groundwater movement and shorter particle travel times within the aquifer. Particle travel times are also influenced by the hydraulic conductivity values used. The
heterogeneous hydraulic conductivity fields generated by the RFIELD code followed strong linear
trends associated with grid cell size (see Figures 5 . trends associated with grid cell size (see Figures 5.2 and 5.3) because of a coding error in fields that were not a erregated properly been corrected, but the runs reported here used stochastic conductivities were not random with respect to spect to cell size. Therefore, hydraulic were random with respect to the grid nodes to spacing in either the $\mathrm{x}$ or $\mathrm{y}$ direction; rather, they refined, heterogeneities in the hydraulic-cos themselves. In areas where the grid spacing had been with larger grid spacing over an equivalent dimetivity values varied on a smaller scale than in areas in one dimension than the other, a linear timension. If the grid nodes were significantly smaller in the longer dimension. Consequently, hydrologic hydraulic conductivity values was established instead of an intended random hydraulic-conductivity field. paths through the simulated tuff aquifer as a straighty field. Figure 5.8 shows three particle travel 4 , and 6 ). The odd-numbered particles $(1,3$ and 5 ) because the variations in the hydraules $(1,3$, and 5) show a more heterogeneous travel path, spaced in the $\mathrm{x}$ and $\mathrm{y}$ direction. Particles numbered values along those paths are more equally narrower grid spacing in the $y$ dimension. The grid node dimension is routed along zones of direction, creating a linear trend to the hydraulic conde dimension is thereby exaggerated in the $x$ direction, creating a linear trend to the hydraulic conductivity in the $x$ direction. The grid spacing is 
illustrated in Figure 5.10; zones of refined node spacing are evident along the $y=-1000,0$, and 1000 planes, and along the $x=0$ plane. The y coordinates for the number 2,4 , and 6 particles tracked are $-1000,0$, and 1000, respectively. The more representative travel times are those of the odd-numbered particles for both aquifers.

Travel times for particles tracked in the first eleven tuff aquifer simulations were significantly greater than the 10,000-year period required by the regulations. These results indicate that transport of radionuclides in the tuff aquifer to the accessible environment is not likely. The maximum-flow simulation (T12) simulated a travel time of 4450 years in the zeolotized unit, the only travel time less than the regulated 10,000 years. Consequently, the first 11 simulations were not used to calculate the effects of human intrusion into the tuff aquifer. Results from simulation T12 only are included in the following section on the human-intrusion scenario.

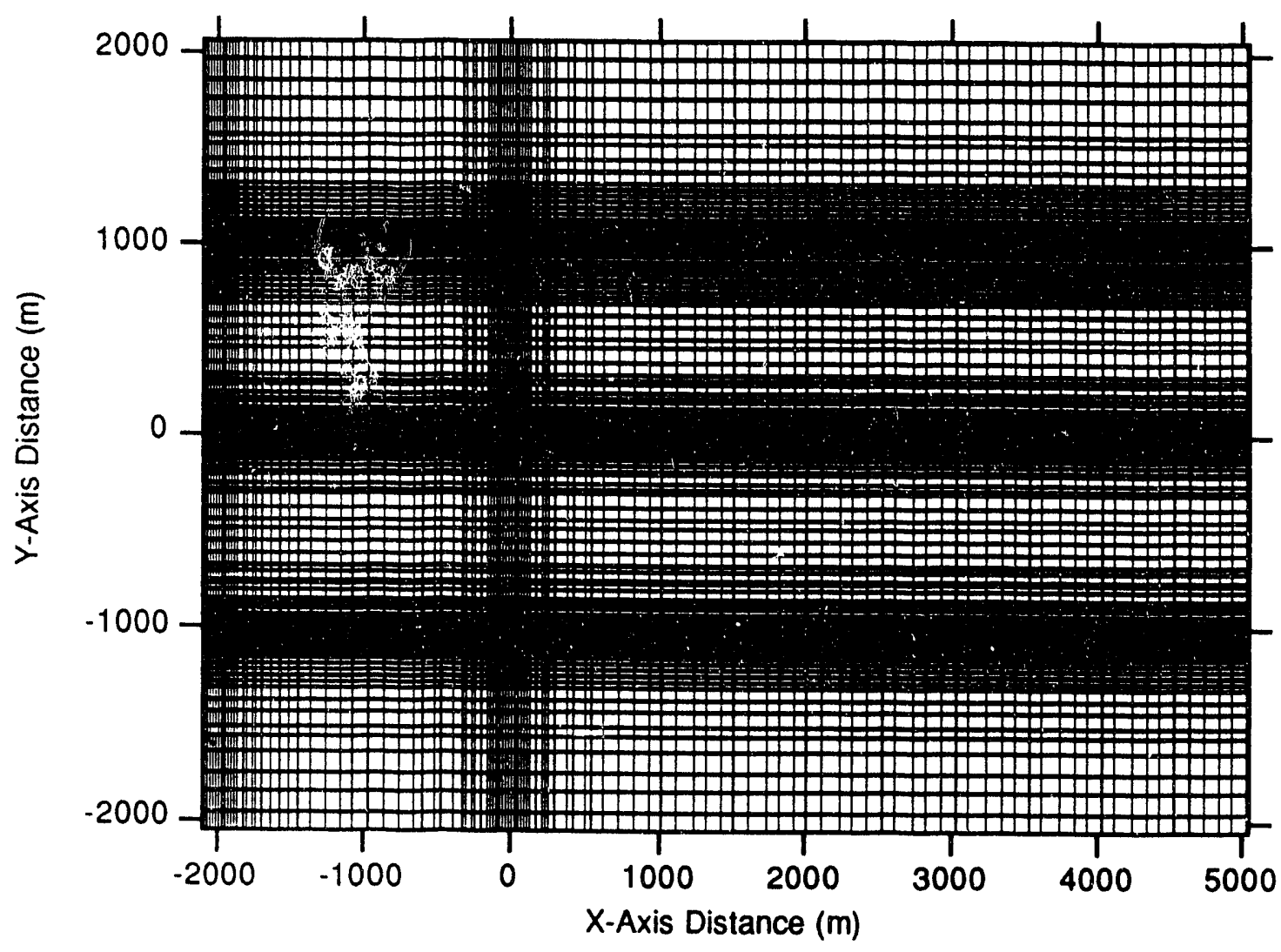

Figure 5.10. Grid Node Configuration for Simulated Carbonate Hydrologic Domain 


\subsection{Human-Intrusion Scenario}

\subsubsection{Method and Assumptions}

The human-intrusion scenario considered a drilling operation in which a borehole is drilled through the potential repository to an elevation below the water table. The drilling rig would, in this scenario, intercept a waste container such that the container's integrity is compromised, permitting the contents of the container to be transported directly to the saturated zone. At the point of aquifer intrusion, radionuclides are released into the saturated zone for transport down-gradient. The location of the drilling intrusion point in the tuff and carbonate saturated-zone models is shown in Figure 5.1. The time of drilling intrusion was defined for each simulation using a lognormal distribution of times between 100 and 10,000 years after repository closure.

Radionuclide release into the aquifer was calculated by the AREST analytical code (Section 3). For each of the ten radionuclides modeled, radionuclide mass was introduced at the rate predicted by AREST (Section 3) from the time of intrusion until 10,000 years, or until depletion of the source. Radioactive decay of the waste was accounted for by AKEST prior to release, and by SUMO after release into the aquifer. Transport was assumed to be in the aqueous phase only for all radionuclides modeled. Radionuclide flux through the simulated domain was calculated until 10,000 years after potential repository closure.

Transport of the radionuclides in the saturated aquifer is calculated using the 12 steady-state flow fields generated in the Undisturbed Scenario portion of this exercise. In addition to the influence of the flow field on radionuclide transport, properties of the aquifer and the radionuclides also determine how transport distributes radionuclides in the saturated zone. The dispersivity and diffusivity of the aquifer were assumed to be constant for all radionuclides modeled in all the simulations done. Storativity was assumed zero for all simulations. The porosity and density were consistent for all the carbonate simulations and for the tuff simulation. The aquifer properties and the values used to define them are listed in Table 5.1.

Sorption of the individual radionuclides to the aquifer is another property governing saturatedzone transport. Radionuclide sorption to the porous media that constitute the aquifer was modeled as both a deterministic and a stochastic property for the carbonate aquifer and as a deterministic property for the tuff aquifer simulated. These sorption values are listed in Table 5.4. Appendix B reproduces Dockery (1991), which has additional comments on these values.

The potential for unsaturated-zone transport of ${ }^{14} \mathrm{C}$ in the gas phase to the saturated zone was considered as part of this modeling exercise. ${ }^{14} \mathrm{C}$ may be released from the potential repository and travel downward to encounter the underlying water table. The release profile of $14 \mathrm{C}$ from the potential repository into the unsaturated zone, its concentration in the gas phase, and its transport in the unsaturated zone concentration of $14 \mathrm{C}$ in the gas phase were calculated by the MSTS code in the Unsaturated Zone Section. Those results are used as input into the maximum-flow simulation for the tuff aquifer (T12) to model ${ }^{14} \mathrm{C}$ aqueous transport.

\subsubsection{Simulation Descriptions}

Simulations were performed to describe tuff and carbonate aquifer responses to human intrusion; each was defined differently. The carbonate aquifer travel times were short enough that radionuclide transport resulting from human intrusion occurred for all but the minimum-flow 
Table 5.4. Deterministic and Stochastic Sorption Values

\begin{tabular}{lccccc} 
& \multicolumn{2}{c}{ Carbonate } & & \multicolumn{2}{c}{ Tuff } \\
\cline { 2 - 3 } \cline { 5 - 6 } Element & Deterministic & Stochastic & & Zeolific Laver & Partially Welded \\
\cline { 2 - 3 } $\mathrm{U}$ & 3 & $1-6$ & & 2.5 & 2.5 \\
$\mathrm{~Np}$ & 0.5 & $0-11$ & & 2 & 2 \\
$\mathrm{Am}$ & 110 & $25-235$ & & 100 & 100 \\
$\mathrm{Pu}$ & 80 & $60-160$ & & 100 & 100 \\
$\mathrm{C}$ & 0 & 0 & & 0 & 0 \\
$\mathrm{Se}$ & 3 & $0-6$ & & 2.5 & 2.5 \\
$\mathrm{Tc}$ & 0 & 0 & & 0 & 0 \\
$\mathrm{Sn}$ & 110 & $60-160$ & & 100 & 100 \\
$\mathrm{I}$ & 0 & 0 & & 0 & 0 \\
$\mathrm{Cs}$ & 10 & $0-135$ & & 50 & 50
\end{tabular}

simulation (Carbonate Simulation 11). Simulations were repeated for the first 10 cases (Carbonate Simulations 1 to 10) for five realizations to obtain a statistical description of the radionuclide transport to $5 \mathrm{~km}$ from the point of intrusion. 'f the tuff simulations done, only the maximumflow simulation (Tuff Simulation 12) had a tw. time short enough to simulate radionuclide transport. Because the tuff aquifer overlies the car conate aquifer, ${ }^{14} \mathrm{C}$ infiltration from the unsaturated zone was also simulated for the maximum-flow tuff aquifer case.

Steady-state flow in the 12 aquifer hydraulic-conductivity fields generated for the carbonate aquifer was simulated using SUMO for the Human-Instrusion Scenario Direct-Injection Case for the carbonate aquifer. A single value was used to represent the sorption coefficient for each of the 10 radionuclides injected into the aquifer, these values are shown in the deterministic column of the carbonate sorption values listed in Table 5.4. Longitudinal and transverse dispersivity were both assumed to be equal to 1 for these simulations. Radionuclide flux, in units of $\mathrm{Ci} / \mathrm{yr}$, across the $5-\mathrm{km}$ boundary as a function of time was calculated for each simulation. These fluxes are shown for Carbonate Simulations 1 through 12 in Figures 5.11 through 5.22, respectively, and for Tuff Simulation 12 in Figure 5.23. The cumulative release of each radionuclide at $10,000 \mathrm{yr}$ across the $5-\mathrm{km}$ boundary from the carbonate aquifer is indicated in Table 5.5, along with the ratio of each flux to the EPA limit for that radionuclide. EPA limits for a 70,000-MTU repository (the approximate size of the current design for the potential repository at Yucca Mountain) are shown in the second column of Table 5.5. 


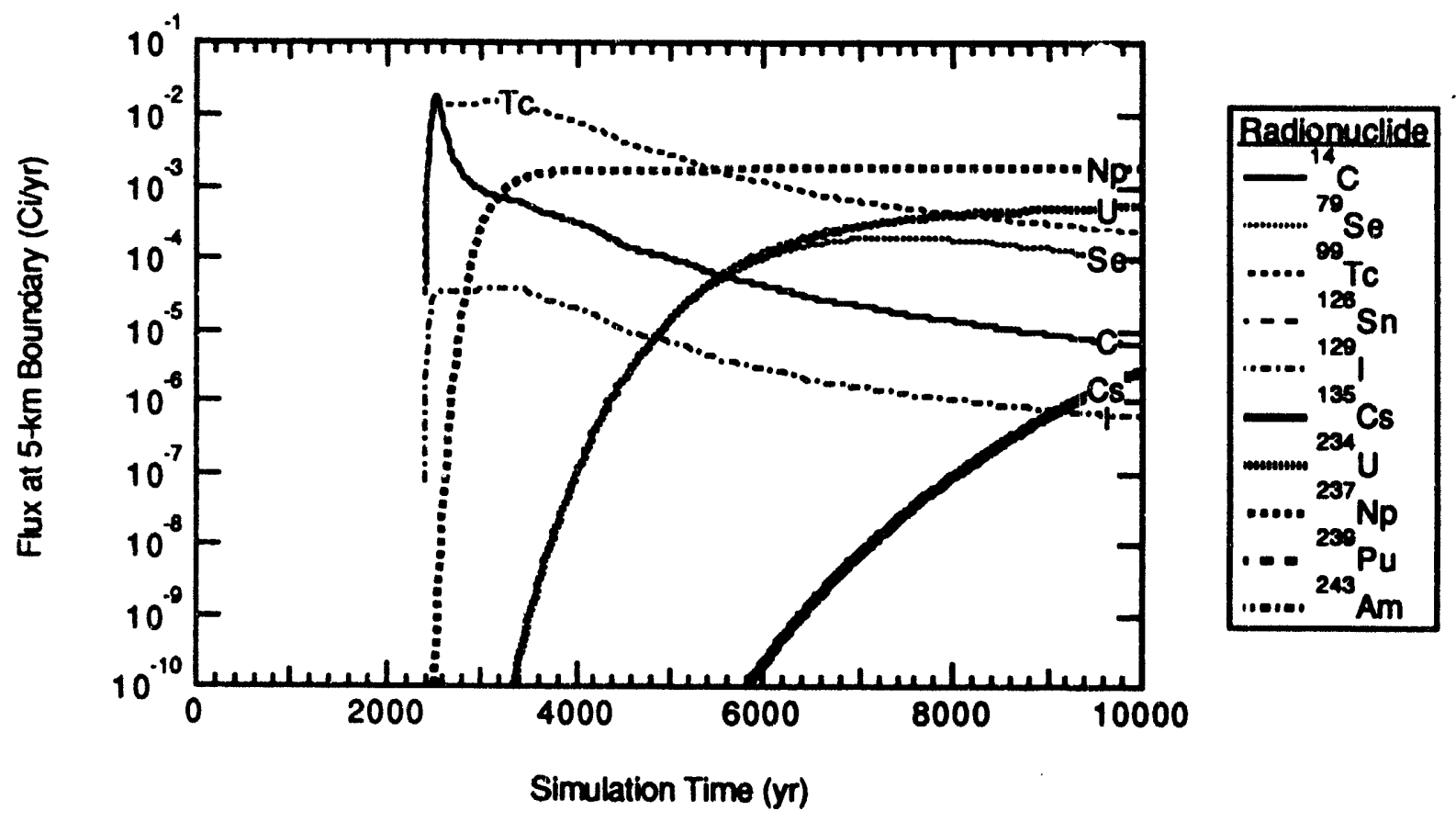

Figure 5.11. Radionuclide Flux at 5-km Boundary for Carbonate Simulation 1

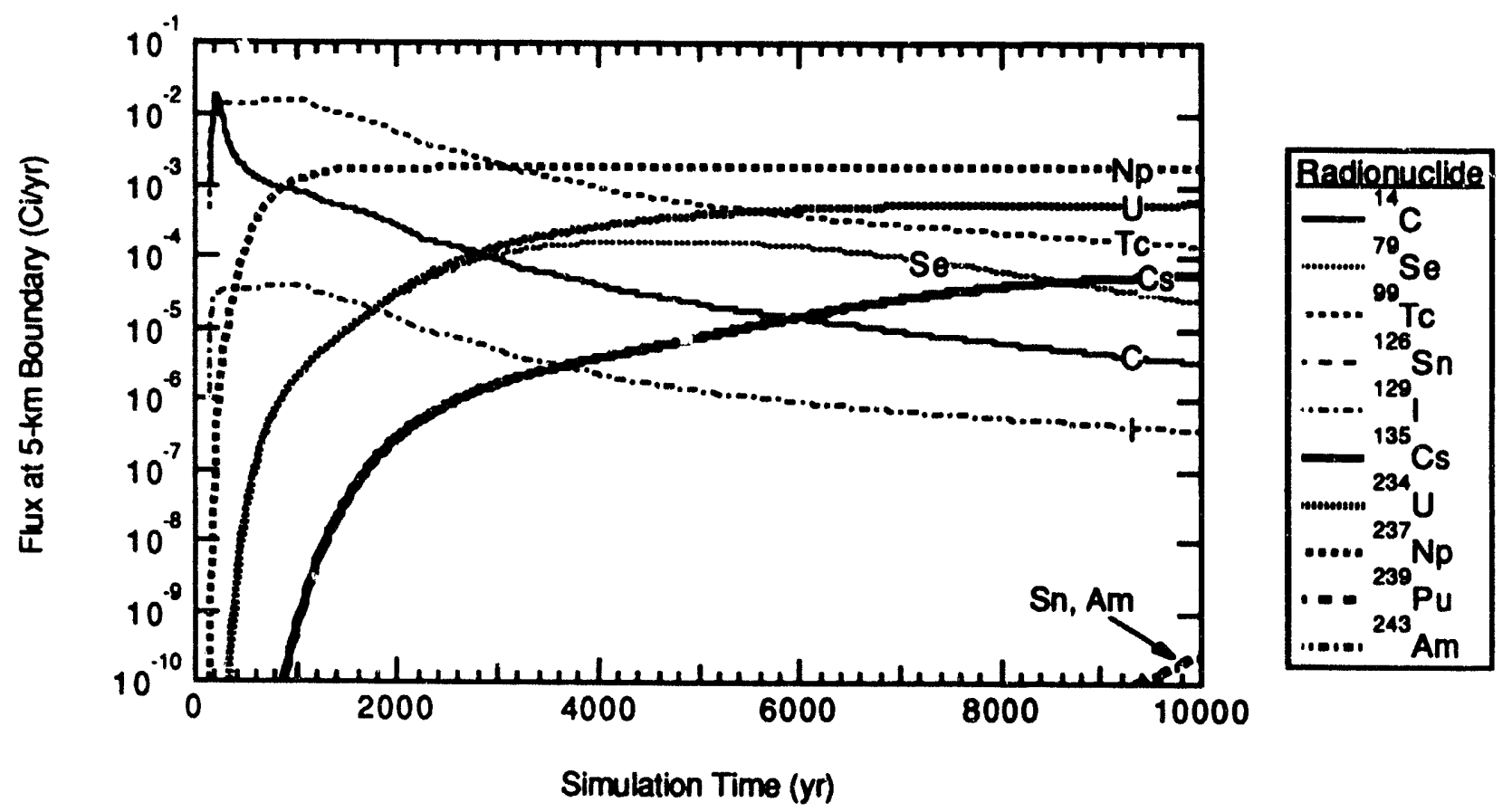

Figure 5.12. Radionuclide Flux at 5-km Boundary for Carbonate Simulation 2 


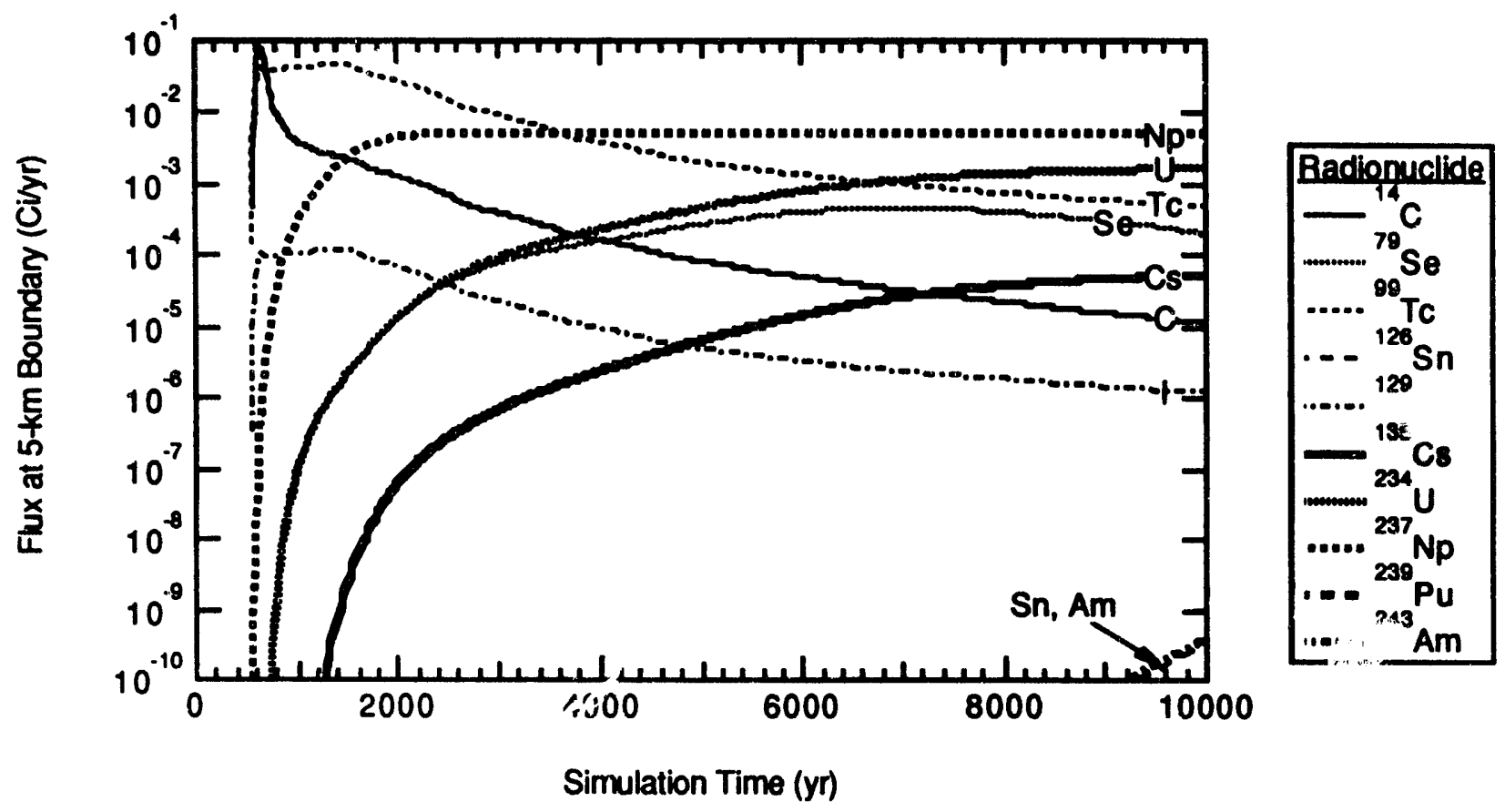

Figure 5.13. Radionuclide Flux at 5-km Boundary for Carbonate Simulation 3

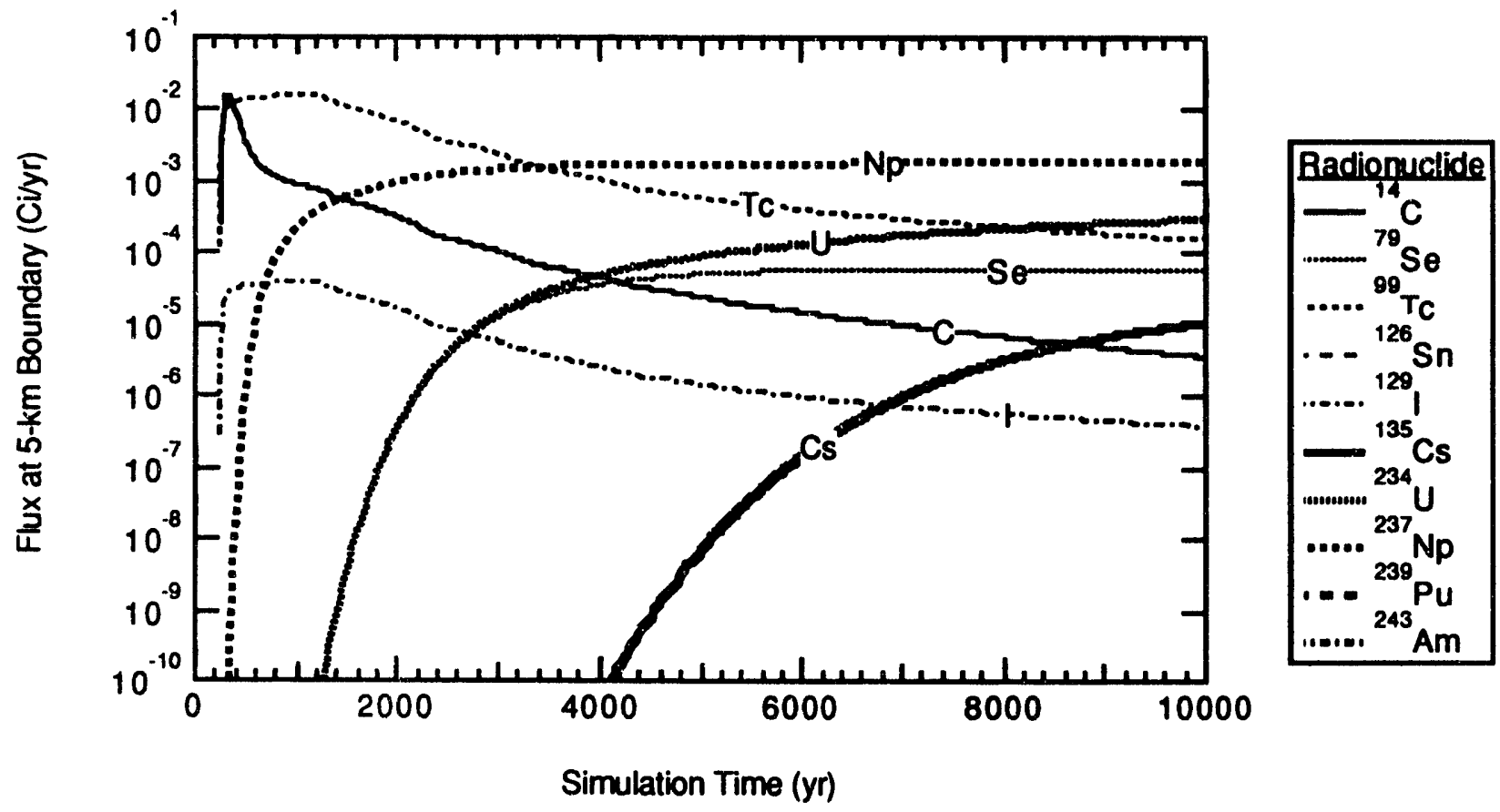

Figure 5.14. Radionuclide Flux at 5-km Boundary for Carbonate Simulation 4 


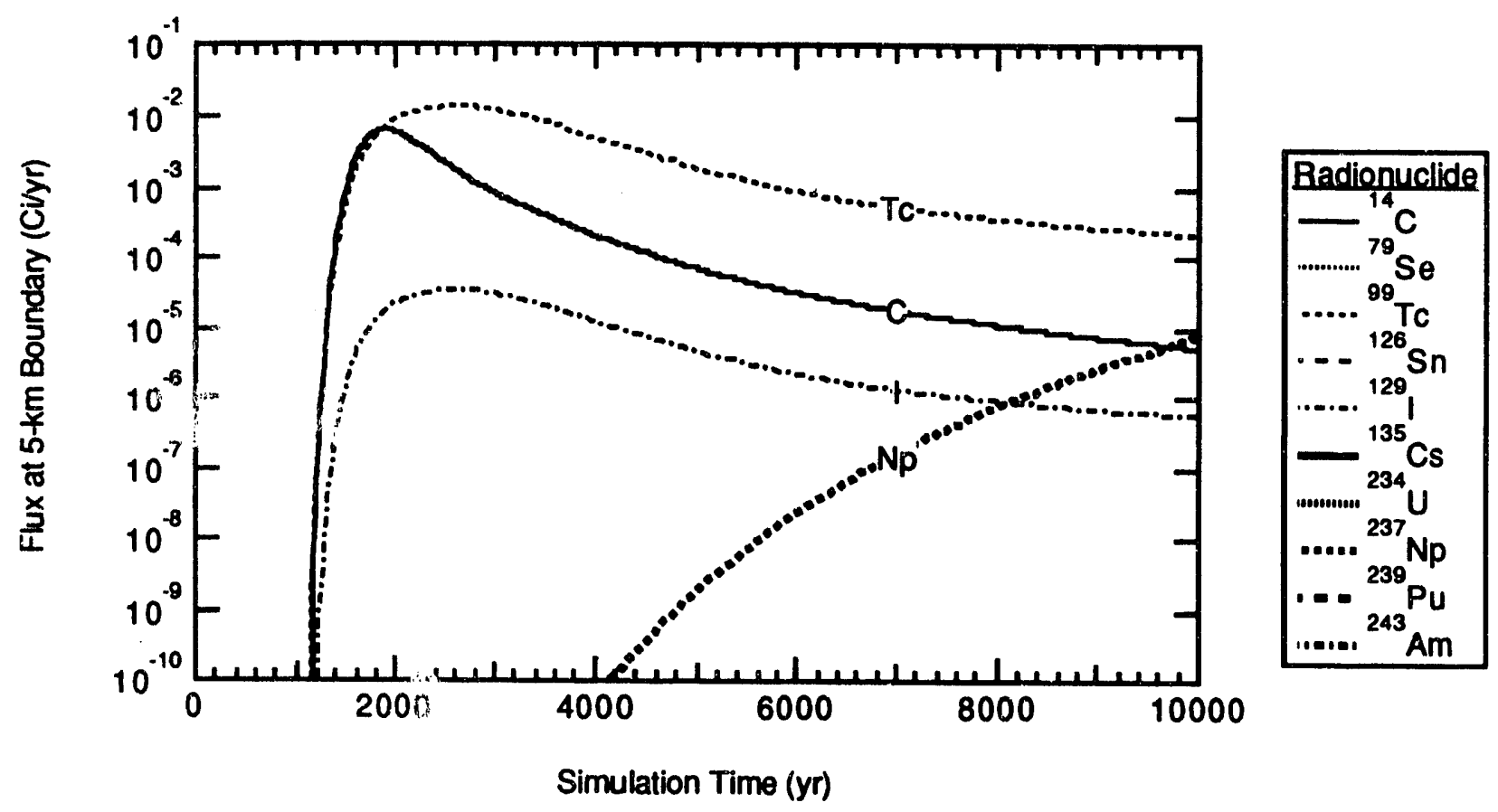

Figure 5.15. Radionuclide Flux at 5-km Boundary for Carbonate Simulation 5

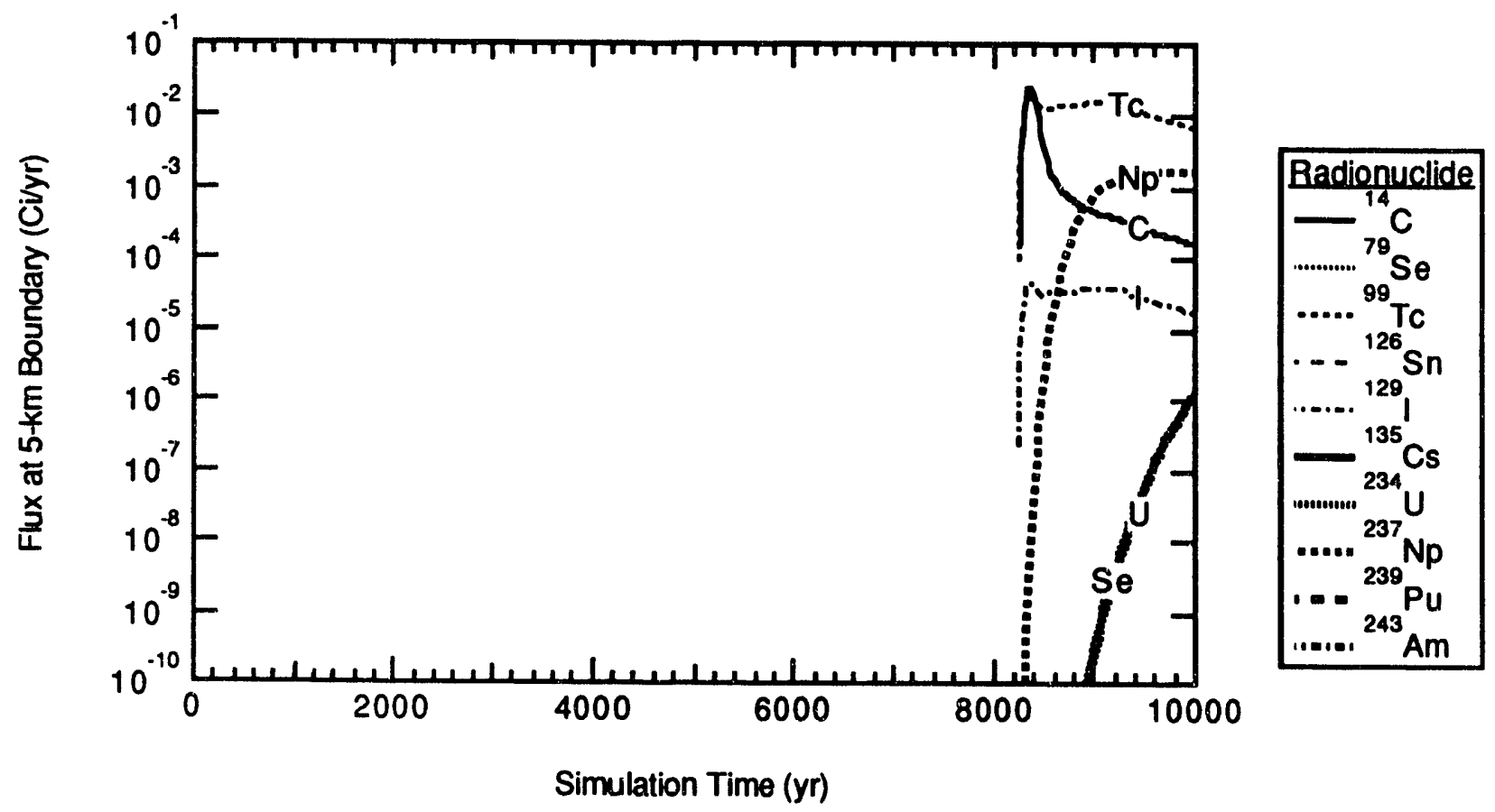

Figure 5.16. Radionuclide Flux at 5-km Boundary for Carbonate Simulation 6 


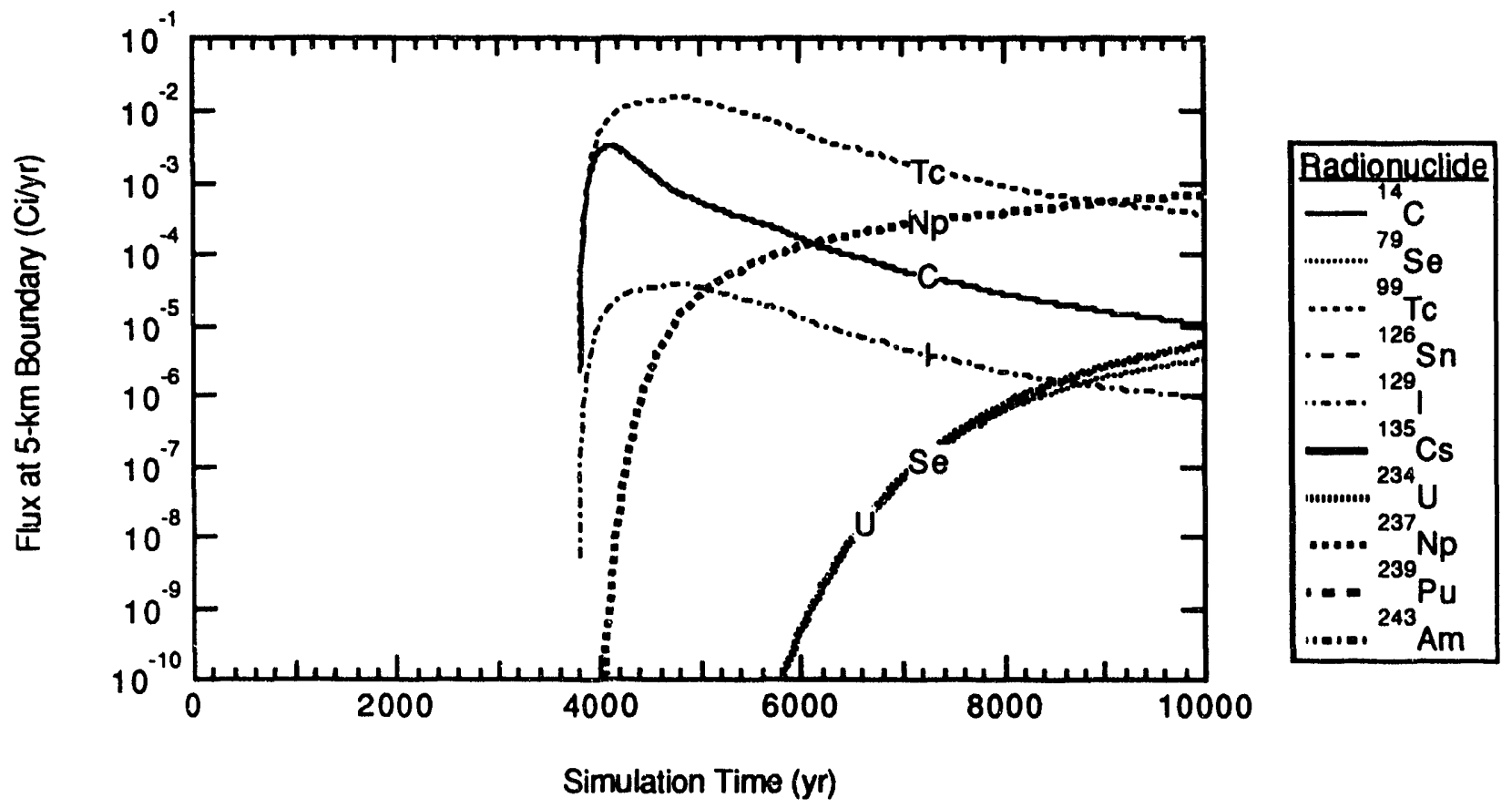

Figure 5.17. Radionuclide Flux at 5-km Boundary for Carbonate Simulation 7

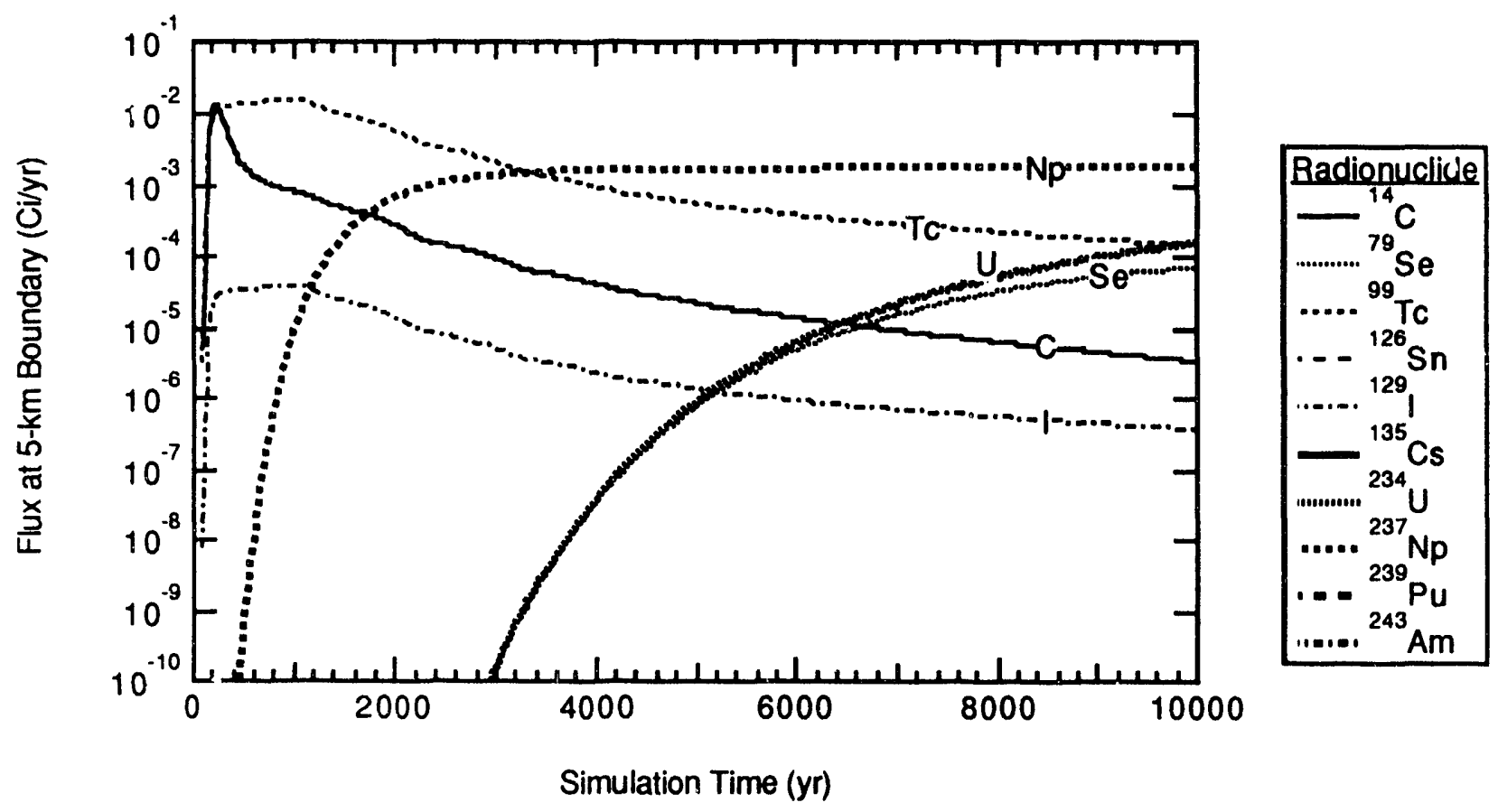

Figure 5.18. Radionuclide Flux at 5-km Boundary for Carbonate Simulation 8 


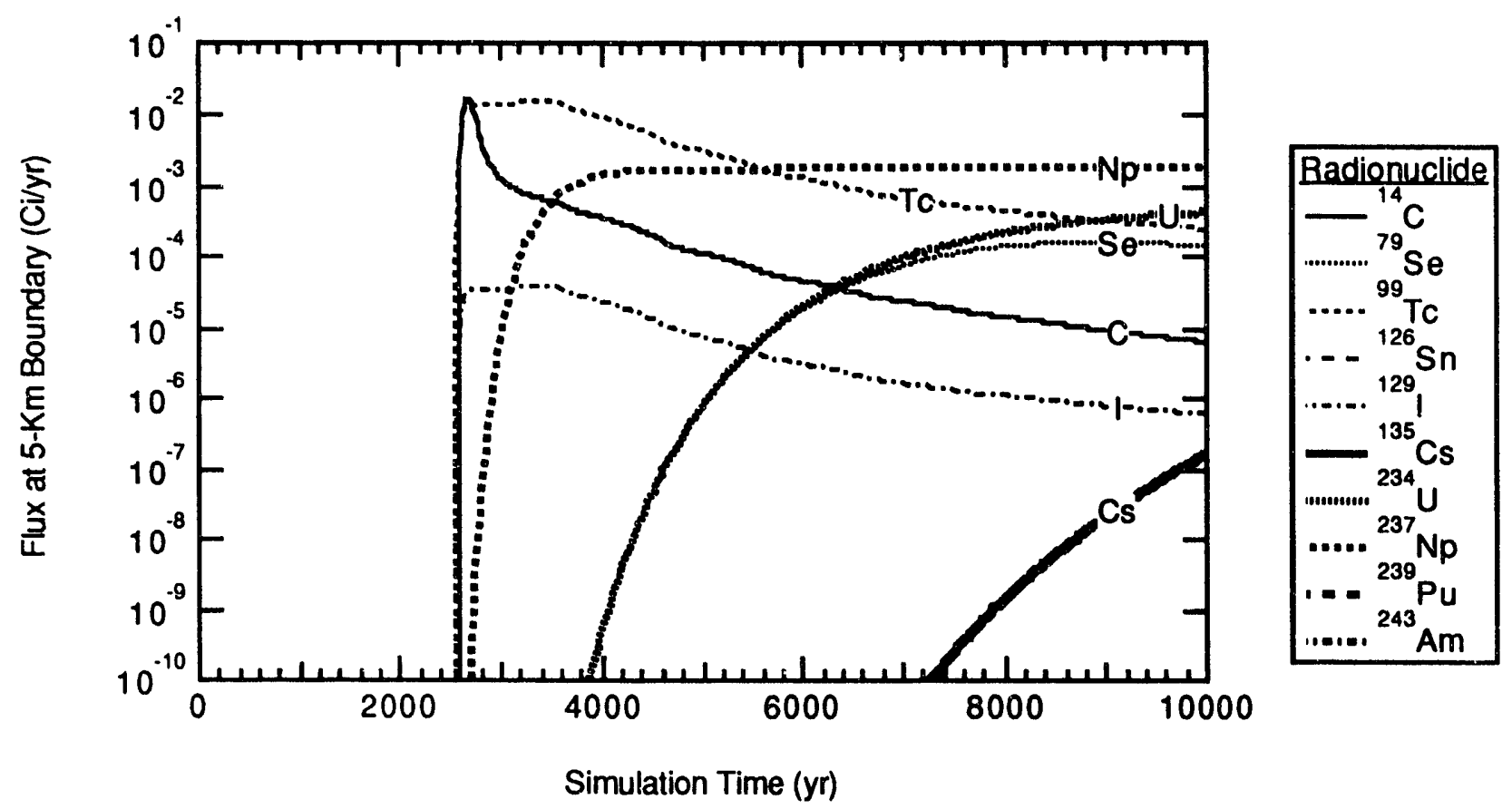

Figure 5.19. Radionuclide Flux at 5-km Boundary for Carbonate Simulation 9
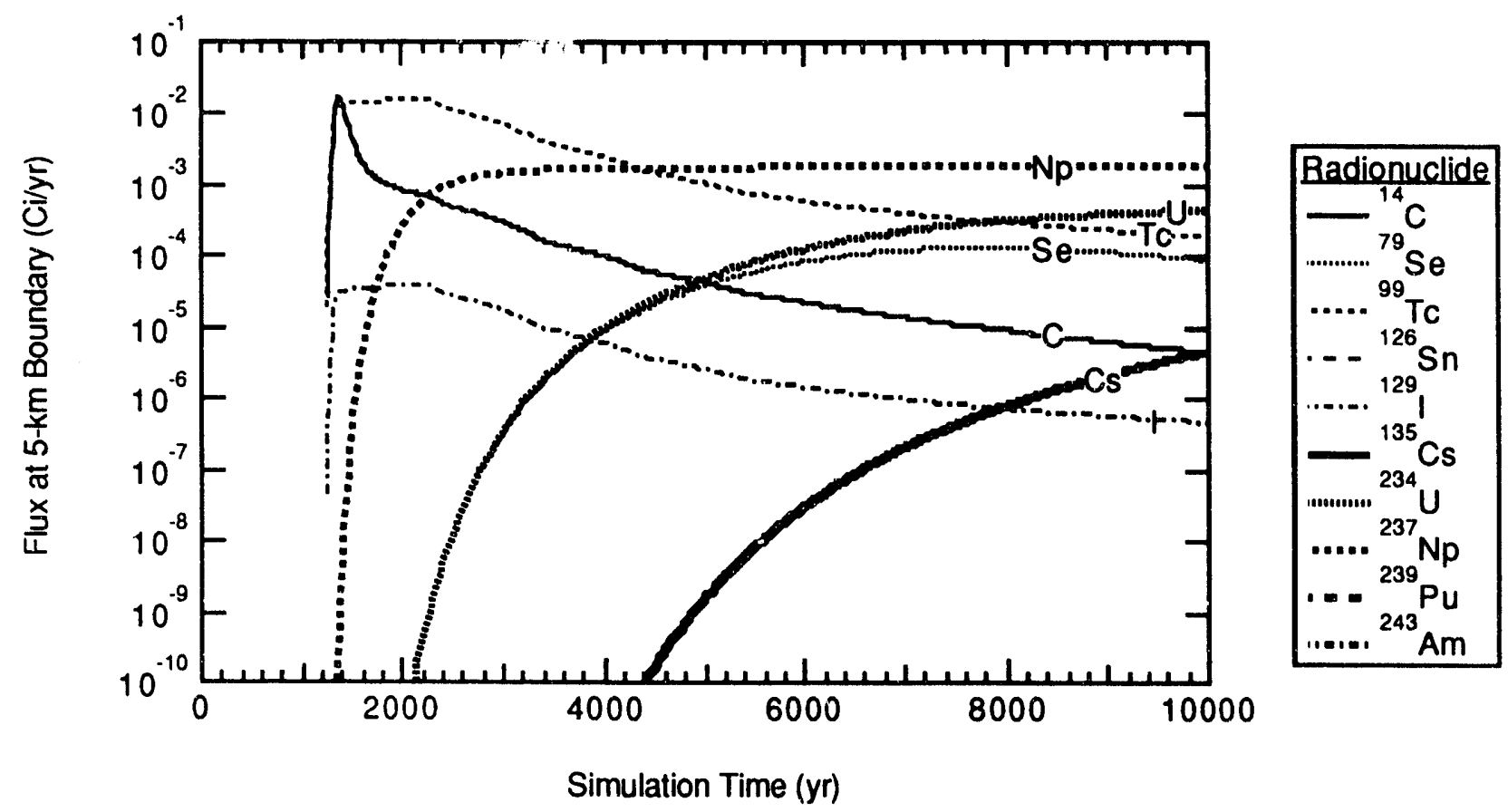

Figure 5.20. Radionuclide Flux at $5-\mathrm{km}$ for Carbonate Simulation 10 


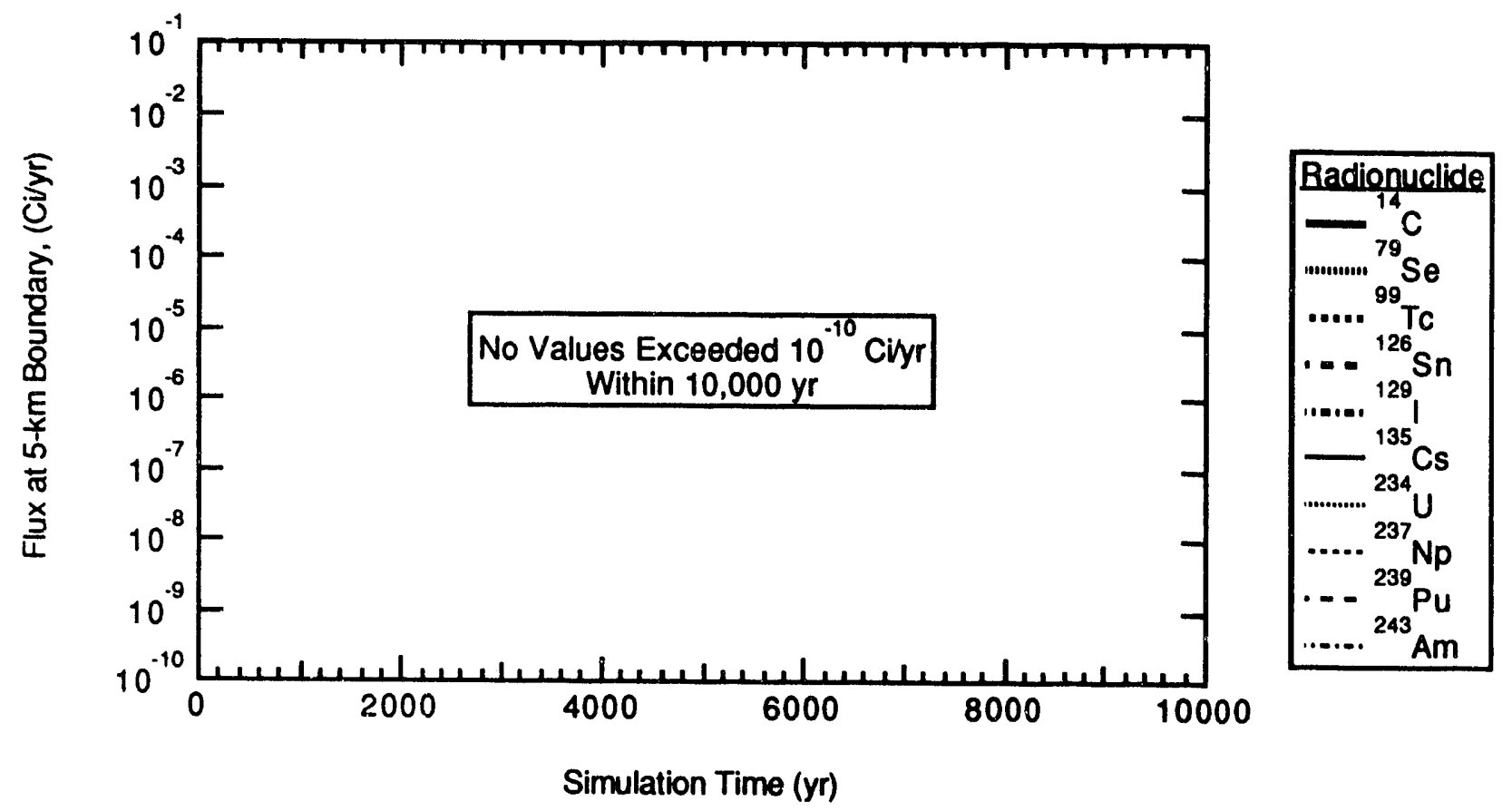

Figure 5.21. Radionuclide Flux at 5-km Boundary for Carbonate Simulation 11

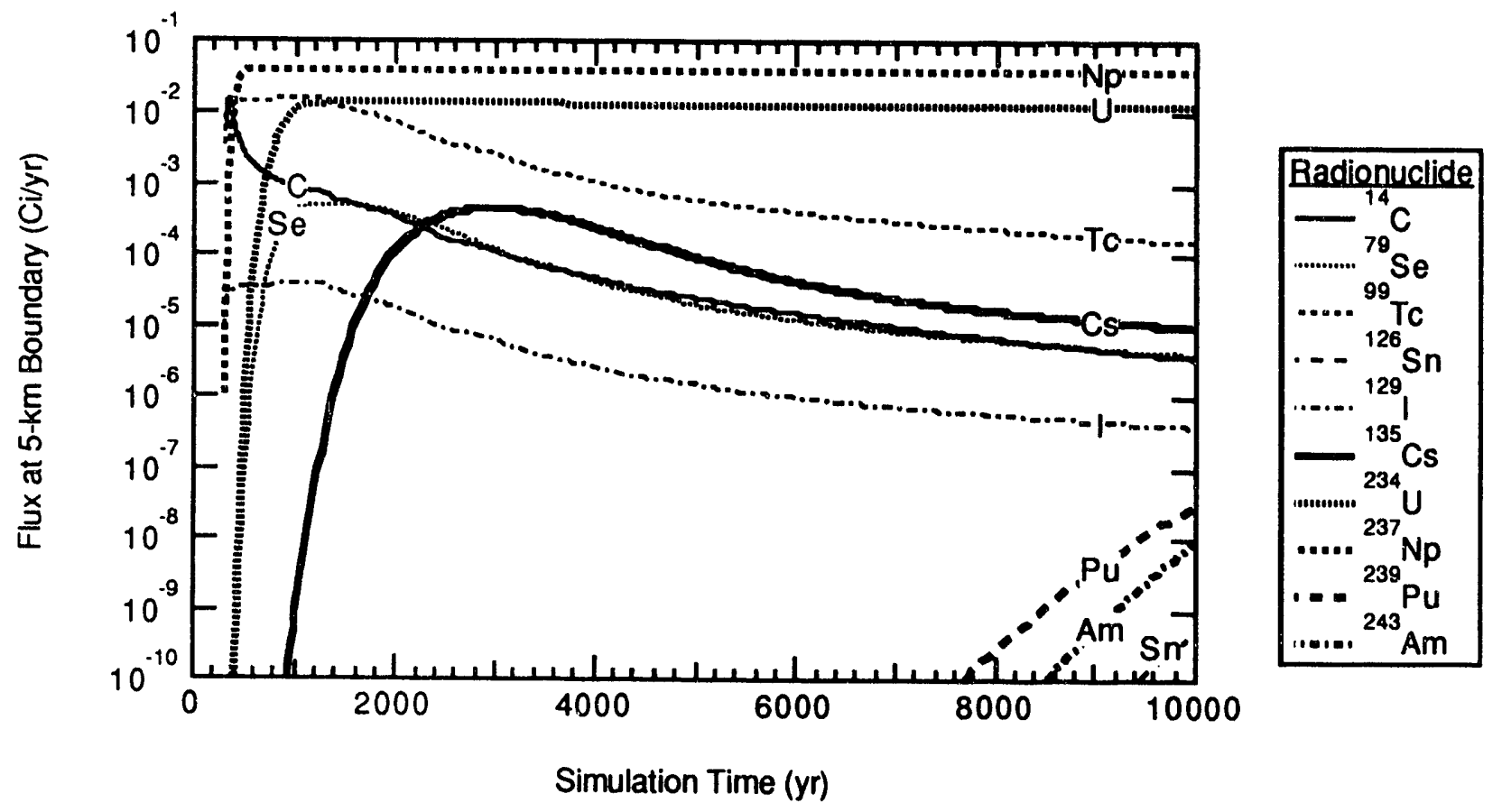

Figure 5.22. Radionuclide Flux at 5-km Boundary for Carbonate Simulation 12 
Table 5.5. Cumulative Radionuclide Releases at 10,000 Years Across the $5-\mathrm{km}$ Boundary for Carbonate-Aquifer Simulations of Human-Intrusion Scenario Direct-Injection Case

\begin{tabular}{|c|c|c|c|c|c|c|c|c|c|}
\hline $\begin{array}{l}\text { Radio- } \\
\text { nuclide }\end{array}$ & $\begin{array}{c}\text { EPA Release } \\
\text { Limit for } \\
\text { 70,000 MTU } \\
\text { Repository (Ci }\end{array}$ & i) $\frac{\mathrm{Ci}}{\text { Carbor }}$ & $\underline{\text { EPA Ratio }}$ & $\begin{array}{l}\text { Ci } \\
\text { Carbor }\end{array}$ & $\begin{array}{l}\text { EPARatio } \\
\text { nate } 2\end{array}$ & $\begin{array}{l}\mathrm{Ci} \\
\text { Carbo }\end{array}$ & $\begin{array}{l}\text { EPA Ratio } \\
\text { nate } 3\end{array}$ & $\begin{array}{l}\text { Ci } \\
\text { Carbor }\end{array}$ & EPA Ratio \\
\hline${ }^{14} \mathrm{C}$ & 7000 & 3.48 & 4.97 & 3.34 & 4.7 & $1.26 \mathrm{E}+01$ & 1.8 & 3.66 & -04 \\
\hline${ }^{79} \mathrm{Se}$ & 700 & $6.15 \mathrm{I}$ & 8.7 & & & & & 3.30E-01 & -06 \\
\hline${ }^{126} \mathrm{~S} n$ & 70000 & $2.66 \mathrm{E}+01$ & $3.80 \mathrm{~F}$ & +01 & 3.80 & $8.06 E+01$ & $1.15 \mathrm{E}-03$ & $2.67 E+01$ & $3.81 \mathrm{E}-04$ \\
\hline${ }^{99} \mathrm{Tc}$ & 700000 & 0 & 0 & 00E-07 & $2.43 \mathrm{E}-13$ & $2.00 \mathrm{E}-07$ & $2.44 \mathrm{E}-13$ & 0 & 0 \\
\hline 129I & 7000 & & 9.3 & & & & & & \\
\hline${ }^{135} \mathrm{Cs}$ & 700 & 1. & 2.39 & $E-01$ & 2.2 & EE-01 & 2.0 & $1.44 \mathrm{E}-02$ & $2.06 \mathrm{E}-07$ \\
\hline $234 \mathrm{U}$ & 70000 & 1.42 & 2.03 E-05 & 2.93 & $4.19 \mathrm{E}-05$ & 5.88 & $8.40 \mathrm{E}-05$ & 9.79E-02 & $1.40 \mathrm{E}-06$ \\
\hline${ }^{237} \mathrm{~Np}$ & 7000 & $1.07 \mathrm{E}+01$ & $1.53 \mathrm{E}-03$ & 01 & $2.09 \mathrm{E}-03$ & & & $1.27 \mathrm{E}+01$ & $1.81 \mathrm{E}-03$ \\
\hline Pu & & 0 & 0 & & & & & 0 & 0 \\
\hline${ }^{243} \mathrm{Am}$ & 7000 & 0 & 0 & $2.00 \mathrm{E}-07$ & $2.17 \mathrm{E}-11$ & 2.00E-07 & $2.94 \mathrm{E}-11$ & 0 & 0 \\
\hline
\end{tabular}

\begin{tabular}{|c|c|c|c|c|c|c|c|c|c|}
\hline \multirow[b]{2}{*}{${ }^{14} \mathrm{C}$} & \multirow[b]{2}{*}{7000} & \multicolumn{2}{|c|}{ Carbonate 5} & \multicolumn{2}{|c|}{ Carbonate 6} & \multicolumn{2}{|c|}{ Carbonate 7} & \multicolumn{2}{|c|}{ Carbonate 8} \\
\hline & & 5.54 & $7.91 \mathrm{E}-04$ & 3.61 & $5.16 \mathrm{E}-04$ & 2.27 & $3.24 \mathrm{E}-04$ & 3.48 & 4.97E-04 \\
\hline${ }^{79} \mathrm{Se}$ & 70000 & 0 & 0 & $1.00 \mathrm{E}-04$ & $2.10 \mathrm{E}-09$ & $3.70 \mathrm{E}-03$ & $5.23 \mathrm{E}-08$ & $1.30 \mathrm{E}-01$ & $1.86 \mathrm{E}-06$ \\
\hline${ }^{126} \mathrm{Sn}$ & 70000 & $2.71 E+01$ & $3.87 \mathrm{E}-04$ & $1.99 \mathrm{E}+01$ & $2.84 \mathrm{E}-04$ & $2.54 E+01$ & $3.63 \mathrm{E}-04$ & $2.67 E+01$ & $3.81 \mathrm{E}-04$ \\
\hline${ }^{99} \mathrm{Tc}$ & 700000 & 0 & 0 & 0 & 0 & 0 & 0 & 0 & 0 \\
\hline $129 \mathrm{I}$ & 7000 & $6.69 \mathrm{E}-02$ & $9.56 \mathrm{E}-06$ & $4.98 \mathrm{E}-02$ & $7.11 \mathrm{E}-06$ & $6.31 \mathrm{E}-01$ & $9.01 \mathrm{E}-05$ & $6.45 \mathrm{E}-02$ & $9.21 \mathrm{E}-06$ \\
\hline${ }^{135} \mathrm{Cs}$ & 70000 & 0 & 0 & 0 & 0 & $2.00 \mathrm{E}-09$ & $2.16 \mathrm{E}-14$ & $3.00 \mathrm{E}-08$ & $3.90 \mathrm{E}-13$ \\
\hline${ }^{234} \mathrm{U}$ & 70000 & 0 & 0 & $2.00 \mathrm{E}-04$ & $2.94 \mathrm{E}-09$ & $5.40 \mathrm{E}-03$ & 7.64E-08 & $2.35 \mathrm{E}-01$ & $3.36 \mathrm{E}-06$ \\
\hline${ }^{237} \mathrm{~Np}$ & 7000 & $6.23 \mathrm{E}-03$ & $8.90 \mathrm{E}-07$ & 1.44 & $2.06 \mathrm{E}-04$ & 1.50 & $2.14 \mathrm{E}-04$ & $1.22 \mathrm{E}+01$ & $1.74 \mathrm{E}-03$ \\
\hline${ }^{239} \mathrm{Pu}$ & 7000 & 0 & 0 & 0 & 0 & 0 & 0 & 0 & 0 \\
\hline${ }^{243} \mathrm{Am}$ & 7000 & 0 & 0 & 0 & 0 & 0 & 0 & 0 & 0 \\
\hline
\end{tabular}

\begin{tabular}{|c|c|c|c|c|c|c|c|c|c|}
\hline \multirow[b]{2}{*}{${ }^{14} \mathrm{C}$} & \multirow[b]{2}{*}{7000} & \multicolumn{2}{|c|}{ Carbonate 9} & \multicolumn{2}{|c|}{ Carbonate 10} & \multicolumn{2}{|c|}{ Carbonate 11} & \multicolumn{2}{|c|}{ Carbonate 12} \\
\hline & & 3.40 & $4.86 \mathrm{E}-04$ & 3.44 & $4.91 \mathrm{E}-04$ & 0 & 0 & 2.81 & $4.01 \mathrm{E}-04$ \\
\hline${ }^{79} \mathrm{Se}$ & 70000 & $4.26 \mathrm{E}-01$ & $6.96 \mathrm{E}-06$ & $8.10 \mathrm{E}-01$ & $1.16 \mathrm{E}-05$ & 0 & 0 & $8.27 \mathrm{E}-01$ & $1.18 \mathrm{E}-05$ \\
\hline${ }^{126} \mathrm{Sn}$ & 70000 & $2.64 \mathrm{E}+01$ & $3.77 \mathrm{E}-04$ & $2.60 \mathrm{E}+01$ & $3.71 E-04$ & 0 & 0 & $2.70 \mathrm{E}+01$ & $3.86 \mathrm{E}-04$ \\
\hline${ }^{99} \mathrm{Tc}$ & 700000 & 0 & 0 & 0 & 0 & 0 & 0 & $2.00 \mathrm{E}-07$ & $2.49 \mathrm{E}-13$ \\
\hline 129$]$ & 7000 & $6.30 \mathrm{E}-02$ & $8.93 \mathrm{E}-06$ & $6.43 \mathrm{E}-02$ & $1.86 \mathrm{E}-05$ & 0 & 0 & $6.61 \mathrm{E}-02$ & $9.44 \mathrm{E}-06$ \\
\hline${ }^{135} \mathrm{Cs}$ & 70000 & $8.00 \mathrm{E}-05$ & $1.08 \mathrm{E}-09$ & $9.05 \mathrm{E}-01$ & $1.29 \mathrm{E}-05$ & 0 & 0 & $9.92 \mathrm{E}-01$ & $1.42 \mathrm{E}-05$ \\
\hline $234 \mathrm{U}$ & 70000 & $7.99 \mathrm{E}-01$ & $1.14 \mathrm{E}-05$ & 3.91 & $5.59 \mathrm{E}-05$ & 0 & 0 & $1.12 E+02$ & $1.60 \mathrm{E}-03$ \\
\hline${ }^{237} \mathrm{~Np}$ & 7000 & $1.01 \mathrm{E}+01$ & $1.44 \mathrm{E}-03$ & $1.18 \mathrm{E}+01$ & $1.69 \mathrm{E}-03$ & 0 & 0 & $3.54 \mathrm{E}+02$ & $5.06 \mathrm{E}-02$ \\
\hline${ }^{239} \mathrm{Pu}$ & 7000 & 0 & 0 & 0 & 0 & 0 & 0 & $1.00 \mathrm{E}-05$ & 2.03E-09 \\
\hline${ }^{243} \mathrm{Am}$ & 7000 & 0 & 0 & 0 & 0 & 0 & 0 & $3.00 \mathrm{E}-06$ & $4.66 \mathrm{E}-10$ \\
\hline
\end{tabular}


The first ten carbonate simulations (Carbonate Simulations 1 through 10) were then repeated for two realizations to allow definition of a statistical distribution of the transport in the saturated zone. These calculations were made using a broader grid spacing than the previous 12 simulations, although the size of the simulated area remained the same $(4000 \mathrm{~m}$ by $7000 \mathrm{~m})$. A distribution of sorption values, shown in the stochastic column of the Carbonate values in Table 5.4 were used to describe the retardation effects of sorption in these simulations. Chain decay from ${ }^{243} \mathrm{Am}$ to ${ }^{239} \mathrm{Pu}$ within the simulated domain was modeled. All Americium was assumed to decay to $239 \mathrm{Pu}$, with an Americium half-life of 7380 years. The dispersivity was defined as 500 in the longitudinal direction and 200 in the transverse direction for all simulations. The cumulative releases for each radionuclide over the two realizations are shown in Table 5.6, along with the respective drilling times.

Only the tuff maximum-flow case (Tuff Simulation 12) was used for transport simulations because the remaining 11 simulations were calculated to have transport times significantly larger than the 10,000-year period defined by the regulatory controls. Calculation of radionuclide flux for the maximum tuff flow simulation used a single sorption value for each radionuclide in each tuff lithology, a longitudinal dispersivity of 500, and a transverse dispersivity of 200 .

Saturated-zone transport of ${ }^{14} \mathrm{C}$ released from the repository in the gas phase was also modeled using Tuff Simulation $12 .{ }^{14} \mathrm{C}$ was introduced at the water table (the upper boundary to the simulated hydrologic domain) along a plane $1 \mathrm{~km}$ in length, and transported through the aquifer in dissolved form. It was assumed that all ${ }^{14} \mathrm{C}$ in contact with the upper boundary dissolved into the saturated zone, and that thermal equilibrium between the gas and the porous media had been attained before the gas was in proximity to the water table. A sorption value of zero was used for the ${ }^{14} \mathrm{C}$ reaction with the porous media, and a longitudinal and transverse dispersivity value of 1 . ${ }^{14} \mathrm{C}$ flux at the $5 \mathrm{~km}$ boundary was calculated as a function of time over 10,000 years. The result is shown in Figure 5.24.

\subsubsection{Analysis}

Radionuclide fluxes across the 5-km boundary show a strong dependence on the sorption values chosen for the individual radionuclides, and the gradient driving the water flow in the flow field. The plots of radionuclide flux for Carbonate Simulations 1 through 10 (Figures 5.11 through 5.20) show values for only seven radionuclides. The remaining three radioisotopes ( $\mathrm{Pu}$, $\mathrm{Am}_{\text {, and }} \mathrm{Tc}$ ) have high enough sorption values that there is no significant flux of these nuclides across the domain boundary. Within the maximum-flow regime shown in Figure 5.22, all radionuclides modeled eventually exceed fluxes of $10-10 \mathrm{Ci} / \mathrm{yr}$ at the $5-\mathrm{km}$ boundary. A range of hydraulic gradients was imposed on the simulated carbonate aquifer between 0.1630 to $6.089 \times 10^{-4}$. The smaller the hydraulic gradient, the longer it takes for the radionuclide flux curves to reach a peak in concentration. It appears that the influence of the hydraulic gradient on the flux concentration is not as significant as that of the sorption coefficients. A better definition of how the radionuclides sorb to the aquifer material will improve our capability to accurately predict their transport.

The tuff simulation showed only three radionuclides transported through the saturated environment. The hydraulic gradient in the tuff aquifer is approximately an order of magnitude less than those modeled for the carbonate simulations. In addition, the hydraulic conductivities of the two tuff lithologies were smaller by at least two orders of magnitude than those of the carbonate. As a result, the flux curves are attenuated substantially in the time period simulated, and only the 
Table 5.6. Cumulative Release of Radionuclides (Ci) to the Saturated Zone at 10,000 Years with Sorption Defined Stochastically

\begin{tabular}{|c|c|c|c|c|c|c|c|c|c|c|c|}
\hline Sim & $\begin{array}{c}\text { Drilling } \\
\text { Time } \\
\text { (years) }\end{array}$ & ${ }^{14} \mathrm{C}$ & ${ }^{79} \mathrm{Se}$ & ${ }^{126} \mathrm{Sn}$ & ${ }^{99} \mathrm{Tc}$ & $129 \mathrm{I}$ & ${ }^{135} \mathrm{Cs}$ & $234 \mathrm{U}$ & $237 \mathrm{~Np}$ & $239 \mathrm{Pu}$ & ${ }^{243} \mathrm{Am}$ \\
\hline 1 & 2465 & 3.48 & 0.615 & 26.6 & 0 & 0.0654 & 0.0017 & 1.42 & 10.7 & 0 & 0 \\
\hline 2 & 147 & 3.34 & 0.745 & 26.6 & $1.70 \mathrm{E}-7$ & 0.0653 & 0.159 & 2.93 & 14.6 & $1.25 \mathrm{E}-8$ & $1.52 \mathrm{E}-7$ \\
\hline $2^{(a)}$ & 147 & 4.88 & 0.844 & 27.2 & $1.23 \mathrm{E}-4$ & 0.0666 & 92.7 & 5.24 & 15.8 & 0 & 0 \\
\hline 3 & 589 & 12.6 & 1.98 & 80.6 & $1.71 \mathrm{E}-7$ & 0.198 & 0.146 & 5.88 & 40.6 & $1.38 \mathrm{E}-8$ & 2.06 E-7 \\
\hline 4 & 259 & 3.66 & 0.33 & 26.7 & 0 & 0.0655 & 0.0144 & 0.0979 & 12.7 & 0 & 0 \\
\hline $4(a)$ & 259 & 2.05 & 0.123 & 4.84 & 0 & 0.012 & 0.193 & 4.03 & 12.1 & 0 & 0 \\
\hline 5 & 1191 & 5.54 & 0 & 27.1 & 0 & 0.0669 & 0 & 0 & $6.23 \mathrm{E}-3$ & 0 & 0 \\
\hline 5 (a) & 1191 & 2.25 & 0.786 & 25.6 & 0 & 0.0632 & 0.897 & 4.25 & 12.8 & 0 & 0 \\
\hline 6 & 8336 & 3.61 & $1.47 \mathrm{E}-4$ & +19.9 & 0 & 0.0498 & 0 & $2.06 \mathrm{E}-4$ & $4 \quad 1.44$ & 0 & 0 \\
\hline $6(a)$ & 8336 & 3.62 & 0.654 & 19.8 & 0 & 0.0499 & 0.654 & 0.878 & 2.68 & 0 & 0 \\
\hline 7 & 3811 & 2.27 & $3.66 \mathrm{E}-3$ & 25.4 & 0 & 0.631 & $1.51 \mathrm{E}-9$ & 5.35E-3 & $3 \quad 1.5$ & 0 & 0 \\
\hline 8 & 129 & 3.48 & 0.13 & 26.7 & 0 & 0.0645 & $2.73 \mathrm{E}-8$ & 0.235 & 12.2 & 0 & 0 \\
\hline $8(a)$ & 129 & 3.13 & 0.82 & 26.5 & 0 & 0.065 & 0.919 & 5.23 & 15.7 & 0 & 0 \\
\hline 9 & 2616 & 3.4 & 0.426 & 26.4 & 0 & 0.0625 & 7.59E-5 & 0.799 & 10.1 & 0 & 0 \\
\hline 9 (a) & 2616 & 2.63 & 0.81 & 26 & 0 & 0.0643 & 0.905 & 3.91 & 11.81 & 0 & 0 \\
\hline 10 & 1308 & 3.44 & 0.493 & 26.6 & 0 & 0.0655 & $4.85 \mathrm{E}-3$ & 1.21 & 12 & 0 & 0 \\
\hline 10 (a) & 1308 & 2.68 & 0.812 & 26.2 & 0 & 0.645 & 0.912 & 4.61 & 13.9 & 0 & 0 \\
\hline 11 & 300 & 0 & 0 & 0 & 0 & 0 & 0 & 0 & 0 & 0 & 0 \\
\hline 12 & 300 & 2.81 & 0.827 & 27 & $1.74 \mathrm{E}-7$ & 0.0661 & 0.992 & 112 & 354 & $1.42 \mathrm{E}-5$ & $3.26 \mathrm{E}-6$ \\
\hline \multicolumn{2}{|c|}{ Sorption } & 0 & 3 & 110 & 0 & 0 & 10 & 3 & 0.5 & 80 & 110 \\
\hline \multirow[t]{2}{*}{$\overline{(a)}$} & tion & listrib & the & & & & & & & & \\
\hline & & $0-0$ & $0-6$ & $60-170$ & $0-0$ & $0-0$ & $0-20$ & 0.6 & $0-1$ & $25-135$ & $60-160$ \\
\hline
\end{tabular}

radionuclides with a zero-sorption value cross the $5-\mathrm{km}$ boundary of the simulated domain with fluxes in excess of $10^{-10} \mathrm{Ci} / \mathrm{yr}$.

Introduction of ${ }^{14} \mathrm{C}$ into the saturated zone was assumed to be a result of complete dissolution of the gaseous phase of carbon into an aqueous phase. The actual concentration that is capable of being dissolved and the chemical reactions of precipitation and sorption are likely to influence the simulation of ${ }^{14} \mathrm{C}$ transport in the saturated zone. A better model of $14 \mathrm{C}$ dissolution and reaction in the aqueous phase and with respect to the tuff lithologies will facilitate a more realistic model of that radionuclides transport in the saturated zone. 


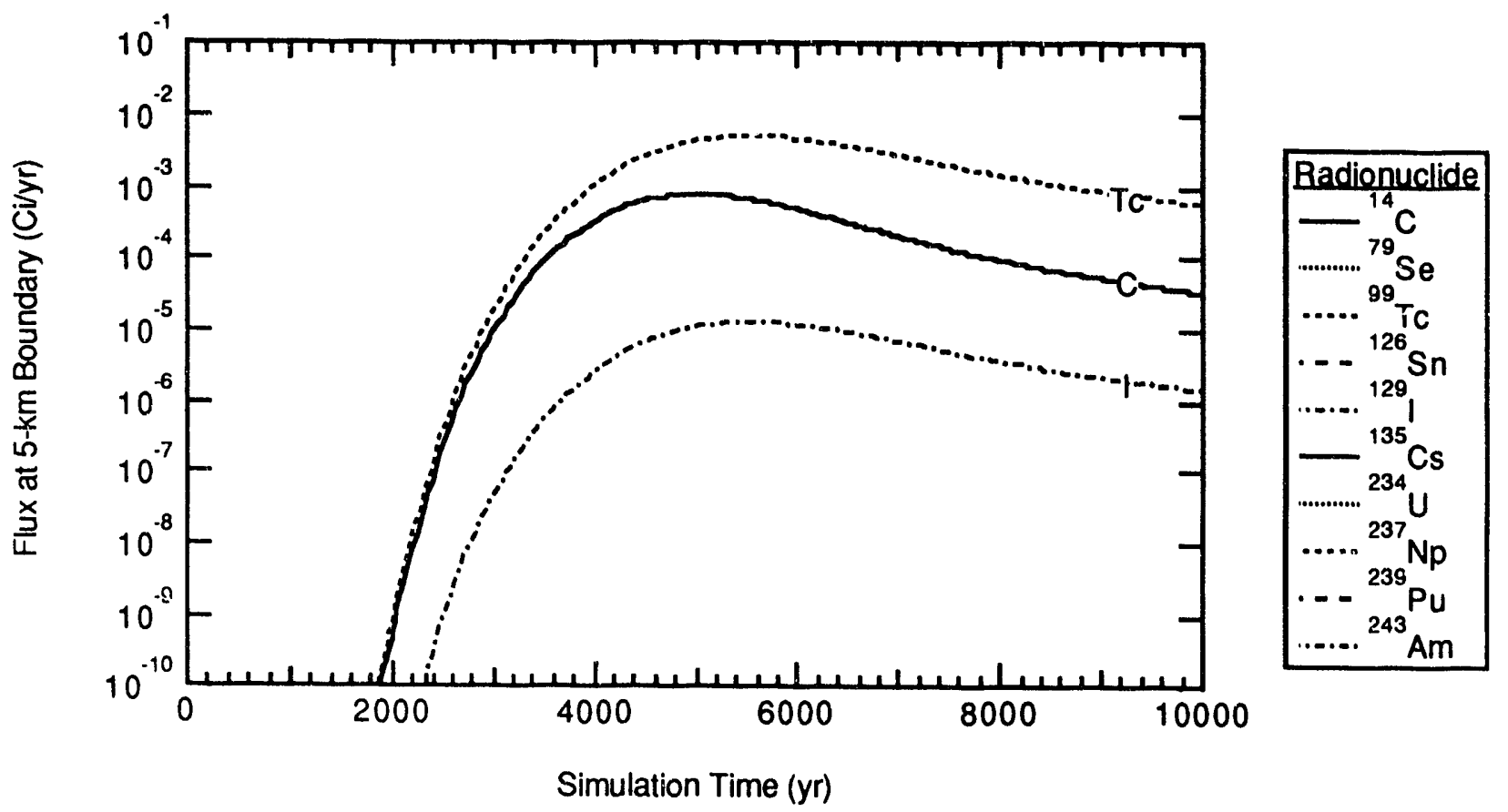

Figure 5.23. Radionuclide Flux at 5-km Boundary for Tuff Simulation 12

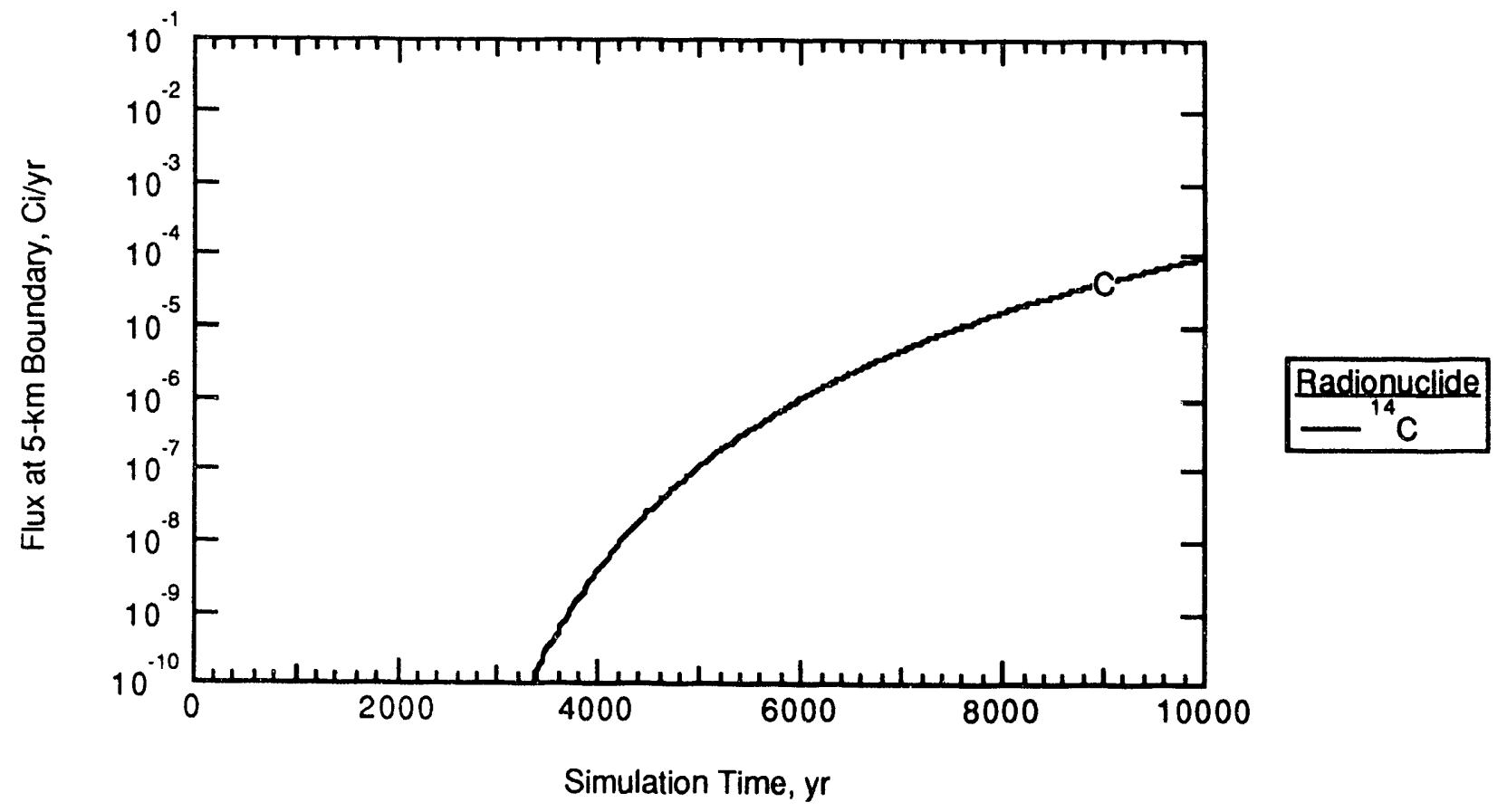

Figure 5.24. ${ }^{14} \mathrm{C}$ Flux Across the 5-km Boundary Using Maximum-Flow Field Parameters 


\subsection{Volcanic Intrusion Model}

The goal of this element of the total system performance assessment is to evaluate the consequences of disruption of the potential repository and the uncontrolled release of radionuclides to the accessible environment because of the subsurface and surface activity of a basaltic magmatic center. The subsurface activity would comprise dikes, sills, and/or other intruded magma bodies, and the surface activity is assumed to be a Strombolian eruption of alkalic basalt and the construction of one or more cinder cones. This scenario is based upon an interpretation of the Quaternary volcanic record in southwestern Nevada and surroundings (Luedke and Smith 1981; Crowe et al. 1983a; Smith and Luedke 1984). In the context of the general total system performance assessment, PNL was asked to model the consequences of this scenario under physical and volcanological rigor and to examine the assumptions, expert opinions, and simplifications used in "abstracted" consequence modeling. The input data and parameters were to be consistent with the results of the investigation described in the Yucca Mountain Site SCP (DOE 1988) or analogous systems.

Because of the limited FY 1991 scope, PNL did not complete these goals. However, the team made important preliminary steps. Miodeling of eruptive probability was conceptual, and this report will only present a discussion of future quantitative activities necessary to the total system performance assessment programmatic objectives. Consequence modeling was advanced slightly further and an exploratory physical model was constructed. The results are preliminary and should only be used to scope out further investigations.

\subsection{Approach}

Physical modeling of magmatic and volcanological processes is not developed (Jaupart and Tait 1990; Luhr and Williams 1991) such that general predictions of eruptive behavior at a given site are justified. Because of this, the general modeling of contaminant fate along a volcanictransport pathway can not produce the level of statistical significance of, for example, a groundwater pathway. In some cases (some examples; Kilauea volcano, Hawaii, Mt. St. Helens, Washington, and Plosky Tolbachik, Russia) where numerous data have been collected, limited predictive modeling or "forecasting" (Tilling 1989) is tenable. Even in these cases, data validation and verification is commonly not statistically significant. This condition exists because of both the infrequent historic occurrence of eruptions and limited extent of data collection and analysis.

Given this condition, however, the modeling of eruptive events can be instructive if certain aspects are explicitly considered:

- The physical parameter appropriate to a problem may be both temporally and spatially scaledependent and can not be generalized.

- The parameters can be both coupled and nonlinear, requiring a solid theoretical and intuitive understanding of the relevant processes and geologic record.

- Volcanic eruptions are not a random process. 
In brief, these considerations define the clear need for site-specific, complex physical modeling of the "most likely" scenario, and these problems are not unique to either the total system performance assessment or to Yucca Mountain.

For this first iteration of total system performance assessment work, we decided that these fundamental problems compounded the anticipated difficulty inherent in creating a model from scratch. For this reason, the PNL team used a simple, but well-described, research model that had undergone peer review and publication in open literature. The model was coupled to a wellverified, Monte Carlo-based, parametric model. The mass fraction of inventory released was to be used as input to the general CCDF consequence model used for base and human-intrusion scenarios. Again, because of its exploratory nature, this work does not carry quantitative significance. It does demonstrate the need for a better understanding of the parameters and objectives of magmatic modeling.

The following sections 1) present the basic rationale and construction of the basaltic volcanism consequence models, 2) describe the results achieved and the qualitative conclusions, 3) discuss some general aspects of current eruptive prediction estimates, and 4) present our findings and recommendations for the next iteration of total system performance assessment calculations.

\subsection{Basaltic Volcanism-Consequence Model Selection}

The primary objective of this part of the project was to locate and adapt a realistic but simple dike-emplacement model and attempt to generate a stochastic set of magmatic emplacement parameters. This activity would test our ability to couple complex physical models to the larger CCDF computational regime.

In defining the details of the basaltic volcanism scenario, the studies of Crowe and Sargent (1979), Crowe et al. (1983a, 1983b, 1986, 1989), Faulds et al. (1991), and Wells et al. (1990) comprised the primary reference sources. These reports suggest that the intrusion of alkalic basalt magma was episodically active throughout the Yucca Mountain area (the area shown in Figure 6.1) over the last 8.5 million years. The conduits fed Strombolian and, rarely, Surtseyan eruptions that constructed small-volume (from $10^{6}$ to $10^{7} \mathrm{~m}^{3}$ ) cinder cones, limited lava flows, and equivalent vent-proximal pyroclastic deposits. Dikes are the most common intrusive bodies. There is no indication that conduits or dike alignment (weakly NNE elsewhere in the region) favored any surface structural lineament (but see below regarding deep structures). It is unclear whether the cones are monogenetic, representing a single eruptive episode (Turrin et al. 1991), or polygenetic, comprising repeated injections and eruptions within the same conduit (Wells et al. 1990). Because of this, the rate or time trend of magma supply is not well constrained.

Eventually it may be necessary, for dose calculations, to model a complete eruptive cycle including the effusion and dispersal of lava and pyroclasts. The general energetics and mechanics of basaltic eruptions have been modeled (Wilson and Head 1981) and tested against actual eruptions (Head and Wilson 1987). Volcanic plume dynamics have been used to model the impact of basaltic components on the atmosphere (Stothers et al. 1986). The inclusion of eruptive dynamics in the problem generates theoretical complications and requires a computational effort beyond the scope of the FY 1991 work. For these reasons, the modeled scenario treats the emplacement of a dike within the accessible-to-human-intrusion, site-wide subsurface. The event does not disperse lava or pyroclasts. By explicitly ignoring eruption, we sacrificed generality and, 


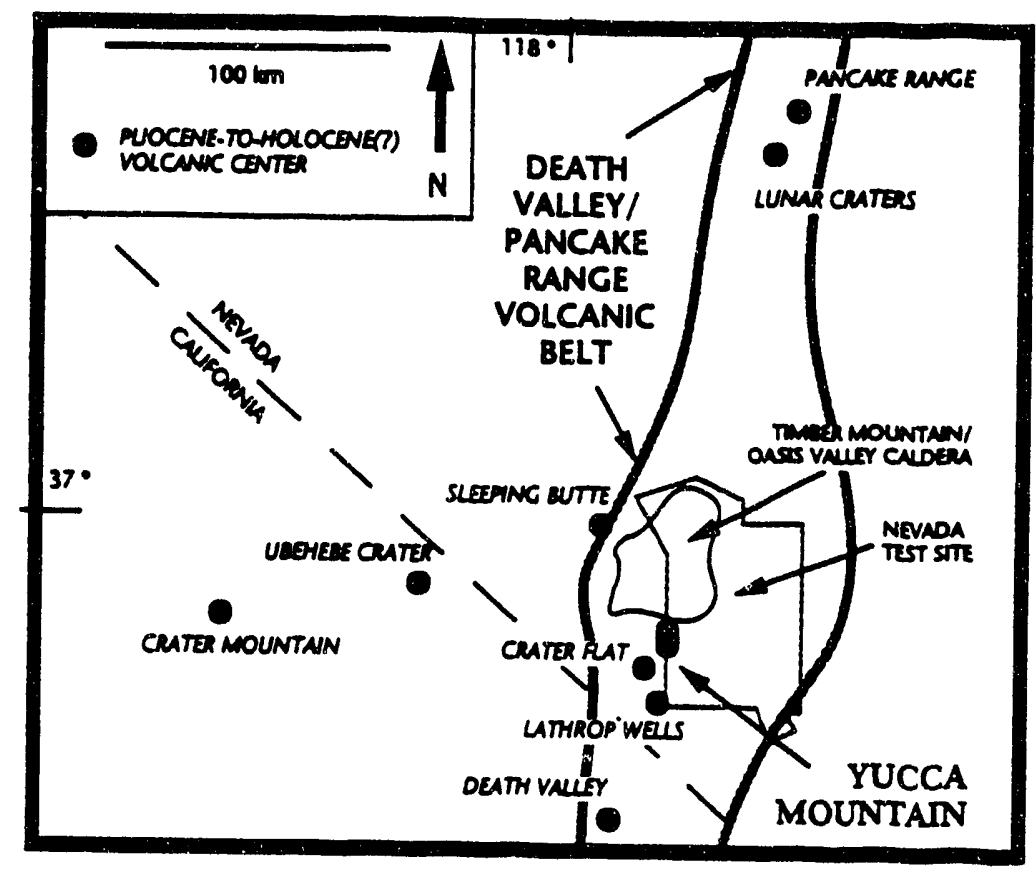

Figure 6.1. Volcanic Centers Near Yucca Mountain

perhaps, an important degree of physical actualism. Despite this, the purely intrusive scenario is a fundamental disruptive event in its own right and represents a useful limiting case.

The mechanics and energetics of dike emplacement have also been examined from a variety of angles; for example, Delaney and Pollard (1982), Rubin and Pollard (1987), Reches and Fink 1988, and Baer and Reches (1991). The model selected was developed by Lister and Kerr (1991). An important contribution of this study is the demonstration that the elastic forces, remote from the crack tip, and the strength of the rock are of second-order importance relative to the balance between the pressure gradient and the viscous forces. This suggests that preferential orientations based upon fault zones or other vertical planes of weakness are not required in dike formation and may be insignificant. This result has been verified by field work, in particular Faulds et al. (1991). It also implies that the coupled thermal and mechanical behavior of the magma is of highest importance to the vitality of the eruptive episode. Another advantage to this model is its relatively simple solution that can be used in an analytical subroutine and later compared to numerical results. Thus, this first calculation has focused on a limited, yet useful, scenario that tests our basic approach to consequence modeling and can be expanded during the development of a more general model.

Several critical assumptions are implicit in using this model. The model assumes that the flow within the dike is steady-state and isothermal. This says, in effect, that the developing portion of the conduit flow, where thermal and mechanical boundary layers are less than the conduit halfwidth, is insignificant relative to its full length. This may not be true. Delaney and Pollard (1982) demonstrated that this scaling can be resolved for a dike by computing the "thermal and mechanical entry effect." Murphy and Marsh (1989) describes the entry lengths $z(m)$ and $z(T)$ as,

$$
z(m)=0.01 \operatorname{Re}_{D} D
$$




$$
z(t)=z(m) \operatorname{Pr}
$$

where

$$
\begin{aligned}
\operatorname{Re}_{\mathrm{D}} & \equiv \frac{\mathrm{Q}}{\mathrm{D} v} \\
\operatorname{Pr} & =\frac{\mathrm{v}}{\kappa} \\
\mathrm{D} & =\text { cond iit half width } \\
\mathrm{Q} & =\text { volumetric flow rate } \\
\mathrm{v} & =\text { kinematic viscosity } \\
\kappa & =\text { thermal diffusivity }
\end{aligned}
$$

Note that the Reynolds number $\mathrm{Re}_{\mathrm{D}}$ is defined where the boundary layer, $\delta$, is equal to the conduit half-width, D. Calculating the thermal entry effect in this simplistic manner results in a value that requires non-steady-state conditions throughout $[(\mathrm{z}(\mathrm{T}) \gg \mathrm{L}$, similar to Delaney and Pollard (1982)]. The analysis, however, assumes constant viscosity, independent of temperature. This is clearly wrong, but can not be resolved without further information. As a first cut, we have assumed steady-state isothermal conditions; future efforts will require a fuller understanding of the particular volcanological and physical conditions of the scenario.

Returning to the model, Lister and Kerr (1991) set up a force balance in which,

$$
p=-g \Delta \rho z-m \mathbf{H}\left\{\frac{\partial w}{\partial x}\right\}
$$

where:

$$
\begin{aligned}
& \mathrm{p}=\text { fluid pressure } \\
& \Delta p=\text { density gradient } \\
& \mathrm{z}=\text { depth }
\end{aligned}
$$

$\mathrm{m}$, an elastic parameter, is defined as the shear modulus divided by one minus Poisson's ratio (see Equation [6.6]). The Hilbert transform, $\mathbf{H}[\bullet\}$, is used to represent the elastic pressure field over the medial plane of the dike. Expressions for continuity and global conservation of fluid are substituted into (6.1b) with some manipulation to give,

$$
3 \mu \frac{\partial w}{\partial t}=-g \Delta \rho z \frac{\partial w^{3}}{\partial z}-m \frac{\partial}{\partial x}\left(w^{3} \frac{\partial^{3}}{\partial x^{2}} H\{w\}\right)
$$

and 


$$
\int_{0}^{b} \int_{-b}^{b} w d x d z=Q t^{\alpha}
$$

where $Q_{t} \alpha$ is a magmatic discharge rate. For the case in which the magma discharge rate is constant $(\alpha=0)$, the flow regime and dike geometry will reach steady state and similarity variables can be defined,

$$
\begin{gathered}
x=b_{N}\left(\frac{3 Q \mu m^{3} z^{3}}{2(g \Delta \rho)^{4}}\right)^{\frac{1}{10}} \xi \\
w(x, z)=b_{N}^{3}\left(\frac{27 Q^{3} \mu^{3}}{8 m(g \Delta \rho)^{2} z}\right)^{\frac{1}{10}} w(\xi)
\end{gathered}
$$

Using the similazity expressions, rewriting Equations (6.3a) and (6.3b), and solving for dike width results in,

$$
\begin{gathered}
w(x, z)=0.904\left(\frac{27 Q^{3} \mu^{3}}{8 m(g \Delta \rho)^{2} z}\right)^{\frac{1}{10}} W(\xi) \\
Q=\frac{2 g \Delta \rho}{3 \eta} \int_{-b(2)}^{b(2)} w^{3} d x
\end{gathered}
$$

with

$$
\begin{gathered}
W=(1-\xi)^{\frac{3}{2}} \\
\xi=0.381 \times\left(\frac{(g \Delta \rho)^{4}}{Q \eta m^{3} z^{3}}\right)^{\frac{1}{10}}
\end{gathered}
$$

all other notation as before, and from which dike widths and lengths can be found. Lister (1990) and Lister and Kerr (1991) can be consulted for the details of this derivation. Lister and Kerr (1991) also develop expressions for sill-like magma bodies and eruptive conduits. However, Equations (6.5a) and ( $6.5 \mathrm{~b})$ are the only results used to date.

A stochastic determination of dike widths and lengths was made by solving Equations (6.5a) and $(6.5 \mathrm{~b})$ as a subroutine within an in-house-developed, Monte Carlo-style simulator. The range, mean, and distribution of input parameters is discussed below. The dike widths and lengths are distributed at random over the chosen domain. In simulation, a ground-water/contaminant distribution field was computed by the SUMO code (see Section 4.1). An entrainment factor was used to quantify the amount cf contaminated solid medium mechanically mixed into the magma, or 


$$
\mathrm{C}_{\mathrm{m}}^{\mathrm{i}}=\frac{\dot{\mathrm{m}}_{\mathrm{m}}}{\dot{\mathrm{m}}_{\mathrm{m}}} \mathrm{C}_{\mathrm{a}}^{\mathrm{i}}
$$

where,

$$
\begin{aligned}
& \mathrm{C}_{\mathrm{m}}^{\mathrm{i}}=\text { concentration of radionuclide } \mathrm{i} \text { released } \\
& \mathrm{C}_{\mathrm{a}}^{\mathrm{i}}=\text { concentration of radionuclide } \mathrm{i} \text { in medium } \\
& \frac{\dot{\mathrm{m}}_{\mathrm{m}}}{\dot{\mathrm{m}}_{\mathrm{m}}}=\text { ratio of mass rates (mass fraction entrained) }
\end{aligned}
$$

Finally, the mass of radionuclide released was incorporated into the CCDF code as described elsewhere.

\subsection{Input Parameters}

The input parameters to the model are listed in Table 6.1. The mass fraction entrained was also an input parameter but was not stochastically modeled. Each of the parameters is discussed below.

\subsubsection{Discharge}

This parameter gives the steady-state magma supply rate, $Q$, volumetrically required to emplace the dike. The appropriate value for $Q$ is not obvious for a dike-emplacement and can not be observed in nature. Nevertheless, this parameter is the single most important variable for scaling the dynamics of a magmatic event (Delaney and Pollard 1982; Wilson and Head 1981). The interpretation of geophysical data collected during Kilauean, Hawaii eruptions permits an estimate on dike-emplacement supply rates during eruptive repose periods (dormancy). Based upon gas emissions, Greenland et al. (1988) estimate the discharge rate across the feeder dikes at Pu'u O'o, Hawaii to be 74 to $158 \mathrm{~m}^{3} / \mathrm{s}$, and Hardee (1987) independently derives a value from recharge-driven, surface-tilt data along the East Rift zone to vary between 10.6 and $69.4 \mathrm{~m} 3 / \mathrm{s}$.

Direct observation of eruptions suggests a volumetric flow rate of $140-400 \mathrm{~m}^{3} / \mathrm{s}$ for the 1969-71 Mauna Ulu, Hawaii eruption and 20-300 m3/s for Pu'u O'o (Wolfe et al. 1987). These are clearly maximum values because of the acceleration of magma in the vent. Magma supply rates associated with the Hekla eruption are estimated at $8700 \mathrm{~m}^{3} / \mathrm{s}$, maximum, and $1500-2000 \mathrm{~m}^{3} / \mathrm{s}$, average (Murphy et al. 1991) and estimates of eruption rates associated with the Roza Member of the Columbia River Basalt Group (Swanson et al. 1979) exceed $10^{5} \mathrm{~m}^{3} / \mathrm{s}$. In fact, there are thermal constraints on the discharge rate implied by the geometry of the conduit (Wilson and Head 1981). These dimensions may, however, differ greatly from field measurement because of posteruptive subsidence and relaxation (Walker 1987). Without a full treatment of the coupling between the conduit geometry and the thermal and mechanical dynamics of the system, the full range was used in the Monte Carlo simulator with a mean of $100 \mathrm{~m}^{3} / \mathrm{s}$ and a lognormal distribution. Future work will not require this restriction and will allow a more physically plausible distribution for discharge. 
Table 6.1. Parameters Used in Basaltic Dike Simulations

\begin{tabular}{|c|c|c|c|c|}
\hline Parameter & Units & Mean & Range & Distribution \\
\hline $\mathrm{Q}$, discharge & $\mathrm{m}^{3 / \mathrm{s}}$ & 100 & $10<>10^{5}$ & lognormal \\
\hline$h$, viscosity & $\mathrm{Pas}$ & 100 & $10<>10^{3}$ & lognormal \\
\hline $\mathrm{m}$, elastic factor & $\mathrm{MPa}$ & 10 & $9<>11$ & normal \\
\hline$\Delta \rho$, density & $\mathrm{kg} / \mathrm{m}^{3}$ & 300 & $10^{2}<>10^{3}$ & lognormal \\
\hline $\mathrm{z}$, source depth & $\mathrm{km}$ & 10 & $\mathrm{n} / \mathrm{a}$ & fixed \\
\hline
\end{tabular}

\subsubsection{Viscosity}

Viscosity measures the displacement rate of the magma in response to shear stress and includes two components. The first component is compositional and is dependent to first order upon the major element and volatile composition of the melt. Anhydrous basaltic viscosities generally range from $10^{3}$ to $10^{7} \mathrm{~Pa}$ s when directly measured at their liquidus temperature (Bottinga and Weill 1972). Water and fluorine greatly lower the viscosity of a silicate liquid, up to 4 orders of magnitude (Dingwell et al. 1985). Pure liquid viscosities appropriate to a Yucca Mountain magma, if assumed similar to the "Rift Basalts" of Crowe et al. (1983b), may be about $100 \mathrm{~Pa}$ s, depending upon water contents.

Another variable that greatly affects viscosity is the percentage of solids (either crystals or entrained fragments) present. Experiments have repeatedly demonstrated (Shaw et al. 1968) that crystallization increases viscosity. Power-law or Bingham-body behavior in silicate melt has been observed in actual eruptions (Sparks et al. 1976) and has been explained as a crystallinitydependent phenomena (Marsh 1981; McBirney and Murase 1984). Several theoretical approaches (Marsh 1981; Murphy and Marsh 1989), which utilize suspension rheology, have proven effective. In some cases, viscous heating of magma has been demonstrated to be important to the emplacement of dikes (Hardee and Larson 1977).

Numerical modeling by Murphy and Marsh (1989) explicitly considered both of these issues and demonstrated that the viscosity of conduit flow was, in effect, self-regulating through viscous dissipation and crystallization. This interaction limited active-flow viscosity close to the liquidus value (less than one order of magnitude). Magma more viscous than this value is stagnant and "wallpapers" the conduit walls. Given these results and the unknown compositional variance in a model Yucca Mountain magma, a mean of $100 \mathrm{~Pa}$ s was chosen with an upper and lower range of one order of magnitude. In a more realistic simulation, the dynamics of this parameter would be model-dependent.

\subsubsection{Elastic Factor and Density Contrast}

The scale of these factors is less controversial, although still not obvious. The elastic factor is composed of the shear modulus (modulus of rigidity), $\mu$, and Poisson's ratio, $v$, for the host rock,

$$
\mathrm{m}=\frac{\mu}{(1-v)}
$$

and $\mathrm{m}=\mathrm{E} / 2(1+\mathrm{v})$. These factors are reasonably well established for basaltic or granitic crust, ex situ, (Clark 1966). The presence of fabric, fractures, and/or fluid, however, can produce wide variations in elastic parameters (Jaeger and Cook 1976). A conservative estimate of $20 \mathrm{MPa}$ was 
used by Lister and Kerr (1991). Using values from the SCP (DOE 1988), a range for the elastic factor, in situ Topapah Springs Formation, is determined between 9.57 to $10.90 \mathrm{MPa}$ and a mean of $10 \mathrm{MPa}$ with a normal distribution was selected for the model.

Under the assumptions of this model, the density gradient, $\Delta p$, represents the sole driving force of the flow. By removing the eruptive vent from the problem, the significant complications of a separate gas phase and transient density variation are avoided. Despite this simplification, the density gradient may still be nonlinear or discontinuous if prior magmatic activity has selectively injected high-density, deep-crustal material throughout. This does not appear to be the case at Yucca Mountain. A value consistent with the difference in density between high-silica tuff 2400 to $2600 \mathrm{~g} / \mathrm{cm}^{3}$, DOE (1988) and alkali basaltic magma 2700 to $3000 \mathrm{~g} / \mathrm{cm}^{3}$, (Maaløe 1985)) would be close to the value used by Lister and Kerr (1991) of $300 \mathrm{~g} / \mathrm{cm}^{3}$.

\subsubsection{Source Depth}

This parameter is of importance to the solution of Equations (6.2) and (6.3), and to several of the assumptions used in this exercise. As indicated above, the steady-state, isothermal assumption is dependent upon the vertical location of the repository/conduit intersection relative to the entire length of the conduit, the entry length problem. While the depth of the potential repository or the depth of a contaminant plume released from the potential repository can be specified or reasonably estimated, the source for magma in the vicinity of Yucca Mountain is vastly more speculative.

Investigations in support of the SCP indicate that there is little evidence for shallow magma chambers or long crustal residence times for magmas contributing to Quaternary basaltic volcanism of the Yucca Mountain region (Crowe et al. 1983a, 1983b, 1986). Crowe et al. (1983b) used a model depth of $35 \mathrm{~km}$ for the estimation of transport times, assuming petrogenesis at the mantle/crust boundary. This may be the case, and further work on the crustal residence times and depth of origin of the Quaternary basalts is planned (DOE 1988). Seismic reflection data from the Death Valley region have suggested that Quaternary basaltic centers are fed from magma chambers coincident to regional detachment, about $15 \mathrm{~km}$ deep (De Voogd et al. 1986). Similar, geophysically revealed magma bodies are founci in other extensional crust (Brown et al. 1979) and a general theory has been advanced explaining the vertical coincidence of magma chamibers, detachment zones, and extended crust (De Voogd et al. 1988; Serpa et al. 1988). The location of detachment zones associated with Basin and Range faulting in southwestern Nevada is an ongoing SCP activity (DOE 1988). Current estimates suggest that this depth elsewhere in Nevada may be slightly more than $10 \mathrm{~km}$ (Anderson et al. 1983).

For this first iteration of total system performance assessment modeling, a $\mathrm{z}$ of $10 \mathrm{~km}$ was used. Future iterations should utilize new SCP data and several reasonable values for $\mathrm{z}$.

\subsubsection{Entrainment Factor}

This parameter was not modeled stochastically. It is difficult to estimate this parameter with any degree of confidence because of several profound problems. The parameter measures the amount of incidental wall rock material entrained in the flowing magma during passive or active construction of the conduit space. Studies (Taubeneck 1970; Walker 1987; Reches and Fink 1988) show that dike walls are, in general, passively displaced by magma with only minor loss of total mass. Nevertheless, accidental rock fragments are apparently eroded from the walls and propagating tip of the dike. The dike tip may be a zone of vigorous hydrofracturing and stoping of material (although still a minor proportion of the total mass of the dike) (Baer 1991). Under any 
modeling scheme, the degree of entrainment specifies the relative abundance of waste or contaminated rock removed to the accessible environment. This parameter has a dominant effect on any dose or consequence calculations. Unfortunately, this parameter is poorly known.

A cursory search of the literature about basaltic centers, Stombolian cones, and feeder dikes worldwide reveals that accidental rock fragments are 1) ubiquitous, 2) rarely ever quantified during routine petrographic examinations, and 3) highly dependent upon the dynamics of the eruption and the stage of the eruption. Within small volcanic centers, similar in scale to the Crater Flats vents, accidental inclusions (distinct from ultramafic, cognate, or cumulate inclusions) can be numerous within the initial stages of an eruption but may rapidly drop off in abundance as the vent develops and the eruptive episode evolves. For example, at Crater 160 in the San Francisco volcanic field, xenoliths are "common" in the spatter associated with the initial stage and in palagonitic tuff, but are less common elsewhere within the sequence (Cummings 1972). Within the 1943 deposits of Paracutin, inclusions primarily occur within volcanic bombs (Wilcox 1954). Other volcanic centers show a similar diversity (Ishizaka et al. 1977 or Shantser 1983). The evolution of inclusion abundance may reflect the kind of stoping and tip-propagation mechanisms effective in establishing or rejuvenating a conduit.

Basaltic dikes and sills demonstrate even wider variance and more spatial heterogeneity in inclusion density. Intrusions such as the Chief Joseph dike swarm, Oregon, contain between 0 and 40\% (Taubeneck 1970) with the suggestion that wider and more vigorous dikes are more "inclusion free." Sills of the Karroo dolerite, South Africa, grade in inclusion density with a high abundance close to the margins and less within the core (Frankel 1969). These examples suggest that the incorporation of accidental clasts is dependent upon shear stress at the walls of a conduit or other magmatic pathway. This would tend to be highest during a thermal or mechanical perturbation (eruptive initiation) and would decline as the mechanical boundary layers, in effect, isolated the flow from the walls. This exact situation has been modeled by Murphy and Marsh (1989), among others, who indicated that the critical factor in establishing this stagnant margin is the crystallization kinetics of the individual melt.

In any case, the entrainment systematics of any given eruption can not, in general, be specified. SCP field studies at the Quaternary centers adjacent to Yucca Mountain have suggested 0.058 volume percent inclusions as a representative figure (Crowe et al. 1983b; Turrin et al. 1991), which is not unusual. There is no indication that this estimate is representative of the entire eruptive episode. Detailed study of several systems analogous to the postulated magmatic scenario could help advance this effort. For the purposes of this initial exercise, the entrainment factor was adopted from the SCP field studies.

\subsubsection{Volcanic Scenario Summary}

In summary, a simple but plausible, mechanically-model based on a review of the literature was used to generate a stochastically-derived set of dike lengths and widths. The model simulates the steady-state intrusion of an isothermal, noneruptive, basaltic dike below the volatile-saturation plane. Input parameters for the model are of highly variable reliability but were taken from analogous systems or SCP data. The dike widths and lengths were combined with a wall rock "entrainment factor" to simulate disruption of the potential repository or its release plume and transport to the accessible near surface. 


\subsection{Results of Basaltic Volcanism-Consequence Model}

As a demonstration of our basic approach, a set of nominal consequence outputs was incorporated into the CCDF code. This exercise produced a qualitative survey of the data and theory required to perform a complex total system performance assessment that considers a basaltic volcanism scenario.

The results of the Monte Carlo simulation of dike widths and lengths is presented as Figure 6.2. The approximate range in dike widths is between 0.25 and $1.5 \mathrm{~m}$, with a mean of $0.5 \mathrm{~m}$. Dike lengths ranged between about 0.75 and $3.0 \mathrm{~km}$, with a mean of $1.5 \mathrm{~km}$. Table 6.2 compiles a list of dike lengths and widths for a variety of examples. The mean volume emplaced would be about $0.75 \mathrm{~km}^{2}$ per vertical $\mathrm{km}$ of material intersected, in this case wall rock contaminated with released waste. Radionuclide distributions in the wall rock was simulated with he SUMO code. Given $233 \mathrm{~m}$ zone of contamination, this results in a volume of affected dike of $1.75 \times 10^{-4} \mathrm{~km}^{3}$. However, with the entrainment factor only a fraction of the wall rock would enter the affected volume, about 0.059 volume percent, and the total contaminated rock incorporated in the dike would be about $100 \mathrm{~m}^{3}$.

With closer examination, however, it is clear that dike lengths and widths produced without a full physical and volcanological analysis are suspect. A dike is only plausible if it remains above its solidification temperature (solids less than about $55 \%$ for basalt) for a time sufficient to allow it to flow into place. As discussed at length by several papers (Lister and Kerr 1991; Murphy and Marsh 1989; Hubbert and Sparks 1989), the cooling and solidification of magma, hence the mobility of a given dike or conduit, is a function of the heat given up to the walls through crystallization relative to the heat advected with the flow, or

$$
S=S(w, \lambda)
$$

where $S$ is the time available for flow, $w$ is the width of the dike and $\lambda$ is a function of both the crystallization heat of the magma and the form of the thermal boundary layer. In this fashion, $S$ is also a function of the thermal entry length (see above). Simply stated, the width and cooling time of a dike or conduit are coupled and can not be specified without a clear statement of the thermal and mechanical scales and dynamics of the problem.

It appears that this approach to modeling basaltic volcanism can be successful. However, a more complete treatment is required that includes the effects of volcanism. Future modeling efforts should include models more specific to Yucca Mountain problems. The conduit/dike emplacement part of the problem can be approached using the code TEMPEST (Trent and Eyler 1989) developed at PNL and modified at the University of Washington's Geophysical Fluid Dynamics Laboratory to model magmatic heat and mass transport. Eruptive column dynamics and dispersion should be developed in a fashion similar to Wilson and Head (1981) and Stothers et al. (1986).

\subsection{Basaltic Volcanism-Occurrence Model}

The scope of FY 1991 work did not include a quantitative mode for the occurrence probability of any volcanic scenarios. The generic Strombolian eruption probability derived by Crowe e al. (1986) was used. Work was begun on a literature search in support of a conceptual model for 


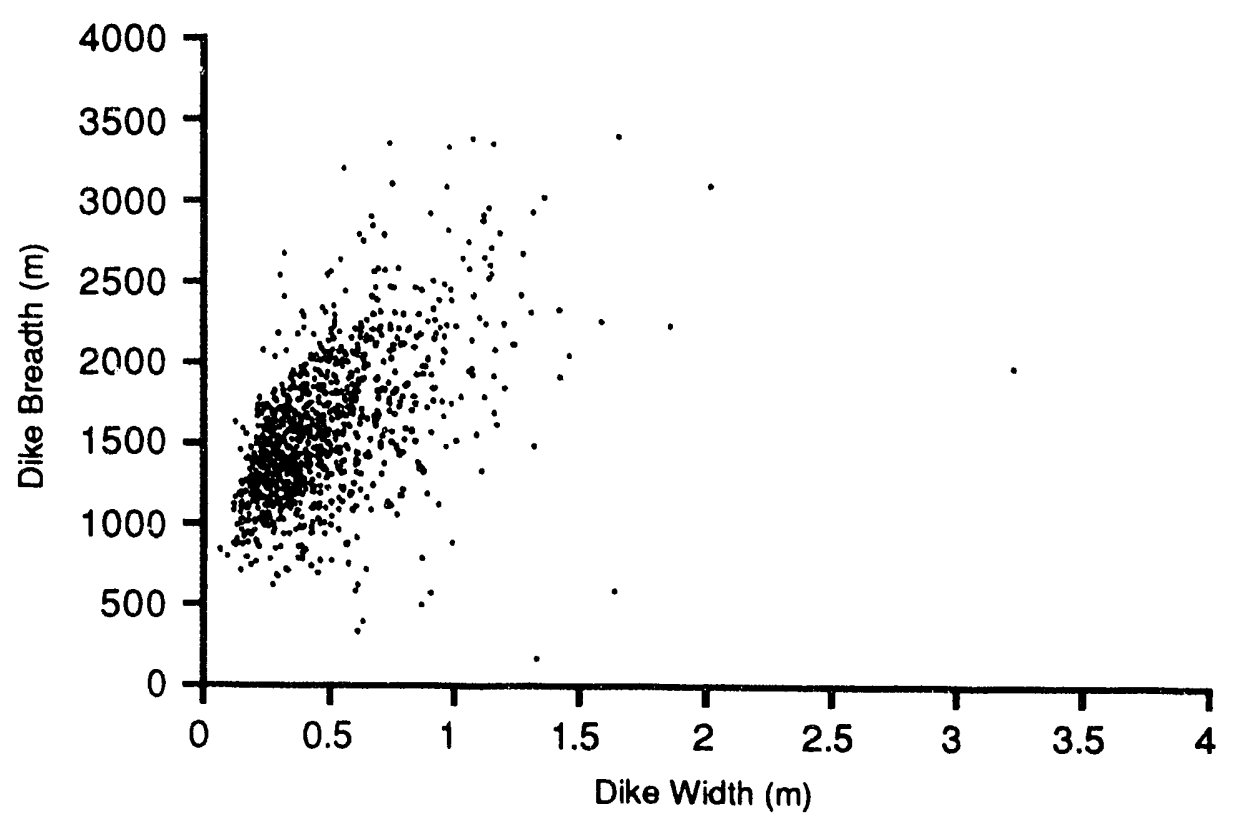

Figure 6.2. Volcanic Dike Dimensions

Table 6.2. Dimensions of Various Basaltic Dikes

Location

Quemado, NM

Kilauea E. Rift

Pu'u O'o model

Koolau, HI

Makhtesh, Ramon Israel
Dike Width (m)

$0.15-6.0$

$1-5$

3.5

0.65

$3-0.2$
Dike Length $(\mathrm{km})$

$1.5-1.0$

$1.0-5.0$

1.14

5 (est)
Reference

Baldridge et al. (1989)

Dvorak et al. (1986)

Wilson and Head (1981)

Walker (1987)

Reches and Fink (1988)

eruptive probabilities. Anticipation of continued work in FY 1991 justified this modest effort. This work is highly dependent upon SCP activities and data. Future work should critically examine assumptions and conditions necessary for probability models and attempt to provide more physical and petrological constraint to the estimates.

Modeling the occurrence probability of an eruption depends upon an estimate of a recurrence interval for a well-defined volcanic event. Within this context, very few studies have defined the occurrence probability of a particular dormant volcano with any statistical or practical degree of rigor. The few success have been dependent upon empirical relationships based upon intense observation or large data bases, for example, Swanson et al. (1983) or Swanson and Kienle (1988). The occurrence probability of a new vent at a previously unperturbed location, like Yucca Mountain, is much more difficult. 
The situation must be placed in perspective with hydrologically-based occurrence modeling (for example, the probability of a water table excursion, the 100-year flood, and so forth) in which the physics, chemistry, and geology of the problem are much further advanced. Also, volcanic events are apparently nonrandom events (Sornette et al. 1991). This would support physical intuition that eruptive vigor is controlled by the thermal and petrologic structure of the crust (Marsh 1981; Murphy 1991). Studies such as Crowe (1980) and Crowe et al. (1983b, 1986) have been highly instructive in identifying the SCP data needs for increased rigor. Ho (1991) pointed out several problems, primarily related to the inconsistent assumption of a constant magma flux term and the noncorrelation of magma production rate with volcanic event rate. Although Ho (1991) raises a number of interesting points, he still assumes a known probability of the volcanic event (Strombolian eruption, sill emplacement, etc.) over time and space. This depends upon an understanding of the thermal and mechanical dynamics implicit in the scenario and can not be assumed a priori or extracted from field data. Sheridan (1990) has also developed a stochastic, volcanic-hazard model for Yucca Mountain that has some capacity for spatial bias and is dependent upon the existing Quaternary record.

Although all of these models are excellent tools for exploring the spatial aspects of the Quaternary record, none is predictive. There is a fundamental problem in these approaches to spatial bias in the rock record. It is necessary to make deterministic assumptions about the controls for volcanism if the spatial bias is considered in the problem. In other words, there must be a mechanical or thermal rationale for the grouping of events in space and in time and extending such an assumption into the future. In a well-constrained system, such as the east rift zone of Kilauea, Hawaii, such a rationale exists to a high degree of verification. Eruptions of the last 20 years nave been extremely restricted in space and correlate nicely with a well-studied "master" conduit (Ryan et al. 1981). At dormant-to-extinct centers, it is common to find a loose spatial correlation between vents and deep structural lineaments, for example the South Sister volcano, Oregon (Scott 1987). This hypothesis was confirmed through deep-drilling at the Inyo crater chain in eastern California (Eichelberger et al. 1988). In other cases, such as the Zuni-Bandera field of western New Mexico (Laughlin et al. 1982) or the Pinacate Volcanic field of Sonora, Mexico (Lynch and Gutmann 1987), the spatial bias is weak to missing, and a causal phenomenon has not been tectonically characterized. Without this geophysical basis, any quantitative projection of spatial variance in a given volcanic field is unwarranted. The cited studies at Yucca Mountain are clearly illustrative; given more SCP data and a better volcanological and physical foundation, such models may be useful to performance assessment.

The causal relationship between the magmatic input rate and the rate of volcanism has been discussed at length in a series of articles by Marsh $(1984,1981)$. The probability of eruption for a given magma body hinges on two conditions: 1) the magma must be available $\left(\mathbf{P}_{\mathbf{M}}\right)$ and 2$)$ the magma must be physically capable of erupting, given an appropriate volcanic scenario $\left(\mathrm{P}_{\mathrm{E}}\right)$. The probability of eruption $\left(\mathrm{P}_{E}\right)$ is a product of the probability $\left(\mathrm{P}_{\mathrm{R}}\right)$ that a magma is rheologically capable of flowing from the conduit or reservoir to the surface (or catastrophically disrupting in an explosive eruption) and the probability ( $\left.\mathrm{P}_{\mathrm{T}}\right)$ that the magma body is at a temperature above this rheological barrier with respect over the time of interest. In other words, $P_{E}\left(=P_{R} P_{T}\right)$ represents the probability of an available melt erupting before it freezes.

The formal application of these ideas to occurrence probabilities has not been worked out; however, certain physical implications are intuitive. The rheological probability depends upon the shear stress and the strain rate of the given eruptive scenario through viscosity, the semi-solid viscosity of the magma as it approaches stagnation. The viscosity is dependent on the crystallization process and fluid dynamics of the system as outlined in Section 2.0. It is well 
established that the limit for fluid behavior is about $55 \%$ for basaltic lava on the surface (Shaw et al. 1968; Marsh 1981; McBirney and Murase 1984), however, other studies demonstrate (Murphy and Marsh 1987; Brandeis and Marsh 1989) that for conduit flow, convection and other particular mechanisms, the rheological limit may be much lower $(<20 \%)$. Furthermore, it is likely that the converse of this theory can be applied in explosive volcanism; in this case, the rheological limit defines a viscosity (and deformation rate) required for magma to be disrupted and expelled, or a strain rate in excess of the tensile strength of the magma (Dingwell and Webb 1989). In summary, the probability that a given magma batch will erupt as a dike or freeze in place is a direct function of its petrological and physical systematics.

The rheological probability is also dependent upon the thermal history of the region. Modeling of multiple intrusive events (Hardee 1982) indicates that individual magma bodies can remain above the rheological limit longer if they traverse "warmed" crust. Thus, the initial magma emplaced in a given region loses more heat to the crust and is less likely to erupt than subsequent bodies, if the regional thermal perturbation is not dissipated. Furthermore, subsequent magmatic episodes will require a lower total flux to stay viable. The upper crust becomes more insulating over time due to the high thermal gradient and the naturally high thermal inertia of upper crustal wall rock.

This has enormous bearing on Yucca Mountain volcanic risk assessments, for example, the polycyclic volcanism question (Crowe et al. 1989; Wells et al. 1990). If individual cones are composed of multiple, temporally discrete pulses of magma, then a nonrandom distribution is strongly suggested and some precondition is limiting melts to existing surface features. In fact, if this hypothesis is true, the $10^{3}$ to $10^{5}$ year probability of occurrence for the existing cones must approach 1, and everything else, including Yucca Mountain, is essentially zero! The thermal consequences of polycyclic volcanism are even more profound, requiring that each magma batch must independently overcome the large thermal contrast with the cold crust to avoid solidifying at depth.

If polycyclic behavior is demonstrated in the Yucca Mountain region, some geologic, mechanical and/or thermal hypothesis is necessary in order to relate magmatic transport to the field evidence. Without this information or a simplistic view of the problem, estimates for recurrence probabilities or repose times at Crater Flats (Crowe et al. 1986) in the current study reduces these results to a limiting case. In general, no quantitative occurrence probability is $w$ :able without establishing the relationship between petrologic, geomorphic, and structural data and geophysical theory. Only in this fashion can predictive volcanology be inferred from the regional geologic data.

\subsection{Results}

The analysis of the volcanic disruption scenario attempted to estimate the amount of each radionuclide that reached the accessible environment (ground surface) as a function of the volcanic event. Modeling links to the source-term model described in Section 3.0 and to the mass transport models described in Section 4.0 were required to accomplish this goal. A new analysis code named HUMAN was developed to automate the volcanism and human-intrusion analyses. Documentation of this code is in preparation. 


\subsubsection{Modeling Link for Volcanic Extrusions}

Each volcanic dike intrusion was assumed to penetrate from deep below the potential repository to the ground surface. Dimensions of the dike are taken from the random set of dike widths and lengths described in Section 6.4. Releases to the surface for each dike depend on the time of the occurrence, the mass transport in the mountain that has occurred prior to the dike intrusion, and also on waste container inventory.

The dike is assumed to entrain rock at or below the potential repository horizon and transport that rock to the ground surface. The amount of nuclides removed with the rock entrainment depends on the amount of transport that has taken place from the potential repository at the time of the intrusion, and the inventory of a waste container if a direct or near hit occurs. The computer runs for far-field transport in the unsaturated zone described in Section 4.0 were used to estimate radionuclide concentrations in the mountain as a function of time. Random dike intrusion times were selected, and then an exhumed radionuclide inventory was calculated assuming the dike vertically penetrates the unsaturated zone.

This modeling link leads to loosely coupled processes. The concentration as a function of time is coupled to the far-field mass transport. However, the far-field transport was not modified to account for thermal or hydrological changes from the volcanic event. Thermal changes are assumed to die away quickly and have little impact on mountain-scale water mass-balance calculations. The impact of ignoring hydrological changes caused by the dike emplacement is unknown. Quite likely the dike will become highly fractured as it cools. If that happens, it may have hydrologic properties that are little different from some of the current rock layers in the mountain.

\subsubsection{Cumulative Complementary Distribution Function for the Volcanic Scenario}

The conditional CCDF for the basaltic dike intrusion scenario is given in Figure 6.3. Each dike was assumed to entrain $0.058 \%$ of the host rock in the volume of the dike between the potential repository level and the ground surface.

In addition to entraining contaminated rock, there were some combinations of model parameters where the contents of one or more waste containers could be entrained in the magma and expelled on the surface. The amount of waste entrained and released to the ground surface for each individual dike, $\mathrm{R}_{\mathrm{i}}$, was calculated with the following formula:

$$
R_{i}=I_{1}(t) D_{i} N_{c} S_{d} F(t)
$$

where $I_{1}(t)=$ the inventory of a single container as a function of time

$$
\begin{aligned}
D_{i}= & \text { a random indicator }(0 \text { or } 1) \text { denoting whether a waste emplacement drift is } \\
& \text { intercepted by a dike } \\
N_{c}= & \text { number of waste containers in the drift } \\
S_{d}= & \text { scaling factor for } N_{c}, \text { and } \\
F(t)= & \text { failure factor for waste containers. }
\end{aligned}
$$




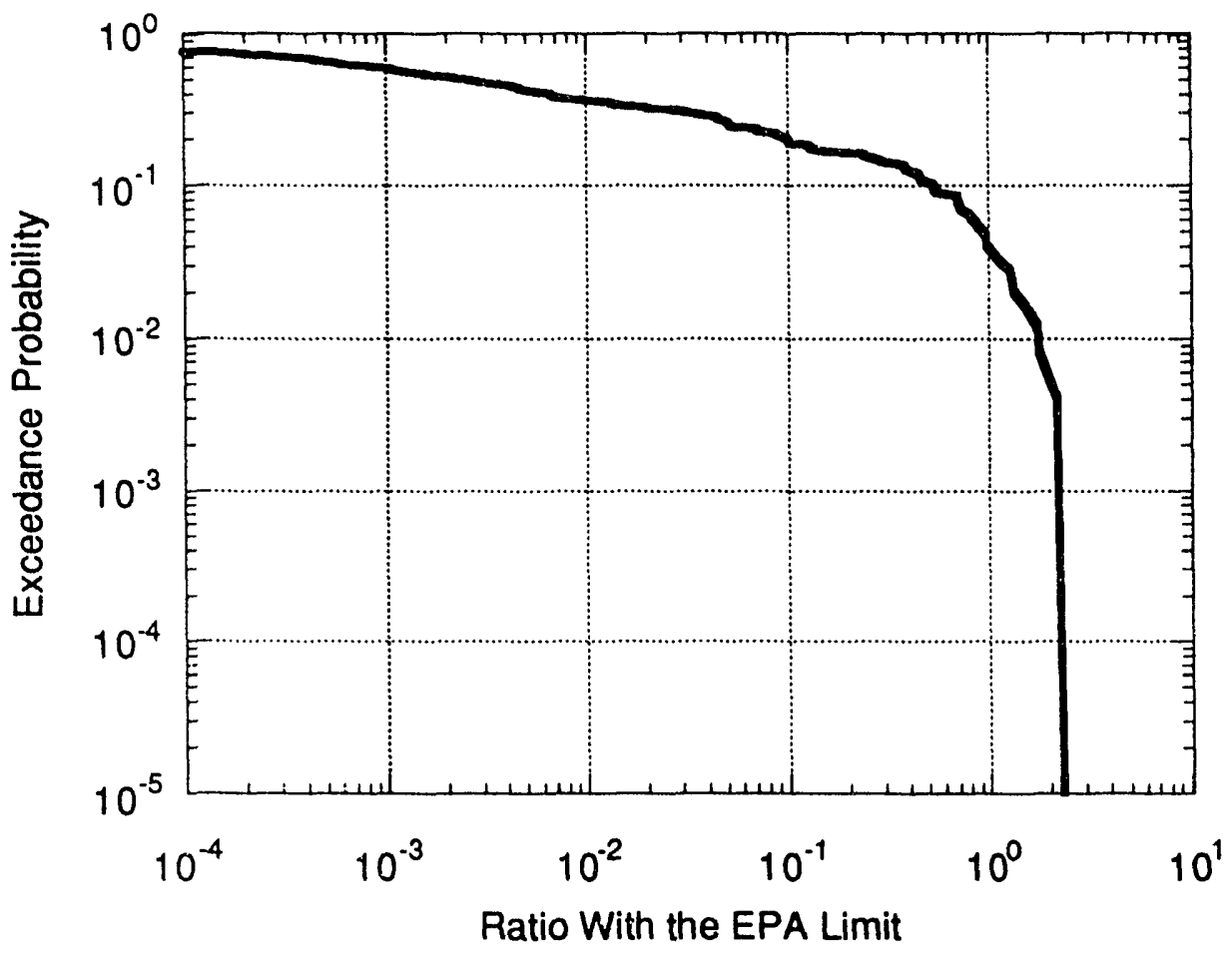

Figure 6.3 Conditional Complementary Cumulative Distribution Function for Basaltic Dike Intrusions

The container inventory was computed in the AREST code as a function of the time since the waste was emplaced using the Bateman equations to model chain decay. The probability of a dike intersecting a drift was set to 0.25 . The number of waste containers in a drift was set to 40 . The spread factor, $S_{d}$, in the drift was modeled as a random uniform $(0,1)$ value. The product of $N_{C}$ and $S_{d}$ modeled the number of waste containers that would physically be contacted by the basalt in the dike. Finally, the failure factor was selected as the function that has the value 0 before 2000 years, the value 1 after 10,000 years and the linear slope 1/8000 between 0 and 1 for times between 2000 and 10,000. This failure fraction indicates that the waste container has enough structural integrity that waste is not entrained in the first 2000 years of repository performance. Between 2000 and 10,000 years successively more containers are compromised to such a degree that they offer no barrier to entrainment of waste by the volcanic dike.

The container inventory was computed in the AREST code as a function of the time since the waste was emplaced using the Bateman equations to model chain decay. The probability of a dike intersecting a drift was set to 0.25 . The number of waste containers in a drift was set to 40 . The spread factor, $S_{d}$, in the drift was modeled as a random uniform $(0,1)$ value. The product of $N_{C}$ and $S_{d}$ modeled the number of waste containers that would physically be contacted by the basalt in the dike. Finally, the failure factor was selected as the function that has the value 0 before 2000 
years, the value 1 after 10,000 years and the linear slope 1/8000 between 0 and 1 for times between 2000 and 10,000. This failure fraction indicates that the waste containe inas enough structural integrity that waste is not entrained in the first 2000 years of repository performance. Between 2000 and 10,000 years successively more containers are compromised to such a degree that they offer no barrier to entrainment of waste by the volcanic dike.

Given the above assumptions, the amount of material moved to the ground surface by a volcanic intrusion can exceed the limits established by the EPA. This study addressed releases from 10 nuclides that represent about $10 \%$ of the inventory of the potential repository (expressed in terms of the EPA limit). If all of the nuclides in the potential repository were considered, the upper tail of this plot would move up about another order of magnitude. Different curves could be obtained by varying the form of the expression for $\mathbf{R}_{\mathbf{i}}$. 


\subsection{Tectonic Disruption Model}

The objective of the tectonics task was to develop a preliminary method to incorporate tectonic process information into total-system models. The approach involved two steps. First, a brief literature survey was conducted to identify tectonic processes potentially affecting the cumulative release of radionuclides to the accessible environment at Yucca Mountain. Second, a representative tectonic model was coupled with the total-system model to examine the impacts of the scenario. Modeling on this disruptive scenario is not as advanced as the modeling for other disruptive scenarios because PNL was not directed to include tectonic processes in this analysis until a majority of the scheduled time for the analysis had already elapsed.

\subsection{Identification of Several Initiating Events}

The purpose of this task was not to develop a new description of potentially active tectonic processes at Yucca Mountain; rather, it was to find ways to incorporate models of tectonic processes into a total-systems analysis. To adequately assess the potential for tectonic activity to adversely affect repository performance, an extensive knowledge is required of at least the following topics:

- history of faulting in the area

- potential movement of primary and secondary faults

- shear stress and rock strengths

- extensional or compression stresses

- potential vibratory ground motion, and

- rock permeability and potential for induced groundwater movement.

Based on a quick review of published literature (McGuire et al. 1991; Kana et al. 1991; Blume 1987; Dockery 1984), at least three tectonic processes were considered to have a potential for perturbing the repository system enough to increase the cumulative release of radionuclides to the accessible environment. These processes are:

- early failure of waste containers due to primary or secondary faulting through the repository horizon

- changes in rock permeability due to faulting sufficient to enhance movement of groundwater, and

- rise in the water table caused by earthquake stresses. 


\subsection{Choice of Representative Initiating Events}

Because of the limited scope of this study, a single initiating event was chosen. As discussed below, the authors considered several events and chose the event deemed most likely to have the greatest adverse impact on repository performance.

The first process considered for modeling was that of early failure of waste containers due to primary or secondary faulting through the repository horizon. This process was not chosen for inclusion in this analysis. The waste containers in this analysis were already assumed to fail in the range 300-1000 years. Some of the reasons for this exclusion are:

- Failure of waste containers earlier than 300 years would not add significant transport time in the context of modeling 10,000 years of transport.

- Liquid-phase release of nuclides from the waste package are assumed to begin after the waste container's surface temperature has cooled below the boiling point. The time when this occurs is already in the range of 300 to 1000 years. One of the assumptions made in the waste package analysis was that release could not occur until the package had cooled, even if it was assumed to have failed earlier.

Potential impacts on the cumulative releases for this event appear limited to the potential for an earlier start on gas-phase releases. This assessment is highly dependent on the assumption that waste packages start failing after 300 years.

The second process considered for modeling was that of changes in rock permeability due to faulting sufficient to enhance movement of groundwater. This process was not chosen for inclusion in this analysis. Some of the reasons for this decision are:

- Some of the rock layers in the transport model are already considered to be highly fractured.

- The Ghost Dance fault was explicitly incorporated as an offset and a fracture zone in the unsaturated zone conceptual model. It was not felt that including an additional fracture zone in the model would yield qualitatively new information

Potential impacts on the cumulative releases for this event appear limited with respect to the liquidphase movement of radionuclides. However, movement of gas-phase $14 \mathrm{C}$ could be significantly altered if a high permeability fracture zone were to be opened between the repository horizon and the ground surface.

The third initiating event considered was a rise in the water table due to earthquake stresses. An earthquake caused by normal faulting relieves tensional stresses, leading to compression of the rock pore space. The mechanism by which the occurrence of an earthquake may induce changes in the water table are described in detail in McGuire et al. (1991). The following model is taken from chapter three of McGuire et al. The increase in the elevation of the water table as the result of the static stress drop associated with an earthquake can be expressed by the relationship

$$
\Delta \mathrm{W}(\mathrm{m})=\Delta \tau(\mathrm{m}) \sin (\theta) \cos (\theta) \mathrm{H}(\mathrm{m}) \mathrm{C}_{\mathrm{RM}} 10^{8}
$$

where 


$$
\begin{aligned}
& \mathrm{WT}(\mathrm{m})=\text { change in the water table elevation for a magnitude m earthquake (m) } \\
& \Delta \tau(\mathrm{m})=\text { static stress drop (bars) } \\
& \theta \quad=\text { fault dip } \\
& \mathrm{H}(\mathrm{m})=\text { vertical extent of faulting }(\mathrm{km}) \\
& \mathrm{C}_{\mathrm{RM}}=\text { compressibility of the gross rock mass including joints and faults }(1 / \mathrm{Pa})
\end{aligned}
$$

The probability that coseismic water table changes will exceed a specified level, $\mathrm{z}$, during a time period $\mathrm{T}$ can be evaluated using the standard formulation for probabilistic seismic hazard unalysis, namely

$$
\mathrm{P}(\Delta \mathrm{WT}>\mathrm{z})=1.0-\exp (-v(\mathrm{z}) \mathrm{T})
$$

where $v(z)$ is the rate at which the coseismic water table elevation exceeds $z$ and is given by the expression

$$
v(z)=\sum_{n} \alpha_{n}\left(m_{0}\right) \int_{m} f(m) P\left(\Delta W T>z \mid m C_{R M}\right) d m
$$

where $\alpha_{n}\left(m_{0}\right)$ is the frequency of earthquakes on fault $n$ with magnitudes greater than a minimum magnitude of interest $\left(m_{0}\right)$ and $f(m)$ is a density function describing the rilative frequency of various magnitude earthquakes. Equation (7.3) is based c data from Doser and Smith (1989), who further assumed that the stress drop for a given magnitude zarthquake is lognormally distributed. This equation was used to compuie the probability of various levels of coseismic water table changes for several values of $C_{R M}$. The results of these caiculations are given in Figure 7.1 .

\subsection{Coupling of Tectonic and Transport Mudels}

Analysis of the impact of tectonic disruptions was accomplished by modifying the hydrology and mass-transport models of the unsaturated zone discussed in Section 4.2. The modification was based on the assumpion that the water table could rise as much as $100 \mathrm{~m}$, as indicated in Figure 7.1. Assumptions behind the model modifications included the following:

- Water table rise was assumed to occur inmediately after repository closure.

- The water table rise was assumed to be permanent. 


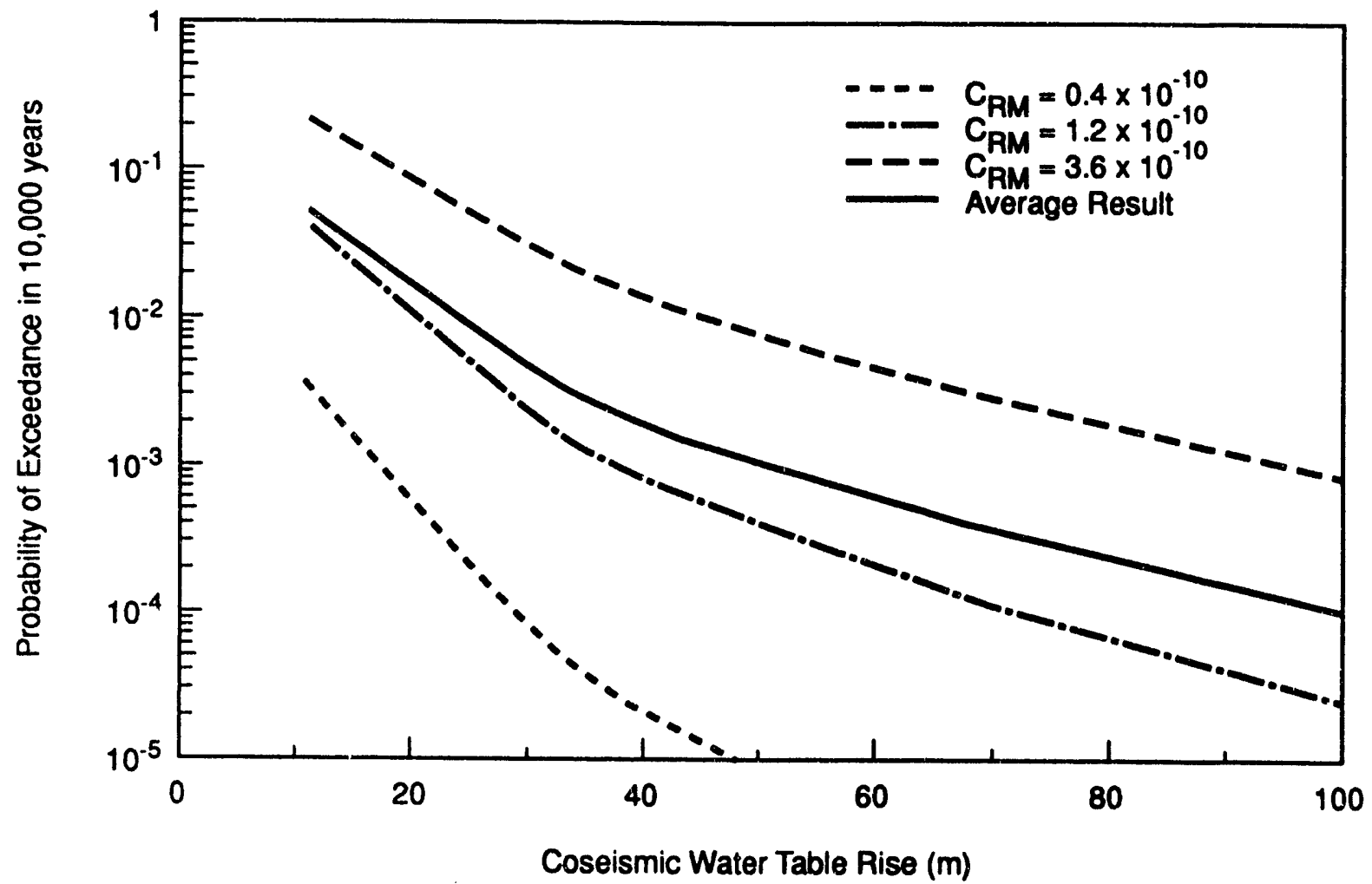

S9204005.1

Figure 7.1. Probability of Coseismic Water Table Change (After Doser and Smith 1989)

\subsection{Cumulative Release Consequences}

Transport analyses for this scenario were carried out using the SUMO cod (see Section 4.2). The mate lai properties for the analysis were the same as described in Section 4.0. The first analysis performed assurned a water table rise of $100 \mathrm{~m}$. This height of water table rise corresponds to an exceedance probability on the order of 10-3. Based on the highest groundwater infiltration rate run by PNL of $0.05 \mathrm{~mm} / \mathrm{yr}$ (this low infiltration PNL staff was able to model in two dimensions: refer to Section 4.2), no significant quantities of radionuclides reached the water table in the first 10,000 years after repository closure. Therefore, this analysis, for recharge rates less than $0.05 \mathrm{~mm} / \mathrm{yr}$, indicated no impact on performance from the coseismic water table rise. This tectonic scenario is based on a compression of pore space, which is considered to lead to a permanently elevated water table, though the model used actually addresses a transient rise in the water table. The permanent rise was assumed because such a rise would have a greater adverse impaci on the performance of the potential repository.

This analysis does not prove that tectonic events would cause no impact on repository performance in the first 10,000 years. However, it does demonstrate one method for coupling information from a tectonic process model into a total-system analysis. Changes could be made to the modeling assumptions that would lead to a significant impact from this scenario. For example, a higher groundwater infiltration rate could shorten nuclide transit times in the unsaturated zone enough that some release to the water table, and on to the accessible environment, would occur. 
Definitive analyses cannot be performed until site-specific data have been collected in the sitecharacterization process. 


\subsection{Human-Intrusion Model}

The latest working draft of the EPA standard requires that analysis of the impacts of human activities be included in performance estimates for a repository. Nonbinding guidance from the EPA on the scope of analysis that should be considered for human-intrusion activities is given in Appendix B of 40 CFR 191.

\subsection{Assumptions}

In this study, the analysis of human-intrusion examined possible consequences of drilling through the repository horizon. All of the drilling cases analyzed considered exploratory drilling for minerals or water. No excavation or mining operations were considered. All drill holes were assumed to have a $30-\mathrm{cm}$ diameter and holes could extend as far as $760 \mathrm{~m}$ below the ground surface. The drill holes were assumed to have no impact on the hydrology of the mountain. The intrusion pathways considered are outlined in Table 8.1.

The occurrence of drilling events was modeled as a homogeneous Poisson process (Hoel et al. 1972, p. 96). The rate parameter for the Poisson process was set to 3 holes per $\mathrm{km}^{2}$ per 10,000 years. This is the suggested maximum rate in 40 CFR 191, Appendix B, for a repository located in rock formations that are not sedimentary in origin. This choice of rate parameter, when coupled with the repository area of $5.6 \mathrm{~km}^{2}$, leads to an expected 17 holes (statistical expectation) penetrating the repository horizon during the first $10,000 \mathrm{yr}$ of repository performance. Also, the probability of a single drilling event hitting a waste container is about 0.00185 . This is based on a geometry argument where the drill hole diameter is $30 \mathrm{~cm}$ and the vertically emplaced waste container has a diameter of $66 \mathrm{~cm}$. Waste container spacing was assumed to be uniform in the $5.6 \mathrm{~km}^{2}$ area of the potential repository.

A detailed analysis was not conducted to choose a drilling rate specific to Yucca Mountain. The suggested drilling rate may be high if the purpose for drilling is to extract groundwater. The ground surface at the repository location is much higher above the water table than many locations within a few kilometers. Also, there are no known deposits of natural resources of economic significance at Yucca Mountain.

Table 8.1. Human-Intrusion Pathways

Intrusion Mechanism

Drilling event misses all waste containers, intersects contaminated rock

Drilling event hits a single waste container
Release Pathway

Release of contaminated drill cuttings to the surface

1. Release of contaminated drill cuttings to the surface

2. Release of contaminated drill cuttings to the surface and injection of waste into the tuff aquifer

3. Release of contaminated drill cuttings to the surface and injection of waste into the carbonate aquifer 
For an exploratory drilling rate of 3 holes per $\mathrm{km}^{2}$ per $10,000 \mathrm{yr}$, simulations of the repository performance for 10,000 yr should always consider multiple drilling events. Thus, questions about modeling human-intrusion deal with drill hole size and location, and drilling technology, instead of whether or not drilling is going to occur.

\subsection{Link to Transport Modeling}

The analysis of drilling events attempted to estimate the amount of each radionuclide that reached the accessible environment as a function of the drilling event. Modeling links to the source term model described in Section 3.0 and to the water and mass-transport models described in Sections 4.0 and 5.0 were required to accomplish this goal.

A new analysis code named HUMAN was developed to automate the human-intrusion analyses. Documentation on this code is in preparation. Many of the functions of this code are described in this section.

\subsubsection{Modeling Link for Exhumed Drill Cuttings}

Each drilling event was assumed to penetrate from the ground surface to at least the repository horizon and to exhume a rock column of diameter equal to the drill string diameter $(30 \mathrm{~cm})$. Some holes were assumed to penetrate to the saturated tuff aquifer approximately $150 \mathrm{~m}$ below the repository. Other holes were assumed to extend approximately another $500 \mathrm{~m}$ below the top of the tuff aquifer and to intercept the carbonate aquifer.

The liquid-phase mass transport model described in Section 4.2 was used to output the activity, expressed in Curies (Ci), of each radionuclide throughout the two-dimensional modeling domain for many different times. The modeling domain for the liquid-phase mass transport extended vertically from just above the repository horizon to the water table. Once a drilling time and location were chosen, this field of radionuclide activities was used in HUMAN to estimate the amount of contamination in the exhumed column of drill cuttings. A important assumption is made in that the drilling event does not perturb the steady-state flow field used in the mass transport simulations.

Drilling locations were chosen randomly along the horizontal dimension of the twodimensional domain of the liquid-phase model. Each location had an equal probability of being chosen. Linear interpolation was used to calculate radionuclide inventories and activities for drilling times between the archived times of source term inventories and radionuclide concentration in vadose-zone water.

\subsubsection{Modeling Link for Drilling Event Intercepting a Waste Container}

Drilling events were assumed to occur where the drill string could intercept one or more waste containers and transport the waste contained within the container. Three possible transport pathways were assumed: 1) exhumation of the container waste to the surface, 2) injection of the container waste into the tuff aquifer, and 3 ) injection of the container waste into the carbonate aquifer.

For each of the container-interception cases the inventory of the waste container is required as a function of time. The method for obtaining the inventory was to use the AREST code to compute the inventory as a function of time for an intact waste container. The AREST code uses an 
implementation of the Bateman equations to track radionuclide decay chains as a function of time resulting from the initial inventory of the waste container.

\subsubsection{Exhumed Waste Container}

The modeling link for exhumed container waste was to simply count the inventory of the waste container in the cumulative release limit. The inventory released was calculated as the product of the time-varying inventory of an intact waste container and a uniform random variable on the interval $[0,1]$. The uniform multiplier was used to mimic the cases where a drill string intercepted the waste container but did not mobilize the entire contents of the waste container. This assumption on inventory would tend to overestimate the inventory of a waste container that had already failed due to some corrosion or stress inducing process and subsequently had the inventory reduced by the quantity of waste transported into the adjacent rock.

\subsubsection{Injection Into an Aquifer}

The modeling link for container waste injected into an aquifer was to include a radionuclide source in the saturated ground water model at the point of injection. The strength of the source term was set equal to the time-varying inventory of an intact waste container. Injection was assumed to occur by a compromise of the container integrity during the drilling event without extracting the contents to the surface, which would allow the contents of the container to fall to the bottom of the evacuated hole after the drill string is withdrawn. Once at the bottom of the hole, the waste form would be immediately exposed to flowing ground water in an aquifer. This case is an unrealistically high bounding case for deep injection of waste by exploratory drilling.

\subsection{Results}

Results for the human-intrusion analysis are presented in Figures 8.1 through 8.3. The figures contain conditional CCDFs, i.e., they contain the CCDF for releases based on the assumption that the case has occurred. Combination of the conditional CCDFs into a system performance estimate is addressed in Section 9.0.

Figure 8.1 contains the CCDF for releases to the surface due to exhuming a contaminated rock column in a drilling event. The releases from this case are very low when compared to the EPA limit. The quantities varied to obtain the curve include drilling time (random with an expected 17 drill holes in each value on the curve) and ground water infiltration rate (limited to less than $0.05 \mathrm{~mm} / \mathrm{yr}$ as discussed in Section 4.2) which affected both the source term release rate and the ground-water transport calculations.

Figure 8.2 contains the CCDF for releases to the surface due to exhuming a contaminated rock column and obtaining a direct hit on a waste container. The quantities varied to obtain this curve include the fraction of a waste container that is exhumed in addition to the values discussed for Figure 8.1. The fraction of a waste container that was exhumed was arbitrarily assigned a uniform probability between 0 and 1 . Note that this curve extends out to 0.1 on the horizontal axis. The contents of the nuclides considered in this study in one waste container yields about 0.1 of the EPA limit. If all nuclides in the repository were considered, and a waste container holds about $2 \mathrm{MTU}$, the inventory is about 1.0 of the EPA limit. Alternate container designs are under consideration which would contain significantly more inventory than the container assumptions used in this study. If the alternate design is implemented, this conditional curve could extend well above the EPA limit. 


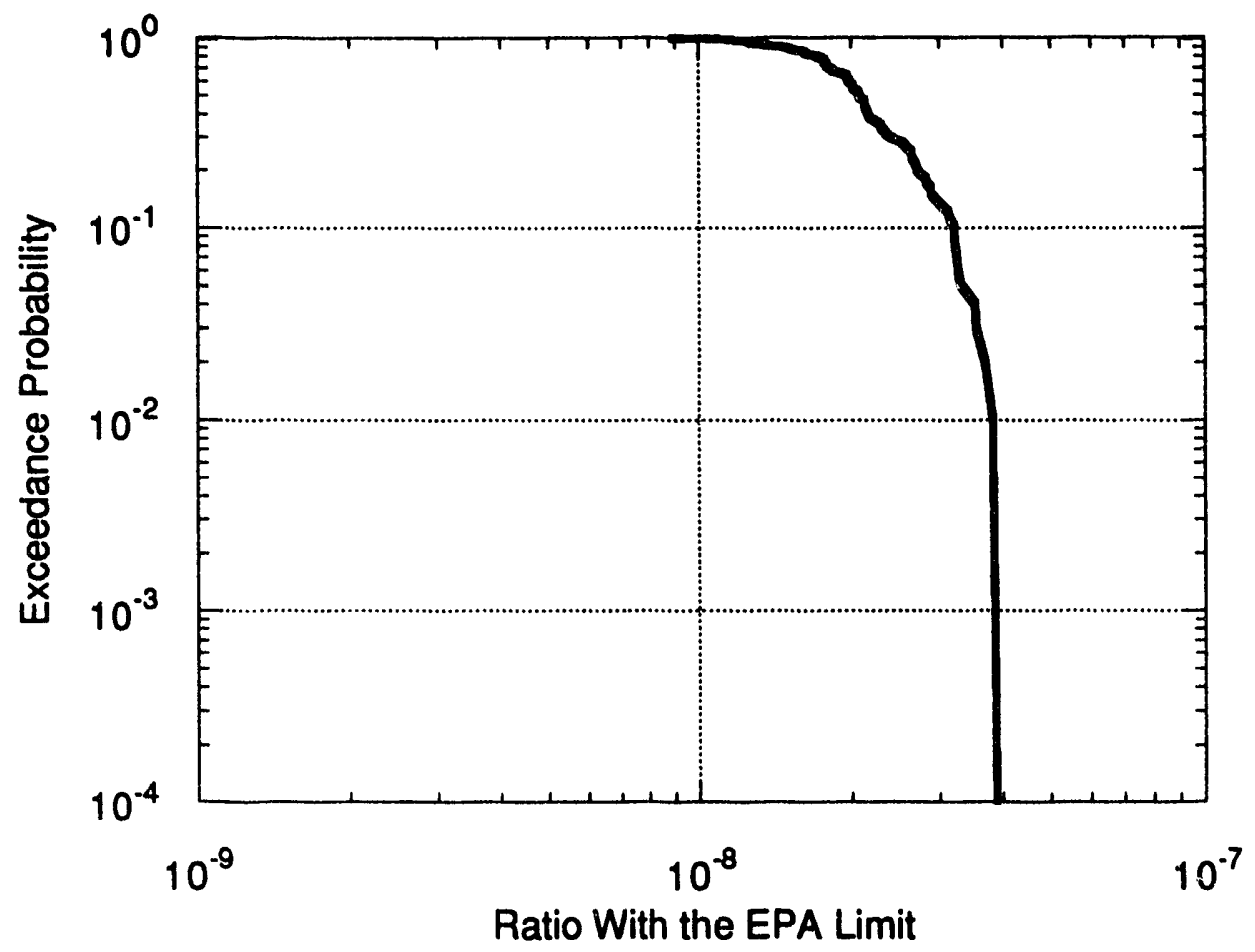

Figure 8.1. Conditional Complementary Cumulative Distribution Function for Contaminated Rock Column Releases to the Surface

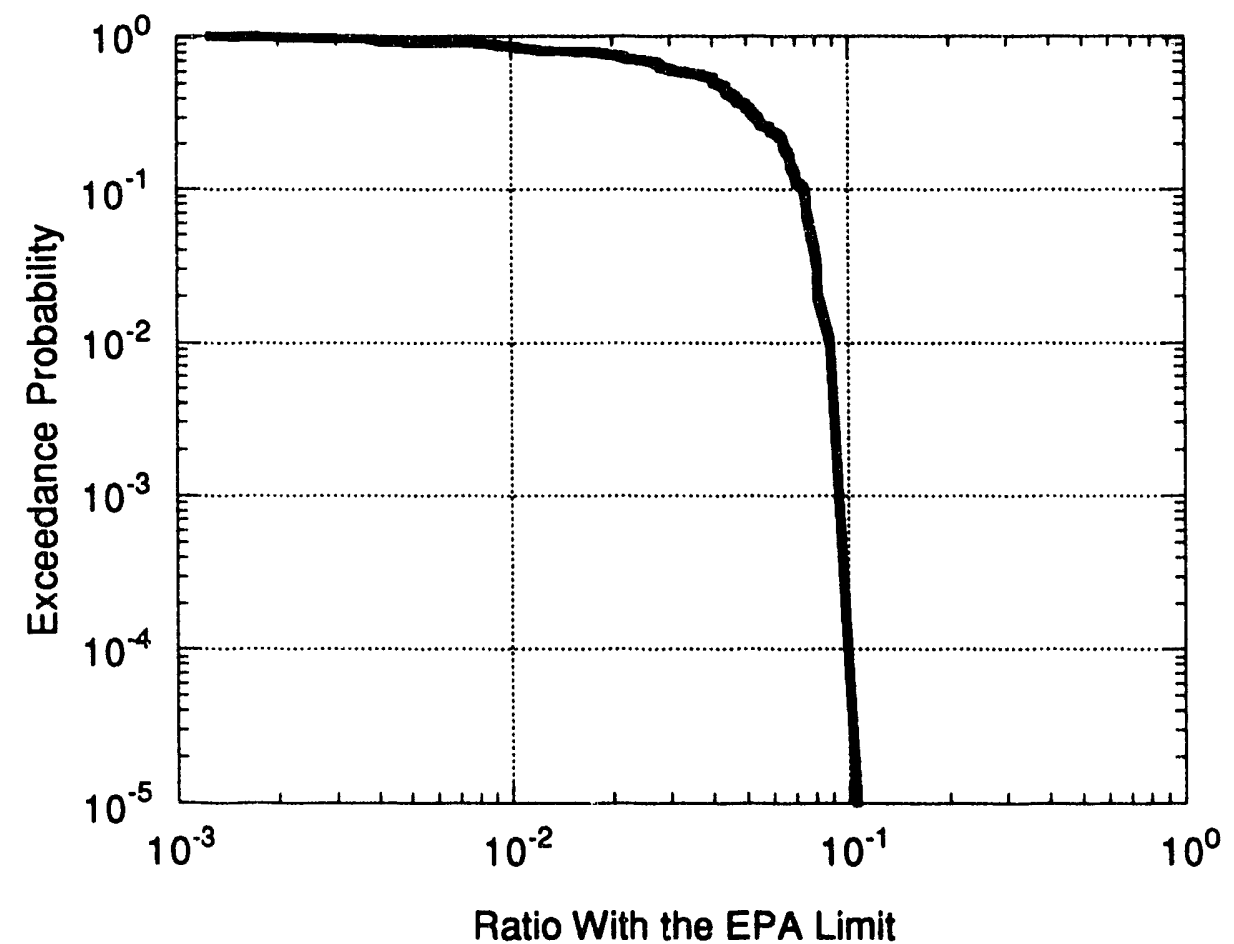

Figure 8.2. Conditional Complementary Cumulative Distribution Function for Surface Releases from Direct Container Hits 
Figure 8.3 contains the conditional CCDF for releases caused by injection of a single waste container into the carbonate aquifer. The quantities varied to obtain this curve include the saturated zone hydraulic gradient, spatially correlated hydraulic conductivity fields, and radionuclide sorption in addition to the values discussed for Figure 8.1. The releases in this curve are lower than the releases to the surface from a direct hit on a waste container. The lower releases are due to transport times and retardation in transport (see Section 5.0). For example, ${ }^{126 \mathrm{Sn},}{ }^{243} \mathrm{Am}$, and ${ }^{237} \mathrm{~Np}$ did not arrive at the accessible environment in any appreciable quantities in the 10,000 year transport analysis.

A conditional CCDF for injection of a waste container into the tuff aquifer is not given here. The ground-water travel times in the tuff aquifer computed for this analysis were long enough (refer to Section 5.0) that there were no releases to the accessible environment through this pathway.

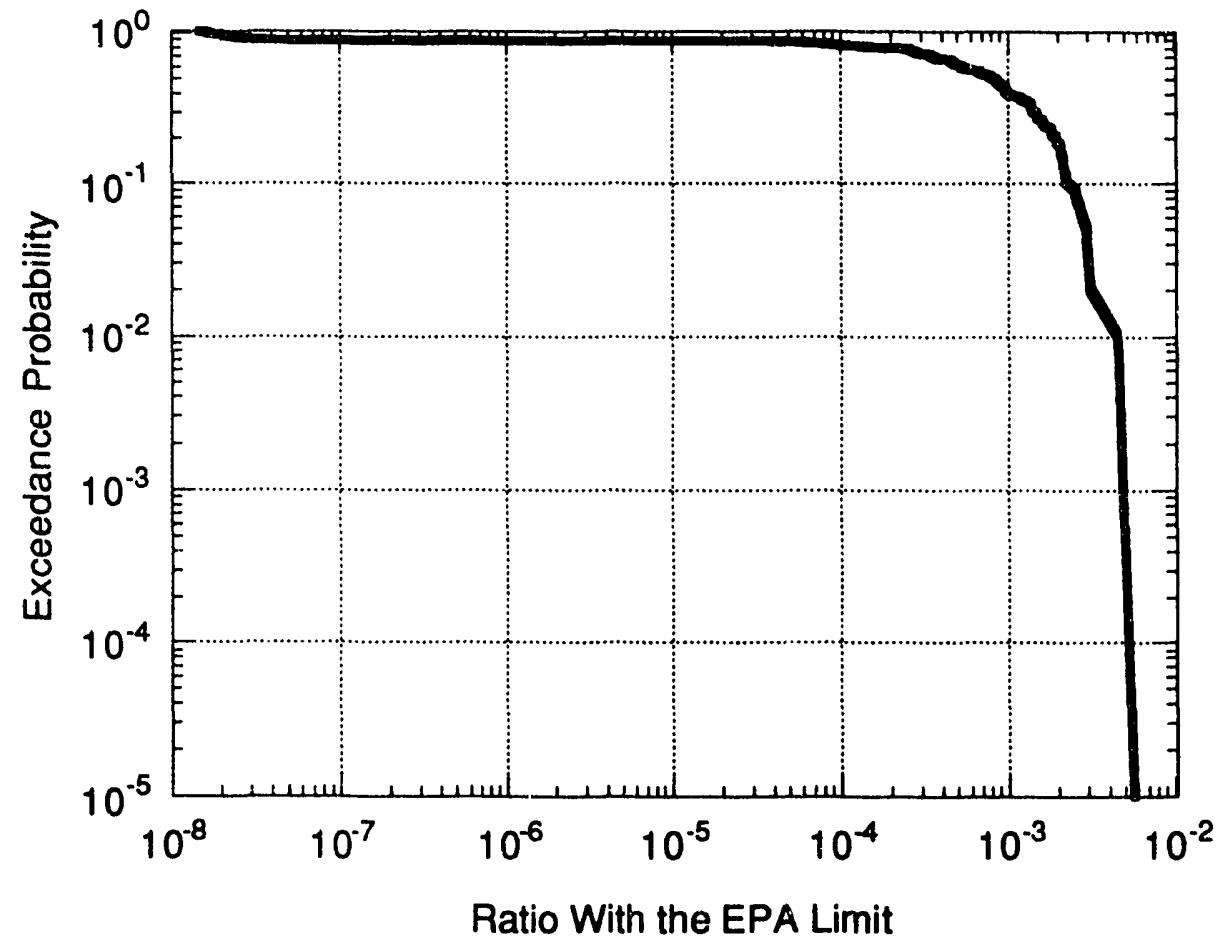

Figure 8.3. Conditional Complementary Cumulative Distribution Function for Carbonate Aquifer Waste Injection 


\subsection{Cumulative Releases for the Total System}

\subsection{Definition of Accessible Environment}

The EPA has established upper limits for the release of radionuclides to the accessible environment as a function of repository inventory (Table 1 of 40 CFR 191). For the purposes of this analysis the accessible environment was the ground surface in the vertical direction and an irregular-shaped boundary (corresponding to the irregular boundary of the potential repository) 5$\mathrm{km}$ from the edge of the repository in the horizontal direction. The accessible environment at the 5$\mathrm{km}$ boundary does not necessarily coincide with the ground surface under these definitions because the ground surface is a physical boundary whereas the $5-\mathrm{km}$ distance is defined by regulations, not geology or topography.

\subsection{Combination of Scenarios}

Release results from each scenario have been computed and displayed as conditional CCDFs. The conditional CCDFs show repository system performance assuming that the individual scenario has occurred. These individual scenarios must then be combined to form a total system performance estimate. The pathway modeling combination for scenario combination is illustrated in Figure 9.1. The effect of tectonism is ignored in Figure 9.1 because it did not cause any releases different from the base-scenario in this analysis. Note that human-intrusion and volcanism calculations are nested within the particular base-scenario run for which they were calculated.

Because five base-scenario simulations were attempted, at infiltrations of $0.0,0.01,0.05$, 0.1 , and $0.5 \mathrm{~mm} / \mathrm{yr}$, we chose the probability of each base scenario $\left(\mathrm{P}_{\mathrm{Bi}}\right)$ to be 0.2 for each release scenario. The probability of human intrusion was 1 , i.e., human-intrusion always occurred. The movement of contaminants within a human-intrusion scenario was divided into: 1) the probability $\mathrm{P}_{\mathrm{H} 0}$ of extracting only a contaminated rock column, set to $0.99815,2$ ) the probability $\mathrm{P}_{\mathrm{H} 1}$ of extracting a rock column and bringing a waste container to the surface, set to $1.7575 \times 10^{-3}, 3$ ) the probability $\mathrm{P}_{\mathrm{H} 2}$ of extracting a rock column and injecting a waste container into the tuff aquifer, set to 0 for this demonstration because no nonzero releases were computed, and 4) the probability $\mathrm{P}_{\mathrm{H} 3}$ of extracting a rock column and injecting a waste container into the carbonate aquifer, set to $9.25 \times 10^{-5}$. The probability of a single drilling event intercepting a waste container was chosen to be 0.00185 using the geometry argument described in Section 8.1. The probability $\mathrm{P}_{\mathrm{H} 1}$ was set to $95 \%$ of this value and $\mathrm{P}_{\mathrm{H} 3}$ was set to $5 \%$ of this value. The probability of volcanism occurring $\left(\mathrm{P}_{\mathrm{V}}\right)$ was set to $1.0 \times 10^{-4}$. The value for $\mathrm{PV}_{\mathrm{V}}$ was chosen somewhat arbitrarily, but is in the range of values suggested in the literature (see Section 6.5).

\subsection{Total System Performance}

Total system performance expressed as a CCDF of normalized releases is given in Figure 9.2. The different shapes on the CCDF can be attributed to the different scenarios being modeled. The first drop on the CCDF is from the human-intrusion scenario, which always occurs, but has low consequence. The flat portion on the curve is from gas-phase release of ${ }^{14} \mathrm{C}$ for one of the five base-scenario infiltration rates. The next hump on the curve is from human-intrusion where 


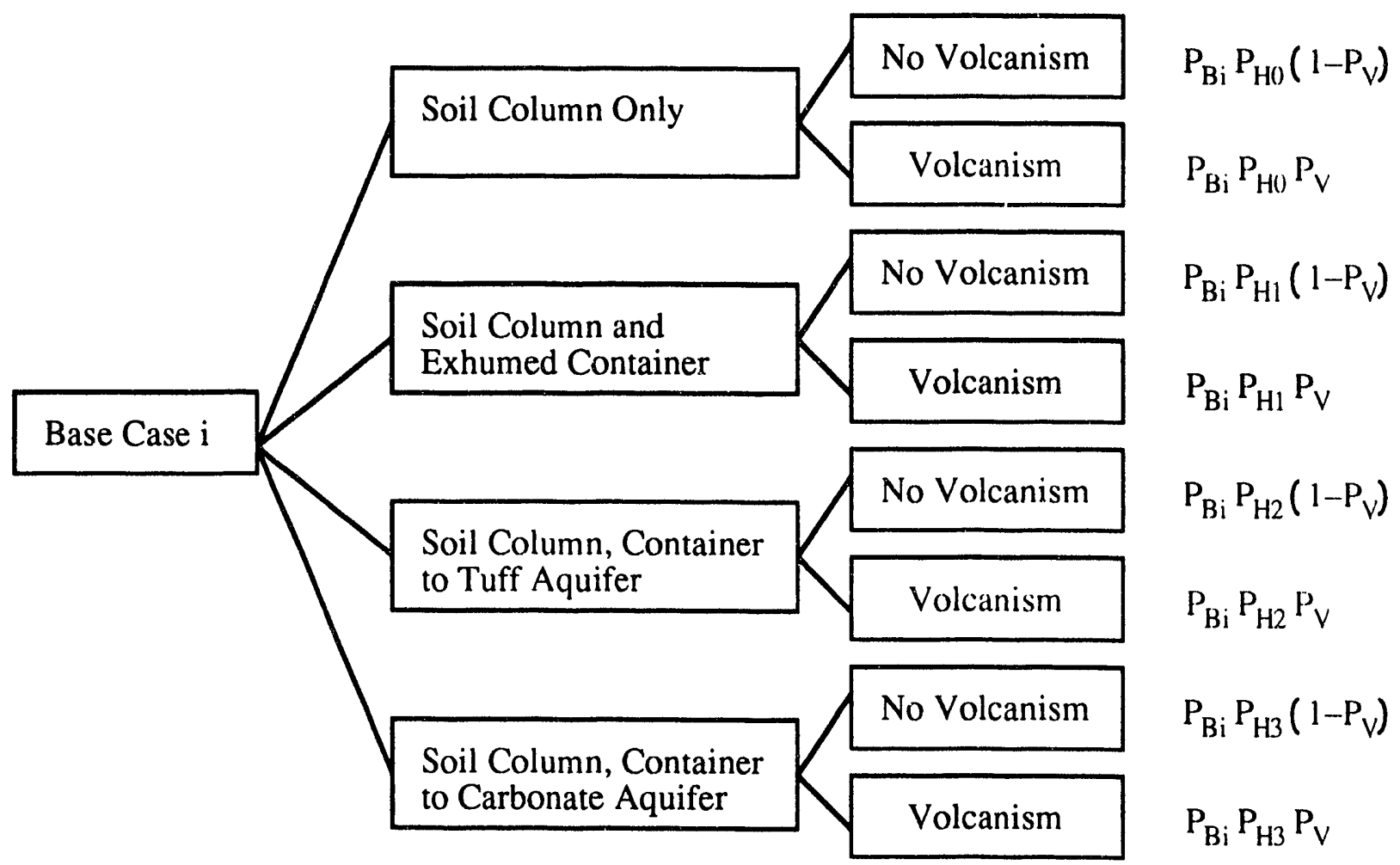

Figure 9.1. Combination of Conditional Complementary Cumulative Distribution Functions

exploratory drilling intersects a waste container. The final tail on the curve is from a volcanism scenario which releases more material, but at a low probability. The EPA limits are shown as the heavy lines and shaded region in the upper right corner of the plot.

The 10 nuclides run in this analysis only account for about $10 \%$ of the repository inventory expressed in terms of the allowable release by the EPA. Consideration of all nuclides would change this curve. First, the human-intrusion and volcanism portions of the curve would move about one order of magnitude larger on the consequence axis. Second, the base-scenario portion of the curve would not change. The base-scenario releases are all due to gas-phase movement of ${ }^{14} \mathrm{C}$, and the entire inventory of ${ }^{14} \mathrm{C}$ was released in this analysis.

The scenarios modeled here are not exhaustive of all possible scenarios that will have to be considered for licensing. However, they were selected because they are believed to contribute among the largest releases of any scenarios to be considered. Definitive site data are still required to reach conclusions on performance that will be valid in a licensing process. After considering the analysis done for this report, the authors conclude that there is no reason to not continue site characterization of Yucca Mountain as a potential site for a high-level nuclear waste repository. 


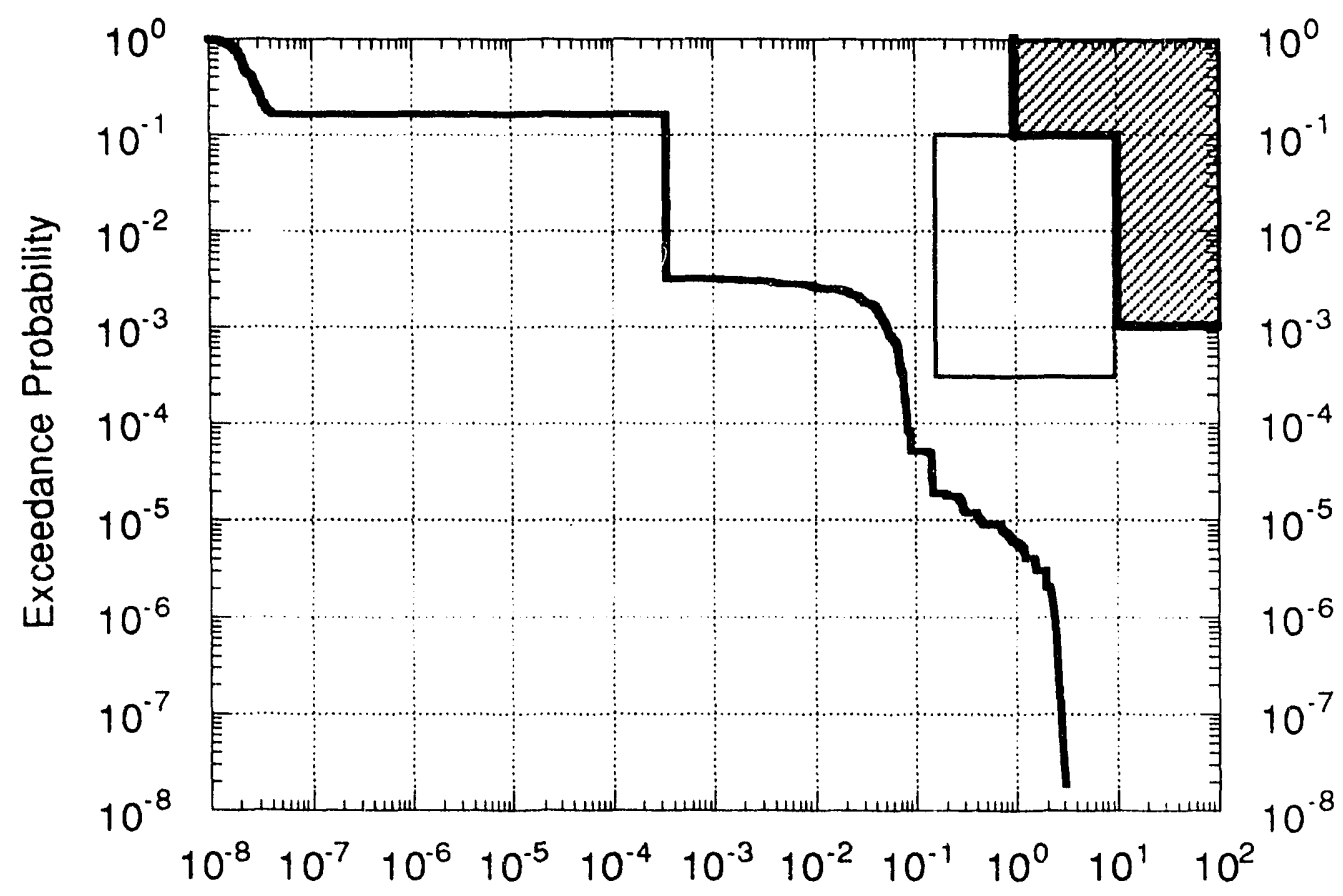

Ratio With the EPA Limit

Figure 9.2. Complementary Cumulative Distribution Function for Total System Performance 


\subsection{Dose Modeling Description and Results}

Pacific Northwest Laboratory has produced dose estimates for several exposure scenarios using both PNL and SNL estimates of radionuclide releases to the accessible environment. In light of proposed changes to 40 CFR Part 191 in EPA's Working Draft 4 (February 3, 1992), it is crucial for the DOE to be able to estimate doses for the potential repository at Yucca Mountain.

The careful, systematic choice of release and exposure scenarios is very important in a definitive analysis of the risk of the potential repository. The dose scenarios modeled in this totalsystems exercise did not receive the careful consideration that a definitive assessment would require. Instead, the dose scenarios chosen here analyze the output of transport models intended primarily for assessing the cumulative release of radionuclides over a 10,000-year period. The exposure scenarios run here are based on work done at the Hanford Site in Washington (Aaberg and Kennedy 1990) and are not necessarily feasible in the dry environment of Yucca Mountain.

The release rates from the engineered barrier system for the PNL simulations were calculated using the AREST code (Liebetrau et al. 1987). The runs performed by SNL were based on a simple release rate model developed by Lawrence Livermore National Laboratory (LLNL). Pacific Northwest Laboratory modeled transport through the geologic media using both the MSTS code (White et al. 1991) and the transport module of the SUMO code (Eslinger et al. 1990). Sandia National Laboratories modeled transport through the geologic media with the TOSPAC code (Dudley et al. 1988). The results from these transport codes were summarized as a set of releases $(\mathrm{Ci} / \mathrm{yr})$ at various times to define the release plume.

The exposure scenarios chosen for the dose calculations necessitated using two codes, SUMO and GENII (Napier et al. 1988). SUMO's dose module was used to evaluate doses from waterborne scenarios. GENII was used to evaluate doses that can be categorized as surface contamination. The dose calculations estimate whole body doses expressed as effective dose equivalent to a representative exposed individual. Doses are also reported by $\checkmark$ gan and nuclide. A detailed listing of the components of the total dose calculated is provided by the codes for the 70year period that has the highest incremental dose.

The simple transport models used did not attempt to identify a maximum concentration and, thereby, a maximum dose; rather, they addressed the cumulative amount of radionuclides released to the accessible environment in 10,000 years. Therefore, the term "representative individual" is used here instead of maximally exposed individual. For some of the cases, the exposure scenario could end up being the scenario evaluated for a maximally exposed individual.

\subsection{Regulatory Requirements for Dose Modeling}

The dose modeling requirement for the 1985 version of 40 CFR Part 191 was limited to consideration of individual doses during the first 1000 years of repository performance. In addition, it applied to undisturbed repository performance only. Working Draft 4 of 40 CFR Part 191 considers implementing both individual and population dose limits. The individual dose limit is again based on undisturbed performance of the repository system, but the time limit is extended to 10,000 years after repository closure, with projection required to 100,000 years post-closure. A limit of $25 \mathrm{mrem} / \mathrm{yr}$ is proposed, with a $4 \mathrm{mrem} / \mathrm{yr}$ limit on the drinking water pathway. The population dose limit considers doses from disturbed repository performance in addition to releases 
from the undisturbed repository. The time period where doses must be computed extends for 10,000 years after repository closure, with projection required to 100,000 years post-closure. The population dose limit is at or below 2.5 million person-rem at a $90 \%$ chance of occurrence, and at or below 25 million person-rem at a $99.9 \%$ chance of occurrence.

The scenarios considered in this report fall into two classes: undisturbed performance (base scenario) and disruptive scenarios. The proposed individual protection values apply only to the SNL releases discussed in Section 10.4.1.2. All other dose estimates apply only to computation of the population dose criteria and should not be compared to the individual protection limit.

\subsection{Description of the Dose Models}

The dose models in SUMO and GENII are based on the approach given in ICRP 26 (1977) and further modified through ICRP 30 and ICRP 40. Both SUMO and GENII calculate dose increments for a 70-year period. The dose module of SUMO can handle sources of any duration. Long-duration doses are calculated as the sum of consecutive 70-year doses. The GENII code calculates dose for a single 70-year period. The 70-year period represents one human lifetime. Both SUMO and GENII calculate internal dosimetry to a number of target organs. The whole body dose is the sum of organ doses multiplied by organ weighting factors for the six whole body organs defined in ICRP 26 (1977) and the five remaining organs (out of a set of 23 organs)

receiving the highest doses. The whole body organs and their weighting factors are given in Table 10.1. The five remaining organs are weighted equally with factor 0.06 . The models also calculate external doses resulting from submersion in contaminated air and dermal contact with contaminated soil. The doses reported here are lifetime effective dose equivalents computed as the sum of the whole body internal dose and the external doses.

The dose module of SUMO currently handles only waterborne releases. Time-reiease pairs are input from a hydrologic transport model in sets each spanning 10,010 years. The; releases are translated to a total number of curies released for each 70-year period in that 10,010-year segment. From these total activity values, environmental concentrations are calculated. The tirst concentration calculated is the population-weighted water concentration. This is usied to calculate soil and sediment concentrations. Further calculations are made to determine leaf concentrations, concentrations in the edible part of plants, and animal product concentrations. The environmental concentrations are combined with library parameters such as bioaccumulation factors and internal dose factors, and doses are then estimated for the various exposure pathways.

\subsection{Scenario Description}

Scenarios for which doses were estimated include base-scenario (undisturbed repository performance) and disruptive scenarios for both waterborne and surface contamination. The waterborne scenarios include:

- failure of waste containers and subsequent dissolution and transport of the waste form under undisturbed repository conditions

- injection of waste into a shallow aquifer from exploratory drilling

- injection of waste into a deep aquifer from exploratory drilling. 
Table 10.1. Whole Body Organ Weighting Factors

$\begin{array}{lc}\text { Organ } & \text { Weighting Factor } \\ \text { Testes/Ovaries } & 0.25 \\ \text { Muscle } & 0.15 \\ \text { Blood Marrow } & 0.12 \\ \text { Lung and Lymph } & 0.12 \\ \text { Thyroid } & 0.03 \\ \text { Bone Surface } & 0.03\end{array}$

The surface contamination scenarios include:

- gaseous release of ${ }^{14} \mathrm{C}$ to the ground surface

- exhumation of the contents of a waste container to the surface from exploratory drilling.

Doses are calculated for a representative exposed individual for each 70-year period. Several exposure scenarios are assumed for the representative individual, depending on the transport scenario considered.

\subsubsection{Waterborne Exposure Scenarios}

There are two exposure scenarios used for waterborne transport modeling. Both scenarios place a receptor well $5 \mathrm{~km}$ down-gradient from the repository.

\subsubsection{Farm Exposure Scenario}

A farm scenario is used when there is enough ground water to support farming activities. The individual is assumed to inhabit a $20,000 \mathrm{~m}^{2} \mathrm{farm}$ on which contaminated irrigation water is used to grow vegetables and water livestock. Assuming that irrigation is used for 6 months of the year at a rate of $150 \mathrm{~L} / \mathrm{m}^{2} / \mathrm{mo}$, the farm scenario requires that at least $1.8 \times 10^{7} \mathrm{~L} / \mathrm{yr}$ of water be available to the well. The individual is assumed to consume $2 \mathrm{~L}$ of contaminated water per day from the well. The farm also supports $100 \%$ of the individual's edible plant, beef, eggs, poultry and milk intake. With the exception of meat intake, all values for consumption rates are taken from the average individual column of Table F.6 of the Hanford Defense Waste Environmental Impact Statement (DOE 1987). The consumption value for meat has been increased by $10 \mathrm{~kg} / \mathrm{yr}$ to estimate consumption of meats other than beef and pork. The consumption rates used for the waterborne scenario farm exposure simulations are given in Table 10.2. The time spent outdoors is assumed to be 4380 hours per year.

\subsubsection{Drinking Water-Only Exposure Scenario}

If there is no significant source of ground water, the exposure scenario is limited to drinking 2 liters of water per day. This scenario is denoted by "Drinking Water Only" in several tables in this section. 
Table 10.2. Consumption Rates for Farm Products

$\begin{array}{lcc} & \text { Rate } & \text { Units } \\ \text { Leafy Vegetables } & 15 & \mathrm{~kg} / \mathrm{yr} \\ \text { Other Vegetables } & 276 & \mathrm{~kg} / \mathrm{yr} \\ \text { Eggs } & 20 & \mathrm{~kg} / \mathrm{yr} \\ \text { Meat } & 80 & \mathrm{~kg} / \mathrm{yr} \\ \text { Milk } & 230 & \mathrm{~L} / \mathrm{yr} \\ \text { Poultry } & 8.5 & \mathrm{~kg} / \mathrm{yr}\end{array}$

\subsubsection{Surface Contamination Exposure Scenarios}

There are two types of exposure for surface contamination scenarios; release of gas-phase ${ }^{14} \mathrm{C}$ and exhumation of contaminated rock. For all surface contamination scenarios, the individual is assumed to be located directly above the repository.

\subsubsection{Driller Exposure Scenario}

In the human-intrusion scenarios, a driller workir $_{6}$ at the site is exposed to inhalation of drilling dust for 1 hour and to other external contamination for 40 hours. This individual has a $5($ )year dose commitment (the continuing dose an individual receives for the remainder of their lite from residual radioactive materials in their body following a 1 -yr exposure).

\subsubsection{Garden Exposure Scenario}

Another exposure scenario is for an individual who resides on contaminated soil for 70 years. This individual is assumed to have a $2,500 \mathrm{~m}^{2}$ fruit and vegetable garden. The consumption rates for this scenario are $25 \%$ of the maximum individual numbers from Table F.6 in the Hanford Defense Waste Environmental Impact Statement (DOE 1987). The value for leafy vagetables is 7.4 $\mathrm{kg} / \mathrm{yr}$ and the value for other vegetables is $160 \mathrm{~kg} / \mathrm{yr}$. No animal products are produced on the contaminated homestead. The individual spends 2920 hours per year outdoors.

\subsubsection{External-Only Exposure Scenario}

The final surface-based exposure scenario is where the individual resides for 70 years on contaminated soil, but the individual does not grow a garden. The individual is assumed to spend 2920 hours per year outdoors.

\subsection{Results}

The dose calculations were based on a source term consisting of release of ten nuclides. The nuclides modeled were ${ }^{14} \mathrm{C},{ }^{79} \mathrm{Se},{ }^{99} \mathrm{Tc},{ }^{126} \mathrm{Sn},{ }^{129} \mathrm{I},{ }^{135} \mathrm{Cs},{ }^{234} \mathrm{U},{ }^{237} \mathrm{~Np},{ }^{239} \mathrm{Pu}$, and ${ }^{243} \mathrm{Am}$. The decay chains used by the dose model based on this set of parent nuclides is given in Table 10.3. The branching fraction for $126 \mathrm{MSb}$ to ${ }^{126} \mathrm{Sb}$ is 0.14 . All other branching fractions are 1 .

The number of simulations run and the exposure scenarios used for each run are given by transport scenario in Table 10.4. Results are presented for each of these runs. The waterbornc 
Table 10.3. Radioactive Decay Chains and Half-Lives

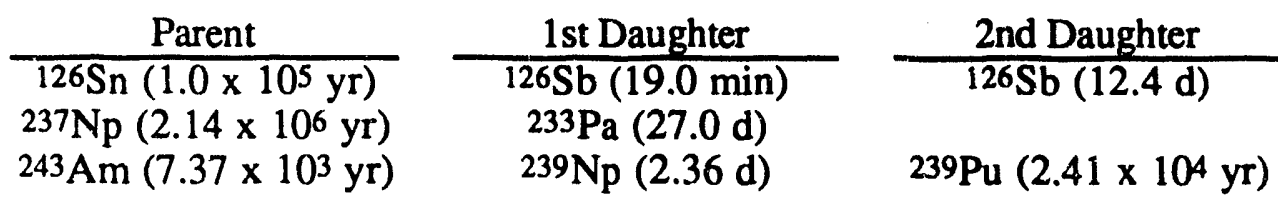

Table 10.4. Summary of Simulations for Which Doses Were Estimated

\begin{tabular}{|c|c|c|c|c|}
\hline & & No. PNL Runs & No. SNL Runs & Exposure Scenario \\
\hline Waterborne & $\begin{array}{l}\text { Base Scenario } \\
\text { HI(b) - Tuff } \\
\text { HI(b) - Carbonate }\end{array}$ & $\begin{array}{c}\mathrm{NR}(\mathrm{a}) \\
\mathrm{NR}(\mathrm{a}) \\
12\end{array}$ & $\begin{array}{l}2 \\
1 \\
1\end{array}$ & $\begin{array}{c}\text { Drinking Water Only } \\
\text { Drinking Water Only } \\
\text { Farm }\end{array}$ \\
\hline Surface & $\begin{array}{l}\text { Base Scenario } \\
\text { HI(b) - Driller } \\
\text { HI(b) - Post-Drilling }\end{array}$ & $\begin{array}{c}3 \\
20 \\
20\end{array}$ & $\begin{array}{l}6 \\
0 \\
0\end{array}$ & $\begin{array}{l}\text { Garden } \\
\text { External Only } \\
\text { Garden }\end{array}$ \\
\hline
\end{tabular}

(a) NR - indicates that there was no release to the accessible environment for the scenario.

(b) HI - human-intrusion.

runs are presented first and the surface contamination runs follow. The waterborne runs expose an individual to either drinking water only or to the farm scenario, depending on the volume of water available to the well. The surface-based human-intrusion runs include exposure to a driller, a postdrilling dweller with a garden, and a post-drilling dweller exposed only externally.

\subsubsection{Waterborne Scenarios}

For all of the waterborne transport scenarios run for these analyses, the flow rate in the aquifer is a major contributor to the water concentration at the well. The water concentration is inversely proportional to the volumetric flow in the aquifer. For both the tuff (denoted by TUF) and carbonate (denoted by CAR) aquifers, a cross-sectional area $10000-\mathrm{m}$ wide by $500-\mathrm{m}$ deep was used to calculate a mixing volume. Increasing the flow rate or mixing width or depth would serve to dilute the radionuclide concentration in water, potentially by several orders of magnitude. An assumption of a further dilution by a factor of 10 was made for withdrawal from a well. No attempt was made to achieve consensus on appropriate values for the aquifer properties or dimensions - this is an assumption that should be scrutinized carefully in future studies. The values used for the flow parameters used by PNL and SNL for the two aquifers are given in Table 10.5 .

\subsubsection{Pacific Northwest Laboratory Results}

The first waterborne scenario presented is a drilling-intrusion scenario modeled by PNL. The scenario was assumed to inject a waste inventory equal to that of one waste container into the deep carbonate aquifer. Pacific Northwest Laboratory ran ten stochastic simulations, a minimum 
Table 10.5. Aquifer Flow Parameters

\begin{tabular}{|c|c|c|c|c|}
\hline & \multicolumn{2}{|c|}{ TUF } & \multicolumn{2}{|c|}{ CAR } \\
\hline & $\overline{\mathrm{PNL}}$ & SNL & PNL & $\overline{\mathrm{SNL}}$ \\
\hline Pore Velocity $(\mathrm{m} / \mathrm{yr})$ & 0.0077 & 4.07 & 60.7 & 230 \\
\hline Porosity & 0.24 & 0.175 & 0.05 & 0.05 \\
\hline Water Flux (m/yr) & 0.00185 & 0.71 & 3.04 & 11.5 \\
\hline
\end{tabular}

Table 10.6. Dose Summary for Pacific Northwest Laboratory Waterborne Human-Intrusion Runs

\begin{tabular}{|c|c|c|c|}
\hline Run ID & Drill Time (yr) & $\begin{array}{c}\text { Time of } \\
\text { Maximum Dose (yr) } \\
\end{array}$ & Maximum Dose (mrem/yr) \\
\hline RUN \#1 & 2465.6 & 2940 & $1.09 \times 10^{-4}$ to $1.09 \times 10^{-1}$ \\
\hline RUN \#2 & 146.8 & 4900 & $3.66 \times 10^{-3}$ to $3.66 \times 100$ \\
\hline RUN \#3 & 589.2 & 7140 & $1.09 \times 10^{-2}$ to $1.09 \times 10^{1}$ \\
\hline RUN \#4 & 259.1 & 9870 & $3.66 \times 10^{-3}$ to $3.66 \times 100$ \\
\hline RUN \#5 & 1190.8 & 9940 & $1.14 \times 10^{-5}$ to $1.14 \times 10-2$ \\
\hline RUN \#6 & 8336.1 & 9870 & $3.20 \times 10^{-3}$ to $3.20 \times 10^{0}$ \\
\hline RUN \#7 & 3811.8 & 9870 & $1.31 \times 10^{-3}$ to $1.31 \times 10^{0}$ \\
\hline RUN \#8 & 128.5 & 9870 & $3.66 \times 10^{-3}$ to $3.66 \times 10^{0}$ \\
\hline RUN \#9 & 2615.6 & 9030 & $3.66 \times 10^{-3}$ to $3.66 \times 100$ \\
\hline RUN \#10 & 1308.0 & 8050 & $3.66 \times 10^{-3}$ to $3.66 \times 10^{0}$ \\
\hline Min Flow & 300.0 & 9940 & $0.00 \times 100$ \\
\hline Max Flow & 300.0 & 4620 & $3.66 \times 10^{-3}$ to $3.66 \times 10^{0}$ \\
\hline
\end{tabular}

ground-water flow rate run, and a maximum ground-water flow rate run. Transport through the hydrologic media and doses were modeled using the SUMO code. The simulations were run for 10,000 years. The time of the drilling event was varied randomly in the stochastic runs and was set to 300 years for both the minimum and maximum flow rate runs. Table 10.6 summarizes the results for the 12 human-intrusion runs. The dose is interpreted as the average dose rate (mrem/yr) received by an individual during a 70 -year period. The range in dose estimates is intended to represent additional uncertainty in mixing volume and well-extraction dilution values.

For the ten stochastic runs and the maximum flow-rate run, the majority of the dose is attributable to ${ }^{237} \mathrm{~Np}$. The primary exposure pathway was dose to the bone surface through ingestion of terrestrial products. For the minimum flow-rate run, the dose was primarily from ${ }^{99} \mathrm{Tc}$ and $129 \mathrm{I}$ to the stomach through ingestion of contaminated drinking water. The ground-water flow assumptions for the minimum flow-rate scenario reduced the capacity of the aquifer to a level such that the exposure pathway was limited to drinking water only. Because the dose was inconsequential for the minimum flow-rate run, detailed results are not presented here.

Detailed results by organ for the maximum flow-rate run (at the upper end of the dose estimate range) are presented in Table 10.7. The organs that received the highest doses are the bone surface, the red marrow, and the liver. 
Table 10.7. Dose by Organ for the Pacific Northwest Laboratory Maximum FlowRate Drilling Intrusion

\begin{tabular}{|c|c|c|c|}
\hline Organ & Organ Dose (mrem/yr) & Organ Weight Factor & Dose After Weighting \\
\hline $\begin{array}{l}\text { Bone Surface } \\
\text { Red Marrow } \\
\text { Liver }\end{array}$ & $\begin{array}{c}80.48 \\
6.896 \\
3.621\end{array}$ & $\begin{array}{l}0.03 \\
0.12 \\
0.06\end{array}$ & $\begin{array}{l}2.41 \\
0.827 \\
0.217\end{array}$ \\
\hline
\end{tabular}

Table 10.8. Dose by Pathway for the Pacific Northwest

\section{Laboratory Maximum Flow-Rate Drilling Intrusion}

\begin{tabular}{lr}
\multicolumn{1}{c}{ Pathway } & Dose (mrem \\
\cline { 3 - 3 } Other Vegetables & 3.3634 \\
Leafy Vegetables & 0.1931 \\
Meat & 0.0680 \\
Drinking Water & 0.0223 \\
Inhalation & 0.0011
\end{tabular}

When the weighting factors for computing whole body dose were applied, $66 \%$ of the $3.66 \mathrm{mrem} / \mathrm{yr}$ dose was through the terrestrial ingestion pathway. For this reason, further runs were made to determine the subpathway contributions more specifically. These results are summarized in Table 10.8 .

Summing over all organs, $92 \%$ of the $3.66 \mathrm{mrem} / \mathrm{yr}$ dose produced in this scenario is through the vegetable ingestion pathway. This pathway has a consumption rate of $276 \mathrm{~kg} / \mathrm{yr}$, a yield of $4 \mathrm{~kg} / \mathrm{m}^{2}$, and a growing period of 90 days.

This scenario assumes that water in the aquifer is withdrawn to support the single farm. If less water were available, then there would not be enough water to support the farming assumption, and doses would then have to be calculated on a drinking water-only scenario. In that case, the doses would drop by about two orders of magnitude relative to the entries in Table 10.8 . It is the lower dose rate that would be compared to the drinking water standard applied by the EPA in 40 CFR Part 191.

\subsubsection{Sandia National Laboratories Results}

Doses were computed for four SNL waterborne runs. Two of the runs were undisturbed performance runs using different conceptual models to produce the release profile at the accessible environment. The first run is referred to as TOS and was produced using the TOSPAC code. The second is referred to as WEE and was produced using a Weeps model. The Weeps model assumes ground-water flow in the unsaturated zone is predominantly through fractures which intercept a small fraction of the repository's waste containers (and a small fraction of the repository inventory). 
The remaining two SNL runs were human intrusion by drilling into the shallow aquifer in the Calico Hills tuff and the deep carbonate aquifer. The shallow aquifer intrusion run is referred to as TUF, and the deep aquifer intrusion run is referred to as CAR.

All SNL simulations were run for a 1-million-year time span. This time span is much longer than required by EPA's regulations, but does examine the question whether there is a sudden large risk from the repository just after the end of the 10,000-year regulatory period. Doses for the two undisturbed performance runs and the tuff-intrusion run were calculated assuming SNL-provided flow parameters for the tuff aquifer. The flow rates for this aquifer are low enough to restrict the exposure scenario to drinking water only. Human intrusion into the deep carbonate aquifer was calculated assuming SNL-provided flow parameters for the aquifer. The properties of this aquifer allow all terrestrial pathways to be included in the simulation. Doses produced for the four SNL runs are summarized in Table 10.9. The time of the maximum dose for the TOS and TUF runs is well beyond the 10,000-year limit in the regulations. The maximum dose in the first 10,000 years is near zero.

Detailed results for the upper end of the dose range are presented for the SNL waterborne case referred to as TOS. The maximum dose occurred in the 70-year period beginning in year 53,410 . The individual residing in this time period would receive a dose rate of $0.43 \mathrm{mrem} / \mathrm{yr}$ over the 70 years. The nuclide $99 \mathrm{Tc}$ provided $74 \%$ of the dose, $25 \%$ was provided by $129 \mathrm{I}$, and $1 \%$ was provided in trace amounts of all the other nuclides. The organs that received the highest dose are the thyroid, the upper and lower large intestines, and the stomach. Table 10.10 gives a breakdown of dose to these organs by nuclide. Weighting factors for calculating whole body doses have not been applied in Table 10.10 . These factors are 0.03 for the thyroid, 0.06 for the upper and lower large intestines, and 0.06 for the stomach.

The second SNL waterborne case is the WEE undisturbed performance scenario. The maximum dose rate of $4.86 \times 10^{-4} \mathrm{mrem} / \mathrm{yr}$ occurred in the 70 -year period beginning at year 4,200 . Nuclide and organ specific doses for this run are to the same organs from the same nuclides as the TOS simulation. The difference in magnitude and time of maximum dose is due to the difference in source between the two conceptual models. The radionuclide source term is much smaller in this run than in the TOS run because only a small fraction of the waste containers were assumed to encounter mobile ground water. Results for the WEE run are given in Table 10.11.

Over $90 \%$ of the dose in the two SNL drilling-intrusion simulations analyzed was contributed

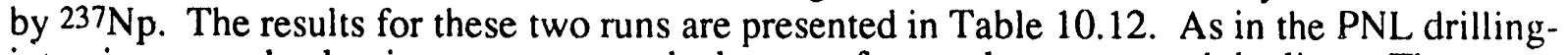
intrusion runs, the dominant organs are the bone surface, red marrow, and the liver. The organ weighting factors have not been applied to the doses given in this table.

Recall that the TUF run provided only enough water for drinking water consumption, while the water flow from the CAR run was sufficient to support a farm scenario. Typically, drinking water contributes only a small fraction of the total dose for a farming scenario. Table 10.8 shows that drinking water contributed less than $0.7 \%$ of the total dose for PNL's maximum flow-rate human-intrusion case. The higher flow rate of the carbonate aquifer allowed rapid transport to the accessible environment, with the maximum dose of $2.1 \mathrm{mrem} / \mathrm{yr}$ occurring in the 70 -year period beginning in year 700. The slower transport time in the tuff aquifer produced the maximum dose of $8.0 \times 10^{-3} \mathrm{mrem} / \mathrm{yr}$ in the 70 -year period beginning in the year 24,360 . 
Table 10.9. Dose Summary for Sandia National Laboratories Waterborne Runs Time of

$\begin{array}{lrrrr}\text { Run ID } & \text { Maximum Dose }(\mathrm{yr}) & & \text { Maximum Dose }(\mathrm{mrem} / \mathrm{yr}) & \text { Exposure Scenario } \\ \text { TOS } & 53,410 & & 4.3 \times 10^{-4} \text { to } 4.3 \times 10^{-1} & \text { Drinking Water Only } \\ \text { WEE } & 4,200 & & 4.9 \times 10^{-7} \text { to } 4.9 \times 10^{-4} & \text { Drinking Water Only } \\ \text { TUF } & 24,360 & & 8.0 \times 10^{-6} \text { to } 8.0 \times 10^{-3} & \text { Drinking Water Only } \\ \text { CAR } & 700 & 2.1 \times 10^{-3} \text { to } 2.1 \times 10^{0} & \text { Farm }\end{array}$

Table 10.10. Dose (mrem/yr) by Organ for Sandia National Laboratories TOS Undisturbed Performance Run

\begin{tabular}{|c|c|c|c|c|}
\hline & Thyroid & $\begin{array}{c}\text { Upper } \\
\text { Large Intestine } \\
\end{array}$ & $\begin{array}{c}\text { Lower } \\
\text { Large Intestine } \\
\end{array}$ & Stomach \\
\hline 1 & $8.6 \times 10-1$ & $2.2 \times 10^{-1}$ & $5.7 \times 10^{-1}$ & $1.8 \times 10^{0}$ \\
\hline 1291 & $3.7 \times 10^{0}$ & $2.2 \times 10^{-4}$ & $2.1 \times 10^{-4}$ & $3.4 \times 10^{-4}$ \\
\hline
\end{tabular}

Table 10.11. Dose (mrem/yr) by Organ for Sandia National Laboratories WEE Undisturbed Performance Run

\begin{tabular}{|c|c|c|c|c|}
\hline & Thyroid & $\begin{array}{c}\text { Upper } \\
\text { Large Intestine } \\
\end{array}$ & $\begin{array}{c}\text { Lower } \\
\text { Large Intestine } \\
\end{array}$ & Stomach \\
\hline${ }^{99} \mathrm{Tc}$ & $9.7 \times 10.4$ & $2.6 \times 10^{-4}$ & $6.9 \times 10^{-4}$ & $2.1 \times 10^{-3}$ \\
\hline 1291 & $3.7 \times 10-3$ & $2.2 \times 10-7$ & $2.1 \times 10^{-7}$ & $3.4 \times 10.7$ \\
\hline
\end{tabular}

Table 10.12. 237Np Dose (mrem/yr) by Organ for Sandia National Laboratories Human-Intrusion Runs

\begin{tabular}{|c|c|c|c|}
\hline & Bone Surface & Red Marrow & Liver \\
\hline TUF & $1.8 \times 10^{-1}$ & $1.4 \times 10^{-2}$ & $8.0 \times 10^{-3}$ \\
\hline CAR & $4.7 \times 10^{1}$ & $3.9 \times 10^{0}$ & $2.1 \times 10^{0}$ \\
\hline
\end{tabular}

\subsubsection{Surface Contamination Scenarios}

The doses resulting from surface contamination were calculated by the GENII code. The GENII code calculates dose for a single 70 -year lifetime. The ${ }^{14} \mathrm{C}$ gas-phase releases to the surface were calculated for both SNL and PNL. A garden exposure was used for this transport scenario. The exposure scenario requires computation of an air concentration $\left(\mathrm{Ci} / \mathrm{m}^{3}\right)$ for ${ }^{14} \mathrm{C}$. The calculation used the average annual wind speed at Yucca Mountain of $3.3 \mathrm{~m} / \mathrm{s}$ (DOE 1988) crossing the square root of the surface area of the repository $\left(5.67 \times 106 \mathrm{~m}^{2}\right.$ [DOE 1988]) and a 
mixing depth. A total air volume $\left(\mathrm{m}^{3} / \mathrm{yr}\right)$ was divided into the source $(\mathrm{Ci} / \mathrm{yr})$ to obtain the average air concentration.

Pacific Northwest Laboratory also calculated doses for two human-intrusion-scenario cases. Both cases are based on drilling resulting in a direct hit that brings the contents of one waste container to the surface. Two fuel types, spent fuel and glass fuel, were considered. Exposure scenarios are to a driller operating the equipment, which intrudes into the repository, and an individual who establishes a homestead on the contaminated soil that remains after the drilling intrusion.

\subsubsection{Pacific Northwest Laboratory Results}

Two dose runs were made for the ${ }^{14} \mathrm{C}$ gas-phase scenario using PNL source-term information. The MSTS code was used to generate a series of releases $(\mathrm{Ci} / \mathrm{yr})$ over time. Doses were estimated for two 70-year periods: at 6500 years and at the maximum release rate observed in the 10,000-year simulation. The average release was not estimated for these simulations. Table 10.13 gives the source, dose, organ receiving maximum dose, and pathway of maximum exposure for the PNL runs.

The ingestion pathways used for the garden scenario are vegetables and a small amount of inadvertent soil ingestion. Because ${ }^{14} \mathrm{C}$ is not retained in the soil, the soil ingestion dose is zero. The pathways responsible for the dose in these simulations are vegetable and leafy vegetable ingestion. If the exposed individual does not grow a garden, the doses for the two cases in the table drop to $7.1 \times 10^{-6}$ and $7.1 \times 10^{-5} \mathrm{mrem} / \mathrm{yr}$, respectively. Given the current arid climate, poor soil, and small water supply, it is hard to visualize a scenario where an individual would grow a garden on Yucca Mountain.

Ten runs were made for each of the two fuel types for each of the two exposure scenarios for the PNL drilling intrusion, assuming a direct hit on a waste container. The stochastic variables were drilling time and waste interception fraction. Table 10.14 summarizes the dose for both exposure scenarios for ten stochastic runs for the spent fuel source.

The organ that received the maximum dose is the bone surface for all runs for both exposure scenarios. The nuclide responsible for most of the dose is $243 \mathrm{Am}$ for the driller and $237 \mathrm{~Np}$ for the post-drilling dweller. The pathway of maximum exposure is soil ingestion for both the driller and the post-drilling dweller. The driller has an exposure time of $\mathbf{4 0}$ hours, while the post-drilling dweller has an exposure time of 70 years.

Table 10.15 gives the results for the drilling-intrusion case when the intercepted waste container is assumed to contain a glass waste form. The difference in the doses to the driller and the post-drilling dweller can be attributed to the difference in source for the two waste types.

The dose to an individual post-drilling dweller is very high, especially for the garden scenario. The current proposed regulation does not impose a dose limit for an individual for this scenario; rather the exposed individual contributes to the population dose limit. It is important to better define the appropriate exposure scenarios to use in dose modeling for an arid site such as Yucca Mountain. The high doses will only occur if it is feasible for an individual to be residing and supporting a garden directly above or adjacent to the potential repository. 
Table 10.13. Pacific Northwest Laboratory ${ }^{14} \mathrm{C}$ Gas-Phase Release Summary

Maximum Maximum

$\underline{\text { Time (yr) Source (Ci/yr) Dose (mrem/yr) Organ Contribution Exposure Pathway }}$

$\begin{array}{rrrrr}6500.0 & 1.0 \times 10^{-3} & 8.5 \times 10^{-5} & \text { Red Marrow } & \text { Ingestion } \\ 10000.0 & 1.0 \times 10^{-2} & 8.5 \times 10^{-4} & \text { Red Marrow } & \text { Ingestion }\end{array}$

$10000.0 \quad 1.0 \times 10^{-2} \quad 8.5 \times 10^{-4} \quad$ Red Marrow Ingestion

Table 10.14. Pacific Northwest Laboratory Direct-Hit Spent Fuel Drilling Intrusion Summary

Driller

Run No. $\quad$ Dose (mrem)

1

2

3

4

5

6

7

8

9

10
$1.4 \times 10^{4}$

$1.1 \times 10^{4}$

$1.4 \times 10^{4}$

$3.7 \times 10^{3}$

$1.2 \times 10^{4}$

$5.6 \times 10^{3}$

$4.6 \times 10^{3}$

$3.8 \times 10^{3}$

$7.6 \times 10^{3}$

$3.7 \times 10^{3}$
Post-Drilling Dose with Garden (mrem/yr)

$2.71 \times 10^{5}$

$2.71 \times 10^{5}$

$2.57 \times 10^{5}$

$8.29 \times 10^{4}$

$2.57 \times 10^{5}$

$1.29 \times 10^{5}$

$7.71 \times 10^{4}$

$6.86 \times 10^{4}$

$1.20 \times 10^{5}$

$9.71 \times 10^{4}$
Post-Drilling External

Dose (mrem/yr)

$3.29 \times 10^{4}$

$2.86 \times 10^{4}$

$3.14 \times 10^{4}$

$9.14 \times 10^{3}$

$3.00 \times 10^{4}$

$1.40 \times 10^{4}$

$1.04 \times 10^{4}$

$8.86 \times 10^{4}$

$1.71 \times 10^{4}$

$8.80 \times 10^{3}$

Table 10.15. Pacific Northwest Laboratory Direct-Hit High-Level Waste Glass Drilling Intrusion Summary

\begin{tabular}{|c|c|c|c|}
\hline Run No. & $\begin{array}{c}\text { Driller } \\
\text { Dose (mrem) }\end{array}$ & $\begin{array}{l}\text { Post-Drilling Dose with } \\
\text { Garden (mrem/yr) }\end{array}$ & $\begin{array}{l}\text { Post-Drilling External } \\
\text { Dose (mrem/yr) }\end{array}$ \\
\hline 1 & $3.5 \times 10^{2}$ & $1.71 \times 10^{4}$ & $3.29 \times 10^{2}$ \\
\hline 2 & $6.8 \times 10^{2}$ & $3.43 \times 10^{4}$ & $6.43 \times 10^{2}$ \\
\hline 3 & $1.7 \times 10^{2}$ & $9.86 \times 10^{3}$ & $1.33 \times 10^{2}$ \\
\hline 4 & $6.6 \times 10^{2}$ & $2.71 \times 104$ & $7.43 \times 10^{2}$ \\
\hline 5 & $8.0 \times 10^{2}$ & $3.71 \times 10^{4}$ & $8.00 \times 10^{2}$ \\
\hline 6 & $3.9 \times 10^{2}$ & $1.57 \times 10^{04}$ & $4.43 \times 10^{2}$ \\
\hline 7 & $2.2 \times 10^{2}$ & $1.06 \times 10^{4}$ & $2.14 \times 10^{2}$ \\
\hline 8 & $3.3 \times 10^{2}$ & $1.43 \times 104$ & $3.29 \times 10^{2}$ \\
\hline 9 & $3.1 \times 10^{2}$ & $1.71 \times 10^{4}$ & $2.57 \times 10^{2}$ \\
\hline 10 & $3.8 \times 10^{2}$ & $2.00 \times 10^{4}$ & $3.29 \times 10^{2}$ \\
\hline
\end{tabular}




\subsubsection{Sandia National Laboratories Results}

Gas-phase release of ${ }^{14} \mathrm{C}$ was estimated by SNL for two conceptual models: the standard total systems model and the Weeps model. Three times were chosen for estimating doses: the time of first release, the time of maximum release, and the time that fell halfway between the two. Results for the standard model are given in Table 10.16. The source term used, the organ receiving the highest dose, and the dominant exposure pathway are included in the table.

Results for the Weeps model were also calculated for three times as described above. The times of first release and maximum release are the same for the Weeps model as for the standard model. Results for the Weeps model are given in Table 10.17. The affected organ and dominant pathway are the same; the difference between the two models is the amount of ${ }^{14} \mathrm{C}$ released to the ground surface.

The garden exposure scenario was used for the six SNL ${ }^{14} \mathrm{C}$ gas-phase release scenario runs. Since ${ }^{14} \mathrm{C}$ is not retained in the soil, soil ingestion is zero for the gas-phase runs. The pathways that produced the doses for these runs are vegetable and leafy vegetable ingestion. If the exposed individual does not grow a garden, the doses for the three times are reduced by about one order of magnitude.

\subsection{Comparision With The Waste Isolation Systems Panel Report}

To tenchmark: the long-term dosimetry code used in the SUMO model, SUMO was used to calculate doses comparable to the doses presented in the Waste Isolation Systems Panel (WISP) report (NAS 1983). The scenario used in the WISP report included terrestrial and aquatic ingestion. Not ail of the terrestrial ingestion pathways used in the WISP report are available in SUMO, but adjustments were made to simulate consumption quantities as nearly as possible. The source used is $1 \mathrm{Ci} / \mathrm{yr}$ of each radionuclide released into a volumetric flow of $1 \mathrm{~m}^{3} / \mathrm{yr}$. The results of both the WISP report and SUMO are presented in Table 10.18.

The WISP doses were based on a PABLM run done by B. A. Napier at PNL. PABLM dosimetry is based on ICRP 2 (1959). The WISP report updated the dose factors for the nuclides $210 \mathrm{~Pb},{ }^{226} \mathrm{Ra}$, and ${ }^{237} \mathrm{~Np}$ to bring them up to ICRP 30 (1979) values. The WISP doses presented in Table 10.18 were then calculated. The dosimetry incorporated in SUMO is based on ICRP 40 (1984). ICRP 30 dose factors for the WISP report were calculated using a 50-year integral and a single intake. SUMO uses a 70-year integral and continuous intake.

The $14 \mathrm{C}$ model underwent major changes between the WISP and SUMO dose calculations. Another modeling change is that SUMO incorporates a soil removal mechanism that is not included in PABLM. This tends to lower the SUMO doses, especially for long-lived nuclides. The 99Tc dose factor varies by approximately an order of magnitude between the two models.

The dose model prescribed in Working Draft 4 of 40 CFR Part 191 is based on ICRP 60 (1991). ICRP 60 has several changes from ICRP 40 although the major concepts of calrulating the effective dose equivalent have been retained. Therefore, the dose estimates prese , $_{\text {ine }}$ would be altered slightly if the ICRP 60 model were applied. 
Table 10.16. Sandia National Laboratories ${ }^{14} \mathrm{C}$ Gas-Phase Release Summary

\begin{tabular}{|c|c|c|c|c|}
\hline Time (yr) & Source $(\mathrm{Ci} / \mathrm{yr})$ & Dose (mrem/yr) & $\begin{array}{c}\text { Maximum } \\
\text { Organ Contribution }\end{array}$ & $\begin{array}{c}\text { Maximum } \\
\text { Exposure Pathway } \\
\end{array}$ \\
\hline 350.0 & $2.11 \times 10^{-4}$ & $1.80 \times 10^{-5}$ & Red Marrow & estion \\
\hline 1950.0 & $6.15 \times 10^{-1}$ & $5.20 \times 10^{-2}$ & Red Marrow & Ingestion \\
\hline 3550.0 & $1.42 \times 10^{0}$ & $1.20 \times 10^{-1}$ & Red Marrow & Ingestion \\
\hline
\end{tabular}

Table 10.17. Sandia National Laboratories ${ }^{14} \mathrm{C}$ Gas-Phase Weeps Model Release Summary

\begin{tabular}{|c|c|c|c|c|}
\hline Time (yr) & Source (Ci/yr) & Dose (mrem/yr) & $\begin{array}{c}\text { Maximum } \\
\text { Organ Contribution } \\
\end{array}$ & $\begin{array}{c}\text { Maximum } \\
\text { Exposure Pathway }\end{array}$ \\
\hline & & & $\mathbf{R}$ & \\
\hline 1 & $2.42 \times 10^{-4}$ & $2.10 \times 10^{-5}$ & Red Marrow & Ingestion \\
\hline & $5.59 \times 10^{-4}$ & $5.00 \times 10^{-5}$ & Red Marrow & Ingestion \\
\hline
\end{tabular}

Table 10.18. Comparison of SUMO and Waste Isolation Systems Panel Dose Results (Sv/yr per unit $\mathrm{Bq} / \mathrm{m}^{3}$ )

\begin{tabular}{|c|c|c|c|}
\hline$\underline{\text { Radionuclide }}$ & WISP Dose & SUMO Dose & SUMO/W \\
\hline${ }^{14} \mathrm{C}$ & $9.21 \times 10^{-7}$ & $1.04 \times 10^{-7}$ & 0.11 \\
\hline${ }^{79} \mathrm{Se}$ & $1.60 \times 10^{-7}$ & $4.25 \times 10^{-7}$ & 2.66 \\
\hline${ }^{99} \mathrm{Tc}$ & $7.03 \times 10^{-10}$ & $1.23 \times 10^{-8}$ & 0.18 \\
\hline $126 \mathrm{Sn}$ & $2.77 \times 10^{-8}$ & $5.79 \times 10^{-7}$ & 2.09 \\
\hline 129I & $2.04 \times 10^{-8}$ & $3.13 \times 10^{-7}$ & 1.53 \\
\hline${ }^{135} \mathrm{Cs}$ & $5.26 \times 10^{-8}$ & $2.89 \times 10^{-7}$ & 0.55 \\
\hline${ }^{234} \mathrm{U}$ & $3.80 \times 10^{-8}$ & $1.97 \times 10^{-8}$ & 0.52 \\
\hline $237 \mathrm{~Np}$ & $1.29 \times 10^{-5}$ & $5.02 \times 10-5$ & 3.89 \\
\hline${ }^{239} \mathrm{Pu}$ & $9.80 \times 10^{-9}$ & $5.40 \times 10-8$ & 0.5 \\
\hline $243 \mathrm{Am}$ & $1.23 \times 10^{-7}$ & $2.20 \times 10-6$ & 1.7 \\
\hline
\end{tabular}

\subsection{Discussion and Conclusions}

One purpose of these calculations was to demonstration a dose modeling capability for DOE YMPO. The current work demonstrates that capability. Further work is required to update the current model to incorporate the changes in ICRP 60. These changes are minor and can be accommodated within the structure of the current computer codes.

Doses can be calculated for the base-scenario releases and most disruptive scenarios using the current models. Extensive work will be required to address dose calculations if a volcanismintrusion scenario is modeled that yields airborne particulates. 
A significant amount of work needs to be done to determine the feasibility of the scenarios for which doses should be estimated, particularly the waterborne scenarios. It is questionable whether enough ground water could be obtained at an arid site, such as Yucca Mountain, to support habitation or farming activities. Also, pumping a significant portion of the aquifer's water from a well or small number of wells would cause variations in regional ground-water flow that are not addressed here.

A major issue in the proposed revisions to 40 CFR Part 191 is consideration of a dose-based limit (based on the model in ICRP 60). Much work must go intc an agreement on the parameters required for dose calculations. Estimates have been made in these simulations for both disturbed and undisturbed performance, while current (vacated) EPA regulations address dose modeling for undisturbed performance only. Also, the scenarios for exposure to surface contamination modeled here ignore any type of controlled zone around the repository. The waterborne scenarios provide for releases at the currently defined 5-km boundary. Other dose modeling issues that should be standardized are specific population and lifestyle questions including acceptable dietary parameters.

This preliminary analysis does not provide any strong evidence that the site will not be suitable for storage of high-level nuclear waste. As expected, some dose estimates given here are high enough to be of regulatory concern. However, these dose estimates are highly dependent upon aquifer properties that have not yet been measured accurately.

The least desirable situation for computing individual doses from drinking water is a well that provides just enough water for a garden or small farm, but its draw-down cone of depression extends laterally by hundreds or thousands of meters. In this case, much of the contaminated water from the repository would be withdrawn from a single well, thereby yielding high doses. Some pump tests in progress (as yet unpublished) indicate that the transmissivity of the tuff aquifer may be several orders of magnitude higher than that assumed in the transport section of this report. If this early result is substantiated, dose estimates will be on the low end of the ranges given here because the contaminated water will be highly diluted. 


\subsection{Summary}

\subsection{Review of the Study Objectives}

The objectives determined at the initiation of this modeling task were to

- identify further conceptual and calculation model development needs

- refine and more fully prioritize identified data needs and help guide site characterization

- define relative sensitivities of total-system performance to the conceptual model, data assumptions, and computational methods

- make a preliminary evaluation of the repository system performance.

All of the objectives were met. The detailed analysis descriptions given earlier and the recommendations given in the following subsections outline several conceptual and computational model development needs. In addition, the descriptions of the specific analyses in earlier sections identify data that are still needed. Guidance to site characterization activities can be achieved in those cases where the sensitivity of the model to missing or poorly defined data indicate a potentially significant change in the performance of the repository. For example, gas permeability in the rock layers above the potential repository horizon may have a large impact on the amount of ${ }^{14} \mathrm{C}$ released to the ground surface. Tests for measuring this quantity are desired early in the site characterization period.

The results presented here provide a crude early indication of repository performance. The performance conclusion should properly be limited to the following kind of statement: "No reason was found not to continue with site characterization activities." To achieve a baseline performance assessment making a definitive statement about repository performance, several additional things must be done. First, a complete set of nuclides of regulatory interest must be analyzed. This study analyzed 10 nuclides out of a set of several dozen of interest. Second, additional site-specific data are needed to calibrate existing models, and other data are required to check the validity of the modeling assumptions. Finally, the computer codes used must be subjected to formal Quality Assurance requirements.

\subsection{Recommendations for Future Work}

We have several general recommendations and several recommendations regarding modeling of specific scenarios. The general recommendations will be addressed in this section.

Recommendations for modeling of specific scenarios are addressed in the following subsections. General recommendations are as follows:

- Future modeling should be conducted using a full set of nuclides of interest in estimating both cumulative release of nuclides and individual and population doses.

- Future modeling should be conducted under appropriate Quality Assurance controls to allow definitive statements of performance based on existing models and data. 
- Considerations for dose modeling should form an integral part of the selection of scenarios, and doses should be computed for each scenario.

- Future modeling should have at least one project (DOE/Yucca Mountain Project Office) review midway through the analysis period that includes principal investigators from every discipline represented in the models.

- All of the waste forms (spent fuel and glass) that will be placed in the repository should be modeled.

\subsubsection{Recommendations for the Choice of Scenarios}

This iteration of performance assessment addressed a few scenarios judged in advance to yield the most severe consequences. The next iteration of performance assessment should probably consider only a few more scenarios than this analysis. The releases from the high consequence disruptive scenarios do not appear at this time to violate the EPA standard. Examination of every scenario may not be necessary if this early indication of performance continues to hold after more definitive site data become available. Specific recommendations for the choice of scenarios include:

- The analysis should still be limited to the release mode in each scenario class expected to have the highest release consequences. An upper bound on the releases can be obtained if the modeling effort is concentrated on the few highest consequence scenarios.

- The choice of which scenarios to examine should still rest on the approach implemented in the current SNL scenario tree analysis. SNL staff have made a concerted effort to identify and document all the combinations of events and processes of possible modeling concern.

- Explicitly model a climate change scenario.

- Add scenario trees that specifically address individual and population doses.

\subsubsection{Recommendations for Modeling the Engineered Barriers}

The models used in the source term analysis were rather simplistic models based on analytic solutions. At the same time, they were as sophisticated as any source term models currently in use. Several changes could be made in the source term models that would provide a better representation of the releases for scenarios considered in this analysis. Specific recommendations for improvements in source-term modeling include the following:

- Implement chain decay in the transport processes of the engineered barriers system model.

- Implement a release model that can examine the effects of having three or more material property zones around the waste container.

- Use a model that allows time transients in hydrologic processes to model climate change, human-intrusion processes, or thermal redistribution of ground water.

- Implement a model that allows spatial variability of hydrologic, thermal, and geochemical parameters. 
- Incorporate a tight link between thermal transient and geochemical information leading to a temperature-dependent solubility coupling.

- Implement a dissolution model for glass waste forms consistent with the glass dissolution data already available.

\subsubsection{Recommendations for Modeling Gas-Phase Transport}

Transport modeling of ${ }^{14} \mathrm{C}$ within the vadose zone of Yucca Mountain requires accurate predictions of two-phase matrix and fracture flow for highly non-isothermal systems; accurate geochemical equilibrium descriptions of $14 \mathrm{C}$ partitioning between the solid, liquid, and gas phases; and predictions of $14 \mathrm{C}$ release rates subject to transient ambient conditions surrounding the waste containers. This analysis demonstrated the strong coupling and transient nature of the thermal and hydrogeologic fields surrounding the repository. The dominant transport mode strongly depends on the geochemical equilibrium, thermodynamic, and hydrogeologic states. Two specific recommendations for future work are:

- This analysis used a geochemical equilibrium model that was solely dependent on temperature and totally ignored solid phase sorption. Additional parameters need to be included in the analysis to determine the geochemical equilibrium state, e.g., aqueous phase $\mathrm{pH}$, mineral phases, ion concentrations, mineral compositions, ion strengths, gas pressures, vapor partial pressures, and temperature.

- A more detailed hydrogeologic conceptual model for the stratigraphy above the repository horizon will be required to more accurately model ${ }^{14} \mathrm{C}$ within the gas phase. Moreover, features, such as the Ghost Dance Fault, should be included in the transport analysis because of their potential as significant pathways for gas phase advection.

\subsubsection{Recommendations for Modeling Liquid-Phase Transport}

After analyzing the scenarios reported in this document, several enhancements to the liquidphase hydrology and mass transport model have been identified. Specific recommendations include:

- Allow transient as well as steady-state hydrologic solutions to be used as the basis for mass transport. This enhancement allows time-dependent modeling to be performed for a climate change scenario, a drilling intrusion scenerio using wet drilling technology, and transients in the water table induced by tectonic events.

- Model several more properties as spatially random, e.g., porosity.

- Implement a more efficient solver in the SUMO code to reduce the amount of computer time required to obtain a hydrologic steady-state solution.

- Model a more complex stratigraphy, and perform transport runs for undisturbed performance that have been calibrated to measured saturation profiles in Yucca Mountain.

Several of these recommendations require additional data specific to the Yucca Mountain site. 


\subsubsection{Recommendations for Modeling Tectonism}

The water-table rise scenario modeled for tectonic disruption of the repository did not yield any increase in releases to the accessible environment. Specific recommendations for future work include:

- Estimate of the probability of occurrence of a water table rise coupled with a climate change yielding a higher ground-water infiltration rate, and model the effects of such an occurrence.

- Estimate the probability of occurrence of a tectonic event that causes container failures early after repository closure, and model the effects of such an occurrence.

The water table rise coupled with the climate change scenario would possibly lead to relatively fast flow paths through the mountain. Early container failures could lead to greatly enhanced releases of highly soluble radionuclides because of more rapid fuel oxidation rates and glass dissolution rates under elevated container temperatures in the presence of atmospheric air.

\subsubsection{Recommendations for Modeling Volcanism}

Due to the limited scope of FY 1991 work, this first round of work on the basaltic volcanism scenario has primarily resulted in recommendations. The few results presented above should only be used for illustration and example. Nevertheless, important insight has been gained to direct future work. These recommendations are:

- "Complex" physical modeling of volcanic consequence scenarios is entirely possible using a combination of existing volcanological fluid mechanics, numerical heat transfer models, and combined analytical investigations.

- Coordination of this effort to ongoing SCP (DOE 1988) field, analytical, and laboratory work is crucial. Additional limited field work is necessary to investigate the entrainment factor in analogous systems. Ongoin, work on analogous volcanic fields and Strombolian cones should continue with emphasis on the detailed eruptive chronology of individual cones.

- Occurrence probabilistic modeling of the Yucca Mountain region also requires a fuller understanding of the volcanology and magma physics of Quaternary systems. The development of eruptive probabilities dependent on the petrological and physical systematics of disruptive scenarios should begin, relying on ongoing SCP activities and limited additional study.

- "Abstracted" consequence modeling and idealized probability modeling of volcanic scenarios should continue but requires a better understanding of the volcanology and physics of the proposed scenarios.

\subsubsection{Recommendations for Combining Consequences into a Complementary Cumulative Distribution Function}

The current methods and models are considered to be adequate for computation of a CCDF from the release data. In the event that even more complex coupled-parameter models are

implemented for scenario analysis, the CCDF generation approach used in Helton et al. (1991) for 
WIPP may have to be adopted. In any case, the required techniques have already been developed and demonstrated.

\subsubsection{Recommendations for Dose Modeling}

Several enhancements to the dose modeling were identified in the process of performing the dose modeling reported here. These enhancements can be summarized as:

- Run transport analyses designed to estimate radionuclide concentrations rather than cumulative release. The dose model could then use the concentrations in the environment directly.

- Perform scenario screening analyses based on the concept of estimating doses rather than cumulative release of radionuclides to the "accessible environment."

- Update the dose model to implement the model given in ICRP 60.

- Develop a set of standard consumption and lifestyle parameters for exposed individuals that is specific to the Yucca Mountain environment.

- Perform a detailed analysis of the aquifer to more accurately determine the ground-water dilution factors for radionuclide concentration estimates. 


\subsection{References}

40 CFR Part 191 (see U.S. EPA 1985).

Aaberg, R.L., and W. E. Kennedy. 1990. Definition of Intrusion Scenarios and Example Concentration Ranges for the Disposal of Near-Surface Waste at the Hanford Site. PNL-6312, Pacific Northwest Laboratory, Richland, Washington.

Amter, S., E. Behl, and B. Ross. 1988. Carbon-14 Travel Time at Yucca Mountain. Disposal Safety Incorporated, Washington, D.C.

Anderson, R. E., M. L. Zoback, and G. A. Thompson. 1983. "Implications of Selected Subsurface Data on the Structural Form and Evolution of Some Basins in the Northern Basin and Range Province, Nevada and Utah." Geological Society of America Bulletin 94:1055-1072.

Apted, M. J., A. M. Liebetrau, and D. W. Engel. 1989. The Analytical Repository Source-Term (AREST) Model: Analysis of Spent Fuel as a Nuclear Waste Form. PNL-6347, Pacific Northwest Laboratory, Richland, Washington.

ASME Steam Tables. 1967. Thermodynamic and Transport Properties of Steam. The American Society of Mechanical Engineers, United Engineering Center, New York.

Baer, G. 1991. "Mechanisms of Dike Propagation in Layered Rocks and in Massive Porous Sandstones." Journal of Geophysical Research 96:11,911-11,930.

Baer, G., and Z. Reches. 1991. "Mechanics of Dike Emplacement and Tectonic Implications of the Ramon Dike System, Israel." Journal of Geophysical Research 96:11,895-11,910.

Baldridge, W. S., F. V. Perry, L. D. Nealey, A. W. Laughlin, and K. H. Wohletz. 1989.

"Excursion 8A: Magmatism Associated with Lithospheric Extension: Middle to Late Cenozoic Magmatism of the Southeastern Colorado Plateau and Central Rio Grande Rift, New Mexico and Arizona." In Southern Rocky Mountain Region, Volume I of Field Excursions to Volcanic Terranes in the Western United States, eds. C. E. Chapin and J. Zidek. Memoir 46, New Mexico Bureau of Mines and Mineral Resources, Socorro, New Mexico.

Barnard, R. W., and H. A. Dockery. 1991. "TSA Problem Outline Consensus." July 26, 1991 Letter Report (reproduced in Appendix C).

Barnard, R. W., M. L. Wilson, H. A. Dockery, J. H. Gauthier, P. G. Kaplan, R. R. Eaton, F. W. Bingham, and T. H. Robey. 1992. TSPA 1991: An Initial Total-System Performance Assessment for Yucca Mountain. SNL91-2795, Sandia National Laboratories, Albuquerque, New Mexico.

Blume, J. A. 1987. Technical Basis and Parametric Study of Ground Motion and Surface Rupture Hazard Evaluations at Yucca Mountain. Nevada. SAND86-7013, Sandia National Laboratories, Albuquerque, New Mexico.

Bottinga, Y., and D. F. Weill. 1972. "The Viscosity of Magmatic Silicate Liquids: A Model for Calculation." American Journal of Science 272:438-475. 
Brandeis, G., and B. D. Marsh. 1989. "The Convective Liquidus in a Solidifying Magma Chamber: A Fluid Dynamic Investigation." Nature 339:613-616.

Brown, L. D., P. A. Krumhansl, C. E. Chapin, A. R. Sanford, F. A. Cook, S. Kaufmans, J. E. Oliver, and F. S. Schlit. 1979. "COCORP Seismic Reflection Studies of the Rio Grande Rift." In Rio Grande Rift: Tectonics and Magmatism, ed. R. E. Reicker, pp. 169-174. American Geophysical Union, Washington, D.C.

Carsel, R. F., and R. S. Parrish. 1988. "Developing Joint Probability Distributions of Soil Water Retention Characteristics." Water Resources Research 24(5):755-769.

Chambre', P. L., T. H. Pigford, W. W.-L. Lee, J. Ahn, S. Kajiwara, C. L. Kim, H. Kimure, H. Lung, W. J. Williams, and S. J. Zavoshy. 1985. Mass Transfer and Transport in a Geologic Environment. LBL-19430, Lawrence Berkeley Laboratory, Berkeley, California.

Clark, S. P., ed. 1966. Handbook of Physical Constants. Geological Society of America, Boulder, Colorado.

Craig, R. W., and R. L. Reed. 1991. "Geohydrology of Rocks Penetrated by Test Well USW H6, Yucca Mountain, Nye County, Nevada." Water Resources Investigations Report 89-4025, U.S. Geological Survey, Washington, D.C.

Croff, A. 1983. "ORIGEN2: A Versatile Computer Code for Calculating the Nuclide Composition and Characteristics of Nuclear Materials." Nuclear Technology 62:335-352.

Crowe, B. M. 1980. Disruptive Event Analysis: Volcanisms and Igneous Intrusion. PNL-2882, Pacific Northwest Laboratory, Richland, Washington.

Crowe, B. M., and K. A. Sargent. 1979. Maior-Element Geochemistry of the Silent CanyonBlack Mountain Peralkaline Volcanic Centers. Northwest Neyada Test Site: Applications to an Assessment of Renewed Volcanism. Open File Report 79-926, U.S. Geological Survey, Washington, D.C.

Crowe, B. M., S. Self, D. Vaniman, R. Amos, and F. Perry. 1983a. "Aspects of Potential Magmatic Disruption of a High-Level Radioactive Waste Repository in Southern Nevada." Joumal of Geology 91:259-276.

Crowe, B. M., B. Turrin, S. Wells, L. McFadden, C. Renault, F. Perry, C. Harrington, and D. Champion. 1989. "Polycyclic Volcanism: A Common Eruption Mechanism of Small Volume Basaltic Volcanic Centers of the Southern Great Basin, USA." New Mexico Bureau of Mines and Mineral Resources Bulletin 131:63.

Crowe, B. M., D. T. Vaniman, and W. J. Carr. 1983b. Status of Volcanic Hazard Studies for the Nevada Nuclear Waste Storage Investigations. LA-9325-MS, Los Alamos National Laboratory, Los Alamos, New Mexico.

Crowe, B. M., K. H. Wohletz, D. T. Vaniman, E. Gladney, and N. Bower. 1986. Status of Volcanic Hazard Studies for the Nevada Nuclear Waste Storage Investigations. LA-9325-MS, Vol. II, Los Alamos National Laboratory, Los Alamos, New Mexico. 
Cummings, D. 1972. Mafic and Ultramafic Inclusions, Crater 160. San Erancisce Mountain Volcanic Field. Professional Paper 800-B, U.S. Geological Survey, Washington, D.C.

Delaney, P. T., and D. D. Pollard. 1982. "Solidification of Basaltic Magma During Flow in a Dike." American Joumal of Science 282:856-885.

De Voogd, B., L. Serpa, and L. Brown. 1988. "Crustal Extension and Magmatic Processes: COCORP Profiles from Death Valley and the Rio Grande Rift." Geological Society of America Bulletin 100:1550-1567.

De Voogd, B., L. Serpa, L. Brown, E. Hauser, S. Kaufman, J. Oliver, B. W. Troxel, J. Willemin, and L. A. Wright. 1986. "Death Valley Bright Spot: A Midcrustal Magma Body in the Southern Great Basin, California?" Geology 14:64-67.

Dingwell, D. B., C. M. Scarfe, and D. J. Cronin. 1985. "The Effect of Fluorine on Viscosities in the System $\mathrm{Na}_{2} \mathrm{O}-\mathrm{Al}_{2} \mathrm{O}_{3}-\mathrm{SiO}_{2}$ : Implications for Phonolites, Trachytes and Rhyolites." American Mineralogist 70:80-87.

Dingwell, D. B., and S. L. Webb. 1989. "Structural Relaxation in Silicate Melts and NonNewtonian Rheology in Geologic Processes." Physics and Chemistry of Minerals 16:508-516.

Dockery, H. A. 1984. Rotation of Late Cenozoic Extensional Stresses. Yucca Flat Region. Nevada Test Site Nevada. Ph.D. Thesis, Rice University, Houston, Texas.

Dockery, H. A. 1991. "Additional $K_{d}$ Information from A. Meijer (9/26/91)." October 2, 1991 Memo (reproduced in Appendix B).

Doctor, P. G., P. W. Eslinger, D. M. Elwood, D. W. Engel, M. D. Freshley, A. M. Liebetrau, P. W. Reimus, D. L. Strenge, J. E. Tanner, and A. E. Van Luik. 1992. An Example Postclosure Risk Assessment Using the Yucca Mountain Candidate Site. PNL-8081, Pacific Northwest Laboratory, Richland, Washington.

DOE (see U.S. Department of Energy)

Doser, D. I., and R. B. Smith. 1989. "An Assessment of Source Parameters in the Cordillera of the Western United States." Bulletin Seism. Society America 79(5):1383-1409.

Dudley, A. L., R. R. Peters, J. H. Gauthier, M. L. Wilson, M. S. Tierney, and E. A. Klavetter. 1988. Physical and Mathematical Bases. Volume 1 of Total System Performance Assessment Code (TOSPAC). SAND85-0002, Sandia National Laboratories, Albuquerque, New Mexico.

Dvorak, J. J., A. T. Okamura, T. T. English, R. Y. Koyanagi, J. S. Nakata, M. K. Sako, W. T. Tanigawa, and K. M. Yamashita. 1986. "Mechanical Response of the South Flank of Kilauea Volcano, Hawaii to Intrusive Events Along the Rift System." Tectonophysics 124:193-209.

Eichelberger, J. C., T. A. Vogel, L. W. Younker, C. D. Miller, G. H. Heiken, and K. H. Wohletz. 1988. "Structure and Stratigraphy Beneath a Young Phreatic Vent: South Inyo Crater, Long Valley, California." Journal of Geophysical Research 93:12,953-13,828. 
Engel, Г. W., A. M. Liebetrau, G. C. Nakamura, B. M. Thronton, and M. J. Apted. 1989. The AREST Code: User's Guide for the Analytical Repository Source-Term Model. PNL-6645, Pacific Northwest Laboratory, Richland, Washington.

Eslinger, P. W., T. B. Miley, and D. W. Engel. 1990. SUMO-System Performance Assessment for a High-Level Nuclear Waste Repository: Mathematical Models. PNL-7581, Pacific Northwest Laboratory, Richland, Washington.

Faulds, J. E., D. L. Feuerbach, and E. I. Smith. 1991. "New Insights on Structural Controls and Emplacement Mechanisms of Pliocene/Quaternary Basaltic Dikes, Southern Nevada and Northwestern Arizona." Geological Society of America Abstracts with Programs 23:A118.

Frankel, J. J. 1969. "The Distribution and Origin of the Effingham Rock Type, a Doerite Derivative of Intermediate Composition in Natal and Zululand, South Africa." In Igneous and Metamorphic Geology, ed. L. H. Larsen, pp. 149-169. Memoir 115, Geological Society of America, Boulder, Colorado.

Greenland, L. P., A. T. Okamura, and J. B. Stokes. 1988. "Constraints on the Mechanics of the Eruption." In The Puu Oo Enuption of Kilauea Volcano. Hawaii: Episodes 1 Through 20. January 3. 1983. Through June 8. 1984, ed. E. W. Wolfe, pp. 155-164. Professional Paper 1463, U.S. Geological Survey, Washington, D.C.

Hardee, H. C. 1982. "Incipient Magma Chamber Formation as a Result of Repetitive Intrusions." Bulletin of Volcanology 4:41-49.

Hardee, H. C. 1987. "Heat and Mass Transport in the East-Rift-Zone Magma Conduit of Kilauea Volcano." In Volcanism in Hawaii, eds. R. W. Decker, T. L. Wright, and P. H. Stauffer, pp. 471-508. Professional Paper 1260, U.S. Geological Survey, Washington, D.C.

Hardee, H. C., and D. W. Larson. 1977. "Viscous Dissipation Effects in Magma Conduits." Journal of Volcanological and Geothermal Research 2:299-308.

Head, J. W., and L. Wilson. 1987. "Lava Fountain Heights and Pu'u 'O'o, Kilauea, Hawaii: Indicators of Amount and Variations of Exsolved Magma Volatiles." Journal of Geophysical Research 92:13715-13719.

Helton, J. C., J. W. Garner, R. D. McCurley, and D. K. Rudeen. 1991. Sensitivity Analysis Techniques and Results for Performance Assessment at the Waste Isolation Pilot Plant. SAND907103, Sandia National Laboratory, Albuquerque, New Mexico.

Ho, C. -H. 1991. "Time Trend Analysis of Basaltic Volcanism for the Yucca Mountain Site." Journal of Volcanological and Geothermal Research 46:61-72.

Hoel, P. G., S. C. Port, and C. J. Stone. 1972. Introduction to Stochastic Processes. Houghton Mifflin, Boston.

Hubbert, H. E., and R. S. J. Sparks. 1989. "Chilled Margins in Igneous Rocks." Earth and Planetary Sciences Letters 92. 
International Commission on Radiological Protection (ICRP). 1959. Recommendations (1958) Report of Committee II on Permissible Dose for Internal Radiation. ICRP Publication 2, Pergamon Press, New York.

International Commission on Radiological Protection (ICRP). 1977. Recommendations of the International Commission on Radiological Protection. ICRP Publication 26, Pergamon Press, New York.

International Commission on Radiological Protection (ICRP). 1979. Limits for Intakes of Radionuclides by Workers. ICRP Publication 30, Pergamon Press, New York.

International Commission on Radiological Protection (ICRP). 1984. Protection of the Public in the Event of Major Radiation Accidents: Principals of Planning: A Report of Committee IV of the International Commission on Radiological Protection. ICRP Publication 40, Pergamon Press, New York.

International Commission on Radiological Protection (ICRP). 1991. 1990 Recommendations of the International Commission on Radiological Protection. ICRP Publication 60, Pergamon Press, New York.

Ishizaka, K., T. Yanagi, and K. Hayatsu. 1977. "A Strontium Isotopic Study of the Volcanic Rocks of the Myoko Volcano Group, Central Japan." Contributions to Mineralogy and Petrology 63:295-307.

Jaeger, J. C., and N. G. W. Cook. 1976. Fundamentals of Rock Mechanics. Chapman and Hall, London.

Jaupart, C., and S. Tait. 1990. "Dynamics of Eruptive Phenomena." In Modern Methods of Igneous Petrology: Understanding Magmatic Processes, eds. J. Nicholls and J. K. Russell, pp. 213-238. Mineralogical Society of America, Washington, D.C.

Kana, D. D., B. H. G. Brady, B. W. Vanzant, and P. K. Nair. 1991. Critical Assessment of Seismic and Geomechanics Literature Related to a High-Level Nuclear Waste Underground Repository. CNWRA89-001, Southwest Research Institute, San Antonio, Texas.

Kang, C. H. 1990. Mass Transfer and Transport of Radionuclides Through Backfill in a Geologic Nuclear Waste Repository. Ph.D. Dissertation, University of California at Berkeley, Berkeley, California.

Kaplan, P. G., G. Gainer, H. Dockery, and R. Barnard. 1991. "Distributions of Hydrogeologic Parameters for the TSA Problem." July 25, 1991 Letter Report (reproduced in Appendix A).

Laughlin, A. W., M. J. Aldrich, M. E. Ander, G. H. Heiken, and D. T. Vaniman. 1982. Tectonic Setting and History of Late-Cenozoic Volcanism in West-Central New Mexico. New Mexico Geological Society, Albuquerque, New Mexico.

Lee, W. W. -L., M. M. Sadeghi, P. L. Chambre', and T. H. Pigford. 1991. Waste-Package Release Rates for Site Suitability Studies. LBL-30707, Lawrence Berkeley Laboratory, Berkeley, California. 
Liebetrau, A. M., M. J. Apted, D. W. Engel, M. K. Altenhofen, D. M. Strachan, C. R. Reid, C. F. Windisch, R. L. Erikson, and K. I. Johnson. 1987. The Analytical Repository Source-Term (AREST) Model: Description and Documentation. PNL-6346, Pacific Northwest Laboratory, Richland, Washington.

Lister, J. R. 1990. "Buoyancy-Driven Fluid Fracture: Similarity Solutions for the Horizontal and Vertical Propagation of Fluid-Filled Cracks." Joumal of Fluid Mechanics 217:213-239.

Lister, J. R., and R. C. Kerr. 1991. "Fluid-Mechanical Models of Crack Propagation and Their Application to Magma Transport in Dykes." Journal of Geophysical Research 96:10,049-10,077.

Luedke, R. G., and R. L. Smith. 1981. Map Showing Distribution Composition and Age of Late Cenozoic Volcanic Centers in Califormia and Nevada. U.S. Geological Survey Miscellaneous Investigations Series Map I-1091-C.

Luhr, J. F., and S. N. Williams. 1991. "Volcanology." In U.S. National Report to International Union of Geodesy and Geophysics 1987-1990, ed. M. A. Shea, pp. 513-531. Quadrennial Report, American Geophysical Union, Washington, D.C.

Lynch, D. J., and J. T. Gutmann. 1987. "Volcanic Structures and Alkalinc Rorks in the Pinacate Volcanic Field, Sonora, Mexico." In Geologic Diversity of Arizona and Its Margins: Excursions to Choice Areas, eds. G. H. Davis and E. M. VandenDolder, pp. 309-323. Special Paper 5, Arizona Geological Survey, Tucson, Arizona.

Maaløe, S. 1985. Principles of Igneous Petrology. Springer-Verlag, Berlin.

Marsh, B. D. 1981. "On the Crystallinity, Probability of Occurrence, and Rheology of Lava and Magma." Contributions to Mineralogy and Petrology 78:85-98.

Marsh, B. D. 1984. "Mechanics and Energetics of Magma Formation and Ascension." In Explosive Volcanism, ed. F. R. Boyd, pp. 67-83. National Research Council, Washington, D.C.

McBimey, A. R., and T. Murase. 1984. "Rheological Properties of Magmas." Annual Review of Earth and Planetary Sciences 12:337-357.

McGrail, B. P., M. J. Apted, D. W. Engel, and A. M. Liebetrau. 1990. "A Coupled ChemicalMass Transport Model for Predicting Radionuclide Release From an Engineered Barrier System Containing High-Level Waste Glass." In Scientific Basis for Nuclear Waste Management XIII, eds. V. M. Oversby and P. W. Brown. Materials Research Society, Pittsburgh.

McGraw, M. A., K. W. Burdick, and P. W. Eslinger. 1991. One-Dimensional Human Intrusion Analysis of the Paleozoic Aquifer. as Part of the Site Suitability Effort at Yucca Mountain. Nevada. PNL-7774, Pacific Northwest Laboratory, Richland, Washington.

McGuire, R. K., D. B. Bullen, N. Cook, K. J. Coppersmith, J. Kemeny, A. Long, F. J Pearson, Jr., F. Schwartz, M. Sheridan, and R. R. Youngs. 1990. Demonstration of a Risk-Based Approach to High-Level Waste Repository Evaluation. EPRI NP-7057, Electric Power Research Institute, Palo Alto, California.

Millington, R. J., and J. P. Quirk. 1959. "Permeability of Porous Media." Nature 183:387-388. 
Montazer, P., and W. E. Wilson. 1984. Conceptual Hydrologic Model of Flow in the Unsaturated Zone. Yucca Mountain. Nevada. U.S. Geological Survey Water Resources Investigation Report 84-4345, U.S. Geological Survey, Denver, Colorado.

Murphy, M. T. 1991. "A Model for the Evolution of the Tatoosh Magmatic Complex, Southern Washington Cascades." Transactions. American Geophysical Union. EOS 72:602.

Murphy, M. T., Long, P. E., and S. Self. 1991. "Duration of Flood Basalt Eruptions: Evidence from the Pomona Flow, Columbia River Basalt." Transactions, American Geophysical Union. EOS, 72:567.

Murphy, M. T., and B. D. Marsh. 1987. "On the Suspension Viscosity of Subliquidus Silicate Melt." Geological Society of America Abstract with Programs 19:365.

Murphy, M. T., and B. D. Marsh. 1989. "The Path-Dependent Crystallization of IntermediateComposition Magma." New Mexico Bureau of Mines and Mineral Resources Bulletin 131:200.

National Academy of Sciences (NAS). 1983. A Study of the Isolation System for Geologic Disposal of Radioactive Wastes, National Academy Press, Washington, D.C.

Napier, B. A., R. A. Peloquin, D. L. Strenge, and J. V. Ramsdell. 1988. Hanford Environmental Dosimetry Upgrade Project. GENII - The Hanford Environmental Radiation Dosimetry Software System. Volume 1: Conceptual Representation. Volume 2: Users' Manual, Volume 3: Code Mainteiance Manual. PNL-6584 Vols. 1, 2, and 3, Pacific Northwest Laboratory, Richland, Washington.

Nitao, J. J. 1988. Numerical Modeling of the Thermal and Hydrological Environment Around a Nuclear Waste Package Using Equivalent Continuum Approximation: Horizontal Emplacement. UCID-21444, Lawrence Livermore National Laboratory, Livermore, California.

Nitao, J. J. 1989. Movement of a Liquid Front in an Unsaturated. Fractured Porous Medium. 2. Mathematical Analysis. UCRL-10i006, Lawrence Livermore National Laboratory, Livermore,
California.

Nitao, J. J., and T. A. Buscheck. 1989. Movement of a Liquid Front in an Unsaturated. Fractured Porous Medium. 1. Physical Theory. UCRL-101005, Lawrence Livermore National Laboratory, Livermore, California.

"Nuclear Waste Policy Act of 1982" (NWPA). Public Law 97-425. U.S. Code, Title 42, Section 10101-10266 (January 7, 1983).

O'Brien, G. M. 1991. Water Levels in Periodically Measured Wells in the Yucca Mountain Area. Nevada. 1989. OFR 91178, U.S. Geologic Survey, Washington, D.C.

Patankar, S. V. 1980. Numerical Heat Transfer and Fluid Flow. Hemisphere Publishing Corporation, Washington D.C.

Penman, H. L. 1940a. "Gas and Vapor Movements in the Soil. I. The Diffusion of Vapors Through Porous Solids." Journal of Agricultural Sciences 30:437-462. 
Penman, H. L. 1940b. "Gas and Vapor Movements in the Soil. II. The Diffusion of Carbon Dioxide Through Porous Solids." Journal of Agricultural Sciences 30:570-581.

Peters, R. R., E. A. Klavetter, I. J. Hall, S. C. Blair, P. R. Heller, and G. W. Gee. 1984. Eracture and Matrix Hydrogeologic Characteristics of Tuffaceous Materials from Yucca Mountain. Nye County. Nevada. SAND84-1471, Sandia National Laboratories, Albuquerque, New Mexico.

Quiring, R. F. 1965. Annual Precipitation Amount as a Function of Elevation in Nevada South of 38.5 Degrees Latitude. U.S. Weather Bureau of Research Statistics.

Reches, Z., and J. Fink. 1988. "The Mechanism of Intrusion of the Inyo Dike, Long Valley Caldera, California." Joumal of Geophysical Research 93:4321-4334.

Ross, B. 1988. "Gas-Phase Transport of Carbon-14 Released From Nuclear Waste into the Unsaturated Zone." Scientific Basis of Nuclear Waste Management XI, eds, M. J. Apted and R. E. Westerman, pp. 273-284, Materials Research Society, Pittsburgh.

Rubin, A. M., and D. D. Pollard. 1987. "Origins of Blade-Like Dikes in Volcanic Rift Zones." In Volcanism in Hawaii, eds. R. W. Decker, T. L. Wright, and P. H. Stauffer, pp. 471-508. Professional Paper 1350, U.S. Geological Survey, Washington, D.C.

Runchal, A. K., and B. Sagar. 1989. PORFLO-3: A Mathematical Model for Fluid Flow. Heat. and Mass Transport in Variably Saturated Geologic Media. Users Manual. Version 1.0. WHC-EP0041, Westinghouse Hanford Company, Richland, Washington.

Ryan, M. P., R. Y. Koyanagi, and R. S. Fiske. 1981. "Modeling the Three-Dimensional Structure of Macroscopic Magma Transport Systems: Applications to Kilauea Volcano, Hawaii." Journal of Geophysical Research 86:7111-7129.

Sadeghi, M. M., T. H. Pigford, P. L. Chambre', and W. W. -L. Lee. 1990. Equations for Predicting Release Rates for Waste Packages in Unsaturated Tuff. LBL-29254, Lawrence Berkeley Laboratory, Berkeley, California.

Sagar, B., and A. K Runchal. 1990. PORFLO-3: A Mathematical Model for Fluid Flow. Heat. and Mass Transpors in Variably Saturated Geologic Media. Theory and Numerical Methods. Volume 1. WHC-EP-M42, Westinghouse Hanford Company, Richland, Washington.

Schelling, F. J. 1987. The NNWSI Project Reference Information Base Version 02.001. SLTR87-6001, Sandia National Laboratory, Albuquerque, New Mexico.

Scott, W. E. 1987. "Holocene Rhyodacite Eruptions on the Flanks of South Sister Volcano, Oregon. In The Emplacement of Silicic Domes and Lava Flows, ed. J. H. Fink, pp. 35-54. Geological Society of America, Boulder, Colorado.

Serpa, L., B. de Voogd, L. Wright, J. Willemin, J. Oliver, and E. Hauser. 1988. "Structure of Death Valley Pull-Apart Basin and Vicinity from COCORP Profiles in the Southern Great Basin." Geological Society of America Bulletin 100:1437-1450. 
Shantser, A. Y. 1983. "Basement Xenoliths in the Eruptive Products of the New Tolbachik Volcanoes and the Problem of the Formation of Magma Conduits in the Upper Crust." In The Great Tolbachik Fissure Eruption, eds. S. A. Fedotov and Y. T. Markinin, pp. 72-82. Oxford University Press, Oxford.

Shaw, H. R., T. L. Wright, D. L. Peck, and R. Okamura. 1968. "The Viscosity of Basaltic Magma: An Analysis of Field Measurements in Makaopuhi Lava Lake, Hawaii." American Journal of Science 266:255-264.

Sheridan, M. 1990. "Chapter 4--Volcano Occurrences." In Demonstration of a Risk-Based Approach to High-Level Waste Repository Evaluation, ed. Risk Engineering Inc., 4.1-4.19. EPRI NP-7057, Electric Power Research Institute, Palo Alto, California.

Smith, R. L., and R. G. Luedke. 1984. "Potentially Active Volcanic Lineaments and Loci in Western Conterminous United States." In Explosive Volcanism: Inception. Evolution and Hazards, ed. F. R. Boyd, pp. 47-66. National Academy Press, Washington, D.C.

Sornette, A., J. Dubois, J. L. Cheminee, and D. Sornette. 1991. "Arre Sequences of Volcanic Eruptions Deterministically Chaotic?" Journal of Geophysical Research 11,931-11,945.

Sparks, R. S. J., H. Pinkerton, and G. Hulme. 1976. "Classification and Formation of Lava Levees on Mount Etna, Sicily." Geology 4:269-271.

Spengler, R., M. Chornack, D. C. Muller, and J. E. Kibler. 1984. Stratigraphic and Structural Characteristics of Volcanic Rocks in Core Hole USW G-4. Yucca Mountain. Nye County. Nevada. Open File Report 84-789, U.S. Geological Survey, Washington, D.C.

Stothers, R. B., J. A. Wolff, S. Self, and M. R. Rampino. 1986. "Basaltic Fissure Eruptions, Plume Heights and Atmospheric Aerosols." Geophysical Research Letters 13:725-728.

Swanson, D. A., T. J. Casadevall, D. Dzurisin, S. D. Malone, C. J. Newhall, and C. S. Weaver. 1983. "Predicting Eruptions at Mt. St. Helens, June 1980 to December 1982." Science 221:13691376.

Swanson, D. A., W. A. Duffield, D. B. Jackson, and D. W. Peterson. 1979. Chronological Narrative of the 1969-71 Mauna Ulu Eruption of Kilauea Volcane. Hawaii. Professional Paper 1056, U.S. Geological Survey, Washington, D.C.

Swanson, S. E., and J. Kienle. 1988. "The 1986 Eruption of Mount St. Augustine: Field Test of a Hazard Evaluation." Journal of Geophysical Research 93:4500-4520.

Taubeneck, W. H. 1970. Dikes of the Columbia River Basalt in Northeastern Oregon. Western Idaho and Southeastern Washington. 271-299, Eastern Washington University Press, Cheney, Washington.

Tilling, R. I. 1989. "Volcanic Hazards and Their Mitigation: Progress and Problems." Reviews in Geophysics 27:237-269.

Trent, D. S., and L. L. Eyler. 1989. TEMPEST: A Three-Dimensional. Time-Dependent Computer Program for Hydrothermal Analysis. PNL-4348, Vol. 1, Rev. 2, Pacific Northwest Laboratory, Richland, Washington. 
Turrin, B. D., D. Champion, and R. J. Fleck. 1991. "40Ar/39Ar Age of Lathrop Wells Volcanic Center, Yucca Mountain, Nevada." Science 253:654-657.

U.S. Department of Energy (DOE). 1986. Environmental Assessment: Yucca Mountain Site Nevada Research and Development Area. Nevada. DOE/RW-0073, Office of Civilian Radioactive Waste Management, Washington, D.C.

U. S. Department of Energy (DOE). 1987. Einal Environmental Impact Statement: Disposal of Hanford Defense High-L evel. Transuranic and Tank Wastes. Hanford Site Richland. Washington. DOE/EIS-0 i i3, Washington, D.C.

U.S. Department of Energy (DOE). 1988. Site Characterization Plan: Yucca Mountain Site Nevada Research and Development Area. Nevada. DOE/RW-0199, Volume II, Office of Civilian Radioactive Waste Management, Washington, D.C.

U.S. Environmental Protection Agency (EPA). 1985. "Environmental Radiation Protection Standards for Management and Disposal of Spent Nuclear Fuel, High-Level and Transuranic Wastes." Title 40, Code of Federal Regulations, Part 191, Final Rule. Federal Register 50:38006-38089.

van Genuchten, M. Th. 1980. "A Closed-form Equation for Predicting the Hydraulic Conductivity of Unsaturated Soils." Soil Science Society America Joumal 44:892-898.

Walker, G. P. L. 1987. "The Dike Complex of Koolau Volcano, Oahu: Internal Structure of a Hawaiian Rift Zone." In Volcanism in Hawaii, eds. R. W. Decker, T. L. Wright, and P. H. Stauffer, pp. 471-508. U.S. Geological Survey, Washington, D.C.

Wells, S. G., L. D. McFadden, C. E. Renault, and B. M. Crowe. 1990. "Geomorphic Assessment of Late Quaternary Volcanism in the Yucca Mountain Area, Southern Nevada: Implications for the Proposed High-Level Radioactive Waste Repository." Geology 18:549-553.

White, M. D., M. D. Freshley, and P. W. Eslinger. 1991. "Simulation of Two-Phase Carbon-14 Transport at Yucca Mountain, Nevada." PNL-SA-20324, Pacific Northwest Laboratory, Richland, Washington.

Wilcox, R. E. 1954. "Petrology of Paracutin Volcano." U.S. Geological Survey Bulletin 965C:281-353.

Wilson, L., and J. W. Head. 1981. "Ascent and Eruption of Basaltic Magma on the Earth and Moon." Journal of Geophysical Research 86:2971-3001.

Wilson, M. L. 1991. A Simplified Radionuclide Source Term for Total-System Performance Assessment. SAND91-0155, Sandia National Laboratories, Albuquerque, New Mexico.

Wolfe, E. W., M. O. Garcia, D. B. Jackson, R. Y. Koyanagi, C. A. Neal, and A. T. Okamura. 1987. "The Pu'u 'O'o Eruption of Kilauea Volcano, Episodes 1-20, January 3, 1983 to June 8, 1984. In Volcanism in Hawaii, eds. R. W. Decker, T. L. Wright, and P. H. Stauffer, pp. 471508. Professional Paper 1260, U.S. Geological Survey, Washington, D.C. 
Wolery, T. J. 1983. EQ3NR - A Computer Program for Geochemical Aqueous Speciation-

Solubility Calculations: User's Guide and Documentation. UCRL-53414, Lawrence Livermore National Laboratory, Livermore, California.

12.11 


\section{Appendix A}

\section{Distributions of Hydrogeologic \\ Parameters for the TSA Problem}




\section{Sandia National Laboratories}

Albuquerque, New Mexico 87185

Date: July 25, 1991

To: Distribution

From: Paul Kaplan, Gabriela Gainer, Holly Dockery, and Rally Barnard

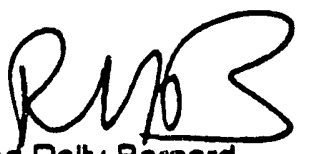

Subject: Distributions of Hydrogeologic Parameters for the TSA problem

\section{INTRODUCTON}

Included in this memo are the values we have compiled for use in the geohydrology problem for the preliminary total-system analyses. We have outlined ranges for the geohydrologic parameter values and distributions for those ranges. We have also provided a brief summary of the sources of the data and the methods used to generate the distributions.

\section{PROBLEM DOMAIN}

The horizontal problem domain is defined as an E-W transect extending from approximately $500 \mathrm{~m}$ east of UE-25a\#1 (in Drillhole Wash) through USW G-4, to USW H-5 (at the crest), as shown in Figure 1. The vertical problem domain will extend from the repository horizon to the water table. The projected position of the repository is shown on Figure 2. Note that distances in Figure 2 are given along the patt:line of the transect. Therefore, from G-4 to UE-25a\#1 the distances will differ from GTM coordinates for those drillholes. The analyses will then be carried through the unsaturated and saturated zones to the accessible environment (located $5 \mathrm{~km}$ from the repository). The problem domain will contain the Ghost Dance Fault. The 2-D treatment of the fault will be modeled by a 14-meter offset and increased tracture permeability (based on density and aperture).

\section{BOUNDARY CONDITIONS}

For the 2-D analyses, the western vertical boundary of the problem (at USW H-5) will be no-flow. The eastern vertical boundary, whict is also no-flow, is $500 \mathrm{~m}$ east of UE-25a. This spacing distance is intended to prevent the no-flow condition from introducing modeling artifacts to the interpretation of flow processes at UE-25a.

Problems will be run from initial saturation and flux conditions to the steady-state consistent with the applied irfiltratio i. The values for infiltration will range fror $0.01-20.0 \mathrm{~mm} / \mathrm{yr}$. Table 1 provides the values provided for the infiltration distribution. Discussion of the Beta distribution values is contained in a following section entitled "Methodology". 
TABLE 1

DISTRIBUTION OF INFILTRATION RATES

Mean

Coefficient of variation

Minimum

Maximum

$\alpha_{\beta}$

$\beta_{\beta}$
1.0

1.0

0.0

39.00

$-0.051282$

35.051282

\section{GEQHYDROLOGIC STRATIGRAPHY AND PARAMEIER VALUES}

The stratigraphy is a simplified version of the PACE-90 hydrostratigraphy, using up to five layers. representing 5 different tuff types (depending on the location along the transect): Layer $1=T p t-T M$ (welded), Layer $2=$ Tpt-TV (vitrophyre), Layer $3=T p t-T N$ (vitric), Layer $4=$ TCb-TN (zeolitic), and Layer : : Tcpp-TP (partially welded). The details of the stratigraphy were determined by reviewing the USGS lithologic logs for dillholes USW H-5, USW G-4, and UE25a \#1 and the PACE-90 nominal-case hydrostratigraphy.

Parameter values are derived from Peters et al. (1984). The PACE-90 hydrostratigraphy was used for reference. Distributions of parameter values for Layers 1, 2 and 4 were obtained from the memo dated 4/15/91 from Kaplan, et al. establishing values used for the site-suitability calculations. Additional analysis of the same data sets was used to obtain similar values for Layers 3 and 5.

\section{MATRIX AND FRACTURE PROPERTY VALUES}

\section{Methodology}

All of the data used to define the expected values for the matrix properties each layer were derived from Peters et al. (1984). Some of these matrix values have been subsequently reported in the PACE-90 report; however, an attempt was made to perform another review of the data to ensure the usage of the most reasonable properties. Also, the Peters, et al. data have undergone many reinterpretations for various reports and calculations. We did not want to inadvertently incorporate other modeling assumptions into our data set, so we decided to only use the original source of the data. In order to. construct the ranges, other information was included in each data set. All of the data for the values for the tractures are trom Carsel and Parish (1988) except for the information on fracture density (Spengler, et al., 1984) and effective fracture aperture (Zimmerman and Vollendorf, 1982). The specific assumptions made for each parameter are discussed in the appropriate sections below. 
A general methodology was used to construct the distributions and ranges for both the matrix and fracture properties. First, as previously stated, the expected value was taken from the appropriate lithology reported in Peters, et al. Next, a maximum range for the values was defined either by 'using a literature search of values for the particular rock type, or by using the physical limits of the given property. For instance, porosity can only range from 0 to १, therefore those numbers define a maximum range. The next step was to try to decrease the range of values using additional Yucca Mountain data and, where available, analog data. In some cases, there were no additional data that could be used to decrease the ranges, so only the maximum range was used. A Beta distribution was generated using the expected value, the coefficient of variation, and the maximum and minimum values. An exponential distribution was used for properties where only an expected value could be identified (Harr, 1987). Because the exponential distribution can be very closely approximated by the Beta distribution, a variation of the Beta distribution was used to generate the random samples given in Appendix 1 .

In Tables 2-6, we provide the mean, maximum, minimum, coefficient of variation, and the $\alpha$ and $\beta$ parameters of the Beta distribution for the following matrix parameters: hydraulic conductivity, porosity, and van Genuchten coefficients $\alpha, \beta$ and $S_{\gamma}$. In this memo, we will call the Beta distribution parameters $\alpha \beta$ and $\beta_{\beta}$ to differentiate them from the van Genuchten $\alpha$ and $\beta$ parameters, which will be designated $\alpha_{V}$ and Bv.

Tables 7-10 give information on fracture properties, including fracture density, effective fracture aperture, and the following parameters: hydraulic conductivity, saturated moisture content, residual moisture content, and van Genuchten coefficients, $\alpha_{v}$ and $\beta_{v}$.

\section{Matrix Hydrogeologic Properties}

Hydraulic Conductivity

Values of hydraulic conductivity for the matrix are shown in Table 2. For hydraulic conductivity, the exponential distribution was used in all cases because the only "known" was the expected value. The coefficient of variation is 1 , from the relationship between the mean and standard deviation in an exponential distribution. The possible range in values $\left(1-10^{-14} \mathrm{~m} / \mathrm{s}\right.$, Freeze and Cherry, 1979, Table 2.3) is so large, that a distribution constructed using the ranges would be meaningless. The expected values for the matrix are from Peters et al., 1984, Table A2. An exponential distribution was generated, then the EXPONENT program (after Har, 1987) was then used to get the Beta distribution parameters: $\alpha_{\beta}, \beta_{\beta}$, maximum and minimum. 
TABLE 2

HYDRAULUC CONDUCTIVTY

$(\mathrm{m} / \mathrm{s})$

$\begin{array}{ccccc}\text { Layer \# Mean } & \text { Coef. Min. Max } \\ \text { Var. } & & & \text { Alphaß }\end{array}$

\begin{tabular}{lllllll}
\hline & & & & & & \\
Layer 1 & $2.00 \times 10^{-11}$ & 1.00 & 0.0000 & $7.93 \times 10^{-10}$ & -0.0526 & 34.078 \\
Layer 2 & $3.01 \times 10^{-12}$ & 1.00 & 0.0000 & $1.27 \times 10^{-10}$ & -0.0473 & 38.298 \\
Layer 3 & $7.99 \times 10^{-11}$ & 1.00 & 0.0000 & $3.11 \times 10^{-9}$ & -0.0515 & 34.894 \\
Layer 4 & $3.01 \times 10^{-12}$ & 1.00 & 0.0000 & $1.27 \times 10^{-10}$ & -0.0473 & 38.298 \\
Layer 5 & $1.4 \times 10^{-8}$ & 1.00 & 0.0000 & $5.43 \times 10^{-7}$ & -0.0515 & 34.869 \\
\hline
\end{tabular}

\section{Van Genuchten Aloha (ov)}

Values of $\alpha_{V}$ for the matrix for the five layers are shown in Table 3. Expected values for $\alpha_{V}$ are from Peters et al. (1984, Table A-2). The range, .0004-137 mm, is based on physical constraints. A pore .0004 $\mathrm{mm}$ in diameter is the smallest pore through which a water molecule can travel. This value is equal to $3 x$ the diameter of a water molecule. The high value is related to maximum pore size that can maintain capillary force. The coefficient of variation comes from data on Apache Leap tuff (Rasmussen et al., 1990. Table 8).

TABLE 3

VAN GENUCHTEN PARAMETER ALPHA

\begin{tabular}{|c|}
\hline Layer \# \\
\hline
\end{tabular}

\begin{tabular}{lllllll}
\hline & & & & & \\
Layer 1 & 0.0057 & 0.37 & 0.0004 & 137.00 & 5.310 & 164029.4 \\
Layer 2 & 0.0033 & 0.37 & 0.0004 & 137.00 & 4.631 & 267879.3 \\
Layer 3 & 0.0265 & 0.37 & 0.0004 & 137.00 & 6.084 & 37177.12 \\
Layer 4 & 0.0220 & 0.37 & 0.0004 & 137.00 & 6.040 & 44644.5 \\
Layer 5 & 0.0140 & 0.37 & 0.0004 & 137.00 & 5.892 & 69422.45 \\
\hline
\end{tabular}




\section{Van Genuchten Beta (BV)}

Values of $\beta_{V}$ for the matrix for the five layers are shown in Table 4. Expected for values for $\beta_{V}$ are from Peters et al. (1984, Table A-2). The range, 1.05-10, is based on physical constraints (Kaplan, 1991). The coefficient of variation of 0.20 comes from Carsel and Parish.

TABLE 4

VAN GENUCHTEN PARAMETER BETA

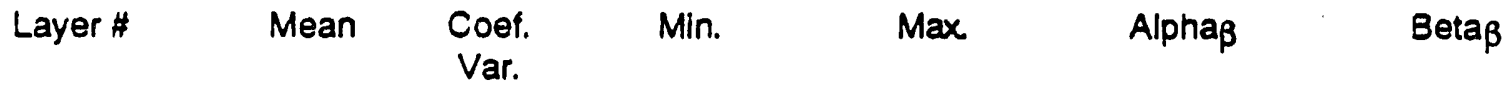

$\begin{array}{lrlllrr}\text { Layer 1 } & 1.798 & 0.20 & 1.050 & 10.00 & 2.881 & 41.56 \\ \text { Layer 2 } & 1.798 & 0.20 & 1.050 & 10.00 & 2.364 & 41.39 \\ \text { Layer 3 } & 2.223 & 0.20 & 1.050 & 10.00 & 4.917 & 38.23 \\ \text { Layer 4 } & 1.236 & 0.20 & 1.050 & 10.00 & -0.4664 & 24.14 \\ \text { Layer 5 } & 2.640 & 0.20 & 1.050 & 10.00 & 6.279 & 32.70\end{array}$

\section{Residual Saturation $S_{r}$}

Values of $S_{p}$ for the matrix for the five layers are shown in Table 5 . Expected for values for $S_{p}$ are from Peters et al. (1984, Table A-2). The parameter $S_{p}$ is defined as the ratio of the liquid-filled porosity to the total fluid porosity and ranges from $0.0-1.0$. The coefficient of variation, 0.20 , is from Apache Leap tuff data (Rasmussen et al., 1990, Table 8).

TABLE 5

VAN GENUCHTEN PARAMETER $S_{r}$

\begin{tabular}{|c|c|c|}
\hline Layer \# & Mean & $\begin{array}{l}\text { Coef. } \\
\text { Var. }\end{array}$ \\
\hline
\end{tabular}

\begin{tabular}{lllllll}
\hline & & & & & & \\
Layer 1 & 0.080 & 0.20 & 0.000 & 1.000 & 21.92 & 262.2 \\
Layer 2 & 0.052 & 0.20 & 0.000 & 1.000 & 22.66 & 432.9 \\
Layer 3 & 0.164 & 0.20 & 0.000 & 1.000 & 19.74 & 104.9 \\
Layer 4 & 0.010 & 0.20 & 0.000 & 1.000 & 23.74 & 32.8 .5 \\
Layer 5 & 0.066 & 0.20 & 0.000 & 1.000 & 22.28 & 179.2 \\
\hline
\end{tabular}




\section{Porosity}

Values of porosity for the matrix of the five layers are shown in Table 6. Expected for values are from Peters, et al. (1984, Table A-2). The maximum range for the value for porosity in all rocks is from 0.0-1.0. The value of 0.20 for the coefficient of variation came from the Apache Leap data.

TABLE 6

POROSITY

\begin{tabular}{|c|c|c|c|c|c|c|}
\hline Layer \# & Mean & $\begin{array}{l}\text { Coof. } \\
\text { Var. }\end{array}$ & Min. & Max & Alphaß & Beta $\beta$ \\
\hline $\begin{array}{l}\text { Layer } 1 \\
\text { Layer } 2 \\
\text { Layer } 3 \\
\text { Layer } 4 \\
\text { Layer } 5\end{array}$ & $\begin{array}{l}0.14 \\
0.09 \\
0.21 \\
0.41 \\
0.24\end{array}$ & $\begin{array}{l}0.20 \\
0.20 \\
0.20 \\
0.20 \\
0.20\end{array}$ & $\begin{array}{l}0.000 \\
0.000 \\
0.000 \\
0.000 \\
0.000\end{array}$ & $\begin{array}{l}1.000 \\
1.000 \\
1.000 \\
1.000 \\
1.000\end{array}$ & $\begin{array}{l}21.14 \\
21.66 \\
18.54 \\
13.34 \\
17.76\end{array}$ & $\begin{array}{r}178.13 \\
228.12 \\
72.51 \\
19.64 \\
58.41\end{array}$ \\
\hline
\end{tabular}

\section{interconnected Fracture Property Values}

Hydrogeologic Parameters

The porous-media equivalent of the fractures will be represented in the equivalent and composite models by sand. These values for the hydrogeologic parameters for the fractures in the two models from above are shown in Table 7 and are derived trom Carsel and Parish (1988). An effective aperture value is provided for those who will be modeling discrete fractures. The data for this value of effective aperture come from an average value derived from data from tests conducted in G-Tunnel in a welced section of the Grouse Canyon Member of the Belted Range Tuff (Zimmerman and Vollendort, et al., 1982).

Although the Grouse Canyon is described as welded at the test location, it is not clear how representative the derived values are for Yucca Mountain tutts.

TABLE 7

FRACTURE HYDROGEOLOGIC PROPERTIES

\begin{tabular}{ll}
\hline$\alpha_{v}$ & $14.5 / \mathrm{m}$ \\
$\beta v$ & 2.68 \\
$\theta_{r}$ & 0.045 \\
porosity & 0.43 \\
$k_{s a t}$ & $8.25 \times 10^{-5} \mathrm{~m} / \mathrm{s}$ \\
aperture & $210 \mu \mathrm{m}$ \\
effective aperture & $99 \mu \mathrm{m}$ \\
\hline
\end{tabular}


The parameter $\theta r$ is defined as the ratio of liquid-filled porosity to the total volume of the rock. For the composite models, the fracture aperture is related to the alpha parameter in the water retention model, sometimes referred to as the "air entry scaling factor". Thus, it is related to a measure of the largest connected pore size ( $r_{a e}$ ) that will start to drain when suction is applied (Wang and Narasimhan, in review). The relationship between the alpha parameter and $r_{a e}$, if the flow channels are represented by an ideal capillary tube is given by the capillary equation:

$$
r_{a \theta}=2(s / r g) a_{V}
$$

where $s$ is surface tension, $r$ is fluid density, and $g$ is gravitational acceleration. If the concept of largest drainable pore size is applied, and the fracture is assumed to be as wide as the diameter of the pore size of the media representing the fracture, then an estimate of the fracture aperture is given by the following:

$$
r_{\mathrm{ae}}=2\left[\left(0.07183 \mathrm{~kg} / \mathrm{s}^{2}\right) /\left(1000 \mathrm{~kg} / \mathrm{m}^{3}\right)\left(9.80665 \mathrm{~m} / \mathrm{s}^{2}\right)\right](14.5 / \mathrm{m})
$$

L'sing an $\alpha_{v}$ value of 14.5 (Carsel and Parish, 1988) gives $r_{a e}=210 \mathrm{~mm}$.

Zimmerman and Vollendort, et al. (1982) used the following equation to calculate saturated hydraulic conductivity :

$$
K_{\text {sat }}=g_{w} e^{2 / 12 m}
$$

where $g_{w}$ is the weight per unit volume, $m$ is viscosity, and $\theta$ is the effective fracture aperture.

Fracture density data for each of the layers are shown in Table 8 . The values were derived from Spengler, et al., 1984.

\section{TABLE 8}

\section{FRACTURE DENSITIES FOR LAYERS $1-5$}

\begin{tabular}{c}
$\begin{array}{c}\text { Layer } \\
\text { Fumber } \\
\text { (fractures/meter }\end{array}{ }^{3}$ ) \\
\hline
\end{tabular}

$\begin{array}{lr}1 & 28.3 \\ 2 & 35.8 \\ 3 & 2.0 \\ 4 & 1.6 \\ 5 & 4.4\end{array}$


For the distribution information, an exponential distribution was run on discrete values for fracture density to get the Beta distribution parameters. Hydrogeologic properties for fractures are shown in Table 9. Means and coefficients of variation came from Carsel and Parrish, 1988.

TABLE 9

FRACTURE HYDROLOGIC PROPERTIES

$\begin{array}{ccccc}\text { Parameter Mean } & \text { Coef. Min. Max } \\ & \text { Var. } & & & \text { Alphaß }\end{array}$

$\begin{array}{llllrrr}K_{S}(\mathrm{~m} / \mathrm{s}) & 8.25 \times 10^{-5} & 0.524 & 0.000 & 0.001 & 2.259 & 32.24 \\ \alpha_{V}\left(\mathrm{~m}^{-1}\right) & 14.5 & 0.203 & 0.001 & 137.0 & 20.589 & 181.41 \\ \beta_{V} & 2.68 & 0.203 & 1.050 & 10.0 & 6.160 & 31.15 \\ \theta_{r} & 0.045 & 0.223 & 0.000 & 1.00 & 18.159 & 405.60\end{array}$

Additional Fracture Information (not used in this exercise)

Information on fracture fill is also available in Spengler, et al. (1984) for G-4. Within the Topopah Spring Member, approximately $20 \%$ of the observed fractures were filled, primarily with silica. These data were derived from 251 fractures in the measured interval. All of the fractures in the Calico Hills unit in G-4 were filled with manganese and iron oxides. These data were derived from only three fractures. As few as $20 \%$ have been observed to be filled in other drillholes.

Although not included in this letter, information on variation in aperture along the length of individual tractures is also available, as well as information on the nature of fracture coatings. No one has expressed a need for this type of data for these calculations. However, if there is an interest in obtaining this information for future calculations, it could be provided.

\section{Eault Property Values}

Tho region containing the fault will be set at one meter in width $M$. Carr, pers. comm.; A. Geldon. pers. comm). The fault properties will be determined by the layer containing each segment of the plane. In general, the fauli region should contain fracture densities one order of magnitude greater than the matrix fracture density W. Carr, pers. comm, 1991). Therefore, the data from Spengler, et al. (1984) for fracture density at G-4 will be multiplied by 10 for each Layer. The resulting values are shown in Table 10. All other properties for the fault region are the same as are given in Table 9. 
TABLE 10

FRACTURE DENSITIES WITHIN THE 1-METER FAULT ZONE

\begin{tabular}{cc}
$\begin{array}{c}\text { Layer } \\
\text { Fumber }\end{array}$ & $\begin{array}{c}\text { Fracture Density } \\
\text { (tractures/meter }\end{array}$ \\
\hline
\end{tabular}

\begin{tabular}{lc}
1 & 283 \\
2 & 356 \\
3 & 20 \\
4 & 16 \\
5 & 44 \\
\hline
\end{tabular}

The fault in Figure 2 is depicted with an offset of $14 \mathrm{~m}$, based on data from the Ghost Dance fault in this area.

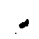

\section{REFERENCES}

Barnard, R. W. and H. A. Dockery, eds., 1991, "Technical summary of the Performance Assessment Calculational Exercises for 1990 (PACE-90), Volume 1: "Nominal Configuration" Hydrogeologic Parameters and Calculational Results, "Sandia National Laboratories Report SAND90-2726.

R. F. Carsel, and R. S. Parrish, 1988, "Developing joint probability distributions of soil water retention characteristics," Water Resources Res., Vol. 24, No. 5.

Freeze, R.A. and J.A Cherry, 1979, Groundwater, Prentice-Hall, Englewood Clitts, NJ, 604pp.

Kaplan, P.G., 1991, A formalism to generate probability distributions for performance assessment modeling. Proceedings of the High Level Nuclear Waste Conference, Las Vegas NV. April 29-May 3, 1991 .

Harr, M.E., 1987, Reliability-Based Design in Civil Engineering, McGraw-Hill, NY, NY, 290p.

Spengler, R.. M. Chornack, D.C. Muller, and J.E. Kibler, 1984, Stratigraphic and structural characteristics of volcanic rocks in core hole IJSW G-4, Yucca Mountain, Nye County, Nevada, U.S. Geological Survey Open File Report 84-789, ip.

Peters, R. R., E.A. Klavetter, I.J. Hall, S.C. 3lair, P.R. Heller, and G.W. Gee, 1984, "Fracture and matrix hydrogeologic characteristics of tuffaceous materials from Yucca Mountain, Nye County, Nevada," Sandia National Laboratories Report SAND84-1471, 64n $\div$ Âp̃pendices.

Rasmussen, T.C., D.D. Evans, P.J. Sheets, ard J.H. Blanford, 1990, "Unsaturated fractured rock characterization methods and data sets at the Apache Leap Tuff site," U. S. Nuclear Regulatory Commission NUREG/CR-5596, 125p.

Wang, J.S.Y. and T.N. Narasimhan, "Processes, Mechanisms, and Parameters governing partially saturated ílow in soil and rock media," Sandia National Laboratories Report SAND88-7054, in review.

Zimmerman, R.M. and W.C. Vollendort, 1982, "Geotechnical field measurements, G-tunnel, Nevada Test Site," Sandia Naticial Laboratories Report SAND81-1971, 27p. 


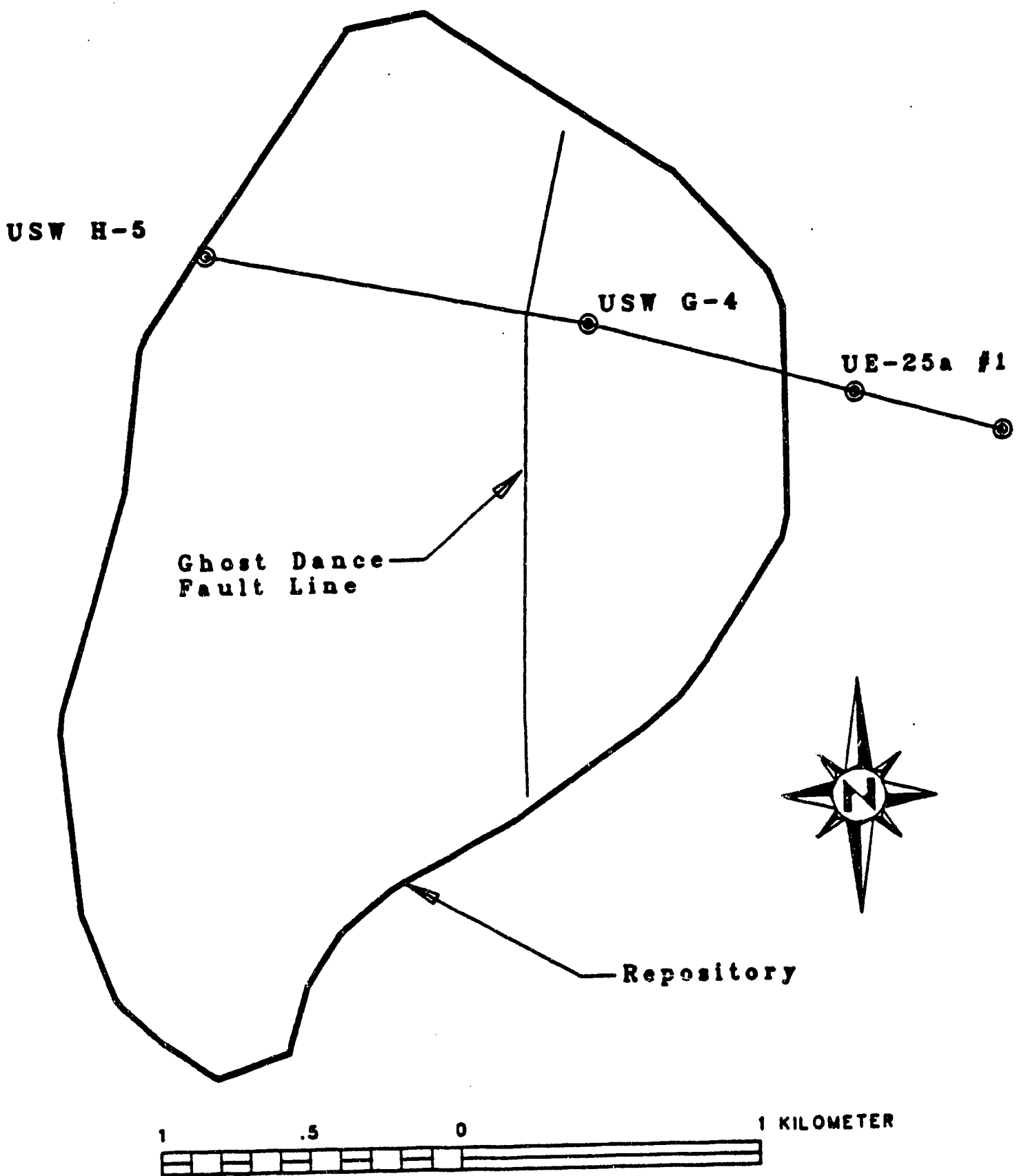

Profile Through USY H-5. $\frac{\text { UST G-4, and UE-25a \#1 }}{\text { Peaturiag gydrosoologte stratleraphy }}$

Figure 1. Problem Domain 


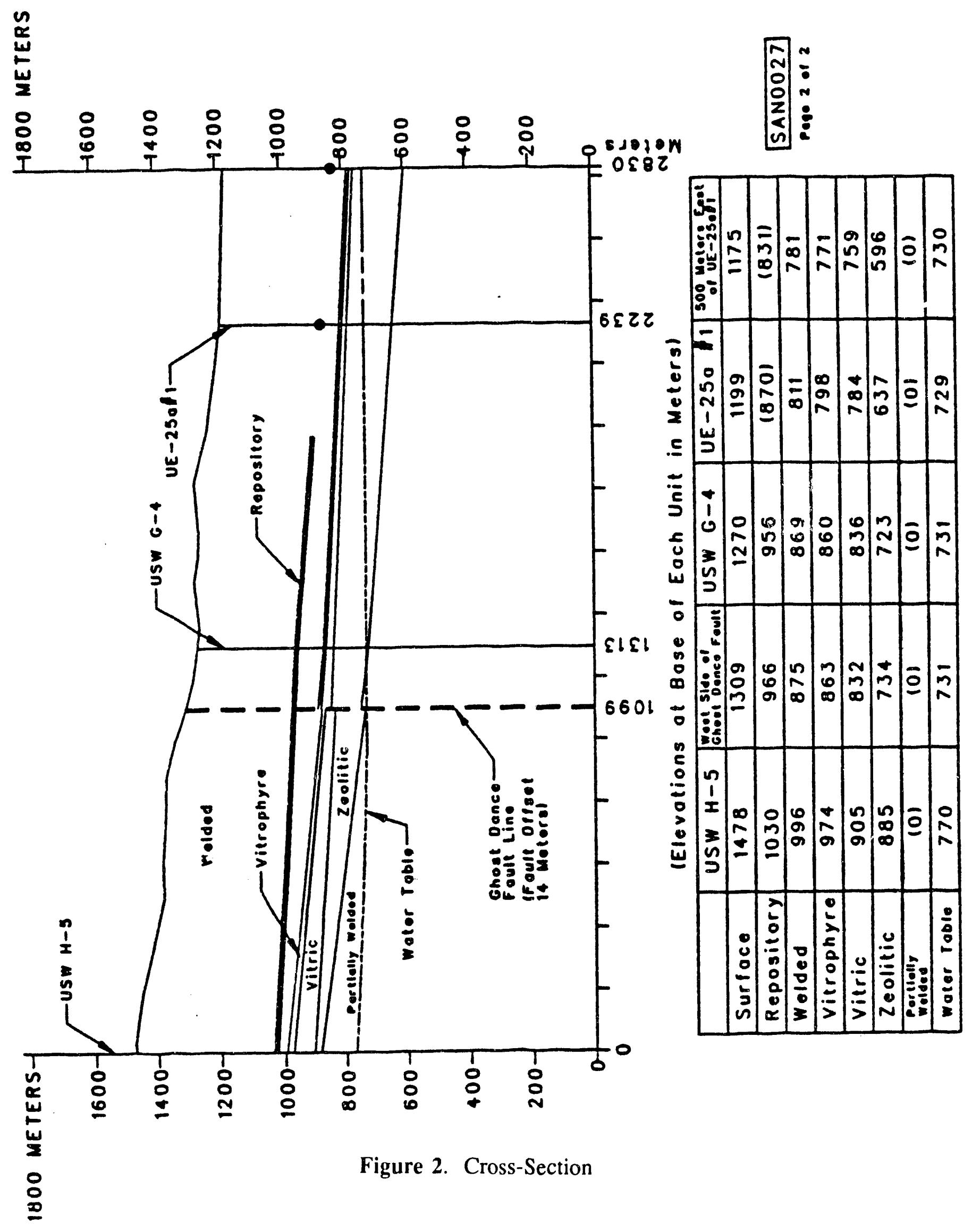


Appendix B

Additional $\mathbf{K}_{\mathbf{d}}$ Information 
$10 / 02 / 91 \quad 10: 35 \quad$ S505 $3 \pm 60083$

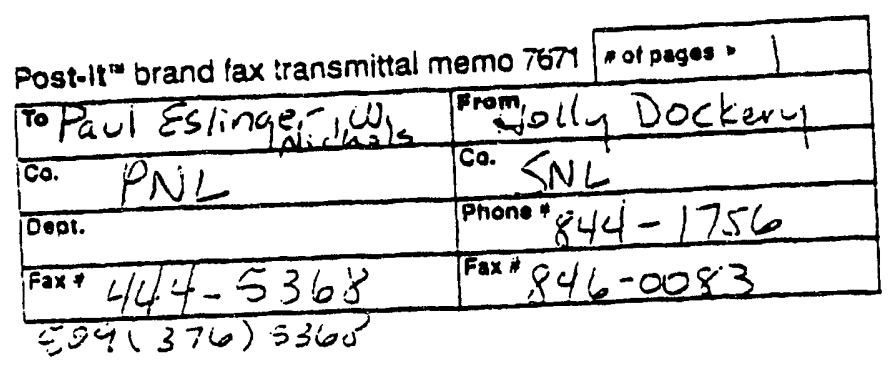

SNL 6310

\section{Sandla National Laboratories}

Albuquerque, New Mexico 87135

LIMITED VALUE INFORMATION

Date: $10 / 2 / 91$

To: R. Barnard, J. Gauthier, M. Wilson (SNL)

P. Eslinger, W. Nichols (PNL)

From: Holly Dockery

Subject: Additional Kd Information from A. Meijer (9/26/91)

This information was obtained from A. Meijer concerning details and assumptions regarding sorption data he provided for the carbonate aquifer at Yucca Mountain. It should be appended to the data table he FAXed to SNI. anit PNL on 9/26/91.

1. The data set was obtained from a report (Lappin, et al., 1991) that included sorption data on the Culebra Formation at the WIPP site.

2. The data table includes values for the matrix rock only, although information for fractures is also available. The tractures at the WIPP site have a relatively high percentage of clays present. We have no information to indicate the presence or absence of excessive clay in fractures at Yucca Mountain.

3. The water chemistry of the indigenous water in the Culebra Formation is assumed, i.e., oxidizing conditions are present. This is a conservative assumption. If the water under Yucca Mountain is in a reducing state, retardation would be greater.

4. The data in the table is for Pu, Am, U, and Np. All other nuclides are assumed to have a value of zero for retardation. However, a caveat should be added. In carbonate rocks, much of the carbon will probably be precipitated iut due to chemical interactions. There is no data available that we know about that tests this assumption.., However, if the retarcation of carbon in the carbonate aquifer is a sensitive parameter, lab studies may be necessary to resolve the issue.

5. Chlorides are present in the Culecra Formation that almost certainly are not present in the carbonate aquifer at Yucca Mountain. Iniormation that is available in the literature indicates that chlorides are probably not important in complexing actinides. Thus, this aspect of water chemistry dissimilarity berween the WIPP site and Yucca Mlountain are not currently expected to be of importance. 


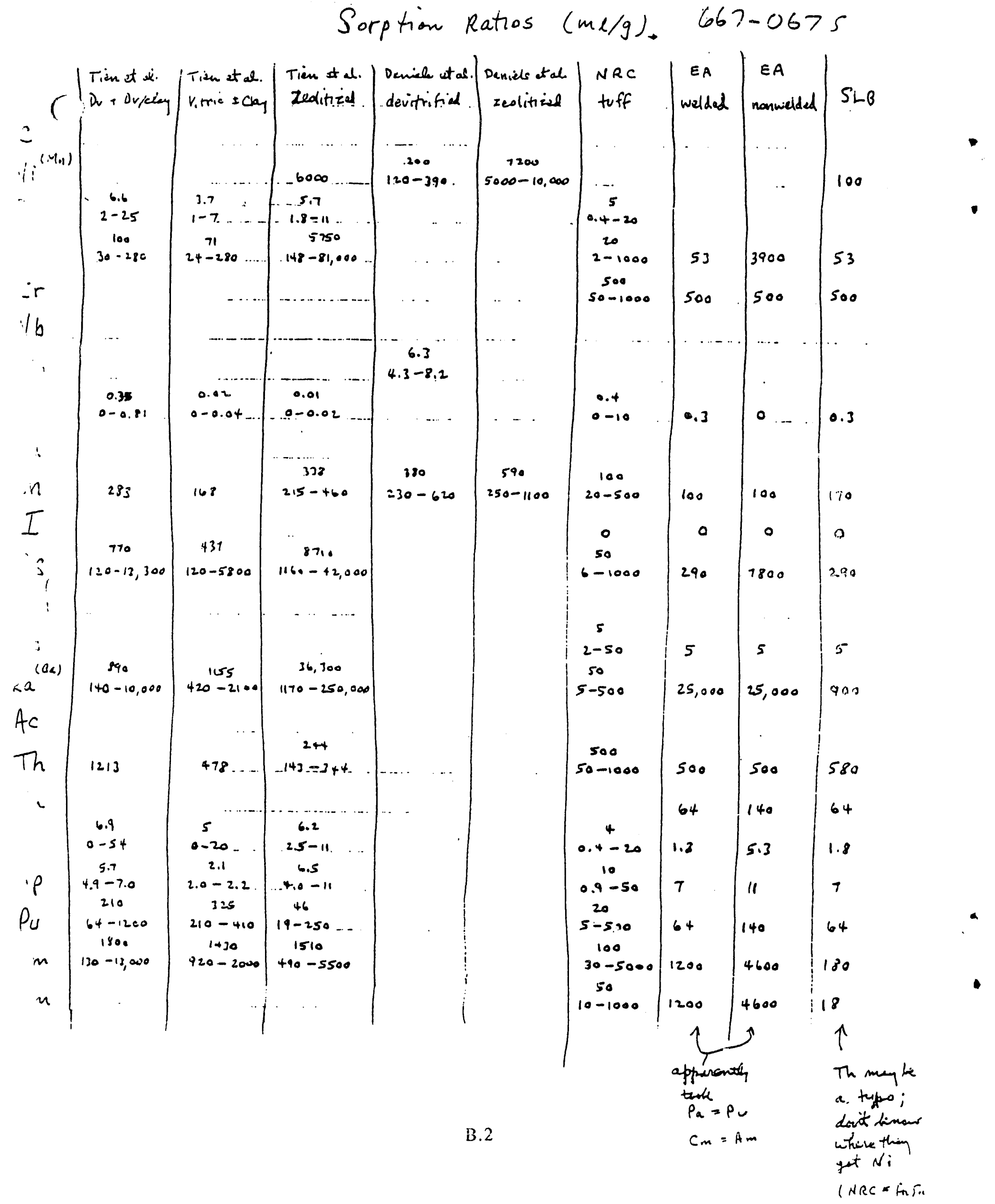




\section{Appendix C}

\section{TSA Problem Outline Consensus}




\section{Sandia National Laboratories}

Albuquerque, New Mexico 87185

Date: July 26, 1991

To: Distribution

Subject: TSA Problem Outline Consensus

Based on meetings held at SNL on July 11 , and at LBL on July 16, the following consensus plan inas been developed for the proposed total-system analyses.

\section{Geohydrology Problem}

\section{Problem Domain and Boundary Conditions}

The horizontal problem domain is defined as an E-W transect extending from approximately 500 in east of UE-25a"1 (in Drillhole Wash) through USW G-4, to USW H.5 (at the crest), as shown in Figure 1. PNL will pertorm a series of 2.D calculations along this line using SUMO. SNL will do a series of 1-D problems using TOSPAC, choosing several individual stratigraphic columns along the transect to describe? the domain.

The vertical problem domain will extend from the repository horizon to the water table. The projected position of the repository is shown on Figure 2. Note that distances in Figure 2 are given along the pathline of the transect. Therefore, from G-4 to UE-25a the distances will differ from GTM coordinates for those drillholes. The analyses will then be carried through the unsaturated and saturated zones to the accessible environment (located $5 \mathrm{~km}$ from the repository).

The problem domain will contain the Ghost Dance Faulk. The 2.D treatment of the fault will be modeled by a 14-meter offset and increased tracture permeability (based on density and aperture). Because of the inability of a 1-D analysis to property handle lateral diversion, etc., the fault will not be considered in those analyses.

For the 2-D analyses, the western vertical boundary of the problem (at USW H-5) will be no-flow. The eastern vertical boundary, which is also no-fiow, is $500 \mathrm{~m}$ east of UE-25a. This spacing distance will prevent the no-flow condition from introducing modeling artifacts to the interpretation of flow processes at UE-25a.

Problems will be run from initial saturation and flux conditions to the steady-state consistent with the ápplied infiltration. 


\section{Seohydrologic Stratioraphy and Parameter Values}

The stratigraphy will be a simplified version of the PACE-90 hydrostratigraphy, using up to five layers (depending on the location along the transect): Tpt-TM (welded), Tpt-TV (vitrophyre), Tpt-TN (vitric), TcbTN (zeolitic), Tepp-TP (partially welded). The details of the stratigraphy will be determined by reviewing the USGS lithologic logs and the PACE-90 nominal-case hydrostratigraphy.

The 2-D problem will treat the stratigraphic layers either as uniform and homogeneous, or as heterogeneous with randomly distributed, correlated properties. The same homogeneous layers used in the 2-D problem will be used in the appropriate rock columns of the 1-D problem.

Parameter values will be derived from Klavetter and Peters, 1984, and the PACE-90 hydrostratigraphy will be used for reference. Distributions of parameter values will be obtained from the memo dated 4/1/5/91 from Kaplan, et al. establishing values used for site-suitability work. Uncertainties and variabilities in materials parameters will be treated by sampling from distributions of probabilities of occurrence using an LHS scheme.

\section{Modeling Techniques}

The 2-D analysis will use only the composite model contained in SUMO. The 1-D analysis will us: Grif the composite model in TOSPAC and the "weeps" model for fracture-dominated flow. Infiltration rate: "ril be varied from about $0.01 \mathrm{~mm} / \mathrm{yr}$ up to values that produce saturation. For a certain range of material properties, steady-state problems using infitrations of $<3 \mathrm{~mm} / \mathrm{yr}$ will work in the composite-model codes. The probabilities of higher infitrations will reflect the likelihood that they are locainzed in time and space. Groundwater infiltration rates will be distributed with exponential uncertainty, using an expected value of $1.0 \mathrm{~mm} / \mathrm{yr}$ (see Figure 3).

Currently, the weeps model in the TSA randomly assigns values to two factors that influence the effect of the infiltration rate specified: the amount of water diverted by layers above the repository and ine percentage of radionuclides sorbed by the matrix during transport by fracture flow. To improve the credibility of the weeps model, these two randomly assigned factors will be replaced with factors whoce values are based on prior work (such as PACE and HYDROCOIN for the diversion of water, and SNL's discrete-fracture analyses for the sorption (Martinez, 1991). 


\section{Source Term and Sorption for all Problems}

\section{Introduction}

As a result of a meeting held at LBL on July 16, 1991, the following aspects of the source term for the total-system analyses have been agreed upon.

The radionuclide source term will use -10 selected radionuclides, which will represent various "classes" of the inventory - high mobility, high inventory, etc. Both radionuclides that produce large releases and those that have large dose effects will be included.

\section{Censtituents}

For geohydrologic analyses, we will use a source term of selected radionuclides. These source term will involve a limited number of radionuclides characteristic of the nuclear waste. The mobilization processes from the waste packages will be consistent with far-field flow and transport assumptions. For gas-transport problems, only ${ }^{14} \mathrm{C}$ will be included. For human-intrusion and possibly volcanic-intrusion surface-release problems, the a large fraction ( $-99 \%$, by activity) of inventory will be included. The choice of which radionuclides to include among the selected few will be based on both amounts released and biological impacts.

The selected radionuclides are: ${ }^{14} \mathrm{C},{ }^{79} \mathrm{Se},{ }^{99} \mathrm{Tc},{ }^{126} \mathrm{Sn},{ }^{129} \mathrm{l},{ }^{135} \mathrm{Cs},{ }^{234} \mathrm{U},{ }^{237} \mathrm{~Np},{ }^{239} \mathrm{Pu}$, and 243 Am. Source terms for transmutation and actinide burning will not be included in the TSA. SNL will only use spent fuel as radionuclide inventory, while PNL will pertorm a spent-fuel problem, and, if time allows, they will also include glassified defense waste.

\section{Geohydrology Source-Term Parameters}

For all source terms not involving mechanical releases, the parameters of the release profiles consist of a delay time, a "ramp-up" time, the duration of release, the slope of the main release, and the peak release rate. For the TSA, releases will be simplified to be in the shape of a "square wave", with instantaneous ramp-up, a constant release rate, and instantaneous termination. Thus, TSA release profiles will be characterized by delay time, duration, and peak rate. Source terms will be provided with expected values and ranges for all parameters and will be expressed anahytically (rather than as tables of values).

Since the geohydrologic analyses are isothermal, analyses will not model processes occurring befora the repository returns to the point where the region can be modeled isothermally. According to work by Pruess and Tsang, after 1,000 years the repository-average temperature is about $75^{\circ} \mathrm{C}$ (still well above ambient, but below the boiling point). Consequently, the source-term releases will not be defined befors 1000 years. 
The flow processes will be divided into matrix-dominated and fracture-dominated flow. For matrixdominated flow, the diffusive and wet-drip water-contact modes will be combined to produce the release mechanism. The source term will be parameterized by infiltration rate only. The source term will reflect local variations in infiltration rates, but will maintain an average value equal to the infiltration rate. For fracturedominated flow, only the wet-drip water-contact mode will be used. The source term will be parameterized by fracture aperture and density and by infiltration through the fractures only (i.e., excluding that portion of the total infittration that is imbibed into the matrix). Flow will be treated as episodic for $1 / 1$ oth of the year. LLNL will provide an analytical expression for the source term to SNL, while PNL will use the AREST code to calculate their source term (however, they will coordinate with LLNL to use the sarne proportions for the diffusive and wet-drip components, and to use the same input parameters).

\section{Gas-Flow Source Tem}

The gas-flow source term will also start after 1,000 years. To simplify the source for the TSA, releases will be considered to occur instantaneously to the far field once the container is breached. Both a fastrelease fraction, which is released at failure, and a matrix-release fraction, which continues at the alteration rate, will be included. The duration for failure of all of the waste packages in the repository will be a random variable ranging from 9,000 to 99,000 years. A constant number of waste package failures per year will be used. In contrast to the geohydrology problem where the water-contact processes affect a limited numbers of containers, this failure distribution assumes that every waste package in the repository fails in the same way.

\section{Human-Intrusion Source Term}

The source term for the human-intrusion direct surface releases will be partitioned according to amount of burnup and decay time since discharge from the reactors. Source terms for "near misses" of waste packages (i.e., exhumation of contaminated rock) will assume that the radionuclide distribution is given by the diffusive portion of the transport calculated in PACE-90, nominal case. For releases directly into the saturated zone, the selecter radionuclides for groundwater transport will be used; however, they will be assumed to be completely dissolved. The source term will be parameterized by the saturated-zone water flow rate.

\section{Sorotion}

Sorption data will be obtained from LANL work and from the PACE-90 compilation. These data will be used in both the unsaturated and saturated zones. 


\section{Schedule}

The geohydrology source terms will be prepared by LLNL, using far-field hydrologic and infiltration parameters provided by SNL. The gas-flow source term will be provided by LBL (W. Lee). The directrelease source terms for human intrusion will be prepared by SNL (R. Bamard). The volcanic source term will be provided by LBL (W. Lee). Source terms are to be available by August 15, 1991, if possible. An absolute deadline of August 31, 1991 was set for final submission of the source term.

\section{Distribution:}

LANL J.A. Canepa

LANL G. A. Valentine

LBL W. W.-L. Lee

LBL T. H. Pigford

LLNL W. G. Halsey

LLNL W.J. O'Connell

LLNL J. Ueng

PNL C. K. Hastings

PNL D. Engle

PNL P. Eslinger

PNL W. Nichols

PNL P. Whitney

YMPO J. M. Boak

YMPO J.R. Dyer

1511 J. S. Rottler

1511 R. R. Eaton

1511 M. J. Martinez

6310 T. E. Blejwas

$6310 A$ L. E. Shephard

6312 F.W. Bingham

6312 R.W. Barnard

6312 W. F. Chambers

6312 H. A. Dockery

6312 J. H. Gauthier

6312 P. G. Kaplan

6312 F. C. Lauffer

6312 T. H. Robey

6312 M. L. Wilson

6313 L. S. Costin

6317 S. Sinnock 


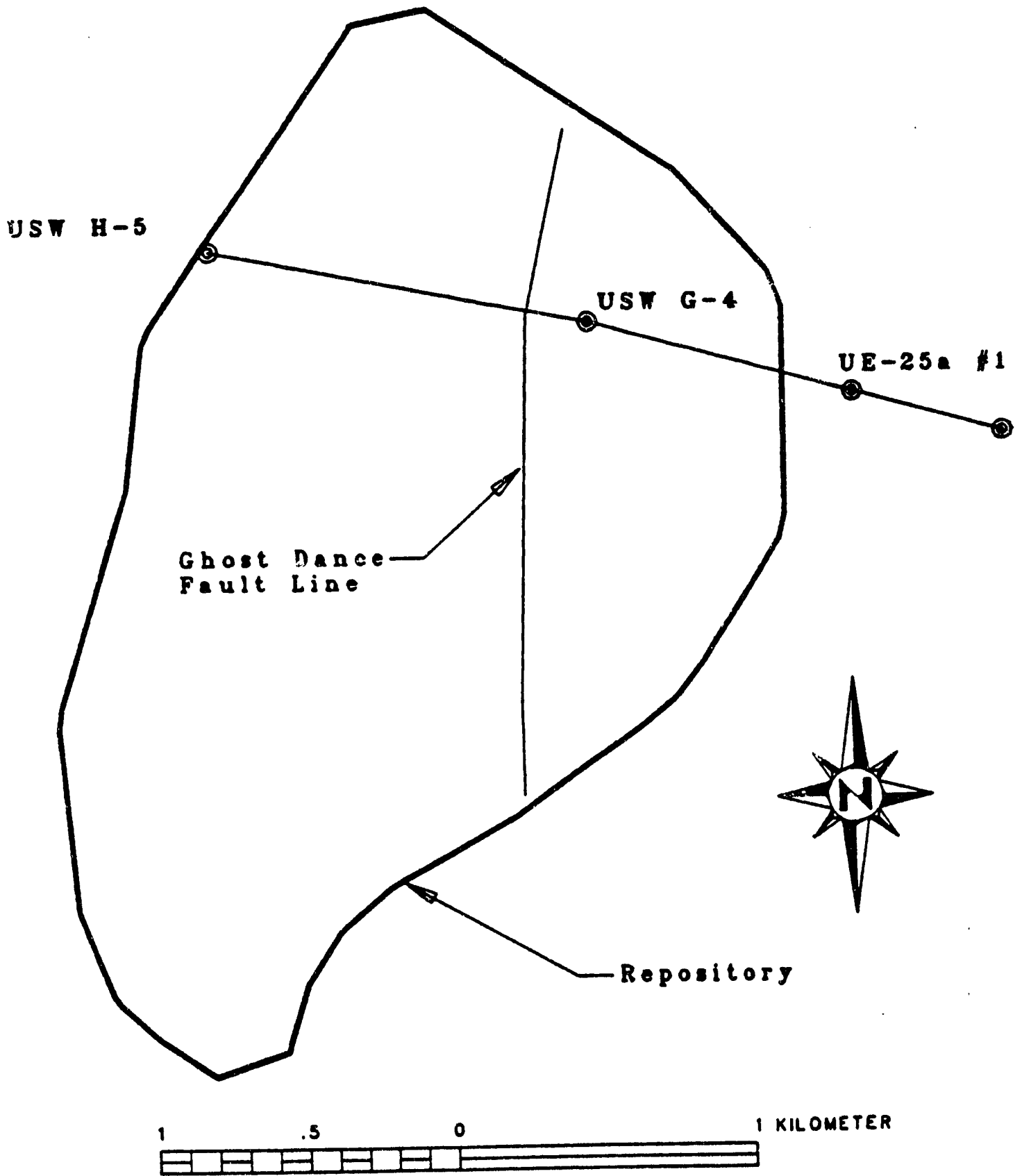

Profile Through USW $\mathrm{H}-5$. $\frac{U S T G-4, \text { and UE-25a \#1 }}{\text { Uaturing groseologle stratigraphr }}$ $\frac{\text { SA N } 0027}{\text { PAB. } 1 \text { of } 2}$

Figure 1. Problem Domain 


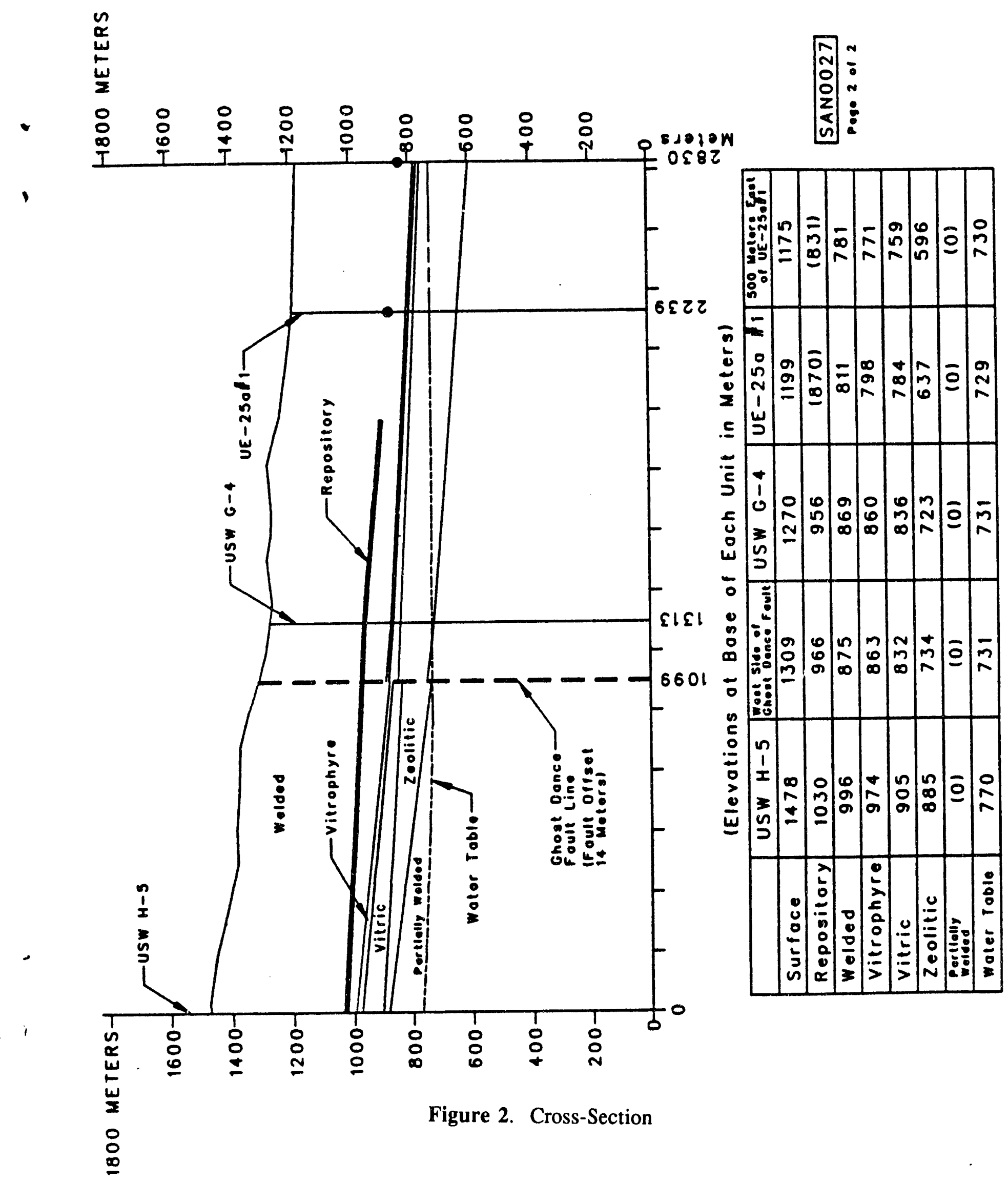

C. 7 


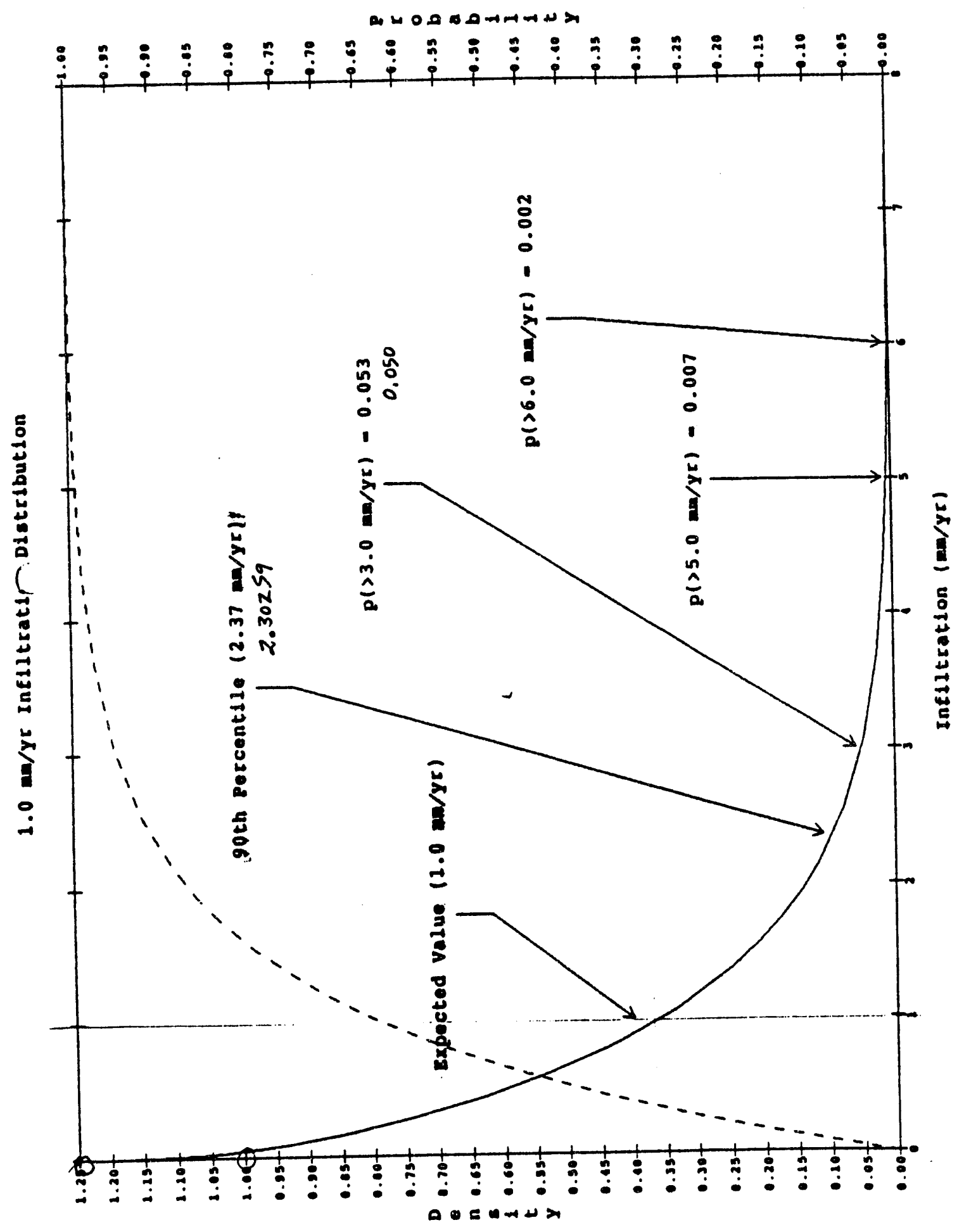

C. 8 


\section{DISTRIBUTION}

No. of

Copies

\section{OFFSITE}

12 DOE Office of Scientific and Technical Information

Technical Information Center

P.O. Box 62

Oak Ridge, TN 37830

8 Yucca Mountain Site Characterization Project Office

U.S. Department of Energy

101 Convention Center Drive

Phase II, Suite 200

P.O. Box 98608

Las Vegas, NV 89193-8608

ATTN: J. M. Boak

J. R. Dyer

C. P. Gertz (5)

J. J. Lorenz

12 Technical riiormation Officer

DOE Nevada Field Office

U.S. Department of Energy

P.O. Box 98518

Las Vegas, NV 89193-8518

D. R. Elle, Director

Environmental Protection Division

DOE Nevada Field Office

U.S. Department of Energy

P.O. Box 98518

Las Vegas, NV 89193-8518

P. K. Fitzsimmons

DOE Nevada Field Office

U.S. Department of Finergy

P.O. Box 98518

Las Vegas, NV 39193-8518
No. of

Copies

A. T. Tamura

Science and Technology Division

Office of Scientific \& Technical

Information

U.S. Department of Energy

P.O. Box 62

Oak Ridge, TN 37831

$9 \quad$ U.S. Department of Energy

1000 Independence Avenue, S.W.

Washington, DC 20585

ATTN: L. Desell

RW-331

S. J. Brocoum

P. Bunton

$\mathrm{RW}-22$

R. A. Milner

RW-331

G. J. Parker

RW-332

J. Roberts

RW-322

J. Roberts

RW-30

S. Rousso

RW-33

T. Wood

$\mathrm{RW}-50$

RW-52

C. L. West, Director

Office of External Affairs

DOE Field Office, Nevada

U.S. Department of Energy

P.O. Box 98518

Las Vegas, NV 89193-8518

C. Anderson

National Academy of Sciences

2101 Constitution Ave. NW

Harris Bldg, Rm 456

Washington, DC 20418

2 Agency for Nuclear Projects

State of Nevada

Evergreen Center, Suite 252

1802 N. Carson St.

Carson City, NV 89710

ATTN: C. H. Johnson

R. R. Loux

Distr. 1 
No. of

Copies

C. R. Allen

Nuclear Waste Technical Review Board 1000 E. California Boulevard

Pasadena, CA 91106

\section{A. Anderson}

Argonne National Lboratory

Building 362

9700 S. Cass Avenue

Argonne, IL 60439

E. Anderson

Mountain West Research

Southwest, Inc.

2901 N. Central Ave., \#1000

Phoenix, AZ 85012-2730

M. L. Baughman

35 Clark Road

Fiskdale, MA 01518

D. A. Beck

Water Resources Division

U.S. Geological Survey

6770 S. Paradise Road

Las Vegas, NV 89119

C. G. Bell, Jr.

Professor of Civil Engineering

Civil and Mechanical Engineering

University of Nevada, Las Vegas

4505 S. Maryland Parkway

Las Vegas, NV 89154

E. P. Binnall

Field Systems Group Leader

Building 50B/4235

Lawrence Berkeley Laboratory

Berkeley, CA 94720

\author{
J. A. Blink \\ Deputy Project Leader \\ Lawrence Livermore Natl Laboratory \\ 101 Convention Center Drive \\ Suite 280, MS 527 \\ Las Vegas, NV 89109
}

No. of

$\underline{\text { Copies }}$

\author{
S. Bradhurst \\ P.O. Box 1510 \\ Reno, NV 89505
}

L. Bradshaw

Nye County District Attorney

P.O. Box 593

Tonopah, NV 89049

G. D. Brewer

Nuclear Waste Technical Review Board

The Dana Building, Room 3516

University of Michigan

Ann Arbor, MI 48109-1115

R. J. Budnitz

President, Future Resource Associates 2000 Center Street, Suite 418

Berkeley, CA 94704

R. L. Bullock

Raytheon Services Nevada

Suite P-250 (MS-403)

101 Convention Center Dr.

Las Vegas, NV 89109

J. A. Canepa

Los Alamos National Laboratory

P.O. Box 1663

Los Alamos, NM 87545

J. E. Cantlon, Chairman

Nuclear Waste Technical Review Board 1795 Bramble Drive

East Lansing, MI 48823

B. W. Colston

Las Vegas Branch

Raytheon Services Nevada

MS 416

P.O. Box 95487

Las Vegas, NV 89193-5487 
No. of

Copies

Community Planning \& Development

City of North Las Vegas

P.O. Box 4086

North Las Vegas, NV 89030

Community Development \& Planning

City of Boulder City

P.O. Box 61350

Boulder City, NV 89006

T. A. Cotton

JK Research Associates, Inc.

4429 Butterworth Place, N.W.

Washington, DC 20016

A. G. Croff

Oak Ridge National Laboratory

$4500 \mathrm{~N}, \mathrm{MS}-6235$

P.O. Box 2008

Oak Ridge, TN 37831-6235

Department of Comprehensive Planning Clark County

225 Bridger Ave., 7th Floor

Las Vegas, NV 89155

2 Desert Research Institute

P.O. Box 60220

Reno, NV 89506

ATTN: J. Fordham

D. Rhode

P. A. Domenico

Nuclear Waste Technical Review Board

Geology Department

Texas A \& M University

College Station, TX 77843

Economic Development Department

City of Las Vegas

400 E. Stewart Avenue

Las Vegas, NV 89101
No. of

Copies

C. E. Ezra

YMP Support Office M.1anager

EG7G Energy Measurements, Inc.

MS V-02

P.O. Box 1912

Las Vegas, NV 89125

J. Fabryka-Martin

Los Alamos National Laboratory

Mail Stop J-514

Los Alamos, NM 87545

L. J. Fiorenzi

P.O. Box 257

Eureka, NV 89316

J. Foremaster

City of Caliente

P.O. Box 158

Caliente, NV 89008

L. D. Foust

Nevada Site Manager

TRW Environmental Safety System:

101 Convention Center Dr.

Suite 540, MS 423

Las Vegas, NV 89109

P. A. Glancy

U.S. Geological Survey

Federal Building, Room 224

Carson City, NV 89701

B. Hastings

TRW Environmental Safety Systems 2650 Park Tower Drive, Suite 80)

Vienna, VA 22180

T. Hay, Executive Assistant

Office of the Governor

State of Nevada

Capitol Complex

Carson City, NV 89710

J. Hayes

P.O. Box 490

Goldfield, NV 89013

Distr.3 
No. of

Copies

D. Hedges

Roy F. Weston, Inc.

4425 Spring Mountain Road, Suite 300

Las Vegas, INV 89102

F. O. Hoffman

Oak Ridge National Laboratory

P.O. Box 2008

Oak Ridge, TN 37831-6036

D. Hoxie

U.S. Geological Survey

P.O. Box 25046

Denver Federal Center

Denver, CO 80225

5 INTERA, Inc.

101 Convention Ctr. Dr.

Phase II, Suite 540

Las Vegas, NV 89193

ATTN: R. W. Nelson (2)

S. Pawah

A. E. Van Luik

H. N. Kalia

D. Langmuir

Nuclear Waste Technical Review Board 109 S. Lookout Mountain Creek

Golden, CO 80401

3 Lawrence Livermore National Laboratory

University of California

P.O. Box 808

Livermore, CA 94550

ATTN: W. L. Clarke

W. J. O'Connell

W. Halsey

Lincoln County Commission

Lincoln County

P.O. Box 90

Pioche, NV 89043
No. of

Copies

\section{H. LoO}

Weston House Idaho Nuclear Co.

P.O. Box 4000, M/S 5219

Idaho Falls, ID 83415

A. Makhijani

Institute for Energy and Environmental Research

6935 Laurel Avenue

Takoma Park, MD 20912

C. John Mann

Department of Geology

245 Natural History Bldg.

1301 West Green Street

Urbana, IL 61801

M. Marshall

c/o LATIR Energy Consultants

Route 7, Box 126 B

Old Santa Fe Trail

Santa Fe, NM 87505

J. E. Martin

Asst Professor of Radiological Health

University of Michigan

School of Public Health

Ann Arbor, MI 48109

J. J. McKetta, Jr.

Nuclear Waste Technical Review Board Department of Chemical Engineering CPE Building 1.450

Austin, TX 78712

H. R. Meyer

C.N.S.I.

750 East Park Drive, Suite 200

Harrisburg, PA 17111

I. Miller

Golder Associates

4104 184th Avenue N.E.

Redmond, WA 98052

Distr.4 
No. of Copies

‥ H. Neill

Director, New Mexico Environmental Evaluation Group

7007 Wyoming Boulevard, N.E.

Suite F-2

Albuquerque, NM 87109

D. W. North

Nuclear Waste Technical Review Board Decision Focus, Inc. 4984 El Camino Real Los Altos, CA 94062

Nuclear Wasie Technical Review Board 1011 Evergreen Way

Blacksburg, VA 24060

NRC Document Control Desk

Divison of Waste Mznagement

Nuclear Regulatory Commission

Washington, DC 20555

ONWI Library

Battelle Columbus Laboratory

Office of Nuclear Waste Isolation

505 King Ave.

Columbus, $\mathrm{OH} 43201$

T. Pigford

Department of Nuclear Engineering

4153 Etcheverry Hall

University of California

Berkeley, CA 94720

\section{J. Pitts}

Lincoln County Courthouse

Pioche, NV 89043

Planning Department

Nye County

P.O. Box 153

Tonopair, NV 89049

V. Poe

P.O. Box 1026

Hawthorne, NV 89415
No. of

Copies

P. T. Prestholt

NRC Site Representative.

301 E. Stewart Avenue, Room 203

Las Vegas, NV 89101

M. Reeves

INTERA, Inc.

6850 Austin Ctr. Blvd, Suite 300

Austin, TX 78731

Repository Licensing $\varepsilon$ Juality Assurance-Project Directorate

Division of Waste Management

Nuclear Regulatory Commission

Washington, DC 20555

Senior Project Mg

Repository Projeci 3 ranch

Nuclear Regulatory Commission

Washington, DC 20555

J. Riley

Heinman Research Laboratories

Charlotte, NC 28207

B. Ross

Disposal Safety, Inc.

1660 L. Street, N.W., Suite 314

Washington, DC 20036

G. Ross

Heath, Chairman

College of Ocean \& Fishery Sciences

583 Henderson hal'

University of Washington

Seattle, WA 98185

R. Rundberg

Los Alamos National Laboratory

Mail Stop J-514

Los Alamos, NM 87545

W. Russo

U.S. Environmental Protection Agency

401 "M" Street SW, ANR 460

Washington, DC 20460 
No. of

Copies

Exploratory Shaft Test Manager

Los Alamos National Laboratory

101 Convention Center Drive

Suite 820, Mail Stop 527

Las Vegas, NV 89101

3 Reynolds Electrical \& Engineering Co.

P.O. Box 98521

Las egas, NV 89193-8521
ATTY:
$\begin{array}{ll}\text { M. J. Dorsey } & \text { MS }-407 \\ \text { D. L. Fraser } & \text { MS }-555 \\ \text { R. F. Pritchett } & \text { MS }-408\end{array}$

G. Van Roekel

Director of Community Development

City of Caliente

P.O. Box 158

Caliente, NV 890978

6 Roy F. Weston, Inc.

955 L'Enfant Plaza, S.W.

Washington, D.C. 20024

ATTN: L. Rickertsen

E. L. Snow

Chris Charles (2)

Janet Docka

Technical Info. Center

10 Sandia National Laboratory

Albuquerque, NM 87185

ATTN: R. Anderson

R. W. Barnard

6312

F. W. Bingham

6312

T. E. Blejwas

6302

H. A. Dockery

6312

R. R. Eaton

1513

T. O. Hunter 6900

P. G. Kaplan 6312

M. Marietta

M. A. Wilson 6312

F. W. Schwartz

Dept of Geololgy and Mineralogy

The Ohio State University

1090 Carmack Road

Columbus, OH 43210-1398
No. of

Copies

3 Science Applications International Corporation (SAIC)

101 Convention Center Blvd, Suite 45()

Las Vegas, NV 89109

ATTN: A. Brandstetter

P. L. Cloke

M. D. Voegele

B. Selinder

190 W. First St.

Fallon, NV 89406

L. Shepard

Ogden Environmental \& Energy Services

7301 A Indian School Rd., NE

Albuquerque, NM 87110

3 Southwest Research Institute

6220 Culebra Road

San Antonio, TX 78228

ATTN: B. Sagar (2)

J. Walton

C. Thistlethwaite, AICP

Associate Planner

Inyo County Planning Dept.

Drawer L

Independence, CA 93526

U.S. Bureau of Reclamation

Code D-3790

P.O. Box 25007

Denver, CO 80225

2 U.S. Environmental Protection Agency

Science Advisory Board

401 M Street, S.W., A-101F

Washington, DC 20460

ATTN: D. M. Clark

K. W. Conway

2 U.S. Geological Survey

2255 N. Gemini Drive

Flagstaff AZ 86001

ATTN: J. H. Sass

S. C. Wu

Distr.6 
No. of

Copies

U.S. Geological Survey 345 Middlerield Road

Menlo Park, CA 94025

ATTN: E. J. Helley

6 U.S. Geological Survey

P.O. Box 25046

Denver CO 80225

ATTN: D. H. Appel

G. L. Ducret

L. R. Hayes

W. R. Keefer

J. M. LaMonaca

J. S. Stuckless

2 U.S. Geological Survey

101 Convention Center Drive

Suite 860 MS 509

Las Vegas, NV 89109

ATTN: R. W. Craig

D. Zesiger

U.S. Geological Survey

P.O. Box 327, MS 721

Mercury, NV 89023

ATTN: A. L. Flint

2 U.S. Geological Survey

106 National Center

12201 Sunrise Valley Drive

Reston, VA 22092

ATTN: J. F. Devine

V.R. Schneider

2 U.S. NRC

Division of Engineering Safety

Washington, D.C.

ATTN: Dick Codell

Seth Coplan NLS-260

Ellis D. Verink

Nuclear Waste Technical Review Board 4401 N.W. 18th Place

Gainesville, FL 32605
No. of

Copies

J. E. Watson, Jr.

Department of Environmental Sciences and Engineering

Campus Box 7400

University of North Carolina at Chapel Hill

Chapel Hill, NC 27599-74()0

P. J. Weeden

Nuclear Radiation Assmt. Div.

U.S. Environmental Protection Agency

Environmental Monitoring Systems Laboratory

P.O. Box 93478

Las Vegas, NV 89193-3478

C. Whipple

Clement International

160 Spear Street, Suite 1380

San Francisco, CA 94105-1535

R. Williams, Jr.

P.O. Box 10

Austin, NV 89310

S. S. C. Wu

Branch of Astrogeology

U.S. Geological Survey

2255 N. Gemini Dr.

Flagstaff, AZ 86001

\section{FOREIGN}

4 AECL, Whiteshell Laboratories

Pinawa, Manitoba

CANADA ROE 1LO

ATTN: K. W. Dormuth

G. S. Lodha

M. Onofrei

S. H. Whitaker

K. Andersson

Karinta-Konsult

P.O. Box 6048

S-183 06 Taby

SWEDEN 
No. of

Copies

M. Bell

International Atomic Energy Agency

Wagramerstrasse 5

P.O. Box 100

A-1400 Vienna

AUSTRIA

R. Barrdahl

Swedish Radiation Protection Institute

P.O. Box 60204

S-01401 Stockholm

SWEDEN

N. A. Chapman

INTERA

Park View Hose, 14B Burton Street

Melton Mowbray, Leicestershire

LE13 1AE

UNITED KINGDOM

L. Wen-Chung

Radwaste Administration

Atomic Energy Council

6F, 65, Lane 144, Keelung Load

Section 4 Taipei

TAIWAN

J. G. T. Chyr

Taiwan Power Company

4F 2 Alley 15, Lane 196, Sec. 4

Roosevelt d., Taipei

TAIWAN

Commission of the European Communities

200 Rue de la Loi

B-1049 Brussells

BELGIUM

E. Eloranta

Finnish Centre for Radiation and Nuclear Safety

P.O. Box 268

SF-00101 Helsinki, FINLAND
No. of

Copies

H. D. Fuchs

Gesellschaft fu Nuklear-Service mbH

Lange Laube 7

D-3000 Hannover 1, GERMANY

I. Fumio

c/o Prof. Swoboda

University of Innsbruck

Technikerstr. 13

A-6020 Innsbruck

AUSTRIA

J. E. Gale

Fracflow Consultants, Inc.

36 Pearson Street

St. John's, Newfoundland A1A 3R1

CANADA

F. Gera

ISMES S.p.A.

Via dei Crociferi 44

00187 Rome

ITALY

G. Gustafson

Department of Geology

Chalmers University of Technology and University of Goteborg

S-412 96 Goteborg

SWEDEN

A. W. Herbert

AEA Technology

Theoretical Studies Department

Harwell Laboratory, B434.4

Oxfordshire, OX11 ORA

UNITED KINGDOM

D. Hodgkinson

INTERA

Chiltern House, 45 Station Road

Henley-on-Thames, Oxon, RGY IA' 1

UNITED KINGDOM 
No. of

Copies
Y. Hwang
Korea Atomic Energy Research Institute
P.O. Box 7, Daeduk-Danji
Taejeon
KOREA

K. Kamemura

Shinozuka Research Institute

5F. Maguna Kogyo Blg. 1-31-13

Yoyogi, Shibuya-ku

Toyko, 151

JAPAN

\section{B. Lanyon}

Geo-Science Limited

The Falmouth Business Park

Bickland Water Road

Falmouth, Cornwall TR 114 SZ

UNITED KINGDOM

\section{H. Leino-Forsman}

VTT, Technical Research Centre of Finland

Otakaari 3 A, P.O. Box 200

SF-02151 Espoo

FINLAND

J. W. Lloyd

School of Earth Sciences

University of Birmingham Edgbaston

Birmingham B15 2TT

UNITED KINGDOM

D. E. Metcalfe

Waste Management Division

P.O. Box 1046, Station B

270 Albert Street

Ottawa

CANADA K1P 5S9
No. of

Copies

4 NAGRA

Hardstrasse 73

CH-543o Wettingen

SWITZERLAND

ATTN: W. Albert

N. R. Correa

R. W. Lieb

P. Zuidema

I. Neretnieks

Department of Chemical Engineering

Royal Institute of Technology

Teknikringen 26

S-100 44 Stockholm

SWEDEN

J.-P. Olivier

OCED/NEA

12 Boulevard des lles

92130 Issy Les Molineaux

FRANCE

O. Olsson

Conterra AB

P.O. Box 493

S-751 06 Uppsala

SWEDEN

J. Palmu

Imatran Voima Oy

Rajatorpantie 8

P.O. Box 112

SF-01601 Vantaa

FINLAND

C. B. Parada

ENRESA

Emilio Vargas, 7

28043 Madrid

SPAIN

G. Ramqvist

ELTEKNO AB

Gruvvagen 1

S-714 00 Kopparberg

SWEDEN 
No. of

Copies

\section{J. A. Steadman}

Building Research Establishment

Structural Performance Division

Garston Watford WD2 7JR

UNITED KINGDOM

O. Stephansson

Department of Engineering Geology

Royal Institute of Technology

S-100 44 Stockholm

SWEDEN

J. Vira

Teollisuuden Voima Oy

Annankatu $42 \mathrm{C}$

SF-00100 Helsinki

FINLAND

R. Yearsley

Inspectorate of Pollution

Room A5.02, Romney House

43 Marsham Street

London, SW 1P 3PY

UNITED KINGDOM

\section{ONSITE}

2 DOE Field Office, Richland

D. C. Langstaff

A5-90

J. J. Sutey

A.5-90)

2 Westinghouse Hanford Corporation

D. W. Langford

S. J. Ouderkirk

B.5-25

K7-34
No. of

Copies

43 Pacific Northwest Laboratory

P. J. Chamberlain

K6-96

L. A. Doremus

K6-96

D. M. Elwood

D. W. Engel

PORTL

P. W. Eslinger (25)

K7-34

K6-96

C. K. Hastings

$\mathrm{K} 6-96$

M. R. Kreiter

T. B. Miley

W. E. Nichols (2)

K $7-9()$

K7-34

M. D. White

K6-77

K6-77

P. D. Whitney

K7-34

Publishing Coordination

Technical Report Files (5)

Routing
R. M. Ecker
M. J. Graham
C. J. Hostetler
P. M. Irving
R. L. Skaggs
C. S. Sloane
P. C. Hays (last)

SEQUIM

K6-78

K6-81

K6-98

$\mathrm{K} 6-77$

K6-()4

K6-86 

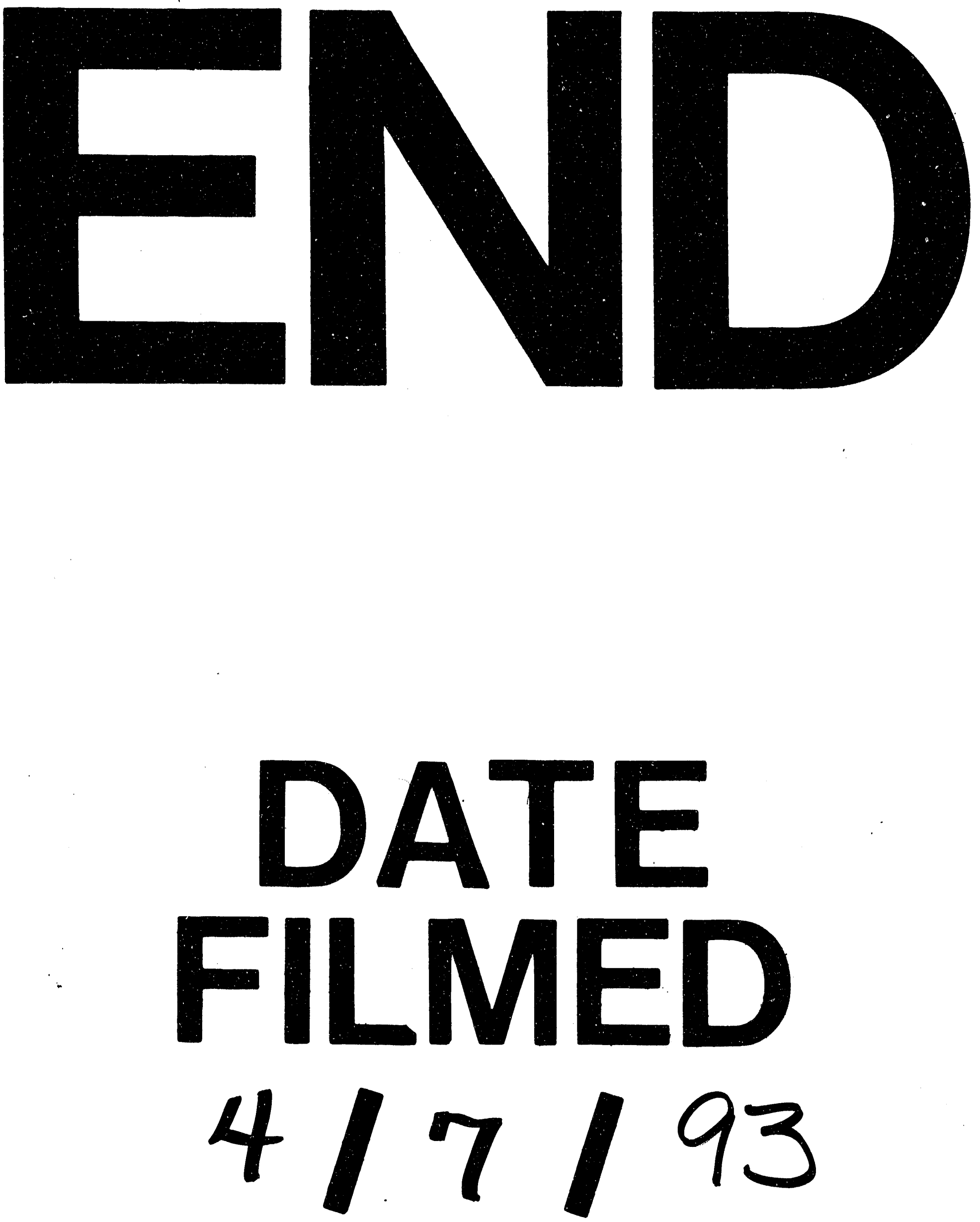
